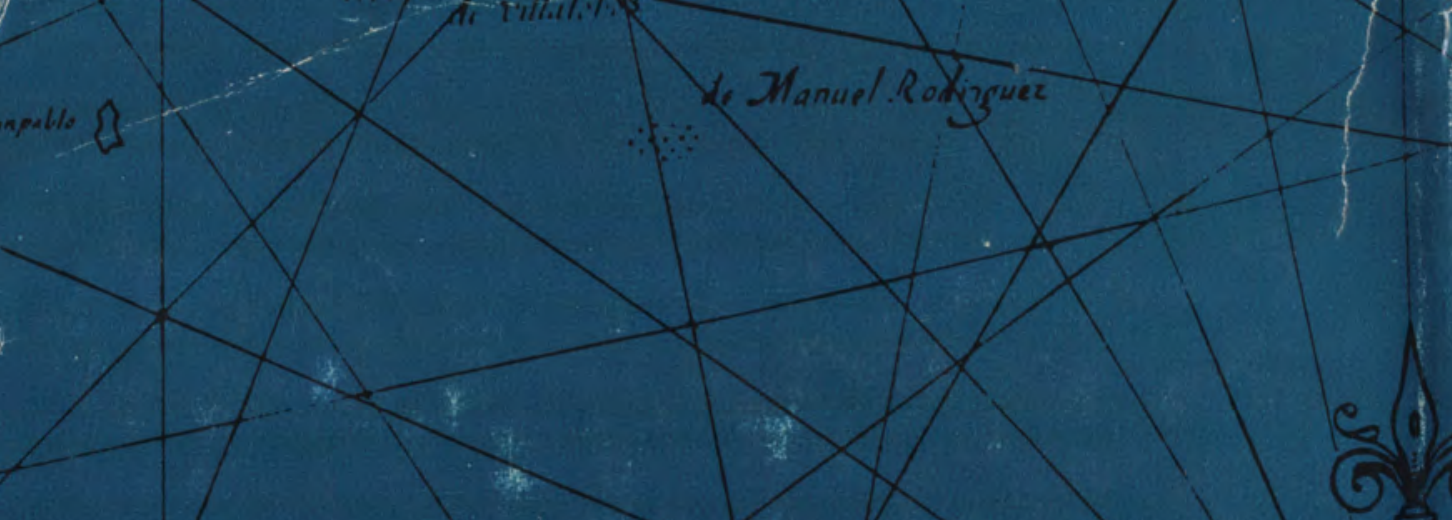

Island Populations of the Pacific

Norma McArthur 
Throughout the nineteenth century there were many, including scholars, who believed that the peoples of Polynesia were doomed to extinction. The reasons suggested for the supposedly dramatic declines in population numbers were many and varied, but few authors questioned the reality of the declines or their universality. In this book a demographer reappraises the basic estimates and counts of some of these populations, setting them in the context of contemporary knowledge and events, in an attempt to trace the demographic fortunes of these island populations in the years before 1956, the year in which censuses were taken simultaneously and more or less uniformly for all but one of these island groups. The book contains much new and hitherto unpublished material, gleaned from such diverse sources as the letters and journals of missionaries in the nineteenth century and contemporary registers of births and deaths. Not only is it an important work of reference for all scholars concerned with these island populations but it is of value to anyone interested in the history or future development of these islands.

The jacket design by

Robin Wallace-Crabbe is based on plate 2 of Tasman's

'Kaart van Zijn Australische Ontdekkingen 1644' published in 1942 by Martinus Nijhoff, and reproduced by permission of the publisher. 
Norma McArthur, B.A.(Melb.), Ph.D.(Lond.), is a Professorial Fellow at the Australian National University. Her interest in demography developed gradually during a flirtation with medical research and a more prolonged engagement with human genetics, and together these add a new dimension to her interpretation of the statistics of populations. Although primarily an academic, she conducted the census of Fiji in 1956 and continues to advise South Pacific governments on their census operations. 
This book was published by ANU Press between 1965-1991. This republication is part of the digitisation project being carried out by Scholarly Information Services/Library and ANU Press.

This project aims to make past scholarly works published by The Australian National University available to a global audience under its open-access policy. 
Island Populations of the Pacific 
By the same author:

Introducing Population Statistics Oxford University Press, 1961 


\section{Island Populations of the Pacific}

Norma McArthur

AUSTRALIAN NATIONAL UNIVERSITY PRESS CANBERRA 


\section{First published 1967}

This book is copyright. Reproduction in whole or part, without written permission of the publishers, is forbidden

Set in 10/12 point Linotype Caledonia and printed on $96 \mathrm{gsm}$ Burnie English Finish paper by Halstead Press Pty Ltd, Sydney Printed and manufactured in Australia

Registered in Australia for transmission by post as a book 


\section{Acknowledgments}

Invidious though it may be to name only some of the many who have helped me over the years, I must pay tribute to the generosity of the late R. P. Gilson, who allowed me to use his notes on the mission, consular and government records for Samoa and the Cook Islands when few of these documents were available in Australia although many are here now on microfilm. His comments on earlier drafts of these chapters were invaluable, and if I have misinterpreted the history of these groups in this final version, I alone should be blamed. Others who kept notes for me when working through records either held elsewhere and not easily accessible from Canberra, or not easily located without excessive patience and tenacity, are C. W. Newbury, Ethel Drus, N. Gunson, R. G. Ward, H. E. Maude and his son, A. M. Maude. In the years since their gratuitous donations to this study it has often been possible to consult the original documents for myself, but this was made easier and less time-consuming by their references. For Nancy Kuskie who endured the tedium of both the microfilm reader and the calculating machine on my behalf I have gratitude and the warmest admiration, and Miriam Gilson who helped with many of the early calculations was lucky to have escaped these last stages towards the completion of this manuscript. Without the help and encouragement of these and many others this book might never have been written, and no doubt there will be some-but I hope not manywho think it should not have been. From this I absolve everybody but myself and one other, to whom the book is now dedicated. 


\section{Abbreviations}

B.C.S.-N.A.

B.P.B.M.

C.A.F.W.P.H.C.

C.S.O.

F.O.C.P.

G.B.P.P.

I.N.S.E.E.

L.M.S.

N.Z.P.P.

S.S.L.

U.N.P.D.

U.S.C.D.-U.S.N.A. Consular Despatches, United States National Archives, Library of Congress, Washington

British Consular Papers concerning Samoa, National Archives, Wellington

Bernice P. Bishop Museum, Honolulu

Central Archives for Fiji and the Western Pacific High Commission

Colonial Secretary's Office

Foreign Office Confidential Print

Great Britain Parliamentary Papers

Institut National de la Statisque et des Études Économiques

London Missionary Society

New Zealand Parliamentary Papers

South Sea Letters. Letters to the Directors or the Foreign Secretary of the London Missionary Society in London; on microfilm in the Mitchell Library, Sydney and the Australian National Library, Canberra

United Nations Department of Social Affairs, Population Division 


\section{Contents}

Acknowledgments

Abbreviations

vi

Introduction

$\mathrm{XY}$

1 FIJI

Pre-censal Population Estimates

1

Census Enumerations 13

Course of Population Change $\quad 26$

Age and Sex Composition $\quad 37$

Registration of Births and Deaths 46

Analyses of Mortality 53

Analyses of Fertility $\quad 57$

Summary $\quad 66$

2 TONGA 68

Pre-censal Population Estimates $\quad 68$

Census Enumerations $\quad 75$

Growth of Population in the Twentieth Century 81

Age and Sex Composition 84

Registration of Births and Deaths 89

Analyses of Mortality $\quad 92$

Analyses of Fertility 94

Summary 96

3 SAMOA 98

Pre-censal Population Estimates 100

Western Samoa: Census Enumerations 115

Growth of Population in the Twentieth Century 123

Age and Sex Composition $\quad 127$

Registration of Births and Deaths 131

Analyses of Mortality $\quad 135$

Analyses of Fertility 137 
American Samoa: Census Enumerations

Growth of Population in the Twentieth Century 143

Age and Sex Composition

Registration of Births and Deaths

Analyses of Mortality -

Analyses of Fertility

Summary

4 COOK ISLANDS

Nineteenth Century Population Estimates

Census Enumerations

Growth of Population in the Twentieth Century

Age and Sex Composition

Registration of Births and Deaths

\section{FRENCH POLYNESIA}

Before 1900: Tahiti and Moorea

Leeward Islands

Marquesas Islands

Austral Islands

Tuamotu and Gambier Islands

Census Enumerations in the Twentieth Century 


\title{
Illustrations
}

\author{
Figures
}

I Numbers of Fijians surviving in each age group in successive censuses of Fiji per 1,000 Fijian births recorded in the appropriate five-year periods

2 Numbers of Tongan males and females surviving in age groups up to 35 years per 1,000 births recorded in the appropriate five-year periods

3 The age pyramid of the population of the Marquesas Islands in 1889 , redrawn from Marestang (1892, p. 361)

\section{Maps}

1 The main islands and island groups of Fiji, showing the approximate location of provinces or districts in the nineteenth century

2 The Kingdom of Tonga

3 The islands of the Samoa Group

4 The Cook Islands, showing their proximity to the western islands of French Polynesia

5 The main islands and island groups of French Polynesia

6 Tahiti. The traditional districts and the sites of the mission stations established during the nineteenth century. (Adapted with permission from Newbury's map in Davies (1961)) 


\section{List of Tables}

1 Fijian population recorded in the first census

2 The populations enumerated in successive censuses of Fiji, 1879 to 1911, by sex

3 The populations enumerated in successive censuses of Fiji, 1921 to 1956, by sex

4 Average annual rates of increase in the component populations of Fiji since 1921

5 Numbers of Fijians enumerated in successive censuses arrayed according to period of birth implied by ages stated

6 Numbers of Indians enumerated in successive censuses arrayed according to period of birth implied by ages stated

7 Child-woman ratios in the Fijian and Indian populations

8 Average annual mortality rates of Fijians, by sex and age in 1946 and 1956

9 Average annual mortality rates of Indians, by sex and age in 1946 and 1956

10 A 'standard' population constructed from the populations enumerated in the 1956 censuses of Fiji, Samoa, Tonga, Cook Islands, and French Polynesia

II Average annual age-specific fertility rates of Fijian and Indian women in Fiji, 1946 and 1956

12 Average numbers of children born to women in each age group of the Fijian and Indian populations, 1956

13 Average annual fertility rates, specific for age and number of previous children, amongst Fijian and Indian women in Fiji in 1956

14 Attainment of motherhood at specified ages by cohorts of Fijian and Indian women

15 The populations reported or recorded for Tonga in various years, by sex

16 Distribution of each 1,000 males and females in Tonga by age in 1939 and 1956

17 Estimated average annual mortality rates per 1,000 males and females in each age group in Tonga in 1939 and 1956

18 Population reported on the islands of the Samoa group at various dates up to 1900

19 The 'Samoan' or 'Native' population and total population enumerated in censuses of Western Samoa since 1900, by sex

20 Death rates from influenza in 1918 in Western Samoa

21 Male and female populations enumerated in Western Samoa in 1951 and 1956 arrayed according to period of birth implied by ages stated 
22 Average annual mortality rates in Western Samoa, by sex and age in 1951 and 1956

23 Estimated age-specific fertility rates in Western Samoa and the average numbers of children born to women in each age group

138

24 Attainment of motherhood at specified ages in Western Samoa

25 The populations enumerated in successive censuses of American Samoa since 1900 , by sex

26 Migrations recorded in American Samoa during 1950, by nationality, sex, and age

27 Numbers of males and females enumerated in successive censuses of American Samoa arrayed according to period of birth implied by ages stated

28 Component populations of American Samoa classified by sex and age in 1956

29 Average annual mortality rates in American Samoa, by sex and age in 1940, 1950, and 1956

30 Average annual age-specific fertility rates in American Samoa in 1940, 1950 , and 1956

31 Average annual fertility rates, specific for age and number of previous children in American Samoa, 1956

32 Average numbers of children born and surviving per woman at each age in American Samoa, 1956

33 Attainment of motherhood in American Samoa

34 Summary of the populations of the various Cook Islands, 1845 to 1902

35 'Native' population recorded in successive censuses of the Cook Islands, 1906 to 1951

36 Average annual rates of increase in 'Native' population in the Cook Islands, 1906 to 1951

37 Populations enumerated at young ages in the Cook Islands in 1951 and 1956 and numbers expected, by sex

38 Populations enumerated in the Cook Islands censuses of 1936, 1951, and 1956 arrayed according to period of birth implied by ages stated

39 Numbers of survivors in each cohort in 1956 and 1951 per 1,000 enumerated in the previous census

40 Number of males and females in each age group per 1,000 enumerated in the Cook Islands in 1936, 1945, 1951, and 1956

41 Numbers of children aged 0-4 years per 1,000 females 15-44 years in the Cook Islands

42 Distribution with respect to age of males and females in various islands in successive censuses

43 Average annual mortality rates for males and females at each age in the Cook Islands, 1945, 1951, and 1956

44 The numbers of deaths recorded for males and females in various islands

45 Estimated infant mortality rates in the Cook Islands

46 Average annual fertility rates in the Cook Islands

47 Numbers of females of selected ages recorded in Cook Islands censuses of 1951 and 1956 
48 Average numbers of children born and surviving to women of completed fertility on each island, 1956

49 Average numbers of children born to women in each age group in the Cook Islands, 1956

50 Numbers of women per 1,000 in each age group in 1956 who had borne no children

51 Number of women per 1,000 at each age in 1956 who had borne their first child before various ages

52 Average numbers of children surviving to women in each age group in the Cook Islands in 1956

53 The populations reported for Tahiti and Moorea for various years between 1829 and 1902

54 The populations reported for the Marquesas Islands for various years between 1840 and 1902

55 Populations of the several islands and island groups in successive censuses from 1902 to 1936 and the totals for French Polynesia

56 Populations of the several islands and island groups in successive censuses from 1926 to 1956

57 Numbers of deaths registered in each administrative district of French Polynesia, 1950 to 1952 , by sex

58 The population of Polynesian origin enumerated in successive censuses of French Polynesia arrayed according to period of birth implied by ages stated

59 Numbers of survivors in each birth cohort of Polynesian origin in 1956 and 1951 per 1,000 enumerated about five years previously

60 Number of children aged 0-4 years per 1,000 women 15-44 years in the population of Polynesian origin, 1946 and 1951

61 The Chinese population of French Polynesia enumerated in 1951 and 1956 arrayed according to period of birth implied by ages stated

62 The population of French Polynesia enumerated in 1951 and 1956 arrayed according to period of birth implied by ages stated

63 Estimated annual average mortality rates in the total population of French Polynesia, by sex and age in 1951 and 1956

64 Average annual infant mortality rates in each administrative district of French Polynesia

65 Estimated annual age-specific fertility rates in French Polynesia, 1951 and 1956

66 Average numbers of children per woman at each age in French Polynesia in 1951 and 1956 


\section{Introduction}

"This book has been long in the making. Conceived in a bleak London winter too many years ago, the initial field work in these and other islands was completed in 1954, and preliminary reports were issued in 1956. iSome of the lessons learned from this survey were put into practice in ithe round of censuses taken in September of that year, when Fiji, Tonga, Samoa and the Cook Islands were censussed simultaneously and more or less uniformly. Both the plan of the enumeration and the schedule were eminently simple; and though the censuses may have been better than many before them, they dispelled all illusions as to the ease of collecting even the simplest demographic facts about these populations. Many of the much-quoted 'facts' of earlier years dissolved readily then into surmise or inventions. It is mainly to dispel old myths, still echoing faintly in the halls of learning and authority, that this study is now offered.

The organization of each chapter follows a fairly uniform pattern. After a brief introduction there is a résumé of pre-censal estimates of populations, setting them in the context of what was known to be happening on the various islands at the relevant times, and thence trying to assess the size of each population, and the courses and sources of change in them, since Europeans discovered the islands. Because this was not always successful, all of the information gleaned from various sources is given-usually in the original words which explains the otherwise excessive use of quotations-in the hope that someone else may be able to discern or detect a pattern. Then follow descriptions of the various censuses and the arrangements made for each, and the analysis of the growth of population as revealed by these census data and the births and deaths which had been reported. The legal provisions for the registration of these latter are outlined before presenting analyses of the levels and patterns of mortality and fertility which prevailed around certain census dates. The concluding chapter is an over-view, interpreting the changes and the likely causes of change in some populations, and trying to explain why others did not suffer in the same way.

The chapters are uneven in texture and length because the data are so variable. For some of the islands of French Polynesia the time span is nearly two hundred years, whereas other island groups were virtually unknown until the 1830 s or even later. Although most of these populations 
have been censussed at least once since 1956, the analysis stops with the populations recorded then because it was the first time that the enumerations of all except French Polynesia coincided, and French Polynesia was censussed only eleven weeks later. The characteristics of the populations of Fiji and Western Samoa were examined in some detail in their respective census reports, and hence only the more salient facts are included here, whereas the data for the populations of Tonga, American Samoa, Cook Islands, and French Polynesia are treated rather more extensively.

In the years that have elapsed since this study was begun the old, hard slogging with a desk calculator to simulate the effects of epidemics or infanticide has been superseded by computers; and although less revolutionary, there have also been some advances in demographic techniques which permit more sophisticated analyses than are used here. But helpful though these are for some purposes, they do not improve the quality of the basic data and the disparities, for example, between average numbers of children as reported in a census and as estimated simply from current age-specific fertility rates, or between survival rates from one age group to the next between censuses as compared with the estimates derived from life tables based on the deaths registered at either end of the intercensal period, have been preserved as indicators of the likely reliability of data from various sources.

Apart from the warnings implicit in these discrepancies, the basic theme of this study remains as it has always been-that if enough were known about these populations at various times in their history, there would be no need to invoke the psychological reasons which Pitt-Rivers and others believed responsible for the supposedly universal decline in island populations in the Pacific when they were brought into contact with the superior 'white' civilization and culture. Shattering epidemics of unfamiliar diseases, which not only killed a large proportion of the population but, through age-selective mortality, left its age structure distorted seemed a more likely alternative to a ubiquitous inferiority complex inspired by runaway sailors and convicts and unscrupulous planters and traders or even some missionaries. It is rather easier to demonstrate that the decline was not universal than to unearth evidence which either supports or negates the hypothesis, but though not proven, the case is put and it is for you to judge. 


\section{$1 \mid F i j i$}

Though the Fiji archipelago contains about three hundred islands, approximately two-thirds of them are uninhabited and the group is dominated by the two main islands, Viti Levu and Vanua Levu. These account for five-sixths of the total land area of 7,055 square miles and the remaining one-sixth is contributed by islands ranging in size from about 200 square miles to mere rocks or coral outcrops breaking the surface of the ocean. The larger islands are volcanic in origin and topographically similar: the land rises through broken hill country to moderately high mountain ranges, densely wooded on their southern and eastern slopes, and covered in grass and reeds on the drier northern and western inclines. The coastal plains and the flood plains of the larger rivers of this dry zone offer the best agricultural land, and the narrow river valleys in the interior and the coastal fringes of the smaller islands support only coconuts and native food crops.

The credit for European discovery of the islands is shared by Tasman and Bligh. In 1643, Tasman narrowly escaped shipwreck off the coast of Vanua Levu and, because of his experience with its treacherous reefs and shoals, Fiji was avoided by mariners for more than a century and a half. In 1789, Bligh sailed through the archipelago from south-east to northwest in the launch of the Bounty, passing between Viti Levu and Vanua Levu and sighting the northern islands of the Yasawas. He returned in 1792, when he discovered and charted many of the islands in the Lau group and, after sighting Viti Levu again, sailed south to Kandavu. During the closing years of the eighteenth century several ships visited Fiji waters, but few of the captains attempted to land. The discovery of sandalwood thickets on Vanua Levu in the early years of the nineteenth century attracted European adventurers who vigorously and tragically exploited these and the Fijians until the sandalwood was cut out ten years later. Few European vessels called then until the bêche-de-mer trade started about 1830, and the only Europeans in the group in the interval were the beachcombers, survivors from wrecked ships or deserters from the crews of sandalwood ships.

The first European missionaries arrived from Tonga in 1835 and, 
though a trickle of white settlers came in their wake, there were few Europeans resident in the group until after 1850. By then, the Wesleyan mission had established itself widely and its 'mission circuits' covered 'most of the districts in Fiji except the interior of Viti Levu, the eastern part of Vanua Levu, a few small islands on the north-east of the Lau group and the Yasawas' (Henderson, 1931, p. 53). Each circuit had its complement of native teachers or pastors who lived in the Fijian villages, and were visited from time to time as opportunity offered by the European missionary in charge of the circuit.

The number of European settlers increased in the late $1850 \mathrm{~s}$ but, except on the smaller islands, few of them ventured far beyond selected areas along the coasts. It was 1865 before some of the more intrepid settlers traversed Viti.Levu from north to south, and later still before the interior of the island had been explored sufficiently to discount the coastal Fijians' belief in the existence of a large lake at the centre of the island. Friendly contact with the people living there was established sometime after 1875 by the first Colonial Government.

Throughout this period, Fiji suffered a succession of native wars, and the disruption of its traditional social patterns was aggravated by the demands of expanding European interests and settlement. The turbulent history of this era culminated in Queen Victoria's government 'graciously' accepting Fiji into the British Empire in 1874. The Deed of Cession, signed by all the high chiefs, marked the reluctant annexation by Britain in the interests as well of the natives as of the white population, that order and good government should be established' in Fiji. Offers to cede the sovereignty of their lands had been made first in 1858 and 1859, but Britain was then unwilling to accept either the offers or the conditions attaching to them. With the unconditional surrender of October 1874 Fiji became 'a possession and a dependency of the British Crown' (Derrick, 1950 , p. 249 ), the island of Rotuma being formally annexed to the colony in 1881 .

\section{Pre-censal Population Estimates}

The size of Fiji's population in the years preceding cession was variously estimated at between 100,000 and 300,000 . Few of the early visitors explained the source of their population figures, or how they arrived at their totals, and many were undoubtedly mere guesses. In the small islands where the people lived clustered in villages on a narrow coastal plain, a count of houses along a stretch of coast could be inflated to give a rough, but not too inexact, estimate of the population. The same method might be applied to larger islands with no great loss of accuracy provided the initial count covered a proportionately larger area, but it is soarcely 

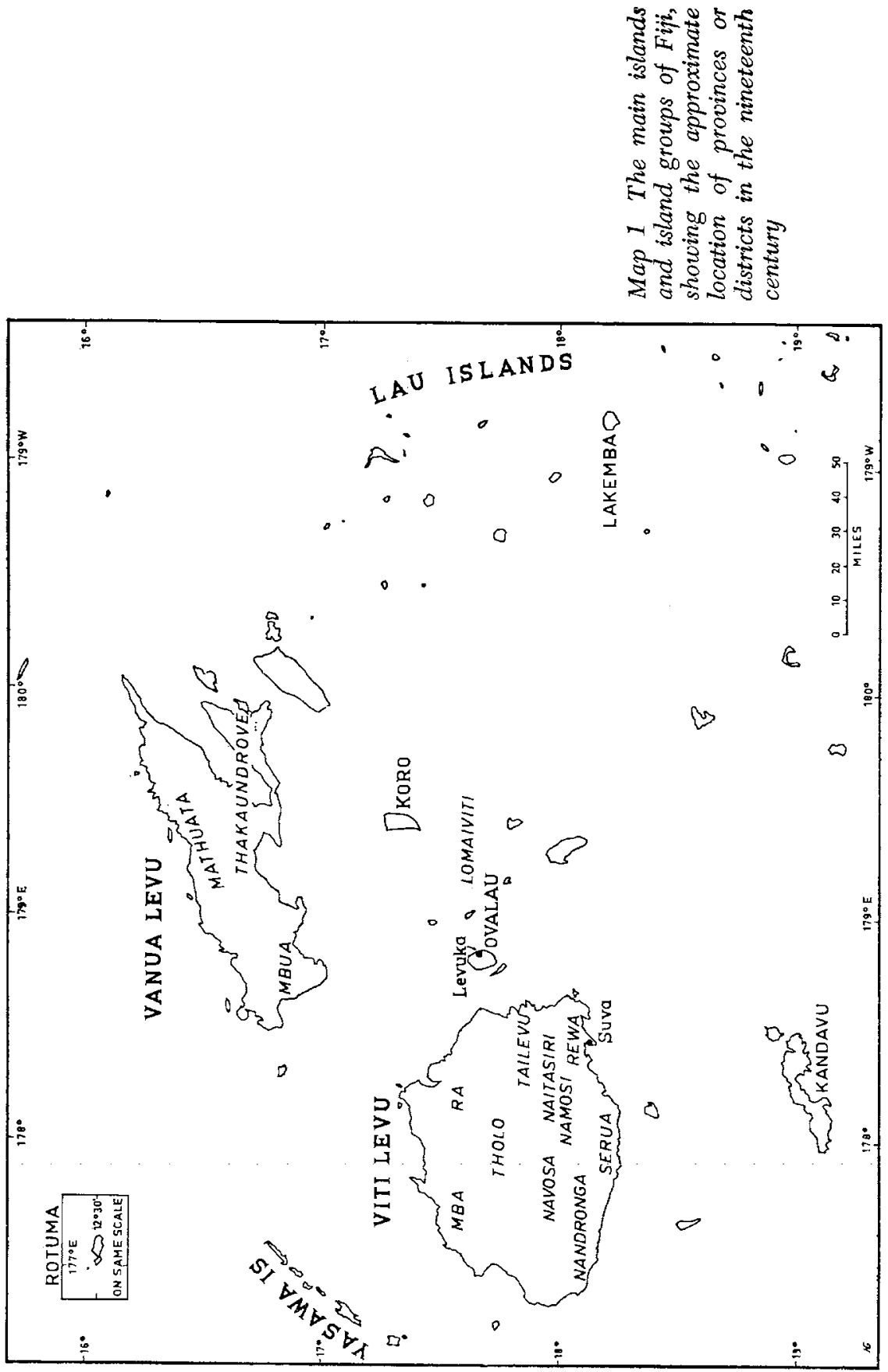
apposite for islands as large as Viti Levu and Vanua Levu, which have approximately 300 miles of coastline enclosing 4,000 and 2,000 square miles respectively. Reasonable and credible estimates of the numbers living in areas such as these require a more extensive knowledge of the islands than anyone possessed until after the middle of the nineteenth century.

One of the most conservative of these early estimates was made by Wilkes, the Commander of the United States Exploring Expedition which spent three months in the Fiji group in 1840. Wilkes 'adopted the plan of counting the inhabitants whenever [he] had an opportunity, in order to check the estimate given [him] by others'. He suspected that the European residents in Fiji tended to exaggerate the numbers of people, particularly those in the interiors of the islands where, he reasoned, 'there is little probability that any person would dwell . . . unless compelled by necessity. He compiled his own estimates of the numbers living in each 'district' or island of the group, allowing only 5,000 for the 'interior'. These numbers summed to a total of 133,500 persons, which he rounded to 'about 130,000 ' because he was 'inclined to believe [his total] rather above than below the actual number of inhabitants' (Wilkes, 1845, 3, pp. $323-4)$.

If his figures for the separate 'districts' of Viti Levu and Vanua Levu are summed, Wilkes recorded a total of 48,000 people for Viti Levu and 40,000 for Vanua Levu if both Taveuni and Rambi are excluded. If these two last are included with Vanua Levu, as is customary nowadays, then the totals for Viti Levu and Vanua Levu are almost equal. As the two islands have roughly the same circumference, Wilkes's counting and estimating were perhaps not far removed from the traditional assumption of mariners that the length of coastline was directly related to the number of inhabitants.

An estimate based on area rather than circumference was put forward by the missionary John Hunt in 1844. After six years in Fiji and periods of duty in all mission circuits, he estimated that the population of the Fiji group numbered 300,000 and, even though his calculation was based on the assumption that the interiors of the two main islands were as densely populated as their coastal areas, this estimate was accepted and quoted for several years. In 1849, Captain Erskine R.N. visited Fiji in the course of the first 'regular periodical inspection of all the islands of consequence within the limits of [the] command' of the officer in charge of the Australian station. He had read Wilkes's account of his expedition and noted the discrepancy between Wilkes's estimate of population and the information given him by the missionaries that the islands do not contain fewer than 200,000 and that probably even 300,000 is not an over 
estimate'. Having heard during this visit of the 'tribes inhabiting the inland districts of the great islands' who had 'never even seen the sea', Erskine clearly preferred a figure larger than Wilkes's but cautiously refrained from committing himself (Erskine, 1853, p. 271).

In 1850 the Reverend Walter Lawry admitted that the earlier mission estimate was probably too high and revised it to a number 'not much exceeding 200,000' (Lawry, 1850, p. 265). His colleague 'Thomas Williams, on the other hand, writing from Fiji some time before 1856, thought Wilkes's estimate 'nearer the truth, though somewhat too low; 150,000, I am convinced, being a truer estimate' (Williams, 1858, p. 102). Apart from Wilkes's assumption that the interiors of the main islands were so thinly populated that the inland districts of Viti Levu would contain no more than 5,000 inhabitants (and those of Vanua Levu apparently none), several of the smaller islands that Wilkes had believed uninhabited did have some people living on them. Williams added on the numbers he thought were needed to correct these deficiencies, and thus obtained the total of 150,000 persons.

Williams also believed that the contemporary Fijian population was much smaller than it had been previously. 'Both on the coast and inland, the population has diminished, within the last fifty years, probably one third, and in some distriots as much as one half. As evidence for this he cited the number of villages (or 'towns') 'ruined in war' and 'the large quantity of waste ground which was once under cultivation' (Williams, 1858 , p. 103). Neither of these criteria bears too close examination. Despite Williams's contention that 'the chiefs do not migrate' and hence a ruined village was 'proof of a minished population', Mrs Smythe (1864, p. 110) listed three consecutive village sites for one group of people in Mathuata; having lived on the island of Mathuata just off the west coast of Vanua Levu, they moved across to the mainland to participate in the bêche-de-mer trade, and when their new settlement was burned by a party of envious Mbauans, the Mathuata people moved to a new site, three miles farther up the coast. This incident could not perhaps be interpreted strictly as 'war', but changes such as these in village sites would entail the creation of new gardens, leaving the old ones desolate. Elsewhere Williams admitted that, although the sacking and burning of villages was the prerogative of the victors in war, not all of the inhabitants of a vanquished village were necessarily exterminated and, if it was customary to destroy the gardens when a village was burned, the survivors would have little option but to start afresh with new gardens near the site of their new village.

The Fijians were probably right in assuring Williams that there had been more of them fifty years previously, but 'war and the murderous 
customs of heathenism' were not, as Williams claimed, entirely responsible for the decrease in their numbers, and it is curious that he makes no mention of the appallingly fatal epidemics that followed at least two of their early encounters with Europeans around the turn of the century. In some parts of Fiji these were still remembered in song and legend many yoars later and a commission appointed in 1893 to inquire into the Decrease of the Native Population' made a 'systematic search for traditions bearing on ... sickness, with the result that the occurrence of at least two epidemics contemporary with the arrival of the first European ships is established beyond a doubt. . . . The first of these seems to have been a lingering disease with the symptoms of headache, intense thirst, loss of appetite, stuffiness of the nose and oppression of the chest', the unfortunate victims of which were eventually strangled, 'doubtless with every mark of affection. ... Whole villages were thus emptied by the sickness and by the famine following it which was caused by the weakness of the people and the expenditure of provisions for funeral feasts'. This epidemic is believed to have occurred in 1791-2 and eleven years later, in 1802-3, there was an outbreak of 'a very acute form of dysentery' to which native tradition ascribed even greater mortality than was experienced in the measles epidemic which raged throughout Fiji in 1875 (Corney, Stewart and Thomson, 1896, pp. 34-5).

The mortality from measles was alleged to be more than 25 per cent and if both of these early epidemics were equally fatal only three-quarters of the population would have survived each outbreak and their numbers would have decreased by almost one-half in twelve years. If the mortality rate in each epidemic had been less than this, so that 80 or 85 per cent survived each time, the reduction in numbers as a result of the two outbreaks would have been of the order of one-third and one-quarter respectively. Provided the age structure of this diminished population was favourable to rapid increase, it might have regained its former size before the next lethal outbreak of 'malignant and obstinate' influenza which swept through most villages in 1839 and killed many people (Derrick, 1950 , p. 62). There had been at least one other epidemic in the intervening years, associated with the visit of two American vessels in 1819, when a disease known amongst the natives as vudi coro spread amongst them but did not cause many deaths. Had the age structure of the population been altered by the early epidemic mortality so that its recovery, even under favourable conditions, would have been slow, the deaths from influenza in 1839 would have retarded this further.

In 1858 , the leading Fijian chief, Thakombau, was being pressed by the United States Government for the payment of 45,000 dollars, as reparations for the looting by Fijians of its Acting Consul's house several 
years before. W. J. Pritchard had just been appointed as the first British Consul to Fiji and through him, Thakombau offered to cede 'not less than 200,000 acres' of land to Great Britain, on condition that the British Government paid his debt to the Americans. Warily, the British Government commissioned Colonel Smythe, an officer of the Royal Artillery, to investigate the willingness of the high chiefs to cede their lands, and advise on the economic opportunities that Fiji might offer and on the probable cost of its administration if it became a colony. His instructions from the Duke of Newcastle before his departure from England in 1860 stated that the whole population of the Group has been estimated at 200,000' (Smythe, 1864, p. 192), and Smythe repeated this figure in the report he submitted more than a year later, amending it only by adding 'of whom 60,000 are numbered as Christian converts'. On his advice the offer of cession was declined and shortly afterwards Pritchard was relieved of his duties as Consul. As they had done on many matters, Pritchard and Smythe disagreed on the size of the population, and in publicly refuting Smythe's allegations of misconduct, Pritchard described his work in Fiji 'alone.... in the midst of 250,000 natives' (W. J. Pritchard, 1866, p. 276).

These numbers are very different from the one advanced by J. B. Thurston a few years later. Thurston had arrived in Fiji by accident and served as mate for several voyages on the mission schooner before acquiring a cotton plantation on Ovalau, an island just off the east coast of Viti Levu. He was one of the party which traversed Viti Levu from north to south in 1865, and was Acting British Consul in Fiji from July 1867 until the end of 1869. He then settled on Taveuni, east of Vanua Levu, but took an active part in the government of Fiji both before and after cession, becoming Governor in 1888. In 1868, he reckoned the population to be 100,000 or 110,000 and considered it was decreasing. His estimate was apparently disregarded because the consular reports from the period immediately preceding the eventual cession of Fiji claimed many more inhabitants.

A book prepared about the time of cession to inform the people of Great Britain about their 'new province in the South Seas' quoted 140,500 as 'a rough estimate of the native population of Fiji in March, 1874 ' (de Ricci, 1875, p. 67). Rough though it may have been, this total represented the sum of the estimated populations of thirteen districts, the names of many of which correspond with those of the present-day provinces although doubtless the geographic boundaries would not. No map was included to show the boundaries of the district, but it is of interest that the populations given for each district were as follows: 


$\begin{array}{lr}\text { Mbua } & 7,000 \\ \text { Mathuata } & 7,000 \\ \text { Thakaundrove } & 15,000 \\ \text { Lau } & 8,000 \\ \text { Kandavu } & 10,000 \\ \text { Central } & 8,000 \\ \text { Tailevu } & 10,000 \\ \text { Naitasiri and Interior } & 20,000 \\ \text { Rewa } & 5,500 \\ \text { Serua } & 5,000 \\ \text { Namosi } & 7,000 \\ \text { Nandronga } & 20,000 \\ \text { Mba and Yasawas } & 18,000 \\ & 140,500\end{array}$

This gives Vanua Levu a population of 29,000 and Viti Levu a total of about 91,000 or perhaps a little more if there were fewer than 2,500 people in the Yasawas. This is a very different distribution from Wilkes's but there is a marked similarity between it and the geographic distribution recorded in the early censuses. In both 1881 and 1891 there were approximately three times as many people on Viti Levu as on Vanua Levu and, if one accepts de Ricci's figure for Vanua Levu's population, the total for Fiji would be reasonably near the mark. If the population of Vanua Levu was exaggerated, then Viti Levu's population was probably grossly over-estimated because Vanua Levu has relatively more coastline per square mile of area and its unknown inland populations are therefore relatively less important.

The figure most often cited as the 'official' estimate of population at cession is 150,000 , but the origin of this is obscure and before the first count could be made, the Fijians suffered a disastrous epidemic of measles. The report of the 1893 Commission gives a graphic description of this epidemic and as copies of this report are now exceedingly rare, the account is here given verbatim:

Introduced by H.M.S. 'Dido' in the persons of the Vunivalu's own son, Ratu Timothe, and his servant, measles spread with unexampled rapidity owing to its dissemination throughout the country on the return to their various districts of the members of a great native meeting which was held at Levuka [the ancient capital of Fiji] a few days after the 'Dido's' arrival. The people were estimated at that time to number about 150,000 , and it is recorded, probably with fair exactitude, that 40,000 died from measles during the epidemic, which overran the whole archipelago in the space of four months and then dis- 
appeared. Whether the Fijians who survived the epidemic of 1875-an event which has become their principal date mark-have had their stamina permanently lowered by it can only be a matter for conjecture. The great mortality caused by this epidemic was partly the consequence of the suddenness with which it befell the people, village by village, every individual being susceptible because unprotected by any previous attack. Whole communities were stricken at one time, and there was no one left to gather food or carry water, to attend to the necessary wants of their fellows, or even, in many cases, to bury the dead. Consequently many must have died of starvation and neglect; but the heavy mortality was also attributable in great measure to the people's dire ignorance of the simplest nursing precautions, to their blind unimpressiveness, their want of ordinary foresight, their apathy and despair. They became at once ... overwhelmed, dismayed, cowed, abandoning all hope of self-preservation, and becoming incapable of any effort to save themselves or others (Comey, Stewart and Thomson, 1896, p. 36).

Elsewhere Corney (1884) cited the populations and deaths reported for some areas, which indicated mortality rates of about 27 per cent for the islands of Ovalau and Koro to the east of Viti Levu, and for the Mba River area in north-west Viti Levu. Amongst the early records now extant in the Central Archives of Fiji and the Western Pacific High Commission are summaries of the numbers of tax-paying males and females, aged people, boys and girls, and children in ' $\mathrm{Ba}$ and Yasawa', which were compiled by the Roko of that district in 1874; and much the same information-believed to have been collected in 1874-for the people living in the various villages on the islands of Ovalau and Koro. If the people from the Yasawa Islands are excluded from the first, the population in the Mba district then was slightly larger than Corney reported, but it is impossible to judge whether he and the Roko included the same people. For both Ovalau and Koro, and more particularly Koro, the alleged census figures are inaccurate unless a few villages-one on Ovalau and three on Koro-were inhabited solely by tax-paying males.

Perhaps Corney had better records than these to work from, but it is surely not coincidence that 27 per cent of 150,000 is only 500 more than the 40,000 deaths 'recorded, probably with fair exactitude' mentioned in the above excerpt. The pre-epidemic populations quoted for Ovalau, Koro, and $\mathrm{Mba}$ were 1,546, 2,543, and 7,925 respectively-an aggregate of 12,014 which represents about 8 per cent of the supposed total population. The mortality on Ovalau was slightly higher than in the other two populations, but it could scarcely be regarded as typical of 
what the people living in other parts of Fiji experienced because probably the whole population congregated in Levuka, on the east coast of the island, for the 'great native meeting'. Doubtless this also attracted relatively larger numbers from islands such as Koro, 40 miles away, than from the more distant parts of Fiji such as the Yasawas, or Mathuata on the north coast of Vanua Levu, or even from the south-western corner of Viti Levu.

The only other figures that have been found for deaths from measles were collected by the Stipendiary Magistrate for the Lau Islands district, 'when the disease [had] pretty nearly exhausted itself and the native population' (Emberson, 1875). The numbers quoted as the pre-epidemic populations are clearly estimates for about two-thirds of the islands, and the mortality rates there tended to be slightly lower than those on the islands where the population may have been counted. The average mortality rate for these was about 21 per cent but, once again, doubts arise as to the true size of the base populations because in a separate 'statement compiled by Joeli Scribe at Lakeba and handed to [Emberson] 18th January 1875', and headed 'Synopsis of Lakeba Census', Emberson queried the numbers given for two of the nine villages listed. One of those suspected of error contained no 'girls', boys' or 'infants'; the other no 'infants' and no 'taxable adults'.

The populations reckoned for these islands before the epidemic ranged from 66 to 1,503, and three of the most southerly and remote islands-with an estimated aggregate population of 1,000-had had no deaths from measles when last heard from on 28 May. The highest mortality rates reported were 30 per cent for each of two of the smallest populations, and only four-including the largest and one of the smallest -lost 25 per cent of their number. For nine of the islands the rates were between 12 and 20 per cent, and on two islands with estimated populations of 700 and 500 only 8 per cent had died of measles. The average loss of population from the islands known to have experienced the disease was less than 19 per cent, and the dispersion of the individual rates about this average suggests that 20 per cent might be a more plausible average for the extent of mortality throughout Fiji than the 27 or 25 per cent customarily quoted.

When the first complete census was attempted in 1879, 108,924 Fijians were counted and it was estimated that a further 3,000 Fijians working on European plantations had not been enumerated. Although the number of births was thought to be 'actually in excess of deaths' (Fiji Blue Book, 1878, p. 123) for at least one of the intervening years, the population which survived the measles epidemic may have been within the range of 110,000 to 112,000 . If the mortality rate in the epidemic 
was 20 per cent, these numbers suggest an upper limit of 140,000 for the population before the epidemic. Had the average mortality rate been lower than this, the pre-epidemic population would have been smaller, and it oould have been 150,000 or above only if the mortality rate from measles was as high as 25 or 27 per cent, which seems unlikely.

Thurston (1876a), Auditor-General in the first Colonial Government, quoted 114,636 as the estimate of the native population of Fiji "prior to the late epidemic ... . [and] exclusive of the "Tholo" or hill tribes", and as none except the very early mission estimates provided as many as 35,000 for the hill tribes of Viti Levu, it must be surmised that Thurston privately disagreed with the official estimate of population at cession. A few years later the hill tribes contained approximately 13,000 people and, assuming that they too suffered in the measles epidemic, their numbers prior to this may have been 16,000 , or at most 18,000 . The addition of either of these numbers to Thurston's basic estimate of 115,000 implies a total population nearer to 135,000 than the maximum suggested above.

Publicly, however, Thurston adhered to the proclaimed figure of 150,000 and in the debate on the taxation bill in the Legislative Council, he outlined how the revenue from the native taxes would be used for the general organisation and progress of the 120,000 people who have so lately submitted themselves to the protection and rule of Her Majesty' (Thurston, 1876b). He had 'supposed' that one-fifth of the population had died in the epidemic, and his guess at the number of taxable people implies a population in 1876 of 92,000 Fijians excluding the hill tribes. It would be surprising, however, if he believed there were then 28,000 people in the interior of Viti Levu, especially as he disputed a total of 107,098 Fijians three years later, claiming that no means exist yet for taking an exact census and I have reason to think that the actual number cannot exceed 100,000' (Thurston, 1879). The disputed total was smaller than the one reported in the first attempt at a colony-wide census in March of that year but, as will be seen later, this count still did not end the controversy about the size or progress of the Fijian population.

When Fiji became a British colony it was not peopled solely by Fijians and Europeans. In the early 1860s cotton was the most promising of Fiji's agricultural industries and to participate in this, the European settlers required land and labour. Many had obtained land but the indigenous Fijians were reluctant to neglect their own gardens for the harder, more sustained work required on European plantations and the settlers were continually seeking more reliable, cheap labour. When a similar demand from planters in Queensland was met by the impor- 
tation of workers from the New Hebrides and other island groups in Melanesia, their example was quickly followed in Fiji. The planter paid the passage money and the cost of recruitment, and asked few questions as to how the labourers were obtained. This labour traffic soon developed into a thinly disguised slave trade and, despite efforts by British and French warships to check it, the infamous 'black-birding' continued. In the late 1860s there was a slump in Fiji cotton; at the close of the Civil War America re-entered the cotton market and cotton growing in Fiji was no longer profitable. As it was then replaced by the cultivation of sugar-cane the demand for cheap labour was increased. After a succession of notorious incidents focussing on Fiji, the Kidnapping or Polynesian Islanders Protection Act was passed in Britain in 1872 , and this helped to regulate the trade somewhat though it was not effectively controlled until Fiji became a British colony in 1874 .

The first Governor of Fiji, Sir Arthur Gordon, arrived in 1875 and he regarded the planters' continual demands for labour as a danger to the stability of the traditional social system of the Fijians. Determined to preserve this order, and familiar with the indenture systems operating in the West Indies and Mauritius, he entered into negotiations with the Government of India and the first Indian immigrants arrived in Fiji in 1879. The terms of their agreements stipulated five years' labour for one employer and, after a further five years' residence in Fiji, they were free either to settle there or to return to their homeland. At least 40 females aged 10 years or over were to accompany every 100 male workers under contract, and though the recruiting agents often had difficulty in filling this quota, the required proportion of females to males seems to have been maintained (Gillion, 1956, pp. 139-57).

Initially the settlers objected to the Indian labourers, much preferring to employ Fijians or, failing them, New Hebrideans and Solomon Islanders. Their objections were over-ruled; however, and most of these so-called 'Polynesians' were gradually repatriated and replaced by Indians. The expansion of the sugar industry towards the turn of the century gave a boost to the immigration of Indians under contract. Encouraged by earlier ventures in sugar-growing in Fiji, the Colonial Sugar Refining Company of Australia bought land there in 1880 and established its first mill at Nausori in 1882. Three other mills were built in the next twenty years, and the peak of Indian immigration to Fiji was reached in the decade 1900 to 1910 . The recruitment of workers under this system ceased in 1916 and in 1920 the Fiji Government cancelled all unexpired contracts.

Despite the large numbers of Indians who passed through or eventually settled in Fiji during this period, and the comparative scarcity 
of Indian females, there was (and still is) little intermarriage between Indians and Fijians or between Indians and other ethnic groups in the population. There has been some intermixture of Fijians and the other groups but, at all times in Fiji's population history since 1879, the Indians have constituted a distinct population within the whole.

\section{Census Enumerations}

Though the populations living in some provinces, or islands, or magisterial districts had been listed and summarized earlier, the first attempt to count the whole population was made in March 1879. In the previous year some of the Stipendiary Magistrates had complied with the request for censuses of their districts, and it seems likely that the original lists for each village were compiled by scribes or other minor native officials, and passed to the magistrates for collation. Some of the original lists and provincial recapitulations still exist-the lists showing the numbers of 'aged' men and women, 'young' men and women, 'youths and boys', and 'girls' in each village, with sometimes the additional category of 'infants'; but the recapitulations were usually limited to the numbers of males, females and persons in each district, with sometimes the numbers of 'able-bodied men' as well.

Where the village and district totals can be checked there are quite frequent errors of addition, and though these seldom amount to more than 2 per cent of a provincial total, it is not surprising that almost none of the figures given in the Fiji Blue Book for 1878 (p. 122) coincide with the numbers of males and females originally reported. Of the fifteen provinces and districts listed there, seven had ostensibly been censussed -one in 1877, the remainder in 1878-and the figures given for the remainder were estimated. These amounted to about 40 per cent of the total of 106,196 Fijians, and in addition there were 1,902 Europeans, 72 'Asiatics', and 3,200 'Polynesians not Fijians', adding to a grand total of 111,370. The returns of the non-indigenous population were provided by the Superintendent of Police and related to people in the colony on 1 March 1879 and 'this estimate can be considered correct'. Perhaps the same could be said for the numbers of males and females given for many of the provinces-including one labelled 'estimate'because they are identical with the numbers released by the Provincial Office in January 1880, and published in the Fiji Times on 17 March, as relating to the census of the native population in March 1879.

The one province for which the numbers shown on the original recapitulation are identical with those in both the 1878 Blue Book and the Fiji Times was 'Colo (Navosa)', and these had been submitted by the Resident Commissioner for Navosa, Tholo, in September 1878 (Le Hunte, 
1878). In November 1878 the Resident Commissioner in another part of Tholo beg[ged] to suggest that the assistance of the Missionaries of the various districts be asked in this matter' of the census because 'the [native] officers do not as yet retain their posts with any degree of permanence in Colo for various reasons' (Carew, 1878), so perhaps any figures collected there in 1878 might also have been retained for 1879 , especially as Carew's letter bears a surly note, initialled by Thurston'Cannot expect anything but an approximation for Colo whether Returns are sent by Commissioner or Missionaries'. It is impossible to assess now how much of the 1878 census data was incorporated in the 1879 results, but in June 1879 the Native Commissioner asked the Governor's permission to employ someone to help with the census. 'Most of the returns from the Provinces are now in but it is simply impossible with the present staff in the office to tabulate and put them into an understandable form without some further assistance' (Wilkinson, 1879).

In the same month Thurston, as Colonial Secretary, forwarded statistical returns of the colony to the Chief Secretary of Victoria, and these showed a total of 107,098 Fijians which was presumably based on some combination of the 1878 figures for some provinces and either estimates for those which had not been censussed in 1878, or perhaps some 1879 totals. In his covering letter Thurston (1879) disparaged the population figures because he believed them too high, and stated that "no means exist yet for taking an exact census'. There was no mention of the census then being processed, and his subsequent distortions of both the date and the figures are curious.

The day chosen for the census was 10 March, but this date was not strictly observed, some provinces being censussed up to one week earlier, some later. On the day nominated the people of each village assembled in its 'town-square' and the headman of the village divided them into groups according to whether they were 'aged', 'middle-aged', 'youths and girls', 'walking children', or 'children unable to walk'. Particular kinds of wood had been chosen to designate each of these groups, and sticks of these were to be notched by the headman, a single notch denoting a male in the appropriate age group, and 'a cross notch for a female'. The sticks were then taken to the Buli of the district, and he and his scribe counted the notches and the scribe wrote down the numbers on a form which was then sent to the Provincial Scribe who copied these on to another form which was sent to the Native Commissioner (McGregor and Solomon, 1880).

This process of enumeration was outlined in the report of a commission appointed the following year to investigate certain alleged errors in the recent census of the Native population'. Dr W. McGregor, 
Chief Medical Officer, and Mr P. S. Solomon, editor of the Fiji Times, constituted the commission and they were allowed only three weeks for their investigations. Though they found 'discrepancies between the official returns and the original numbers obtained in enumerating the people' in some areas they visited, they believed 'the general result of the census ... sufficiently near the truth for ordinary purposes' and 'the grand total, so far as [they could] judge ... not very far from being correct'. Nevertheless, they advocated that 'a simpler method of taking the census . . . be adopted' and that another census be taken 'at some early date' (McGregor and Solomon, 1880, pp. 36-7, 43).

'Sufficiently near the truth' though it might have been, the 1879 census was not complete because, in addition to the Fijians living in parts of Tholo province who were not re-enumerated, Fijians who were absent from their village, working in the towns or on European plantations, were not included. Governor Gordon (1880a) considered that approximately 3,000 Fijians were excluded for this reason, and this number was accepted by the members of the 1893 Commission. In 1881 there were only 520 Fijians enumerated 'on estates'-and an estimated 480 employed on coastal vessels-(Des Voeux, 1881b), but as there were then about 3,000 more Polynesians and Asiatics, and only 200 more Europeans, than had been reported in 1879, the number of absentees estimated for 1879 seems reasonable.

While admitting that 'for all practical purposes the census of 1879 was found sufficient', Thurston (1881) nevertheless chose to mis-date it and distort the figures. In the draft of his report for the Fiji Blue Book for 1880 , he referred to two censuses of the colony, one taken in the present year (1881), but . . not yet published' and the other 'the first attempt to take the Fijian population . . . in January, 1880' when the total population was 124,902. The numbers of Europeans, Fijians, Polynesians and Asiatics ostensibly in the population at that date are almost identical with those given by Governor Des Voeux (1881a and b) in despatches to the Colonial Office in July and August 1881, these latter relating to the population enumerated in April of that year, and quite different from the numbers reported in the Fiji Blue Book for 1878 as the exogenous population of 1 March 1879.

Thurston's population of 115,635 Fijians in January 1880 was divided into descriptive age groups of children, youths, middle-aged, and aged, without distinction of sex, and the numbers in these categories bear a marked resemblance to those published in the Fiji Times in March 1880 and reproduced in the report of the 1893 Commission as relating to the population enumerated in March 1879 (Corney, Stewart and Thomson, 1896, pp. 117-24). These figures are given in Table 1 and it will be 
TABLE 1 Fijian population recorded in the first census as quoted by Thurston (1881) and the Fiji Times (1880)

\begin{tabular}{|c|c|c|c|c|}
\hline & \multirow{2}{*}{$\begin{array}{l}\text { Thurston } \\
\text { Persons }\end{array}$} & \multicolumn{3}{|c|}{ Fiji Times* } \\
\hline & & Males & Females & Persons \\
\hline Aged & 17,574 & 7,967 & 8,607 & 16,574 \\
\hline Middle-aged & 36,245 & 17,922 & 17,323 & 35,245 \\
\hline Youths & 28,444 & 13,642 & 10,802 & 24,444 \\
\hline Children & 33,372 & 17,962 & 14,699 & 32,661 \\
\hline Total & 115,635 & 57,493 & 51,431 & 108,924 \\
\hline
\end{tabular}

*Excludes Fijians absent from their village, estimated to number 3,000.

observed that, except for the children, the numbers in the two series differ only in the thousands digit, Thurston having added 1,000 persons to each of the aged and middle-aged and increased the number of youths by 4,000 . The number of children was increased by 711-a curious number to choose except that it brought the total to the required 115,635 , the number that had been recorded in the census of April 1881 and known in the colony in July even if not 'published' by November.

The more comprehensive census of 1881 inaugurated the series of decennial censuses which continued until 1921. All sections of the population were enumerated, though it is only for the Fijian population that the method of enumeration has been recorded. The census procedure was embodied in a regulation, No. 1 of 1881, of the Native Regulation Board, the text of which is as follows:

\section{RESPECTLNG THE CENSUS OF THE PEOPLE}

1. The people of the land shall be numbered on Monday, the fourth day of April, 1881. They shall be numbered by towns. The Chief of a town shall be responsible for the proper taking of the Census of the people of his town-that is, of all who sleep in his town-on the Sunday night previous, whether they be strangers or Taukeis.

2. The sticks by which they shall be numbered shall be square; one corner shall be notched for the aged; the second corner shall be notched for the full-grown, and the third corner for the youths, and the fourth corner for the children, one notch for each individual. Two sticks shall be provided for each town-one for males and one for females. The head of these sticks shall be painted a different colour: that for males shall be Black, and that for females shall be yellow. On the end of the corner of each stick shall be written 'Qase', 'Uabula', 'Cauravou', and 'Gone', for both male and female. 
3. It shall be the duty of the Buli of each district to appoint one man as enumerator to each town of his district, who shall go to the town for which he is appointed, taking the sticks with him on the Saturday previous to the Monday named, and with the Chief of the town, or an officer appointed by him for that purpose, shall proceed to number the people and mark the sticks by notches as above described. It shall be the duty of the person appointed by the Buli to number the males, and the Chief of the town, or the person appointed by him shall number the females and notch the sticks.

4. After the numbering of each town, the two numerators, together with the chief of the town, if he be not one, shall on the Tuesday following take their sticks to the Buli, who shall count and record the number of the people of such town on the Census papers provided. After they have been counted and recorded on the Census paper, the paper shall be rolled round the two sticks and bound together, which being completed, the numerators and the chief of the town will have performed their duty, and each numerator shall be paid one shilling by the Buli for his services from the Provincial Tax.

5. When the Buli of the district shall have completed the number and record of each town of his district, he shall then bind the sticks and papers of all his towns and take them to the Roko, and he shall remain with the Roko till the Vunivola has counted and recorded the Census of that district on the two prepared forms: one copy shall be given to the Buli and the other retained by the Vunivola.

6. When the number and record of each province is finished, the Roko shall send the Vunivola, with all the sticks and the papers, and other things used for the numbering of the people, to Nasova.

7. If anyone, without just cause, shall be absent from his town on Monday, the fourth day of April, or is disobedient in any matter relative to taking the Census, he may be fined in any amount not exceeding one shilling.

8. If any Buli, Chief of town, or any person engaged in taking the Census, refuses or neglects to perform his duties, or performs them improperly, or if any other person in any way disturbs or spoils the taking of the Census, or falsifies the returns by increasing the number, or by decreasing the number, he may be fined in an amount not exceeding ten shillings.

This, it was recognized, was

a somewhat primitive system-the best that could be devised to suit the capacity of the natives at that time, when some approximation to accuracy was all that could be hoped for-but not to be relied upon to produce anything more than a rough estimate of the population. Any tendency to error on the part of the enumerators would have 
TABLE 1 Fijian population recorded in the first census as quoted by Thurston (1881) and the Fiji Times (1880)

\begin{tabular}{|c|c|c|c|c|}
\hline & \multirow{2}{*}{$\begin{array}{l}\text { Thurston } \\
\text { Persons }\end{array}$} & \multicolumn{3}{|c|}{ Fiji Times* } \\
\hline & & Males & Females & Persons \\
\hline Aged & 17,574 & 7,967 & 8,607 & 16,574 \\
\hline Middle-aged & 36,245 & 17,922 & 17,323 & 35,245 \\
\hline Youths & 28,444 & 13,642 & 10,802 & 24,444 \\
\hline Children & 33,372 & 17,962 & 14,699 & 32,661 \\
\hline Total & 115,635 & 57,493 & 51,431 & 108,924 \\
\hline
\end{tabular}

*Excludes Fijians absent from their village, estimated to number 3,000.

observed that, except for the children, the numbers in the two series differ only in the thousands digit, Thurston having added 1,000 persons to each of the aged and middle-aged and increased the number of youths by 4,000 . The number of children was increased by 711-a curious number to choose except that it brought the total to the required 115,635, the number that had been recorded in the census of April 1881 and known in the colony in July even if not 'published' by November.

The more comprehensive census of 1881 inaugurated the series of decennial censuses which continued until 1921. All sections of the population were enumerated, though it is only for the Fijian population that the method of enumeration has been recorded. The census procedure was embodied in a regulation, No. 1 of 1881, of the Native Regulation Board, the text of which is as follows:

\section{RESPECTING THE CENSUS OF THE PEOPLE}

1. The people of the land shall be numbered on Monday, the fourth day of April, 1881. They shall be numbered by towns. The Chief of a town shall be responsible for the proper taking of the Census of the people of his town-that is, of all who sleep in his town-on the Sunday night previous, whether they be strangers or Taukeis.

2. The sticks by which they shall be numbered shall be square; one corner shall be notched for the aged; the second corner shall be notched for the full-grown, and the third corner for the youths, and the fourth corner for the children, one notch for each individual. Two sticks shall be provided for each town-one for males and one for females. The head of these sticks shall be painted a different colour: that for males shall be Black, and that for females shall be yellow. On the end of the corner of each stick shall be written 'Qase', 'Uabula', 'Cauravou', and 'Gone', for both male and female. 
3. It shall be the duty of the Buli of each district to appoint one man as enumerator to each town of his district, who shall go to the town for which he is appointed, taking the sticks with him on the Saturday previous to the Monday named, and with the Chief of the town, or an officer appointed by him for that purpose, shall proceed to number the people and mark the sticks by notches as above described. It shall be the duty of the person appointed by the Buli to number the males, and the Chief of the town, or the person appointed by him shall number the females and notch the sticks.

4. After the numbering of each town, the two numerators, together with the chief of the town, if he be not one, shall on the Tuesday following take their sticks to the Buli, who shall oount and record the number of the people of such town on the Census papers provided. After they have been counted and recorded on the Census paper, the paper shall be rolled round the two sticks and bound together, which being completed, the numerators and the chief of the town will have performed their duty, and each numerator shall be paid one shilling by the Buli for his services from the Provincial Tax.

5. When the Buli of the district shall have completed the number and record of each town of his district, he shall then bind the sticks and papers of all his towns and take them to the Roko, and he shall remain with the Roko till the Vunivola has counted and recorded the Census of that district on the two prepared forms: one copy shall be given to the Buli and the other retained by the Vunivola.

6. When the number and record of each province is finished, the Roko shall send the Vunivola, with all the sticks and the papers, and other things used for the numbering of the people, to Nasova.

7. If anyone, without just cause, shall be absent from his town on Monday, the fourth day of April, or is disobedient in any matter relative to taking the Census, he may be fined in any amount not exceeding one shilling.

8. If any Buli, Chief of town, or any person engaged in taking the Census, refuses or neglects to perform his duties, or performs them improperly, or if any other person in any way disturbs or spoils the taking of the Census, or falsifies the returns by increasing the number, or by decreasing the number, he may be fined in an amount not exceeding ten shillings.

This, it was recognized, was

a somewhat primitive system-the best that could be devised to suit the capacity of the natives at that time, when some approximation to accuracy was all that could be hoped for-but not to be relied upon to produce anything more than a rough estimate of the population. Any tendency to error on the part of the enumerators would have 
been to overstate the numbers of their people and, therefore, their importance (Thomson, 1892a, p. 106).

There may also have been some exaggeration in the figures because of a confusion as to the date of the enumeration. March 7 was originally chosen by the Fijian officials and the census was taken on this day in many areas. In Mba province this was the only count made but some places were enumerated twice and their numbers may have been duplicated in the preliminary total (Des Voeux, 1881b). This may explain the difference between the initial count of 115,635 (which included an estimate of 480 aboard coastal vessels) for the Fijian population and the final total of 114,748 . There were changes subsequently in the numbers first given for other sections of the population, and as all were increased one might infer either delays or difficulties in enumerating the people living on some European estates. Rotuma, formally annexed later that year, was not included in the general enumeration, but the Resident Commissioner 'furnished' a census 'return' sometime before the end of September which showed a total of 2,450 (Emberson, 1881).

The second decennial census was apparently more sophisticated but no more informative. The notched sticks of 1881 were replaced by less colourful forms on which the persons sleeping in each village on the night of 5 April 1891 were to be recorded by name.

On the whole, fair intelligence was shown by the enumerators; but there can be no doubt that errors, both intentional and ignorant, occurred, which in the aggregate amounted to a considerable number. The forms each contained 81 spaces for names, and in no less than 2.49 per cent of the villages, the form was exactly filled up. In one village .... it was afterwards found that 60 names had been omitted. The enumerator, either thinking that his task was completed, or having spoilt one form and being unprovided with a second, neglected to record any more names (Thomson, 1892a, p. 106).

About two-thirds of the fifty-six villages whose population numbered exactly 81 or some multiple of 81 had failed to record some of their population and, though the total number not counted was negligible compared with the total population, many of the persons omitted were infant females, 'these presumably supposed to be of least account, or, from a native point of view, not worth the trouble of enumeration' (Stewart, 1892, p. 118). If this were true, then perhaps infant females tended to be disregarded elsewhere in this count, and the female population was larger than was recorded.

Apart from this source of under-enumeration, the 1891 census returns were further suspect because, in some areas, the natives felt that the 
census preceded an increase in the tax assessment, and this 'naturally formed a strong motive for understating the population' (Thomson, 1892a, p. 106). The failure to enumerate the crews of inter-island vessels at sea, or in harbours other than Suva or Levuka was also attributed to this fear. Some further comments on the method of enumeration at this census were made by Assistant Colonial Secretary Stewart in the 'Minute' which accompanied the Twelfth Annual Report on the Vital Statistics of the Native Population; year 1890 and 1891.

The census in many places appears to have been taken from memory. A few men with good memory are called into the chief's house, and, beginning with the chief, go down the scale of importance until they arrive at the youngest female in the town. Probably the Census is as correctly given in that way as in any other. Some of the District Scribes appear to have been perfunctory in the work of the Census, taking the names of the people on loose sheets of paper and afterwards filling up the returns therefrom, in some instances having in the meantime lost a portion of the papers (Stewart, 1892, p. 118).

Notwithstanding these known errors and omissions, Stewart concluded 'that the Census of 1891 is the most correct that has been taken', demonstrating its correctness at some length by comparisons with the two previous censuses, the ecclesiastical returns of 1881 and 1891, and the registers of births and deaths during the inter-censal periods. Once again, however, the arrangements for enumerating the non-Fijian sections are not recorded, although by this time the Indian population numbered 7,500 , two-thirds of them being males.

In the third decennial census, taken on 31 March 1901, the Fijian population was enumerated on forms similar to those used in 1891. This time instructions were issued with the schedules explaining that if there were more than 81 people in a village the listing of names was to be continued on a second schedule. Despite this, $2 \cdot 6$ per cent of the villages again returned forms with exactly 81 names, and of those that were returned to the provinces for checking all were held to be correct and complete. The Native Commissioner was responsible for the enumeration of the Fijians, and he distrusted the accuracy of the count, claiming that too few Fijians had been recorded. Nevertheless, he had 'no reason to believe that this census is less correct than that taken in 1891, so that on both occasions the population has been given as accurately as it is possible to obtain where Natives are the enumerators' (Sutherland, 1902, p. 46). The enumeration of the non-Fijian population in 1901 was arranged by the Registrar-General, and the only details of organization given in his report on this part of the census were that 
'some 6,000 forms were distributed . . . to the various magistrates of the Colony with instructions as to the enumeration that would be required' (Dods, 1901, p. 444).

In 1911 a commissioner was 'appointed to superintend the taking of the Census of the Colony on the night of Sunday, the 2nd of April, $1911^{\prime}$ and there was, therefore, no division of authority and responsibility for this enumeration such as had happened previously. In the conclusion of the census report, the Commissioner mentioned briefly that 'all magisterial districts . . . were divided into convenient enumeration divisions and an enumerator assigned to each. Each enumerator was supplied with a set of detailed instructions based on the general instructions approved by the Local Government Board [of Great Britain]. Six different schedules were used for the general census and one special form for Fijians living in their native communities.' The latter were enumerated either by the village headman or, if he was illiterate or otherwise incompetent, by a scribe from the district or provincial office.

The remainder of the population was apparently expected to complete their own schedules, although some help was given to the 'timeexpired Indian immigrants and their families, very few of whom can read or understand either English or Fijian, in which languages the schedules were printed'. The enumeration of Rotuma was 'much hampered' by the severe epidemic of measles then raging on the island, and the Resident Commissioner was not prepared to guarantee the return as being absolutely correct'. Despite all the difficulties of enumeration, the Census Commissioner considered that 'there is every reason to believe that the Census tables now submitted are as accurate and reliable as can reasonably be expected under the prevailing conditions' (Boyd, 1911, pp. 5, 14-15).

The tabulations for the European, Half-caste and Indian populations of 1911 were more detailed than those for Fijians, Rotumans, and socalled Polynesians. Though Rotumans were classified in broad groups of chronological age, this classification was no more detailed than the descriptive age groups of children, youths, adults, and aged still regretfully used for the Fijian and Polynesian populations. The other populations were tabulated according to chronological age in the customary five-year age groups, further classified according to marital status within each age group. The question on marital status was not asked of Fijians or Rotumans, and its irrelevance to the Polynesians was apparent in the replies given or not given on their schedules. Reconstructing the schedules from the tabulations, the questions not asked of Fijians and Rotumans but asked of all others were chronological age, marital status, 
birthplace, and occupation. This last was also recorded for Fijians living away from their villages.

Uniformity with respect to the tabulations for each of the component populations appears first in the report on the 1921 census, the authors of which had been responsible only for the final analysis and tabulation of the returns, and not for the organization of the census. Consequently no details are given of 'the preliminary work of dividing the Colony into enumeration areas, the appointment of enumerators, and the arrangements for the distribution and collection of the Census schedules', but it is clear from the Census Ordinance (No. 27 of 1920) that once again there were different procedures for enumerating the Fijians living in their villages and the remainder of the population. The villagers were enumerated by their headman or his deputy: elsewhere, schedules were left at all inhabitated dwellings before 24 April, and it was the responsibility of the 'occupier' to 'fill up or cause to be filled up the said schedule to the best of his knowledge and belief so far as relates to all persons dwelling in his house. . . The enumerators were then to collect the forms on 25 April and to

complete any of the said schedules which shall upon delivery appear defective and correct those of the said schedules which they shall find to be erroneous and shall copy the schedules when completed and corrected into books to be provided for that purpose and shall add thereto an account according to the best of their information of all other persons living within the division who shall not be included in the schedules so collected ... (Boyd and Stewart, 1922, p. vii).

The copying of schedules recording the name age sex nationality religion education infirmities rank profession occupation oondition as to marriage relation to head of family and birthplace of every living person who abode in every house' in an enumerator's area would be an unenviable task, and one might doubt that this procedure would increase the legibility of the returns, to say nothing of their accuracy (Boyd and Stewart, 1922, pp. vi, vii, xxxvii).

Such transcription was apparently not required again for the 1936 census, the ordinance for which (No. 32 of 1935) lays down a procedure which does not otherwise differ materially from that for the 1921 census, either in the method of enumeration or in the particulars to be recorded. The census date was 26 April 1936 and although seven different schedules were used, the main difference between them was the language or languages in which they were printed so that they would 'more readily be understood by the various races in the Colony'. The Census Commissioner subsequently reported with regret: 
There was found to be a considerable divergence in the accuracy and care with which schedules had been completed in the several parts of the Colony. In the majority of cases the explanations supplied seem to have been sufficiently explicit to be understood, and in most parts of the Colony the supervision was such that it was no difficult matter to obtain the statistical information required. In some, however, it was disappointing to find whole schedules with the occupation column left blank, and in others to find the word "cultivation" only, with nothing to show what type of cultivation was being carried out. In known sugar-cane areas the benefit of the doubt was given to cane cultivation (Burrows, 1936, p. 3).

When the schedules were received in Suva, the data recorded on them were transcribed on to cards, with one card for each person on a schedule, and these were then sorted by hand and counted. This method of tabuIation was apparently an innovation, and the tabulations compiled differ from those of earlier censuses in their observance of provincial boundaries instead of the more or less arbitrarily defined boundaries of magisterial districts used formerly.

There was some revision of these provincial boundaries before the next census was held on 3 October 1946. This enumeration covered all persons who were in Fiji at midnight on 2 October, irrespective of whether they were permanent residents or transient visitors. Though few of the reports on the earlier censuses are explicit as to whether it was this de facto population which had been enumerated, or whether only the resident or de jure population had been recorded, the presumption is that all related to the de facto population. The procedure for the 1946 enumeration is set out most comprehensively in the report and, for the first time, the whole of the census procedure was uniform for all sections of the population. A specimen of the schedule used is bound with the report, and schedules printed in either English, Fijian, or Hindi (Nagri script) were distributed to all inhabited dwellings, each householder being responsible for completing the schedule for his household.

The enumerators (who should more properly be called collectors in this case) were issued with printed instructions and, in addition to distributing and collecting the schedules, were required to check through them with the householder on collection. An enumerator covered from 55 to 70 households on an average, and this was calculated to be roughly equivalent to between 250 and 350 persons per enumerator. The geographic division of the colony into enumerators' areas of suitable size was the responsibility of the District Commissioners and their staff, who were Superintendents of Census in the province or provinces constituting their administrative districts. They also "held as many meetings as [were] 
thought necessary to instruct [the] officials in the work required of them, while the Commissioner of Census toured the Colony and addressed gatherings at all main centres of population'. For two or three months before census date, publicity was given in the press and on the radio to the taking of the census, and the Commissioner felt that "every possible precaution [had] been taken to ensure accuracy and a full count of the population' (Gittins, 1947, pp. 5, 9).

He must nevertheless have been aware that some precautions might have been overlooked for, when the details relating to each person recorded on a schedule were being transcribed by 'sorter clerks' on to the compilation cards used for tabulating, it was found that

Some sorters encountered 'lucky piles' of schedules, by which is meant that the schedules were fairly correctly filled, and that they were clear and readable; others, and these were the great majority, had to deal with schedules, the entries on which, for a variety of reasons, were unsatisfactory. The writing in many cases was far from good, and the clear and implicit instructions on the schedules as to the manner in which they should be filled in were not always obeyed (Gittins, 1947, p. 9).

The impression that the whole scheme might have been over-ambitious and ill-suited to 'the capacity of the natives at that time' (Thomson, 1892a) is reinforced by comments elsewhere in the report concerning the standard of replies to specific questions. Increase in the scope of the census was traditionally the objective of each successive census-taker and by 1946 the personal questions on the census schedule amounted to seventeen main questions, three of which had either two or three parts, and these were supplemented by several questions on infirmities, housing and poultry. With a total of thirty-three questions it was a formidable schedule for anyone to complete but better suited to a population more sophisticated than Fijis.

It would be unfair to attribute this lack of realism to any one person or even to a group of persons. The Commissioner of Census in 1946 was an administrative officer, as were his predecessors, temporarily relieved of his normal duties to organize the census. He had had no training in either demography or statistics, and such advice as was available to him was based largely on the experience of census-taking in Australia and New Zealand. That this might not be applicable without modification to Fiji was not generally appreciated, nor was it likely that any departure from acknowledged procedures would have been acceptable without the backing of 'expert opinion'. This was sought when the 1956 census was contemplated and, as a result, the present author was 
appointed Census Commissioner, knowing as little about Fiji as the previous Commissioners had known about demography, and with as little practical experience of census-taking as they had had.

The plan that was devised was the outcome of a critical survey of population statistics throughout several Pacific territories and it served as the model for contemporary censuses in four of these. For Fiji, the scope of the questionnaire was drastically reduced and the census was conducted strictly as an enumeration, with trained enumerators completing the schedules for all households. The enumeration was spread over two weeks, with the enumerators making two calls at each household within the areas assigned to them. The first visit occurred in the ten days preceding the oensus date, and the enumerator then recorded the details required about each person who could be expected to be in that household on the night of 26 September. These records were checked and amended as necessary on the second round of his area soom after this date.

As far as possible Fijian households were enumerated by Fijians, and Indian households by Indians, but all schedules were completed in English so that the data could be processed in Australia. The editing and coding of schedules was done in Fiji but all stages of tabulating, from the marking of cards through to the final tabulations, were done by the Commonwealth Bureau of Census and Statistics, Canberra. Officers of the District Administration in Fiji were again responsible for the division of the colony into enumerators' areas, for the selection and much of the training of enumerators and for their supervision during the enumeration.

Excluding the three questions on fertility which were asked of all females aged 15 years and over, there were only ten questions on the schedule, and close scrutiny of several thousands of completed schedules suggests that this approaches the upper limit to the scope which should be attempted in a full enumeration at the present time. The importance of accuracy and consistency in recording was emphasized in all instructions to enumerators and, though a few clearly lacked adequate training and supervision, the results were reasonably good. Perhaps the next Census Commissioner will have different views.

Before examining the data from these various official censuses, it will be profitable to recapitulate their objectives and probable accuracy. The 1879 census was primarily a count of Fijian heads, 'sufficient' for all practical purposes but acknowledged to be incomplete. It would be better regarded as an informed estimate than as a census, even though the enumerated population was classified by sex and broadly by age. The 1881 census was the first comprehensive count of all sectors of the 
population. The Fijians living in the villages were again recorded by notches on sticks and, though confusion between males and females was unlikely, there could be many slips between the corners of the sticks which denoted the four age groups. As in 1879 the counting of notches and the subsequent compilation procedure from village to district to province gave scope for error; and on these grounds alone one might justifiably doubt the accuracy of the final tabulation. Thomson (1892a) thought the count exaggerated and his colleague Stewart (1892) preferred the result of the 1879 census. There is no record of how the remainder of the population was enumerated.

In both 1891 and 1901 whole villages were recorded on forms which had spaces for 81 names and some enumerators did not bother to start new forms when the first were full. For various reasons the 1891 census was believed to under-state the Fijian population, though probably by only a small margin. In 1901, the Native Commissioner considered his census no less correct than its predecessor. For neither of these censuses is it clear how the non-Fijian sectors of the population were enumerated, but it seems probable that only sex and descriptive age were recorded for all except the 'whites' and 'half-castes'.

There was a change in census procedure in 1911, when one man was responsible for the whole operation. Fijians living in village communities were treated differently from the remainder of the population, but their religion, infirmities, and literacy were recorded as well as their sex and whether they were children, youths, adults, or aged. This was the last occasion on which age was so recorded; in all subsequent censuses chronological age was substituted, even though it was appreciated that for many Fijians (and Indians and some others) this could only be estimated. From 1921 onwards the census schedules have been essentially the same for all sectors of the population, and the procedure for enumeration followed until 1956 suggests that those responsible were more concerned with the counting of heads than with determining the characteristics of the population.

Until 1946 each Fijian village was enumerated by its headman or his deputy and, though the headman would know and be able to account for every person in his village, chronological age would mean as little to him as to most villagers. In 1946 each household had its own schedule and, as had happened with all other sectors of the population in each census from 1911 (or perhaps earlier) until 1946, the schedule was completed by some member of the household. More than literacy is required if forms are to be filled in intelligently and few heads of households in Fiji would be accustomed to form-filling. The schedules were ostensibly 
checked on collection, but it is doubtful if this checking went beyond a tally of the number of persons in the household and the number listed on the schedule.

\section{Course of Population Change}

The populations recorded in each census from 1879 to 1911 are given in Table 2, and their numbers from 1921 to 1956 in Table 3. For the first half of this period the Fijian population predominated in the total even though its size declined progressively in each census. On census figures alone this decline continued until 1921 but the turning-point had in fact been reached in the period 1905-11, and thereafter there was a consistent excess of births over deaths in each year except 1918 when more than 5,000 Fijians died in the influenza epidemic. In 1921, only 54 per cent of the population of Fiji were Fijians and 39 per cent were Indians. Since then the Fijian and Indian components have together contributed more than 90 per cent of the total, but the relative roles of each have changed gradually so that, in 1956, 49 per cent of the total were Indians and less than 43 per cent Fijians.

The Fijian population suffered severely in the measles epidemic of 1875. This was the first major outbreak of disease for more than seventy years, and in four months probably one-fifth or more of the population died. Four years later there were about 112,000 Fijians in the colony and their number may have increased slightly during the next two years. Such increase as occurred was not evenly distributed and the births and deaths that were being recorded showed net gains to the population in some areas and losses through excessive mortality in others (Gordon, $1880 \mathrm{~b}$ ). Although there was an outbreak of influenza in 1883 (Corney, 1884), there seems to have been no epidemic that entailed abnormal mortality amongst Fijians until 1884, when at least 3,000 persons died in an outbreak of whooping cough. In 1885-6 there were three further epidemics-of dengue fever, dysentery, and influenza-which together resulted in at least 1,000 deaths. Another outbreak of epidemic influenza occurred in 1891 and, in the same year, whooping cough reappeared in the colony. About 1,500 deaths were attributed to these two diseases in 1891 and, though some of these deaths may have been of people who would have died within a few years anyway, this batch of introduced diseases caused the deaths of at least 5,500 Fijians.

The source of these estimates of the excess mortality due to epidemics is an analysis of Fijian births and deaths registered throughout the intercensal period 1881-91, in which the Native Lands Commissioner Thomson noted that whenever the Colony is free from epidemic diseases of European origin the native population does not decrease' (Thomson, 
TABLE 2 The populations enumerated in successive censuses of Fiji, 1879 to 1911 , by sex

\begin{tabular}{|c|c|c|c|c|c|c|}
\hline $\begin{array}{l}\text { Component } \\
\text { population }\end{array}$ & Sex & 1879 & 1881 & 1891 & 1901 & 1911 \\
\hline Fijian: Total & $\begin{array}{l}\mathrm{P} \\
\mathrm{M} \\
\mathrm{F}\end{array}$ & $\begin{array}{c}108,924^{*} \\
57,493 \\
51,431\end{array}$ & $\begin{array}{r}114,748 \\
60,899 \\
53,849\end{array}$ & $\begin{array}{r}105,800 \\
56,445 \\
49,355\end{array}$ & $\begin{array}{l}94,397 \\
50,357 \\
44,040\end{array}$ & $\begin{array}{l}87,096 \\
46,110 \\
40,986\end{array}$ \\
\hline Children & $\begin{array}{l}\mathrm{M} \\
\mathrm{F}\end{array}$ & $\begin{array}{l}17,962 \\
14,699\end{array}$ & $\begin{array}{l}20,873 \\
16,305\end{array}$ & $\begin{array}{l}18,292 \\
16,172\end{array}$ & $\begin{array}{l}15,287 \\
13,113\end{array}$ & $\begin{array}{l}14,372 \\
12,968\end{array}$ \\
\hline Youths & $\begin{array}{l}\mathrm{M} \\
\mathrm{F}\end{array}$ & $\begin{array}{l}13,642 \\
10,802\end{array}$ & $\begin{array}{r}12,738 \\
8,760\end{array}$ & $\begin{array}{r}11,850 \\
6,957\end{array}$ & $\begin{array}{r}10,079 \\
6,465\end{array}$ & $\begin{array}{l}9,709 \\
6,095\end{array}$ \\
\hline Adults & $\begin{array}{l}\mathrm{M} \\
\mathrm{F}\end{array}$ & $\begin{array}{l}17,922 \\
17,323\end{array}$ & $\begin{array}{l}18,605 \\
19,520\end{array}$ & $\begin{array}{l}18,975 \\
18,186\end{array}$ & $\begin{array}{l}18,167 \\
17,004\end{array}$ & $\begin{array}{l}15,885 \\
15,322\end{array}$ \\
\hline Aged & $\begin{array}{l}\mathrm{M} \\
\mathrm{F}\end{array}$ & $\begin{array}{l}7,967 \\
8,607\end{array}$ & $\begin{array}{l}8,683 \\
9,264\end{array}$ & $\begin{array}{l}7,328 \\
8,040\end{array}$ & $\begin{array}{l}6,824 \\
7,458\end{array}$ & $\begin{array}{l}6,144 \\
6,601\end{array}$ \\
\hline Chinese & $\begin{array}{l}\mathrm{P} \\
\mathrm{M} \\
\mathrm{F}\end{array}$ & $\begin{array}{l}+ \\
+ \\
+\end{array}$ & $\begin{array}{l}\ddagger \\
\ddagger \\
\ddagger\end{array}$ & $\begin{array}{l}\ddagger \\
\ddagger \\
\ddagger\end{array}$ & $\begin{array}{l}t \\
t \\
t\end{array}$ & $\begin{array}{r}305 \\
276 \\
29\end{array}$ \\
\hline European & $\begin{array}{l}\mathrm{P} \\
\mathrm{M} \\
\mathrm{F}\end{array}$ & $\begin{array}{l}+ \\
+ \\
+\end{array}$ & $\begin{array}{r}2,671 \\
1,879 \\
792\end{array}$ & $\begin{array}{r}2,036 \\
1,273 \\
763\end{array}$ & $\begin{array}{r}2,459 \\
1,531 \\
928\end{array}$ & $\begin{array}{l}3,707 \\
2,403 \\
1,304\end{array}$ \\
\hline Indian & $\begin{array}{l}\mathrm{P} \\
\mathrm{M} \\
\mathrm{F}\end{array}$ & $\begin{array}{l}+ \\
+ \\
+\end{array}$ & $\begin{array}{l}588 \\
388 \\
200\end{array}$ & $\begin{array}{l}7,468 \\
4,998 \\
2,470\end{array}$ & $\begin{array}{r}17,105 \\
11,353 \\
5,752\end{array}$ & $\begin{array}{l}40,286 \\
26,073 \\
14,213\end{array}$ \\
\hline Part-European & $\begin{array}{l}\mathrm{P} \\
\mathrm{M} \\
\mathrm{F}\end{array}$ & $\begin{array}{l}+ \\
+ \\
+\end{array}$ & $\begin{array}{l}771 \\
387 \\
384\end{array}$ & $\begin{array}{r}1,076 \\
529 \\
547\end{array}$ & $\begin{array}{r}1,516 \\
759 \\
757\end{array}$ & $\begin{array}{l}2,401 \\
1,217 \\
1,184\end{array}$ \\
\hline Rotuman & $\begin{array}{l}P \\
M \\
F\end{array}$ & $\begin{array}{l}+ \\
+ \\
+\end{array}$ & $\begin{array}{l}2,452 \S \\
1,126 \\
1,326\end{array}$ & $\begin{array}{l}2,219 \\
1,056 \\
1,163\end{array}$ & $\begin{array}{l}2,230 \\
1,036 \\
1,194\end{array}$ & $\begin{array}{l}2,176 \\
1,043 \\
1,133\end{array}$ \\
\hline $\begin{array}{l}\text { Other Pacific } \\
\text { Islanders }\end{array}$ & $\begin{array}{l}\mathrm{P} \\
\mathrm{M} \\
\mathrm{F}\end{array}$ & $\begin{array}{l}+ \\
\dagger \\
+\end{array}$ & $\begin{array}{r}6,100 \\
5,629 \\
471\end{array}$ & $\begin{array}{r}2,267 \\
1,923 \\
344\end{array}$ & $\begin{array}{r}1,950 \\
1,584 \\
366\end{array}$ & $\begin{array}{r}2,758 \\
2,429 \\
329\end{array}$ \\
\hline All others & $\begin{array}{l}\mathrm{P} \\
\mathrm{M} \\
\mathrm{F}\end{array}$ & $\begin{array}{l}+ \\
+ \\
+\end{array}$ & $\begin{array}{r}156 \\
93 \\
63\end{array}$ & $\begin{array}{l}314 \\
143 \\
171\end{array}$ & $\begin{array}{l}467 \\
254 \\
213\end{array}$ & $\begin{array}{l}812 \\
457 \\
355\end{array}$ \\
\hline All components & $\begin{array}{l}\mathrm{P} \\
\mathrm{M} \\
\mathrm{F}\end{array}$ & $\begin{array}{l}+ \\
+ \\
+\end{array}$ & $\begin{array}{r}127,486 \\
70,401 \\
57,085\end{array}$ & $\begin{array}{r}121,180 \\
66,367 \\
54,813\end{array}$ & $\begin{array}{r}120,124 \\
66,874 \\
53,250\end{array}$ & $\begin{array}{r}139,541 \\
80,008 \\
59,533\end{array}$ \\
\hline
\end{tabular}

*Excludes Fijians working as labourers for Europeans, estimated to number 3,000 .

$\dagger$ Not enumerated.

$\ddagger$ Included with 'All others'.

§stimate only: Rotuma was annexed after the census had been taken. 
TABLE 3 The populations enumerated in successive censuses of Fiji, 1921 to 1956 , by sex

\begin{tabular}{|c|c|c|c|c|c|}
\hline Component populations & Sex & 1921 & 1936 & $1946^{*}$ & 1956 \\
\hline \multirow[t]{3}{*}{ Fijian } & $\mathrm{P}$ & 84,475 & 97,651 & 118,070 & 148,134 \\
\hline & $\mathbf{M}$ & 44,022 & 49,869 & 59,862 & 74,989 \\
\hline & $\mathrm{F}$ & 40,453 & 47,782 & 58,208 & 73,145 \\
\hline \multirow[t]{3}{*}{ Chinese $\dagger$} & $\mathrm{P}$ & 910 & $1, \dot{7} 51$ & 2,874 & 4,155 \\
\hline & $\mathbf{M}$ & 845 & 1,476 & 2,105 & 2,624 \\
\hline & $\mathrm{F}$ & 65 & 275 & 769 & 1,531 \\
\hline \multirow[t]{3}{*}{ European } & $\mathrm{P}$ & 3,878 & 4,028 & 4,594 & 6,402 \\
\hline & $\mathbf{M}$ & 2,297 & 2,263 & 2,467 & 3,374 \\
\hline & $\mathrm{F}$ & 1,581 & 1,765 & 2,127 & 3,028 \\
\hline \multirow[t]{3}{*}{ Indian } & $P$ & 60,634 & 85,002 & 120,414 & 169,403 \\
\hline & M & 37,015 & 48,246 & 64,988 & 88,359 \\
\hline & $\mathrm{F}$ & 23,619 & 36,756 & 55,426 & 81,044 \\
\hline \multirow[t]{3}{*}{ Part-European } & $\mathbf{P}$ & 2,781 & 4,574 & 6,142 & 7,810 \\
\hline & M & 1,454 & 2,325 & 3,195 & 4,008 \\
\hline & $\mathrm{F}$ & 1,327 & 2,249 & 2,947 & 3,802 \\
\hline \multirow[t]{3}{*}{ Rotuman } & $P$ & 2,235 & 2,816 & 3,313 & 4,422 \\
\hline & M & 1,129 & 1,413 & 1,696 & 2,232 \\
\hline & $\mathrm{F}$ & 1,106 & 1,403 & 1,617 & 2,190 \\
\hline \multirow[t]{3}{*}{ Other Pacific Islanders } & $\mathrm{P}$ & 1,564 & 2,353 & 3,717 & 5,320 \\
\hline & $\mathbf{M}$ & 1,271 & 1,470 & 2,145 & 2,839 \\
\hline & $\mathrm{F}$ & 293 & 883 & 1,572 & 2,481 \\
\hline \multirow[t]{3}{*}{ All others } & $P$ & 789 & 204 & 514 & 91 \\
\hline & $\mathbf{M}$ & 431 & 132 & 273 & 50 \\
\hline & $\mathrm{F}$ & 358 & 72 & 241 & 41 \\
\hline \multirow[t]{3}{*}{ All components } & $\mathbf{P}$ & 157,266 & 198,379 & 259,638 & 345,737 \\
\hline & $\mathbf{M}$ & 88,464 & 107,194 & 136,731 & 178,475 \\
\hline & $\mathrm{F}$ & 68,802 & 91,185 & 122,907 & 167,262 \\
\hline
\end{tabular}

*Classification adjusted to correspond with other censuses (Gittins, 1947, p. 59). †Includes Part-Chinese in 1946 and 1956, probably also in 1936. 
$1892 \mathrm{~b}$, p. 59). In the years unmarred by such outbreaks-1881-3 and 1887-8-the numbers of births registered exceeded the numbers of deaths, and by as many as 559 in 1888. This document was prepared for the consideration of the 1893 Commission (of which Thomson was a member) appointed to examine the replies received to a circular letter in which the Colonial Secretary expressed concern over the decrease in the Fijian population as revealed by the 1891 census, and invited the opinions of the European colonists as to the causes of and remedies for this decrease. The commission was formally appointed in March 1893 and perhaps because it exceeded its terms of referenoe by conducting independent inquiries on its own behalf, the publication of its valuable though voluminous report was delayed until 1896.

A relevant point overlooked by Thomson was that the small numbers of deaths in the non-epidemic years were partly the consequence of the high mortality in the intervening years; the epidemics merely advanced the deaths of people who would have died sometime later, so that there was a 'heaping' of deaths in epidemic years which would tend to lower the number of deaths likely to occur in each of the next few years. The amount of heaping likely would depend on the nature of the disease concerned and on the age incidence of mortality; because the deaths most likely to be advanced in time are those of aged or elderly people, a disease which attacks only persons aged less than 25 years would not lead to much 'heaping' in an epidemic year, whereas an outbreak confined to people over 60 years of age would cause much. Even at its maximum the effect would be rather transitory, lasting perhaps for no more than two or three years after the epidemic, but during this period the number of deaths in a year might fall below the number of births so that population numbers would increase.

In the next decade, however, the Fijian population did decrease steadily even though the colony was reputed to have been free from any major outbreak of disease. The deaths recorded during the years 1891 to 1900 consistently exceeded the numbers of births registered and the situation was watched anxiously by both the government and the Fijian chiefs. Registrations of the births and deaths occurring in each district ultimately reached the Roko, the principal Fijian official in each province, and if he found that the number of deaths in a particular village or particular area greatly exceeded the births, the Buli responsible for that area was usually called upon to explain why this had happened. Consequently the registration during this period can be regarded as virtually complete, especially as regards births, though there may have been some concealment of deaths to avoid troublesome questioning.

Nevertheless the births recorded fell from an average of 4,220 per 
year between 1881 and 1890 to 3,920 annually between 1891 and 1895, and to an average of 3,495 per year between 1896 and 1900 . The births in each period fluctuated around these averages, but there was quite an abrupt transition between the numbers recorded before 1890 and after 1895 which suggests rapid changes either in the reproductive capacity of the population or in their fertility habits.

For better or for worse the Deed of Cession altered the status of women in Fiji. Several witnesses to the 1893 Commission deplored the changes that had occurred since European contact, pointing to the lack of restraint on young girls before marriage, their 'disinclination for the restraints of lawful marniage' (Thomson, 1892b, p. 60), and their reluctance to bear children. None of these allegations can be substantiated but as the missionaries had frowned on polygamy and child marriage, suppressing them wherever possible, some upheaval in the attitudes of both sexes to marriage was inevitable, and a change in the attitude of women to child-bearing would be a natural enough corollary. One might reasonably doubt, however, that this alone would have caused the comparatively sharp decline that occurred in the number of births in the 1890s.

The reproductive capacity of the population would be reduced suddenly either by severe mortality as in an epidemic or by there being fewer women attaining the ages associated with high fertility than the numbers at ages beyond these. There were only two epidemics between 1890 and 1895, and both occurred in 1891 causing at least 1,500 deaths. $\mathrm{Had}$ all of these victims been women of reproductive age these two epidemics might have accounted for the initial fall in the number of births, but as there were no further outbreaks during the decade, the second alternative-of a distorted age structure-must be examined.

The most likely source of distortion in the age composition of the Fijian population was the 1875 measles epidemic. As this was their first experience of the disease, one might assume that virtually every member of the population was attacked, but this does not necessarily mean that the age incidence of mortality was uniform throughout the population. If whole villages became infected more or less simultaneously so that there was no one capable of attending the sick, the persons least capable of looking after themselves and therefore most likely to die of starvation and neglect would be the very young and the very old.

It might therefore be argued that the very young unweaned infants ran a double risk of mortality-their own particular risk of dying from measles and the risk of starvation if the mothers were severely infected and eventually died. If infant females were genuinely of 'least account' in Fijian communities (Stewart, 1892, p. 118), the chances of a female 
surviving the double risk of mortality would be less than those for a male infant. Depending on the probability of survival for a female infant in the event of her mother's death, a 20 per cent risk of dying from infection (for both mothers and infants) would lead to a reduction of between 20 and 36 per cent in the number of female infants: if death from starvation was certain, only 64 per cent would survive both measles and the mother's death, and if there was an even chance of their being taken by a foster-mother, 72 per cent would survive the epidemic.

This enhanced mortality risk would concern infants aged less than 2 years in 1875, and the remainder of the cohort at average age 20 in 1895 would be the survivors of the births which occurred in the immediate post-epidemic period. If $N$ women had produced an average of $n$ births a year before 1875 and the mortality rate amongst them and their husbands in the epidemic was 20 per cent, the number of births expected in the immediate post-epidemic years would have been of the order of $0.64 n$. If the mortality rate was higher than 20 per cent, relatively more marriages would have been disrupted by the death of either or both partners, and a mortality rate of 25 per cent could be expected to decrease the annual births by nearly one-half. The number of births each year would rise again gradually as new unions were formed, but the cohort consisting of the survivors of the infants born in the two years preceding the epidemic and the births of the three immediate post-epidemic years would be very much smaller than the cohorts on either side of it, and this and the younger cohort would be the two which were largely responsible for the births in Fiji for about fifteen years after 1895 .

Changes such as these in the age composition would be obscured in the descriptive age groups used in the census data. The range of chronological ages that Thomson assigned to each group (1892a, p. 109) equated 'children' to ages less than 15 years, 'youths' and 'adults' to the range 15 to 50 years with the division at 25 years for males and 21 years for females, and 'aged' to more than 50 years. The distinction between 'youths' and 'adults' was presumably one of marital status as well as age, and amongst females 'adults' probably included females beyond reproductive ages. Nevertheless the number of 'adult' females decreased progressively from 1881 to 1891 to 1901 , though with a relatively greater decrease between 1881 and 1891 than over the next decade. The greatest change that occurred between 1881 and 1891 was the decrease in the number of female 'youths' and as this group would include the crucial 1873-7 birth cohort, the census data confirm the hypothesis given above.

After the 1891 outbreaks of influenza and whooping cough, Fiji was 
free from major epidemics until 1903, when measles was again introduced into the colony. Apparently it was not possible to compile from the records the number of deaths directly due to this disease, although the report of the 1911 Census (Boyd, 1911) mentions the occurrence of the epidemic and commented that the decrease among Fijians in that year was 2,481'. From this, and from the data on the birth and death rates in 1903 as compared with years unmarred by such outbreaks, it is possible to estimate what is probably the minimum number of deaths that could be ascribed directly to the epidemic.

The crude birth rate in 1903 was about 36 per thousand population, and the crude death rate about 65 per thousand. For the years 1902 and 1904, the crude death rate was somewhere between 40 and 50 per thousand population, and assuming that the average rate in non-epidemic years was 45 per thousand, the deaths in excess of this in 1903 were probably the direct consequence of the outbreak of measles. The total number of deaths which occurred in 1903 are estimated at between 5,700 and 5,900 and if $20 / 65$ of these were directly attributable to the epidemic, the number of deaths from measles in 1903 was between 1,770 and 1,810 .

The ages of the victims in this second measles outbreak would be very different from those of the first because measles is one of the diseases against which one acquires some measure of protection, and usually complete immunity, from one exposure to infection. It can reasonably be assumed that all survivors from the 1875 epidemic were immune to subsequent infection, and the population 'at risk' in 1903 was therefore restricted to persons born since 1875. The 1,800 deaths from measles in 1903 were therefore deaths of persons aged less than 28 years and, though this mortality would have both immediate and delayed effects on the numbers of births in subsequent years, it would not anticipate many of the deaths likely to occur in these years. In fact, the number of deaths continued to exceed the number of births each year until 1905 when, for the first time in many years, the situation was reversed and the births exceeded the deaths. From then until 1912 the numbers of births and deaths recorded each year were nearly equal, with an excess of births in some years and in others an excess of deaths. These oscillations ceased after 1911 and, except for one year since then, the births registered each year have consistently exceeded the number of deaths.

The exceptional year was 1918, when Fiji was swept by the pandemic of influenza. The epidemic is thought to have been introduced by a ship from New Zealand, which called first at Suva and then at Levuka before proceeding to Samoa and Tonga whence it returned to Suva. The initial 
outbreak occurred in Suva and, as the incidence increased there, many of the Fijians went home to their villages. This effectively spread the infection throughout the whole colony and, in his report to the Legislative Council, the Acting Chief Medical Officer commented:

It is estimated that $80 \%$ of the native and Indian population were attacked by the disease; the percentage of the European population was probably half that or less. With some exceptions those under 15 years were attacked, but suffered lightly; from that age to 40 or 45 the incidence was high, and the death rate very heavy, the latter particularly so in robust males with an inclination to adiposity. It was also particularly deadly in the puerperal state. After 45 the susceptibility to the disease and the severity of it rapidly decreased; many had slight attacks and few elderly people died. This may possibly be due to immunity produced by an attack during the 1890 epidemic, which visited Fiji without doing much harm. The epidemic lasted five or six weeks, and for a time disorganised the whole community ... There were upwards of 8,000 deaths or $5 \%$ of the total population. The deaths of the different races were as follows:

$\begin{array}{lcc} & \begin{array}{c}\text { Deaths } \\ \text { No. }\end{array} & \begin{array}{c}\text { Rate per cent } \\ \text { of population }\end{array} \\ \text { Europeans } & 69 & 1 \cdot 41 \\ \text { Fijians } & 5,154 & 5 \cdot 66 \\ \text { Indians } & 2,553 & 4 \cdot 17 \\ \text { Half-castes } & 76 & 2 \cdot 75 \\ \text { Others } & 293 & 6 \cdot 93\end{array}$

The loss to the country is increased by the fact that so large a percentage of the deaths occurred amongst those in the prime of life (Montague, 1919, pp. 4-5).

This account is notable because it indicates the age incidence of mortality and morbidity, and unique because it couples the Fijian and Indian populations, implying that both were equally susceptible to the virus that caused the epidemic. The death rate cited for the Indian population was lower than the Fijians' rate, perhaps because there were fewer 'robust males with an inclination to adiposity' amongst the Indians, perhaps because of the distorted age and sex composition of the Indian population at that time and, with the selective mortality evinced in this outbreak, the number of deaths that occurred would depend largely on the population structure.

The age compositions of the two populations before the epidemic are not known. The Fijian population was first classified according to chronological age in 1921 and, though the Indian population had been tabulated 
in five-year age groups in 1911, there was much migration between then and 1918. The peak of Indian immigration to Fiji seems to have been in the previous decade and in the ten years ended 31 December 1910 an average of 2,316 Indian labourers arrived each year while only 482 were repatriated. There were also some free immigrants, who paid their own passages and were not therefore registered with the Immigration Department, and they were estimated to number 'not less than 250 annually' (Boyd, 1911, p. 6). The termination of the indenture system in 1916 and the release of all Indians still under contract in 1920 changed the pattern of net migration markedly, but in 1921 it was estimated that there had been a net gain of approximately 660 persons each year from 1911 to 1921 (Boyd and Stewart, 1922, p. xv). Though their numbers are known with fair exactitude, no details of the age or sex of these migrants were recorded.

Montague's account of the epidemic suggests that virtually all of the influenza deaths came from the age range 15 to 44 years, and this is consistent with the age incidence reported throughout the world (van Rooyen and Rhodes, 1948, p. 563). Assuming that there was no sex differential in mortality, and that the numbers at ages $17 \frac{1}{2}$ to $47 \frac{1}{2}$ years in 1921 approximated to the numbers of survivors aged 15 to 45 in 1918, the death rate amongst Fijians at these ages was $12 \frac{1 / 2}{2}$ per cent, and $7 \frac{1 / 2}{1 / 2}$ per cent among Indians. Though this estimate of the Indian rate is less reliable than the Fijian because of the migration that occurred between 1918 and 1921, there is a much larger difference between the two specific rates than between the crude death rates and, as the specific rates attempt to allow for differences in age composition between the two populations, this difference suggests that the Fijians were relatively more susceptible to influenza than were the Indians.

With mortality rates of this magnitude confined to persons of reproductive age, the diminution of the number of births expected in the year or so following the epidemic would be of the order of 23 per cent for Fijian births and less than 15 per cent for Indians. The births registered in each population in the five years $1917-21$ are as follows:

$\begin{array}{lrr} & \text { Fijian } & \text { Indian } \\ 1917 & 3,267 & 2,196 \\ 1918 & 3,100 & 2,266 \\ 1919 & 2,479 & 1,806 \\ 1920 & 3,105 & 2,147 \\ 1921 & 2,712 & 2,396\end{array}$

Fijian births in 1919 were 22 per cent lower than the average of the two preceding years, but Indian births were 19 per cent lower. This 
deviation from expectation for the Indian population is probably of no significance; were the basic data more reliable, this excessive decline in births might indicate higher mortality amongst Indians than was recorded, or perhaps a differential acting against Indian females.

This was the last major epidemic in Fiji and since then the margin of births over deaths has tended to increase each year in both Fijian and Indian populations. By 1921 natural increase was already contributing largely to the total annual increase in the Indian population; such details as there are of the population movements between Fiji and India after 1921 indicate that the numbers leaving the colony more or less balanced the numbers arriving, and for the five years preceding 1936 the difference between the numbers of Indians entering and leaving the colony. was considered to be 'in favour of those leaving' (Burrows, 1936, p. 5). Between 1937 and 1946 the opportunities for travel between India and Fiji were so limited that it can be assumed that the volume of migration during those years was negligible, and the records for the postwar years, leading up to the 1956 census, indicated a very small net loss over the decade.

The growth of the populations since 1921 was analysed in some detail in the report on the 1956 census (McArthur, 1958), and only a brief recanitulation will be given here. There are differences between the rates of increase of the various component populations, and frequently differences between the growth of male and female sectors. Some of the minor component populations, especially the Chinese and Part-Chinese and Other Pacific Islanders, have been augmented by immigration in recent years and this has accelerated the growth of their female nopulations. The sharp increase in Other Pacific Islanders between 1936 and 1946 was due to the settlement of Rambi Island by Gilbertese (Banabans) in 1945 and almost half of the increase since then came from the expansion of this initial settlement and the re-settlement of Ellice Islanders on nearby Kioa Island. The European component is also affected by migration and, as the distinction between this and the partEuropean component is becoming somewhat artificial, the two have been combined in Table 4, which shows the average annual rates of increase for the various component populations over the three most recent intercensal intervals.

The three populations minimally affected by migration are the Fijian, Indian, and Rotuman, and each exhibits a distinctive growth pattern. The increase in the Fijian population has accelerated throughout the period 1921 to 1956 , and this is directly associated with the decline in mortality. The changes in mortality will be discussed later, but elsewhere (McArthur, 1961, pp. 46-7) it has been estimated that the levels of 
TABLE 4 Average annual rates of increase in the component populations of Fiji in the inter-censal intervals since 1921

\begin{tabular}{lccc}
\hline \multicolumn{1}{c}{ Component population } & \multicolumn{3}{c}{ Average annual rate of } \\
& $1921-36$ & $1936-46$ & $1946-56$ \\
\hline Chinese and Part-Chinese & $4 \cdot 45$ & $5 \cdot 07$ & $3 \cdot 75$ \\
European and Part-European & $1 \cdot 65$ & $2 \cdot 24$ & $2 \cdot 86$ \\
Fijian & $0 \cdot 98$ & $1 \cdot 92$ & $2 \cdot 29$ \\
Indian & $2 \cdot 27$ & $3 \cdot 55$ & $3 \cdot 46$ \\
Rotuman & $1 \cdot 55$ & $1 \cdot 63$ & $2 \cdot 93$ \\
Other Pacific Islanders & $0 \cdot 89$ & $4 \cdot 14$ & $3 \cdot 64$ \\
All components & $1 \cdot 56$ & $2 \cdot 74$ & $2 \cdot 91$ \\
\hline
\end{tabular}

mortality amongst Fijians in 1936, 1946, and 1956 were roughly in the ratio of $3: 2: 1$. Except for a minor setback in 1937, for which the depleted 1919 cohort was probably responsible, the numbers of births each year has increased steadily since the early 1930s and, as relatively more of the children born survived infancy and childhood, the age structure of the population now favours more rapid growth than in the past. The predominance of males in the Indian population of 1921 has faded gradually as the older male immigrants died and both male and female segments were augmented by equivalent numbers of births each year. There was no acceleration in the growth of the total Indian population over the two decades from 1936 to 1956 but, as the population increased by more than 40 per cent in the last inter-censal interval, a sharp rise in the rate of growth can be anticipated.

This process of aocelerated growth has already begun in the Rotuman population. When the island was annexed by Great Britain in 1881, its population was estimated to be 2,450 and each successive enumeration from 1891 to 1921 recorded a population of about 2,200. The measles epidemic that was in progress during the 1911 enumeration had caused at least 50 deaths before the counting started and the total of 326 deaths from measles would have reduced the population to about 1,900 by mid-1911. The crude death rate from measles was about 15 per cent but, as most of the Rotuman deaths registered in 1911 were of persons aged 0-4 and 21-45 years and measles accounted for two-thirds of these (MacDonald, 1912, pp. 20-1), mortality amongst persons of reproductive age in 1911 was probably higher than this. As one would expect in a small population, the number of births each year fluctuated widely but the average for the three years following the epidemic was only 90 births 
per year whereas an average of 114 per year had been recorded in the preceding decade.

Though this was probably the most fatal epidemic experienced by Rotuma's population since annexation, numbers over the two decades between 1891 and 1911 were probably not as stable as the census figures indicate, and over the next decade-1911 to 1921-the population must have increased at an average rate of about 1 per cent per year. Rotuma escaped the 1918 epidemic of influenza, and though the influenza introduced from Fiji in December 1928 'prostrated' the population for about six weeks, only 31 of the 2,260 Rotumans on the island died (Montague, 1929, p. 4). This was the only epidemic recorded for the 1921-36 inter-censal period and it seems to have had no discernible effect on the numbers of births recorded for Rotumans in subsequent years.

The rates of increase given in Table 4 for the next two inter-censal intervals are slightly misleading because the census classification of 1946 is not strictly comparable with that used in 1936 and 1956. In both 1936 and 1956 the offspring of Rotumans married to non-Rotumans were assigned to the same population as their father: in 1946, the offspring of Rotumans married to persons other than Rotumans or Fijians were included in the 'all others' residue. Hence the Rotuman population is under-stated in 1946 as compared with 1936 and 1956, but the inclusion of all 'Rotuman-Others' (55 males and 42 females) recorded in 1946 would be no more correct than their exclusion. If they are included, the average rates of increase over the two inter-censal periods become 1.83 per cent and 2.62 per cent; hence, one might conclude that the Rotuman population increased by between 1.63 and 1.83 per cent per year between 1936 and 1946, and by an average rate of between 2.62 and 2.93 per cent annually from 1946 to 1956 .

From 1946 the number of Rotuman births recorded each year has increased markedly and the population can be expected to increase even faster in the future. Not all of this increase occurs on Rotuma itself, and the numbers of Rotumans enumerated in Fiji have increased faster than their population, from 123 in 1921 to 273 in 1936 and again to 569 in 1946. In 1956 almost one-third of all those classified as Rotumans were enumerated in Fiji and just under 3,000 were living on the island.

\section{Age and Sex Composition}

The changes and rates of change in total numbers are directly associated with changes in the age and sex structure of the populations and, on the whole, the data are less reliable for these than for the total numbers enumerated. In Tables 5 and 6 the Fijian and Indian populations 
TABLE 5 Numbers of Fijians enumerated in successive censuses arrayed according to the period of birth corresponding to the ages tabulated in the census ('Not stated' ages have been distributed)

\begin{tabular}{|c|c|c|c|c|c|}
\hline $\begin{array}{l}\text { Period } \\
\text { of birth }\end{array}$ & \multicolumn{3}{|c|}{ Number of males at censuses of } & 1956 & $\begin{array}{c}\text { Age in } \\
1956\end{array}$ \\
\hline $1952-56$ & & & & 12,593 & $0-4$ \\
\hline $1947-51$ & & & & 10,460 & $5-9$ \\
\hline $1942-46$ & & & 9,253 & 8,908 & $10-14$ \\
\hline $1937-41$ & & & 8,246 & 7,825 & $15-19$ \\
\hline $1932-36$ & & 7,161 & 7,389 & 6,525 & $20-24$ \\
\hline $1927-31$ & & 6,123 & 5,554 & 5,350 & $25-29$ \\
\hline $1922-26$ & & 5,774 & 5,109 & 4,465 & $30-34$ \\
\hline $1917-21$ & 5,488 & 4,613 & 4,614 & 4,241 & $35-39$ \\
\hline $1912-16$ & 5,604 & 4,297 & 3,960 & 3,799 & $40-44$ \\
\hline $1907-11$ & 4,658 & 3,724 & 3,428 & 2,976 & $45-49$ \\
\hline $1902-06$ & 3,520 & 2,990 & 2,525 & 2,130 & $50-54$ \\
\hline $1897-01$ & 3,102 & 2,920 & 2,298 & 1,761 & $55-59$ \\
\hline $1892-96$ & 3,112 & 2,175 & 1,655 & 1,393 & $60-64$ \\
\hline $1887-91$ & 3,231 & 2,156 & 1,534 & 1,061 & $65-69$ \\
\hline $1882-86$ & 3,160 & 2,053 & 1,945 & 714 & $70-74$ \\
\hline $1877-81$ & 2,630 & 1,530 & 1,098 & 371 & $75-79$ \\
\hline $1872-76$ & 2,354 & 1,834 & 672 & 234 & $80-84$ \\
\hline $1867-71$ & 2,057 & 976 & 247 & 87 & $85-89$ \\
\hline \multirow{3}{*}{ Before 1867} & 5,106 & 1,543 & 334 & 96 & 90 and over \\
\hline & \multicolumn{4}{|c|}{ Number of females at censuses of } & \\
\hline & 1921 & 1936 & 1946 & 1956 & \\
\hline $1952-56$ & & & & 12,137 & $0-4$ \\
\hline $1947-51$ & & & & 9,854 & $5-9$ \\
\hline $1942-46$ & & & 8,790 & 8,227 & $10-14$ \\
\hline $1937-41$ & & & 7,919 & 7,754 & $15-19$ \\
\hline $1932-36$ & & 6,966 & 6,950 & 6,809 & $20-24$ \\
\hline $1927-31$ & & 6,043 & 5,716 & 5,572 & $25-29$ \\
\hline $1922-26$ & & 5,296 & 5,517 & 4,481 & $30-34$ \\
\hline $1917-21$ & 5,486 & 4,708 & 5,184 & 4,159 & $35-39$ \\
\hline $1912-16$ & 5,598 & 4,700 & 3,967 & 3,432 & $40-44$ \\
\hline $1907-11$ & 4,311 & 3,862 & 3,029 & 2,665 & $45-49$ \\
\hline $1902-06$ & 3,414 & 3,043 & 2,444 & 2,139 & $50-54$ \\
\hline $1897-01$ & 3,253 & 2,500 & 2,025 & 1,792 & $55-59$ \\
\hline $1892-96$ & 3,314 & 2,253 & 2,000 & 1,460 & $60-64$ \\
\hline $1887-91$ & 3,313 & 2,003 & 1,370 & 1,055 & $65-69$ \\
\hline $1882-86$ & 2,563 & 2,031 & 1,678 & 781 & $70-74$ \\
\hline $1877-81$ & 2,293 & 1,243 & 750 & 415 & $75-79$ \\
\hline $1872-76$ & 1,835 & 1,447 & 492 & 251 & $80-84$ \\
\hline $1867-71$ & 1,753 & 631 & 166 & 94 & $85-89$ \\
\hline Before 1867 & 3,320 & 1,056 & 211 & 68 & 90 and over \\
\hline
\end{tabular}


TABLE 6 Numbers of Indians enumerated in successive censuses of Fiji. arrayed according to the period of birth corresponding to the ages stated in the census ('Not stated' ages have been distributed)

\begin{tabular}{|c|c|c|c|c|c|}
\hline \multirow{2}{*}{$\begin{array}{l}\text { Period } \\
\text { of birth }\end{array}$} & \multicolumn{4}{|c|}{ Number of males at censuses of } & \multirow{2}{*}{$\begin{array}{c}\text { Age in } \\
1956\end{array}$} \\
\hline & 1921 & 1936 & 1946 & 1956 & \\
\hline $1952-56$ & & & & 16,723 & $0-4$ \\
\hline $1947-51$ & & & & 14,329 & $5-9$ \\
\hline $1942-46$ & & & 11,563 & 11,983 & $10-14$ \\
\hline $1937-41$ & & & 10,393 & 9,273 & $15-19$ \\
\hline $1932-36$ & & 7,013 & 7,512 & 7,348 & $20-24$ \\
\hline $1927-31$ & & 6,820 & 6,602 & 6,128 & $25-29$ \\
\hline $1922-26$ & & 5,357 & 4,698 & 4,678 & $30-34$ \\
\hline $1917-21$ & 5,292 & 4,635 & 4,456 & 4,215 & $35-39$ \\
\hline $1912-16$ & 4,565 & 3,673 & 3,179 & 3,163 & $40-44$ \\
\hline $1907-11$ & 2,398 & 2,446 & 2,473 & 2,342 & $45-49$ \\
\hline $1902-06$ & 1,547 & 1,964 & 1,709 & 1,534 & $50-54$ \\
\hline $1897-01$ & 2,381 & 2,011 & 1,699 & 1,261 & $55-59$ \\
\hline $1892-96$ & 4,819 & 3,050 & 1,939 & 1,906 & $60-64$ \\
\hline 1887-91 & 5,473 & 2,585 & 2,423 & 1,345 & $65-69$ \\
\hline $1882-86$ & 3,566 & 2,894 & 3,044 & 1,015 & $70-74$ \\
\hline $1877-81$ & 3,171 & 2,001 & 1,372 & 491 & $75-79$ \\
\hline $1872-76$ & 1,362 & 1,962 & 920 & 365 & $80-84$ \\
\hline $1867-71$ & 1,338 & 728 & 377 & 127 & $85-89$ \\
\hline \multirow[t]{3}{*}{ Before 1867} & 1,103 & 1,107 & 628 & 133 & 90 and over \\
\hline & \multicolumn{4}{|c|}{ Number of females at censuses of } & \\
\hline & 1921 & 1936 & 1946 & 1956 & \\
\hline $1952-56$ & & & & 16,574 & $0-4$ \\
\hline $1947-51$ & & & & 14,126 & $5-9$ \\
\hline $1942-46$ & & & 11,659 & 11,933 & $10-14$ \\
\hline $1937-41$ & & & 10,301 & 9,222 & $15-19$ \\
\hline $1932-36$ & & 6,923 & 7,307 & 6,897 & $20-24$ \\
\hline $1927-31$ & & 6,632 & 5,782 & 5,495 & $25-29$ \\
\hline $1922-26$ & & 4,799 & 4,751 & 4,428 & $30-34$ \\
\hline $1917-21$ & 5,126 & 4,233 & 4,089 & 3,807 & $35-39$ \\
\hline $1912-16$ & 4,265 & 3,205 & 2,942 & 2,694 & $40-44$ \\
\hline $1907-11$ & 2,048 & 2,197 & 1,917 & 1,744 & $45-49$ \\
\hline $1902-06$ & 1,662 & 1,679 & 1,538 & 1,216 & $50-54$ \\
\hline $1897-01$ & 1,990 & 1,392 & 1,093 & 782 & $55-59$ \\
\hline $1892-96$ & 2,789 & 1,833 & 1,412 & 943 & $60-64$ \\
\hline $1887-91$ & 2,430 & 1,114 & 880 & 461 & $65-69$ \\
\hline $1882-86$ & 1,198 & 1,269 & 898 & 362 & $70-74$ \\
\hline $1877-81$ & 1,041 & 439 & 316 & 143 & $75-79$ \\
\hline $1872-76$ & 362 & 602 & 286 & 133 & $80-84$ \\
\hline $1867-71$ & 385 & 132 & 87 & 28 & $85-89$ \\
\hline Before 1867 & 323 & 307 & 168 & 56 & 90 and over \\
\hline
\end{tabular}


recorded in each census since 1921 are arrayed according to the period of birth corresponding to the ages given in the census tabulations, and no adjustments have been made for the alteration in census date from late April in 1921 and 1936 to approximately five months later in the year in 1946 and 1956. The data are not therefore strictly comparable from census to census, but the lack of comparability between 1936 and 1946 would not greatly affect the general conclusion that exact chronological age is relatively unimportant to both Fijians and Indians.

Since 1921 the Fijian population has been subject to so little migration that it can be regarded as a 'closed' population. The only large-scale movements of Fijians that have occurred concerned units of the Fiji Military Forces which were engaged in the 1939-45 war and in the Malaya campaign in 1955-6, and these had returned to Fiji before the relevant censuses were taken. Each year a few students leave Fiji for further study in Australia or New Zealand, but these usually return within three or four years of their departure. One would expect, therefore, that the only change in cohort size between censuses would be a decrease, the magnitude of which would depend on the age of the cohort during the inter-censal period. Between 1921 and 1936 all cohorts of males and females decreased, though not according to any regular pattern. Between 1936 and 1946 two of the male cohorts and two of the female cohorts increased in size, and the survival pattern for the remainder was somewhat curious. Between 1946 and 1956 all cohorts decreased in size but again there were curious anomalies in the proportions of survivors.

For various reasons one would expect that the ages stated in 1956 were likely to be more correct than those of earlier censuses. Even if the population as a whole was no more familiar with the concept of chronological age in 1956 than it had been in previous years, most of the enumerators were and they censored statements of age before recording them on the schedules. When the enumerated Fijian population, arrayed in birth cohorts, was compared with the numbers of births registered in each five-year period (McArthur, 1958, p. 14) the pattern of survival that emerged was reasonably compatible with the age of the cohorts and their previous mortality experience, and the proportions of survivors in each birth cohort are shown in Fig. 1, plotted against their age in 1956.

Excluding the first decade of age, the smooth curve which best fits these points tends to lie above the proportion of survivors in the first half of each decade and below the proportion in the second. The reason for this became apparent when the preferences for unit digits of age were computed. There is a systematic error in the digit preferenoes given 


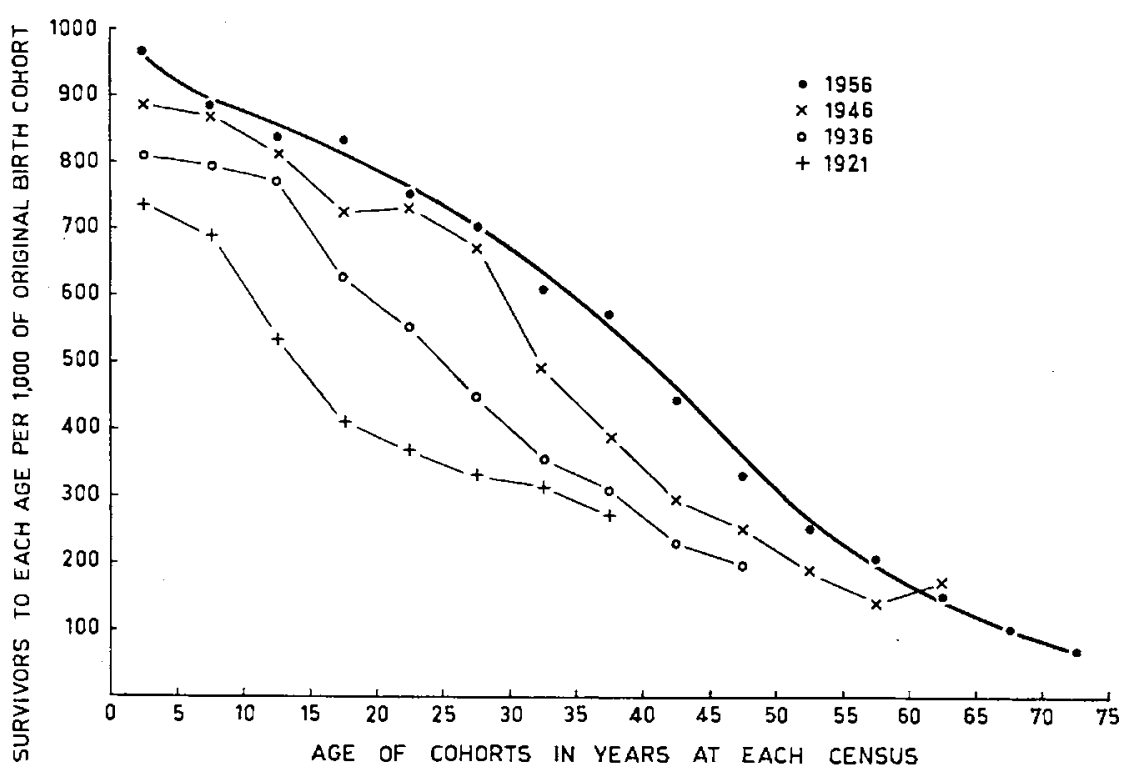

Fig. 1 Numbers of Fijians surviving in each age group in successive censuses of Fiji per 1,000 Fijian births recorded in the appropriate five-year periods

in McArthur (1958, p. 12), but both males and females of the Fijian component tended to favour ages with 6 as the terminal digit, and avoid ages ending in 1 . Though for females this avoidance was compensated by a preference for 'round' ages such as 20,30 , etc., the sum of the Fijians' preferences for unit digits between 0 and 4 summed to less than the 50 per cent which would indicate neither preference nor avoidance. Hence the numbers of persons at ages 20-24, 30-34 . . years are slightly under-stated and the numbers at ages 15-19, 25-29 . . . years correspondingly exaggerated.

Unfortunately it was not possible to examine the survival patterns of males and females separately because the births registered each year have been tabulated by sex only since 1947 . Since then the sex ratio of births each year has averaged about 52 males per 100 births and, if this ratio held for earlier years, the numbers of females at ages 15 to 29 years are rather higher than one would expect. This suggests that there may have been some down-grading in the ages of females and, if this happened consistently, it would explain the apparent deficiency of survivors from the 1907-11 and 1912-16 birth cohorts. Both of these cohorts were too young to have suffered much mortality in the 1918 influenza 
epidemic and, as the later outbreaks-of dysentery in 1921, whooping cough in 1925, and dysentery again in 1929-30-were relatively circumscribed in their effects, they would not have experienced any exceptionally high mortality during their 40 to 50 years of life.

Comparison of the numbers enumerated at ages $0-9$ years with the numbers expected from the births and deaths that were registered in the ten years preceding the census were not very reassuring about the accuracy with which individual ages were specified if the registrations were complete but, as the enumerated population exceeded the numbers expected, it is unlikely that all births had been registered before the census was taken. The preferences for unit digits of age shown by the population within the age range 13 to 62 years indicated that age was wrongly reported for at least 2.6 per cent of Fijian males and 4.0 per cent of Fijian females in 1956, which was a considerable improvement on the probable accuracy of ages recorded in 1946, when at least 6.9 per cent of the males and 11.3 per cent of females reported the unit digit incorrectly. Nevertheless, the ages recorded for Fijians in 1956 were probably still only approximations to their true ages.

For the earlier censuses, the proportions of survivors among the original birth cohorts follow a more erratic course than in 1956. The 1946 census is the worst in this respect and this was the only census in which the schedules were completed by a member of the household. For the comparison between the numbers of Fijians recorded in each age group in 1936 and 1921 and the initial size of the birth cohorts, the recorded births were adjusted to allow for a census date at the end of April and the proportions of survivors at each age formed relatively smooth curves. The progressive changes in the shape of these curves from census to census attest to the improvement in mortality that has occurred over the period, and from the graphs in Fig. 1 and the numbers in Table 5 it appears that, in both 1936 and 1946, the ages 10-14 years were favoured by Fijian males, probably at the expense of ages 15-19 years, and the ages most favoured by Fijian females were 20-24 and 25-29 years, many of whom should be spread over older age groups. The twenties and thirties appear to have been popular ages in 1921, especially amongst the females, and some of them should probably be transferred to higher ages.

Only for 1946 is it possible to check the numbers enumerated at ages 0-4 years with the numbers expected from the births and deaths registered in the preceding five years. The number of births and the number of deaths at each year of age up to 5 years registered in each year from 1941 to 1946 were given in the 1946 census report and, though these data do not distinguish males and females, the number of births and 
infant deaths of each sex for 1945 and 1946 were tabulated subsequently. Estimates compiled from these latter agreed reasonably well with the numbers of males and females enumerated at age 0: there were 7 males fewer than the 2,160 expected and an excess of 79 females in an expected total of 1,995 . The numbers enumerated at age 1 were approximately 10 per cent below the estimated numbers but with relatively large surpluses at ages 3 and 4 years, the total enumerated at ages $0-4$ years exceeded the expected total of 17,618 Fijians by 361 .

The reliability of the ages recorded for the Indian population cannot be checked as thoroughly as for the Fijians because the initial size of the birth cohorts is unknown for all except the three youngest cohorts, virtually all of whom were born in Fiji, and until 1936 at least there was still migration to and from India. The populations enumerated in each census since 1921 are shown in Table 6 and, ignoring the changes that occurred in cohort size between 1921 and 1936, there is as little consistency in the behaviour of the Indian cohorts over the inter-censa] intervals as there was amongst the Fijians.

Starting with the premise that ages in 1956 were probably more reliable than in previous censuses, there would appear to have been under-enumeration of both males and females at ages 0-4 years in both 1936 and 1946. Between 1946 and 1956, and between 1936 and 1946 for Indian females, this increase in the size of the youngest cohort from one census to the next was accompanied by an inordinately large decrease in the cohort aged 5-9 years in the earlier census; and this see-saw pattern between consecutive cohorts continues through to the 1907-11 cohort of males and the 1917-21 cohort of females. Thereafter there is a more regular decline in cohort size from census to census except for the accumulation at each census in the age group 60-64 years.

When the numbers enumerated at each year of age between 0 and 9 in 1956 were compared with the numbers expected from the relevant birth and death registrations (McArthur, 1958, p. 15), there appeared to be neither under- nor over-enumeration at ages less than 1 year, but there were far too few of both sexes enumerated at 1 year of age. This deficit dominated the age group 0-4 years and was only partly cancelled by the large numbers enumerated at age 3 years. In the age group 5-9 years, the numbers enumerated at each ago consistently exceeded the numbers expected, and this implies either that there was some delay in the registration of births or that the ages of children were down-graded by parents or enumerators.

In 1946 also there had been good agreement between the numbers of males and females enumerated and expected at ages less than 1 year, but the pronounced deficit in the numbers enumerated at 1 year of age 
was more than balanced by surpluses at ages 3 and 4 years. The data needed to check the 5-9 years age group were not then available but, as the total Indian births registered in the five years 1937-41 were 19,297 and the number of Indians enumerated at ages 5-9 in 1946 was 20,694, there probably was either down-grading of ages in the census or incomplete registration of births, or perhaps some of both.

The preferences for unit digits of age were computed for the Indian population within the age range 13 to 62 years in the two recent censuses. In 1956, both males and females strongly favoured 'round' ages at the expense of those with 1 and 9 as the terminal digit. Ages ending in 5 were less favoured, but nevertheless the sum of the preferences for unit digits of 5 to 9 exceeded 51 per cent.

The summary index (Bachi, 1953; Myers, 1954) for the minimum proportion of age mis-statements was $8 \cdot 7$ per cent for males and $11 \cdot 3$ per cent for females. In 1946, the heaping at digits 0 and 5 and the avoidance of 1 was more exaggerated than in 1956 and, with at least $14 \cdot 2$ per cent of males and 22.0 per cent of females mis-reporting the unit digit of age, the 1946 age distributions for the Indian population are probably quite spurious. Though they appear to be more reliable in 1956, they should not be accepted with much confidence yet.

Except for the Europeans, the minor component populations tend to show the same disregard for chronological age as the Fijians and Indians. Though there may have been some slight improvement in 1956 as judged by the preferences shown for unit digits of age, the numbers of males and females at each age in these populations are too small to permit valid conclusions from techniques dosigned essentially for large populations. Apart from their smallness, the interpretation of data concerning these minor components is made difficult because they do not constitute distinct entities within the population and, except perhaps in a census report, their characteristics should not therefore be examined in isolation. Barring large-scale immigration to Fiji, their numbers are now never likely to exceed more than 7 or 8 per cent of Fiji's total population and, as only about three-quarters of their numbers in 1956 could be regarded as permanent inhabitants of Fiji, demographically they are unimportant and will accordingly be ignored for the most part in the ensuing pages.

Even allowing for the inaccurate data on age, the age structure of each of the two major component populations has changed quite considerably since 1936. The proportion of the population aged less than 15 years has increased gradually, from 38 to 42 per cent for the Fijian and from 44 to more than 50 per cent for the Indian population. For the Fijians, this change is probably associated with changes in mortality 
because, in each census population, the females of reproductive age represent a constant 22 per cent of the total Fijian population and 44 per cent of all Fijian females. In the Indian population, the number of females of reproductive age has doubled in the twenty-year period, though their share in the total population has increased only from 17 to 19 per cent and they represent a constant 40 per cent of all Indian females.

Perhaps the greatest change that has occurred has been in the sex composition of the Indian population. In 1956 the cohorts born after 1936 contained almost equal numbers of males and females and, had there been no mis-statement of age, it is probable that the equality of the sexes would have extended to the two older cohorts at least. The preponderance of males became especially marked in the cohorts aged 40 years and over in 1956, and as the sex ratio increased so did the proportion of persons born in India or Pakistan. About two-thirds of Indians in the age range 45 to 59 years were born in Fiji but at ages beyond these less than 10 per cent were Fiji-born. Twenty years earlier these predominantly male immigrants would have constituted a relatively large part of the total population, and the disproportion of the sexes in this total was therefore relatively greater than in later years when the population had been augmented solely by roughly equal numbers of males and females born each year in Fiji. Since 1936, the number of Indian females has increased faster than the number of males and the distortion of the sex ratio in the Indian population is gradually disappearing.

Perhaps a better comparative index of changes in age structure is the ratio between the numbers of children aged 0-4 years and the females of reproductive age in the population. Although women aged 15-44 years in a census were not entirely responsible for the births of these children, their number is closely related to the number of couples capable of reproduction at the time, and this ratio is therefore a crude measure of the extent of current replacement of population as well as a summary index of the age structure. The child-woman ratios for the Fijian and Indian populations enumerated in 1936, 1946 and 1956 are given in Table 7, expressed as the number of children aged $0-4$ per 1,000 women aged 15 to 44 years.

As there may have been some under-enumeration of children in both components in 1936, the increases in the ratios between 1936 and 1946 were probably smaller than they appear but, relative to the numbers of women of appropriate ages in the two populations, there has been a progressive increase in the number of Fijian children from census to census and, though the number of Indian children probably rose between 1936 and 1946, there may have been some decline in 
TABLE 7 Child-woman ratios in the Fijian and Indian populations enumerated in the censuses of 1936, 1946, and 1956

\begin{tabular}{ccc}
\hline Census of & Fijian & Indian \\
\hline 1936 & 671 & 959 \\
1946 & 698 & 1,105 \\
1956 & 771 & 1,024 \\
\hline
\end{tabular}

recent years. Despite this change, the replacement of the Indian population has been at a consistently higher level than the Fijians', excceding it by roughly 50 per cent.

As the children aged 0-4 in a census are the survivors of the births that occurred during the preceding five years, the reasons for these variations in the child-woman ratio emerge from the study of mortality and fertility in these populations. Figures have already been quoted for the births occurring in these populations at different times and, as the registered births and some deaths have been used to assess the accuracy of data with respect to age in the census enumerations, it will be as well to examine these registration data before completing the appraisal of the population structure as revealed by the censuses.

\section{Registration of Births and Deaths}

For Fijians, the registration of births and deaths began in 1877 when the Native Regulation Board passed a regulation (No. 13 of 1877) 'Respecting the registration of births and deaths', which was subsequently approved by the Legislative Council. It required that:

1. Every birth shall be reported to the Buli within one week, under a penalty of one shilling to be imposed upon the father, or the owner of the house, in which the birth occurred.

2. Every death shall be at once reported to the Buli, under a penalty of two shillings to be imposed upon the head of the house in which the death occurs.

3. The Buli shall register every birth, and every three months shall forward a copy of his register to the Roko Tui. On islands where there are no Bulis, it shall be the duty of the chief of the town to report to the Roka Tui.

4. The Buli shall register all deaths in the same manner as in births, and the Provincial Scribes shall from time to time as may be directed by the Governor, forward a copy of such register of births and deaths to the Registrar-General. 
This regulation has been amended several times without greatly altering the procedure of registration, and the relevant paragraphs of the current Fijian Affairs Regulation No. 14 of 1948 are as follows:

2. There shall be kept in the Provincial Office in each Province a book to be called the Register of Births and a book to be called a Register of Deaths. Every birth and every death of which notification has been received in the Provincial Office shall be entered by the Provincial Scribe in the relevant register.

4. Within two months after the birth of any child, whether born alive or still-born and whether the birth took place in a village or elsewhere, the father or the mother or, in default of the father and the mother, the next of kin within whose knowledge the birth took place, shall give to the Buli of the Tikina in which such child was born, or to the nearest Buli, particulars thereof as specified in Form 1 hereof, and the Buli shall forward the same to the Provincial Scribe of the Province who shall enter the particulars in the Register of Births.

Provided that in the case of a child born in the Tikina of Suva or in that portion of the Tikina of Naitasiri lying on the right bank of the Waimanu river, the persons charged as aforesaid with the duty of reporting a birth may within two months after such birth report the particulars thereof at the office of the Registrar-General instead of reporting them to the Buli.

8. Within one month of every death in a village or elsewhere, the next of kin of the deceased person or, if such next of kin is absent, the nearest relative within whose knowledge the death took place shall give to the Buli of the Tikina in which the death occurred, or to the nearest Buli, particulars of the death as specified in Form 2 hereof. The Buli shall forward the same to the Provincial Scribe who shall enter such particulars in the Register of Deaths.

Provided that where any death has taken place within a radius of three miles of the General Post Office, Suva, the persons charged herein with the duty of notifying the Buli shall report the death forthwith at the Central Police Station and may within one month of such death report the particulars thereof at the office of the Registrar-General instead of reporting the same to the Buli.

12. It shall be the duty of the Provincial Scribe to check all particulars entered in Forms 1 and 2 hereof as prescribed under the provisions of this Regulation, and to ensure that all such particulars are set down therein. The same shall be registered by him in the Register of Births or the Register of Deaths, as the case may be.

14. The Provincial Scribe shall, on or before the fifteenth day of every month, submit to the Roko all the forms provided for in the 
preceding sections of this Regulation sent to him during the previous month together with a certificate in Form 3 hereof. The Roko shall forthwith forward all such forms together with the certificate of the Provincial Scribe to the Registrar-General.

For the non-Fijian population registration was required initially under the prevailing English ordinance of 1854, and from 1892 under the Ordinance No. 2 of 1892 (Fiji) and its subsequent amendments and revisions. The Ordinance now in force prescribes the establishment of district registries, each in the charge of a District Registrar, who is required to maintain a register of all births, deaths, and marriages notified to him, and to forward returns of these each month to the Registrar-General. The District Officers are automatically District Registrars and the Registrar-General's Office is the central registry for all births, deaths, and marriages occurring in the various sectors of the population.

The sections of the Ordinance which relate to the general registration are:

14. In each case of the birth of any child in the Colony (whether born alive or still-born), it shall be the duty of the parent and, in default of the parent, the tenant of the house or place in which to his knowledge the child is born, and of each person present at the birth, and of the person having charge of the child, to inform the Registrar, within two months next after such birth, of all particulars concerning the same according to the forms of registration....

22. In each case of the death of any person it shall be the duty of the tenant of the house or place, and each person present at the death, to furnish to the Registrar, within one month next thereafter, information to the best of his knowledge and belief of all the particulars concerning the same aocording to the forms of registration....

The provisions for illegitimate births and late registrations are similar for the Fijian and non-Fijian populations, and there is space on the back of each of the registration forms for the appropriate declarations relating to these. Still-births are treated as special cases in both the Fijian Affairs Regulation and in the Ordinance. In the former:

5. Where a child is still-born the Buli or the Registrar-General, as the case may be, shall report the still-birth forthwith to the nearest Fijian Magistrate who shall thereupon hold an inquiry into the cause thereof and forward his report with the finding to the nearest District Officer. ...

and in the latter: 
27. (1) No person shall bury or permit or procure to be buried the body of any deceased child as if it were still-born.

(2) No person shall bury or permit or procure to be buried or otherwise dispose of the body of any still-born child before there is delivered to him either-

(a) a written certificate that such child was not born alive signed by a registered medical practitioner who was in attendance at the birth or has examined the body of such child; or

(b) a declaration signed by some person who would, if the child had been born alive, have been required by this Ordinance to give information concerning the birth to the effect that no registered medical practitioner was present at the birth or that his certificate cannot be obtained and that the child was not born alive; or

(c) if there has been an inquiry, an order of the magistrate.

Section 10 of the Ordinance provides for a separate register in which still-births are to be recorded by the Registrars, but since the final clause of the Ordinance states that the provisions of this Ordinance relating to births and deaths shall not apply to native Fijians', the purpose of the reporting of Fijian still-births to the nearest District Officer (who is also District Registrar) is not clear. Hence, for the nonFijian population, still-births are included in the Birth Registers and in the special register, but not in the Death Registers; for the Fijian population, they are also recorded in the Birth Registers, but the Regulation is not explicit on the subsequent procedure.

The Fijian Affairs Regulation and the Ordinance are at variance also with respect to the requirement of a burial permit. The Regulation makes no mention of such, although section 9 states:

It shall be the duty of the Buli on receiving information of the death in a village or elsewhere of a child under the age of one year, or of a person over the age of one year who has not been attended by a Government Medical Officer during his last illness, to inform forthwith the nearest Fijian Magistrate. The Magistrate shall thereupon hold an inquiry into the cause of the death and forward a report with his finding to the nearest District Officer.

If a Government Medical Officer has attended the deceased in his last illness, he is to provide the person responsible for the notification of the death with a certificate stating the cause of death, and this certificate accompanies the registration form to the Provincial Scribe and thence to the Registrar-General. 
The Ordinance, on the other hand, requires that:

25. The Registrar, immediately upon registering any death or as soon thereafter, as he shall be required so to do, shall, without fee or reward, deliver to the person furnishing the particulars required for registration a certificate under his hand ... that such death has been duly registered, and such certificate shall be delivered by such person or other person having charge of the funeral to the minister or officiating person who shall be required to bury or perform any religious service for the burial. If any dead body shall be buried for which no certificate shall have been so delivered, the person who shall bury the same, or perform any funeral or religious service for the burial, or who shall in any other way dispose of the body, shall forthwith give notice of the fact to the Registrar: .. .

Every undertaker or other person who shall bury or otherwise dispose of any dead body shall forthwith cause to be transmitted to the Registrar a certificate thereof ... countersigned when practicable by two respectable householders.

26. With respect to certificates to the cause of death-

(a) the Registrar shall from time to time furnish printed forms of certificates of the cause of death free of charge to every registered medical practitioner residing or practising in the Colony;

(b) in case of death of any person who has been attended in his last illness by a registered medical practitioner that practitioner shall sign and transmit a certificate of the cause of death to the Registrar and the cause of death as stated in such certificate shall be entered in the register together with the name of the certifying medical practitioner;

(c) where an inquiry is held on the body of any deceased person a medical certificate of the cause of death when medical evidence has been taken shall be transmitted by the magistrate together with his finding to the Registrar.

The format of the forms prescribed for registrations of births and deaths under the Fijian Affairs Regulation and under the Ordinance differ slightly, but the information recorded is essentially the same for Fijians and non-Fijians. In the registration of a birth, the date and place of the birth, the name of the child, and its sex are stated; and this is followed by details of the marriage of the parents as well as the full name, age and birthplace of each, and the number of previous children. The registration forms for deaths show the date and place of death with details of the name, sex, age and offspring of the deceased, the names of the deceased's parents and spouse, and some information on the cause of death. 
Though the period of grace allowed for the registration of a death is unexceptional, the two months' grace allowed for the registration of a birth seems unduly long and likely to lead to under-registration. No independent check on the completeness of birth registrations has ever been attempted, but from the comparison of the population enumerated at ages 0 to 9 years in 1956 with the expected survivors from the births registered in the preceding decade, it seemed likely that roughly $2 \frac{1 / 2}{2}$ per cent of the Fijian male births and 5 per cent of the Fijian female births that had occurred had not been registered, and that the corresponding figures for the unrecorded Indian births were 11/. per cent for males and 3 per cent for females.

Some part of this discrepancy between the birth registrations and the census may have arisen through mis-statements of age in the census but, accepting that both sets of data being compared contained inaccuracies, these estimates of the extent of under-registration were probably minimum estimates because this last inter-censal period was exceptional in that both major component populations were given incentives to register births. Before admitting children to schools or to certain examinations, the Education Department insisted on having copies of their birth certificates and, for the Fijians, there was the further incentive in the need to establish a child's right to ownership of land by having its name inscribed in the Register of Native Lands. Both of these, it was contended, led to rather more 'late' registrations than usual of births that had occurred some years previously, and to duplicate registrations of births which had been registered under a name since forgotten. Both late and duplicate registrations were counted as births of the calendar year in which they were registered and therefore helped disguise the full extent of under-registration.

Despite this suspected under-registration of births, the natural increase and net migration recorded for the inter-censal period exceeded the numerical difference between the populations enumerated in 1946 and 1956. Assuming that both census counts were accurate, the only feasible explanation for the loss of roughly 1,200 persons from each of the major component populations was that this number represented unregistered deaths. If this was so, then between 10 and 11 per cent of all deaths in each component escaped registration, and the failure to register occurred more frequently for males than for females. Though female ignorance of the legal requirements associated with a death might explain this sex differential, the more frequent failure to register births of females would also contribute to the apparently more complete registration of female deaths. The estimate of 10 per cent for the unrecorded mortality might therefore be conservative and there may be as many as 15 per cent of 
deaths in each component population each year which are not registered.

There are some deaths which, by their very nature, are excluded from this estimate and these are the deaths of infants born in the inter-censal period whose births were never recorded. The long period of grace allowed for the registration of a birth encourages the omission from both the birth and death registers of infants who die soon after birth, and the extent of the unrecorded infant mortality cannot be checked from any of the data now being collected. Though there is reason to believe that these omissions used to occur more frequently than they do now, there is no way of substantiating this nor of discovering whether the omissions occur more frequently in one component than in the other.

Since 1947 the numbers of births and deaths in each component population registered each year have been published in the annual reports of the Registrar-General, with the deaths for Fijians and Indians tabulated by sex and age, and the births classified by sex, age of mother and rank of birth. As one year's data for populations as small as these were considered inadequate for a reliable analysis of the mortality and fertility experienced by the 1946 census population, the corresponding tabulations were compiled for the births and deaths registered in 1945 and 1946, and this exercise revealed how little significance the Fijian population at least attached to chronological age.

Details such as the ages of the parents, the date of their marriage and the number of children born before the one being registered should not be entirely unrelated; yet it was not uncommon to find glaring inconsistencies between the facts as stated on the birth certificates. One Fijian birth registered in 1945 was the eighth child of a woman aged 24 who had been married in 1924; another was the sixth child of a woman aged 18 in 1945 who had been married in 1929; another the seventh child of a woman aged 20 in 1945 whose date of marriage was given as 1910. A sample count of similar inconsistencies in every fourth volume of the birth registers for 1945 and 1946 amounted to approximately 10 per cent of the Fijian births registered therein, and there were probably at least as many births for which the age of mother was incorrectly stated but which could not be detected readily from internal evidence. The patent inconsistencies occurred less frequently in the records of Indian births and no more than 2 or 3 per cent claimed marriage at 5 or 6 years of age or births at 7,8 , or 9 years.

The ages reported in the death registers of this period would be no more reliable than those from the birth registers, and perhaps less accurate because the scope for mis-statement is relatively greater. What may have happened to the quality of the data recorded in the registers since 1946 is a matter for conjecture, and though one might hope for 
some improvement, this cannat be relied upon. To some extent the misstatements of age in the registration data will be nullified by comparable age mis-statements in the census data, so that the rates measuring the frequency of some event in the population may bear some resemblance to reality, but how much? That cannot be assessed and the analyses of these data are accordingly presented with the realization that even the most cautious interpretations of them may not reflect the true state of affairs in the Fijian and Indian populations.

\section{Analyses of Mortality}

In any population there are random fluctuations each year in the number of deaths likely to occur at each age, and in populations as small as these, each of the chance variations receives greater weight in the mortality rate than it would in larger populations. Hence deaths registered in either two or three years centring on the census years have been

TABLE 8 Average annual mortality rates of Fijians, by sex and age: deaths per 1,000 population in each age group

\begin{tabular}{|c|c|c|c|c|c|c|c|c|}
\hline \multirow{3}{*}{$\begin{array}{l}\text { Age } \\
\text { group }\end{array}$} & \multicolumn{4}{|c|}{ Males } & \multicolumn{4}{|c|}{ Females } \\
\hline & \multicolumn{2}{|c|}{1946} & \multicolumn{2}{|c|}{1956} & \multicolumn{2}{|c|}{1946} & \multicolumn{2}{|c|}{1956} \\
\hline & Rate & S.E. & Rate & S.E. & Rate & S.E. & Rate & S.E. \\
\hline $0^{*}$ & $81 \cdot 5$ & $5 \cdot 7$ & $49 \cdot 4$ & $2 \cdot 8$ & $70 \cdot 9$ & $5 \cdot 6$ & $44 \cdot 9$ & $2 \cdot 8$ \\
\hline 1 & $51 \cdot 0$ & $5 \cdot 1$ & $23 \cdot 4$ & $3 \cdot 1$ & $48 \cdot 6$ & $5 \cdot 2$ & $20 \cdot 4$ & $3 \cdot 0$ \\
\hline $2-4$ & $12 \cdot 4$ & $1 \cdot 5$ & $5 \cdot 0$ & 0.8 & $11 \cdot 1$ & $1 \cdot 5$ & $4 \cdot 7$ & 0.8 \\
\hline $5-9$ & $4 \cdot 0$ & $0 \cdot 7$ & $1 \cdot 3$ & $0 \cdot 4$ & $4 \cdot 2$ & $0 \cdot 7$ & $2 \cdot 3$ & 0.5 \\
\hline $10-14$ & $3 \cdot 4$ & $0 \cdot 7$ & $1 \cdot 7$ & 0.4 & $3 \cdot 7$ & 0.7 & $1 \cdot 2$ & 0.4 \\
\hline $15-19$ & $5 \cdot 9$ & $1 \cdot 0$ & $1 \cdot 3$ & 0.4 & $5 \cdot 4$ & $1 \cdot 0$ & $1 \cdot 8$ & 0.5 \\
\hline $20-24$ & $6 \cdot 5$ & $1 \cdot 1$ & $2 \cdot 6$ & 0.6 & $7 \cdot 1$ & $1 \cdot 1$ & $2 \cdot 2$ & 0.6 \\
\hline $25-29$ & $7 \cdot 4$ & $1 \cdot 3$ & $3 \cdot 1$ & $0 \cdot 8$ & $7 \cdot 2$ & $1 \cdot 2$ & $3 \cdot 2$ & 0.8 \\
\hline $30-34$ & $8 \cdot 6$ & $1 \cdot 5$ & $3 \cdot 2$ & 0.8 & $7 \cdot 4$ & $1 \cdot 4$ & $3 \cdot 9$ & 0.9 \\
\hline $35-39$ & $7 \cdot 6$ & $1 \cdot 5$ & $3 \cdot 6$ & 0.9 & $9 \cdot 5$ & $1 \cdot 8$ & $5 \cdot 1$ & $1 \cdot 1$ \\
\hline $40-44$ & $12 \cdot 3$ & $2 \cdot 2$ & $5 \cdot 2$ & $1 \cdot 2$ & $10 \cdot 5$ & $2 \cdot 1$ & $5 \cdot 1$ & $1 \cdot 2$ \\
\hline $45-49$ & $15 \cdot 8$ & $2 \cdot 6$ & $8 \cdot 8$ & $1 \cdot 7$ & $12 \cdot 4$ & $2 \cdot 5$ & $6 \cdot 2$ & $1 \cdot 5$ \\
\hline $50-54$ & $24 \cdot 0$ & $3 \cdot 8$ & $13 \cdot 0$ & $2 \cdot 5$ & $14 \cdot 2$ & $2 \cdot 6$ & $8 \cdot 7$ & $2 \cdot 0$ \\
\hline $55-59$ & $26 \cdot 9$ & $4 \cdot 1$ & $21 \cdot 9$ & $3 \cdot 5$ & $22 \cdot 9$ & $4 \cdot 0$ & $8 \cdot 1$ & $2 \cdot 1$ \\
\hline $60-64$ & $52 \cdot 1$ & $5 \cdot 0$ & $34 \cdot 2$ & $4 \cdot 9$ & $52 \cdot 1$ & $5 \cdot 4$ & $33 \cdot 0$ & $4 \cdot 7$ \\
\hline $65-69$ & $52 \cdot 8$ & $6 \cdot 8$ & $36 \cdot 9$ & $5 \cdot 8$ & $48 \cdot 0$ & $7 \cdot 8$ & $24 \cdot 7$ & $4 \cdot 8$ \\
\hline $70-74$ & $106 \cdot 6$ & $11 \cdot 9$ & $87 \cdot 1$ & $10 \cdot 6$ & $121 \cdot 3$ & $14 \cdot 7$ & $59 \cdot 8$ & $8 \cdot 5$ \\
\hline $\begin{array}{l}\text { over } \\
\text { and }\end{array}$ & $114 \cdot 7$ & $13 \cdot 2$ & $95 \cdot 7$ & $10 \cdot 5$ & $130 \cdot 0$ & $17 \cdot 3$ & $64 \cdot 3$ & $8 \cdot 5$ \\
\hline
\end{tabular}

*Infant mortality rate per 1,000 live births registered. 
TABLE 9 Average annual mortality rates of Indians in Fiji by sex and age: deaths per 1,000 population in each age group

\begin{tabular}{|c|c|c|c|c|c|c|c|c|}
\hline \multirow{3}{*}{$\begin{array}{l}\text { Age } \\
\text { group }\end{array}$} & \multicolumn{4}{|c|}{ Males } & \multicolumn{4}{|c|}{ Females } \\
\hline & \multicolumn{2}{|c|}{1946} & \multicolumn{2}{|c|}{1956} & \multicolumn{2}{|c|}{1946} & \multicolumn{2}{|c|}{1956} \\
\hline & Rate & S.E. & Rate & S.E. & Rate & S.E. & Rate & S.E. \\
\hline $0^{*}$ & $50 \cdot 5$ & $4 \cdot 4$ & $47 \cdot 1$ & $2 \cdot 4$ & $43 \cdot 6$ & $4 \cdot 1$ & $39 \cdot 0$ & $2 \cdot 2$ \\
\hline 1 & $6 \cdot 7$ & $1 \cdot 7$ & $6 \cdot 3$ & $1 \cdot 4$ & $5 \cdot 7$ & $2 \cdot 6$ & $5 \cdot 7$ & $1 \cdot 4$ \\
\hline $2-4$ & $2 \cdot 1$ & 0.6 & $1 \cdot 8$ & 0.4 & $2 \cdot 2$ & 0.6 & $1 \cdot 9$ & 0.4 \\
\hline $5-9$ & 0.9 & $0 \cdot 3$ & 0.6 & $0 \cdot 2$ & $1 \cdot 0$ & $0 \cdot 3$ & 0.9 & 0.2 \\
\hline $10-14$ & $1 \cdot 0$ & 0.4 & 0.8 & 0.3 & $1 \cdot 2$ & 0.4 & 1.0 & 0.3 \\
\hline $15-19$ & $2 \cdot 0$ & 0.6 & $1 \cdot 4$ & 0.4 & $4 \cdot 4$ & 0.9 & $2 \cdot 2$ & 0.5 \\
\hline $20-24$ & $1 \cdot 9$ & $0 \cdot 6$ & $1 \cdot 2$ & 0.4 & $4 \cdot 3$ & 0.9 & $3 \cdot 1$ & 0.7 \\
\hline $25-29$ & $2 \cdot 1$ & $0 \cdot 7$ & $1 \cdot 6$ & 0.5 & $4 \cdot 7$ & $1 \cdot 1$ & $2 \cdot 9$ & 0.7 \\
\hline $30-34$ & $3 \cdot 1$ & $1 \cdot 0$ & $2 \cdot 1$ & $0 \cdot 7$ & $8 \cdot 3$ & $1 \cdot 7$ & $4 \cdot 6$ & $1 \cdot 0$ \\
\hline $35-39$ & $3 \cdot 0$ & $1 \cdot 1$ & $3 \cdot 2$ & 0.9 & $8 \cdot 4$ & $2 \cdot 1$ & $4 \cdot 1$ & $1 \cdot 0$ \\
\hline $40-44$ & $7 \cdot 4$ & $2 \cdot 1$ & $6 \cdot 0$ & $1 \cdot 4$ & $8 \cdot 0$ & $2 \cdot 3$ & $6 \cdot 9$ & $1 \cdot 6$ \\
\hline $45-49$ & $8 \cdot 0$ & $2 \cdot 2$ & $12 \cdot 8$ & $2 \cdot 3$ & $9 \cdot 8$ & $3 \cdot 0$ & $10 \cdot 9$ & $2 \cdot 5$ \\
\hline $50-54$ & $17 \cdot 2$ & $3 \cdot 0$ & $15 \cdot 3$ & $3 \cdot 1$ & $14 \cdot 4$ & $3 \cdot 2$ & $17 \cdot 3$ & $3 \cdot 7$ \\
\hline $55-59$ & $10 \cdot 5$ & $2 \cdot 1$ & $19 \cdot 4$ & $3 \cdot 9$ & $16 \cdot 3$ & $4 \cdot 3$ & $19 \cdot 2$ & $4 \cdot 9$ \\
\hline $60-64$ & $27 \cdot 0$ & $2 \cdot 9$ & $30 \cdot 5$ & $3 \cdot 9$ & $36 \cdot 7$ & $6 \cdot 3$ & $40 \cdot 3$ & 6.4 \\
\hline $65-69$ & $21 \cdot 9$ & $3 \cdot 9$ & $29 \cdot 8$ & $4 \cdot 6$ & $34 \cdot 8$ & $10 \cdot 3$ & $38 \cdot 0$ & $8 \cdot 9$ \\
\hline $70-74$ & $49 \cdot 3$ & $7 \cdot 1$ & $75 \cdot 0$ & $8 \cdot 3$ & $73 \cdot 4$ & $15 \cdot 4$ & $74 \cdot 6$ & $13 \cdot 8$ \\
\hline $\begin{array}{c}75 \text { and } \\
\text { over }\end{array}$ & $66 \cdot 3$ & $7 \cdot 9$ & $129 \cdot 3$ & $10 \cdot 1$ & $113 \cdot 7$ & $19 \cdot 9$ & $180 \cdot 6$ & $20 \cdot 3$ \\
\hline & 00 & & 128 & 101 & 110 & 12 & 1000 & 20. \\
\hline
\end{tabular}

*Infant mortality rate per 1,000 live births registered.

used to estimate the average annual mortality rates at each age in the census populations. The age-specific mortality rates for males and females in the Fijian and Indian populations of 1946 and 1956 are given in Tables 8 and 9, and the rates for 1946 represent the average annual mortality of the three calendar years 1945-7 and those for 1956 the average of the two years Ootober 1955 to September 1957. The ages at death for 1945 and 1946 were summarized from the death certificates held by the Registrar-General in Suva and those for 1947 were taken from his Annual Report for that year. The tabulations for the year preceding the 1956 census and the year following it were kindly provided by the Registrar-General. The mortality rate at age 0 years in each instance is the average annual infant mortality rate, in which the deaths at ages less than 1 year were referred to the number of births registered and not to the population aged 0 in the census. The approximate standard 
error associated with each rate is given, and this indicates the range of variation which could be expected to occur by chance in each rate.

However unreliable ages may be in either the censuses or the death registers, the rates given in Table 8 for Fijians show that there has been a marked change in the level of mortality in this population over the decade. For both males and females the age-specific rates for 1956 are much lower than those for persons of the same age and sex in 1946, and it is only at ages beyond 45 years for males and within the age range 30 to 45 years for females that the decrease in rates is not statistically significant. The Indian population, on the other hand, shows no such dramatic change in mortality between 1946 and 1956. The age-specific rates for males are essentially the same in the two series except perhaps at the oldest ages and, though there has been some reduction of mortality amongst females of reproductive age over the decade, the differences between the rates do not reach levels of statistical significance.

At neither period was there any real sex differential in mortality amongst the Fijians. The infant mortality rates for males were slightly higher than the corresponding female rates, but this is common to many populations and the rates at all other ages were virtually the same for males and females. In the Indian population, however, mortality amongst females of reproductive age tended to be higher than amongst males of the same ages and, though this tendency was more pronounced in 1946, it persisted in 1956. At both periods, the mortality rates for Indian females at these ages were closer to the Fijian rates than to the mortality of Indian males, and the difference was sufficiently large not to be accounted for by mis-statements of age. Only at ages less than 15 years were the rates for Indian females less than those of their Fijian counterparts in 1946, whereas Fijian male mortality then exceeded the Indian at practically all ages. By 1956 the excess mortality amongst Fijian males was statistically significant only at ages 1-4 years, and these were the only ages at which the mortality of the two female populations differed. Though the mortality of Fijians in childhood has been more than halved over the decade, deaths at these ages in 1956 were three to four times more frequent than amongst Indian children.

The similarity between the level of mortality in the two populations in 1956 and the extent of the changes in mortality in both over the decade are illustrated by the standardized mortality rates obtained by applying the age-specific mortality rates of Tables 8 and 9 to a 'standard' population of 100,000 persons. This standard is a conglomerate of the populations recorded in the 1956 censuses of Fiji, Samoa, Tonga, Cook 
TABLE 10 A 'standard' population constructed from the populations enumerated in the 1956 censuses of Fiji, Samoa, Tonga, Cook Islands, and French Polynesia

\begin{tabular}{crrr}
\hline Age group & Males & Females & Persons \\
\hline $0-4$ & 9,300 & 8,886 & 18,186 \\
$5-9$ & 7,513 & 7,179 & 14,692 \\
$10-14$ & 6,399 & 6,104 & 12,503 \\
& & & \\
$15-19$ & 5,546 & 5,236 & 10,782 \\
$20-24$ & 4,336 & 4,181 & 8,517 \\
$25-29$ & 3,613 & 3,631 & 7,244 \\
$30-34$ & 3,034 & 2,847 & 5,881 \\
$35-39$ & 2,614 & 2,419 & 5,033 \\
$40-44$ & 2,229 & 1,995 & 4,224 \\
& & & \\
$45-49$ & 1,818 & 1,557 & 3,375 \\
$50-54$ & 1,443 & 1,307 & 2,750 \\
$55-59$ & 1,097 & 974 & 2,071 \\
$60-64$ & 904 & 782 & 1,686 \\
$65-69$ & 654 & 571 & 1,225 \\
$70-74$ & 443 & 402 & 845 \\
75 and over & 497 & 489 & 986 \\
& & & \\
All ages & 51,440 & 48,560 & 100,000 \\
& & & \\
\hline
\end{tabular}

Islands and French Polynesia: each contributed 20,000 persons distributed by age and sex as in their enumerated populations and the age and sex composition of this combined population is given in Tablo 10. The deaths which would have occurred in this population had the mortality rates for Fijians and Indians in 1946 and 1956 applied are as follows:

$\begin{array}{clcc}\text { Fijian } & & 1946 & 1956 \\ & \text { Male } & 841 & 456 \\ \text { Indian } & \text { Female } & 732 & 356 \\ & & & \\ & \text { Male } & 344 & 387 \\ & \text { Female } & 419 & 408\end{array}$

The standardized mortality rate for the Fijian population in 1946 was therefore $15 \cdot 7$ per 1,000 persons, and this had fallen to $8 \cdot 1$ per 1,000 by 1956 whereas the Indian rate of $7 \cdot 6$ per 1,000 in 1946 increased slightly to 8.0 per 1,000 in 1956 . The mortality for both males and females in 
the Fijian population was virtually halved over the decade and though there was no change between 1946 and 1956 in the mortality amongst Indian females, there may have been a slight increase in the Indian male mortality. Assuming that the registration of deaths is equally complete in the two populations, the chances of survival for Indian males are probably still a little better than for their Fijian counterparts, but the reverse may hold for the female populations. Comparisons between the numbers of deaths for males and females of the same population are not valid because the age distributions of the male and female sectors of the standard population are different.

Before 1947, only the numbers of deaths and crude death rates were published annually and these give little indication of the extent of mortality in populations whose age composition is changing. A rough guide to the level of mortality that prevailed in the earlier populations is given by comparing the numbers of deaths recorded for them and the numbers expected had the 1956 age-specific mortality rates for each sex applied in them. Had the populations enumerated in 1936 experienced the 1956 mortality rates there would have been approximately 900 Fijian and 690 Indian deaths in the year following the census, whereas the numbers recorded were of the order of 2,500 Fijian and 800 Indian deaths. Similarly, the deaths expected in the 1946 oensus populations on this basis would have been 990 Fijian and 1,020 Indian deaths, and the numbers estimated from the registrations for 1946 and 1947 were roughly 1,880 Fijian and 920 Indian deaths. Acknowledging that registration may not be uniformly complete over the period, these comparisons suggest that the decline in mortality amongst Fijians between 1946 and 1956 was part of a continuing process, whereas mortality in the Indian population has been relatively stable for many years.

\section{Analyses of Fertility}

Since 1947 the Registrar-General has also published the numbers of births registered each year in considerable detail. Though the numbers of still-births recorded for the Fijian, Indian, and Other populations are tabulated only by age of mother, the live births to each of these components of population are tabulated according to the maternal age and order of birth, as well as by the age of the father and the month of birth. The live births to Fijians and Indians are then used to calculate fertility rates for women in each five-year age group and rather more detailed gross reproduction rates using maternal ages at birth in single years of age. The numbers of males and females amongst the registered births is given only for the total births to the three populations-Fijians, Indians, and Others. 
To maintain uniformity with the mortality analyses, the age-specific fertility rates given in Table 11 for Fijian and Indian women in 1946 are the average annual rates derived from births registered in the three calendar years 1945-7 referred to the 1946 census populations, and the 1956 rates were estimated from the average numbers of births registered in the two years October 1955 to September 1957 and the populations enumerated at the centre of that period. As with the deaths, the details for 1945 and 1946 were extracted personally from the birth certificates, those for 1947 were taken from the Registrar-General's Annual Report for that year, and the Registrar-General kindly provided the relevant data for 1955-7. The 'total fertility', shown in the final row of Table 11 is the sum of the age-specific fertility rates in each population multiplied by five.

TABLE 11 Average annual age-specific fertility rates of Fijian and Indian women in Fiji: births registered per 1,000 females at each age in censuses of 1946 and 1956

\begin{tabular}{|c|c|c|c|c|c|c|c|c|}
\hline \multirow{3}{*}{$\begin{array}{l}\text { Age } \\
\text { group }\end{array}$} & \multicolumn{4}{|c|}{ Fijian } & \multicolumn{4}{|c|}{ Indian } \\
\hline & \multicolumn{2}{|c|}{1946} & \multicolumn{2}{|c|}{1956} & \multicolumn{2}{|c|}{1946} & \multicolumn{2}{|c|}{1956} \\
\hline & Rate & S.E. & Rate & S.E. & Rate & S.E. & Rate & S.E. \\
\hline $10-14$ & - & - & * & * & 3 & 1 & * & * \\
\hline $15-19$ & 64 & 3 & 53 & 3 & 243 & 6 & 161 & 4 \\
\hline $20-24$ & 256 & 6 & 274 & 5 & 313 & 7 & 350 & 6 \\
\hline $25-29$ & 251 & 6 & 285 & 6 & 274 & 7 & 325 & 6 \\
\hline $30-34$ & 202 & 6 & 206 & 6 & 223 & 8 & 240 & 6 \\
\hline $35-39$ & 141 & 6 & 142 & 5 & 158 & 8 & 176 & 6 \\
\hline $40-44$ & 61 & 5 & 62 & 4 & 74 & 7 & 78 & 5 \\
\hline $45-49$ & 25 & 3 & 19 & 3 & 32 & 5 & 33 & 4 \\
\hline $\begin{array}{l}\text { Total } \\
\text { fertility }\end{array}$ & & 990 & &, 205 & & 5,600 & & 815 \\
\hline
\end{tabular}

*Less than 1.

For both Fijians and Indians there appears to have been in increase in the frequency of births to women aged 20-24 and 25-29 years over the decade and, though this may be real, at least part of it can be attributed to mis-statements of age in the population at risk. At both censuses, the twenties were popular with females of both components and the denominators of these rates are probably larger than they should be. As the concentration of females at ages 20-24 and 25-29 was more 
:marked in 1946 than in 1956, the denominators of the 1946 rates are urelatively more inflated and the rates accordingly lower than those for 1956. Except for these problematical changes in the rates at ages 20-24 and 25-29 years, the pattern of fertility amongst Fijian women has not altered over the decade. However, there has been a change in the Indian pattern, and the smaller frequency of births to females aged 15-19 years in 1956 is relatively greater than the changes at other ages. Again one cannot be sure how much of this is due to the mis-reporting of ages in the census and registration data but, as the proportions of females married at these ages declined markedly over the decade, some decline in the frequency of births was to be expected.

The striking contrast is between the Fijian and Indian patterns of fertility. Indian women of all ages have births more frequently than do the Fijian women, especially during the first half of the reproductive period. Though both Fijians and Indians complete roughly 60 per cent of their total fertility before the age of 30 years, by this age the Indians have had 30 per cent more births than the Fijians and this excess is maintained to the end of the reproductive period. Previously there may have been an even larger difference between the fertility at young ages in the two populations because higher rates than these would be needed to produce the average numbers of children born to Indian women at each age which were recorded in the 1956 census.

The average numbers recorded in the census and the estimates computed from these age-specific fertility rates for 1956 are shown in Table 12. Because the latter take no account of mortality amongst the women of reproductive age, one would expect the numbers recorded in the census data to be a little larger than the numbers estimated. Acknowledging this, there is therefore reasonably good agreement between the two series of averages for Fijians but quite large discrepancies between the census data and the estimates for Indian women at ages 20 to 39 years. The recorded numbers exceed the estimates by rather more than is likely to be accounted for by mortality, and the greatest differences occur at ages 25-29 and 30-34 years. Average numbers of this magnitude would require fertility rates of the order of 245,350 , and 430 per 1,000 women at ages 15-19, 20-24, and 25-29 respectively, dropping to 170 and 130 per 1,000 in the next two age groups, and this unlikely sequence suggests that there may have been some down-grading by the enumerators in the ages recorded for Indian women. If the numbers of children born to these women were correctly recorded, their inclusion in the younger age groups would tend to raise the averages for these groups whereas their exclusion from their proper group would have little effect on the average there. At the same time, this suspected down-grading of ages 
TABLE 12 Average numbers of children born to women in each age group of the Fijian and Indian populations as recorded in the census of 1956 and as estimated from the age-specific fertility rates for 1956

\begin{tabular}{|c|c|c|c|c|}
\hline \multirow[b]{2}{*}{$\begin{array}{l}\text { Age } \\
\text { group }\end{array}$} & \multicolumn{2}{|c|}{ Fijian } & \multicolumn{2}{|c|}{ Indian } \\
\hline & $\begin{array}{c}\text { Census } \\
\text { averages }\end{array}$ & $\begin{array}{l}\text { Estimated } \\
\text { averages }\end{array}$ & $\begin{array}{c}\text { Census } \\
\text { averages }\end{array}$ & $\begin{array}{c}\text { Estimated } \\
\text { averages }\end{array}$ \\
\hline $15-19$ & 0.09 & $0 \cdot 13$ & $0 \cdot 35$ & $0 \cdot 40$ \\
\hline $20-24$ & $1 \cdot 10$ & 0.95 & $2 \cdot 23$ & $1 \cdot 68$ \\
\hline $25-29$ & $2 \cdot 58$ & $2 \cdot 35$ & $4 \cdot 25$ & $3 \cdot 37$ \\
\hline $30-34$ & $3 \cdot 80$ & $3 \cdot 57$ & $5 \cdot 73$ & $4 \cdot 78$ \\
\hline $35-39$ & $4 \cdot 79$ & $4 \cdot 44$ & $6 \cdot 60$ & $5 \cdot 82$ \\
\hline $40-44$ & $5 \cdot 47$ & $4 \cdot 95$ & $6 \cdot 73$ & $6 \cdot 45$ \\
\hline $45-49$ & $5 \cdot 88$ & $5 \cdot 15$ & 6.94 & $6 \cdot 73$ \\
\hline $50-54$ & $5 \cdot 73$ & $5 \cdot 20$ & $6 \cdot 81$ & $6 \cdot 81$ \\
\hline $55-59$ & $5 \cdot 95$ & $5 \cdot 20$ & $6 \cdot 45$ & $6 \cdot 81$ \\
\hline 60 and over & $5 \cdot 33$ & $5 \cdot 20$ & $5 \cdot 81$ & $6 \cdot 81$ \\
\hline
\end{tabular}

would also imply greater frequencies of births to women in the decade of age 25 to 34 years than appears in Table 11.

A more penetrating comparison between the frequency of births in the two populations is given in Table 13, where the births registered in the average of the three calendar years 1955-7 are referred to the populations 'at risk' at each age with each number of previous children as recorded in the 1956 census. These are average annual age- and parity-specific birth rates per 1,000 women at risk, and because they relate to a slightly different period of time, the age-specific rates shown in the final column are not identical with those of Table 11. To simplify presentation, the standard errors associated with the rates are omitted, but as the population at risk is often very small, some of the standard errors are quite large and many of the apparent differences in rates are not statistically significant.

Those that are significant reveal the Fijians' reluctance to start childbearing at young ages or to have more than a total of six or seven births. The essential comparisons in Table 13 are between the frequencies of births to Fijian and Indian women at each age in each column. Though the most popular age for first births is between 20 and 24 years in both populations, these are also the most common ages for second and third births to Indian women. Almost as many Fijians have their first child at ages $25-29$ as at $20-24$ years whereas, in the Indian population, second 


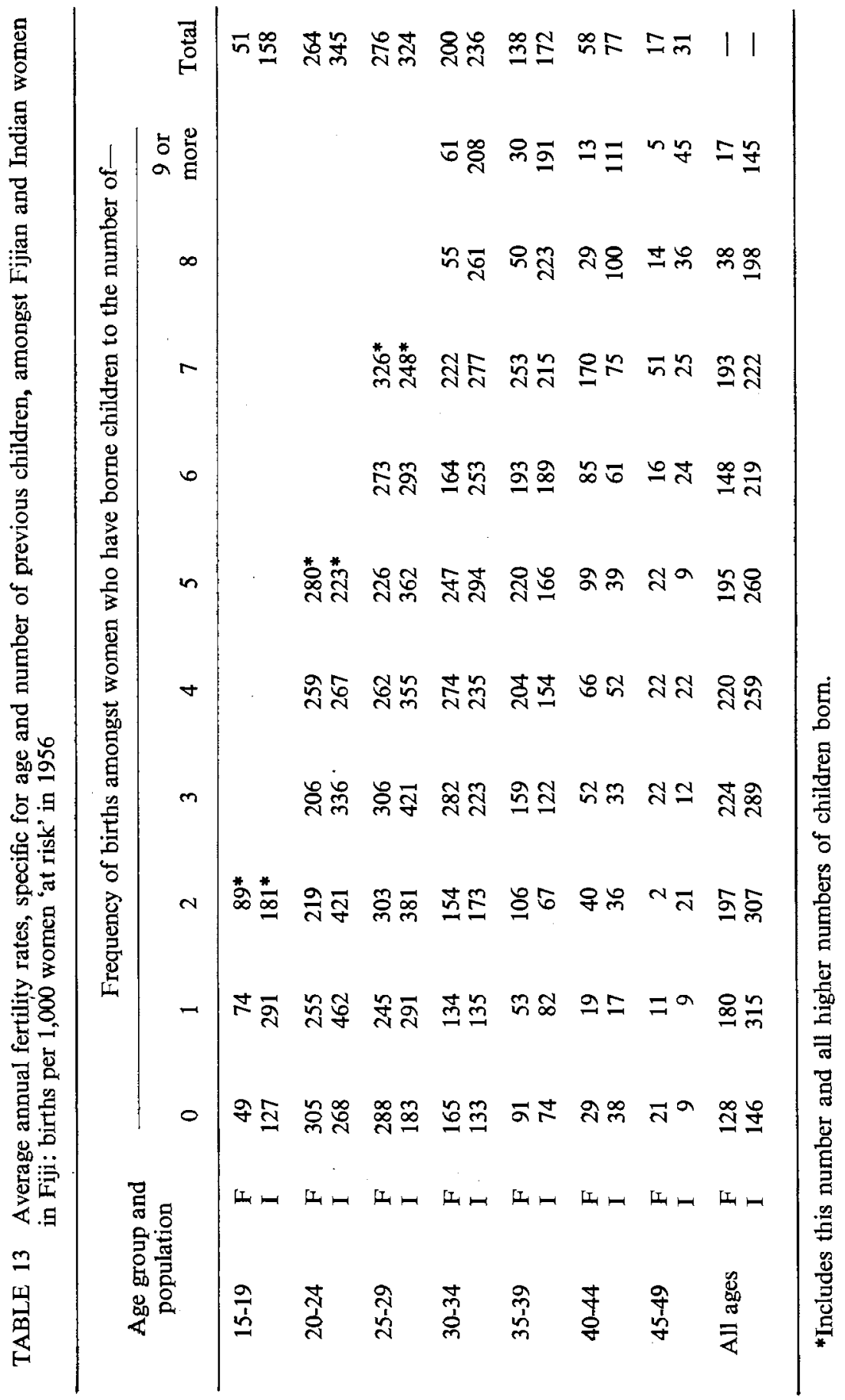


births occur as frequently amongst women aged 15-19 as to those aged 25-29 years. The majority of third and fourth children are born to Indians between the ages of 20 and 29 but the Fijian women tend to postpone their fourth birth to the 25-34 years decade of age, by which age the Indian women are having their fifth, sixth, or seventh birth. At ages beyond 30 years, the only rates which are significantly different are those for ninth or higher order births.

In an attempt to determine which of maternal age or birth order was the major source of difference between the two populations, the ageand parity-specific birth rates for Indians were applied to the Fijian population at risk in 1956 . This resulted in a total of 7,280 births a year, which is roughly one-third higher than the recorded average of 5,443 for Fijians in the three years 1955-7, and the distributions of these 'expected' births according to maternal age and to rank of birth were very different from those recorded for the Fijian births. The values of $\chi^{2}$ obtained in the two comparisons were so far in excess of the tabulated values for their respective numbers of degrees of freedom that their relative magnitudes can be assessed only approximately, but it seems probable that there is little to choose between them and that the smaller number of Fijian births as compared with those of the Indian population derives from fewer births to women of all ages and parities each year.

This pattern could be anticipated from the fertility data recorded in the 1956 census when every female aged 15 years or over was asked the number of children born to her who were still living, the number who had died and her age at the birth of her first child. The total number of children born to each was the sum of the numbers living and dead, and these were tabulated as stated even though it was suspected that some enumerators had sometimes recorded the total number of births in the column for 'living' children. Hence both the average numbers of children born and the average numbers of living children may be exaggerated in the census data, and at some ages the exaggeration may have been further enhanced by the enumerators' tendency to down-grade female ages.

The average numbers of children born to Fijian and Indian women at each age in 1956 were given in Table 12 and part of the difference between the parallel means for the two populations stems from the higher proportion of Fijian females of reproductive age who had borne no children. Even if these are excluded from the comparison, the numbers of children borne by Indian females exceed the average performance of Fijian women of the same ages and, as one would expect from the mortality data given earlier, relatively more of the Indian children born had survived to the census date. The average numbers of children born 
before each age indicated that the Indian women had shorter intervals between births than did the Fijians, and that they began reproducing at younger ages.

This latter was amply confirmed by the analysis of the ages at which women of both populations had borne their first child. The proportion of each cohort who had attained motherhood before the ages of 20, 25, and 30 years was given in the census report (McArthur, 1958, p. 31), and the data are reproduced in a slightly different form in Table 14 to

TABLE 14 Attainment of motherhood at specified ages by cohorts of Fijian and Indian women: rate per 1,000 females at risk in each age group at census of 1956

\begin{tabular}{|c|c|c|c|c|c|c|}
\hline \multicolumn{7}{|c|}{ Age at first birth } \\
\hline \multirow{2}{*}{$\begin{array}{l}\text { Age group } \\
\text { in } 1956\end{array}$} & \multicolumn{2}{|c|}{ Before 15 years } & \multicolumn{2}{|c|}{ 15-19 years } & \multicolumn{2}{|c|}{ 20-24 years } \\
\hline & Fijian & Indian & Fijian & Indian & Fijian & Indian \\
\hline $15-19$ & 1 & 8 & & & & \\
\hline $20-24$ & 2 & 22 & 305 & 678 & & \\
\hline $25-29$ & 3 & 50 & 312 & 717 & 673 & 660 \\
\hline $30-34$ & 3 & 50 & 313 & 754 & 635 & 615 \\
\hline $35-39$ & 4 & 47 & 317 & 721 & 617 & 637 \\
\hline $40-44$ & 2 & 62 & 294 & 704 & 644 & 640 \\
\hline $45-49$ & 1 & 57 & 293 & 676 & 654 & 653 \\
\hline $50-54$ & 2 & 68 & 294 & 636 & 634 & 640 \\
\hline $55-59$ & 2 & 43 & 283 & 635 & 653 & 504 \\
\hline 60 and over & 1 & 23 & 231 & 492 & 631 & 511 \\
\hline All ages & 2 & 35 & 297 & 689 & 643 & 616 \\
\hline
\end{tabular}

show the rate at which each cohort of Fijian and Indian women attained motherhood. The number of Fijians who had had a child before the age of 15 years is negligible and there seems to have been a decrease in this frequency in recent years in the Indian population, the probable causes of which will be discussed later. Amongst the Fijians, about 30 per cent of each cohort attained motherhood between 15 and 19 years of age, and two-thirds of those who had not had a child at these ages had their first birth within the next five years. Cumulatively, this means that 75 per cent of Fijian women had borne a child before reaching the age of 25 years, and by age 30 seven-eighths of all cohorts had had at least one child. 
The rates for the Indian cohorts are much higher than those for the Fijians and vary much more from cohort to cohort. On the average, rather more than two-thirds of the Indian women had had their first child when they were 15-19 years old and approximately 60 per cent of those who reached age 20 without children had their first birth before the age of 25 years. The attainment of motherhood at ages 15-19 years increased as the age of the cohort increased to a maximum of 75 per cent for the cohort aged 30-34 years and then declined progressively. The rates at which those who survived to age 20 without any children attained motherhood are more or less complementary to the rates for first births at ages 15-19 and, in general, the higher the rate at ages 15-19 the lower the rate at 20-24 years. There are exceptions to this rule but these occur largely at the older ages where ages were known to be unreliable.

It is, in fact, knowing how the ages at first birth were often estimated that arouses suspicion concerning the high frequencies for early first births amongst the cohorts aged 30 to 39 years. Realizing that age was likely to be known only for the younger members of this population, the enumerators were told how to use known ages as a basis for estimating the unknowns. One of these ploys was the consistency between the present age of a woman, her age at the birth of her first child, and the present age of that child if it was still living. If her present age could be established or confirmed from some other source-by comparison with the age of her husband, for example-and the age of the eldest child was known, her age at the first birth could be obtained by subtracting one from the other.

The enumerators learned this lesson all too well; for many of the older women who were living in the same household as one or more of their children, the age at first birth recorded for them was the difference between their present age and the age of the son or daughter present in the household, irrespective of their birth rank in her family. As the ages of these old women were probably exaggerated, their age at first birth was often much higher than was likely in view of the scarcity of women amongst the early Indian immigrants to Fiji, and in some instances physiologically impossible. The ages of women in their thirties or forties in 1956 were probably the most difficult of all to estimate and, as noted elsewhere, the enumerators tended to down-grade them. Ages at first birth obtained by the subtraction of the age of the oldest child were therefore equally far below the actual ages; and it is of course possible that some enumerators assumed an age at first birth of 14 or 15 years and proceeded to estimate present age by adding the age of the oldest child.

Whichever way it was done, age at first birth was probably understated for at least some of the women recorded at ages 30 to 39 years, 
and over-stated for women aged 60 years and over. It is therefore possible that there was no great difference in reproductive performance between the various cohorts of Indian women, and that the pattern has been relatively constant for many years with 70 per cent having their first child before the age of 20 and almost 90 per cent of them with at least one child before they were 25 years old. As the Fijian women attained cumulative frequencies of this order by ages 25 and 30 years, their average reproductive span is effectively at least five years shorter than the Indians'.

Unfortunately the data tabulated for the 1946 census are not strictly comparable with those for 1956 because the questions concerning the numbers of children born and surviving were asked only of women who were or had been married. The definitions of 'marriage' for census purposes were not the same in the two censuses, and comparison with the 1956 census data indicated that not all of the women who claimed never to have married in 1946 had had no children (McArthur, 1958, p. 29). There is therefore no basis for comparison between the average numbers of children born to women at each age in the two census populations and, in view of the age mis-statements in both, no way of establishing conclusively whether or not there has been a decline in the fertility of Indian women at very young ages.

The deviation shown by the two youngest cohorts in the frequency of births amongst them before they attained 15 years of age (Table 14) confirms the decline in the age-specific fertility rates at ages less than 20 in 1956 (Table 11), and a difference of this magnitude between the rates for 1946 and 1956 could scarcely be accounted for by the depreciation of numbers in the age group 15-19 years in 1946 or its inflation in 1956. Moreover, in 1945-6 only 50 per cent of all births to Indian women aged 15-19 years were first order births but in 1955-7 this proportion had risen to 60 per cent. Taken together, these changes suggest an increasing tendency amongst Indian women to defer first births, and a likely correlate of this would be a tendency to postpone marriage.

The displacement of some Indian females aged 15-19 years in 1946 into the age groups on either side would probably have little effect on the proportions married at these ages in the census, but if there was consistent down-grading in the ages of females as suspected for 1956, the proportion of the cohort aged 15-19 years who had married might have been exaggerated. Accepting the census data at their face value, the proportion of unmarried Indian females aged 15-19 years increased markedly over the decade from 25 per cent in 1946 to 54 per cent in 1956 , and this was accompanied by an increase in the frequency of bachelors from 78 to 94 per cent at ages $15-19$ and from 22 to 38 per 
cent at ages 20-24 years. The differences between the 1946 and 1956 frequencies are all too large to have been caused by any but the grossest age mis-statements and, as the definition of 'marriage' was more liberal in 1956 than in 1946, there clearly has been a change in the marriage pattern for the Indian population.

The effect that changes such as these may have on fertility cannot be gauged yet, but it is by no means certain that they will lead to any reduction in total fertility. The estimated age-specific fertility rates for 1951 which were computed from the Indian births registered in the three years 1950-2 and a population constructed by interpolation between those recorded in the two censuses, suggested that the changes in the fertility rates at each age were progressive, and that the decline in fertility at ages 15-19 years was being offset by increased fertility among these cohorts at ages 20-24 and 25-29 years. If this tentative inference from incomplete data is correct, then the postponement of first births may do no more than alter the spacing of births throughout the reproductive span, without reducing the total number of children born to each female (McArthur, 1959).

\section{Summary}

Any estimate for the size of Fijis population before cession can only be very approximate, partly because the early censuses were seldom considered accurate even by those responsible for them, and partly because two of the three best-known estimates of mortality from measles in 1875 relate to small islands whose experience in the epidemic was not necessarily typical of the extent of mortality elsewhere. Undoubtedly this epidemic was exceptional because the conditions for its spread could hardly have been more favourable, and equally certainly none of the pre-censal estimates of population emanating from missionaries or explorers can be regarded seriously when early colonial administrators, with far greater resources at their command, doubted the reliability of their censuses.

Whatever the size of the initial Fijian population, this and subsequent epidemics influenced its growth over the next thirty years, and perhaps longer. Although many of the later epidemics were relatively minor, or perhaps confined only to a limited area, the decrease in the numbers of births each year coincided with the years in which the presumably depleted cohorts born just before and just after the 1875 measles epidemic attained reproductive age, whereas the deaths each year probably reflected more of the current epidemics or their absence than the distorted age structure of the population consequent upon the measles epidemic. After 1905 the birth and death rates each year were practi- 
cally equal, and from 1911 onwards the Fijian population increased except in 1918 when both Fijians and Indians in Fiji suffered in the pandemic of influenza.

The Indian population in Fiji had its origins in Gordon's wish to preserve what he regarded as traditional Fijian society. The first Indians came to Fiji in 1879 and there was a constant succession of indentured labourers from then until 1916 when the indenture system was terminated. Many who had worked in Fiji either stayed on or were allowed to return, and the 1921 census recorded 100 Indians in Fiji for every 140 Fijians. They probably suffered less in the influenza epidemic than the Fijians, and the differential rates of growth since are such that the rate of increase for the Indian population is higher than for the Fijian.

Because of a younger age at marriage for Indian girls, and a greater frequency of births at all ages, the fertility of Indian women is much higher than that of the Fijians. Although there are signs that the age at marriage for women rose between 1946 and 1956, and the age-specific fertility rates at young ages fell accordingly, the birth rate in the Indian population was still higher than in the Fijian and the death rates only marginally different. Standardized mortality rates indicated that the death rate among Fijians almost halved between 1946 and 1956, but while Fijian females may have had some slight advantage in 1956 over Indians of the same sex, the chances of survival for Fijian males were minimally less favourable than for Indian males in Fiji.

On the other hand, the age composition of the Indian population in 1956 was more favourable to rapid increase than the Fijian because about 50 per cent of its total was aged less than 15 years as compared with 42 per cent of the Fijian, so that the reproductive capacity of the Indian population would increase relatively more each year than the Fijian. With average completed Fijian families at least one child smaller than the Indian families, and expectations of life at birth all more than 60 years but differing by about three years for males and hardly at all for females, within a few years the relationship that existed between the numbers of Fijians and Indians in 1921 may be completely reversed, and there may be 140 Indians to 100 Fijians in Fiji. 


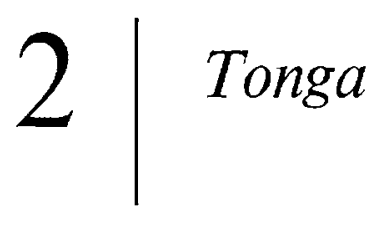

The Kingdom of Tonga contains three distinct groups of islandsTongatapu, Ha'apai, and Vava'u. The principal island is Tongatapu, low and irregular in shape because of its shallow lagoon, and the northern group of Vava'u takes its name from the next largest island in the kingdom. Ha'apai, the central group, consists of three clusters of small low-lying islands, and to the north and west of this chain are several outlying volcanic islands of which the largest are Niuafo'ou and Niuatoputapu. The total land area of the group is 256 square miles (A. M. Maude, 1966, p. 218) and almost half of the inhabited area is contributed by the main island of Tongatapu. Niuafo'ou's 13.4 square miles were uninhabited for thirteen years following volcanic activity on this island in September 1945.

The northern volcanic islands Niuafo'ou and Niuatoputapu were the first in the group to be discovered by European navigators, but the first European known to land on any island was Tasman who discovered Tongatapu and nearby 'Eua in 1643. In 1773, Cook re-discovered Tongatapu and 'Eua and later in the voyage he provisioned his ship at Nomuka in southern Ha'apai. On his third visit in 1777, Cook discovered islands in the other clusters of the Ha'apai group and these were visited by Maurelle after his discovery of Vava'u in 1780. At this time Tongatapu, Ha'apai and Vava'u were separate political entities, although several centuries before they had been united under a strong dynastic rule which had crumbled through delegation of authority within the dynasty. At the end of the eighteenth century the peaceful feudal states were disrupted by Tongan warriors returning victorious from the Fijian wars, and their political rivalries and intrigues plunged Tonga into nearly fifty years of civil war.

\section{Pre-censal Population Estimates}

The earliest record of population for Tonga or any part of it is Cook's estimate that 'not less than ten or twelve thousand people' were 'drawn together, for the most part, by mere curiosity' while his two ships were at Tongatapu in 1777, and that fewer than 5,000 assembled on Lifuka, 
an island in the Ha'apai group, to watch the marines exercise. The number of people attending the entertainment given in Cook's honour on Tongatapu

could not be computed exactly, on account of the inequality of the ground; but, by reckoning the inner circle, and the number in depth, which was between twenty and thirty in many places, we supposed that there must be near four thousand. At the same time, there were round the trading plaoe at the tent, and straggling about, at least as many more; and some of us computed, that, at this time, there were not less than ten or twelve thousand people in our neighbourhood; that is, within the compass of a quarter of a mile (Cook, 1821, 5, pp. 319,357$)$.

The trebling of the number contained in a confined space to cover the stragglers and those otherwise engaged seems overly generous, and as Gifford (1929) pointed out, the population of Tongatapu on an occasion such as this would be swelled by visitors from both Vava'u and Ha'apai as well as the inhabitants of nearby 'Eua. Following Cook's last visit, at least five navigators called at various islands in the group before the end of the eighteenth century, and the crews of almost all of these either landed or made contact with the Tongans. D'Entrecasteaux and his party were the only ones to land on Tongatapu, and the naturalist Labillardiere reported that in their estimation 'at least four thousand' natives assembled for the entertainment arranged for them by the king in April 1793 (Labillardiere, 1800, 2, p. 139).

The first missionaries landed from the Duff in 1797. They were all artisans sponsored by the London Missionary Society and the warmth of their welcome faded as their stocks of tradesmen's tools and other articles made of iron dwindled. Inevitably they quarrelled with the few runaway sailors and escaped convicts living precariously amongst the Tongans, and the beachcombers took their revenge by maliciously misrepresenting the intentions and activities of their rivals. Wood (1938) recounts that the Tongans, suspicious as always of foreigners, readily believed that the missionaries had been sent from England to spread disease amongst them and that the purpose of their religious services, conducted in English and closed to the Tongans because of their 'irreverent curiosity', was to hasten the deaths of all Tongans so that England could acquire the land of Tonga. The story gained credence because the king and many of the chiefs had died at about that time, though it is not clear whether or not these deaths were associated with any widespread outbreak of disease. The missionaries quickly lost prestige and, in the confusion and lawlessness that followed the incident that sparked the civil war in 1799, 


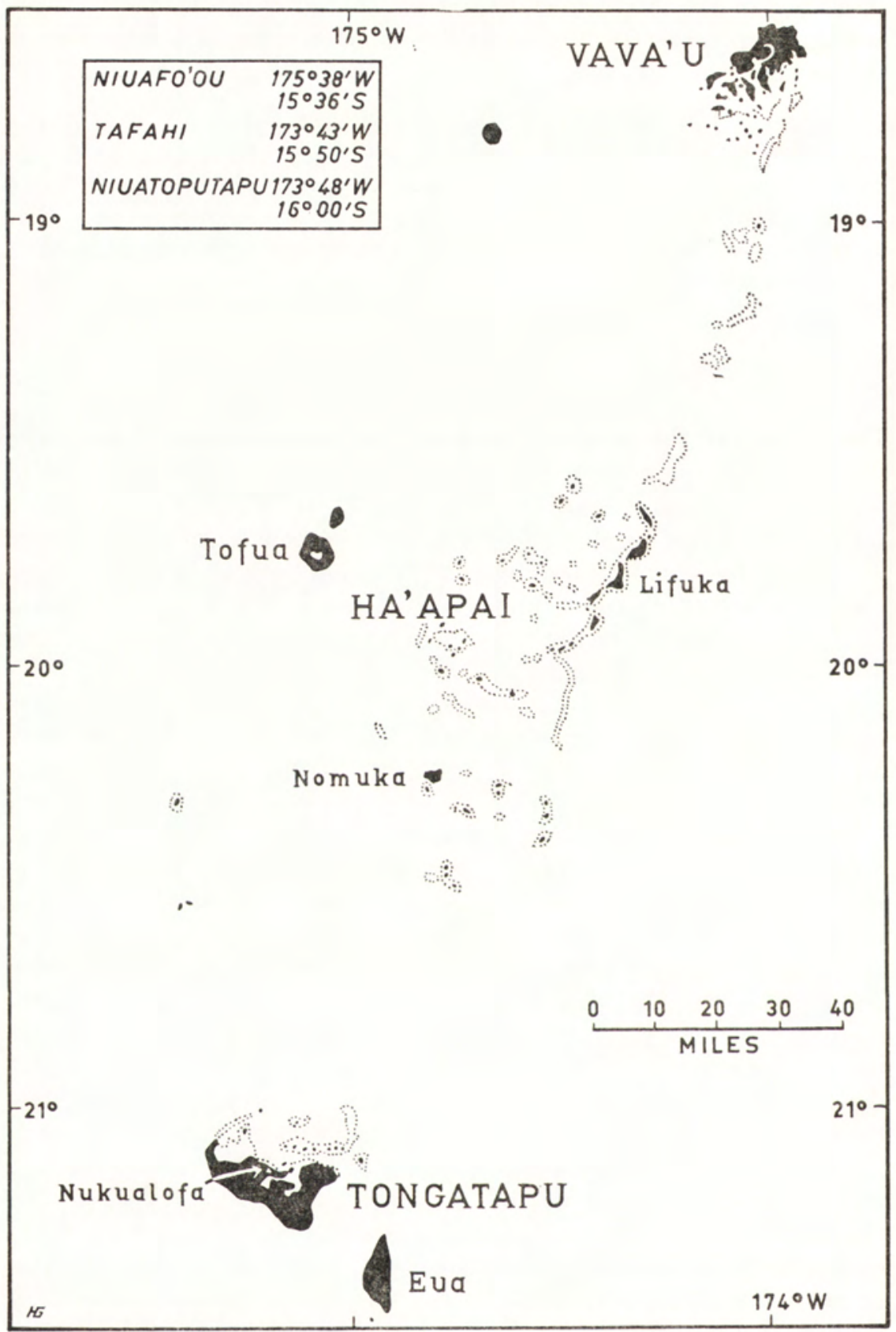

Map 2 The Kingdom of Tonga 
three were clubbed to death. The survivors took refuge together for some months until they were rescued in 1800 and taken to Sydney.

The London Missionary Society's Duff had called at Tahiti en route to Tonga in 1797 and, though no outbreak of disease was reported for Tahiti in that year, some infection may have been introduced on one or other of the ship's visits to Tongatapu. According to Thomson (1894), 'the first sickness preserved by tradition is the "ngangau" (lit. headache), a new disease that ravaged the group about the year 1776, but which was not associated in the natives' minds with the visit of Captain Cook three years before. Of this many hundreds are said to have perished' (Thomson, 1894, p. 372).

Some doubt as to Thomson's dating of this epidemic arises because one of Gifford's Tongan informants mentioned 'a great epidemic called ngangau (pain in the head)' which was 'brought by a vessel from Fiji' in a context which suggests from internal evidence that the 'great' epidemic occurred in 1812. Had there been more than one outbreak of this disease, Thomson would probably have mentioned it; if he dated the initial opidemic wrongly, then it is unlikely that there had been any abnormal outbreak of disease following the visit of any European vessel during the eighteenth century. On the other hand, Thomson and his colleagues on the 1893 Commission in Fiji found no traditions there which suggested opidemics in Fiji in either 1776 or 1812; the two severe outbreaks which they believed they could date were thought to have occurred in 1791-2 and 1802-3.

With the outbreak of the civil war in 1799, the Tongans in the southern islands congregated in palisaded villages and were reluctant to go out to their unprotected gardens to plant and cultivate food crops. As a result, both Tongatapu and Ha'apai suffered a severe famine and it is estimated that at least one fourth of the population died in the period, 1799-1826, as the victims of war and famine' (Wood, 1938, p. 33). The authority for this estimated loss from the population is not cited, but if the epidemic of ngangau occurred in the middle of this period it would have contributed to the total. Gifford's informant claimed that the sickness raged badly in the three groups, Tonga, Haapai and Vavau. It is said that they were not able to carry the dead away and bury them. It was at this time that the war [the campaigns of 1812-45] came to the remnant of people that escaped' (Gifford, 1929, p. 209).

Although there were few Europeans resident in the group during this period, the first decade of the nineteenth century was the boom period of the sandalwood trade in Fiji and, despite the Tongans' reputation for pillaging European ships, many of those engaged in the sandalwood trade called at Tonga en route to Fiji. It was also a port 
of call for trading ships and a trader who called at Tongatapu in 1803 was told by 'a person between two and three years resident amongst them' that the population of all the southern islands had 'suffered considerably' as a result of the civil war; the inhabitants were then by no means numerous' and 'the number of females exceeds that of the opposite sex in a two-fold proportion, owing to a continual depopulation consequent on destructive usages and perpetual warfare' (Turnbull, 1813, p. 394). He also reported that there had been 'an unusual scarcity' of food in Vava'u in 1801.

After the capture in 1806 of the privateer Port-au-Prince on which he served as a clerk, Mariner (Martin, 1818) lived in Tonga for four years under the protection of the powerful and ruthless chief Finau and his son. Mariner and the other members of the crew whose lives had been spared joined Finau in his various campaigns, but though he frequently estimated the number of canoes or warriors concerned in a particular skirmish, Mariner made no estimate of the total number of people there might have been in the islands. A Wesleyan missionary from Australia arrived in Tongatapu in 1822, but for personal reasons he stayed only one year and his successors did not arrive until 1826. Earlier that year two native pastors, trained in Tahiti by the London Missionary Society, were induced to stay in Tonga instead of proceeding to Fiji, and slowly all of the missionaries gained converts. By 1835, the people of both Vava'u and Haapai were nominally Christians but Tongatapu remained religiously and politically divided for many years.

In 1830, the population of Tongatapu was reputed to be 12,000 and that of Vava'u 'between five and six thousand, but this was a guess' (Waldegrave, 1833, pp. 186, 192). Three years later a missionary reported that the islands of the Ha'apai group might contain 4,000 people, but this was not near the number of inhabitants formerly resident upon them' because the population had 'been thinned by exterminating wars, by famine and other evils' (Watkin, 1833).

In 1840, the two ships of the United States Exploring Expedition called at Tongatapu and Commodore Wilkes recorded that the population of the Tonga Islands, as now given by the missionaries, is 18,500, viz:

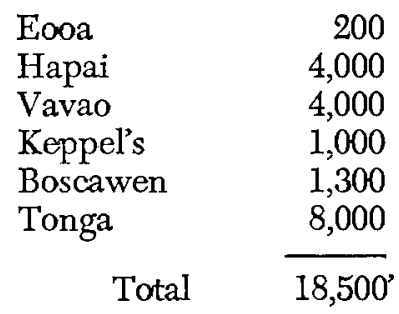


(Wilkes, 1845, 3, p. 29). The Tongan name of Keppel's Island is Niuatoputapu and Boscawen is Tafahi, a small cone-shaped extinct volcano which rises abruptly from the ocean to a height of 2,000 feet. In recent years there has been only one very small village on Tafahi and it is unlikely that its population in 1840 was larger than nearby Niuatoputapu's. Gifford apparently assumed that Wilkes or the missionaries had confused Tafahi and Niuafo'ou and he translated Wilkes's 'Boscawen' as Niuafo'ou in his tabulation of the population of Tonga 'by principal islands and island groups' (Gifford, 1929, p. 6).

The 1840 estimate is strangely at variance with Lawry's statement that in 1847 'the population of the Friendly Islands is estimated by the Missionaries at about fifty thousand' (Lawry, 1850, p. 245). Three years later he was planning an edition of 20,000 copies of the Tongan translation of the Bible, and he wrote "war has ceased, for the present; but I do not leam that, so far, the population has much increased' (Lawry, 1851, p. 27). Niuafo'ou's population was perhaps the first to be counted: in 1850 one of the eight European missionaries then in Tonga visited the native teachers on Niuafo'ou and 'found twelve hundred and twelve persons on the island' (Lawry, 1851, p. 95) whereas previously it was thought Niuafo'ou had 'about eight hundred inhabitants' (Lawry, 1850, p. 258). Probably neither Wilkes's nor Lawry's estimate was much more than a guess and, though the population of the whole group at midcentury may have exceeded 18,500 , a total of 50,000 Tongans is improbable.

In 1845 Taufa'ahau, already ruler of Ha'apai and Vava'u, was elected to govern Tongatapu and thus he became king of all Tonga. His authority was not universally accepted on Tongatapu and when Erskine visited there in 1849 he found 'a strong heathen party whose objections to join the rest of their countrymen arise, however, more from a political than a religious feeling' (Erskine, 1853, p. 12). Their opposition was crushed in the last battle of the civil war in 1852 and Tonga was at peace, a united and independent kingdom of between 20,000 and 30,000 people.

This was the range within which Erskine set the population and though he was reluctant to be more precise, the population was probably not much above 20,000 in 1852. If there had been excessively high mortality throughout the period 1799-1826, in which the males suffered more than the females, the number of births each year during this period was probably low, and the children that were born probably had relatively poor chances of survival. In 1826 there would have been few persons aged less than 27 years and, even if the births and chances of survival rose after 1826, in 1841 the depleted cohorts of the 1799-1826 period comprised virtually all of the females of reproductive age in the 
population. There would be no very great increase in the number of births each year until after 1851, or perhaps later, and it is not unreasonable to conclude that the total population remained fairly stable between 1840 and 1852.

Perhaps contributing to this stability were the 'numerous' Tongans then living in Fiji, mostly for only short periods though with a steady stream of replacements. Early in 1848 they were marshalled by Ma'afu, a member of Tonga's ruling family, who within five years had conquered all of the Lau Islands, and within fifteen years had come near to making Fiji a dependency of the Tongan crown'. In 1859, Ma'afu was reputed to command 3,000 of his countrymen, who 'under one pretext or another -protecting Tongan teachers, aiding rebellious chiefs, bullying Fijians into indiscretions, and levying tribute- . . carried war' to many parts of Fiji, and Derrick (1950, pp. 75, 130-1) believed that Ma'afu's ambition for an 'empire' stretching from the New Hebrides to Samoa was frustrated only by Thakombau's offers and eventual cession of Fiji to Britain in 1874. Hence there may have been several thousand Tongans in Fiji during much of this period, some of whom may never have returned to Tonga.

In 1865, the population of Tongatapu was reported to be between 9,000 and 10,000 and Vava'u's was 'said to be 4800 , showing a considerable decrease of late years' (Meade, 1871, pp. 211, 306).

The causes of this [diminution] are supposed to be emigration to other groups, shipwrecks, and the destructive effects of certain epidemics, such as intermittent fevers, diarrhoea, whooping cough, which have very recently done great mischief. The population has also suffered from other diseases such as dysentery, phthisis, scrofula, affections of the bladder, ophthalmia, different kinds of ulcers, and a disease known by the name of tona, which very much resembles framboesia (Brenchley, 1873, p. 102).

The relative incidence of, or mortality from, the various diseases was not stated, but if the populations of the other Tongan islands shared this catalogue with the unfortunate inhabitants of Vava'u, the total population of the kingdom in 1865 was probably still about 20,000 . On the other hand, it may have been larger; in 1874, a trader who had lived in various islands of the Pacific submitted a memorandum to the New Zealand Parliament in which he claimed that Tonga's population was 'probably not less than 25,000 ' (Sterndale, 1874, p. 2).

It seems that there may have been an epidemic of some kind soon after 1874, probably about 1877 or 1878 when the missions were at the height of their power both temporally and spiritually. The outbreak was 
mentioned in the course of a debate in the Tongan Legislative Assembly in 1891, when the members were discussing whether or not flirting should continue to be a punishable offence. Those against the cabinet's proposal to abolish it from the penal code waxed eloquent and one of the members

who generally talks sense, reminds the house that thirteen years ago a similar measure was passed, and that within three months an epidemic attacked the people, but when the measure was repealed the sickness abated. He only mentions the fact without drawing any deduction, except that there is room for belief that the Almighty does expect higher things from Tonga than from other countries (Thomson, 1894, p. 273).

One might infer from this that, whatever the disease had been, it had not caused excessive mortality, nor was it associated in any way with the 1875 measles epidemic in Fiji.

The principal European adviser to the Tongan Government at this time was the Reverend Shirley Baker, who became Premier in 1880 and remained in office for ten years. Towards the end of his term there was much dissension in Tonga because Baker had flagrantly violated the constitution he had helped devise, and had misappropriated government funds. When he was finally dismissed in 1890, the Treasury was empty and Thomson, on loan from the Fiji Government, spent nine months in Tonga in 1890-1 disentangling and reorganizing the kingdom's financial affairs and legal code. Subsequently, Thomson was a member of the 1893 Commission on the depopulation of Fiji and in 1900, he returned to Tonga to negotiate the Treaty of Friendship and Protection on behalf of the British Government. Because of his interest in matters concerning the growth or otherwise of populations, he recorded some of the pertinent facts about Tonga's population at the end of the century in his published reminiscences.

\section{Census Enumerations}

Although the 1891 census is the first for which data are now available, there probably were some earlier counts because the 1862 legal code imposed a head-tax on all Tongan males aged 16 years or more and introduced laws relating to the lease of land to taxpayers. The registration of births and deaths began about 1867 and Thomson certainly implied that census-taking was not an innovation in 1891.

It was the census year, and the law provided that the Minister of Police should be responsible for the numbering of the people. His arrangements were somewhat primitive, ... [he] simply ordered 
his policemen to visit every village and write down the names of the inhabitants. In a country where every individual is known if not related to the enumerator, not many omissions are likely to have been made. The total census of the natives was 19,196 (Thomson, 1894, p. 371).

Elsewhere he quoted the official figures of the census published in the Fetuu Aho of the 26th June, 1891:

$\begin{array}{lrr}\text { Total Population } & & 19,196 \\ \text { Adult males } & 5,281 & \\ \quad \text { females } & 5,142 & \\ \text { Children, males } & 2,910 & \\ \quad \text { females } & 2,940 & \\ \text { Children under 5 years, } & \\ \quad \text { both sexes } & 2,923\end{array}$

There was a decrease in population from January 1889 to March 1891 of 530 , or a decrease of 27.61 per mille in $2 \frac{1 / 4}{4}$ years, without counting Niuatoputapu and 'Eua. The average annual birth-rate was 18 per mille, and the death rate 28 per mille' (Thomson, $1892 \mathrm{~b}, \mathrm{p} .61$ ).

The official report of this census, discovered by Crozier (undated), claimed a total of only 19,186, with 10 fewer children than Thomson quoted. The distribution of population by islands adds to this smaller total, and as both Niuatoputapu and 'Eua are included in this listing, the vague doubts as to completeness engendered by Thomson's exclusion of them from the estimates of decrease are removed. Nevertheless, a total of 19,186 is rather smaller than would be expected from later population figures and the natural increase which Thomson quoted for the last nine years of the century, so the 1891 count may have been incomplete.

There was an outbreak of measles in Tonga in 1893, which was thought to have been introduced from New Zealand. Fiji's experience of a measles epidemic eighteen years before was vivid in Tongan memories and they took ... some precautions against the after-effects of the disease; but, nevertheless, one-twentieth of the population was carried off, and the remainder was so demoralised that it was threatened with famine' (Thomson, 1894, p. 286). The epidemic started in Tongatapu and though Thomson implies that it spread throughout the group, this is not clearly stated. The estimated loss from the population was presumably calculated from the number of deaths registered and may therefore be reasonably accurate, even though 5 per cent of the population recorded in 1891 is suspiciously close to 1,000 . 
When Thomson revisited Tonga in 1900, 'the mission returns put the total population at 19,968' and the Chief Justice gave him a summary of the births and deaths registered from January 1890 to December 1899. The total population was divided amongst the districts and outlying islands and, though 'Eua is not listed separately, its population was probably included with Tongatapu's. The numbers given for the five districts do not tally with those quoted by Gifford (1929) for 1900, but as Gifford did not cite the source of his figures and Thomson did not state the year to which the mission returns referred, the discrepancies need not be elaborated. In round figures, there were 8,400 people on Tongatapu and 'Eua, between 5,100 and 5,200 in Ha'apai, 4,600 in Vava'u and just over 700 and 1,100 on Niuatoputapu and Niuafo'ou respectively.

This geographic distribution of population is not very different from the mission estimate for 1840. Both Vava'u and Ha'apai were accorded larger populations in 1900 than in 1840, and the increase was relatively greater in Ha'apai which would be difficult either to enumerate or estimate because its population is spread over so many small islands. The populations of Niuatoputapu and Niuafo'ou had diminished slightly by 1900 , but part of this decrease may have been due to emigration to larger or less isolated islands in the group. This comparative stability gives point to Thomson's observation that Tonga's population was stationary, or slightly decreasing, but . . . there has been no very marked decline, as in Hawaii, New Zealand, and Fiji since the beginning of the nineteenth century' ('Thomson, 1902, p. 180).

In fact, more births than deaths were registered in the nine years 1891-9, but Thomson was reluotant to admit that Tonga's population might have increased.

I do not regard the numbers of births and deaths with any confidence, partly because I know the haphazard way in which the registers are kept, and partly because, assuming the total population of the kingdom to be not less than 19,000 , the death-rate is represented as low as eleven per thousand and the birth-rate as high as twenty-six per thousand, which is very unlikely, seeing that families of more than three living children are rare. Nevertheless, the Tongans are all agreed that, in spite of a devastating epidemic of measles in 1893, there has been an increase of population of over 200 in the nine years: the returns say 203 (Thomson, 1902, pp. 179-80).

Likely though it is that the registers were incomplete, Thomson had not queried their reliability for the previous decade (1881-90) when the crude death rate was 36 per 1,000 and 'the registers of the births and 
deaths ... showed the population to be steadily decreasing, not so much on account of excessive mortality as of a low birth-rate' (Thomson, 1894, p. 371).

Compared with a crude birth rate of between 35 and 40 per 1,000 in the Fijian population at this time, Tonga's birth rate was low and Thomson blamed the 'grim social code of the missionaries' which led young girls to defer marriage 'until the last possible bridegroom [had] left [them] for a younger generation' (Thomson, 1902, pp. 373-4). Perhaps the postponement of marriages did reduce the number of births likely to occur each year, but this nine-year period was unusual because of the measles epidemic in 1893. If mortality in this outbreak was spread evenly throughout all age groups, the number of births in the year or two following the epidemic would have been almost 10 per cent less than the numbers which would have occurred had there been no epidemic, and there might have been an even larger decline. The crude birth rate is not very efficient for comparative purposes unless the populations being compared are similar in age structure and, in view of their respective histories, this would not be expected of the Fijian and Tongan populations of 1890 to 1900 .

Both populations were enumerated in 1891 and, assuming that the same sort of people were described as 'children' in each, these constituted 45 per cent of the Tongan population but only one-third of the Fijian. Adjustment for this factor alone would account for roughly half the difference between the crude birth rates, and if the average number of births each year could be referred to the numbers of females of reproductive age, the difference between the levels of fertility in the two populations would probably vanish. The number of Fijian females aged between about 15 and 50 years in 1891 was 25,000 and an average of 3,750 Fijian births were registered annually over the next decade. Probably only 4,000 of the 5,142 'adult females' recorded in Tonga's 1891 census were women of reproductive age and, if the average fertility rate for Fijians is applied to this number, about 600 births would be expected in Tonga each year. Although this number exceeds the 500 births a year implied by the crude birth rate, it is not at all inconsistent with the aftermath of the measles epidemic and the fertility rate of at least 150 births per 1,000 females of reproductive age which might be estimated from the child-woman ratio for the census population.

It would seem, therefore, that high mortality rather than low fertility determined the course of population growth in Tonga in the latter part of the nineteenth century. The proportions of the population in the categories of 'adults' and 'children' in 1891 suggest that the accessions to the population may have increased sharply after 1876, and this 
accords with what could be expected as a consequence of exceptionally heavy mortality during the first half of the civil war. The youngest of the depleted 1799-1826 cohorts would have effectively completed their reproductive life by about 1865 , but their contribution to the number of births each year would not have been very large after 1855. The women then in the first half of the reproduotive period were the relatively small cohorts born after 1826 but, as the numbers of females attaining reproductive age after 1855 were probably much larger than the numbers completing their child-bearing, the number of births could be expected to increase and the effect of this increase would be apparent in the numbers of births occurring twenty to twenty-five years later.

A crude birth rate of 26 per 1,000 population implies a total of 4,500 births in nine years and, if there was a difference of only 203 between the numbers of births and deaths registered, the death rate could only have been as low as 11 per 1,000 population if there had been more than 2,500 deaths from measles in 1893 which Thomson excluded from his calculation. If there were only 1,000 deaths as he claimed and a natural increase of 200 between 1891 and 1900, the average annual death rate in Thomson's population of 'not less than 19,000' would have been at least 22 per 1,000 in non-epidemic years, rising to an average of 25 per 1,000 population for the whole period. A death rate of 11 per 1,000 and a birth rate of 26 per 1,000 throughout the nine years would have produced an increase of at least 1,800 in population, and this is belied by the population figures quoted by both Thomson and Gifford.

Gifford (1929) listed the numbers of 'full-blooded Tongans' on the principal islands and island groups in the years 1900, 1902, 1905, 1906, $1909,1911,1915$ and then annually from 1917 to 1921 . He cited no source for these figures, but they may have been taken from official enumerations, even though their chronological sequence is odd. The earliest census legislation known was incorporated in the Town Regulations Act of 1903, and this stipulated only that 'the Minister of Police shall appoint a time for taking the Census and the Mayor and Town Officer in each village shall be responsible for the correctness of the census in their village'. Some Ministers of Police may have been more assiduous than others in carrying out this part of their duties, but there are now no official records of censuses earlier than 1911.

The population was enumerated on 3 April 1911 and the one table published in the Tonga Government Gazette, No. 20 of 21 October 1912 gave the numbers of Tongan subjects and foreigners living in each district. The Tongan subjects were classified as either Tongans, Halfcastes or Other Pacific Islanders, and the foreigners were divided into Europeans, Half-castes and Other Pacific Islanders. They were 
enumerated again on 26 April 1921 and the tabulations published in the Tonga Government Gazette for 1921 show the inhabitants of each district in the same two nationality groups, further classified by sex and age. The four categories of age were translated into English as 'aged', 'middle', 'young' and 'infants', but the Tongan equivalent of this last is better translated by 'children'. Other items recorded in this census were religion, type of dwelling, the number of live animals of various kinds and firearms owned by the people. No details of the arrangements for either of these enumerations accompanied the published tables.

The next census seems to have been held on 27 April 1931 and there was an enumeration on this day each year until 1939. The scope of the agricultural section of these censuses was expanded to include the numbers of 'useful trees' and quantities of 'growing crops' as well as the numbers of mares and stallions, cattle, goats, pigs, sheep and poultry. The marital status of each person was recorded and though the tabulation of the population by the descriptive age groups used in 1921 was compiled only for 1931, this information was probably recorded each time. Many of the enumeration books used for the census of 27 March 1939 were still available in Nukualofa in 1953 and it was thought that similar books had been used for all enumerations since 1931 .

These books were as unwieldy as might be expected for a combined inventory of population, livestock and agricultural resources. The books

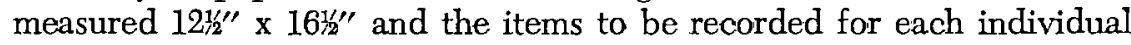
spread over two pages. Excluding the impersonal details of type of dwelling and ownership of animals and food crops, there were eleven items to be recorded for each of the 34 individuals who could be listed on a page and for three of these-sex, marital status, and nationalitythe alternative replies were awarded separate columns, thereby facilitating both recording and summarizing. Each Town Officer was required to list all the people domiciled in his village on the night of 27 March by name, and to record their religion, sex, age, marital status, nationality, place of birth, occupation, literacy, ability to speak English, and their infirmities; then followed the type of dwelling, the livestock owned and the food crops being grown under or above ground.

This catalogue of information for each village was compiled on the village green, whither all the registered taxpayers of the village were summoned. Provided all families were represented there, all would be well and the census 'as correctly given in that way as in any other' (Stewart, 1892, p. 118). But as some families would contain no taxpayers and some taxpayers would ignore the summons or perhaps become impatient and leave before divulging their share of information, the census may not have been as complete as might be imagined (Tupouniua, 
1958 , p. 3). When the inventory for the village was completed, the enumeration books were returned to the Office of the Minister of Police and the data were summarized there.

There was no further enumeration then until 1950, when the Town Officers were asked to count the numbers of men, women, and children in their villages on the night of 15 July so that the proportion of the population dependent on agriculture might be estimated for the 1950 World Census of Agriculture. This was a simple head-count, presumably of the total population, and the only details now extant are the numbers of males and females in each village in each district (Crozier, undated).

In 1956 new census legislation was introduced and a Census Officer, not the Minister of Police, was made responsible for the organization of a census. This enumeration was modelled closely on Fiji's and related to the population in the kingdom on 27 September 1956. Except for details of types of dwellings, the particulars requested on the household schedules were identical with those for $F_{i j i}$ and, as in Fiji, in the ten days preceding the census date, the enumerators visited each house in the areas assigned to them to record the details required about the members of the households, returning on census day or during the next two days to check their completed schedules. These data were subsequently transferred on to peripherally punched cards, one card for each and every person recorded on the schedules, and the cards were then sorted manually and counted. The tables which were compiled were published in a report on the census which describes the details and difficulties of the procedures for collection and tabulation (Tupouniua, 1958). This is Tonga's first census report and though the tables are not always arithmetically consistent, this enumeration is probably the most complete record there has been of the population.

\section{Growth of Population in the Twentieth Century}

The populations recorded in various censuses since 1911 and those reported for other years of this century are given in Table 15. In the few years for which details of the non-Tongan populations are now available, their contribution to the total populations is so small that they can be ignored in the discussion of the growth of Tonga's population. For the most part, the population of the kingdom will be treated as a geographic unit because the changes which occur in the numbers of inhabitants recorded on individual islands between censuses are such as to arouse considerable doubts as to the accuracy of either the recording or summarizing of the data. These curiously inconsequential fluctuations are, of course, reflected in the size of the total population, but sometimes an inexplicable increase in one population is offset by an equally 


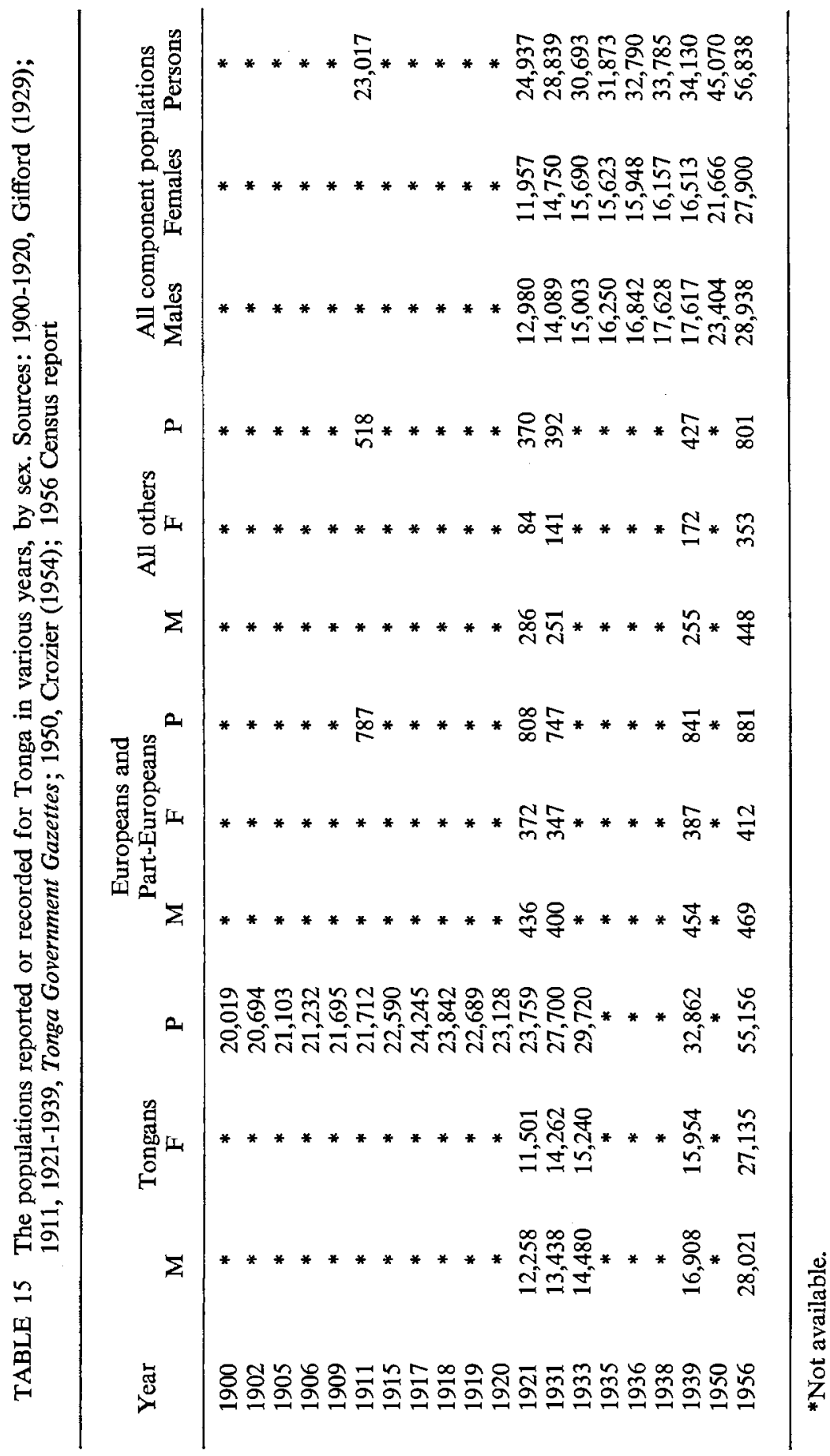


inexplicable decrease in another so that the total recorded may not be too wide of the mark. On the average, Tongatapu and 'Eua contain just under half of the total population; Ha'apai and Vava'u jostle for second place with Ha'apai's population exceeding Vava'u's for the first half of the period and Vava'u taking the lead from about 1931.

Until 1915, there was little change in population numbers each year, though the number of births probably exceeded the deaths by a narrow margin in most years. There was a sudden rise in 1917 and the numbers declined in each of the next two years. The smallness of the population in 1919 is probably directly related to an epidemic of influenza at the end of 1918 which almost certainly originated with the same ship believed to be responsible for the outbreaks in both Fiji and Western Samoa, and which discharged cargo in Tonga early in November 1918. Lambert (1934) claimed that 1,595 Tongans died in the epidemic, though Wood stated that 'the influenza epidemic of 1919 caused 1,000 deaths' (Wood, 1938, p. 64). If the populations recorded for 1918 and 1919 are correct, Lambert's figure appears the more plausible and gives a crude death rate from influenza comparable with Montague's (1919) for Fijians.

The peak in population numbers in 1917 is probably due to an arithmetic error; more than three-quarters of the total increase is accounted for by an increase of nearly 1,300 in Tongatapu's population between 1915 and 1917, and Gifford's figures show a decrease of almost 500 in this population between 1917 and 1918, although it fell by only 400 in the following year when it is known an epidemic occurred and the total population decreased by about 1,200 . Hence it is probable that Tonga's population increased slowly but steadily until 1918 and, after an initial setback caused by the influenza epidemic, resumed its increase thereafter.

If the census figures for 1921 and 1931 are correct, there was an increase of 16.6 per cent in population over the decade, but the male population increased at an average rate of 0.9 per cent a year and the female population increased annually by $2 \cdot 2$ per cent. The switch from an excess of males in the 1921 census population to an excess of females in 1931 and 1933, with a reversion to a substantial excess of males in all later censuses is implausible. The births and deaths registered in each year during this decade were published in the Annual Reports of the Chief Justice and, although the numbers for at least one year are known to be incomplete, there was an excess of males amongst all births registered during the decade. If these and the census enumerations were correct, 3,735 males died between 1921 and 1931 but only 1,930 females. Unfortunately the deaths of males and females were not distinguished 
in these published statistics, but the total of at least 4,513 deaths recorded is considerably less than the 5,665 required for the reconciliation of the two censuses and the births registered.

This discrepancy between the recorded natural increase and the inter-censal increase in population was not uniform throughout all districts of Tonga, but the outstanding exception was Vava'u where the recorded natural increase was less than the difference between the two census populations. In particular, the female population of Vava'u increased by 1,499 over the inter-censal period and, as the births of only 1,195 females were registered there between 1922 and 1931, the most likely source of the change in the sex ratio is an arithmetic error in the census returns for Vava'u district in 1931. If the female population of Vava'u was over-stated, the population for the kingdom would have increased more slowly over this decade than the census figures indicate.

If the various enumerations until 1939 are ignored, the population increased by 38 per cent in the eighteen years from 1921 and the annual increments of 1.8 per cent per year for the male and female sectors of the population are as similar as one would expect from the sex ratios of the births registered in this interval. Over the next seventeen and a half years-from March 1939 to September 1956-the population increased by 68 per cent, corresponding to average annual rates of increase of 2.9 and 3.1 per cent for males and females respectively. Estimates of population derived by interpolation between the 1921, 1939, and 1956 totals at these average annual rates of increase tally reasonably well with those recorded except that, for 1931 and 1933, the numbers of males and females were reversed. Assuming that the three basic counts were reasonably accurate, the Tongan population probably doubled in the twentyfive or twenty-six years preceding 1956.

\section{Age and Sex Composition}

The first year for which there is a distribution of the population by chronological age is 1939. In 1921 the population was tabulated, if not recorded, according to descriptive ages and, though it is claimed that Tongans know instinctively into which of these categories of age any particular person should be put, on enquiry there seemed to be no range of chronological ages associated with each category which was both generally acceptable to informants and could be sustained by the numbers of persons assigned to each group in the censuses. In 1939 chronological ages were recorded and, as many of the books used then were still available in 1953, the population recorded in them was summarized by sex and single years of age. Only 16,706 males and 15,824 females were covered by this second count whereas initially 17,617 
males and 16,513 females had been recorded. A few books had apparently been lost or destroyed in the years since 1939, but the second count was sufficiently complete to permit a reasonable estimate of the age distribution of the total population.

For both males and females the distribution by single years of age had pronounced peaks at the round ages 20,30,40, etc., and minor peaks at ages with 8 as the unit digit. The inordinate preference for round ages was only partly compensated by the avoidance of ages with unit digits of 1 to 4 , and as the favouring of ages with 8 as the terminal digit was cancelled by the avoidance of those ending in 7 , the preferences for ages in the first half of each decade of age summed to more than 53 per cent for males and 58 for females. As the summary indioes of preference indicated that the unit digit of age was incorrectly stated for. at least 20 per cent of males and more than 30 per cent of females within the age range 13 to 62 years, the ages reported in the 1939 census of Tonga wore clearly very approximate.

Nevertheless, the distribution of males and females over the customary five-year age groups is given in Table 16. The numbers at individual ages 0 and 1 year are distinguished because there seems to have been some under-enumeration of children aged less than 1 year in the census. The numbers expected at these ages were estimated from the published summaries of births and deaths and, allowing for the incompleteness of this second count of the population, the numbers enumerated at age 0 were only three-quarters of the 657 males and 604 females expected. The numbers expected at age 1 year-564 males and 552 females-agreed closely with the numbers enumerated so that if some infants were recorded as 1 year of age, some of the 1-year-olds must have been moved to age 2. The deaths at ages beyond 1 year are not published in sufficient detail to permit reliable estimates of the numbers expected at ages 2 to 4 years, but the suspicion of under-enumeration is sustained by crude estimates of the numbers of males and females expected at grouped ages $0-4$ years.

Hence, the population of Tonga in 1939 was probably a little larger than was recorded and, in view of this and the uncertainty about the ages reported, somewhat arbitrary adjustments were made to the recorded data to derive the probable age distributions of the male and female sectors of the population which are shown in the middle columns of Table 16. According to this, 45 per cent of both males and females were less than 15 years of age and just over 40 per cent were in the reproductive age range 15 to 44 years, with 25 per cent concentrated in the first half of this period. The median age for both males and females was about 17 years. Given this age structure and the assumption of no gross 
TABLE 16 Distribution of each 1,000 males and females in the Tongan population by age in 1939 and 1956

\begin{tabular}{|c|c|c|c|c|c|c|}
\hline \multirow[t]{2}{*}{$\begin{array}{l}\text { Age } \\
\text { group }\end{array}$} & \multicolumn{2}{|c|}{$\begin{array}{c}\text { Enumerated* } \\
\text { population: Nos. }\end{array}$} & $\begin{array}{r}\text { Es } \\
\text { pro }\end{array}$ & $\begin{array}{l}\text { ated } \\
\text { tions }\end{array}$ & \multicolumn{2}{|c|}{$\begin{array}{c}1956 \\
\text { Proportions at } \\
\text { each age }\end{array}$} \\
\hline & Male & Female & Male & Female & Male & Female \\
\hline 0 & 493 & $433)$ & & & & \\
\hline 1 & 560 & $535\}$ & 169 & 170 & 181 & 173 \\
\hline $2-4$ & 1,637 & 1,619 & & & & \\
\hline $5-9$ & 2,506 & 2,369 & 151 & 150 & 145 & 143 \\
\hline $10-14$ & 2,111 & 2,083 & 127 & 131 & 123 & 120 \\
\hline $15-19$ & 1,732 & 1,561 & 104 & 98 & 110 & 105 \\
\hline $20-24$ & 1,288 & $1,383 \chi$ & & & 86 & 89 \\
\hline $25-29$ & 1,052 & $1,066\}$ & 141 & 155 & 73 & 82 \\
\hline $30-34$ & 1,064 & $1,114\{$ & 112 & 115 & 63 & 62 \\
\hline $35-39$ & 817 & $708\}$ & 113 & 115 & 50 & 51 \\
\hline $40-44$ & 784 & $851\}$ & 76 & 75 & 40 & 39 \\
\hline $45-49$ & 477 & $333\}$ & 16 & 15 & 33 & 29 \\
\hline $50-54$ & 707 & $720\}$ & 61 & 56 & 26 & 28 \\
\hline $55-59$ & 309 & $173\}$ & 61 & 56 & 23 & 22 \\
\hline $60-64$ & 437 & $424\}$ & 38 & 33 & 16 & 17 \\
\hline $65-69$ & 199 & $95\}$ & 38 & 33 & 10 & 12 \\
\hline $70-74$ & 201 & $164\}$ & & & 8 & 11 \\
\hline 75 and over & 138 & $112\}$ & 20 & 17 & 13 & 17 \\
\hline Not stated & 194 & 81 & & & & \\
\hline All ages & 16,706 & 15,824 & 1,000 & 1,000 & 1,000 & 1,000 \\
\hline
\end{tabular}

* Relates only to population recorded in the enumeration books which were still available in 1953.

distortion in the sex composition at any age, the Tongan population could be expected to increase as it did between 1939 and 1956.

In the 1956 census, most of the enumerators were school-teachers and the importance of reporting age as accurately as possible was emphasized both in the training of the enumerators and in the general publicity for the census. As a result, the distribution of the population by single years of age no longer showed the concentration of people at the 'round' ages 20 , 30, etc., and the extent of mis-statement of unit digits of age fell to 5.6 per cent for males and $5 \cdot 4$ per cent for females. Both males and females within the age range 13 to 62 years favoured ages ending 
in 6 and 8 , and although ages with 1 as the unit digit were conspicuously avoided, on the whole, ages in the second half of each decade of age were more favoured than those in the first half.

Though the extent of mis-statement was greater, the pattern of preferences resembles that for the Fijians in 1956, and on these grounds alone one might conclude that the Tongan enumerators shared the Fijian enumerators' tendency to down-grade ages when the exact age was unknown. This is confirmed to some extent by the irregular changes in the proportions of the total male and female populations contributed by successive cohorts given in Table 16, but even more by the comparison between the sizes of cohorts in the two censuses.

Allowing for under-enumeration at ages less than 1 year in 1939, the proportions of the four cohorts aged from 0 to 19 years in 1939 to survive to ages $17 \frac{1}{2}$ to $36 \frac{1}{2}$ years in 1956 were $931,907,913$, and 911 per 1,000 males and 957, 991, 942, and 937 per 1,000 females respectively. On the 1939 mortality experience for males and females, the proportion of each cohort that could be expected to survive from their average age in 1939 to their average age in 1956 was respectively $916,899,875$, and 880 per 1,000 males and $927,920,904$, and 890 per 1,000 females recorded in 1939.

Assuming some decline in mortality over the inter-censal interval, the two younger male cohorts behaved as would be expected, but the deviations shown by the males aged 10 to 19 years in 1939 suggest either an avoidance of these ages in 1939 or a preference for ages between 25 and 34 years in 1956. Compared with the males, rather more of each cohort of females survived the inter-censal years than would be expected unless there had been a dramatic fall in the mortality of females, and a relatively greater change for them than for the males. This is not apparent in the limited mortality data available for Tonga and the surfeit of survivors amongst the female cohorts is, therefore, probably due to the favouring of ages between 20 and 35 years for females in 1956. The proportions of survivors in the older cohorts reflect the effects of comparatively gross mis-statements of ages in 1939, particularly in regard to a concentration of persons at ages 20 to 29 years and the avoidance of ages in the second half of each decade of age.

The more fundamental comparison between cohort size in 1956 and the initial birth cohorts can be made only for cohorts aged less than 35 years because the births registered in Tonga each year have been summarized only since 1922. The births of males and females are given separately, but as Tongan and non-Tongan births are not distinguished and the statistics for a few years are not available, exact comparisons are not possible. However, the estimated proportions of Tongan survivors 
amongst the original cohorts of births are illustrated in Fig. 2 and, though the proportions of the male cohorts surviving to census date might be fitted to a reasonably smooth curve, the survival pattern of the female cohorts is curious.

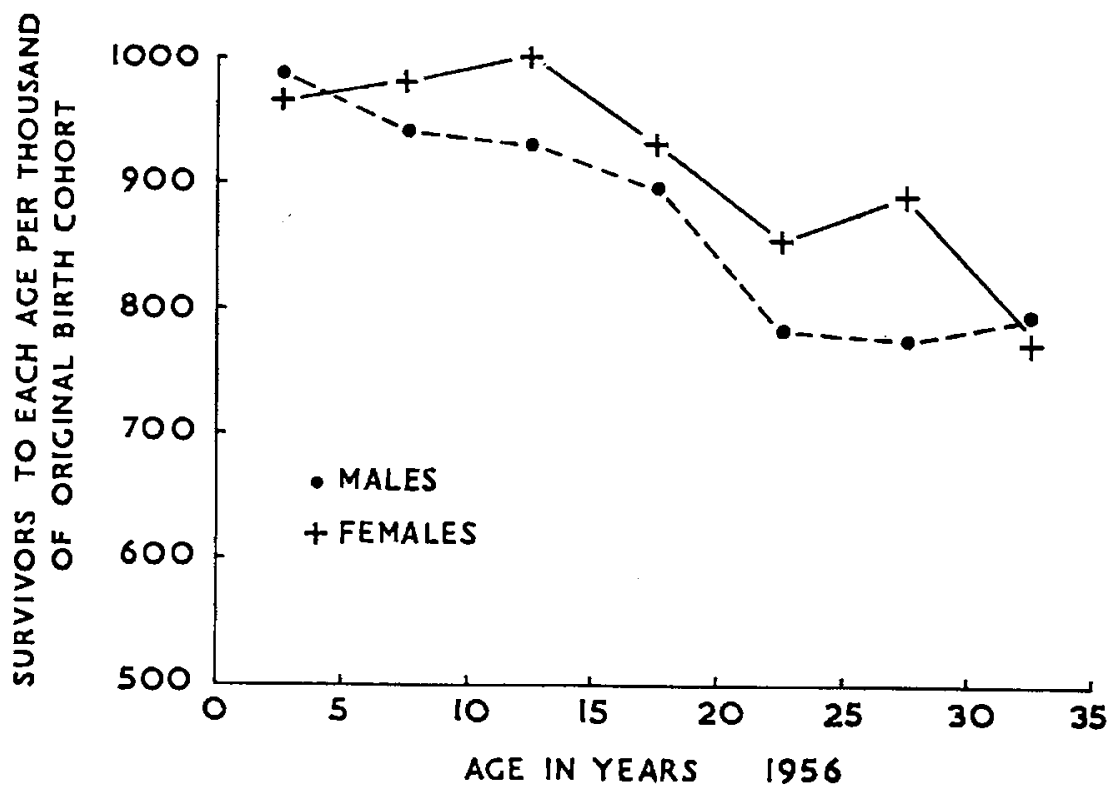

Fig. 2 Numbers of Tongan males and females surviving in age groups up to 35 years per 1,000 births recorded in the appropriate five-year periods

As there is more incentive for Tongan parents to register the birth of a male child, the statistics of female births may be deficient, but this alone could scarcely account for the disparity between the proportions of survivors in the male and female cohorts at all ages between 5 and 30 years. The difference between the survival rates of males and females in the youngest cohort is not statistically significant, and the proportion of Tongan survivors amongst all births registered is so high that any under-enumeration at ages less than 1 year in this census seems unlikely. Faulty estimation of the numbers of births of each sex for the years 1945-7 may be responsible for part of the rise in the proportion of female survivors at ages 5 to 14 years, but the birth statistics for all previous years are available so this cannot account for the apparent concentration of females at ages 25-29 years which confirms the preference for these ages which was evident in the comparison with the 1939 data. The most 
likely explanation for the deviant behaviour of the female cohorts in both comparisons is that the exact ages of females were known less often than the ages or years of birth of the males, and the ages guessed or estimated by the enumerators or their informants for the females tended to under-state the real age.

As a result of the mis-statement of age for females, the sex ratio in the population changes from a marked excess of males at ages up to 19 years to equality at ages 20-24 and to a surplus of females at ages 25-29 years before reverting to an excess of males at all ages up to 60 years. This reversal in the sex ratio of the 1927-31 and 1932-6 cohorts was not apparent in 1939, and the births recorded in these years showed a consistent excess of males except for the one year 1934 when 592 male and 599 female births were registered. Hence, unless the males of these cohorts suffered exceptionally high mortality between 1939 and 1956, an excess of females at the relevant ages in 1956 would not be expected if age had been reported accurately.

Acknowledging the mis-statements of age in both censuses, the age structure of the Tongan population probably did not change greatly during the seventeen and a half years interval. There may have been a slightly higher proportion of the total population at ages $0-4$ years in 1956 which, in turn, may have been the consequence of relatively more females in the first half of the reproductive period in 1956 as compared with 1939, although some part of this concentration is due to inaccurate reporting of age. The median age for males was $17 \cdot 2$ years and $17 \cdot 9$ for females and approximately 44 per cent of the population was aged less than 15 years. About 42 per cent of the total were between 15 and 44 years of age, and the number of females attaining reproductive age each year after 1956 should be considerably in excess of the numbers completing their fertility. With relatively few people at ages beyond 60 years, the losses from the population through death are likely to be small compared with the accessions through births and, in the absence of any radical change in either mortality or fertility, the population can be expected to increase. Its rate of increase will be determined by the patterns of mortality and fertility and the data relating to these will now be examined.

\section{Registration of Births and Deaths}

The most recent legal provision for the registration of births and deaths is the Registration Act, No. 9 of 1947 which provides for the registration of names, births, deaths, and marriages. The sections relevant to the recording of births and deaths are as follows: 


\section{Births}

9. (1) The parent of every Tongan child born in the kingdom, whether such child be born alive or not, shall within the fourteen days of the birth of such child furnish to the Sub-Registrar of the District in which such child is born such particulars regarding such child as may be prescribed by Rules made in that behalf by Her Majesty in Council.

(2) If the parent of any child born in the kingdom, whether alive or not, shall fail to furnish the prescribed particulars regarding such child the occupier of the place in which such child is born and every person present at the birth of such child shall inform the SubRegistrar of the District in which such child is born of the birth of such as shall be within his knowledge.

(3) On receipt of the particulars required by this section to be given regarding the birth of any child the Sub-Registrar shall forthwith register the birth of such child.

Provided that where such particulars shall be furnished to him more than fourteen days after the birth of any child the Sub-Registrar may require the person furnishing the same to verify the same in such manner as he may see fit.

\section{Deaths}

10. In the case of the death of any Tongan it shall be the duty of the occupier of the premises where the death occurs and of every person present at such death to furnish to the best of his ability to the Sub-Registrar of the District in which such death occurs such particulars regarding the dead person and the circumstances of death as may be prescribed by Rules made by Her Majesty in Council.

I1. Any person who shall find or have knowledge of any dead body lying exposed shall forthwith inform a police officer or town or district officer.

12. Any person holding an Inquest under any law for the time being in force relating to the holding of Inquests shall immediately after conclusion of the same furnish to the Sub-Registrar of the District in which such inquest is held a copy of the finding of such inquest together with such particulars relating to the dead person upon whose body such inquest shall have been held as may have been ascertained by him in the course thereof.

28. Her Majesty in Council may make Rules for the following purposes:

(a) providing for the allocation of duties in connection with the adininistration of this Act;

(b) prescribing the forms of the records to be kept by the Registrar and Sub-Registrar; 
(c) prescribing the particulars to be furnished by any persons for any of the purposes of this Act....

Although printed in the revised edition of the Law of Tonga as at 1 January 1948, this Aot has not yet been fully implemented but the principal difference between this and the earlier Act of 1926 which covered registration is the period of grace allowed. Formerly, thirty days were allowed for the registration of both births and deaths, and the 1947 Act stipulates that births be registered within fourteen days though no time limit is sot for the registration of a death. This may be an oversight, but as a fairly cursory examination of the dates of death and registration recorded in several death registers showed that the time between the two events frequently exceeded thirty days, it may indicate acceptance of the inevitable.

The details required for the registers of births and deaths have remained virtually unaltered since the earliest registrations in about 1867. When a birth is registered, the child's name, place of birth, date of birth, and sex are recorded, together with the names of the parents and their birthplaces, and whether or not the child is legitimate. The age of the mother is not recorded, nor is the rank of the birth. The death register shows the name of the deceased, his or her sex, age, marital status, number of children born and number still surviving, as well as the place and date of death, the date of registration, and the names of the parents and the clergyman officiating at the burial.

The penalty for failure to comply with any of the provisions of this Act or of any Rules made thereunder' is 'a fine not exceeding fifteen pounds or ... imprisonment with hard labour not exceeding one year' (Section 26), and as every Tongan male aged 16 years or over, legitimately born, is legally entitled to the lease of $8 \%$ acres of farm land on payment of the necessary tax, parents have an additional incentive to register the birth of a male child. Recently birth certificates have been required before children are admitted to certain schools and frequently also when young people seek employment but, nevertheless, it is a known fact (though the exact number is not yet known) that the births of a number of Tongan people have not been registered' and in 1956 the number was thought to be sufficiently large to warrant a special plea to parents not to omit mention of children whose births had not been registered (Tupouniua, 1958, p. 7). Tempting though it is to assume that, for practical reasons, negligence in regard to registration would concern deaths more frequently than births, this may not be so.

The reconciliation of the census populations of 1921 and 1939 with the births recorded required at least 10,091 deaths whereas only 8,050 
had been registered over the interval. Although under-enumeration of infants is suspected for the 1939 census, at least an equivalent number of children less than 1 year of age is likely to have been omitted from the 1921 census, and the registration of deaths during this period was probably less than 80 per cent complete. The statistics of births and deaths for the years between 1939 and 1956 are incomplete, but the difference between the inter-censal change in population numbers and an estimate of the number of births registered required about 6,500 deaths and, as 6,017 were registered in twelve and a half years of the seventeen and a half year period, the deaths which escaped registration were probably fewer than the unrecorded births. No accurate estimate can be made of the frequency with which births are not registered in Tonga, but if the extent of under-registration is the same as in the Fijian population and approximately 5 per cent of all Tongan births are not registered, then the reconciliation of the 1939 and 1956 census populations indicates that the registration of deaths is still little more than 80 per cent complete.

\section{Analyses of Mortality}

The statistics of deaths registered in each district each year which are published in the Annual Reports of the Department of Justice isolate deaths at ages less than 1 year from the remainder, but do not specify the deaths of males and females separately. By courtesy of the Registrar and the Government of Tonga, the deaths registered in three-year periods centring on 1939 and 1956 have been summarized by sex and chronological age. The data for 1938-40 are incomplete because the registers for Niuafo'ou for these years were not available in 1953. In computing the average annual mortality rates for 1939, the population of Niuafo'ou was excluded from the total and the remainder distributed over the age groups according to the estimated distributions for males and females given in Table 16. Except for unregistered deaths, the data for 1955-7 are believed to be complete, and the average annual mortality rates per 1,000 males and females at each age in the two census populations are shown, with their standard errors, in Table 17.

The mortality rate at age 0 in each instance is the infant mortality rate, in which the deaths at ages less than 1 year were referred to the births registered in the appropriate period of years. For consistency with all other mortality tables, the rates for 1938-40 are given correct to one decimal place, but this precision is not warranted by the quality of the data. The ages stated in the death registers are likely to be no more accurate than were the ages in either census and, though some of 
TABLE 17 Estimated average annual mortality rates per 1,000 males and females at each age in the Kingdom of Tonga in the years 1938-40 and 1955-7

\begin{tabular}{|c|c|c|c|c|c|c|c|c|}
\hline \multirow{3}{*}{$\begin{array}{l}\text { Age } \\
\text { group }\end{array}$} & \multicolumn{4}{|c|}{$1938-40^{*}$} & \multicolumn{4}{|c|}{$1955-57$} \\
\hline & \multicolumn{2}{|c|}{ Males } & \multicolumn{2}{|c|}{ Females } & \multicolumn{2}{|c|}{ Males } & \multicolumn{2}{|c|}{ Females } \\
\hline & Rate & S.E. & Rate & S.E. & Rate & S.E. & Rate & S.E. \\
\hline $0+$ & $65 \cdot 7$ & $9 \cdot 4$ & $47 \cdot 2$ & $8 \cdot 5$ & $45 \cdot 8$ & $6 \cdot 3$ & $45 \cdot 6$ & $6 \cdot 7$ \\
\hline $1-4$ & $7 \cdot 2$ & $1 \cdot 8$ & $7 \cdot 3$ & $1 \cdot 8$ & $8 \cdot 4$ & $1 \cdot 4$ & $8 \cdot 4$ & $1 \cdot 5$ \\
\hline $5-9$ & $2 \cdot 9$ & $1 \cdot 1$ & $2 \cdot 8$ & $1 \cdot 1$ & $1 \cdot 1$ & 0.5 & $1 \cdot 2$ & $0 \cdot 5$ \\
\hline $10-14$ & $2 \cdot 7$ & $1 \cdot 1$ & $3 \cdot 1$ & $1 \cdot 3$ & $1 \cdot 1$ & 0.6 & $1 \cdot 0$ & 0.5 \\
\hline $15-19$ & $9 \cdot 4$ & $2 \cdot 3$ & $5 \cdot 2$ & $1 \cdot 8$ & $2 \cdot 5$ & 0.9 & $1 \cdot 3$ & $0 \cdot 7$ \\
\hline $20-24$ & $9 \cdot 0$ & $2 \cdot 6$ & $5 \cdot 1$ & $1 \cdot 9$ & $2 \cdot 3$ & $1 \cdot 0$ & $3 \cdot 0$ & $1 \cdot 1$ \\
\hline $25-29$ & $6 \cdot 6$ & $2 \cdot 5$ & $8 \cdot 2$ & $2 \cdot 8$ & $3 \cdot 0$ & $1 \cdot 1$ & $2 \cdot 2$ & $1 \cdot 0$ \\
\hline $30-34$ & $4 \cdot 4$ & $2 \cdot 0$ & $6 \cdot 9$ & $2 \cdot 5$ & $2 \cdot 4$ & $1 \cdot 1$ & $3 \cdot 9$ & $1 \cdot 5$ \\
\hline $35-39$ & $5 \cdot 7$ & $2 \cdot 6$ & $9 \cdot 0$ & $3 \cdot 6$ & $2 \cdot 7$ & $1 \cdot 4$ & $3 \cdot 3$ & $1 \cdot 5$ \\
\hline $40-44$ & $6 \cdot 3$ & $2 \cdot 8$ & $7 \cdot 1$ & $2 \cdot 9$ & $7 \cdot 7$ & $2 \cdot 5$ & $7 \cdot 4$ & $2 \cdot 6$ \\
\hline $45-49$ & $11 \cdot 8$ & $4 \cdot 9$ & $18 \cdot 1$ & $7 \cdot 3$ & $9 \cdot 1$ & $3 \cdot 1$ & $5 \cdot 7$ & $2 \cdot 6$ \\
\hline $50-54$ & $15 \cdot 9$ & $4 \cdot 7$ & $14 \cdot 0$ & $4 \cdot 4$ & $24 \cdot 6$ & $5 \cdot 5$ & $8 \cdot 7$ & $3 \cdot 3$ \\
\hline $55-59$ & $27 \cdot 8$ & $9 \cdot 3$ & $36 \cdot 8$ & $14 \cdot 4$ & $17 \cdot 7$ & $5 \cdot 1$ & $5 \cdot 5$ & $3 \cdot 0$ \\
\hline $60-64$ & $38 \cdot 6$ & $9 \cdot 2$ & $25 \cdot 3$ & $7 \cdot 7$ & $41 \cdot 9$ & $9 \cdot 2$ & $22 \cdot 8$ & $6 \cdot 7$ \\
\hline $65-69$ & $54 \cdot 7$ & $16 \cdot 0$ & $53 \cdot 2$ & $23 \cdot 1$ & $40 \cdot 7$ & $11 \cdot 3$ & $16 \cdot 1$ & $6 \cdot 9$ \\
\hline $70-74$ & $55 \cdot 8$ & $16 \cdot 1$ & $92 \cdot 0$ & $22 \cdot 6$ & $54 \cdot 6$ & $14 \cdot 2$ & $48 \cdot 9$ & $12 \cdot 1$ \\
\hline 75 and & & & & & & & & \\
\hline over & $163 \cdot 1$ & $31 \cdot 3$ & $219 \cdot 2$ & $39 \cdot 3$ & $136 \cdot 8$ & $23 \cdot 9$ & $86 \cdot 2$ & $16 \cdot 5$ \\
\hline
\end{tabular}

*Excluding Niuafo'ou for which registers of deaths were not available.

†Infant mortality rate per 1,000 live births registered.

the irregularities in the 1939 population have been smoothed, no allowance was made for age mis-statement in the 1956 population.

Assuming that the deaths that were not registered in each period were distributed identically with respect to sex and age, at neither period was there any significant difference between the mortality experience of males and females of the same ages beyond their first year of life. In 1938-40 male infants had a smaller chance of survival than females, but in 1955-7 the infant mortality rates for males and females were identical and comparable in magnitude with contemporary rates in the Fijian and Samoan populations.

The most striking change since 1939 is the decline which has occurred in the mortality of both males and females at ages 15 to 39 years and, to a lesser extent, at ages 5 to 14 years. There has been no change in the mortality at ages 1-4 years or at ages beyond 45 years, 
although the populations at these latter ages are so small that chance fluctuations in the numbers of deaths in any year may produce quite large variations in the rates. The net effect of these changes in the levels of mortality over the period is summarized in the standardized mortality rate (obtained by applying the two series of age-specific rates for males and females to the standard population given in Table 10) which has fallen from 12.0 deaths per 1,000 population per year in $1938-40$ to $7 \cdot 9$ deaths per 1,000 population in 1956 .

Though the reduction of one-fifth in the mortality of infants is significant for the future growth of the Tongan population, the decline in mortality amongst persons of reproductive age is of more immediate relevance to its rate of growth because the mortality rates of 1955-7 indicate that at least 900 of each 1,000 girls now attaining 15 years of age can be expected to survive to the end of the reproductive period whereas formerly only 812 of each 1,000 aged 15 years could be expected to survive to age 45 . This lessening of mortality effectively lengthens the average reproductive span from $27 \cdot 3$ to $28 \cdot 9$ years and thus increases the average period of exposure to the risk of pregnancy by $I \cdot 6$ years.

\section{Analyses of Fertility}

Despite this increased risk of pregnancy, the average annual fertility rate estimated from the registered births has decreased from $197 \pm 5$ births per 1,000 females aged 15 to 44 years in 1939 to $173 \pm 3$ in 1956. As the age of the mother is not recorded in the birth registers, the minor differences in the distribution of women within the relevant range of ages at the two censuses cannot be taken into account, but the slightly greater concentration of women at ages less than 30 years in 1956 would be expected to increase the fertility rate rather than decrease it. The series of age-specific fertility rates which, when applied to the 1939 census population, resulted in the average number of births registered in the years 1938-40 was the mean of the two series relating to American Samoa in 1939-41 and 1949-51, and if these mean age-specific rates are applied to Tonga's 1956 census population, the result is a fertility rate of 204 births per 1,000 women aged 15 to 44 years. The rate recorded was only 85 per cent of this and though the registration of births may have been less complete in 1955-7 than in 1938-40, the difference of 15 per cent is rather too large to be accounted for by increased deficiencies in registration.

Under the circumstances it is regrettable that, through a misunderstanding, the cross-tabulation of women by their age in 1956 and their age at the birth of their first child was not compiled from the census 
schedules. For those women known to have borne children the median age at first birth was 21.5 years but there is no information available on the numbers of women in each cohort who had borne their first child before certain specified ages. It is also unfortunate that, in the tabulation of the women by age and the number of children they have borne, women for whom the number of children was not stated appear to have been regarded as having borne no children. In all of the 1956 censuses in which the same three questions on fertility were asked, replies to them were recorded less frequently than for any other question on the schedule and, though it is reasonable to assume that women for whom these details were not given did not deviate from the appropriate population average, the equation of 'not stated' with 'no children' invalidates any inferences concerning the average numbers of children born or surviving to women at each age which might be computed from these census data.

The one comparative index of fertility remaining from the census data is the child-woman ratio and, in 1956, there were 843 children aged $0-4$ years per 1,000 women aged 15 to 44 . In the raw data for 1939 the value of this index was 790 , but if some allowance is made for the suspected under-enumeration at ages less than 1 year, there may have been as many as 824 children per 1,000 women of reproductive age. The infant mortality in the three years around 1956 was slightly lower than it had been in 1938-40 and this would contribute to the difference between the values of the child-woman ratios in the two census populations. It probably would not be sufficient to mask any but a very small decline in fertility in recent years, but elucidation of this must await the next enumeration.

The child-woman ratio for Tonga in 1956 was roughly half-way between those for the Fijian and Samoan populations, even though there were relatively more unmarried women at each age in Tonga than in either Fiji or Samoa. The apparently higher age of Tongan females at marriage would be expected to have some effect on the average numbers of children born to each woman, but it seems that this may be offset by shorter intervals between successive births than the Fijian women seem to observe. The average numbers of children born to those women known to have children rose from less than 2 at ages 20-24 years to more than 7 at ages beyond 40 years. These are slightly smaller than the numbers for Samoan women of the same ages, but higher at each age than the comparable averages for Fijian women. The late age at marriage does not, therefore, depress fertility very much and, in fact, at ages between 20 and 34 years there were more allegedly single females at each age than there were women with no children, and this latter number 
was swelled by the inclusion of women for whom the number of children was not stated.

\section{Summary}

Although Tonga's population may have been larger before the beginning of the civil war than at its end, it seems likely that its size changed relatively little during the remainder of the century. If the mortality was as high as has been suggested throughout the period 1799-1826, around 1825 there may have been fewer people in the cohorts aged less than 25 years than the numbers in several of the older cohorts, so that for a time the deaths might have exceeded the births each year. There was probably no very great increase in the numbers of births annually until after the end of the war in mid-century, and from then on the population may have increased slowly, though probably unevenly despite Tonga's apparent freedom from epidemics of high mortality.

There may of course have been more outbreaks of introduced disease than were reported, but the progress of an epidemic through a chain of small islands may have been slower than in the populations on the only two comparatively large islands in the group, and communications between these may have been only sporadic. However, communication with Fiji increased markedly after the civil war ended, and for many years there were several hundreds, perhaps even about 3,000, Tongans in Fiji. Though many may have stayed for only two years or less, some may have remained longer and others not have returned to Tonga at all. Derrick's (1950, pp. 118-31) account implies that all of the Tongan visitors to Fiji were males, and their absence may have slowed the growth of Tonga's population if many were away for long periods, but probably little if the visits lasted only a year or two.

From 1891 onwards the population seems to have grown slowly but irregularly from fewer than 20,000 to about 24,000 by 1918 , when the Tongans probably suffered their most devastating epidemic in which perhaps one-tenth or more of the populations on some islands died. In 1893 there had been an outbreak of measles which caused the deaths of perhaps 1,000 people, and the two numbers reported for the influenza epidemic suggest a minimum of 1,000 and a maximum of nearly 1,600 victims. The deaths were probably not distributed uniformly throughout the group in either epidemic, and some islands may not have been affected, so that the death rate on those which were was probably higher than the total numbers, both of deaths and population, suggest.

Since 1919 the population has more than doubled. Neither the birth nor death registration is very complete, but what seems appropriate inflation of the birth and death rates current around 1956 makes no 
difference to the estimate of an annual growth rate then of at least $2 \cdot 8$ per cent per year. The birth rate was probably nearer to 40 per 1,000 population than the 36 reported, and the death rate was probably about 10 instead of the 8 per 1,000 population recorded. Unless the registration was less efficiont around 1956 than around 1939-and it may have been -the risks of mortality among children aged more than 4 years and young adults may have fallen during the period, and there may also have been declines among infants and older people as well. Making some fairly arbitrary adjustments to the age-specific mortality rates to allow for under-registration, the expectations of life at birth around 1956 were then about 61 years for males and 67 for females.

The average size of a completed Tongan family was probably intermediate between Fijian and Samoan families, and perhaps 90 per cent of all children born will survive to reproduce. With relatively better chances of survival in 1956 than formerly, the age composition of the population then indicates the likelihood of a faster rate of growth in this population after 1956 than had occurred previously, unless there was an upward turn in mortality or a downward turn in fertility. If mortality has continued at its 1956 level for males, the Tongan Government is likely to be in difficulties before 1971 if every male aged 16 years or more pays his tax and claims his 8\% acres of land because, without reclamation, there will not then be enough land in the whole Kingdom for much more than an average of $6 \%$ acres per adult male. 


\section{Samoa}

The islands of the Samoa group lie almost parallel to the equator and about $14^{\circ}$ south. From west to east in this chain the principal islands are Savai'i, Upolu, and Tutuila, diminishing progressively in size and tailing off to the three small islands of the Manu'a group and the uninhabited Rose atoll. Between Savai'i and Upolu are the small islands of Apolima and Manono which are part of the same volcanic system as the dorsal mountain ranges of the larger islands. Although the pattern of settlement has changed from time to time, the Samoans prefer the coast to the rugged mountains of the interior and to date, the area of the islands has been of less significance than their circumference. The villages are scattered rather unevenly along the narrow coastal plains and the north coast of Upolu has long been the densest area of settlement.

European discovery of the Samoan islands is usually accredited to Roggeveen's 'three ship expedition' which sailed through the group from east to west in 1722 . In 1768, Bougainville also sighted the eastern islands, and because so many of his men were sick with scurvy, a party was sent ashore at the first obvious landing place to cut wood and get fresh fruit for the sick. As the boats pulled away from the shore there was a shower of stones and arrows, and one sailor was slightly wounded (Bougainville, 1771, pp. 243-5). In 1787 a less fortunate party from the La Pérouse expedition landed on the north coast of Tutuila to procure fresh water and, their casks filled, the party was preparing to return to the boats when it was attacked by the Samoans and twelve Frenchmen were killed. This affray caused later navigators to distrust the Samoans and, except for the Pandora searching for the mutineers of the Bounty in 1791, no European vessel intentionally visited Samoa for more than thirty years. Kotzebue called there in 1824 and was so enraged by the covetousness of the Samoan visitors to his ship that he 'warned all navigators against venturing among these treacherous cannibals' (Ellison, 1938, p. 20).

In 1830, the pioneer missionary John Williams escorted a group of eight Tahitian teachers to Samoa and settled them on Savai'i under the 


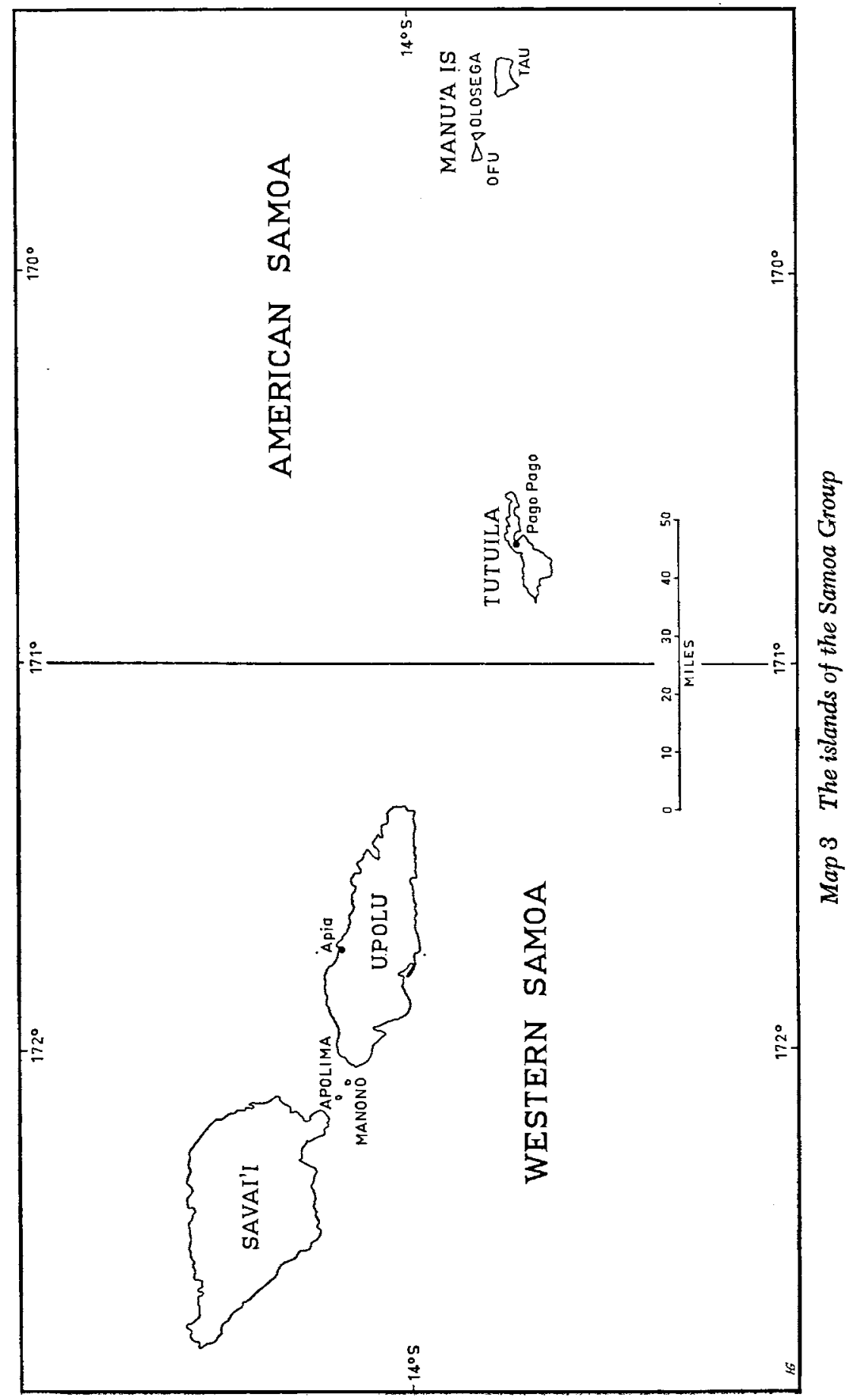


protection of the powerful chief Malietoa. Malietoa was busily avenging the death of one of his relatives when the missionaries arrived, but 'this disastrous war' terminated soon after Williams in his Messenger of Peace left Samoa. He returned nearly two years later to visit the teachers and commented on the number of runaway sailors, and other Europeans, who reside among the people, and do them incalculable mischief. Many of these were convicts from New South Wales' (J. Williams, 1838, pp. 335, 463). In 1835 two European missionaries from London Missionary Society stations in the Society Islands 'proceeded to the islands' and in June 1836 six more arrived from England 'to occupy the field permanently' (Murray, 1863, pp. 451, 452). According to Wilkes (1845, 2, p. 128), some Wesleyan missionaries arrived at about the same time as the representatives of the London Missionary Society, but 'differences . . . arose between the two parties of missionaries, which were finally adjusted between the two boards in London, and the Wesleyans abandoned this field for that of the Feejee Group'.

\section{Pre-censal Population Estimates}

As in Fiji and Tonga, the resident missionaries were responsible for the estimates of population quoted by Wilkes and reproduced here in Table 18. More than three-quarters of the total of 56,600 Samoans was attributed to the two main islands, Upolu and Savaii i, and when Wilkes was there in 1839, there was one European missionary on Tutuila, six on Upolu, three on Savai'i and one on Manono. All but one of these had been in Samoa for less than three years, ministering to 14,850 "professors of Christianity' (Wilkes, 1845, 2, p. 130) and training 'such as were considered eligible for evangelistic and educational work' (Murray, 1863, p. 457). Hence, Manono's total of 1,100 was probably the only estimate that had much foundation in fact, and those for the larger and more rugged islands of Upolu, Savai'i and Tutuila were likely to be highly speculative. For Tutuila, in fact, Wilkes claimed a population of 8,000 in 1839, but ten years later Erskine referred to Tutuila's population as 'having been called four thousand ten years since' (Erskine, 1853, p. 60).

Visiting Samoa in 1849, Erskine was likely to be better informed about the population than Wilkes had been because the Reverend J. B. Stair, who spent seven years in Samoa from 1838 to 1845, claimed that 'a successful census' was made by the missionaries in 1845. 'But even then, through native prejudices, it was difficult to obtain correct returns from some of the districts. It was considered that the population at that time was about 40,000; an under-estimate, probably, but it certainly did not exceed $45,000^{\prime}$ (Stair, 1897, p. 58). No details of this 


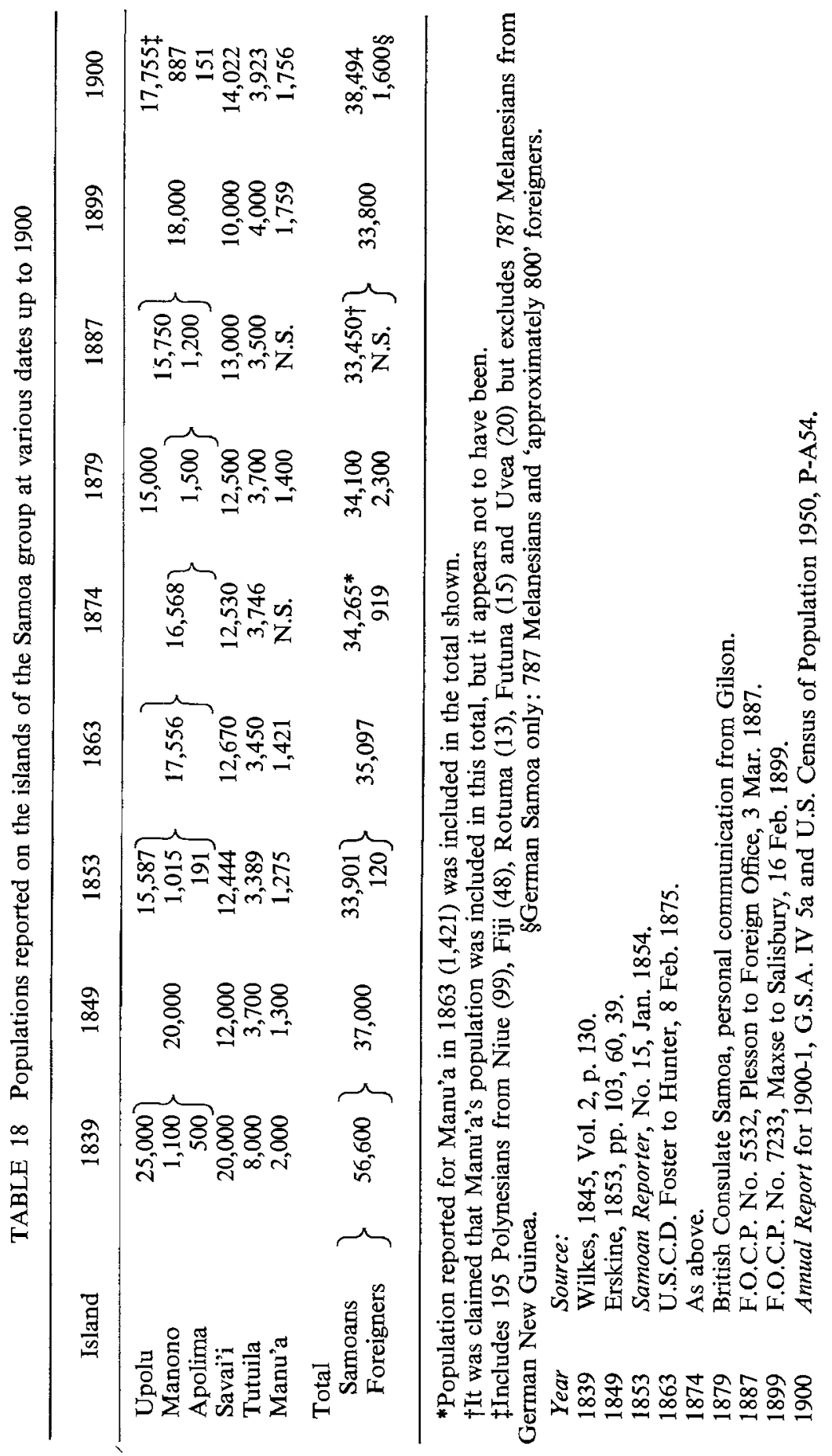


count have survived, but it was referred to in a report to the Foreign Office by the first British Consul to Samoa, the Reverend George Pritchard, in a context which implied exaggeration of earlier estimates rather than any dramatic decline in population numbers. With his enthusiasm for British annexation of islands in the Pacific, Pritchard was extolling Samoa for European colonization; there was much surplus land and though "it has been stated that the whole group contains 60,000 , but from a census lately taken by the missionaries it is evident they do not exceed $40,000^{\prime}$ (G. Pritchard, 1845).

The early mission 'censuses' were compiled by the missionaries going from village to village to preach, counting the numbers in each gathering and attributing that number to the village-ignoring or ignorant of the fact that they were preaching, not only to the inhabitants of the village concerned, but also to those who had followed them from villages visited earlier and some from other nearby villages who joined the assembly. If this method was used in the 1845 'census', the numbers recorded then may well be exaggerated and Stair's opinion to the contrary nothing more than reluctance to believe that the population was so much smaller than everyone had previously thought. As this 'census' was presumably the basis for the population figures quoted by Erskine, they too may be exaggerated, but whether they were or not they serve to demonstrate the reliability of Wilkes's much-quoted estimate.

Between Wilkes's and Erskine's visits, there had been at least two severe epidemics of influenza as well as the minor outbreaks that occurred 'almost annually' after its introduction by the Messenger of Peace in 1830 , and which in many cases [were] fatal to old people and those who [had] been previously weakened by pulmonary diseases' (Turner, 1861 , p. 222). Although Turner gave May 1837 as the date of the first major epidemic, this is not confirmed from other sources. In June 1839 the missionary at Pago Pago reported that there had been an epidemic on Tutuila in April, during which 'between 30 and 40 died' (Murray, 1839), and in November 1839 the missionary at Apia wrote that there had been an outbreak of influenza on Upolu earlier in the year which had not been bad at first, but which left 'pulmonary complications' and 'vast numbers [were] taken off months after the disease itself was removed' (Mills, 1839). The second 'unusually severe and fatal' outbreak started in November 1846 and continued until January 1847 (Turner, 1861, p. 222; Erskine, 1853, p. 103). Erskine reported 'sixty deaths . . . in one district of 2,500 people, and even a larger proportion in some marshy and damp situations'.

In 1848, Manono, part of Savai'i and the greater part of Upolu were involved in a conflict which continued sporadically until the end of 
1853, but the casualties were heaviest in the first year's engagements. On Upolu, 'the bulk of the people were crowded together in camps' (Murray, 1863 , p. 454), so that even the gardens that had not been destroyed in the fighting were neglected. A storm at the end of 1848 ruined many of the surviving food crops and, in 1849, there were reports of much sickness throughout all of the islands, largely as a result of 'the hooping cough, said to have been imported in a vessel from Tahiti, [which] made its appearance for the first time, causing, in conjunction with the war, but in a larger proportion, a calculated reduction of five per cent of the population in a period of eighteen months' (Erskine, 1853, p. 104). On Upolu, many children died of whooping cough and, in the course of a few months' on the north coast of Savaii, it caused the deaths of 'a hundred and fifty persons, mostly the infirm and sickly children' (Pratt, 1849).

Although the estimate of mortality from influenza which Erskine quoted may be a little higher than that reported by Murray for Tutuila in the 1839 epidemic, neither exceeds a rate of 25 deaths per 1,000 population. Assuming that this epidemic mortality was additional to the normal mortality each year, and that in non-epidemic years the crude birth and death rates were equal, the maximum decline in population that would have occurred as a result of the two epidemics was 5 per cent $\left[\left(1-0.975^{2}\right) \times 100\right]$. If the outbreak of whooping cough and fighting in 1849 then caused the deaths of 50 per 1,000 population, these three disasters together would have reduced the population by about 10 per cent over the decade between Wilkes's and Erskine's visits.

Given mortality rates such as these in the epidemics, the decline in population numbers could have exceeded 10 per cent only if there were fewer births than deaths even in non-epidemic years, and in one part of the group at least this was not the case. Erskine (1853, p. 39) reported that there had been six more births than deaths in Manu'a in the six years preceding the outbreak of whooping cough, even though this population had also experienced the 1846-7 influenza epidemic. On more general grounds it might be argued that if a death rate of 50 per 1,000 in an epidemic was considered to be high, the rate in non-epidemic years was presumably much less than this and as later evidence suggests that the crude birth rate in the Samoan population at this time was in the region of 35 to 40 births per 1,000 population, it is unlikely that there were fewer births than deaths in most years.

On Tutuila, the population was thought to have decreased from 4,000 to 'from 3600 to 3700 souls' (Erskine, 1853, p. 60) over the decade but this decline may be exaggerated because doubts were later expressed as to the reliability of the initial count of villages on the more populous 
part of the island (Bullen, 1846). The Tutuilans had been forbidden by their chiefs to take part in the civil war then raging in the western islands, but as they had suffered outbreaks of dysentery during 1844 and 1845 which were not reported elsewhere, there is no reason to suppose that the decrease in their numbers was proportionately much less than in the remainder of the group. Hence, on the basis of Erskine's figures, it seems likely that a more reasonable estimate of the population of Samoa at the time of Wilkes's visit would be in the region of 40,000 and if Erskine's figures were exaggerated, the total population in 1839 may have been less than this.

From the reports and correspondence of the missionaries, Gilson (1957) estimated that the casualties in the first year of the 1848-53 war were between 150 and 200. Fighting started again in March 1851 but stopped after one big engagement and a few skirmishes when probably 100 persons were killed. There was a recurrence of fighting for two or three months from August 1853 during which about 80 men were killed. Although the parties remained in camps until at least the end of 1854, there were no further casualties and the total for the period 1848-54 was probably between 350 and 400 . In April 1850 there was a tremendous hurricane that caused much damage on the north coast of Upolu and this and the plague of caterpillars that followed it caused a shortage of food (Hardie and Turner, 1850). 'In 1851, another new disease surprised the natives, viz. the mumps. It was traced to a vessel from California, and soon spread all over the group. Scarcely a native escaped. It answered the usual description of the attack given in medical works, and passed off in ten days or a fortnight' (Turner, 1861, pp. 222-3), from which it might be assumed that there was no excessive mortality from this cause.

In January 1854 the London Missionary Society's Samoan Reporter quoted census figures for each island for 1853, commenting that there had been a decrease in numbers and that there was a marked excess of males in the population. The only part of this 'census' which has been found in the mission records relates to the Pago Pago district on Tutuila (Powell, 1853), and this listed the numbers of men, women, boys and girls in each village. Presumably each missionary compiled similar lists which were combined, irrespective of expressed uncertainties about some of the figures, to the total of 33,901 Samoans, consisting of 11,736 men, 9,844 women, 6,456 boys and 5,865 girls. As 'the bulk' of Upolu's population and presumably many from Manono and Savai'i were living in camps where heathen abominations that had long been abandoned were revived, and evil of every kind abounded' (Murray, 1863, p. 454), one might justifiably doubt the reliability of some of the data, though 
it would be hard to say whether the numbers would be under- or overestimated.

Three years later, the Samoan Reporter repeated the figures from the 1853 'census', commenting that the numbers had not changed much in the interval. However, in July 1854 Manu'a's population was reputed to be 1,311 and with 26 deaths and 55 births recorded between August 1854 and August 1855 (Powell, 1854, 1856) there had been an increase of 65 since the 1853 'census'. In 1855, the Pago Pago district of Tutuila contained 1,752 inhabitants where there had been 1,743 in 1853 (Powell, 1858), and this same figure of 1,752 was quoted again in 1862 for the population of this district. The complementary Leone district then contained 1,981 people and the total of 3,733 for the whole of Tutuila in 1862 represents an increase of 344 since the 1853 'census'. Manu'a in 1862 had 1,468 inhabitants (Powell, 1862) which is 193 more than in 1853 and an increase of 124 since August 1855.

These mission figures are larger than the numbers quoted for Tutuila and Manu'a by the American Consul Foster in 1875 as relating to the population in 1863. No source was given for Foster's figures (column 5 of Table 18) but all non-Samoans were included. Apia was then the centre of 'foreign' population and in November 1858 there were 124 Europeans, 125 'half-caste' children and 52 other islanders (mostly from the Cook Islands) living in the 'Apia district' (Murray, 1858). Earlier it had been reported that the number of 'half-caste' children on Upolu alone was said to exceed 300 (Murray, 1856), so that the addition of a further 200 'foreigners' to the 301 in Apia in 1858 might be a conservative estimate for the total in the group in 1863 . There probably were not as many as 1,000 'foreigners' at this date, however, and as this is the difference between Faster's and the 1853 census totals, the Samoan population may have increased slightly between 1853 and 1863 .

In 1863, one of the vessels engaged in the Peruvian slave trade called at Apia harbour 'but would not come to anchor' (J. C. Williams, 1863) and no Samoans were taken. In 1864 and 1865 quarrels broke out independently between villages or groups of villages in each of Savai'i, Tutuila and Manu'a. These were purely local affairs: in Savaii, there was much damage to houses and gardens, but no fighting occurred (King, 1864); on Tutuila, 5 people were killed and many driven from their lands, and in Manu'a, 'several persons [were] killed and wounded on both sides' (Powell, 1865a). Later in 1865, the population of Tutuila was reported as 1,293 men, 1,191 women, 765 boys and 699 girls, totalling 3,948 (Powell, 1865b). This total was reproduced in an article by Powell in the Chronicle of the London Missionary Society in 1868; approximate populations were given for all other islands except Savai'i, 
but these were clearly based on the 1853 'census' figures, amended only for Tutuila and Manu'a, and the alleged total of 34,700 Samoans may well have been an under-estimate.

During this decade, the German trading firm of Godeffroy's had established itself firmly in Samoa. Its manager, Theodore Weber, was shrewd and unscrupulous and, through his efforts, Godeffroy's soon became the most powerful commercial company in the Pacific and an equally powerful force in Samoan politics. Wesleyan missionaries reentered the field and there was intense rivalry between the missions, the British, American and German commercial interests and the three consuls, each faction desirous of exploiting Samoa and the Samoans to their own particular advantage. When a dispute occurred in 1869 over the succession to the highest Samoan rank and title of Malietoa, and 'the whole island [of Upolu] and Manono and Savai'i as well' (Turner, 1869) became involved in the war which ensued, the Samoans alienated large areas of land to those Europeans who were prepared to supply them with arms or credit to purchase arms. The war continued into 1870 and when, through mission intervention, fighting ceased temporarily at the end of August 1870, 136 men had been killed in the previous eight months and 'about fifty' of these were from Manono (Turner, 1870).

For Godeffroy's, Weber had established cotton and copra plantations on some of the land acquired from the Samoans, and in 1870 'about 400 Polynesians imported by them from elsewhere into Samoa' were employed to work on these (Sterndale, 1874, p. 3). Some of these were from Niue Island, but more, according to Sterndale who was employed by Godeffroy's for two years, from the Gilbert and Marshall Islands. In a despatch to the Foreign Office in January 1870 the British Consul Williams claimed that many Line Islanders were being brought to Samoa 'and these people [were] treated badly' (J. C. Williams, 1870) and in the trade report for 1870 , he mentioned that there were about twenty 'foreigners' living as traders on Tutuila, two-thirds of whom were British subjects married to Samoan women (J. C. Williams, 1871).

Land alienation continued apace throughout 1871 and 1872 and, early in 1872, the war on Upolu flared up again, though there were few casualties. In 1874, the mission arranged a census of the Samoans and the figures, released in January 1875, were forwarded to the second Assistant Secretary of State by the American Consul in Samoa with a note that they were 'said to be accurate' (Foster, 1875). Nevertheless, no figure for Manu'a was included and the total Samoan population reported for 1874 (column 6 of Table 18) contained the number previously quoted for Manu'a in 1863. The 919 'foreigners' shown separately consisted of 204 Europeans, 236 'other Polynesians', 4 Chinese, 
and 475 'imported labourers'. There is no mention of 'half-castes' either here or in the Acting British Consul's despatch of January 1875 to the Foreign Office, in which he reported the nationalities of the 158 European 'male heads of families' then in Samoa, and rounded off the census of the 'foreign' population with 4 Chinese, 475 'imported labourers' and 200 'foreign natives' ( S. F. Williams, 1875).

In his 1874 memoranda, Sterndale wrote that the population of the whole Samoan group is commonly estimated at about 40,000, of which one-half reside upon Upolu, which includes Manono' and 'more than one-third reside on Savaii' (Sterndale, 1874, pp. 10, 8). However, as he claimed that Savai'i was 'somewhere about 250 miles round', whereas the greatest circumference reported by others was 150 miles, Sterndale's population figures might also be exaggerated. This same figure for the population was also quoted by the American Commercial Agent in 1878: 'Since the census of the missionaries, some years ago, there has been a small increase in the population, which may now be estimated as approaching 40,000 souls. This statement is made on the representation of the missionaries and disinterested parties' (Goward, 1878, p. 31).

Great Britain's acceptance of Fiji as a colony in 1874, and the apprehension about the growing influence of the United States in Samoa, encouraged the British residents to scheme for the annexation of Samoa by Britain. As a result of petitions made first to the British in Fiji, and then to the United States to annex or protect Samoa, treaties of "peace and friendship' were signed with each of the three interested powers in 1878-9. This compromise was as unsatisfactory for the European residents as for the Samoans and, in 1879, the Acting High Commissioner in Fiji reported to the Foreign Office that 'the great calamity of civil war is imminent among the fine race of men who inhabit the Samoan Group'. 'The population of the group is probably about 35,000 natives, and the town of Apia may contain 400 or 500 whites including the sailors of the vessels which are in port. There is also a large half-caste population, the system of having native mistresses having been even more indulged in here than in other parts of Polynesia' (Gorrie, 1879).

Earlier in 1879 a British Consul had forwarded a report on Samoa to the Western Pacific High Commission in Fiji in which he gave population figures for each island based on information collected from many different sources' (Gilson, 1957). These are shown in column 7 of Table 18 and essentially they are the same, both in magnitude and geographic distribution, as the data from the 1874 mission 'census'. At the end of 1879 , a less sanguine view was taken by the new British Consul at Apia who commented in a report on Samoan Trade and Commerce for 1879 that the Samoan population was decreasing, being 
then only about 30,000 as against 35,000 in 1870 . He also claimed there were then 2,000 'imported Polynesians' and 300 Europeans in Samoa (Graves, 1879). The source of the population estimate is not given nor are the reasons for the alleged decline in numbers and although some fighting had occurred in the latter half of the year, the American Consul reported only 'thirty odd' casualties in November in the biggest battle of the war (Dawson, 1879).

The British Consulate's estimate of population was revised three years later to 31,000 Samoans, 1,800 'imported Polynesians', and 300 Europeans (Churchward, 1883). At about the same time, the Catholic Bishop in Apia (Lamaze, 1882) claimed a population of at least 42,000 for Samoa, with 24,310 people on Upolu, 12,790 on Savaii i and 5,000 on Tutuila. Manono and Apolima are probably included in the total for Upolu, and it is possible that the 5,000 for Tutuila relates to the population of all the eastern islands, including Manu'a. If this were so, Upolu's is the only population out of step with most of the population estimates made after 1850. As these are in reasonable agreement with what purported to be a census in 1874 , it is unlikely that there were roughly 6,000 more people on Upolu in 1882 than in 1874, even assuming that all of the imported Polynesians' were on this island. In March 1883 Upolu was struck by a severe hurricane which caused some loss of life' and ruined many houses and chapels. Food crops were destroyed and there was soon a serious famine, with 'much want and near starvation' (Mathieson, 1883).

In 1886, Thurston (then Colonial Secretary in Fiji) visited Samoa on behalf of the British Government and, after less than two weeks there, returned to Suva from whence he wrote a report 'upon the Condition of the Samoan Islands'. Some figures for the Samoan population were given in the introductory section of the report, but these related only to the islands of Upolu and Manono, Savai'i and Tutuila. Manu'a was cursorily dismissed because, beyond language and origin, the people have little in common with the two large islands, and take no permanent or practical part in their politics' (Thurston, 1886). The populations attributed to Upolu and Manono, Savai'i and Tutuila were 16,000, 13,000, and 3,500 respectively and allowing for Thurston's disregard for statistical accuracy, these are sufficiently close to the numbers from the mission census of 1874 to presume that this was still the most recent count available.

Because of its disinterest in Samoan politics, Manu'a was also omitted from the population estimates submitted to the Foreign Office in 1887 by Baron Plessen, the German Ambassador to Great Britain. Purporting to show the relative strength of the two rival Samoan factions in each of the traditional districts except Manu'a, these population 
estimates had no doubt been prepared by the German Consulate in Samoa and, although a footnote to the table claimed that the population of Manu'a was included in the total of 33,450 Samoans, this is unlikely because this number is the sum of the populations given for all other districts. The details are given in column 8 of Table 18 and if these estimates were reasonably correct, the population of Samoa in 1887 was probably nearer to 35,000 than to 33,500 .

The tension which had been mounting in Samoa throughout the decade found expression towards the end of 1888 in a new outbreak of civil war which dragged on into 1889, causing the deaths of several hundreds of Samoans (Gilson, 1957). The Germans tried to re-establish their 'puppet king' Tamasese by force, at which the United States and Great Britain protested indignantly and promptly despatched tokens of their own naval forces to Samoa. Early in 1889, six warships were anchored in the harbour at Apia when a hurricane struck the north coast of Upolu, wrecking all vessels except the British H.M.S. Calliope which rode out the storm at sea. In April 1889 representatives of Great Britain, Germany, and America met in Berlin to devise a new agreement for Samoa which 'recognised the islands as forming an independent native kingdom with its own government' (Keesing, 1934, p. 70), and provided for the tripartite supervision of the kingdom. By July 1889 there was great hardship in Samoa, almost amounting to famine, which was as much the aftermath of the war as a direct consequence of the hurricane (de Coatlogon, 1889).

Late in 1891 there was a 'memorable visitation' of influenza and 'large numbers of people died on the more populous islands of the Group' (Collier, 1893). Less than two years later, Samoa was in the throes of an epidemic of measles which has prostrated the whole group. . . . the mortality has not been excessive; though in some villages [on Upolu] the deaths have possibly reached ten per cent of the population this is by no means general, in some towns no deaths having occurred' (Carne, 1893). The mildness of the epidemic was confirmed by editorial comment in the Samoa Times during September 1893 and in October it was reported that there had been only 25 deaths from measles 'on the northern coast [of Upolu]. . . . as regards the southern coast line, we have no reliable report, but if a large number of deaths had occurred, wo should without doubt, have received intelligence'. Consular correspondence during September and October 1893 also claimed that there had not been many deaths though measles was very common (CusackSmith, 1893). When the epidemic had 'expired' in February 1894, the editor of the Samoa Times 'guessed' (without explaining the basis of his guess) that the epidemic had been responsible for 'at least three hundred 
deaths' although some of these had been caused by a kind of dysentery which attacked persons convalescing from measles.

A somewhat contradictory account of the epidemic was given in the annual report of the Methodist missionary on Savai'i in 1893.

This is the first experience of measles the Samoans have had and it is an exceedingly bitter one. All are being, or have been, attacked, and many have been carried off. The death-rate is very high notwithstanding all the precautions which have been taken to keep it down. Most of the natives have exercised commendable self-restraint in respect to bathing and diet, and are carrying out the directions they have received in a most praiseworthy manner. They have heard so much respecting the malignant nature of the epidemic which a few years ago visited Fiji, and also about the great mortality in Tonga during the present year, that they have obeyed the instructions of the doctors and missionaries with unusual promptitude (Collier, 1893).

Was it the reported mortality rate of 5 per cent in Tonga's first measles epidemic that prompted another Methodist missionary to comment almost a year later that "quite 1,600 [Samoans] died during the epidemic, or subsequently, as a result of it' (Bleazard, 1894)? At this time there was no civil registration of deaths except perhaps among the 'foreign' population of Apia: the missions probably maintained records of some sort, but the London Missionary Society still had the largest following and the total mortality for Samoa could only have been compiled with their help. On the other hand, a mortality rate comparable with Tonga's would not be unexpected if similar 'precautions against the after-effects of the disease' (Thomson, 1894, p. 286) were taken in both populations, and there may well have been considerable local variations in the extent of mortality that escaped the notice of residents of Apia. However, analogy with Fiji's first measles epidemic was probably the basis for Lambert's unsubstantiated statement that the Samoan population suffered 'a serious setback in 1893, when measles was first introduced' (Lambert, 1934, p. 11).

Just before the measles epidemic in 1893, there was a short but exoeptionally savage recurrence of civil war which continued with relatively minor skirmishes throughout much of 1894. 'Epidemic upon epidemic, and the long-continued war, have been followed by a severe famine in the greater part of the Group. Plantations, which of necessity, had been much neglected during the measles, were left to ruin during the excitement of the war, consequently the scarcity of food became very great' (Bleazard, 1894). Early in 1895 'a great deal of sickness' was 
reported on Upolu, and it was claimed that epidemics are much more frequent and severe since the two memorable visitations of influenza and measles in 1891 and 1893 respectively. The Samoans are not as robust as they were formerly, and thousands of them are physically incapable of throwing off even comparatively slight attacks of sickness' (Collier, 1895).

Although Savai'i appeared to have escaped much of this sickness in 1895, for 1896 Bleazard reported 'a time of unprecedented drought and famine' on the island. 'When the drought and famine had somewhat abated there followed an epidemic of diarrhoea and dysentery, resulting in death to a great number of children. Had it not been for this epidemic I think we might safely state that there would have been an increase in the population of this island for the year' (Bleazard, 1896). There is no mention of either drought, famine or dysentery in the corresponding report for Upolu and Manono in 1896; in fact, a time of peace and prosperity is implied by the Samoans' interest in building big churches whereas formerly their money had been spent on building war canoes (Collier, 1896).

Despite the missionary's optimism, it was an uneasy peace that was shattered by the death in 1898 of Malietoa, who had been proclaimed king under the Samoa Act of 1889. As there were two rival claimants to the kingship-Mata'afa and the deceased Malietoa's son Tanu-the provisions of the Samoa Act were observed and Malietoa's successor was chosen by the Chief Justice of the Supreme Court. Ignoring the wishes of the majority of Samoans, he proclaimed Tanu king; Mata'afa's supporters refused to accept this decision and in January 1899 the disputants fought a brief engagement at Apia in which the rebel party was victorious. In March, an American warship arrived to enforce the Supreme Court's appointment and, during March and April, there was extensive warfare between Mata'afa's supporters and the rival claimants. While about 6,000 warriors from Upolu and Savai'i engaged in handto-hand fighting, the Upolu villages that supported Mata'afa were shelled by the warship; after the shelling, raiding parties landed and burned the villages and plantations. Several hundreds of Samoans must have been killed outright in the bombardment, and still more died subsequently in the famine that resulted from the prolonged absence of men from the villages and the havoc caused by the shelling and burning (Gilson, 1957 ).

The population figures given in column 9 of Table 18, ostensibly relating to 1899 , were taken from a British Consular despatch written in February of that year, in which it was stated that tho population of Samoa (exclusive of the Manu'a group, which takes no part in local 
politics . . .) can be taken as 32,000 all told . . Upolu and the small adjacent islands, by far the most densely populated, contain about 18,000 inhabitants, Savai'i about 10,000 and Tutuila 4,000' (Maxse, 1899). The population of Manu'a was given elsewhere in this document as 1,759, with no more indication of its source than was given for the other figures. The prime importance of these data, however, is that they reveal the probable discrepancies between the estimates of population quated for the last two decades of the nineteenth century and the populations that would have been recorded in enumerations.

The populations shown in the final column of Table 18 were enumerated on the various islands in 1900 . Joint intervention by the three interested powers in 1899 to resolve the disputed succession led to the abolition of the kingship and a new agreement in which tripartite control of Samoa was abandoned. In return for certain territorial concessions in Africa and elsewhere in the Pacific, Britain withdrew from Samoa, leaving Germany and the United States to partition the group. By the Treaty of Friendship with Samoa signed in 1878, 'naval vessels of the United States [had] the privilege of entering and using the port of Pago Pago (on Tutuila), and establishing therein and on the shores thereof a station for coal and other naval supplies for their naval and commercial marine' (Ellison, 1938, p. 91), and the Treaty of Berlin, signed in November 1899, gave the United States undisputed rights over all Samoan islands east of longitude $171^{\circ}$ West of Greenwich, i.e. Tutuila and Aunu'u, the Manu'a group (Ta'u, Olosega, and Ofu) and the uninhabited Rose atoll.

The remaining islands-Upolu (including the islets of Fanuatapu, Namua, Nu'utele, Nu'ulua and Nu'usafe), Manono, Apolima, and Savai'i -became a German colony and continued as such until its occupation by New Zealand military forces in 1914. In 1920, the former German Samoa was formally declared a mandated territory under the League of Nations covenant, with New Zealand exercising the mandate on behalf of Great Britain. It became known as the Territory of Western Samoa and, when the League of Nations was superseded by the United Nations, the Trusteeship Agreement provided that the Government of New Zealand, as the administering authority, shall have full powers of administration, legislation and jurisdiction over Western Samoa, subject to the provisions of the trusteeship agreement and to the Charter of the United Nations' (Preamble to Samoa Amendment Act, 1947: quoted in N.Z.P.P. A-4, 1953). At a plebiscite held in May 1960 the Western Samoans 'endorsed .... the proposed termination of the Trusteeship Agreement at the end of 1961' by an 'overwhelming' majority (Davidson, 1961, p. 92). The United Nations General Assembly acceded to their 
wishes, and Western Samoa became an independent state on 1 January 1962.

The Treaty of Berlin was ratified by the United States Senate in February 1900 and the islands of American Samoa were placed under the jurisdiction of the Secretary of the Navy. Almost immediately the chiefs of Tutuila and Aunu'u ceded their lands to the United States, but it was 1904 before the chiefs of Manu'a were persuaded to do likewise and not until 1929 were these cessions formally accepted by the United States Congress. In the meantime, the territory was administered by the Navy Department as 'Naval Station, Tutuila', and this continued until 1951 when the responsibility for administration was transferred to the Department of the Interior. The first Constitution of this insular possession of the United States' was ratified and approved in April 1960 and became effective as 'the basic law of the territory' in October (1960 Annual Report of the Governor of American Samoa).

Although the populations of Western and American Samoa have been administratively separate since 1900 , the people themselves observe no such sharp distinotion. The population of Manu'a appears to have always been comparatively self-contained, but Tutuila has strong traditional associations with the eastern sector of Upolu, and the ties of the Samoan aiga (or clan) are ultimately stronger than their allegiance to foreign powers. Nevertheless, from 1900 on the two populations must be treated separately because, until 1956, they were censussed at different times and each territory has its own regulations concerning the registration of births and deaths. When the two populations were enumerated simultaneously in 1956, the islands which had a population of just over 40,000 in 1900 contained 117,401 inhabitants.

Reviewing the estimates of population which preceded the Treaty of Berlin and partition, there is little reason to think that the Samoan population in the first half of the nineteenth century was ever much larger than at the century's close. The numbers given to Wilkes were based on very superficial knowledge of the islands and were later tacitly admitted to have been exaggerated. In the mission 'census' of 1845 it had been 'difficult to obtain correct returns for some of the districts' and, except that the total recorded then was so very much smaller than was expected, Stair probably had no more reason for believing the total of 40,000 under-stated than for the contrary view.

The deserted village sites and ruined plantation walls presumed to indicate loss of population were in an area of Upolu not long since devastated by war, and the population that survived was 'scattered among other villages' (Stair, 1897, p. 57). This scattering was customary after a defeat in war; the villagers went into exile for perhaps several 
years until their lands were reconquered, and they would then return to build a new village on the site of the old. There would probably have been some substantial redistribution of population during and after each of the major battles and minor regroupings after skirmishes. As these happened quite frequently in Samoa during the nineteenth century, it would not have been easy to keep track of the population, particularly on the larger islands.

The 1853 'census' is probably the first realistic estimate of population, although not necessarily completely accurate. Both Upolu and Savai'i had been extensively engaged in warfare during the previous five years and in 1853, much of their populations was still living in fortified camps. Gilson (1957) estimated that between 350 and 400 persons were killed in battles during this period, and the war casualties therefore amounted to about 1 per cent of the population. In addition, there were two epidemics between the 1845 and 1853 'censuses', one of which caused the deaths of perhaps 5 per cent of the population and, though the extent of mortality in the influenza outbreak in 1847 is not known, it was probably less fatal than whooping cough. Assuming that all of these together caused a decrease of as much as 10 per cent in the population, its size in 1845 would have been just under 38,000 provided that the deaths from causes other than influenza, whooping cough and war were equal to the number of births that occurred over the interval.

For a population that has trebled its size in less than sixty years of this century, there is a surprising reticence in the nineteenth century writings concerning the numbers and frequencies of births in Samoa. Almost invariably they emphasize losses from the population, but in the 1853 'census' 36 per cent of the population were described as either 'boys' or 'girls' and the crude birth rate in the Fijian population of 1891, which had roughly the same proportion of children, was between 35 and 40 births per 1,000 population each year. The only Samoan figures for midcentury relate to the population of Manu'a in 1854-5 when there were about 42 births per 1,000 population (from Powell, 1854 and 1856), but even the lower Fijian rate of $3 \frac{1}{2}$ to 4 per cent would go far towards compensating for losses from the population in non-epidemic years, especially if epidemics caused no more than 'a calculated reduction of five per cent of the population in a period of eighteen months' (Erskine, 1853, p. 103).

There is some confirmation of a birth rate in excess of the death rate during the decade 1853-63, but the number of deaths occurring during this period may have been reduced by the prior deaths in epidemics of 'old people' and 'the infirm and sickly children'. The effects of these various epidemics on the numbers of births in subsequent years would 
depend on the age incidence of mortality, but if people of all ages were equally susceptible, a mortality rate of 5 per cent, the highest rate reported for any of the nineteenth century epidemics, would have caused a reduction of less than 10 per cent in the number of births and an even smaller reduction in the birth rate. Hence, even the most pessimistic interpretation of the evidence suggests no very great decrease in population numbers in Samoa before mid-century; the population probably never exceeded 37,000 or 38,000 and the sporadic wars, famines, and outbreaks of disease checked its growth only very temporarily.

Few epidemics were reported during the second half of the century until the closing decade and, though the Samoans' resistance to disease may have been lowered by the periodic famines or shortages of food, the general trend in the population was towards increase. The last mission count of the population was made in 1874 and these numbers were repeated, with little variation, for the next twenty-five years even though the population must have been increasing quite markedly in some years. The net increase before 1888 was probably larger than would have occurred for the remaining years of the century because the Samoans suffered war, famine, and disease between 1888 and 1894 and several hundreds of them were killed in 1899.

Hence, the reconstruction of Samoa's population from all the evidence available for the nineteenth century suggests fluctuations in total numbers within the relatively narrow range of 34,000 to 39,000 . In most years the birth rate was probably a little higher than the death rate, but this relationship may have been temporarily reversed by sporadic outbreaks of disease and the disturbances of intermittent warfare. Certainly there was no sustained decline in numbers, although the margin between births and deaths was probably not very great until after 1875 . The eventful history of this period and the lack of any central authority precluded any population counts and the experience of contemporary Fiji, allied to the earlier population declines in the Cook Islands and French Polynesia, may have encouraged consular officials and missionaries to decry the possibility of increase in Samoa's population. However, all illusions about its stability or decrease must have been dispelled by the censuses taken within a few months of its partition into Western and American Samoa.

\section{WESTERN SAMOA}

\section{Census Enumerations}

Germany assumed control of the western islands of Samoa on 1 March 1900 and the first Governor summoned all the chiefs to Mulinu'u, the 
seat of government, on 15 August to take the oath of allegiance. While they were there, the Governor ordered 'a general Samoan census' and it was verbally explained to the District Chiefs and the village mayors how the census was to be carried out. By October 15th, 1900 all the districts of the Islands had punctually handed in their lists and the lists had been made out with extraordinarily great care' (translation from Annual Report, 1900-1).

This census covered the 'native' population only and 'native' was defined as 'Samoans and other coloured tribes' except the 'black boys' who had been imported from German New Guinea to work on plantations in Samoa and who did not come under the control of Samoan officials and [were] outside Samoan jurisdiction'. The 'other coloured tribes' included Niueans, Fijians, Rotumans, Futunans, Uveans, and all 'Half-castes' who were not the 'descendants of a legal union of a foreigner and a native' or those descended from 'non-legal unions' who had been declared non-'native' by the Governor or an Imperial Judge.

As only the numbers of 'natives' of each sex in each village within the various traditional political districts were listed in the first Annual Report, it is probable that sex was the only item recorded in this first count. Some details from a 'police census' of the 'foreign' population of Apia were also included, but 'foreigners' living away from Apia were not recorded in either count.

Between July and September 1902 a similar record was made of the 'native' population and though this resulted in a total almost identical with the 1900 count, the German officials perhaps began to doubt the advisability of allowing two months for the enumeration of a population as peripatetic as the Samoans. In 1906, when the population was next recorded, a day ( 1 October) was specified for the census and printed forms were distributed to all pulenu'us (village headmen or mayors) with instructions that visitors to the village were to be listed separately from the permanent inhabitants. When listing the people in his village on 1 October by name, the pulenu'u was required to indicate whether they were adult males or females, boys or girls, and to state their religion. The same form was used in the last census under German administration, relating to the 'native' population on 1 October 1911. The 'foreign' population was not recorded at the same time as the 'native', but 'a statistical inventory of non-Samoans was made annually from 1906 onward' (U.N.P.D., 1948, p. 6).

Many years later, these early population counts were described as 'evaluations .... which [were] of the nature of local estimates rather than census enumerations in modern terminology' (N.Z. Census Report for 1921, p. 74) and in 1924, the Chief Medical Officer in Western 
Samoa doubted that the returns for either the 1906 or 1911 enumerations (but particularly those for 1906) had been checked sufficiently to eliminate

those cases of duplications which have to be guarded against in Samoa. The Samoans do a great deal of travelling from district to district, and when the census is taken the travellers are more than likely listed in the returns from two villages, the pulenu'u of their home village including their names in his returns to show the true size of his village-this in spite of instructions to the contrary (N.Z.P.P. A-4A, 1924, p. 7).

A census taken by the New Zealand occupation forces on 1 July 1917 was also discredited for this reason, and the estimate of the population of Samoa at that date must be rejected as too high'. This census enumerated the 'native' population only and assuming that the 1911 census under German administration had been accurate, and that the systems of recording births, deaths and migrations begun by the German authorities in 1905 functioned efficiently, the Chief Medical Officer claimed that the 1917 census over-stated the 'native' population by 980 persons. As there is room for doubt as to the completeness of the birth and death registers at any time in Samoa, the 1917 census was perhaps more accurate than this comparison indicated.

The first complete count of the population was made on 17 April 1921 and it was

carried out by the Western Samoan administration on behalf of the New Zealand Census and Statistics Office. For the European community the forms employed in New Zealand were adopted; for other sections special forms were printed in Apia. Part of the compilation of results was made at Apia and part in the Census Office (N.Z. Census Report for 1921, p. 74).

Nothing is known of the procedure followed in this enumeration nor of the questions asked of non-Europeans and, although this 'first census proved more successful than might have been anticipated', 'a careful rechecking of the returns [in Samoa] during the succeeding twelve months showed duplications to the number of 735 ' (N.Z.P.P. A-4A, 1924, p. 7). The initial figures were accordingly revised in the General Report on the New Zealand census and the only details given of the 'Native Samoan' population were the numbers on Upolu (including Manono and Apolima) and Savai'i classified as either 'Adults' or 'Children' by sex.

As other Pacific Islanders and Chinese who were not indentured labourers were ostensibly included with the European population in this 
census, one might doubt that the 'Native Samoan' population was the same as the legal category of 'Samoan' that had been defined in the Samoa Act of 1921, by which 'a Samoan means a person belonging to the Polynesian race, whether by pure or mixed descent but does not includo: (a) persons registered as Europeans in accordance with any regulations or ordinance in force in Samoa; or (b) the legitimate children of a father who is a European either by birth or registration as aforesaid. A European is any person other than a Samoan.' Hence, the 'Native Samoan' population of 1921 may not be identical with what the German authorities described as 'native population', but the difference between them would probably be no larger than those introduced by the amendments to the Samoa Act in later years.

This was the last census taken as part of the general New Zealand census, and the subsequent enumerations were held in accordance with regulations issued periodically under 'The Census Ordinance, 1925' of Western Samoa. The first of these was taken on 1 January 1926 and

in order to obtain as accurate a census as possible, steps were taken on this occasion to educate the Native officials in this work, and the forms used were made as simple as possible. Two months before the date of the census all the Pulenu'us (headmen) of the villages were brought in and instructed in the filling-in of the forms, sample copies of which were issued to them. Then during December officials visited the villages and again explained the forms to the Pulenu'us. The figures obtained are as accurate as it is possible to get in the present stage of Native development.

A Native census is easier to take in Western Samoa at the present time than a European one. Many of the Europeans cannot read, write, or speak any language but Samoan, or can do so only very imperfectly (N.Z.P.P. A-4A, 1926, p. 23).

The information recorded for either 'Natives' or 'Europeans' in this enumeration was not specified in this account, but the tables included for the 'Native' population showed the numbers of 'various Pacific races represented in Samoa', the numbers of males and females in each of four descriptive age categories on Upolu, Manono and Apolima, and Savai'i, the numbers of adherents to each of five religions, and the geographic distribution of the population by district. For the 'European' population there was a table showing the age (in five-year age groups to 25 years, and ten-year groups thereafter) and sex of Europeans and the various grades of part-Europeans, from which persons of Chinese ancestry were excluded because Chinese and part-Chinese 'admixtures' with either Europeans or Polynesians were tabulated separately by sex and 
similar groups of age. These were combined in the remaining tabulations for the 'European' population which showed their religion, nationality, conjugal condition, and country of birth. In addition to the 36,688 'Samoans' and 2,498 'Europeans' enumerated, there were 890 Chinese and 155 Melanesian contract labourers about whom no details were recorded.

The regulations concerning the 1936 census were published in the Western Samoa Gazette, No. 97 of 26 October 1936, and these prescribed what was to be recorded for each of the Samoan and European populations, and the persons responsible for their enumeration. 'The Census of Samoans shall be taken under the direction and control of the Secretary of Native Affairs, Mulinuu, and of the Resident Commissioner, Tuasivi, Savaii.' The latter was also responsible for the census of Europeans on Savai'i, but the Inspector of Police, Apia was in charge of the enumeration of Europeans in the remaining islands, and the Chinese Commissioner had the direotion and control of the Census relating to all Chinese and other labourers employed in accordance with or under the conditions of "The Labour Ordinance, 1933"'.

Except in cases of necessity, all Samoans shall refrain from making malagas (journeys) on the 4th day of November, 1936' and 'it shall be the duty of every Samoan to report to the Enumerator or Enumerators if appointed of the village or area or place in which he is at or before 8 o'clock on the night of the 4th day of November, 1936, for the purpose of having his name and other necessary particulars entered on the Census form'. The 'particulars' prescribed were name; age in years; whether a matai, taule'ale'a, small boy or infant, or female equivalents; the village where born; whether a Samoan, Tongan, Fijian or other Pacific Islander; religion; occupation if any; whether at school; whether a permanent resident or a visitor to the village; and if a visitor, the village of permanent residence; 'in exactly what village sleeping on the night of the census', and 'remarks'.

The schedule of information for Europeans was also quite formidable, requiring name, relationship to head of household, sex, date of birth and age, marital status, country of birth, period of residence in Western Samoa, nationality, race, occupation, religion, intentions as to permanent residence in Western Samoa, country of permanent residence if other than Samoa, and details of war service. Presumably these items were recorded by the head of a household for all members of his household, and it was his responsibility to return the form (or forms) to the relevant census officer before the 14th day of November, 1936.

Although provisional totals from this enumeration were published in the New Zealand Census Report for 1936, the census was disowned by the Census and Statistics Department as being not in any way a part 
of the general census of New Zealand' (p. 11). Summaries for the 'Samoan' population comparable with those from the previous census were given in an appendix to the Annual Report for the year ended 31 March 1937, but apparently no tabulations were compiled for the 'European' population in that year. 'Every precaution was taken during the census to obtain an accurate record of the population, and it can safely be said that the . . f figures are substantially correct' (N.Z.P.P. A-4, 1937, p. 6).

The regulations made for the 1936 census have been given in detail because they were re-issued, with only minor variations, for each of the next two censuses, taken on 25 September 1945 and 1951. In 1945, the only changes were of the dates and the replacement of the Chinese Commissioner by the Commissioner of Labour to direct the census of the imported contract labourers. The 'Samoan' population was tabulated according to the same characteristics as in previous years, but the data are not strictly comparable because the legal definition of 'Samoan' had been changed in 1944 to allow the illegitimate descendants of Europeans to claim 'European' status, and those Melanesians who had been permitted to stay in Samoa to claim 'Samoan' status. The 'European' population was summarized by sex in four age groups (0-5, 6-15, 16-20, and 21 years and over), and by racial groups, religion, marital status, and country of birth.

In 1951, the schedule for 'Samoans' was expanded to include questions on marital status, the number of children born alive to married women, and literacy. The procedure for their enumeration was as before, and the 'European' population was provided with 'personal schedules' (printed in both English and Samoan) containing the questions listed in the 1936 regulations plus one for married women on the number of children borne and a householder's covering schedule' to which the personal schedules for all members of a household were to be attached. The tabulations compiled for this census were very different from those from earlier enumerations. The distinction between the 'Samoan' and 'European' populations was retained throughout, but the tabulations were uniform except for those questions which were asked only of 'Europeans'. Neither the statistical summaries nor the report prepared by the District Affairs Branch of the Secretariat to the Government of Western Samoa were ever published, although some provisional tables appeared in the Annual Report for 1952 and final figures in the Annual Report of 1953 and in the report on the 1956 census (N.Z.P.P. A-4, 1953, pp. 161-3; 1954, pp. 169-71).

The innovations in the 1951 census schedule had been recommended in a report, published in 1948 by the United Nations Population Division, 
which reviewed the growth of population in Western Samoa in relation to its economic resources. The 'more complete and more accurate statistical picture of the demographic situation of the territory' (U.N.P.D., 1948 , p. 42) urged was, however, marred by 'various unexpected circumstances, such as staff illness etc.,' and

the preparation, organisation, and actual running of the census was severely handicapped. That the census has proved to be reasonably successful is largely due to the creditable work performed by officers called in at extremely short notice to take over the task of controlling the organisation. However, as was to be expected these officers could not overcome all the difficulties which arose, and consequently the census generally has suffered from the lack of coherent planning, direction and preparation, with the result that final returns are not as accurate as is desirable (MS. report on Population Census of 1951).

Because of the difficulties encountered with the 1951 census in both the enumeration and the processing of data, outside assistance was sought for the 1956 census and this led to the appointment of a Census Commissioner who, like Fiji's, knew as little about the territory as the previous census-takers had known about demography. The form and content of the enumeration was very similar to Fijis and the chief differences between the schedules were the more detailed question concerning occupation and the record of legal status in Western Samoa.

The population was enumerated uniformly on a household basis, a household in Samoa being the group of persons who slept in the same house on the night of 25 September. The majority of enumerators were school-teachers who, during the nine days preceding 25 September completed the schedules for all households in the areas assigned to them, and revisited these households on or soon after census day to check and amend (if necessary) their provisional records. The schedules were checked in the field by the supervisors and again for consistency in the Census Office. The data recorded for each person were then transferred on to peripherally punched sorter cards from which all the various tabulations were compiled. The procedure followed in both the collection and processing of data is described in the report on this census (Jupp, 1958), and replicas of the household schedule and tabulation card are included.

The populations enumerated in the various censuses since 1900 are shown in Table 19, the 'Samoan' or 'native' population by sex and island of enumeration when known, the total population by sex only. Although the definition of 'Samoan' has changed from time to time, the 'native' 


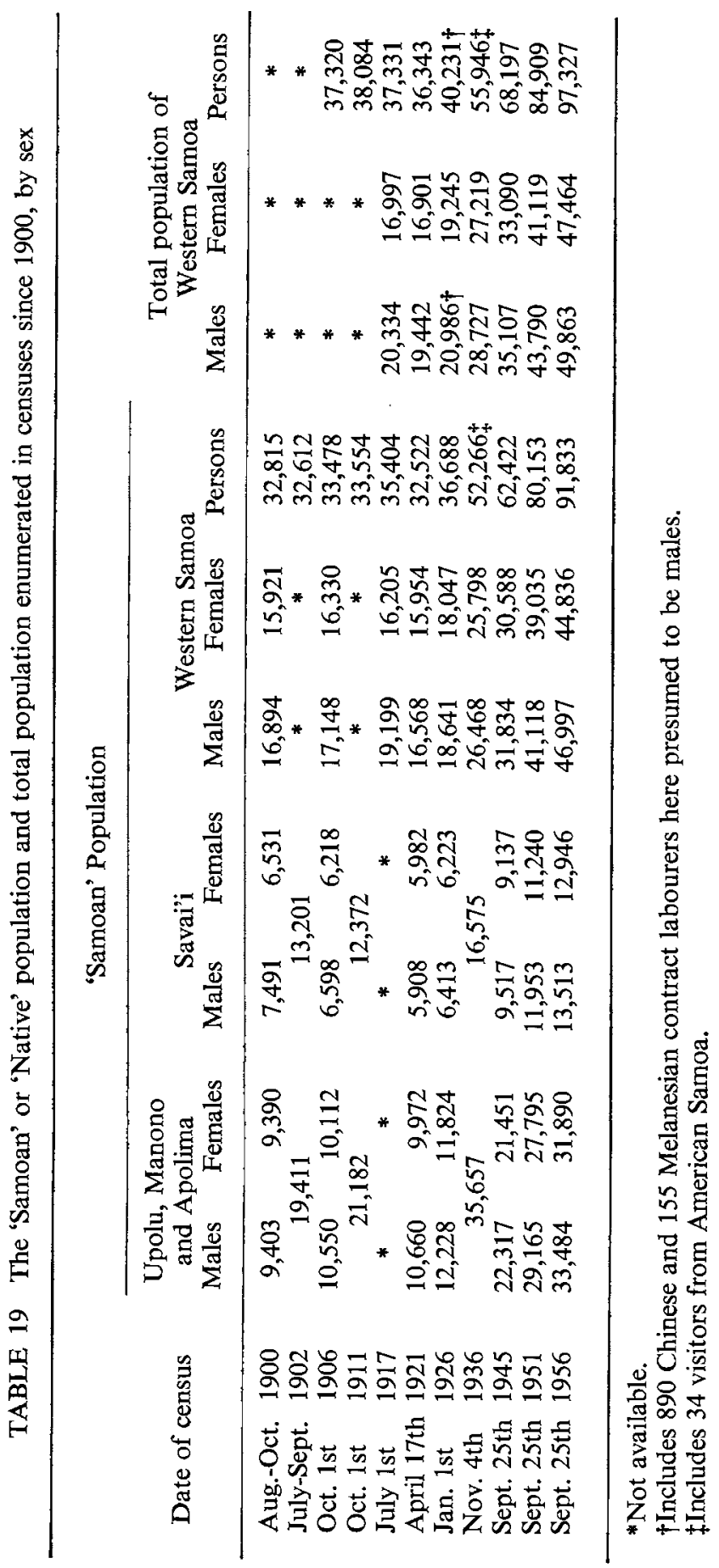


populations recorded in the first four censuses probably refer to the same sort of people each time, and the changes introduced by the Samoa Act and its various amendments since 1921 would have greater significance for individuals within the population than for the population as a whole. In each census since 1945 the question on legal status seems not to have been understood by all respondents and in 1956, with yet another change in definition in prospect with Samoa's independence, the legal dichotomy was ignored in all of the detailed tabulations: instead, the population was divided into five component populations which were defined broadly on the basis of ethnic origin and can therefore be expected to remain relatively uniform in future.

When examining the growth of Samoa's population up to 1945 , the United Nations Population Division rearranged the populations recorded in the various censuses into groups roughly comparable with these component populations, but as the legal distinction between 'Samoan' and 'European' is observed in the registers of births and deaths, and to some extent also in the migration records, the essential demographic analyses must be made either in these terms or for the population as a whole. As persons electing for 'Samoan' status in 1956 constituted more than 94 per cent of the population, and the Samoan and Part-Samoan components together contributed more than 98 per cent of the total, the other sectors of the population are numerically unimportant.

\section{Growth of Population in the Twentieth Century}

The salient features in the growth of Western Samoa's population since 1900 were reviewed in the report prepared by the United Nations Population Division (1948) and again in the 1956 census report (Jupp, 1958). Despite epidemics of dysentery and whooping cough in 1907 and measles and dysentery in the first half of 1911 in which many young children died, the population increased under German administration and, if the early enumerations contained relatively more duplications than the later ones, the increase was perhaps greater than the census figures indicate. To offset this, there was also some redistribution of population during this period which probably involved the transference of some people from German to American Samoa.

The volcanic eruption on Savai'i in 1907 caused no loss of life, but the inhabitants of several villages migrated to Upolu when their lands were engulfed by lava and the sea mists that rose as the hot lava flowed into the sea destroyed all vegetation growing over a large part of the island so that even villages unharmed by the eruption were without food. Their migration aggravated the shortage of land and food that had developed on Upolu because of the illegal sale of lands acquired by right 
of conquest in the latter part of the nineteenth century. Many of these sales were confirmed by the International Land Commission and, before its activities terminated in 1894, at least 135,000 acres of Samoan land had been alienated (Gilson, 1957).

More than half of these lands had been acquired by German nationals who had established some small plantations, but much of the land remained unclaimed until the political situation was clarified in 1899. The Samoans continued to live on and use the land despite its sale and many of them had to be forcibly evicted when, with the increasing security of the German administration, the Europeans wished to extend their cultivation and to this end claimed their lands. The Samoans rebelled, as they had done four or five years previously, against the German régime, and though the revolts were quelled without any fighting or loss of life, some of the rebels may have crossed to American Samoa.

The increase in population between the 1906 and 1911 enumerations is small, but there were more births than deaths recorded in most years during the inter-censal period. On Savaii 2,892 births (1,559 male and 1,333 female) were recorded in the five-year period 1907-11 and, in a total of 2,558 deaths, 1,786 were the deaths of children, more than onethird of which occurred between July and December 1907 and April to June 1911. The births recorded for the whole of Western Samoa in the calendar years 1907-11 corresponded to crude birth rates of 41 to 44 births per 1,000 population, while the death rate ranged from 28 per 1,000 population in non-epidemic years to 46 and 54 per 1,000 population in 1907 and 1911 (U.N.P.D., 1948, p. 51).

The high death rate in 1911 was caused by outbreaks of measles and dysentery between April and June and, as the first measles epidemic had occurred only eighteen years before, it is not surprising that most of the deaths in 1911 were amongst children. If the crude death rate was 5 per cent, the mortality amongst the measles-susceptible population was probably of the order of 10 per cent and, as the 1907 outbreaks of dysentery and whooping cough had also been responsible for the deaths of many children, the population enumerated on 1 October 1911 probably contained many fewer children relative to the total than did the 1906 population. This change in the age structure would have no immediate effect on the growth of the population, but it would depress the number of births likely to occur a few years later and thus slow down the rate of population increase.

The figures for births and deaths may not be complete, but the numbers of births registered exceeded the deaths recorded in each year between 1912 and 1917, and the Chief Medical Officer in 1924 reckoned the net gain to the population over the inter-censal interval 1911 to 1917 
to be more than 3,000 (N.Z.P.P. A-4A, 1924, p. 7). In 1915 there was another outbreak of measles, but as the population at risk in this epidemic was probably small-consisting mainly of children aged less than 4 years and those older people aged less than 22 who had escaped the earlier infection-fewer deaths than births were recorded in that year.

The next epidemic was probably the most devastating the Samoans ever experienced, with mortality comparable with that of the 1875 measles epidemic in Fiji. Within seven days of the arrival of the S.S. Talune from Auckland via Fiji, 'pneumonic influenza was epidemic in Upolu; . . . it spread with amazing rapidity throughout Upolu, and later throughout Savai'i . . . up to the 31st December, 1918, 7,542 persons died of influenza, or as a consequence of the prevalence of influenza' (N.Z.P.P. H-31c, 1919, p. 3). Although it is claimed that both births and deaths were over-registered because the time was one of great disorganisation; numbers of the Native officials had died, and their work was being carried out by untrained men' (N.Z.P.P. A-4A, 1924, p. 7 ), and later estimates put the number of deaths from influenza at about 6,250 (N.Z.P.P. A-4, 1924, p. 43), the Samoan Epidemic Commission cited the death rates for men, women, and children on Upolu and Savai'i shown in Table 20.

TABLE 20 Deaths from influenza in 1918 per 1,000 men, women, and children in Western Samoa (taken from N.Z.P.P. H-31c, 1919, p. 4)

\begin{tabular}{lrrc}
\hline Population & Upolu & Savai'i & Western Samoa \\
\hline Men & 304 & 285 & 295 \\
Women & 220 & 218 & 219 \\
Children & 110 & 98 & 104 \\
\hline Total & 212 & 200 & 206 \\
\hline
\end{tabular}

Compared with the figures given for populations before and after the epidemic, these rates contain minor arithmetic errors, but the corrections do not alter the general picture that Upolu's population suffered slightly greater mortality than Savai'i's, and that the risk of dying was much greater for adult males than for adult females and both ran higher risks than children. Mortality rates of 30 and 22 per cent respectively amongst adult males and females would disrupt 45 per cent of matings and one would therefore expect the births occurring during 1919 to be proportionately reduced. Excluding the births recorded for 
1918 because they are believed to be in error, the average number of births per year from 1915 to 1917 was 1,632: in 1919, 1,167 births were registered and, as this number represents a reduction of approximately 30 per cent, the mortality rates during the epidemic were perhaps exaggerated by about 50 per cent.

A correction of this magnitude to the epidemic mortality rates is almost twice as large as the corrective figure $(1,300$ deducted from the total of 7,542 deaths) usually quoted (N.Z.P.P. A-4, 1924; U.N.P.D., 1948 ) and it is possible that births were recorded more completely after the epidemic than before it. In 1920, the number of births increased to 1,671 falling to 1,299 in 1921 to rise again in later years, especially during the three years 1924-6. Although part of this increase was undoubtedly due to the new regulations concerning registration which were promulgated in 1923, the remainder is the expected consequence of such age-selective epidemic mortality. The lower mortality rates of 'children' during the epidemic would lead, within a few years, to the influx of relatively large numbers of females to reproductive ages and this increase in the reproductive capacity of the population could be expected to raise the number of births each year above its former level.

The other consequence of the change in age structure caused by the age-selective epidemic mortality would be apparent in the numbers of deaths a few years later when there would be relatively few people attaining the ages associated with high risks of mortality. This doublebarrelled effect would widen the margin between the births and deaths each year and the population could be expected to increase faster than it had done formerly, even with no change in the levels of mortality and fertility in the population.

Between 1921 and 1926 the 'Samoan' population increased at an average annual rate of 2.5 per cent but the increase in numbers between the 1926 and 1936 censuses was 3.3 per cent a year. During the next decade the rate could be expected to fall slightly because the number of births each year would not increase as fast when the small cohort born in the post-epidemic years attained child-bearing ages, but there would be a second wave of increase in births about the middle of the next decade which had its origin in the initial rise consequent upon the age-selective mortality in 1918.

In the absence of epidemics, the number of deaths each year would not be expected to increase much until the 1950s and although there were outbreaks of disease-of dysentery in 1923-4, whooping cough in 1926, 1936-7, and 1950, of measles in 1936-7, and meningitis and pneumonia in 1943-4-all were more circumscribed in their effects than the earlier epidemics, and only the first caused mortality comparable 
with the rates experienced in the first decade of this century. During the Mau disturbances of 1928-32 registration was notoriously incomplete, but if the deaths exceeded the births in any year of that period, such natural decrease was cancelled by large increases in other years.

The populations recorded in successive censuses show clearly that the fluctuations in the numbers of births that could be expected as a result of the 1918 epidemic have occurred, and the average annual rates of growth over inter-censal periods alternate from high to low. Between 1936 and 1945 the 'Samoan' population increased by only $2 \cdot 1$ per cent per year; between 1945 and 1951 the rate doubled, and fell to $2 \cdot 8$ per cent a year between 1951 and 1956. The rate of increase during this last inter-censal period was damped by emigration and should this cease, the growth of Samoa's population will continue to be dominated by vagaries in the number of births that occur each year because mortality is now a relatively unimportant source of change in population numbers. If emigration continues, the rate of increase will be doubly depressed because of the changes induced in the age and sex compnsition of the population.

\section{Age and Sex Composition}

Although chronological age was recorded in all censuses after 1926, the population was summarized only by descriptive age groups until 1951 and, except for the youngest tama or teine meamea, the chronological equivalents are different for males and females. Samoan girls cease being 'children' at younger ages than boys, so that even the rudimentary dichotomy into 'adults' and 'children' is of doubtful value. In 1951, both the 'Samoan' and 'European' populations were tabulated in five-year age groups and the numbers of males and females contained in each age group are arrayed in birth cohorts in Table 21. The figures relate to the total population enumerated because, although persons of 'European' status were divided into 'Full Europeans' and 'Part-Europeans', the Part-Europeans of 'Samoan' status were not differentiated from other Samoans. As there were only 614 'Full Europeans' in the population in 1951 (446 males and 168 females), their inclusion in the birth cohorts is of as little significance as the inclusion of the 662 persons (393 males and 269 females) in the European component in 1956.

The 1951 enumeration was hastily prepared and the enumerators were given scant briefing on what was required of them. In general, the pulenu'u of each village was the enumerator for his village and, although he was also the registrar of births and deaths for the village, his concept of chronological age was probably as sketchy as most villagers'. In 1956, most of the enumerators were school-teachers and the importance of 
recording age as accurately as possible was emphasized both in their training and in the publicity for the census. Both age and date of birth were asked, and the enumerators were instructed to check one against the other. Nevertheless, the unit digit of age was stated incorrectly for at least 9.0 per cent of males and 9.9 per cent of females aged between 13 and 62 years, and the frequency of incorrect reports for the Samoan component population (which is not the same as the 'Samoan' population used above) was a little higher than these. (The preferences given in Jupp, 1958, p. 24 contain systematic errors.)

TABLE 21 Male and female populations enumerated in Western Samoa in 1951 and 1956 arrayed according to the period of birth corresponding to the ages tabulated in the censuses

\begin{tabular}{lrrrrr}
\hline $\begin{array}{c}\text { Period of } \\
\text { birth }\end{array}$ & $1951^{*}$ & $1956 \dagger$ & 1956 & $1951^{*}$ & $1956 \dagger$ \\
\hline $1952-56$ & & 9,793 & $0-4$ & & 9,016 \\
$1947-51$ & 7,969 & 8,059 & $5-9$ & 7,317 & 7,391 \\
$1942-46$ & 6,939 & 6,582 & $10-14$ & 6,197 & 6,012 \\
& & & & & \\
$1937-41$ & 6,123 & 5,182 & $15-19$ & 5,118 & 4,852 \\
$1932-36$ & 4,324 & 3,633 & $20-24$ & 4,196 & 3,880 \\
$1927-31$ & 3,493 & 3,523 & $25-29$ & 4,000 & 4,011 \\
$1922-26$ & 3,211 & 2,861 & $30-34$ & 3,549 & 2,638 \\
$1917-21$ & 2,642 & 2,622 & $35-39$ & 2,574 & 2,379 \\
$1912-16$ & 2,316 & 1,805 & $40-44$ & 2,090 & 1,657 \\
& & & & & \\
$1907-11$ & 1,788 & 1,673 & $45-49$ & 1,528 & 1,457 \\
$1902-06$ & 1,405 & 1,216 & $50-54$ & 1,184 & 1,186 \\
$1897-01$ & 1,007 & 873 & $55-59$ & 1,064 & 853 \\
$1892-96$ & 656 & 665 & $60-64$ & 591 & 695 \\
$1887-91$ & 686 & 552 & $65-69$ & 722 & 546 \\
$1882-86$ & 455 & 311 & $70-74$ & 350 & 356 \\
Before 1882 & 619 & 447 & 75 and over & 509 & 503 \\
\hline
\end{tabular}

*Excludes 143 males and 111 females for whom no age was recorded.

†Excludes 66 males and 32 females for whom no age was recorded.

The pattern of preferences for unit digits was the same for both males and females. Ages ending in 0 and 8 were favoured and those with terminal digits of 1 and 3 were avoided, so that unit digits between 0 and 4 received less than 47 per cent of preferences instead of the theoretically expected 50 per cent and the numbers contained in the age groups $15-19,25-29, \ldots$ years were, therefore, probably exaggerated 
at the expense of the intervening age groups. If this same pattern occurred in 1951, comparisons between the size of cohorts in 1951 and 1956 will be distorted because cohorts in the favoured second half of each decade of age in 1951 attained the less-favoured age group in 1956, and vice versa.

In both censuses, the numbers recorded in the three youngest cohorts exceeded the numbers of births registered during their appropriate periods of birth, and there is clearly little point in attempting to relate the census populations to the original cohorts of births. The size of the successive cohorts declines quite markedly up to ages 20-24 years for males in both censuses and for females in 1956, though not in 1951 when the numbers at ages 15-19 and 20-24 years were nearly equal. For the three decades of age between 20 and 50 , the numbers in the first and second half of each decade are very similar, but there is quite a marked decline between the numbers in one decade of age and the next. Although the similarity between the numbers in the two halves of each decade of age is rather more pronounced in the 1956 data than in the 1951 population, this coincidence suggests down-grading of ages on both occasions and, when in doubt, the enumerators tended to underestimate age.

As the 1947-51 cohort increased between 1951 and 1956, there may have been some under-enumeration at ages 0-4 years in 1951, even though the numbers enumerated exceeded the number of births registered during the five preceding years. The estimates of the numbers expected at ages less than 1 year, 1 year, and $0-4$ years in 1951 which were compiled from the appropriate statistics of births and deaths indicated that there may have been some confusion between ages 0 and 1 year, but that at least 7 per cent of births occurring between 1947 and 1951 had not been registered. If there was under-enumeration of this cohort in 1951, an even higher proportion of births had not been registered, and the registrations may have been as incomplete as during the five years preceding the 1956 census when at least 14 per cent of births escaped registration (Jupp, 1958, p. 23).

Western Samoa's is not a 'closed' population and between 1951 and 1956 there was a recorded net loss through migration of 1,453 males and 704 females (Jupp, 1958, p. 12). The ages of these emigrants are not known, but the changes in the size of the 1932-6 and 1937-41 cohorts suggest that the bulk of the emigrants were persons aged between 15 and 24 years. The loss from the 1937-41 cohort over the inter-censal period may be exaggerated; the excess of males at ages 10-14 years in 1951 was so much greater than in any other age group that the differentiation between males aged less than 15 and those a little older is suspect. 
Return migration might account for the increase in the numbers of males and females in the 1927-31 cohort between the censuses, but it is more likely that this increase is due to mis-statements of ages in both enumerations. This cohort aged from 20-24 to 25-29 years in the intercensal period and the popularity of ages $25-29$ years at the expense of ages 30-34 years in both counts would be sufficient to explain this increase in cohort size and the apparent loss of females from the cohort born 1922-6. The favouring of ages 25-29 years would also increase the size of the 1927-31 cohort relative to the younger 1932-6 cohort, and the reversal in their size in 1956 probably stems from the combination of age misstatements and the emigration of women in their early twenties.

Had there been no migration over the inter-censal period, the sex ratios at each age may have provided a clue as to whether age was reported more correctly for males than for females, but as migration occurred and its pattern is known only very imperfectly, perhaps even erroneously, variations in the proportions of males in the population at each age are difficult to interpret. In 1951, there were substantially more males than females at ages up to 15 years, roughly comparable numbers at ages 15-19 years, and an excess of females at ages 20-29 which was especially marked in the first half of this decade of age. At ages beyond 30 years there was a preponderance of males in most age groups. In 1956, the surplus of males at young ages persisted to age 20 , and again there was an excess of females in the decade $20-29$ years, but this was more pronounced in the second half of the decade than in the first and it may reflect the undue favouring of ages $25-29$ years for females rather than the loss of males through emigration.

Nevertheless, emigration from Western Samoa between 1951 and 1956 was probably more extensive than the official records of migration indicate. Estimates of the numbers that could be expected to survive from one age group to the next over the inter-censal interval were given in the census report (Jupp, 1958, p. 25) and, assuming that all deaths were registered, the net loss through migration from the population aged 5 years and over in 1951 during the subsequent five years was 2,840 males and 2,025 females. This total of 4,865 is more than twice the recorded net emigration (1,453 males and 704 females), and if the migration records were complete, then nearly two-thirds of the deaths that occurred were not registered. However, as there are no restriotions on the movement of Samoans between Western and American Samoa, the deficiencies of the migration records are the more likely source of the discrepancy.

Emigration, age mis-statements, and under-enumeration of young children all contribute something to the change between 1951 and 1956 
in the age composition of the populations recorded. In 1956, 49 per cent of males and 47 per cent of females were aged less than 15 years, which left little more than half the population to be distributed over all other ages. With only 48 per cent of males and 45 per cent of females aged less than 15 in 1951, the proportions of population contained in the other age groups are higher than they would have been had there been no under-enumeration, and this and emigration may be sufficient to account for the decrease from 42 per cent in 1951 to 40 per cent in 1956 for the population within the age range 15 to 44 years. If age was stated correctly in both censuses, there were almost twice as many females in the first half of this age range as in the second, but at least part of this concentration within the range 15 to 29 years probably results from the misroporting of age. The numbers of males and females at ages 45 to 59 years in 1956 had increased slightly relative to the total populations of each sex, but there was little change in the proportion of population aged 60 years and over.

The median ages in 1956 were 15.4 years for males and 16.4 years for females, and this difference between the sexes is probably the consequence of more extensive migration of older males. The childwoman ratio of 854 children aged 0-4 years per 1,000 women aged 1544 years in 1951 is almost certainly too low, but the more complete enumeration of children in 1956 would account for only part of the rise in this ratio to 969 children per 1,000 women of reproductive age in 1956. The emigration of childless women and any reduction that might have occurred in the mortality of infants and children would both contribute to the increase. The analysis of the mortality data and of the fertility data collected in the censuses follows the outline of the registration system and the reliability of its operation.

\section{Registration of Births and Deaths}

The registration of births and deaths was first introduced in Western Samoa in 1905, but as the German system was thought not to function efficiently, the New Zealand civil administration revised it in 1923. The regulations were published in the Western Samoa Gazette No. 47 of 1928 as the Board of Health Regulations No. 3 and the relevant sections are as follows:

REGISTRATION OF BIRTHS OF SAMOANS.

3. (1) Within seven days after the birth of any Samoan child ... the following particulars shall be furnished to the Pulenu'u of the village, and to the Fa'amasino (native magistrate) of the District in which the child was born: 
(a) Date of birth.

(b) Place of birth.

(c) Christian or first name.

(d) Sex of the child.

(e) Condition of child (whether alive or dead when born).

(f) Name of father.

(g) Residence of father (Village and district in which father resides).

(h) Name of mother.

(i) Residence of mother (Village and district in which mother resides).

(j) Signature of informant.

(k) Residence of informant.

(1) Date of registration.

(m) Signature of official registering the birth.

(2) The father and the mother of the child shall be responsible for duly furnishing to the Pulenu'u and to the Fa'amasino, the particulars hereinbefore referred to in respect of the birth of any Samoan child.

4. (1) On receipt of the particulars of the birth of any Samoan child as aforesaid, the Pulenu'u and the Fa'amasino shall enter the same in the Register of Births and on a duplicate sheet to be supplied for the purpose...

(2) On receipt of any particulars of the birth of any Samoan child, notwithstanding that the full particulars required by these regulations have not been furnished, the Pulenu'u and the Fa'amasino shall enter the particulars furnished in the Register of Births and on the duplicate sheet as aforesaid.

REGISTRATION OF DEATHS OF SAMOANS.

5. (1) Within seven days from the date of the death of any Samoan occurring..... the following particulars shall be furnished to the Pulenu'u of the Village, and to the Fa'amasino of the district in which the death occurred.

(a) Date of death.

(b) Place of death.

(c) Name of deceased.

(d) Residence of deceased (Village and district in which the deceased resided).

(e) Age of deceased (if known).

(f) Sex of the deceased.

(g) The name of the father of the deceased.

(h) Residence of the father of the deceased.

(i) The name of the mother of the deceased. 
(j) Residence of the mother of the deceased.

(k) If deceased married, name of husband or wife.

(l) Number and sex of children living (if any).

(m) Cause of death.

(n) Signature of informant.

(o) Residence of informant.

(p) Such other particulars as the Administrator may from time to time determine.

(2) Every person present at the death is responsible for the notification of such death, and they shall choose one of their number to furnish to the Pulenu'u of the Village and to the Fa'amasino of the district the particulars hereinbefore referred to.

6. (1) On receipt of the particulars of the death of any Samoan as aforesaid, the Pulenu'u and the Fa'amasino shall enter the same in the Register of Deaths and on a duplicate sheet to be supplied for the purpose...

(2) On receipt of any particulars as to the death of any Samoan. notwithstanding that the full particulars as required by these regulations have not been furnished, the Pulenu'u and the $\mathrm{Fa}$ amasino shall enter the particulars furnished in the Register of Deaths and on the duplicate sheet aforesaid.

7. (1) On the death of any Samoan who has been attended in his last illness by a registered Medical Practitioner, that Practitioner shall sign and deliver or cause to be delivered to the Secretary for Native Affairs, a certificate on a form to be provided for the purpose by the Secretary for Native Affairs, stating to the best of his knowledge and belief the causes of death (both primary and secondary), the duration of the last illness of the deceased, and such other particulars as may be required by the Secretary for Native Affairs.

(2) The immediately preceding sub-clause of this regulation does not absolve any persons mentioned in sub-clause 2 , Clause 5 of these regulations from the duty of reporting such death to the Pulenu'u of the Village and the Fa'amasino of the district in which the death occurred.

The only difference in procedure before independence was that the duplicate registrations were forwarded to the Postmaster who replaced the Secretary for Native Affairs as Chief Registrar. He was also the only Registrar for persons of 'European' status, for whom registration was according to the regulations in force in New Zealand and these allow thirty days for the registration of a birth and sixty days for deaths. There 
is no special provision for the registration of still-births among Samoans, and such births are ostensibly recorded in both birth and death registers.

If the short period of grace allowed Samoans for registration was designed to ensure that all births and deaths were registered, it seems not to have been particularly successful, even if the years 1927-34 when many Samoans flagrantly ignored government regulations (and especially those concerning registration) are excluded. In each of the last two censuses the number of children enumerated at ages less than 15 years exceeded the number of births registered in the preceding fifteen years. Working back from the numbers recorded at ages $0-4,5-9$, and 10-14 years in 1956 to the numbers of births that would be needed to produce these survivors to each age, it appears that registration has been uniformly deficient over the period, with about 15 per cent of births not registered.

The probabilities of survival used to derive the estimated numbers of births were based on the deaths registered in Samoa with no allowance for their probable incompleteness, and the extent of this cannot be estimated from the recent census data because of the inaccurate reporting of age and the unknown migration pattern. The United Nations Population Division compared the numbers of deaths registered with the numbers implied by the increases of population recorded during the intervals between certain censuses, taking into account the probable level of the birth rate and the records of immigration and emigration' and concluded that the registration of deaths was 'about three-fourths complete during the period 1906 to 1911', little more than half between 1926 and 1936, and 'only about 65 per cent complete' between 1936 and 1945. It was acknowledged that this comparison gave only 'a very rough indication of the extent of the deficiency' because of the likelihood of errors in the census data, the migration records and the assumptions about the birth rate (U.N.P.D., 1948, pp. 22, 23).

The neglect of registration for many of the years between 1926 and 1936 was deliberate and, as the numbers of births and deaths occurring between 1936 and 1915 would reflect the secondary effects of the 1918 influenza epidemic, the actual deficiency in registration was probably less than the 35 per cent estimated. A comparable estimate for the 194551 inter-censal period indicated that if only 85 per cent of births were registered, the deaths recorded during this interval were less than threequarters the number expected if the migration records were accurate. In view of the discrepancies between the numbers expected and enumerated in 1956 (Jupp, 1958, p. 25) it must be doubted that the migration records are accurate and, therefore, the registration of deaths is perhaps more than 75 per cent complete. As there is even less incen- 
tive to register a death than a birth it is unlikely, however, that more than 85 per cent of deaths are registered.

These are average figures and there would probably be some variation from year to year in the extent of deficiency. Unless the omissions are a random sample of the deaths occurring amongst males and females at all ages, the death rates based on such incomplete data may be quite misleading as to the level and pattern of mortality in this population even if the ages recorded in the death registers and census populations were reliable. As all age statements are suspect, and registration may be either more or less deficient for males than for females, the mortality statistics for this population must be interpreted with the utmost caution.

\section{Analyses of Mortality}

Until 1956 the maximum information published about deaths registered in Western Samoa each year were the numbers of 'Samoans' and 'Europeans' who died at ages less than 1 year, 1-4 years, 5-9 years, and 10 years and over without distinction of sex except in the total number of deaths for the year. Since 1956, each Annual Report (N.Z.P.P. A-4) contains a very detailed summary of registered deaths by age but not by sex, listing the numbers of infants dying each day during the first week of life, each week during the first month and each month during the first year of life, and thereafter the number of persons who died at ages 1-4 years and then by quinquennial age groups to 85 years.

As the published data were inadequate for a mortality analysis relating to the 1951 census population, a more detailed summary was compiled from the death registers in Apia for the three years centring on the census year. Subsequently the deaths registered in the three years 1955-7 were summarized by sex as well as by age, and the average annual mortality rates computed for males and females at each age in the relevant census populations are given in Table 22. The mortality rate at age 0 in each instance is the infant mortality rate per 1,000 live births, and all rates refer to the total population, 'Samoans' and 'Europeans' together. Because of all the known deficiencies in the basic data, the standard error of each rate is included even though the true mortality rate at each age may lie outside the range of the rate shown here plus or minus three times its standard error.

Except perhaps amongst infants in 1950-2, there is no difference between the mortality rates for males and females of the same age that attains levels of statistical significance; nor are there any differences between the parallel rates for each sex in 1950-2 and 1955-7 except perhaps among infant males. The higher mortality among male births in 1950-2 may be due to more complete registration for males than for 
TABLE 22 Average annual mortality rates in Western Samoa, by sex and age: registered deaths per 1,000 population in each age group

\begin{tabular}{crrrrrrrr}
\hline & \multicolumn{4}{c}{ Males } & \multicolumn{5}{c}{ Females } \\
Age group & \multicolumn{1}{c}{$1950-2$} & \multicolumn{2}{c}{$1955-7$} & \multicolumn{2}{c}{$1950-2$} & \multicolumn{1}{c}{$1955-7$} \\
& Rate & \multicolumn{1}{c}{ S.E. } & Rate & S.E. & Rate & S.E. & Rate & S.E. \\
\hline $0^{*}$ & $57 \cdot 6$ & $5 \cdot 8$ & $46 \cdot 0$ & $4 \cdot 7$ & $44 \cdot 2$ & $5 \cdot 5$ & $42 \cdot 1$ & $4 \cdot 7$ \\
$1-4$ & $11 \cdot 1$ & $1 \cdot 3$ & $9 \cdot 1$ & $1 \cdot 1$ & $8 \cdot 8$ & $1 \cdot 2$ & $7 \cdot 9$ & $1 \cdot 1$ \\
$5-9$ & $1 \cdot 9$ & $0 \cdot 5$ & $1 \cdot 9$ & $0 \cdot 5$ & $1 \cdot 7$ & $0 \cdot 5$ & $1 \cdot 5$ & $0 \cdot 5$ \\
$10-14$ & $1 \cdot 5$ & $0 \cdot 5$ & $1 \cdot 4$ & $0 \cdot 5$ & $1 \cdot 0$ & $0 \cdot 4$ & $0 \cdot 6$ & $0 \cdot 3$ \\
& & & & & & & & \\
$15-19$ & $2 \cdot 5$ & $0 \cdot 8$ & $1 \cdot 0$ & $0 \cdot 4$ & $1 \cdot 7$ & $0 \cdot 6$ & $1 \cdot 4$ & $0 \cdot 5$ \\
$20-24$ & $2 \cdot 6$ & $0 \cdot 9$ & $2 \cdot 6$ & $0 \cdot 8$ & $1 \cdot 5$ & $0 \cdot 6$ & $1 \cdot 3$ & $0 \cdot 6$ \\
$25-29$ & $1 \cdot 8$ & $0 \cdot 7$ & $1 \cdot 8$ & $0 \cdot 7$ & $2 \cdot 4$ & $0 \cdot 8$ & $2 \cdot 2$ & $0 \cdot 7$ \\
$30-34$ & $3 \cdot 5$ & $1 \cdot 1$ & $3 \cdot 3$ & $1 \cdot 1$ & $4 \cdot 8$ & $1 \cdot 4$ & $3 \cdot 8$ & $1 \cdot 2$ \\
$35-39$ & $4 \cdot 2$ & $1 \cdot 3$ & $3 \cdot 9$ & $1 \cdot 2$ & $6 \cdot 5$ & $1 \cdot 8$ & $3 \cdot 6$ & $1 \cdot 2$ \\
$40-44$ & $7 \cdot 6$ & $2 \cdot 1$ & $5 \cdot 2$ & $1 \cdot 7$ & $5 \cdot 9$ & $2 \cdot 0$ & $5 \cdot 4$ & $1 \cdot 8$ \\
& & & & & & & & \\
$45-49$ & $8 \cdot 5$ & $2 \cdot 4$ & $7 \cdot 6$ & $2 \cdot 1$ & $8 \cdot 1$ & $2 \cdot 6$ & $8 \cdot 2$ & $2 \cdot 4$ \\
$50-54$ & $13 \cdot 5$ & $3 \cdot 6$ & $12 \cdot 6$ & $3 \cdot 2$ & $11 \cdot 9$ & $3 \cdot 3$ & $8 \cdot 7$ & $2 \cdot 8$ \\
$55-59$ & $19 \cdot 8$ & $5 \cdot 4$ & $17 \cdot 6$ & $4 \cdot 4$ & $6 \cdot 8$ & $3 \cdot 4$ & $7 \cdot 0$ & $2 \cdot 9$ \\
$60-64$ & $28 \cdot 6$ & $6 \cdot 3$ & $21 \cdot 6$ & $5 \cdot 6$ & $18 \cdot 0$ & $4 \cdot 9$ & $19 \cdot 7$ & $5 \cdot 3$ \\
$65-69$ & $26 \cdot 3$ & $7 \cdot 5$ & $35 \cdot 0$ & $7 \cdot 8$ & $23 \cdot 7$ & $8 \cdot 1$ & $20 \cdot 2$ & $6 \cdot 0$ \\
$70-74$ & $52 \cdot 4$ & $13 \cdot 3$ & $55 \cdot 7$ & $13 \cdot 0$ & $38 \cdot 3$ & $12 \cdot 3$ & $31 \cdot 8$ & $7 \cdot 5$ \\
75 and over & $82 \cdot 1$ & $14 \cdot 9$ & $81 \cdot 3$ & $12 \cdot 9$ & $82 \cdot 4$ & $16 \cdot 8$ & $53 \cdot 0$ & $10 \cdot 0$ \\
\hline
\end{tabular}

*Infant mortality rate per 1,000 live births registered.

females, but if there was a sex differential in infant mortality in 1950-2 it was not apparent in 1955-7. The mortality rates at ages 1-4 in 1950-2 may be exaggerated because of under-enumeration at these ages in the 1951 census, and there probably has been as little change in these rates as in those at all other ages.

Provided that all of the deficiencies are reproduced more or less exactly in both sets of data, one might infer from this comparison that whatever the level and pattern of mortality in Western Samoa might be, there has been no very great change in recent years. For what little they are worth, the average annual mortality rates obtained by applying these age-specific rates for males and females to the standard population (Table 10) are $7 \cdot 8$ deaths per 1,000 population in 1950-2 and an average of 6.8 deaths per 1,000 population in 1955-7. As almost half of the difference between the two standardized rates is contributed by the decline in registered mortality at ages 0-4 years in 1955-7, the lessening in the risks of dying at all other ages is negligible. Were all deaths registered, the picture might be quite different. 


\section{Analyses of Fertility}

As the age of the mother is not recorded in the birth registers in Western Samoa, the only direct measure of the frequency of births in this population is the general fertility rate and, analytically at least, incomplete registration of births therefore matters less than the underregistration of deaths. Until 1950, the statistics of births published in the Annual Reports related to births registered in the year ended 31 March; there was then a report for the nine months ended 31 December 1950 and each report since then has covered a complete calendar year. To avoid the purely random fluctuations in the numbers of births each year, the average numbers registered per year over the same two three-year periods as before were referred to the female populations enumerated at ages 15 to 44 years in 1951 and 1956. Assuming that the number of births registered during the first quarter of 1950 was one-fourth of the total registered during the year ended 31 March 1950, each 1,000 women aged 15 to 44 years in 1951 produced an average of 189 births a year and the comparable average for 1955-7 was 196 births per 1,000 women of reproductive age in 1956. As each of these rates has a standard error of 3 , there is clearly no difference of any significance between them and, if 15 per cent of all births are not registered, the fertility rate in Western Samoa may be about 225 births per 1,000 women of reproductive age.

High though this rate is, it is confirmed by the set of age-specific fertility rates implied by the average numbers of children born to women at each age in 1956 and which, when applied to the census population, lead to a general fertility rate of 240 births per 1,000 women aged 15 to 44 years. Because the effects of age mis-statements and migration are more marked in the fertility data than elsewhere, these estimated agespecific fertility rates do not form the regular sequence one would expect and alternative estimates were derived from the age and parity-specific fertility rates for American Samoa, with some adjustment for the probable under-registration of births in that territory.

As in Fiji and Tonga, all females aged 15 years or over in Samoa in 1956 were asked the number of children born to them who were still living and the number who had died, and the total number of children born to each was taken to be the sum of the living and the dead. In American Samoa, both the age of the mother and the rank of the birth are recorded in the birth registers and average annual age-specific fertility rates for women of each parity were computed from the births registered in the three years 1955-7 and the tabulation of women by their age in 1956 and the number of children they had borne. These rates were 
then applied to the population at risk for births in Western Samoa in 1956 to estimate the number of births of each rank that could be expected amongst women of each age. The age-specific fertility rates obtained by summing the numbers of births expected at each age irrespective of birth rank and dividing by the population at risk were then inflated uniformly to allow for the probable non-registration of 5 per cent of births in American Samoa, and these estimated fertility rates for Western Samoa are shown in Table 23.

Had these rates applied in Western Samoa for many years before 1956, they would have yielded the average numbers of children at each age given in column 2 of Table 23, and although an increase of 10 per

TABLE 23 Estimated age-specific fertility rates per 1,000 women at each age in Western Samoa, and the average numbers of children born to women in each age group as estimated from the fertility rates and as recorded in the census of 1956

\begin{tabular}{ccccc}
\hline & \multicolumn{2}{c}{ Estimated } & & \\
Age- & $\begin{array}{c}\text { Ag56 Census* } \\
\text { specific } \\
\text { fertility } \\
\text { rates }\end{array}$ & $\begin{array}{c}\text { Average } \\
\text { number of } \\
\text { children } \\
\text { per woman }\end{array}$ & $\begin{array}{c}\text { 1956rage number of } \\
\text { children per woman }\end{array}$ \\
\hline $15-19$ & 47 & $0 \cdot 12$ & $0 \cdot 14$ & Surviving \\
$20-24$ & 316 & $1 \cdot 03$ & $1 \cdot 33$ & $0 \cdot 12$ \\
$25-29$ & 386 & $2 \cdot 78$ & $2 \cdot 96$ & $2 \cdot 18$ \\
$30-34$ & 242 & $4 \cdot 35$ & $4 \cdot 60$ & $3 \cdot 88$ \\
$35-39$ & 208 & $5 \cdot 47$ & $6 \cdot 06$ & $5 \cdot 01$ \\
$40-44$ & 66 & $6 \cdot 16$ & $6 \cdot 76$ & $5 \cdot 37$ \\
$45-49$ & 20 & $6 \cdot 37$ & $7 \cdot 24$ & $5 \cdot 56$ \\
$45-59$ & - & $6 \cdot 42$ & $7 \cdot 27$ & $5 \cdot 41$ \\
60 and over & - & $6 \cdot 42$ & $6 \cdot 93$ & $4 \cdot 21$ \\
\hline
\end{tabular}

*Jupp, 1958, pp. 36 and 91.

cent in the basic rates would have produced better agreement with the average numbers of children recorded for women of various ages in the census, the age-specific fertility rates shown are probably reasonable estimates of the provailing levels of fertility, even if a little conservative. In the female population enumerated in 1956 they would have yielded 4,277 births which is equivalent to a general fertility rate of 220 births per 1,000 women aged 15 to 44 years and this accords quite well with 
the recorded fertility rate for Western Samoa adjusted for underregistration of births.

The average numbers of children born and surviving to women at each age in 1956 are reproduced in Table 23 from the census report (Jupp, 1958, pp. 36, 91) and, here as elsewhere, the numbers may be exaggerated somewhat because of the way in which the question was framed. In addition, the down-grading of ages by the enumerators would tend to raise the average numbers of children born to women in the younger age groups while the averages for the older cohorts would not be greatly altered by the omission of some of their members. However, emigration probably has an even greater effect on the average number of children born to women in each cohort; because it is more practicable for women without children, or with few children, to emigrate, those who remain in the population are not a representative sample of their cohort.

Despite the probable exaggeration of averages for the younger cohorts, the numbers of ohildren increase very regularly throughout the two decades of age between 20 and 39 years and, if the pattern of fertility has remained constant, the differences between successive means imply an average interval of just over three years between births within this age span. The interval between successive births lengthens at ages beyond 40 years, but the average completed family of more than 7 children is high by any standards, especially when the chances of survival are such that three-quarters of the children born to women aged 45 to 59 years in 1956 were still living at census date and an even greater proportion of those born or yet to be born to women of reproductive age can be expected to survive in the future.

Though this high level of fertility may have been equalled by the older cohorts of Indian women in Fiji, their patterns of family formation are very different and the Samoans resemble the Fijians more than the Indians in their attainment of motherhood. The proportions of each cohort to bear at least one child before the ages of 20,25 , and 30 years are given in the census report (Jupp, 1958, p. 35) and, partly because of the comparatively small numbers in most cohorts, partly because of age mis-statements, there is some variation in the pattern from cohort to cohort. The data are given in an abridged form in Table 24 and the frequencies shown there are the average rates at which the various cohorts attained motherhood.

The cohorts of reproductive age in 1956 were relatively homogeneous with less than 1 per cent bearing a child before the age of 15 years and more than one-third before 20 years of age. As in Fiji, the period of greatest risk for a first birth is between the ages of 20 and 25 years 
TABLE 24 Attainment of motherhood at specified ages: rate per 1,000 females at risk in grouped cohorts in Western Samoa

\begin{tabular}{|c|c|c|c|}
\hline \multirow[b]{2}{*}{$\begin{array}{c}\text { Age in } \\
1956\end{array}$} & \multicolumn{3}{|c|}{ Age at first birth } \\
\hline & $\begin{array}{l}\text { Before } \\
20 \text { years }\end{array}$ & $\begin{array}{l}20-24 \\
\text { years }\end{array}$ & $\begin{array}{l}25-29 \\
\text { years }\end{array}$ \\
\hline $20-24$ & 362 & & \\
\hline $25-29$ & 344 & 606 & \\
\hline $30-44$ & 351 & 594 & 525 \\
\hline $45-59$ & 299 & 571 & 545 \\
\hline 60 and over & 171 & 489 & 502 \\
\hline
\end{tabular}

and almost three-quarters of the relevant cohorts had borne a child before they were 25 and half of the remainder before the age of 30 years. Among the older cohorts, the proportions to attain motherhood before age 20 declined with increasing age in 1956, and this initial defection was not compensated by higher frequencies of first births between the ages of 20 and 25 nor between 25 and 30 years of age.

For some of these women, and especially the four cohorts aged from 50 to 69 years in 1956, the attainment of motherhood before one of the three specified ages may have been interrupted by the influenza epidemic of 1918. Unfortunately, quinquennial ages in 1918 cut across the age groups and cohorts of 1956; the younger members of the 1897-1901 cohort, for example, would have been less than 20 in 1918-19, but the remainder were between 20 and 25 years old. However, unless there was some differential mortality in the epidemic or since, one would not expect progressively fewer of the older cohorts to have borne a child before the age of 20 than had the cohorts whose marriage plans were most likely to have been upset by the epidemic, although the lack of eligible males may account for the lower rates for first births between the ages of 20 and 29 shown by the women aged 60 years and over in 1956 .

No data comparable with these were collected in earlier censuses. In 1951 women who were or had been married were asked the number of children they had borne, but the replies were acknowledged to be unreliable both in respect to marital status and the numbers of children recorded. Some of these were 'of necessity adjusted arbitrarily by census officials' (MS. report on Population Census of 1951) when the data were being tabulated, but it is not clear whether the numbers of children recorded were 'adjusted' so as to be commensurate with the age reported 
for the mother or vice versa, or whether the tabulations relate to all women who had borne children irrespective of the marital status originally recorded.

Until similar data become available in later enumerations, it can only be assumed that about one-third of all women in Western Samoa have their first child before they are 20 years old and 60 per cent of the remainder attain motherhood within five years. Successive births occur at fairly regular intervals, with only 7 or 8 per cent of all women having no children at all and one-third bearing ten or more children. If the statistics of deaths are more reliable than is believed and there is no migration, even the conservative estimates of current fertility lead to annual increments of more than $3 \frac{1}{*}$ per cent and at this rate the population will double in just under twenty years.

Even more significant for a population where two-thirds of all males aged 15 years and over in 1956 were engaged in agriculture is the rate at which the work force will increase: in the absence of any marked increase in mortality, only emigration will prevent increments of about 4 per cent a year in the number of males aged between 15 and 59 years, and the 'village' and 'other' agriculture which supported less than 17,000 males in 1956 may be the only means of livelihood for at least twice this number within fifteen years. As less than one-ifth of the total land area is at present under cultivation, and about half of the unused land is suitable for cultivation by traditional Samoan methods (Pirie, 1960), neither the increase in population nor in the work force present the problems likely to be encountered in Tonga. The exploitation of these untapped resources of land will, however, entail economic and sacial changes which may well alter the demographic future of this population as much as emigration in recent years has changed American Samoa's.

\section{AMERICAN SAMOA}

\section{Census Enumerations}

Until 1920 the population was enumerated at irregular intervals under the instructions of the various commandants of Naval Station, Tutuila who were given the title of 'Governor' from 1905. Except for the numbers recorded for each administrative district in 1900, 1901, 1903, 1908, 1912, and 1916, nothing is known about these counts, and only for the last two censuses were the numbers of males and females published.

In 1920, a census was 'taken by the Governor of American Samoa in accordance with the plans prescribed by the Director of the Census' and the tabulations compiled showed the population of each district, county and village classified according to race and sex, and the total population 
classified by age and marital condition, besides data as to school attendance, illiteracy and occupations' (Hill, 1922, pp. 1232, 1233). This was the first of the decennial censuses of American Samoa taken as part of the United States censuses of population and, though the details of the 'plans prescribed' are known only for the 1950 census, the procedure in earlier enumerations probably varied as little as the scope of the questionnaires.

The questions asked in 1950 were name, relationship to head of household, race, sex, age last birthday, marital status, the highest grade completed at school, school attendance for persons aged 5 to 24 years, ability of persons aged 25 years or more to speak English, place of birth, and two questions on the occupations followed by persons aged 14 years and over during the previous year. These were ranged horizontally across the questionnaire, with brief but explicit instructions heading each column and, below these, ruled spaces in which to record the replies for each of the 20 or 25 persons who could be listed on the form.

The duties and responsibilities of 'crew leaders' (or supervisors) and enumerators were explained in instruction booklets prepared by the United States Bureau of the Census and the printed instructions were supplemented locally with practical training which included trial runs with the questionnaires under supervision. Starting on 1 April, the enumerators were allowed a week or so in which to visit all dwellings in the areas assigned to them and record the names and other particulars of the persons who usually slept in each dwelling. Households were listed consecutively on the forms and each page was filled before a new one was started. When all households within an area had been listed, the completed forms were checked by a 'crew leader' to ensure that all questions had been answered, and all forms were then returned to Washington for processing. facto.

Strictly speaking, the population recorded was neither de jure nor de

In accordance with usual Census practice, each person enumerated ... was counted as an inhabitant of his usual place of residence or usual place of abode, which is generally construed to mean where he lives and sleeps most of the time. . . . Visitors found staying in private homes were not ordinarily interviewed there. Information on persons away from their usual place of residence was obtained from other members of their families, landladies, etc. If an entire family was expected to be away during the whole period of the enumeration, information on it was obtained from neighbours. A matching process was used to eliminate duplicate reports for persons who reported for themselves while away and were also reported by their families at home (1950 Population Census Report P-B54, 1952, pp. 3, 4). 
Explicit as this is for persons whose usual place of residence was American Samoa, it is not at all clear whether visitors from other islands, and especially Western Samoa, were included or excluded and, as American Samoans reciprocally visiting friends or relatives in Western Samoa would presumably be enumerated, the accuracy of the total count hinges on the enumerators' interpretation of their instructions in this regard.

This difficulty was avoided in the extraordinary enumeration in 1956 when the population of American Samoa was censussed at the same time as the population of Western Samoa and both censuses were de facto. The scope of the enumerations and the procedures for collection and tabulation were identical and, except for two tables which were compiled subsequently, the results for American Samoa wero published in a cyclostyled report (Cool, 1957) issued within six months of the census date. This was the first time that fertility data were collected in a census of American Samoa, and the only time so far that the questions were asked of all women, regardless of marital status.

\section{Growth of Population in the Twentieth Century}

The populations recorded in successive censuses of American Samoa are shown in Table 25 and, except for a small decrease in population between 1900 and 1901 which may be due to errors in either count, each census revealed a larger population than its predecessor. The

TABLE 25 The populations enumerated in successive censuses of American Samoa, 1900 to 1960 , by sex and island

\begin{tabular}{cccccc}
\hline & Tutuila & Manu'a & \multicolumn{3}{c}{ American Samoa ${ }^{2}$} \\
Date & & & Males & Females & Persons \\
\hline 1900 & 3,923 & 1,756 & $*$ & $*$ & 5,679 \\
1901 & 3,960 & 1,603 & $*$ & $*$ & 5,563 \\
1903 & 4,193 & 1,695 & $*$ & $*$ & 5,888 \\
1908 & 4,925 & 1,855 & $*$ & $*$ & 6,780 \\
1912 & 5,454 & 1,797 & 3,836 & 3,415 & 7,251 \\
1916 & 5,885 & 1,665 & 3,939 & 3,611 & 7,550 \\
1920 & 6,185 & 1,871 & 4,139 & 3,917 & 8,056 \\
1930 & 7,809 & 2,147 & 5,208 & 4,847 & 10,055 \\
1940 & 10,164 & 2,597 & 6,612 & 6,296 & 12,908 \\
1950 & 15,954 & 2,819 & 9,818 & 9,119 & 18,937 \\
1956 & 17,307 & 2,767 & 10,107 & 10,047 & 20,154 \\
1960 & 17,250 & 2,695 & 10,164 & 9,889 & 20,051 \\
\hline
\end{tabular}

*Not available.

†Swain's Island was annexed in 1925 and its population is included in all censuses thereafter. 
increases have not been particularly regular although the only untoward event in the first two decades of naval administration was a hurricane which devastated Manu'a in 1915, damaging food crops so severely that two-thirds of the population were taken to Tutuila until the houses and gardens were restored. The population escaped the influenza epidemic in 1918 because, when the outbreak was at its height in Western Samoa, the Governor imposed a strict quarantine on all vessels entering the port of Pago Pago (N.Z.P.P. H-31c, 1919, p. 5). In 1925, Swain's Island was annexed to American Samoa and its population was included in all censuses thereafter. There were 99 people on the island in 1930, 147 in 1940, 164 in 1950 but only 80 in 1956.

Between 1900 and 1912, the population of American Samoa increased by more than 25 per cent and the period of most rapid growth was from 1903 to 1908. As there were revolts against the German régime in Western Samoa in both 1904-5 and 1908-9, it is not unlikely that some of the protagonists sought refuge in American Samoa, drifting back to Western Samoa a few years later. There was little difference in the size of the populations recorded in 1912 and 1916 and, as the number of females increased more than the males, there may well have been an exodus to Western Samoa when the New Zealand military forces assumed control there. The differential rate of increase in the male and female segments persisted between 1916 and 1920, but the increases during the next two decades were roughly parallel for males and females at about $2 \frac{1 / 2}{2}$ per cent per year.

There was a spectacular rise in population numbers between 1940 and 1950 , with a relatively greater increase for males than for females. The population as a whole increased by $46 \cdot 7$ per cent, which is equivalent to an average rate of just under 4 per cent per year, and again it is unlikely that this spurt was due to augmented natural increase. The 1940 population contained 955 persons born in Western Samoa or other Pacific islands; in 1950, 1,908 of the persons recorded were born in Western Samoa and 212 came from other islands of the Pacific. As the estimated natural increase for the decade 1940-50 was about 4,700 and the net increase recorded was just over 6,000, immigration probably contributed more than one-fifth of this total.

Over the next six and a half years, population growth slackened to less than 1 per cent per year and, as the natural increase recorded in the inter-censal period was approximately 4,100 , the net loss through emigration was in the region of 3,000 persons. Probably only two-thirds of this number could be regarded as 'permanent' emigrants because, in September 1956 only 1,729 of the population enumerated in American Samoa had been born in Western Samoa as compared with 1,908 in 1950. 
In Western Samoa, on the other hand, in September 1951 only 553 of the 'Samoan' population had been born outside Western Samoa, but five years later 1,386 persons claimed American Samoa as their birthplace. In this interchange of population American Samoa therefore lost at least 1,000 people and probably fewer than 2,000 migrated away from the Samoa group during this period.

These frequent movements of population between the two Samoas are relatively more important for the smaller American Samoan population than for Western Samoa's. The 'foreign-born' population recorded in censuses has been tabulated by 'race' and sex since 1940, with the Western Samoa-born distinguished only for 1950 and 1956. However, the volume of traffic annually between the two territories is indicated in a summary that was compiled by the Customs Officer at Pago Pago from his records for the year 1950. Based on ships' manifests, the numbers shown in Table 26 cover more than inter-Samoa population movements, but the 'oversea' migration for Samoans was thought to be relatively insignificant, and the majority of persons whose nationality was not recorded would be Samoans or part-Samoans.

In April 1950, there were 16,457 'native-born' Polynesians and partPolynesians enumerated in American Samoa and, assuming that no individual left more than once in the year or returned more than once, the recorded inward and outward migrations of American Samoans amounted to at least one-tenth of the 'native-born' population. Perhaps even more significant for a population as small as this is the net gain through migration of 1,672 persons in one year, approximately 1,000 of whom were adult males, fairly evenly distributed over all ages within the range 20 to 64 years. Apart from a concentration at ages 20-24 years, the immigrant females were also fairly evenly spread over a wide range of ages.

As this is the only year for which such statistics have been compiled in American Samoa, it is not known whether 1950 was an exceptional year in regard to migration between the two territories. There are no comparable data for Western Samoa because the Commissioner of Police there records only persons going to or arriving from countries beyond the seas' (Permits Ordinance, 1921). However, movements of this magnitude annually between the two populations make nonsense of separate territorial censuses, either in respect to total numbers or of population structure.

\section{Age and Sex Composition}

The numbers of males and females recorded in successive censuses are arrayed in Table 27 according to periods of birth approximating to 


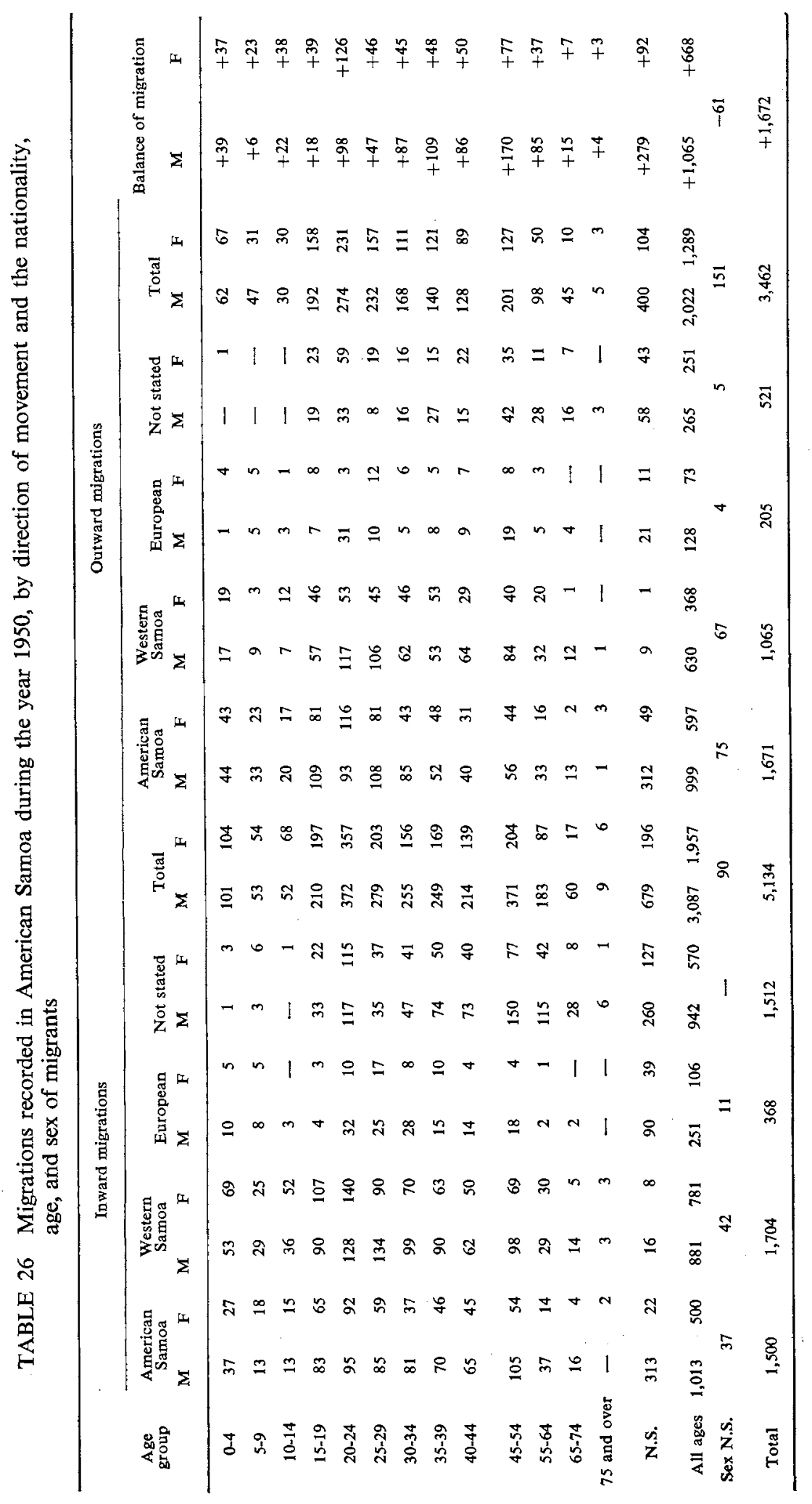


the ages stated. Had all of the decennial censuses been taken on 1 January, the periods of birth and ages would have coincided, but except in 1920 and 1956, the censuses related to populations as at 1 April. In 1920, the population was enumerated on I January, but Swain's Island was not then part of American Samoa and the cohorts are not therefore strictly comparable with those recorded in subsequent censuses. The 1956 census referred to the population as at 25 September, but as the cohorts shown in Table 27 were compiled from the dates of birth recorded for each individual, they probably are reasonably consistent with the earlier data.

It is impossible to ascertain who acted as enumerators in the decennial censuses. As there was no registration of births until 1900, in 1920 the census enumerators were obliged to estimate the ages of most Samoans over 20 years of age. The reported ages of the population under 20 years are believed to be fairly accurate and the ages of the older people are probably sufficiently accurate for a classification by broad age groups' (Hill, 1922, p. 1253). In the next census, the five-year age groups were extended to age 35 and ages beyond this were grouped in ten-year periods, but all subsequent censuses have retained five-year age groups through to ages 75 and over. Before 1950, 'not stated' ages were tabulated as such and distributed pro rata before publication. In 1950 'when the age of a person was not reported, it was estimated on the basis of other available information such as marital status, school attendance, employment status, age of other members of the household, and type of household' (1950 Population Census Report P-B54, 1952, p. 4).

Almost all of the enumerators in 1956 were school-teachers and they received the same printed instructions as the enumerators in Western Samoa, which stressed the importance of reporting ages as accurately as possible. Nevertheless, the tabulation of the population by single years of age indicated that age had been wrongly reported for at least $5 \cdot 3$ per cent of males and 5.8 per cent of females aged between 13 and 62 years. Both males and females tended to avoid ages ending in 5 and favour those with 8 or 6 as the unit digit, but whereas the preferences shown by the men were evenly divided between the first and second half of a ten-year age group, there was such a marked avoidance by the women of ages ending in 1 that their preferences for unit digits between 0 and 4 summed to less than 48 per cent. Because of the 'flag raising' in 1900, age 56 was especially popular with both sexes.

This ceremony in 1900 marked the cession of Tutuila to the United States and its use as a yardstick in the estimation of ages is apparent in all censuses from 1930, particularly amongst males. Except in 1950, the 1900-4 cohort of males has been larger than the cohorts on either 
TABLE 27 Numbers of males and females enumerated in successive censuses of American Samoa arrayed according to approximate periods of birth corresponding to the ages tabulated in the censuses

\begin{tabular}{|c|c|c|c|c|c|c|}
\hline \multirow{2}{*}{$\begin{array}{l}\text { Period of } \\
\text { birth }\end{array}$} & \multicolumn{5}{|c|}{ Number of males at censuses of } & \multirow{2}{*}{$\begin{array}{c}\text { Age in } \\
1950\end{array}$} \\
\hline & $1920^{*}$ & 1930 & 1940 & 1950 & 1956 & \\
\hline $1950-54$ & & & & & 1,837 & \\
\hline $1945-49$ & & & & 1,839 & 1,599 & $0-4$ \\
\hline $1940-44$ & & & & 1,542 & 1,254 & $5-9$ \\
\hline $1935-39$ & & & 1,152 & 1,236 & 1,011 & $10-14$ \\
\hline $1930-34$ & & & 1,034 & 1,137 & 684 & $15-19$ \\
\hline $1925-29$ & & 892 & 868 & 774 & 575 & $20-24$ \\
\hline $1920-24$ & & 737 & 717 & 774 & 522 & $25-29$ \\
\hline $1915-19$ & 641 & 646 & 552 & 608 & 460 & $30-34$ \\
\hline $1910-14$ & 557 & 528 & 501 & 527 & 371 & $35-39$ \\
\hline $1905-09$ & 410 & 394 & 353 & 327 & 277 & $40-44$ \\
\hline $1900-04$ & 379 & 421 & 387 & 324 & 293 & $45-49$ \\
\hline $1895-99$ & 336 & 359 & 276 & 245 & 114 & $50-54$ \\
\hline $\begin{array}{l}1890-94 \\
1885-89\end{array}$ & 686 & 518 & $\begin{array}{l}211 \\
166\end{array}$ & $\begin{array}{l}133 \\
111\end{array}$ & $\begin{array}{r}108 \\
98\end{array}$ & $\begin{array}{l}55-59 \\
60-64\end{array}$ \\
\hline \multirow[t]{3}{*}{$\begin{array}{c}1880-84 \\
\text { Before } 1880\end{array}$} & 1,130 & 713 & $\begin{array}{l}149 \\
246\end{array}$ & $\begin{array}{l}110 \\
131\end{array}$ & 125 & 65 and over \\
\hline & \multicolumn{5}{|c|}{ Number of females at censuses of } & \\
\hline & $1920 *$ & 1930 & 1940 & 1950 & 1956 & \\
\hline $1950-54$ & & & & & 1,706 & \\
\hline $1945-49$ & & & & 1,699 & 1,470 & $0-4$ \\
\hline $1940-44$ & & & & 1,333 & 1,212 & $5-9$ \\
\hline $1935-39$ & & & 1,096 & 1,114 & 971 & $10-14$ \\
\hline $1930-34$ & & & 988 & 1,024 & 801 & $15-19$ \\
\hline $1925-29$ & & 810 & 828 & 856 & 729 & $20-24$ \\
\hline $1920-24$ & & 722 & 646 & 752 & 529 & $25-29$ \\
\hline $1915-19$ & 630 & 580 & 582 & 523 & 458 & $30-34$ \\
\hline $1910-14$ & 545 & 493 & 523 & 472 & 331 & $35-39$ \\
\hline 1905-09 & 363 & 405 & 374 & 324 & 262 & $40-44$ \\
\hline $1900-04$ & 332 & 424 & 325 & 282 & 279 & $45-49$ \\
\hline 1895-99 & 354 & 313 & 238 & 248 & 151 & $50-54$ \\
\hline $\begin{array}{l}1890-94 \\
1885-89\end{array}$ & 774 & 494 & $\begin{array}{l}187 \\
159\end{array}$ & $\begin{array}{l}137 \\
142\end{array}$ & $\begin{array}{l}129 \\
123\end{array}$ & $\begin{array}{l}55-59 \\
60-64\end{array}$ \\
\hline $\begin{array}{c}1880-84 \\
\text { Before } 1880\end{array}$ & 919 & 606 & $\begin{array}{l}121 \\
229\end{array}$ & $\begin{array}{r}74 \\
139\end{array}$ & 134 & 65 and over \\
\hline
\end{tabular}

*Excluding the population of Swain's Island which was annexed to American Samoa in 1925. 
side of it and usually markedly larger than the older cohort. As females showed this preference only in 1930 and 1956, it is perhaps only for the latter, when date of birth was asked, that the year 1900 is particularly relevant. In 1930, the 1900-4 cohort was aged 25-29 years and the changes in cohort size from one census to the next suggest that ages 25-29 have always been popular for females.

Migrations would have contributed to the variations in cohort size between censuses and it is therefore virtually impossible to use cohort comparisons to assess the reliability of ages recorded in the censuses. Comparisons between the numbers enumerated at certain ages and the numbers expected on the basis of births and deaths recorded are also worthless, except perhaps at ages less than 1 year. Tabulations of the 'native'- and 'foreign-born' populations by age at each census would have been interesting, but probably not very helpful because of the prolonged and continual interchange of population between Western and American Samoa.

What is crucial in regard to all of the decennial censuses is how the enumerators interpreted their instructions as to who was to be recorded. If persons temporarily absent from their households were included whether they were in American Samoa or not at the time of the enumeration, and visitors from Western Samoa were recorded as well, the numbers of persons in some age groups would be exaggerated and this would introduce distortions into the proportional distributions of populations by age. The 1956 population is the only one free of this doubt and the numbers and proportions contained in each age group are shown in Table 28. Comprehensive tabulations of the 1930,1940, and 1950 populations will be found in the report on the 1950 census of the United States but these are not strictly comparable with the 1956 data.

Although the population as a whole is dominated by the Samoan component, the deficiency of Samoan males at ages 20-24 and 25-29 years in 1956 was masked in the total population by a concentration at these ages in the 'All Others' component. However, allowing for the popularity of ages 25-29 for Samoan females, there had already been fairly extensive migration of Samoan males before 1956, especially of those aged 25-29 years, and this deficit enhanced the proportions of the male population at young ages. The median age for males was only $15 \cdot 0$ years whereas it was $16 \cdot 5$ for females even though there was an excess of males at all ages less than 20 years. Had age been reported as correctly for females as for males there would probably have been an excess of females at all ages beyond 20 years.

The distribution of the male and female sectors of the population over broad age ranges is very similar to Western Samoa's, although 


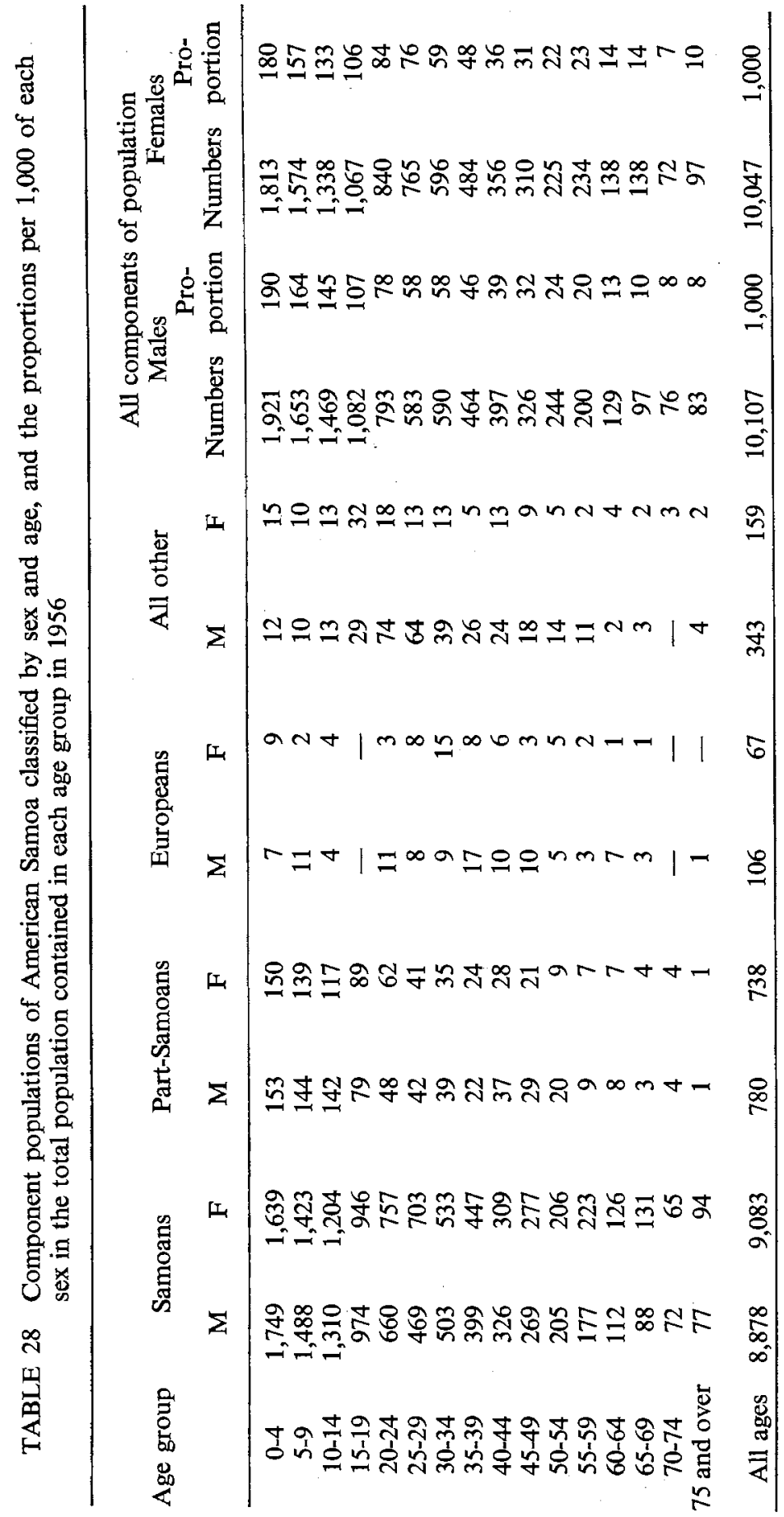


there are minor deviations in the proportions contained in some fiveyear age groups. There has been slightly more emigration of males aged 20 to 29 years from American than from Western Samoa, but more remarkable than this is the difference between the two populations in the distributions of males and females at ages less than 15 years. The population of American Samoa contained relatively more children aged 10-14 years and fewer children aged 0-4 years than were reported for Western Samoa and, as 41 per cent of females in both populations were within the age range 15 to 44 years, the child-woman ratio for American Samoa-909 children aged 0-4 per 1,000 women aged 15-44-was smaller than Western Samoa's. Both populations contained roughly equivalent numbers of children at ages 5-9 years, and the relatively more numerous 10-14 year-olds in American Samoa suggest either some reduction in the level of fertility in that population in recent years, or the emigration of small family groups. Although there is no statistical evidence for the latter as yet, some small change in the fertility pattern is confirmed by the statistics of births.

\section{Registration of Births and Deaths}

The registration of births and deaths began very soon after the establishment of the naval administration in American Samoa, but it is generally conceded that the coverage was not very complete before 1928 when the Department of Public Health became interested in the collection of mortality statistics (Coulter, 1941). When the office of Attorney-General was created in 1931, the system of registration was embodied in new regulations and, in the Code of American Samoa, 1949, the AttorneyGeneral was still the Registrar for births and deaths. Subsequently this duty was transferred to the Clerk of the High Court, but the procedure for registration is otherwise unaltered.

The relevant sections of Chapter VI of the Code of American Samoa are as follows:

Sec. 407. Births to be reported to Village Chiefs:

The father or mother of every child born within the limits of American Samoa, or in the case of death, absence or inability of the father or mother, the owner of the house or place in which such child shall have been born, shall give information to the Village Chief of the place within which such child shall have been born, of such birth, and such further particulars to the best of his knowledge or belief, as may be required by the Village Chief, ...

Sec. 408. Deaths to be reported to Village Chiefs:

In each case of the death of any person, it shall be the duty of the occupant of the house or place in which such death took place 
and of the relatives of the deceased to give notice forthwith to the Village Chief, with such particulars concerning the death as may be required by the Village Chief, ...

Sec. 411. Births and deaths to be reported by the Village Chiefs to Public Health Department:

The Village Chief shall report all births and deaths, with such particulars as may be required, within ten days following such birth or death to the Public Health Department. These birth and deaths certificates, with such comment as pertinent, will be forwarded to the Clerk of the High Court via the Public Health Officer on the first available transportation after receipt. The director of the Samoan Hospital shall report all births and deaths occurring at the hospital to the Clerk of the High Court via the Public Health Officer.

Sec. 414. Permit for burial required:

In the case of the death of any native, no burial of the body shall take place until permit for same has been issued by the County Chief of the County in which said burial is to be made. In case of the absence of the County Chief permit shall be issued by the County Chief's Clerk. In case of the death of any non-Samoan person, permit to bury shall be issued only by the Clerk of the High Court.

The forms now in use for the registration of births and deaths are neatly designed and are printed in English on one side with a Samoan version on the reverse.

There is no separate provision for the registration of still-births and, in practice, these are usually registered as both births and deaths with an appropriate 'remark' on the death certificate. There are penalties for the breach of these regulations but, although deaths must be reported to the village chief 'forthwith', no time is specified for the initial notification of a birth and presumably the onus is on the village chief if more than ten days is allowed to elapse between occurrence and notification. The necessity for a burial permit should ensure completeness of registration of deaths, but this cannot be checked because of the lack of regular statistics of migrations.

The probable coverage of birth registrations cannot be assessed very accurately for the same reason, but the numbers of persons enumerated at ages 0-4 years in 1940, 1950, and 1956 exceeded the numbers expected from the births and deaths registered in each preceding five years. The discrepancies decreased in extent progressively with each census and, assuming neither gains nor losses of population at these ages through migration, about 12 per cent of births were not registered before 1940, ten years later about 7 per cent had not been registered and probably less than 5 per cent escaped registration between 1951 and 1956. If 
there were losses through migration during any of these periods, these figures represent minimum deficiencies in registration; if there was immigration of children aged 0-4 years, the coverage was accordingly more complete than these comparisons suggest.

\section{Analyses of Mortality}

The numbers of deaths that oocur each year are customarily published in the Annual Reports for American Samoa, but seldom in any greater detail than the total number of deaths and the number of 'infant' deaths without distinction of sex. The sex and age of the deceased are recorded in the death registers and, since 1955, the deaths registered each year have been summarized by sex and single years of age up to 5 years and in quinquennial age groups thereafter. The Clerk of the High Court courteously provided the tabulations of deaths registered in the years 1955-7 and these relate to the total population whereas the summaries that had been compiled personally some years earlier from the death registers for 1939-41 and 1949-51 concerned only the non-European populations. The inclusion of the European populations in 1940 and 1950 would make little difference to the average annual mortality rates, specific for sex and age, derived from these tabulations and the appropriate census populations, but the data for 1940 and 1950 are not sirictly comparable with those for 1956.

The average numbers of deaths per 1,000 males and females at each age in a year of each period are given in Table 29 , and the mortality rate at age 0 in each case is the infant mortality per 1,000 live births, with still-births excluded from both numerator and denominator. The numbers of deaths and people in five-year age groups beyond 19 years are too small to justify retention of the more detailed classification and, even with ten-year age groups, the standard errors associated with the rates approach half the magnitude of the rates themselves so that, statistically, few of the rates are significantly different from zero, and none is different from the rate at the same age in any other population.

Nevertheless, there probably was some decline in the risk of mortality at most ages between 1940 and 1950 although there has been no appreciable improvement since. The rates for 1950 and 1956 are remarkably consistent for both males and females, and in no year was there any difference between the mortality experienced by males and females of the same ages. Between 1940 and 1950, however, deaths amongst infants and young children were probably halved and the mortality risks of young adults also lessened. Though the standardized mortality rates may be misleading because they ignore the probable range of variability in the individual rates, the 1940 series lead to an average of 16.9 deaths 


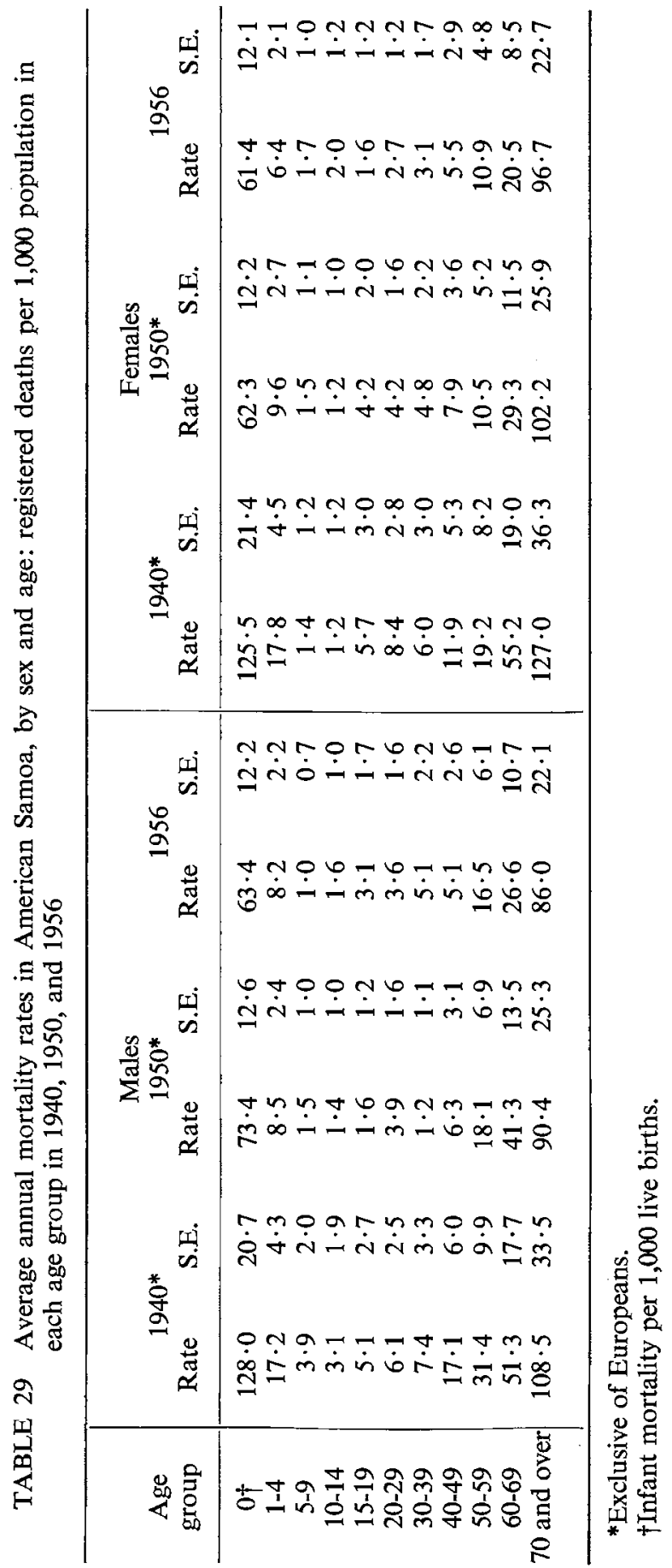


per 1,000 persons in the standard population per year, and the rates for 1950 and 1956 to 9.9 and 8.5 deaths per 1,000 population respectively.

Both the age-specific rates and the standardized rates for 1950 and 1956 are somewhat higher than those for Western Samoa in 1951 and 1956, and comparisons between the standardized mortality rates suggest that, if all deaths are registered in American Samoa and the level of mortality in both populations is the same, registration in Western Samoa might cover 80 per cent of the deaths. On the same basis, the differences between the rates for males and females in the two populations indicate a sex differential in the completeness of registration which is of the order of 85 per cent for males and 75 per cent for females. The fertility data collected in 1956 provided some confirmation of the similarity of mortality levels in the two populations, and these indicated that the chances of survival for the offspring of American Samoan women were, if anything, slightly better than for the children born to Western Samoans.

\section{Analyses of Fertility}

As mentioned previously, the birth registers in American Samoa record both the age of the mother and the number of children she has borne before the birth being registered. Because no information regarding fertility was collected in censuses before 1956, the data on birth rank could not be used, but the births registered during the years 1939-41 and 1949-51 were summarized according to the age of the mother and tabulations of births by maternal age and rank of birth. for the years 1955-7 were kindly provided by the Clerk of the High Court. The average annual age-specific fertility rates computed with reference to the relevant census populations are given in Table 30 and the more detailed rates for 1955-7, specific for age of mother and the number of previous children as stated in the 1956 census, are shown in Table 31.

The fertility rates for 1940 are in general lower than the parallel rates for 1950 , but the differences between them diminish if allowance is made for the probable extent of registration coverage at the two periods. In addition, the rates for 1940 are averages based on the births registered during two years and ten months only and if there is any seasonal variation in births in American Samoa, the omission of the births registered during June and July 1941 may have depressed the average numbers per month throughout the period. If the 1940 rates relate to only 88 per cent of the births that occurred and the 1950 rates to 93 per cent as was indicated earlier, there is less difference between them than between the 1950 and 1956 rates similarly adjusted for under- 
registration. The greatest change that has occurred concerns women aged 15-19 and 20-24 years and, though the declines in fertility at these ages are not statistically significant, together they have probably caused a reduction of about 10 per cent in the total fertility (which is five times the sum of the age-specific rates) between 1950 and 1956.

TABLE 30 Average annual fertility rates per 1,000 women at each age in American Samoa in 1940, 1950, and 1956

\begin{tabular}{|c|c|c|c|c|c|c|}
\hline \multirow{2}{*}{$\begin{array}{l}\text { Age } \\
\text { group }\end{array}$} & \multicolumn{2}{|c|}{1940} & \multicolumn{2}{|c|}{1950} & \multicolumn{2}{|c|}{1956} \\
\hline & Rate & S.E. & Rate & S.E. & Rate & S.E. \\
\hline $15-19$ & 57 & 9 & 64 & 8 & 36 & 6 \\
\hline $20-24$ & 252 & 18 & 309 & 16 & 275 & 15 \\
\hline $25-29$ & 304 & 20 & 336 & 17 & 356 & 17 \\
\hline $30-34$ & 242 & 22 & 271 & 19 & 222 & 17 \\
\hline $35-39$ & 178 & 21 & 196 & 18 & 184 & 18 \\
\hline $40-44$ & 56 & 15 & 54 & 13 & 57 & 12 \\
\hline $45-49$ & 28 & 12 & 17 & 8 & 22 & 8 \\
\hline Total & \multirow{2}{*}{\multicolumn{2}{|c|}{5,585}} & \multirow{2}{*}{\multicolumn{2}{|c|}{6,235}} & \multirow{2}{*}{\multicolumn{2}{|c|}{5,760}} \\
\hline fertility & & & & & & \\
\hline
\end{tabular}

The more detailed analysis given in Table 31 suggests that, irrespective of age, women without children were extremely reluctant to change that state. The frequency of births amongst those who had already borne children was not so very different from the rates for Indian women in Fiji when the magnitude of the standard errors is taken into account, but the frequencies of first births in 1955-7 in American Samoa were very much lower than for either Fijians or Indians in Fiji. This recent change in the pattern of fertility in American Samoa is confirmed by the data collected in the 1956 census, much of which is summarized in Tables 32 and 33. The basic data relating to total numbers of children born to women in each age group (Table 32) and the ages at which the women of each cohort had their first child (Table 33) were not included in the official tabulations but were compiled subsequently.

Except at ages less than 25 years, the average numbers of children borne by women in each age group accord with the numbers expected on the basis of the adjusted 1950 age-specific fertility rates and deviate little from the corresponding means for Western Samoa. Completed families in American Samoa are slightly smaller than in Western Samoa, but relatively more American Samoan women claimed to have borne no 


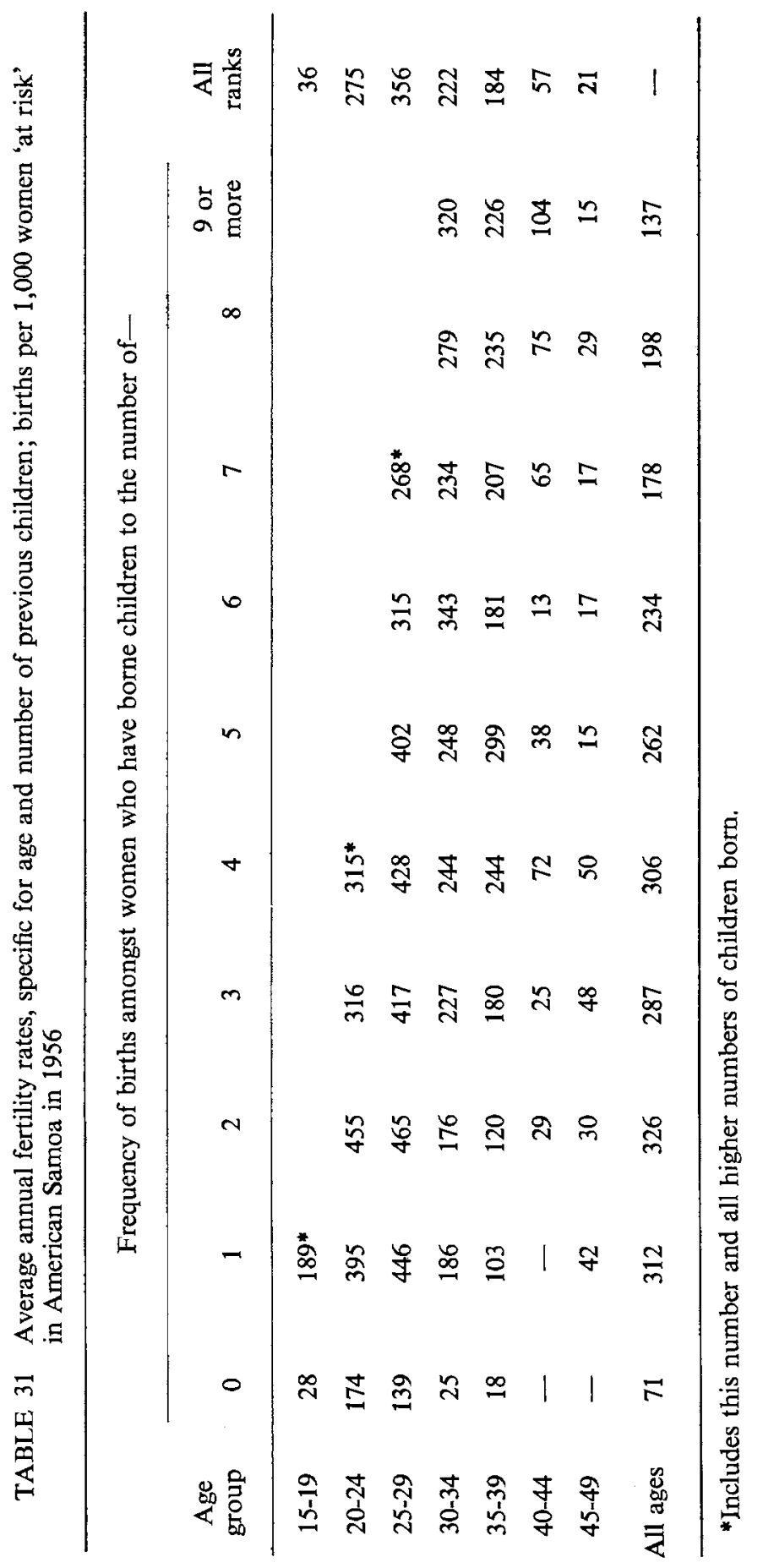


TABLE 32 Average numbers of children born and surviving per woman at each age, the frequencies of women without children, and the average number of children borne by women at each age known to have children: American Samoa, 1956

\begin{tabular}{|c|c|c|c|c|}
\hline \multirow{2}{*}{ Age group } & \multicolumn{2}{|c|}{$\begin{array}{l}\text { Average numbers of children } \\
\text { per woman }\end{array}$} & \multirow{2}{*}{$\begin{array}{c}\text { Number of } \\
\text { childless } \\
\text { women per } \\
1,000\end{array}$} & \multirow{2}{*}{$\begin{array}{c}\text { Average } \\
\text { number of } \\
\text { children per } \\
\text { fertile woman }\end{array}$} \\
\hline & Born & Surviving & & \\
\hline $15-19$ & 0.07 & 0.06 & 950 & $1 \cdot 33$ \\
\hline $20-24$ & $1 \cdot 03$ & 0.96 & 520 & $2 \cdot 14$ \\
\hline $25-29$ & $2 \cdot 94$ & $2 \cdot 63$ & 200 & $3 \cdot 67$ \\
\hline $30-34$ & $4 \cdot 44$ & $3 \cdot 83$ & 135 & $5 \cdot 14$ \\
\hline $35-39$ & $5 \cdot 82$ & $4 \cdot 83$ & 118 & $6 \cdot 60$ \\
\hline $40-44$ & $6 \cdot 23$ & $4 \cdot 90$ & 116 & $7 \cdot 05$ \\
\hline $45-49$ & $7 \cdot 08$ & $5 \cdot 49$ & 93 & $7 \cdot 81$ \\
\hline $45-59$ & $6 \cdot 68$ & $5 \cdot 01$ & 116 & $7 \cdot 56$ \\
\hline 60 and over & $5 \cdot 87$ & $3 \cdot 55$ & 154 & $6 \cdot 94$ \\
\hline
\end{tabular}

TABLE 33 Attainment of motherhood in American Samoa: numbers per 1,000 in each cohort with first births before specified ages, and rates of attainment at specified ages per 1,000 females at risk in each cohort

\begin{tabular}{ccccccc}
\hline $\begin{array}{c}\text { Age in } \\
1956\end{array}$ & \multicolumn{2}{c}{$\begin{array}{c}\text { Numbers per 1,000 in each } \\
\text { cohort with first birth } \\
\text { before age }\end{array}$} & \multicolumn{4}{c}{$\begin{array}{c}\text { Numbers per 1,000 at risk } \\
\text { whose age at first birth was }\end{array}$} \\
& $\begin{array}{c}20 \\
\text { years }\end{array}$ & $\begin{array}{c}25 \\
\text { years }\end{array}$ & $\begin{array}{c}\text { years } \\
\text { years }\end{array}$ & $\begin{array}{c}\text { Before } \\
20 \text { years }\end{array}$ & $\begin{array}{c}20-24 \\
\text { years }\end{array}$ & $\begin{array}{c}25-29 \\
\text { years }\end{array}$ \\
\hline $20-24$ & 248 & & & 248 & & \\
$25-29$ & 319 & 710 & & 319 & 574 & \\
$30-34$ & 341 & 732 & 850 & 341 & 593 & 442 \\
$35-39$ & 310 & 722 & 840 & 310 & 598 & 423 \\
$40-44$ & 321 & 696 & 837 & 321 & 553 & 462 \\
$45-49$ & 281 & 722 & 875 & 281 & 613 & 549 \\
& & & & & & \\
$45-59$ & 245 & 680 & 835 & 245 & 576 & 483 \\
60 and over & 166 & 600 & 749 & 166 & 520 & 374 \\
\hline
\end{tabular}


children and if they are excluded, the differences between the two populations vanish.

The deviant group in American Samoa are the women aged between 15 and 24 years, significantly more of whom had had no children while the reproductive performance of those who had borne children was identical with their counterparts in Western Samoa. Only 5 per cent of women aged 15-19 years had had a child and of the 48 per cent aged 20-24 years who had done so, only half had their first birth before they were 20. This frequency is significantly less than the average for all cohorts of reproductive age in 1956, though ostensibly no different from the performance of cohorts of completed fertility.

The behaviour of the various cohorts in their attainment of motherhood is presented in two ways in Table 33: the cumulative frequencies are given for comparison with the data published in the census reports for Fiji and Western Samoa, and the rates of attainment amongst the populations at risk at each age are consistent with the form of presentation used here. As elsewhere, the ages at which the older cohorts attained motherhood are probably less reliable than those for whom this was a recent event, and the apparently higher age at first birth among cohorts aged 45 years and over is probably largely fictitious.

Ignoring these and the aberrant 20-24 year-old cohort, less than onethird of American Samoan women had a child before the age of 20 years, about 60 per cent of the remainder had their first child within the next fivo years, and less than half of those who reached the age of 25 without children ever attained motherhood. Each of these rates is depressed by the relatively large numbers of childless women at each age and, somewhat curiously, these occur almost twice as often in American Samoa as in Western Samoa even though relatively more of the women aged 25 years and over in American Samoa were or had been married in 1956. It is possible that some of the women for whom the enumerators made no entry on the schedule may have been tabulated as having had no children and, if this happened, the differences noted here between the two Samoan populations are almost certainly spurious.

The recent change in fertility at young ages cannot be doubted and it is probably related to the wave of emigration that started before 1956 and has gathered momentum since. If the ages stated in the censuses mean anything, there was a loss between 1950 and 1956 of approximately 1,200 males and 800 females within the age range 20 to 45 years and the cohort which suffered the greatest depletion was the 1930-4 cohort of males. These young men were of the ages when they were most likely to marry, and their loss from the population may have reduced the chances of marriage for some of the young girls. Unfortunately, the 1950 
census report contains only summary totals of the numbers of males and females in each marital state unclassified by age, but in 1956 there were significantly more single women aged $15-19$ and 20-24 years in American Samoa than in Western Samoa and negligible differences between the proportions of males at these ages who were not married. If this difference between the two populations in the age of women at marriage is of recent origin, it probably reflects both the lack of eligible males in American Samoa and the deliberate avoidance of marriage by young women who hope to emigrate. Irrespective of their marital status, this last is probably the cogent motivation for the avoidance of pregnancies by American Samoan women aged less than 25 years.

\section{Summary}

Most of the figures quoted for Samoa's population during the nineteenth century derive from mission counts, and only three of these covered most if not all islands in the group. The first was made in 1845 , ten years after the London Missionary Society established its mission, and it may have been less reliable than the other two. However, the 1853 count was made towards the end of one of the periodic wars, when the Samoans on both Upolu and Savai'i were still living in fortified camps; and as the census allegedly taken in 1874 included a number for Manu'a that had been reported eleven years previously, probably none of the totals was particularly accurate. Given the extent of mortality experienced in epidemics and wars at various times and the propensity of Samoan women to reproduce, it might reasonably be doubted that the numbers of Samoans changed much from year to year before 1875, and probably increased in most years from then onwards.

This growth may not have been uniform in all of the islands; the population in the small islands of the Manu'a group, for example, was increasing quite rapidly before this date, and its virtual exclusion from many of the population estimates after 1863 leads to misleading totals for the group as a whole. The widespread belief in the decrease of this population following European discovery and settlement was probably inspired by the Tamentable' and 'woeful' decreases which had been reported by an earlier contingent of missionaries in Tahiti and the Cook Islands. Their preoccupation with deaths rather than births is understandable when disasters such as hurricanes and epidemics and famines could be turned to advantage in hastening conversions.

Since 1900 the population has more than trebled, but until 1956 the Samoans west of $171^{\circ}$ west of Greenwich were enumerated at different times from those living in islands east of this longitude, even though 
there was much movement between them. Since New Zealand assumed Great Britain's mandate over the western islands in 1920, censuses of Western Samoa have been taken in the years when New Zealand's population was enumerated, and American Samoa has been censussed as part of the U.S. decennial censuses. There was perhaps more reason for non-co-operation during the German régime in Western Samoa, when American Samoa offered a refuge to dissidents and rebels from the western islands, but would not greater uniformity, in respect of censuses and birth and death registrations, now benefit both governments?

American Samoa seems to have avoided major outbreaks of disease, but under the German régime in Western Samoa there were sporadic though not very fatal epidemics of dysentery, whooping cough, and measles, and in 1918 the people suffered in the second wave of the worldwide influenza epidemic. The repercussions of the age-selective mortality in this outbreak have been apparent in the inter-censal growth rates since, even though the population has continued to increase. There has also been some exchange of population between the two territories, and the vagaries of this movement are more evident in the much smaller American Samoan population than in Western Samoa's. In the postwar years there has also been some migration overseas, especially from American Samoa where, in consequence, relatively few women aged 15 to 24 years in 1956 had borne children.

The registration of births and deaths is probably more complete in American Samoa than in Western Samoa, and the crude birth and death rates of 39 and 7 per 1,000 population respectively for the combined population around 1956 are undeniably too low. The level of mortality had not changed much between 1950 and 1956 in either population, and the Samoans have an expectation of life at birth of more than 60 years, and probably nearer to 65 for females. Samoan women who survive to the end of their reproductive period have had an average of more than 7 children, and though their pattern of fertility with age differs from that of Indian women in Fiji, their ultimate achievement is not very different. As at least 90 per cent of those born will themselves survive to reproduce, the potential for population increase in Samoa is great. 


\section{Cook Islands}

The fifteen islands of the Cook Group contain a total land area of only 88 square miles and more than four-fifths of this is contributed by the seven inhabited islands of the Lower Group. Rarotonga and Mangaia are the largest of these and the remaining islands, ranked in size, are Atiu, Mauke, Aitutaki, Mitiaro, and Manuae. Except for the last, these are all high islands of volcanic origin whereas the smaller northern islands are, with one exception, coral atolls, each a ring of islets encircling a lagoon. Two of the atolls-Palmerston and Suwarrow-and the small coral island of Nassau seem not to have been inhabited except for short periods, and some of the larger northern islands-Penrhyn, Pukapuka, Manihiki, and Rakahanga-were settled from Rarotonga.

During his second voyage to the Pacific, Cook discovered Manuae (or Hervey's Island) and Palmerston, and the latter was revisited on his third voyage when he discovered Mangaia, Atiu and the small uninhabited atoll of Takutea in the Lower Group (Cook, 1821). Though ho sailed close to Rarotonga he did not see it, and Rarotonga's first European visitors were probably the mutineers of the Bounty in 1789 (H. E. Maude, 1958). The island was sighted again in 1813, and early the following year a party, under the command of Philip Goodenough, left Sydney to search for Rarotonga with its 'supposed treasures of sandalwood' (Maude and Crocombe, 1962, p. 40).

The island was discovered but there was no sandalwood, and while the ship was loading a substitute cargo trouble arose 'through the Europeans' disregard of native custom, and in particular property rights'. Four of the crew and the 'captain's consort' were killed in revenge-the latter having 'the unenviable distinction of being the only European woman in all Polynesia to be eaten'-but Goodenough finished loading his ship and, before sailing, abducted a 'substitute consort', another Rarotongan woman and a man (Maude and Crocombe, 1962, pp. 41, 44). When the ship headed for Sydney, the women were put ashore at Aitutaki and the 'substitute consort' was still there in 1823 when the missionary John Williams called at the island. Williams determined to return her and some other Rarotongans who had drifted to Aitutaki 


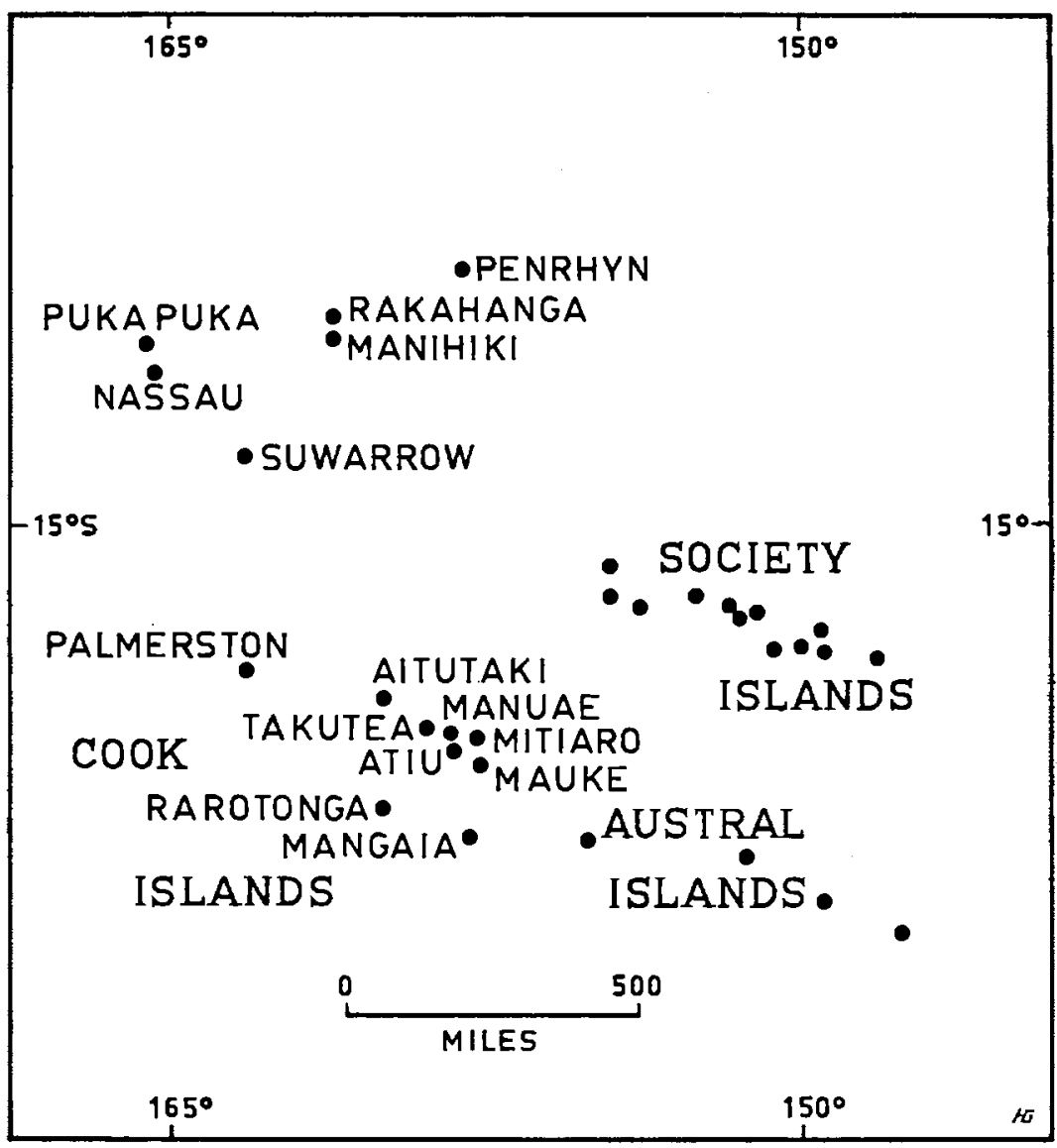

Map 4 The Cook Islands, showing their proximity to the western islands of French Polynesia

in a canoe to their island, and he succeeded in this only after the chief of Atiu had escorted him to Mauke and Mitiaro, and from Atiu set him on course for Rarotonga (J. Williams, 1838, pp. 87-90, 97).

Native mission teachers trained in the Society Islands were left on each of the newly discovered islands; two had been in Atiu for three months before Williams's visit in 1823 , and two were sent to Mangaia a few months later. The teachers were visited from time to time by representatives of the London Missionary Society from the Society Islands, and in 1827 European missionaries first settled on Rarotonga. This was the only island to have resident missionaries-as distinct from native teachers or pastors-until one was sent to subdue a heathen 
faction on Aitutaki in 1839. Another established residence on Mangaia in 1845 , and one or other of these periodically visited the native teachers stationed in the other islands. There was no substantial settlement by private traders or planters on any of the islands until the 1860s and according to Gilson (1952), it was 'vague rumours of a French invasion, together with the growth of the local trade in spirits, [which] led the chiefs and their reluctant mission advisers to sue for outside support' in 1888. A British Protectorate was then established, but this arrangement proved to be unworkable and the islands were annexed to New Zealand on 13 May 1901.

\section{Nineteenth Century Population Estimates}

Despite the smallness of the islands and the relatively long and often close surveillance by the missionaries, details of the population during the nineteenth century are meagre. The records for Rarotonga's population are more complete than those for many of the islands, and especially for the more remote northern atolls, where the data are limited to numbers of inhabitants in various years scattered throughout the century with no certainty that they were founded on contemporaneous counts. There is no doubt that some of the missionaries resident in the Group did count and record the island populations, and if the census for Mangaia of December 1880 (see p. 177) is any guide to their usual praotice, the populations were perhaps recorded initially in more detail than has survived in their letters and reports. Because of the differences in quality as well as quantity, the extant data are presented for each island in turn, with a summary reconstruction wherever possible of the course of population change and the causes contributing to it.

John Williams estimated the populations of the various islands of the Lower Group on his several visits to them between 1823 and 1833, and he reckoned the total in the seven islands to be 'from 14,000 to 16,000 persons', 'about 6,000 or $7,000^{\prime}$ of whom were on Rarotonga. Shortly before his first visit to this island 'a very disastrous war had taken place' and the two smaller political groups of Avarua and Arorangi had been defeated by the third group of Takitumu. One of the defeated chiefs told Williams that "four score and ten were slain", on the side of the conquerors, and "five score" on that of the conquered" ( $\mathrm{J}$. Williams, 1838 , pp. 19, 20,153,213), but these were perhaps the casualties in the final battle only. In his old age Maretu, one of the first Rarotongans converted to Christianity, wrote a history of the Cook Islands in which he asserted that 730 people had been killed in the war that started soon after Goodenough's visit and ended only about six months before Williams's visit in 1823 (Maretu, 1871). A duration of seven years- 
seven winters, seven summers-is confirmed by Land Court and other indigenous records (Crocombe, 1961) and Maretu, then a young man in his twenties, would have known personally many of those killed.

The Tahitian mission teacher who remained on the island when Williams and his colleague left in 1823 was joined by a second teacher five months later. When Williams returned to Rarotonga in 1827, escorting the missionary couple who were to live there, between two and three thousand' Rarotongans attended the church services ( $\mathrm{J}$. Williams, 1838, p. 115) and within four or five years, the remainder were persuaded to accept the new religion. The people gathered into four settlements, but their traditional tripartite grouping was retained and this distinction was observed by the missionaries in many of their records of population.

The early years of the Rarotongan mission were eventful, and there was little respite between successive disasters. The earliest letters to the Directors of the Society in London commented on the widespread prevalence of disease, and towards the end of 1829 a season of heavy rains caused a famine. This was followed by an epidemic of a disease which one of the resident missionaries described as 'an inflammatory fever akin to typhus' (Pitman, 1830a): to Maretu it was simply dysentery, and a missionary who was not then in the Group later asserted that the outbreak was one of dysentery 'together with fever and ague' (W. Gill, 1856, p. 36).

Whatever the disease was, it caused many deaths. By chance, Williams visited the island while the epidemic was raging; at least 600 people were already dead and the infection had just reached the more populous district of Takitumu (J. Williams, 1838, p. 280). Pitman (1830b) reported a total of 800 deaths before August 1830 and Maretu claimed that one thousand people were buried at Rangititi and six hundred were buried at Araungaunga. . . . Sometimes there would be ten burials in one day and sometimes there would be twenty. After three months the people ceased dying'. As Maretu assisted at the funeral services, his figures are probably more reliable than W. Gill's hearsay evidence that 'so great were its ravages, at one time, that the known deaths numbered one hundred a day' (W. Gill, 1856, p. 36).

A severe hurricane struck the island in December 1831, destroying the food crops so that 'many died of starvation, all were much injured in constitution, and weakness and disease were induced' (W. Gill, 1856, p. 46). The famine was prolonged by an invasion of caterpillars and locusts which attacked the newly-planted taro and coconuts; and in January 1833 the island suffered again in a violent storm, which ruined 'a good share of the food' although the damage was less extensive than 
it had been in the 1831 hurricane (Pitman, 1832, 1833). Nevertheless, in 1834 there were about 1,300 children attending schools in the Takitumu district, and Avarua and Arorangi had school attendances of 750 and 500 children respeotively (Buzacott, 1834).

In June 1836 the missionary in Takitumu district submitted returns of the births and deaths which had occurred 'since 1834', and these showed a total of 248 births and 198 deaths, with roughly twice as many deaths among 'adults' as amongst 'children' (Pitman, 1836). In March 1837 there was an epidemic of influenza in this district (Pitman, 1837); and the missionary at Avarua reported that 'a virulent scrofulous disease which has affected the islanders of late' was causing many deaths (Buzacott, 1838a). This 'nondescript' disease had been introduced some time towards the mid-1830s by a native teacher who had presumably come from the Society Islands to Rarotonga. Subsequently Buzacott wrote

We had no idea of the disease being contagious, but it spread on every side like a plague, until it had compassed the whole island. First the inmates of the chief's house, where the teacher lived, were taken ill-all were affected, and several died. The mortality went on increasing, until deaths amounted to 500 annually, and the births scarcely 100. This state of things continued many years (Buzacott: quoted by Sunderland and Buzacott, 1866, p. 104).

Certainly in 1838 there were 264 deaths recorded in Avarua and Arorangi and only 58 births (Buzacott, 1838b), and almost identical numbers of births and deaths were reported for Takitumu for the year ended July 1839 (Pitman, 1839).

In 1840 the missionaries at Avarua and Arorangi compiled 'censuses' of their respective populations, and almost 60 per cent of the total of 2,295 recorded were males. In Avarua there were 702 males in a total of 1,183 (Buzacott, 1840), and in Arorangi 642 males in a total of 1,112 (W. Gill, 1841). No details but sex were given for Avarua, but in Arorangi almost half were described as 'children' and the preponderance of males was as marked amongst them as among the 'adults'. As only 48 of the 247 adult females were 'unmarried', many of the 122 adult males similarly classified would have to look elsewhere for wives, especially as there were already more males than females 'married'.

The population of the third district-Takitumu-was not counted until 1854, but the births and deaths that occurred there each year were recorded continuously from July 1838 (Pitman, 1848, 1849b, 1851; Buzacott, 1852, 1854a), and the combination of these data with the 1854 'census', assuming no migration over the interval, leads to an 
estimated population of 2,050 in Takitumu in 1840. If this is added to the numbers recorded for Avarua and Arorangi, the population for the whole island in 1840 was in the vicinity of 4,350 . With the numbers of births and deaths given above, and guesses for some intervening years, this figure is not incompatible with a total population of between six and seven thousand before 1830 .

In March 1841 there was another hurricane, which was followed by storms in June and December, but there was no further epidemic until July 1843 when dysentery was introduced from a whaling ship and caused about 130 deaths (Pitman, 1843a). The total number of deaths in Rarotonga during 1843 was 443 , and there were only 100 births. W. Gill (1856, p. 72) gives the figure of 3,300 for the population at the close of 1843 , and this is reasonably consistent with an estimate compiled from the 1854 population figures and the annual returns of births and deaths over the interval. A hurricane in March 1846 caused widespread damage and there was a shortage of food for the rest of that year. An outbreak of influenza during the first three months of 1847 caused an unspecified number of deaths (W. Gill, 1847b), and there was a recurrence of influenza and an outbreak of whooping cough in 1848 (Sunderland and Buzacott, 1866, p. 108). In 1850, the population experienced an epidemic of mumps and in January 1851 'the whole community was visited with severe attacks of fever, ague and influenza; many thus afflicted died' (W. Gill, 1856, p. 107).

Towards the end of 1847 the missionaries mentioned in their letters that some of the young men were leaving the islands, either as crew on ships which called frequently at the various islands, or to work on plantations in Tahiti (Pitman, 1847; W. Gill, 1847c). By the middle of 1849 it was thought that about 200 young men had left Rarotonga, few of whom would return (Pitman, 1849a). Efforts were made to restrain them, but during 1853 (which was apparently the first year for which records were kept of the numbers leaving), 85 youths left the island, and only 29 returned (Buzacott, 1854a). This emigration of young males may account for the small discrepancy between W. Gill's estimate of a population of 3,300 in 1843, and the estimate of just over 3,200 derived from the 1854 'census' and recorded births and deaths. As the restraints appear to have been less effective in Takitumu than in either Avarua or Arorangi (Pitman, 1847), the population of the island at the end of 1840 may have been nearer to 4,500 than to the 4,350 persons estimated above.

The 'census' of 1854 (Buzacott, 1854b) showed the population of each district in three categories-adults, children aged 3-20 years, and infants-with sex distinguished only for adults and children. The numbers were as follows: 


\begin{tabular}{|c|c|c|c|c|c|c|}
\hline \multirow[t]{2}{*}{ District } & \multicolumn{2}{|c|}{ Adults } & \multicolumn{2}{|c|}{$\begin{array}{l}\text { Children } \\
\text { 3-20 years }\end{array}$} & \multirow[t]{2}{*}{ Infants } & \multirow[t]{2}{*}{ Total } \\
\hline & $\mathrm{M}$ & $\mathrm{F}$ & $\mathrm{M}$ & $\mathrm{F}$ & & \\
\hline Avarua & 289 & 177 & 109 & 96 & 64 & 735 \\
\hline Arorangi & 187 & 150 & 163 & 95 & 31 & 626 \\
\hline Takitumu & 419 & 287 & 130 & 102 & 75 & 1,013 \\
\hline Total & 895 & 614 & 402 & 293 & 170 & 2,374 \\
\hline
\end{tabular}

As they stand, the populations are not homogeneous with respect to either sex or age as far as both of these characteristics are specified; and it is not easy to decide whether there were differences in composition between the populations in the various districts, or whether the discrepancies derive entirely from varying definitions for 'adults', 'children', and 'infants' such as would occur if the censuses were not compiled by the one person.

Comparisons between the numbers of infants per adult female in each district, and the average annual numbers of recorded births per adult female indicate that there probably was some difference between the districts in the definition of 'infants'. The figures per 1,000 adult females, with the standard errors associated with the rates in parentheses, are given below; and the comparative consistency in the birth rates throughout the island during the period $1851-3$ belies the variability in the numbers of infants per adult female in the census. Apart from the widespread influenza outbreak of January 1851 (W. Gill, 1856, p. 107), there is no mention of any disease that may have caused differential mortality amongst infants born in each district, although this possibility cannot be entirely ignored.

\begin{tabular}{lcc} 
District & $\begin{array}{c}\text { Infants per 1,000 } \\
\text { adult females } \\
\text { (Census, 1854) }\end{array}$ & $\begin{array}{c}\text { Average annual births, } \\
1851-3, \text { per } 1,000 \\
\text { adult females in } 1854\end{array}$ \\
Avarua & $362(36)$ & $124(25)$ \\
Arorangi & $207(33)$ & $133(28)$ \\
Takitumu & $261(26)$ & $120(19)$ \\
\multicolumn{1}{c}{ Total } & $277(18)$ & $124(13)$
\end{tabular}

If the differentiation between 'infants' and 'children' was variable, the distinction between 'children' and 'adults' was probably even less uniform and the division at age 20 years both spurious and unrealistic if people were marrying younger than this. Ignoring this division, the sex ratio in the total population was effectively the same in 1854 as it had been in Avarua and Arorangi in 1840, and this implies either that the young men who had left the island were not excluded from this 
census, or that the female sector of the population had suffered relatively heavier mortality than the males in the intervening years.

Sex was seldom specified in the returns of births and deaths, but if these returns were complete, there was a relatively greater decrease in the population of Takitumu between 1840 and 1854 than in either Avarua or Arorangi. During the five-year period 1839-43 the excess of deaths over births averaged about 200 per year in Takitumu; in the next fiveyear period, this average dropped to 50 , and from 1849-53 it was less than 20 per year (Pitman, 1848; W. Gill, 1848, 1849, 1850, 1851; Buzacott, 1852, 1854a). Annual birth and death statistics for Avarua and Arorangi are available for the years 1844-53 (W. Gill, 1845a, 1846, 1847a, 1847d, 1848, 1849, 1850, 1851; Buzacott, 1852, 1854a) and, ignoring migrations, in 1844 the population of these two districts combined would have been about the same size as Takitumu's. But whereas Takitumu's population averaged 38 births and 88 deaths a year between 1844 and 1848, there were 47 births and 81 deaths annually in Avarua and Arorangi. Over the next five years there was little change in the average numbers of births, but the deaths decreased by about 30 a year in both populations. Throughout the decade the differences between the average numbers of births in the two halves of the population were greater than those between the numbers of deaths, and though this pattern may have been the result of different age compositions, the smaller number of births in Takitumu may have refleoted the drift of 'restless' young people from Takitumu towards Avarua which was the port of call for most of the ships visiting the island (Pitman, 1847).

After 1854, the population data given by the missionaries become very meagre. There were only two more returns of births and deaths, one for 1855 and one for 1857 (Buzacott, 1856, 1858). In 1854, measles was introduced into the Cook Islands from Tahiti, but it is not clear whether this infection reached Rarotonga or not. In their description of "the woeful decrease of population' on Rarotonga, Sunderland and Buzacott (1866, p. 109) cite an epidemic of measles in 1854; and W. Gill (1856, p. 119) implied that there had been an outbreak on Rarotonga in that year although he did not state specifically that the island was affected. The only local epidemics mentioned in the mission correspondence for 1854 were those of Aitutaki and Mangaia (Royle, 1854; W. W. Gill, 1854) and, as far as one can gather, these occurred during October, or perhaps even earlier in the year. If the infection was introduced into Rarotonga, it is unlikely that this happened before the beginning of December, because a letter dated 5 December from Rarotonga mentioned only that the outbreaks in Mangaia and Aitutaki had been less severe than the one in Tahiti (Buzacott, 1854b). This would put the date for 
any measles outbreak on Rarotonga as some time after 5 December, in which case it would probably have carried over into January 1855.

There is no record of the numbers of births and deaths in Rarotonga in 1854, and it is not clear whether the 1855 return refers to the whole island or to only part of it. Contrary to the usual practice, the figures were not given for each district and although the number of deaths was about average for the whole island at this time, the number of births reported was little more than half the average for previous years (Buzacott, 1856). Had there been uniform mortality rates at all ages except the very young in the 1830 epidemic and throughout the period 1838-43, there may well have been a decrease in the number of births occurring in a year about 1855. At this time, the survivors from the presumably depleted cohort born between 1828 and 1832 would have been of average age 25 years and, therefore, having their greatest effect in depressing the number of births, while the cohort ten years younger, born during the worst period of the 'scrofulous' disease and also very small, was just attaining reproductive age. In a population as small as Rarotonga's it is not inconceivable that the net effect of this combination, together with some purely chance variation, may have been sufficient to halve the number of births occurring in one year.

However, if the return for 1855 related to the whole population, then Rarotonga either did not experience an epidemic of measles in 1854-5 or the mortality in the outbreak was surprisingly low for what was probably their first acquaintance with the disease. If the return related to only part of the population, there may have been an epidemic of measles on Rarotonga, but again it is unlikely that mortality was very high and, in this case, also unlikely that persons of reproductive age were fatally susceptible to the infection. Birth and death records for 1856 may have provided some further clue as to the likelihood of an epidemic, but the next record available relates to 1857 (Buzacott, 1858).

The total number of births reported then was somewhat higher than in 1855 , but there were very small numbers of births for both Takitumu and Arorangi compared with those reoorded for Avarua and, moreover, the numbers were inconsistent with the numbers of 'adult' females in each district in 1854 and with the average numbers of births each year during the period 1849-53.

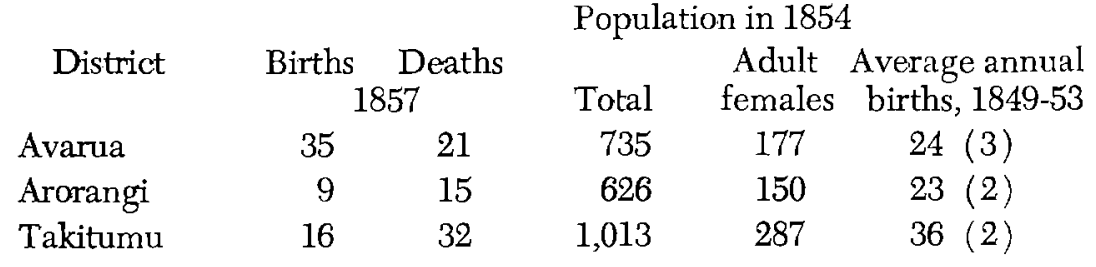


The increase in the number of births in Avarua is rather greater than one would expect from chance fluctuations, especially in view of the presumed consequences of the early epidemic mortality. The most obvious explanation for Avarua's inconsistency is that, after 1854, the port attracted more and more young people, and from Arorangi as well as from Takitumu. However, this cannot be substantiated in any way because in 1857 the last of the original band of European missionaries on Rarotonga left the island, and the state of the population thereafter was given scant space in the letters of the one missionary stationed there.

About 1860 whaling in Pacific waters was no longer considered profitable, but the exploitation of guano deposits gained favour and some of the labour for this was hired in Rarotonga (Krause, 1861, 1862). In 1863, a 'new' disease was reported in Rarotonga, but no details were given of its nature or symptoms, its prevalence or its fatality (Krause, 1863a). Equally indefinite and unsatisfactory is the population figure quoted for 1863: the number given-'about 2,400' (Krause, 1863b)-is probably the 1854 'census' total, on the assumption that there had been no change in population numbers over the interval. The years 1866 and 1867 brought severe storms (Krause, 1866, 1867) and in the middle of 1867, a new missionary arrived.

In November 1867 he claimed that there were only 1,856 people on Rarotonga (Chalmers, 1867), but neither the source of this figure, nor the geographic distribution of the population nor its composition with respeot to age and sex were given. Nor was there mention of the numbers of persons who were absent from the island, but three years later he asserted that the young men cared little for leaving their own lands except to work on guano islands, where they were well-treated and received good pay. The earlier restraints on emigration by chiefs and missions were no longer in force, and the majority of the men returned to the island when their contracts expired (Chalmers, 1870).

While few, perhaps, of the Rarotongans left their island at this time, its population was soon augmented by natives from other islands in the Group, particularly from Mangaia. In 1872 the chiefs of Mangaia removed their prohibition on people leaving the island, and whereas there had always been a few who dared to leave despite the ban, within three or four months of the lifting of the restrictions about 100 Mangaians were reported to be living on Rarotonga (Chalmers, 1872) and in the first year of freedom, 150 young men left Mangaia (Harris, 1873). A mission 'census' of January 1872 showed a population of 1,936 on Rarotonga (W. W. Gill, 1872), and in 1876 young Mangaians were still emigrating to the island (Harris, 1876). The number of Europeans on 
the island was also increasing steadily, and in 1881 there were 70 of them on Rarotonga, 'quietly pursuing their different callings' (W. W. Gill, 1881a).

At this time the number of deaths was only 'very slightly in advance' of the number of births each year (W. W. Gill, 1880), but if later reports are correct, the margin between the two must have widened subsequently. Even with the immigration from other islands to offset the population losses through natural causes, Hutchin (1891b) alleged a net decrease of 116 in population between 1882 and 1890, and Chalmers (1890) claimed a still greater decline of 400 in the thirteen years from 1878 to 1890 . As this would have been the period when the relatively small cohorts born after 1855 were at the peak of their child-bearing, there may have been a downward swing in the number of births each year and unless the number of deaths fell proportionately, the rate of decrease in the population would have been accelerated.

In 1895 Rarotonga had its first official census and the British Resident explained that this was

the first attempt to obtain accurate information by papers filled in in detail by each household. The information asked was necessarily limited, but the natives now understand the work and more can be done on the next occasion. . . . The population of 2,454 is much in excess of the estimates which had hitherto been accepted, the highest of which placed it as under two thousand (N.Z.P.P. A-3, 1896, p. 1).

This statement accompanied a tabulation of the population in each of the five administrative districts into which the island was divided, classified by age in the age groups less than 5 years, 5-10 years, 10-20 years, 20-50 years, and over 50 years. Apparently the sex of each individual was not recorded initially, for the New Zealand Government's request for the number of males and females at each age necessitated a supplementary census six or seven weeks later.

Despite this double enumeration, the accuracy of this particular count was doubted when the next census, taken on 7 March 1901, revealed nearly 300 persons fewer than the total at 30 June 1895. A new resident had been appointed in 1898, and he considered that the difference in population totals did 'not denote a decreasing population so much as an over-estimation of the people at the first census' (N.Z.P.P. A-3, 1902, p. 16). A census taken in the following year showed a still further reduction in the total population of Rarotonga, from 2,209 persons in 1901 down to 2,060 in 1902 (N.Z.P.P. A-3, 1907, p. 2).

The details of this latter enumeration have not been found, so it is not known what explanation may have been offered for this 
discrepancy; and although correspondence relating to the 1906 census indicates that the 1902 enumeration provided the numbers of males and females in each of the age groups under 5 years, 5-9 years, 10-14 years, and 15 years and over, the figures published for comparison with those of the 1906 enumeration showed only the total population, without distinction of sex, for each island in 1902. Like his predecessor, the Resident Commissioner in 1907 disparaged all censuses but his own, asserting that 'as this is the first occasion on which the figures have been compiled with any measure of accuracy, no true comparison can be made with the returns of previous years' (N.Z.P.P. A-3, 1907, p. 1).

All prejudices aside, there probably were inaccuracies in these early censuses, but it may well be that some of the 'over-estimation' in 1895 was due to the recording of people who belonged' to a village though absent, working elsewhere in the Pacific, at the time of the census. By 1900, the number of absentees from the Cook Islands had reached such magnitude that a regulation was passed to limit the number of natives who could be enlisted for labour on islands outside their own Group (N.Z.P.P. A-3, 1901, p. 11). Despite this regulation, it was estimated that three years later there were about 400 Cook Islanders in Tahiti alone (N.Z.P.P. A-3, 1904, p. 74). There may, therefore, have been an increased exodus in the late 1890s when Rarotonga was experiencing a trade depression, caused partly by increased competition for markets in New Zealand and partly by the local plant diseases which were attacking the exportable crops. Changes from time to time in the numbers of absentees would account for at least some of the changes in total population numbers recorded in successive censuses.

Although age was not specified for a fairly high proportion of the population in two of the districts in 1895, the districts for which the details were reasonably complete contained almost three-quarters of the total population. Here there was an excess of males at all ages, but there was no marked difference between the male and female sectors in the proportion of population in each age group. Each had roughly 10 per cent of its total under 5 years of age, 15 per cent aged 5-10 years, 20 per cent aged $10-20$ years, 46 per cent aged $20-50$ years, and 9 per cent aged more than 50 years.

If these ages mean anything at all, there was a marked scarcity of children aged less than 5 years, both in relation to the number of children aged 5-10 years and to the number of women of reproductive age. Less than half of the women aged 20-50 years had a child under 5 years of age, whereas more than two-thirds had children aged botween 5 and 10 years. There probably was some confusion between the two age groups, but if all or nearly all the young children were counted, 
there had been either very heavy mortality amongst the children born in the years $1890-5$, or considerably fewer births during this period than in the preceding five years, or some combination of both. The sex ratio for children under 5 years was not grossly distorted, so presumably whatever underlay their scarcity concerned males and females to the same extent.

This distribution by age and sex included Europeans, Chinese and part-Europeans as well as Cook Island Maoris and natives of other Pacific islands. About two-thirds of the total population were born in Rarotonga, and a further 20 per cent were natives of other islands in the Lower Group. These proportions had not altered significantly by 1901, when the Rarotongan-born population numbered about 1,500 persons, with a smaller preponderance of males than in earlier years, and about 30 per cent of persons aged between 16 and 39 years. As all children born on Rarotonga would be shown as Rarotongan-born irrespective of the island of origin of their parents, these figures do not indicate very much about the survivors of the original population of Rarotonga, and were the data available, it is clear that the population of the Lower Group should be considered as a whole from about 1870 onwards, or perhaps even earlier.

Whatever the inaccuracies of the various counts, there can be no doubt that Rarotonga experienced a severe decline in population numbers during the nineteenth century, and that introduced diseases contributed very substantially to this process. The first recorded epidemic occurred in 1830 and accepting John Williams's and the early missionaries' estimates of a population numbering between six and seven thousand in the late $1820 \mathrm{~s}$, the mortality rate in this outbreak was perhaps between 20 and 25 per cent. Within a few years the island was ravaged by a 'virulent scrofulous disease' which attacked 'limbs, eyes, glands, etc.' (Buzacott, 1838a and b), and Rarotonga's population decreased from about 4,500 in 1840 to fewer than 3,300 at the end of 1843 . During the next decade mortality declined markedly, despite several outbreaks of influenza and other diseases, but the death rate was still higher than the birth rate and by 1854 the population had fallen to fewer than 2,400 . Its course during the next fifty years is scantily documented, but the decrease seems to have continued, possibly faster at some periods than at others, to a total of about 1,500 Rarotongan-born in 1900 .

The susceptibility of the population to these introduced diseases may have been accentuated, particularly in the early years of contact, by the frequent food shortages caused by the storms and hurricanes that swept over the island. Heavy rains and famine preceded the 1830 epidemic and the 'scrofulous' disease was introduced, probably from Tahiti, at a time when the people had suffered, or were suffering, a 
prolonged period of famine. Both caused exceptionally high mortality, although Maretu's retrospective tally of burials may be as exaggerated as Buzacott's recollection (quoted by Sunderland and Buzacott, 1866, p. 104) that the 'nondescript disease, resembling scrofula' caused 'upwards of five thousand' deaths in 'a little over sixteen years' while 'not more than five hundred births' had occurred. The births and deaths recorded at the time suggest that, at its peak, this disease caused more than 500 deaths a year, but that its virulence waned after about five years and the excess of deaths over births fell from about 400 a year to less than 80 by 1850 .

The margin between births and deaths decreased still further in later years, but it is impossible to decide whether the excess of deaths was a more significant factor in the decrease of population for most of the century than were losses through emigration. There seems to have been no severe outbreak of disease entailing exceptionally high mortality on Rarotonga after 1850, but there may well have been periods when there were comparatively few births, partly as a consequence of sucoessive distortions of the age structure, though there may also have been low individual fertility in which the prolonged absence of young men on the guano islands and elsewhere may have been relevant. There are no data from which to estimate any index of individual fertility, and although the scarcity of children aged less than 5 years in 1895 might imply low fertility, high infant mortality or innocently inefficient enumeration could produce a similar effect.

The role of migration in Rarotonga's population history is decidedly unclear. As early as 1845 young men were leaving the island, but as there was a surplus of males in the population then, the emigration of single adults would not have affected its reproductive capacity. Later in the century, Rarotonga attracted immigrants from other islands in the Lower Group, and although these constituted one-fifth of the population recorded in 1895, there would have been others for whom migration to Rarotonga was but an intermediate step in their migration away from the Group. It is impossible to guess whether all or any of these immigrants would be included in the mission records of populations or deaths, or whether any who returned from abroad settled on Rarotonga or returned to their own lands. Probably the largest single source of immigrants to Rarotonga at any date was the population of nearby Mangaia.

Mangaia is the second largest island in the Cook Group, and when two native teachers from the London Missionary Society station in Tahiti were sent there in 1823 , its population was thought to number between two and three thousand. There had already been one outbreak 
of an unidentified disease, which was introduced by the mission ship on its first visit a few months prior to the teachers' arrival, and had 'proved exceedingly fatal; the infant and the aged, the chieftain and the peasant, falling alike beneath its deadly influence' (J. Williams, 1838, pp. 19,82). During the next twenty years, Mangaia was visited frequently by representatives of the mission, but there is no record of further epidemics until 1843, when the outbreaks of dysentery on Rarotonga and Aitutaki were followed by one on Mangaia (Pitman, 1843b). Despite this infection in 1843 and indications that the peculiar disease which was then prevalent in Rarotonga had been introduced into Mangaia, in 1844 it was claimed that Mangaia's population of 'roughly three thousand' was increasing (Pitman, 1841, 1844).

The high incidence of tuberculosis and 'glandular disorders' amongst the population was noted by Mangaia's first resident missionary when he arrived in 1845, and his census of the island's population disclosed a total of 3,567 persons (G. Gill, 1846). Rather more than 60 per cent of them were described as 'children', and these were divided into two groups-those whose parents were living, and those whose parents were dead. About 20 per cent of all 'children' were orphans but, orphaned or not, there was a marked preponderance of males amongst them which was not apparent amongst the 'adults'. The numbers in each category were as follows:

$\begin{array}{lccc} & & \text { Males per } \\ & \text { Males } & \text { Females } & \begin{array}{c}1,000 \text { persons } \\ \text { Adults }\end{array} \\ \begin{array}{l}\text { Children whose parents: } \\ \text { were living }\end{array} & 1,095 & 676 & 492(14) \\ \text { were dead } & & 697 & 610(12) \\ \quad \text { Total } & 291 & 156 & 651(23) \\ \quad 2,138 & 1,429 & 599(9)\end{array}$

The census is dated 1 January 1846, and although Gill included some figures for births and deaths, he did not specify the period to which these referred, nor were the sexes differentiated. There was, however, an excess of 58 births over the deaths recorded, and if (as appears likely from subsequent returns) the data related to a year, the number of births per adult female on Mangaia was roughly twice the rate on Rarotonga at this period.

Mangaia was in the path of the hurricane of March 1846 but once again there was a sizeable excess of births recorded, and the population at the end of 1846 was 3,604 . Towards the end of 1847 , there was an epidemic of 'scarlatina' on the island, to which Gill attributed many deaths although the actual number recorded for 1847 was not very 
different from the numbers in earlier years. Mangaia's growing trade contacts about this time led to the emigration of young men from the island, either as crew on the boats calling there, or as servants to the European residents in Tahiti. Attempts had been made to take some of the women away as servants, but this had been forbidden by the chiefs. Gill claimed that many of the young men returned after six or eight months, and his estimate of the population at the end of 1847 ignored such absentees. The high birth rate, and the favourable excess of births over deaths, continued through 1847 to give a total population, including absentees, of 3,668 (G. Gill, 1848).

There were no further returns of population for some years, although it must be presumed that the emigration continued unabated, for in 1850 Gill reported that few of the natives who joined the crews of whaling ships survived, and that while Tahiti had once attracted 'many' young people, California had recently become their goal. A year later, some of these had returned, bringing new diseases back with them so that disease on the island was becoming worse each year (G. Gill, 1851). In 1854, measles was introduced by a Tahitian schooner, and although W. W. Gill claimed that the epidemic caused many deaths (W. W. Gill, 1854), G. Gill reported 113 births and only 44 deaths in this year. His figure for the total population in December 1854 was 2,926 (G. Gill, 1854). Five years later this total had fallen to 2,306 persons, and in 1867 there were only 2,237 people on the island (W. W. Gill, 1867). A few Mangaians had been taken away by the Peruvian slavers in 1863 (W. W. Gill, 1863b), but this steady loss of population was attributed to the voluntary emigration that occurred despite the prohibitions of the chiefs on people leaving the island.

At the beginning of 1872 Mangaia's population was stated to be 2,266 (W. W. Gill, 1872), but later that year the chiefs withdrew their ban on emigration, and within three months 100 had crossed to Rarotonga (Chalmers, 1872) and within a year 150 young men, 'the strength of the land', had left and only 10 returned (Harris, 1873). The emigration of young men to Rarotonga and Tahiti continued steadily for some years, and it was alleged that the number of deaths increased (Harris, 1876) although no details were given of the numbers occurring each year, either then or later.

A mission 'census' of December 1880 gave Mangaia's population as 2,124 , but in a footnote the missionary stated that the total number on Mangaia at this date (Jan. 7, 1881) does not perhaps exceed two thousand $(2,000)$ since many young men who are away from Mangaia have been added to this list' (Harris, 1881a). This 2,124 consisted of 384 married couples, 58 widowers and 150 widows, and a remainder of 
622 males and 526 females. Not much can be inferred about the structure of Mangaia's population from these data, but assuming that the last group consisted of persons below marriageable ages, then the median age of the population was below the age at marriage and, unless marriage occurred at exceptionally late ages for both males and females, the age composition of the population was relatively favourable to increase.

When reporting this census to the direotors of the London Missionary Society, Harris claimed that the slight decrease in population which had occurred in the past ten years was only partly due to the abrogation of the prohibition on emigration (Harris, 1881b), and in 1892 he was concerned (although the chiefs apparently were not) that the population had continued to decrease until it was then only 1,700 which was 600 less than it had been 22 years previously (Harris, 1892). A mission periodical of February 1900 quoted Mangaia's population in 1895 as 1,821 persons, and commented that only part of its decrease to 1,541 in 1900 was attributable to emigration (Te Karere, 1900).

The first official enumeration of Mangaia coincided with the second census of Rarotonga in March 1901. This showed a total population of 1,577 on Mangaia, of whom 762 were males and 815 females. In addition, there were 206 Mangaians counted on Rarotonga, which number presumably excludes the Rarotongan-born children of Mangaian parents. Of the Mangaians enumerated on Rarotonga, 101 were males and 105 females; 29 were aged less than 16 years, 119 were aged $16-39$ years, and the remaining 58 were aged 40 years or more (N.Z.P.P. A-3, 1902, p. 16). Apparently no attempt was made to obtain the ages of the people living on Mangaia at this census, and there must have been some who distrusted even the number reported because all official population figures for the Cook Islands in 1902 cite Mangaia's former total of 1,541 persons (N.Z.P.P. A-3, 1907, p. 2).

The decrease in Mangaia's population was much less dramatic than was the case on Rarotonga and, initially at least, different in origin. The source of the initial decline in the 1850s appears to have been the emigration of a considerable proportion of the population, although later in the century introduced diseases may have contributed more substantially. As G. Gill's census of 1845 indicated a large excess of male children as compared with the number of female children, the emigration of young adult males during later years would not necessarily have altered the reproductive capacity of the population significantly, and at least until the 1870s, more births than deaths were recorded each year. In later years it was alleged that the deaths exceeded the births each year, and this was perhaps the consequence of the continued emigration 
of young adults which depleted the reproductive capacity of the population and left relatively large numbers of old people on the island. However, the data are too incomplete to distinguish clearly what was happening in the population and whether the decrease in the latter years of the century had its origin in the pattern of emigration or in introduced diseases.

The only other island to have a resident European missionary during the nineteenth century was Aitutaki, the population of which was thought to be about two thousand persons when John Williams left two native teachers from Tahiti there in 1821 (J. Williams, 1838, p. 20). Though quickly converted, some of the Aitutakians later rejected the mission teaching, and for at least ten years there were sporadic skirmishes between the 'heathen' and 'Christian' parties on the island. The Christian party gained in strength, but when the first European missionary was stationed there in 1839 , he and his followers were harassed for a few months by an active band of non-converts (W. Gill, 1856, pp. 207-10). The presence of such a group was not mentioned subsequently, but its continued existence in the population may account for the almost complete lack of any precise population data for Aitutaki during the nineteenth century.

On his arrival in 1839, the missionary Royle found much disease amongst a population which he thought would number about 2,000 persons (Royle, 1840). In 1841, Aitutaki was 'laid prostrate by a hurricane . . . and the food plantations were entirely devastated' (W. Gill, 1856, p. 211). Notwithstanding this, Royle reported in May 1843 that there had been thirty-five whaling vessels in port during the past year and much trading, which suggests that the population recovered quickly from the effects of the hurricane. Later in 1843 there was an outbreak of dysentery which resulted in 100 deaths (Pitman, 1843b), and although the source of infection on Aitutaki was not specified, the crew from one of the visiting whaling boats was held responsible for its subsequent introduction into Rarotonga (Pitman, 1843a).

The first hint of people leaving the island to work elsewhere was given in 1847 when Royle (1847) reported that in June a government ship from Tahiti had come to pick up men and that the captain of the vessel had behaved 'very gentlemanly'. No details were given of the number of men engaged or of the conditions or duration of their employment. The matter was not mentioned again in the mission correspondence, and it is not known whether the men were returned to Aitutaki subsequently, or whether they were the first or the only group recruited to work in Tahiti.

Royle's letters mention no outbreak of disease on Aitutaki for some 
years after 1843, and while Rarotonga experienced epidemics of influenza in 1847, whooping cough in 1848 and mumps in 1851, Aitutaki apparently escaped unscathed. With Royle's medical knowledge, it is conceivable that outbreaks of epidemic proportions may have been averted; nevertheless, when whooping cough occurred amongst the population in 1887, reference was made then to a previous outbreak of this disease which had caused 75 deaths, but no date for this was given (Lawrence, 1887).

One epidemic known to have occurred was that of measles in 1854. In this year, Aitutaki suffered both a hurricane and an earthquake, and 'the famine which ensued was most grievous' (W. Gill, 1856, p. 225). Shortly afterwards measles was introduced by a schooner from Tahiti (Royle, 1854) and quickly spread throughout the island until the whole population became prostrate' (W. Gill, 1856, p. 226). The total number of deaths caused by this outbreak was not recorded: in November 1854 Royle reported that there were 'already' 71 persons dead, and a month later Buzacott wrote that the outbreak in Tahiti had been more severe than those in either Mangaia or Aitutaki. The mortality reported in Tahiti represented a crude death rate of approximately 10 per cent of the population: the total number of deaths recorded for Mangaia during 1854 represented a crude mortality rate of less than $1 \frac{112}{2}$ per cent. On Aitutaki, at least 71 persons died from measles in 1854 .

For all of this time there is no record of even an estimate of the number of people on the island. In 1870, it was claimed that the chiefs of Aitutaki had forbidden the emigration of people from the island (Chalmers, 1870), but no details were given of the years during which this prohibition was enforced. A mission 'census' at the beginning of 1872 attributed a population of only 1,450 to Aitutaki (W. W. Gill, 1872), although in 1877 a total of 1,646 inhabitants was reported for the island (Harris, 1877). Some increase in mortality had been noted after Royle's departure (W. W. Gill, 1881b), but the next figure quoted for the population-a total of only 1,146 persons in 1881-was thought to be incomplete (Harris, 1882). From 1886 to 1890 there were 93 more deaths than births recorded (Lawrence, 1890), although apart from the outbreak of whooping cough in 1887 (Lawrence, 1887) there appears to have been no exceptional cause of high mortality during this period. At the first official enumeration of the population in 1902, a total of 1,170 persons was reported for Aitutaki (N.Z.P.P. A-3, 1907, p. 2), but this did not include '149 natives absent in ships or at the guano island' (N.Z. Official Year Book, 1903).

The recorded population data for the remaining islands of the Lower Group consist of little more than a succession of bare totals for each 
population, numbers either counted or estimated by the missionaries on their infrequent visits to the native teachers stationed on the islands. Atiu is the largest island of the four and when it was discovered in 1777, Captain Cook reckoned that the population 'must have been at least two thousand. For those who welcomed us at the shore bore no proportion to the multitude we found among the trees, on proceeding a little way up' (Cook, 1821, 5, p. 264). In 1823 the London Missionary Society sent two Raiatean teachers there and the population was then considered to be 'something under 2,000' ( J. Williams, 1838, p. 19).

In August 1842 the population was counted and there were then only '985 men, women and children' on the island (Krause, 1843). When W. Gill visited Atiu in 1843 the population numbered 1,000 (W. Gill, 1856, p. 237), but two years later he reported only 900 persons there (W. Gill, 1845b). By 1852 this population had apparently increased to a total of 1,200 (W. Gill, 1852). Beoause of the resistance and influence of the chiefs, none of the people were taken from the island by Peruvian slavers in 1862-3, and Harris (1882) claimed that Atiu contained 1,002 people in 1882. Three years later 200 of Atiu's total population of 1,000 were allegedly in Tahiti (Hutchin, 1885), but it would seem that theirs was only a temporary absence for in 1890 the population total was given as 1,218 persons (Harris, 1890). The only outbreak of disease recorded for Atiu was the prevalence of dysentery amongst the people in 1891 (Hutchin, 1891c), and this may have contributed to the difference between the 1890 population total and the number recorded in the first official enumeration in 1902, when the population was listed as 918 persons (N.Z.P.P. A-3, 1907, p. 2).

With population figures so scattered throughout the century, and so little information on events which may have occurred in the intervening years, one cannot ascertain whether the fluctuations in numbers derive from faulty counting, or inconsistencies about the inclusion of absent workers (if there were any such), or whether the numbers did vary quite widely from time to time. The clue to the variability may have been given by Lawrence (1898) who commented that the people of Atiu lived on their own lands in the bush, away from the mission station, and as a consequence of this the schools were poorly attended and the people 'hard to manage'.

About three years before Williams discovered Mauke, the island had been devastated by a severe storm which caused a famine, and subsequently there was an outbreak of a disease which, though not very fatal, was nearly universal'. Taking advantage of their weakness, warriors from Atiu invaded the island, and the population, previously considerable, was, by the dreadful massacre that ensued, reduced to 
about three hundred' ( J. Williams, 1838, pp. 277-8, 18). A native teacher was left on the island in 1823 and when Gill visited there in 1845, he estimated the population to be about 250 persons (W. Gill, 1845b). In 1852 he reported a total of 320 persons on Mauke, and in 1871 his successor, W. W. Gill, reckoned the inhabitants to number between 300 and 400 , with 40 males absent on contract labour on a guano island (W. W. Gill, 1871). By 1882, this number had apparently increased to 487 (Harris, 1882), and although Hutchin reported in 1885 that Mauke's population, still showing an excess of females, was recovering from the most recent massacre by warriors from Atiu 'four years ago', this cannot be substantiated from other sources and there are no later figures for Atiu in this century. The official estimate of the population in 1902 was 370 persons (N.Z.P.P. A-3, 1907, p. 2).

Mitiaro is the smallest of the permanently inhabited islands of the Lower Group, and traditionally its inhabitants are kin to the people of Atiu. Describing his initial visit in 1823, Williams (1838, pp. 18-19) remarked that by famine and invasion this island has likewise been depopulated; there not being one hundred persons remaining. W. Gill (1845b) estimated that there were 100 people on the island in 1845 , and 120 there in 1852: W. W. Gill reported 180 persons in 1872, and Harris 207 in 1882 and 223 in 1890. The first decrease in numbers was signalled by Lawrence in 1898 when he reported only 212 inhabitants, and if these and the official estimate for 1902 are correct, there was a rapid decrease to only 165 in the period between 1898 and 1902 (N.Z.P.P. A-3, 1907, p. 2).

To complete this record of the populations of the Lower Group there remains but the brief history of Manuae (or Hervey's Island) which was discovered by Cook on his second voyage in 1773. When John Williams visited there in 1823 he had expected to find 'a considerable population', but instead he learned that

by their frequent and exterminating wars, they had reduced themselves to about sixty in number, ... Some six or seven years after this I visited the same island again, and found that the miserable remnant of the former population had fought so frequently and so desperately, that the only survivors were five men, three women and a few children! and at that period there was a contention among them as to which should be king! (J. Williams, 1838, p. 18).

Some years later, the 'miserable remnant' abandoned the island and went to live on Aitutaki. Manuae was then leased from time to time to various Europeans or inhabited for short periods by people from Aitutaki who had rights to lands there. In 1893 it was formally leased as a copra 
plantation, although for a time part of the island was reserved for use as a penal settlement. In 1902 Manuae's population was estimated to be 10 (N.Z.P.P. A-3, 1907, p. 2).

TABLE 34 Summary of the populations of the Cook Islands reported or estimated from mission and other records for various years, and the numbers enumerated or estimated in 1902

\begin{tabular}{lccccccc}
\hline \multicolumn{1}{c}{ Island } & 1845 & $1854-5$ & $1871-2$ & 1881 & 1899 & 1900 & 1902 \\
\hline Rarotonga & 3,000 & 2,374 & 1,936 & 2,000 & $\ddagger$ & $\ddagger$ & 2,060 \\
Mangaia & 3,500 & 2,926 & 2,266 & 2,000 & $\ddagger$ & $\ddagger$ & 1,541 \\
Aitutaki & $2,000^{*}$ & $1,750^{*}$ & 1,450 & $1,146 \dagger$ & $\ddagger$ & $\ddagger$ & $1,170 \S$ \\
Atiu & 900 & 1,200 & $1,100^{*}$ & 1,002 & $\ddagger$ & $\ddagger$ & 918 \\
Mauke & 250 & 320 & 350 & 487 & $\ddagger$ & $\ddagger$ & 370 \\
Mitiaro & 100 & 120 & 180 & 207 & $\ddagger$ & $\ddagger$ & 165 \\
Manuae & $10^{*}$ & $10^{*}$ & $10^{*}$ & $10^{*}$ & $\ddagger$ & $\ddagger$ & 10 \\
Lower Group & & & & & & & \\
$\quad$ Total & 9,760 & 8,700 & 7,292 & $6,852 \dagger$ & $\ddagger$ & $\ddagger$ & 6,234 \\
& & & & & & & \\
Penrhyn & $\ddagger$ & $\ddagger$ & 300 & $\ddagger$ & 417 & 389 & 445 \\
Manihiki & $\ddagger$ & $\ddagger$ & 407 & $\ddagger$ & 590 & 570 & 484 \\
Rakahanga & $\ddagger$ & $\ddagger$ & 400 & $\ddagger$ & 370 & 400 & 400 \\
Pukapuka & $\ddagger$ & $\ddagger$ & 340 & $\ddagger$ & 409 & 505 & 505 \\
Northern Group $\|$ & $\ddagger$ & $\ddagger$ & 1,447 & $\ddagger$ & 1,786 & 1,864 & 1,834 \\
& & & & & & & \\
\hline
\end{tabular}

*Guesses by the author.

$\uparrow$ Possibly incomplete.

$\ddagger$ Not available.

$\S N o t$ including 149 natives absent 'in ships or at the guano island' (N.Z. Official Year Book, 1903).

||Excluding Palmerston and Suwarrow.

Putting together the data for the years when estimates or counts of the inhabitants of most islands are given in the mission records, the population of the Lower Group may have decreased from about 10,000 in 1845 to fewer than 9,000 in 1855 . The decline continued at roughly the same rate from then until 1870, when the population numbered between 7,000 and 7,500, but it appears to have slackened during the remaining years of the century so that, in 1900 , there were between 6,000 and 6,500 people inhabiting the islands of the Lower Group. The contributions of each island to these totals are given in Table 34, and it will be noted that the numbers for Aitutaki in 1845 and 1855, and for Atiu in 1871, are guesses only and there is some doubt about the accuracy of some of the remaining figures as well. 
The more scattered and isolated Northern Cook Islands were neglected by the London Missionary Society until the middle of the nineteenth century, although all had been discovered by European explorers much earlier, and the names of at least two of the islandsTongareva (or Penrhyn) and Manihiki-were known to the missionaries through the legends of some of the islands of the Lower Group, and from stories told by the captains and crews of vessels calling at Rarotonga. Two Rarotongan mission teachers were sent to Manihiki immediately an opportunity offered in 1849, but the inhabitants of Penrhyn had shown themselves so inhospitable to strangers that no attempt was made to send teachers there until 1854. Pukapuka, the most westerly of the atolls, was the last to receive mission teachers.

In 1862 and 1863 these Northern Islands were amongst those raided by the vessels which had been chartered to engage 10,000 Polynesians to work in the copper mines of Peru and on guano deposits in the Chincha Islands. Ostensibly, the natives were to be recruited under contract, but no such terms were honoured by either the recruiters or the employers, and when the island chiefs proved reluctant to allow their people to leave their islands, the slavers used all sorts of ruses to entice the islanders aboard their ships.

After the depredation of Rapa Nui (or Easter Island) in 1862, the French minister at Lima protested vigorously and the French Government at Tahiti took action against the raiders in the South Pacific, capturing six or seven vessels before the raiding was stopped. The British joined in the activities against the slavers, but there was little that could be done to prevent the vessels, supposedly repatriating the islanders a year or two later, from dumping their human cargoes on the nearest island, irrespective of their island of origin and irrespective of the diseases which many of them had acquired. Some of the missionaries collected details of the approximate numbers taken to Peru from the various islands, but the repatriation of those who survived the experience was so haphazard that the numbers who returned from Peru were never recorded (W. W. Gill, 1863a, 1863b, 1863c; Krause, 1863a; Royle, 1865).

Of the Northern Cook Islands, Penrhyn probably suffered more than any other from the labour traffic, although if the account given by Buck (1932a, p. 8) is correct, the story is rather different from the usual one. Like many atolls, Penrhyn is not just one island but a ring of islets encircling a lagoon about thirteen miles across. At least four European ships called there in the first half of the nineteenth century, and in 1841 the islets were thought to have a total of 1,300 inhabitants (W. Gill, 1856, p. 277). In 1853 the Chatham was wrecked on one of the islets 
and Lamont, the trader who had chartered the brig, and some of the crew were marooned on Penrhyn for some months.

Lamont's narrative of Penrhyn depicts a people living rather precariously on the various islets, at war with one another and constantly on guard to protect their food crops from hostile raiding parties. Some weeks after the wreck, there was an outbreak of a disease 'resembling an intermittent fever' for which the survivors of the wreck were blamed even though many of them also suffered in the epidemic. The disease spread rapidly throughout all of the islets and caused many deaths, but the mortality was particularly heavy amongst the group of people who had befriended the castaways (Lamont, 1867, pp. 264, 269, 273). Before the epidemic Lamont was received hospitably by several groups, some of them hostile to one another, and despite the sickness he continued to visit other islets until he and his companions were rescued by a whaling ship. Unfortunately, he made no estimate of the numbers of people there might have been on any of the islets either before or after the epidemic, nor can one infer whether the total would amount to only a few hundreds or to several hundreds.

The castaways were taken to Rarotonga and almost immediately three native pastors were chosen from the London Missionary Society's training institution there and taken to Penrhyn. They landed in March 1854 in the company of two natives of the island who had gone with Lamont to Rarotonga, and their teachings were readily accepted. Encouraged by the pastors, the people then congregated into four villages and their old enmity was either forgotten or perhaps translated into petty rivalries between the congregations. Buck's informants in 1929 considered that, when the slavers came in 1862, their promises of the money to be earned in Peru showed both pastors and people how their desire for churches 'worthy of the worship of God' could be quickly realized, and it was thus by common consent that some of their number embarked, to die 'as slaves in exile' (Buck, 1932a, p. 8).

Three estimates of the numbers taken from Penrhyn to Peru have been found: the highest is the trader Sterndale's (1874, p. 17) 'not less than 1,000 persons (probably more)', and the lowest a conservative 250 estimated by W. W. Gill (1863a). In his investigations of the activities of the slavers, Gill discovered that 130 people from Penrhyn had been taken to Tahiti at about that time, under contract to work for the French Government there for two years, and the departure of these two groups left only 88 people on the island. The aggregate of Gill's figures indicates a population of about 500 on Penrhyn early in 1862 .

Royle (1865), on the other hand, claimed that there had been 700 people on Penrhyn before the slavers had reduced their number to 60 . 
When he visited the island in 1865, he found 111 Micronesians who had been left there by a ship from Peru, and he took 35 of them across to Manihiki and Rakahanga. These were the survivors of a group of 150 Gilbertese who had been taken to Peru in 1863 and, when refused permission to land there, were brought back and dumped on Penrhyn (J. C. Williams, 1864). Subsequently they were all given employment on Fanning Island and eventually were returned from there to the Gilbert Islands some time before 1878 (Bingham, 1878). In $1871 \mathrm{~W}$. W. Gill reported a population of 300 on Penrhyn but Sterndale, who lived on Manihiki for about a year and a half at about that time, reckoned Penrhyn's inhabitants to number only about 150 (Sterndale, 1874, p. 17).

When the island was annexed to Great Britain in 1889, its population of 373 persons was considered to be 'more prosperous' than it had been for many years (Harris, 1890), but the following year the missionary reported that the incidence of leprosy on Penrhyn was increasing (Harris, 1891). This disease is thought to have been introduced in 1885 by a Penrhyn native who had lived for several years in Samoa with a Hawaiian leper, and who manifested the disease after his return to the island. During the next twenty years there were 43 cases of leprosy on Penrhyn which could be traced to him, and 31 of these ended in death (Maui Pomare, 1906 quoted in Lambert, 1926, p. 34). When Captain Tupper of H.M.S. Pylades visited the island in 1899 there were 29 lepers in a total population of 417 persons whose general health was poorer than Tupper had found on other islands of the Northern Group where there was practically no sickness at all (Tupper, 1899). In 1900, the population was reputed to be only 389 (Te Karere, 1901) which suggests that the lepers had not been included, but unless there had been a sudden influx of returning labourers there is some inconsistency between these numbers and the total of 445 persons recorded in the official enumeration of 1902 (N.Z.P.P. A-3, 1907, p. 2).

The population data for Manihiki and Rakahanga are no more comprehensive than those for Penrhyn. Manihiki and Rakahanga are atolls only 25 miles apart and until the middle of the nineteenth century, the population moved back and forth between them so that one atoll was uninhabited while the people lived on the other. When food beoame scarce on the inhabited atoll, the entire population boarded double sailing canoes and crossed to the other atoll, visible only from a point midway between the two. Occasionally the fleet of canoes would be caught by unexpected storms, and in 1849 one of these craft was blown off its course when crossing from Manihiki to Rakahanga. The crew was rescued 80 miles away by a whaling ship which landed them at Manuae, and it was some time before they were taken from there to Aitutaki and 
thence back to Manihiki in the missionary ship John Williams. On their return from Aitutaki, they were accompanied by two native mission teachers and within three years the majority of the population was converted to Christianity (Buck, 1932b, pp. 4, 8).

At this time there were about 1,200 people living on Manihiki, more or less concentrated in two villages or settlements (W. Gill, 1856, p. 273). Shortly after the teachers' arrival, more than 20 people were drowned when another storm overtook a fleet of twenty canoes, containing about 200 people, crossing to Rakahanga to collect coconuts. The teachers tried to dissuade the people from continuing with such voyages and suggested that they should divide into two groups, one group to live permanently on Manihiki and the other to live permanently on Rakahanga. This change was resisted by the chiefs and in 1852, two European boats were given to the London Missionary Society for the use of the teachers on Manihiki.

W. Gill visited Manihiki in that year, and he supported the teachers in their attempts to persuade the chiefs to establish permanent settlements on both atolls (W. Gill, 1856, p. 274). Sometime within the next ten years the population did divide and W. W. Gill (1863a) reported that 'entire families' totalling 87 people were taken from Rakahanga by the Peruvian slavers in 1862 , but the raiders had failed in their numerous attempts to entice people from Manihiki because the chiefs would not allow them to leave. The initial size of the two groups is not known, but in $1871 \mathrm{~W}$. W. Gill (1871) reported 407 inhabitants on Manihiki and 400 on Rakahanga.

Sterndale (1874) perhaps had the explanation for at least part of the reduction in population size from about 1,200 to 800 or 900 in little more than twenty years. From about 1860, Manihiki became famous for its beautiful women and

their numbers were very speedily reduced, by the extensive traffic in women, which sprang up. ... Tahitians, Peruvians, and other strolling mariners who chanced to visit them, bought, enticed, or kidnapped them, until they became scarce upon their own land. For the last fifteen years, Manihiki women have been in great request among the Europeans in all the chief trading ports of the Pacific Isles, . . . greedily sought after as house servants or concubines (Sterndale, 1874, p. 14).

The young women themselves had but one ambition, to run away in any ships whatever, in hope to be carried to foreign places to become the mistresses of Europeans, for whom they have an unconquerable liking. The young men also left the island, going away to work in 
Honolulu, Tahiti or on the guano islands, so that "on their own island few remain permanently but the aged and the infants'. Just how these latter came to be there is not clear, but after living among them for a year and a half, Sterndale considered Manihiki's population to number 'about 500', and Rakahanga's 'about 400' (Sterndale, 1874, pp. 14, 15).

By 1899, the records of the Rarotongan pastors on both islands showed that Manihiki's population had increased to either 580 or 590 'natives and half-castes', and Rakahanga's population had decreased to 370 (Tupper, 1899). Some of the latter, however, may have been on Manihiki where there was a European agent for the 'Pacific Islands Co. of Sydney and London'. Rakahanga's population was cited as 400 and Manihiki's as 570 in 1900 (Te Karere, 1901), but when Manihiki was censussed in 1902 there were only 484 inhabitants. Rakahanga was not included in this census, and the official estimate of its population repeats the mission's total of 400 (N.Z.P.P. A-3, 1907, p. 2).

Some of this variability in Manihiki's population was perhaps due to the presence or absence of transient divers, fishing for pearl-shell in the lagoon, as well as to the arrivals and departures of persons recruited under contract for work in other islands in the Pacific. The Pacific Islands Company was only one of several interested in copra, pearl-shell, coconut oil and guano, and in the latter years of the century it was 'working' several islands which it had rented from the British Government, recruiting labourers from where it could in the Pacific (Tupper, 1899).

Pukapuka attracted scant attention for nearly a century after its discovery, and probably no more than three European ships called there between 1765 and 1857 when the first native missionaries landed (Beaglehole, 1938, p. 5). Early in 1863 two ships engaged in the Peruvian slave trade took away 140 people (including 10 children and a mission teacher and his wife) on the pretext of going to make coconut oil on Palmerston Island (W. W. Gill, 1863a). It was thought that before this the population had been 600; in 1871 this had fallen to an estimated 340 persons (W. W. Gill, 1871). Sterndale, differing as usual from the missionaries' figures, claimed that Pukapuka's three large cays, set in 'a great triangular reef about 35 miles in circuit', contained 'less than $300^{\prime}$ inhabitants in 1874 although they were once densely populated (Sterndale, 1874, p. 13). In 1890, however, Pukapuka was listed as having 489 inhabitants (Harris, 1890). Nine years later Tupper (1899) reported that the population is now 409, but they could not tell me how many of each sex, and how many children, the missionary (a Rarotongan) keeps the Register of deaths and binths etc. He did not show it to me.' Few of these figures accord with the total of 505 cited in Te Karere (1901) for 
1900, and repeated as the official estimate for Pukapuka's population in 1902 (N.Z.P.P. A-3, 1907, p. 2).

In 1902, there were a further 145 persons in the Northern Cook Islands-115 on Palmerston Island and an estimated 30 on Suwarrow. Discovered by Cook in 1774 (Cook, 1821, 5, p. 283), Palmerston consists of a ring of nine or ten islets encircling a lagoon about 8 miles in diameter. From about 1857 a trader in Tahiti had a small group of from 10 to 15 people working on the island, and in 1863 he arranged that William Marsters would go there, receiving no wages except the proceeds from the sale of the coconut oil. Marsters was still there in 1874 when Sterndale wrote that no 'systematic use' was being made of the island and that it had no permanent inhabitants. By 1888 , Marsters claimed that he and his family had planted 200,000 coconuts on the islets surrounding the lagoon, and that it would be 'a great pity to drive my children away from the island as it is the only home they have got' (Marsters, 1888). Marsters died on Palmerston in 1899 and the majority of the 115 persons recorded in the census of 1902 were related directly or by marriage to Marsters and his three wives.

Suwarrow, 'a ribbon of coral . . . enclosing a calm lagoon' of about the same size as Palmerston's (Cowan, 1936, p. 62), has a long and colourful history stemming from its reputation as a 'treasure island'. At least three searchers unearthed buried gold there, but few people have lived there for more than a few months. During the latter half of the nineteenth century parties from other islands were taken there from time to time to dive for shell, and in 1875, Sterndale was employed by an Auckland company to establish a trading station there. Using labour from other islands, the main island was cleared and planted with taro, bananas, and coconuts, but in the following year there was a dispute between Sterndale and his employers as to the ownership of the island and Sterndale was forcibly removed (Cowan, 1936, pp. 62-97). The island was annexed to Britain in 1889, and ten years later it was one of the islands which had been rented by the Pacific Islands Company and natives from the 'Western Pacific' were being employed to collect pearlshell (Tupper, 1899). They worked under contraot and were returned to their island of origin when the contract expired.

These bald and often inconsistent figures for each island at various times reveal little of the population history of the northern atolls. Except for the epidemic on Penrhyn in 1853, there is no record of any outbreak of disease, but it would be surprising if these populations escaped the infections from visiting ships which occasionally proved so devastating to other island populations. During the first half of the century ships probably called less frequently at the northern atolls than in the islands 
of the Lower Group, but during the second half of the century it seems that the atolls supplied workers for several islands in the Pacific as well as slaves for Peru. At least one batch was recruited from Penrhyn to work in Tahiti in 1861 or 1862, and a further 49 in 1866 (Nowbury, 1957, p. 163); and people from Rakahanga were regularly employed on Fanning Island while tho young people from Manihiki allegedly escaped on any vessels they could. It is a matter for conjecture whether such people would be included in the mission estimates of populations, particularly as all these estimates relate to a time when the European missionaries themselves showed little interest in population figures.

The first year for which the populations of the four major atolls were given in the mission records is 1871 and these figures are shown in Table 34. The aggregate then was less than 1,500 which was roughly 100 more than Sterndale estimated two or three years later, and at least 500 fewer than had been in the islands before the visits of the ships engaged in the Peruvian slave trade. The next year for which there are figures for all four islands simultaneously is 1899 when Captain Tupper was given the population of each by the mission teachers, at least one of whom did not know the numbers of males and females, or the numbers of children and adults. Te Karere quoted populations for 1900, presumably from the same source, and there was an official enumeration on some islands in 1902, which may or may not have been carried out independently of the mission teachers. These three sets of figures show some differences in the totals for individual islands but the aggregate in each case was approximately 1,800 persons, and this excludes the numerous children and grandchildren of William Marsters and his wives on Palmerston Island.

Discounting the improbable and baseless figure of 1,300 for Penrhyn's population in 1841, it might be guessed that the population of the northern atolls at mid-century was between 2,000 and 2,500, so that the population of the entire group at that date may have been as much as 11,000 . Twenty years later there were probably fewer than 9,000 inhabitants in all the islands and about 8,000 at the turn of the century. These totals may be exaggerated because of the numbers who had left their islands, either for another island in the Group or for other parts of the Pacific; and during the second half of the century emigration, either enforced or voluntary, probably played a more significant role in the decreases of population that occurred than did mortality from introduced diseases. Mortality was probably still quite high and in some years 
there may have been more deaths than births-a state of affairs which was perhaps not unrelated to the emigration or at least the prolonged absences of young men. Except for Rarotonga's population in the early years of mission activity, the data are often demonstrably inconsistent and perhaps the most significant fact to emerge is that even on islands as small as these, where the population was usually gathered into a few villages, the mission records rarely give unequivocal numbers of inhabitants at any time, and still more rarely unbiased or quantitative accounts of the sources of change in these numbers.

\section{Census Enumerations}

Rarotonga had its first official enumeration of population in 1895, and the populations of both Rarotonga and Mangaia were recorded in 1901. Some islands (including Rarotonga) were censussed in the following year, but Mangaia was not, nor were the smaller islands of the Lower Group, Mauke, Mitiaro, and Manuae. In the Northern Group the census covered only Penrhyn, Manihiki, and Palmerston. The first comprehensive census of all the inhabited islands was taken in 1906, and this and all subsequent enumerations corresponded with the general censuses of population in New Zealand. As island territories are not included under the Dominion's permanent census legislation, until 1961 special regulations were required for each enumeration. These were accordingly held at quinquennial intervals from 1906 to 1926 , and then in 1936, 1945, and 1951, reverting to a five-year interval with the census of 1956." Except for the first and the three most recent censuses, the scope of inquiry in each was specifically decided by the Census Office (later the Census and Statistics Department) in Wellington, and the results of each census from 1906 to 1945 were then published either as appendices or as separate parts of the New Zealand census reports.

In 1906 a Mr Percy Brown was appointed Enumerator, and the information he was to collect was the most that could be supplied for the 275 he was to be paid. It was suggested that he record the numbers of male and female adults and children in five-year grouped ages, their birthplace and nationality, together with details of occupation, religion, education and school attendance (N.Z.P.P. A-3, 1906, p. 54). The Resident Commissioner declined to attempt such a detailed reoord because the people were suspicious of censuses, and he thought the only hope of making a 'fairly correct' count was to keep the census simple, and list

- The Cook Island Census Regulations 1961 (1961/87) prescribe that 'the census of population of the Cook Islands (including Niue) shall be taken in the year 1961 and in every fifth year thereafter'. The data to be collected are also specified. 
only male and female adults and ohildren under 18 years. The population of Mangaia had already been enumerated in this fashion and he expected that he himself would enumerate another three of the islands (N.Z.P.P. A-3, 1906, p. 57). The data published the following year show the numbers of males and females aged less than 16 years and more than 16 years on each island, distinguishing between 'whites and half-castes living as whites' and 'natives and half-castes living as natives'. The absentees were recorded separately (N.Z.P.P. A-3, 1907, p. 1).

In 1911, an attempt was made to record all that had been asked for previously, and although this caused 'great difficulties', the Resident Commissioner considered that the information for the Lower Group was 'fairly correct' because these islands had been enumerated by European 'sub-enumerators', most of whom were officers of the Administration. In the Northern Islands, however, he had had 'to rely upon the Natives themselves to supply the information'. On some islands there were 'local registers' which helped the sub-enumerators to discover the ages of the people, and where these were not available, age was 'arrived at from circumstances in the life of the person and the appearance, coupled with personal knowledge' of the sub-enumerator (N.Z. Census Report for 1911, pp. xvi, xvii).

The same information about the population was sought in the census of 1916, and no comments were made on the difficulties or otherwise of obtaining such details. The enumerator on Rarotonga pointed out, however, that it was almost impossible to discover how many palm trees and stock each person owned, partly because they did not know, partly because they feared that the census was a preliminary to taxation (N.Z. Census Report for 1916, p. xvi). This engendered suspicion of the census amongst the people and because of this, the questions on property were omitted from all subsequent enumerations.

The form and scope of the census, and the census procedure continued unchanged then until 1945. The schedules and enumeration books were sent out from New Zealand several months before the date chosen for the census, and 'facilities for enumeration' were provided by the Resident Commissioner. An 'enumerator' was appointed and he was responsible for the selection and supervision of the sub-enumerators who recorded the 'native' population in 'sub-enumeration books'. Either the New Zealand or, after 1921, the Western Samoan schedules were used for the 'non-native' population, and these were completed by the occupiers of dwellings as in New Zealand.

There was a change in the definition of 'native' and 'non-native' in 1926, and the data of the first four censuses are not therefore comparable with those of subsequent enumerations. Before 1926, 'native' women 
married to Europeans and all half-castes who were living as Europeans had been classified as 'non-native', In 1926, the 'native' population was defined as 'all persons of half or more native blood' irrespective of mode of living, and persons with less than half 'native blood' were regarded as 'non-natives' (N.Z. Population Census, 1926, II, p. 1).

The next significant change in procedure was the alteration in the timing of the census from April to September. From 1906 the Cook Islands had been censussed at the same time as the New Zealand population and, except in 1916, this was done in April. The hurricane season in the Cook Islands lasts until March or April and because of this there was always difficulty in getting the census material out to the islands in time. Thus in 1926, for example, the islands of Rarotonga, Mangaia, Aitutaki and Atiu were enumerated on 20 April, Penrhyn on 1 May, Mauke and Mitiaro on 10 May and the remaining islands 'a little later' (N.Z. Population Census, 1926, II, p. 1). In 1945 it was decided to hold the census in September and this resulted in 'the first synchronous census of all islands in the Group' (N.Z. Population Census, 1945, II, p. 1).

This was the last occasion on which the census tabulations were done in New Zealand, and the last census for which all of the data recorded in the census have been published. Except for comments in the introductory notes to the reports on the 1936 and 1945 censuses that the actual field work of the census was in the hands of the Administration authorities for the Cook Islands', and that 'the census documents were checked in the islands and finally tabulated by the Census and Statistics Department' (N.Z. Population Census, 1945, II, p. 1), the background of organization for these censuses is obscure. No clues as to the identity of any enumerator or sub-enumerator are given, nor is it clear whether the 'census documents' were checked in each island before forwarding to Rarotonga, or whether all were checked there.

It can probably be presumed that the census organization did not differ greatly from the procedure for the 1951 census when the Registrar of Courts at Rarotonga directed the operation and the Resident Agents were responsible for the enumeration of the population living on the islands under their charge. Except for Maoris who were attached to European households, particulars of the indigenous population were recorded by enumerators, in books which allowed the listing of 40 persons per page. The questions were printed in English and ranged horizontally across a double-span folio page. The order and spacing of the questions were somewhat illogical, with relatively more space allotted to questions requiring either numbers or abbreviated replies than to those for which the answers were to be written in full. And unless the 


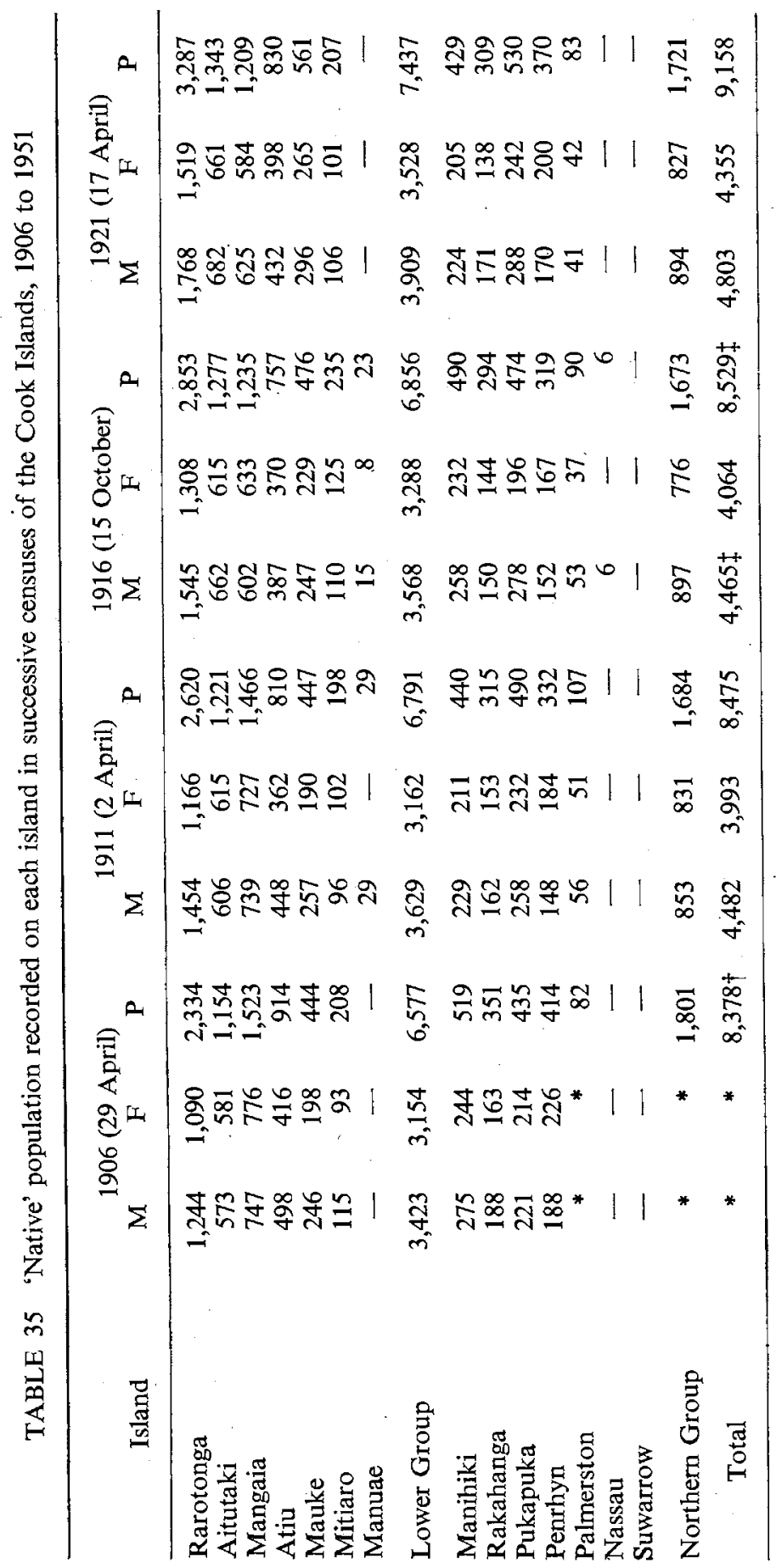




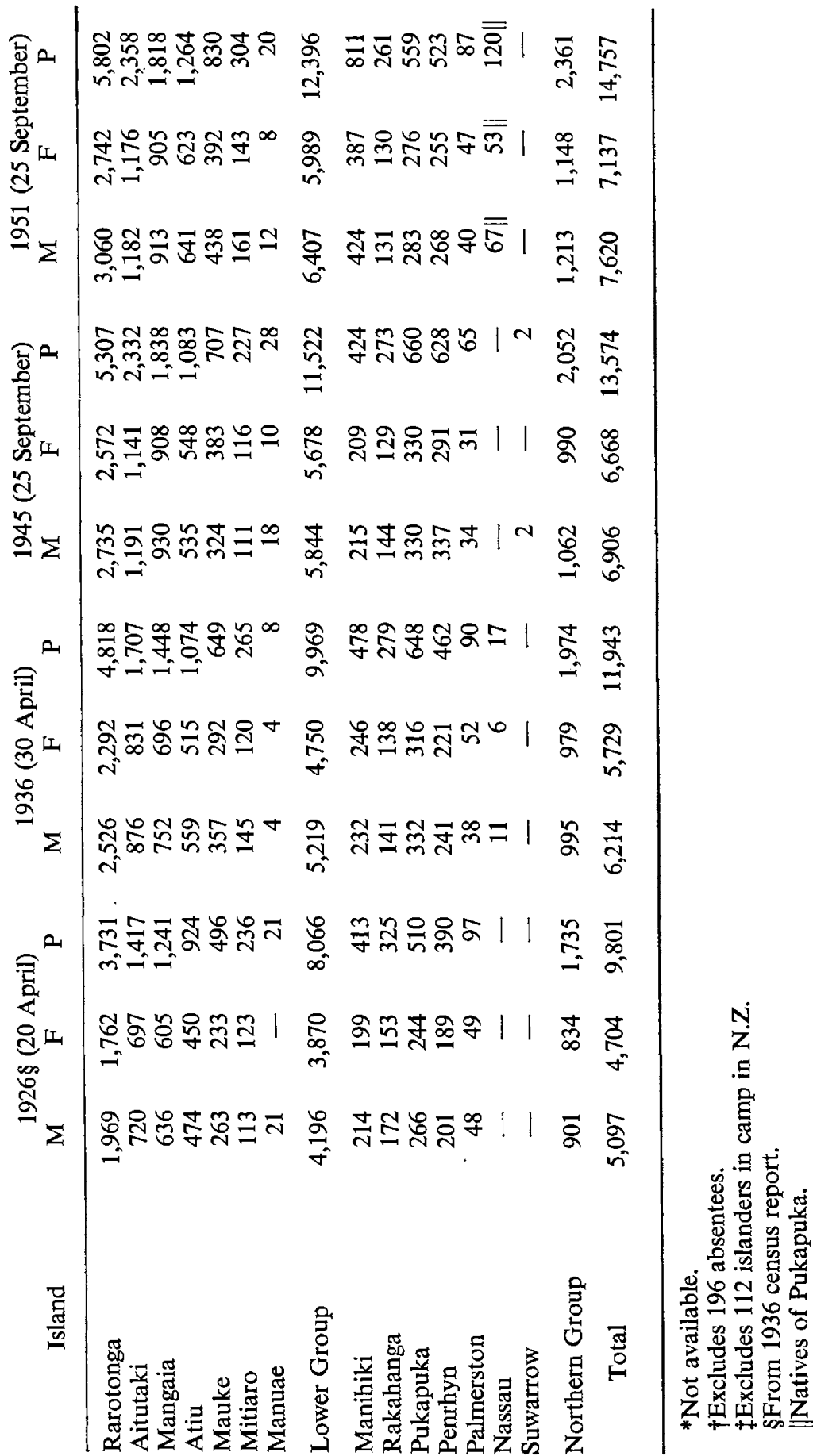


enumerators were very familiar with the English language, or were given additional detailed instructions in the vernacular, the questions were phrased rather too concisely. In 1951, the majority of enumerators were either clerioal assistants to the Resident Agents or school-teachers, and only in the smaller outer islands was there likely to be any gross misunderstanding as to what was to be recorded.

Twelve questions were asked in 1951-name, sex, age last birthday, race, birthplace, village or district of enumeration, occupation, religion, marital status, number of children born alive (to married women only), and two questions on literacy-the question on the number of children born having been added only in this year. As there is no tabulation of the population by marital status in 1936, it would seem that this question was added in 1945. The comparatively recent inclusion of these two additional demographic questions probably explains the illogicality in the sequence of questions in the enumeration books, which had been supplied as usual from the Census and Statistics Department of New Zealand. This time, however, the census documents were not returned there for processing, and the data were summarized in Rarotonga under the direction and supervision of the Registrar of Courts. The results were not published in full and if tabulations were compiled for the non-native population they are no longer available. Even for the 'native' population there was no tabulation of married women according to the number of children they had borne.

By 1956 the 'natives' were described as Maoris, but in the census no distinction was made between any sector of the population and all were enumerated on a uniform household schedule. The procedure for this census conformed broadly with that followed in the other Pacific territories (except French Polynesia) which were enumerated at the same time. The schedules and the instructions to enumerators were printed in both English and the vernacular, and the number of questions per person was reduced to nine, with three additional questions for females aged 15 years and over. Except on Rarotonga, the Resident Agents were again responsible for the enumeration of the island or islands delegated to them and, as in 1951, the Registrar of Courts at Rarotonga was in charge of the whole census operation. Enumerators were usually school-teachers, clerks to the Resident Agents, or other government servants and in the ten days preceding 25 September they completed the schedules for all households in the areas assigned to them, returning to check this information on or soon after census date.

The completed schedules were forwarded to Rarotonga where the information recorded about each individual was transferred on to a personal card (not punched) and these were then sorted by hand and 
counted. The whole tabulating process was performed by one person and the accuracy of the tabulations was unintentionally checked some two years later when additional tables were compiled from the cards for the female population, and in every instance the numbers in an age group agreed with those of the original tabulations. However, the distinction between what was formerly described as 'native' and 'nonnative' population was not retained, and consequently some comparisons with previous censuses are not possible. This is a relatively minor impediment for most comparisons and there have been other changes, either in definition or in the form of presentation, in earlier statistics whioh cause greater inconvenience in the systematic examination of the Cook Islands population.

\section{Growth of Population in the Twentieth Century}

The 'native' populations recorded on each island at successive censuses from 1906 to 1951 are shown in Table 35, and the average annual rates of increase in the total 'native' population over each inter-censal period are given in Table 36. Even when their numbers were known, persons

TABLE 36 Average annual rates of increase in 'Native' population over inter-censal periods

\begin{tabular}{lrrr}
\hline & \multicolumn{2}{c}{ Per cent increase per year over period } \\
Inter-censal period & Male & Female & Total \\
\hline $1906-11$ & \multicolumn{2}{c}{ Not available } & $0 \cdot 32$ \\
$1911-16$ & $1 \cdot 67$ & $1 \cdot 54$ & $0 \cdot 12$ \\
$1916-21$ & $1 \cdot 20$ & $1 \cdot 55$ & $1 \cdot 59$ \\
$1921-26^{*}$ & $2 \cdot 00$ & $1 \cdot 99$ & $1 \cdot 37$ \\
$1926-36$ & $1 \cdot 13$ & $1 \cdot 62$ & $2 \cdot 00$ \\
$1936-45$ & $1 \cdot 64$ & $1 \cdot 14$ & $1 \cdot 30$ \\
$1945-51$ & & & $1 \cdot 40$ \\
\hline
\end{tabular}

${ }^{*}$ Change in definition of 'native' in 1926 to conform with New Zealand definition.

absent from the Cook Islands at census dates were ignored in computing the average annual rates of increase because the numbers who subsequently returned from abroad are not known. For some islands the populations recorded in successive enumerations vary just as much as did the mission counts of last century, and although the total 'native' population has increased since 1906, these increases have not been shared by all islands. 
Nor have the rates of increase been particularly uniform for the male and female sectors of the population. If the 112 males in camp in New Zealand in Ootober 1916 were included in the 'native' population recorded then, the average annual rates of increase in the male sector and in the total population between April 1911 and Ootober 1916 rise to 0.38 and 0.36 per cent respectively; and the increases over the next four and a half years to April 1921 fall to 1.08 and 1.30 per cent per year respectively. Hence, it is only for the decade 1926-36 that the male and female populations may have increased uniformly, although the differential rates of increase between 1921 and 1926 were at least partly due to the new definition of 'native' adopted in 1926 which would tend to inflate the inter-censal increase in the female sector of the population.

Had the 1926 classification been used in earlier years, the 'native' population would have increased faster after annexation than it appeared to do, even though the reliability of some of the earlier counts may be questioned. Until 1917 there was no civil registration of births and deaths and no complete records of migration, so the sources of such increases-return migration, less emigration, or natural increase-cannot be identified. After 1916 the growth of the population accelerated and the period of maximum growth was from 1926 to 1936. This decade is probably the earliest period for which the birth and death registrations might not be too incomplete, and the recorded gains from natural increase and migration were 2,128 and 297 respectively. Together these exoeed the net inter-censal increase of 2,142 persons, but allowing for some under-registration of deaths, and perhaps fewer duplications in the 1936 enumeration, natural increase clearly predominated in the population growth over the decade.

After 1936, the rate of increase ostensibly dropped back to its former level of less than 1/3/2 per cent per annum. Until 1956, however, the natural increase and migration recorded in inter-censal periods cannot be reconciled with the population counts at each end of the periods. The number enumerated in 1945 was smaller than the number expected on the basis of the 1936 count and recorded statistics, and if this expected number was correct, approximately 5 per cent of the 'native' population were not enumerated in 1945. If the 'native' population enumerated in 1945 is advanced to 1951 in the same way, the 1951 count was roughly $22^{\frac{1}{2}}$ per cent smaller than the total expected; but the reoorded migration and natural increase for the total population between 1951 and 1956 agree closely with the population increase observed.

These deviations imply either successively fewer duplications in each enumeration or steady improvements in the completeness of the 
continuous records, or perhaps greater efficiency in both operations. Except in 1956 it was never clearly stated whether the population reoorded was de jure or de facto, and there may well have been some individuals absent from their home islands who were recorded both there and wherever they happened to be at census date. If this alternative is ignored and all counts" from 1936 are assumed reliable, the population enumerated in 1945 contained 519 males and 196 females fewer than were expected. If these numbers represent unrecorded deaths, then more than 25 per cent of all deaths were not registered in this period, but as the relatively larger deficit of males as compared with females suggests that the migration records for the wartime period may not have been complete, a fairer estimate of the maximum extent of under-registration would perhaps be one based on females only. In this case, less than 15 per cent of deaths were not registered and this implies that 310 males left the Group without being recorded.

Accepting the continuous records between the 1945 and 1951 censuses at their face value, the population expected in 1951 exceeded the population enumerated by 115 males and 280 females. If these in their turn represent unrecorded deaths, then. less than 83 per cent of all deaths which occurred in the period were registered, although the registration of the male deaths would have been 94 per cent complete. Again it is more likely that this deficit is compounded of unrecorded migrations as well as unregistered deaths, and the smaller total deficit in 1951 as compared with 1945 probably indicates greater efficiency in the maintenance of the annual records. Certainly the agreement between the numbers expected and enumerated in 1956 is as close as one can expect when one juggles populations as at the end of September and annual statistics relating to the year ended $31 \mathrm{March}$.

Whether the rate of growth is estimated from the census enumerations or from the continuous records, the Cook Islands population has increased more slowly than any other in the region during recent years, and this slow rate has been maintained despite some reduction in mortality and little effective change in the level of fertility. The changes in mortality and fertility will be discussed later, but the decline in the rate of increase of population since 1936 is clearly attributable to emigration; although the arrivals have exceeded the departures in some years, the net movement over the period was away from the Cook Islands, and this movement may have been more extensive than is indicated by the annual statistics of migrations.

New Zealand is now the chief country of immigration for Cook

" Total populations because the differentiation between Maori and European is not retained consistently in the annual statistics published in N.Z.P.P. A-3. 
Island Maoris but they are also to be found, admittedly in smaller numbers, in most territories of the South Pacific. The largest of such groups formerly was on Makatea in French Polynesia. Between 1942 and 1955, the French Phosphate Company of Oceania recruited Cook Islanders on one-year contracts to work the guano deposits on the island (N.Z.P.P. A-3, 1956, p. 38), and the 1946 census of French Oceania (as it was known until 10 August 1957) noted that 357 Cook Islanders were living on Makatea. Five years later this number had decreased to 289, and although the last of the labourers were due to be repatriated in April 1956 (N.Z.P.P. A-3, 1956, p. 38), the provisional récapitulation of the 1956 census showed 135 Cook Islanders still in French Polynesia in December 1956, with 48 on Makatea (I.N.S.E.E., 1950, 1954; Jour. Off. des E.F.O., No. 11, 1957, p. 338).

At the same time, the numbers of persons born in the Cook Islands who were included in successive censuses of New Zealand increased from 157 in 1936 to 393 in 1945 , to 999 in 1951 and finally to 1,992 in 1956, while the numbers claiming to be Cook Island Maoris increased from 103 in 1936 to 354 in 1945 and to 2,320 in 1956. In the 1951 census report, Cook Island Maoris and Niueans were bracketed together, but estimates of the number of Cook Islanders present in New Zealand in 1951 derived from ancillary tables on place of birth suggest that they may have numbered about 950 (see also Hooper, 1961, p. 13). In each census there were also relatively large numbers of 'other or undefined Polynesians' 374 in 1936, 484 in 1945, 2,265 in 1951, and 1,195 in 1956-some of whom were born in the Cook Islands, and until 1951 there was also a further category designated by 'Polynesian/Maori' (N.Z. Population Censuses: 1936, VII, pp. 21, 22; IX, p. 2; 1945, VII, pp. 23, 24; VIII, p. 2; 1951, V, pp. 15-18; 1956, VI, pp. 23-6; VII, pp. $37-9)$.

Even without these vagaries of definition, there is no way of reconciling inter-censal increases or decreases in the receiving countries with inter-censal emigration from the Cook Islands. The path from Cook Islands censuses to New Zealand's is not necessarily direot, even for Cook Island Maoris born in the Cook Islands. Many men who worked on Makatea renewed their contraots until they had saved enough money for their fare to New Zealand (Hooper, 1961, p. 12), and just as Europeans or part-Europeans born in the Cook Islands may be either temporarily or permanently domiciled in New Zealand, so are Cook Island Maoris born in New Zealand free to travel back and forth provided they can pay the boat or air fares. Hence the most (though not necessarily complete) information on emigration from the Cook Islands is likely to stem from comparisons between the sizes of cohorts 
in successive censuses there and, provided age is stated reasonably accurately, these have the additional advantage of pin-pointing the ages at which the greatest numbers of males and females are emigrating.

\section{Age and Sex Composition}

Some indications as to the reliability of ages recorded in the early censuses have already been given. In 1906 the only classification attempted was the division for males and females at 16 years, and in 1911 the populations of two islands-Pukapuka and Palmerston-were not classified by age. In both 1921 and 1926 'in certain islands a proportion of the Natives returned their ages as either under 15 years, under 45 years or over 45 years' and, including those for whom age was not stated, more than 6 per cent of each total population was so olassified (N.Z. Census Report for 1921, V, 1925, pp. 67-72; N.Z. Population Census, 1926, II, pp. 1, 3). In 1936, these grouped ages were used for just over 1 per cent of the total (N.Z. Population Census, 1936, II, 1937, p. 5). By 1945, the ages were 'fairly accurate in the circumstances, though estimation had to be resorted to in some instances' (N.Z. Population Census, 1945, II, 1947, p. 2), but the Registrar of Courts (who was in charge of the 1951 and 1956 censuses) considers that since 1945

people have become more birth-date conscious. A good enumerator will endeavour to get a reasonably good approximation to the age of each person, and I should think children's ages would be 90 per cent correct. Error would increase proportionately with the increase in the ages of the people giving the information ... . and would be much greater in the outer islands than in Rarotonga, especially in the remote atolls (Trenn, 1954).

Except at ages less than 5 years in 1951 and 1956, the population of the Cook Islands has not yet been tabulated by single years of age and their preferences for ages with certain unit digits are not therefore known. Comparisons between the numbers expected and enumerated at ages less than 1 year, 1 year, and for grouped ages $0-4$ years in both 1951 and 1956 (Table 37) indicate that the extent of under-enumeration for this age group in the censuses was probably of the same order of magnitude as the under-registration of births; but both censuses showed some deficit of children aged I year compared with the numbers expected from the birth registrations, and this defioit was particularly marked in 1951. However, this scarcely warrants the assumption that the Cook Island Maoris share other Polynesians' avoidance of ages with unit digits of 1 or 2 , even though such avoidance may give rise to artificial fluc- 
tuations in any cohort's chances of survival from one age group to the next over a five-year inter-censal interval.

It is the period since 1936 that is particularly relevant to the study of emigration and one might hope that ages during this period are better approximations than in earlier years. Since 1936, however, censuses have been taken at intervals of nine, six and five years and as the populations were tabulated only in five-year age groups, it is only for the 1936, 1951, and 1956 census populations that the same birth oohorts appear, and their survivors cannot be completely identified because the ages of the 'native' population only are available for 1951 and in 1956 the distinction between Maori and non-Maori was not retained. Nevertheless, the numbers of males and females recorded in these three censuses are given in Table 38, arrayed according to the period of birth implied by the ages stated in each census.

TABLE 37 Populations enumerated at young ages in 1951 and 1956 and numbers expected from births and deaths recorded in relevant years, by sex

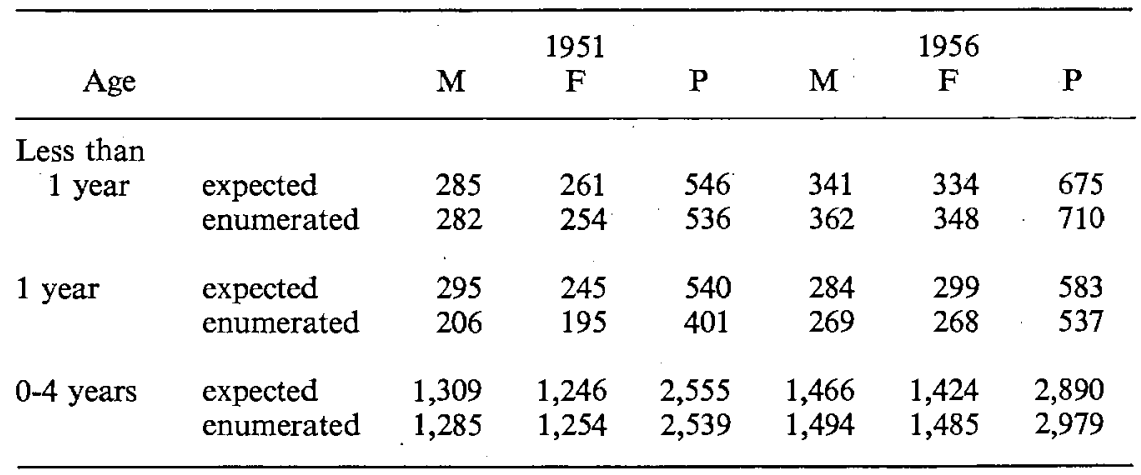

Because of the comparative uncertainty about the reliability of age statements, all of the age distributions were subjected to a simple smoothing process, and the proportions of each cohort to survive each inter-censal interval are shown in Table 39. Before computing these, the numbers of each sex in each cohort in 1951 were inflated proportionately to the excess of the total population of the relevant sex over the corresponding 'native' population. With only 207 males and 115 females to distribute over the whole range of ages, the errors introduced by this proportionate spreading would not be large.

Even with these smoothed age distributions there was no gradual decline in the chances of survival from one census to the next as the 
TABLE 38 Populations enumerated in the censuses of 1936, 1951, and 1956, according to their period of birth and age in 1956

\begin{tabular}{crrrrrrr}
\hline $\begin{array}{c}\text { Period of } \\
\text { birth }\end{array}$ & 1936 & $1951^{*}$ & 1956 & 1936 & $1951^{*}$ & 1956 & $\begin{array}{c}\text { Age in } \\
1956\end{array}$ \\
\hline $1952-56$ & & & 1,494 & & & 1,485 & $0-4$ \\
$1947-51$ & & 1,286 & 1,306 & & 1,255 & 1,238 & $5-9$ \\
$1942-46$ & & 1,131 & 1,048 & & 1,123 & 1,026 & $10-14$ \\
$1937-41$ & & 1,093 & 1,021 & & 939 & 888 & $15-19$ \\
$1932-36$ & 1,000 & 785 & 755 & 989 & 773 & 639 & $20-24$ \\
$1927-31$ & 950 & 615 & 591 & 830 & 598 & 517 & $25-29$ \\
$1922-26$ & 783 & 542 & 485 & 711 & 489 & 405 & $30-34$ \\
$1917-21$ & 616 & 426 & 444 & 631 & 435 & 390 & $35-39$ \\
$1912-16$ & 547 & 393 & 387 & 527 & 340 & 331 & $40-44$ \\
$1907-11$ & 490 & 336 & 303 & 431 & 254 & 255 & $45-49$ \\
$1902-06$ & 359 & 257 & 255 & 352 & 240 & 230 & $50-54$ \\
$1897-01$ & 331 & 227 & 185 & 306 & 212 & 191 & $55-59$ \\
$1892-96$ & 271 & 171 & 152 & 258 & 134 & 132 & $60-64$ \\
$1887-91$ & 307 & 146 & 118 & 229 & 144 & 116 & $65-69$ \\
$1882-86$ & 244 & 101 & 84 & 189 & 82 & 73 & $70-74$ \\
Before 1882 & 478 & 123 & 67 & 417 & 128 & 69 & 75 and over \\
Total & 6,376 & 7,632 & 8,695 & 5,870 & 7,146 & 7,985 & \\
\hline
\end{tabular}

*'Native' population only. The European population at this census was 207 males, 115 females.

TABLE 39 Numbers of survivors in each cohort in 1956 and 1951 per 1,000 enumerated in the previous census

\begin{tabular}{|c|c|c|c|c|}
\hline \multirow{2}{*}{$\begin{array}{l}\text { Birth } \\
\text { cohort }\end{array}$} & \multicolumn{2}{|c|}{$\begin{array}{c}\text { Survivors in } 1956 \text { per } \\
1,000 \text { enumerated in } 1951\end{array}$} & \multicolumn{2}{|c|}{$\begin{array}{l}\text { Survivors in } 1951 \text { per } \\
1,000 \text { enumerated in } 1936\end{array}$} \\
\hline & Males & Females & Males & Females \\
\hline $1947-51$ & 972 & 963 & & \\
\hline $1942-46$ & 913 & 926 & & \\
\hline $1937-41$ & 914 & 897 & & \\
\hline $1932-36$ & 938 & 830 & 799 & 789 \\
\hline $1927-31$ & 909 & 831 & 694 & 734 \\
\hline $1922-26$ & 915 & 829 & 701 & 708 \\
\hline $1917-21$ & 987 & 888 & 719 & 695 \\
\hline $1912-16$ & 941 & 958 & 728 & 641 \\
\hline $1907-11$ & 923 & 978 & 718 & 627 \\
\hline $1902-06$ & 905 & 931 & 726 & 697 \\
\hline $1897-01$ & 841 & 924 & 717 & 651 \\
\hline $1892-96$ & 835 & 897 & 617 & 598 \\
\hline $1887-91$ & 784 & 788 & 502 & 601 \\
\hline $1882-86$ & 827 & 940 & 424 & 439 \\
\hline Before 1882 & 532 & 531 & 264 & 312 \\
\hline
\end{tabular}


age of the cohorts increased. Instead, the proportion of survivors amongst the male cohorts between 1951 and 1956 fell sharply from 97 per cent for the youngest cohort to 91 per cent for all cohorts but one born between 1922 and 1946, rose abruptly to 99 per cent for the 1917-21 cohort and then declined more or less conventionally as the age of the cohorts increased. For the females there was a more gradual deoline in the chances of survival at young ages: starting at 96 per cent for the 1947-51 cohort, it fell to 83 per cent for the three cohorts born between 1922 and 1936, rose gradually again to 98 per cent for the 1907-11 cohort and then declined as one would expeot with increasing age.

To estimate the population expected in 1956 if mortality was the sole source of losses over the period, the probabilities of survival from one age group to the next were computed from male and female life tables based on the smoothed average annual age-specific mortality rates for the two periods 1950-2 and 1955-7. When these were applied to the graduated populations of 1951 , inflated so as to be comparable with those of 1956, the survivors expected at ages 5 years and over in 1956 were 7,353 males and 6,782 females. As the numbers enumerated at these ages in 1956 were 7,192 males and 6,504 females, the loss that might be attributed to emigration was therefore 161 males and 278 females, and this total of 439 persons aged 5 years and over is not very different from the 463 persons of all ages computed from the migration recorded for years ended 31 March adjusted to years ending 30 September by assuming that arrivals and departures were spread evenly throughout the year.

This figure may, however, be too low because for some cohorts the expected numbers of survivors were fewer than the numbers recorded in 1956, and as the cohorts particularly affected in this way were the youngest and oldest cohorts of both sexes, the levels of mortality estimated for persons of their ages were perhaps too high. If persons born before 1902 are disregarded, the estimated net loss from migration was of the order of 200 males and 330 females. Whichever estimate is selected, the total volume of emigration between 1951 and 1956 is reasonably consistent with both the net migration recorded and the inter-censal change in population numbers, and all estimates indicate more emigration of females during this period than of males.

This difference between males and females was not apparent at young ages; of children aged 5-14 years in 1951, less than 7 per cent of males and 6 per cent of fermales had left the population before 1956, and one might therefore guess that boys leave, presumably for school, a little earlier than girls. The 7 per cent loss from the 1942-6 cohort was the greatest from any cohort of males over this period, and although the 
loss from the 1937-41 cohort approached this, surprisingly few (less than 3 per cent) of the 1932-6 cohort left the population between 1951 and 1956. About 5 per cent of males from the two older cohorts may have emigrated during this period, but very few of the males born before 1922 did so.

The pattern for females was apparently quite different. Roughly twothirds of all females who left the population between 1951 and 1956 were born between 1922 and 1936, and these three cohorts lost about 12 per cent of their number during those five years. The 1917-21 cohort was depleted by more than 6 per cent, but thereafter cohort size tended to be larger than was expected. This could mean either that their mortality during the period was less than was estimated, or that there had been some gain from immigration at these ages. Undoubtedly the greatest loss from the population, both numerically and relatively, between 1951 and 1956 was of females at all ages from their late teens through to their early thirties.

The other half of Table 39 shows the relative numbers of survivors in 1951 from the cohorts enumerated in 1936 and, except for children aged less than 15 years in 1936, the chances of 'survival' in the population were generally greater for males than for females. There are no detailed statistics of deaths for any years before 1944, but some of this sex differential in 'survival' may be due to a sex differential in mortality, because mortality rates in childhood and at most ages up to the end of the female reproductive period were higher for females than for males in both 1944-6 and 1950-2.

The figures for the 1927-31 and 1922-6 cohorts of males suggest that there had been some loss from these cohorts through emigration over the fifteen-year interval, and probably some loss also from the 1917-21 cohort. Amongst the females, the cohorts with the fewest survivors in 1951 were the two which passed through the ages of maximum reproduction-from 20-24 to 35-39 years for one, and from 25-29 to 40-44 for the other-between 1936 and 1951, and emigration may therefore have played only a minor role in depleting their strengths. The total migration recorded over this interval was a net loss of 189 males and 365 females, but the comparisons of cohort size in successive censuses suggest that a much greater loss than this actually occurred.

One would expect this loss of children and young adults from the population to distort its age structure, so that children aged 0-4 years and older persons would constitute relatively larger proportions of the total population than they would otherwise do. That there has been a slight change in the proportions of both males and females at ages $0-4$ years in 1956 as compared with earlier years can be seen in Table 40 , in which 
the populations enumerated in the various censuses have been reduced to 1,000 persons of each sex, with the numbers in each age group proportional to this total. The age distributions for 1956 are not strictly comparable with those of earlier years, but the classification of the total population by age is available for 1936 and 1945, and the greatest difference then between the numbers of 'natives' and all races in these proportionate distributions was a matter of 3 in 149 at ages 5-9 years in 1936. Hence, the inclusion of population other than 'native' in 1956 makes very little difference.

TABLE 40 Number of males and females in each age group per 1,000 enumerated at all ages in the 'Native' populations of 1936, 1945, and 1951 and in the total population of 1956

\begin{tabular}{|c|c|c|c|c|c|c|c|c|}
\hline \multirow{2}{*}{$\begin{array}{l}\text { Age } \\
\text { group }\end{array}$} & \multicolumn{4}{|c|}{ Males } & \multicolumn{4}{|c|}{ Females } \\
\hline & 1936 & 1945 & 1951 & 1956 & 1936 & 1945 & 1951 & 1956 \\
\hline $0-4$ & 158 & 161 & 169 & 172 & 170 & 172 & 176 & 186 \\
\hline $5-9$ & 152 & 164 & 149 & 152 & 141 & 155 & 157 & 155 \\
\hline $10-14$ & 125 & 135 & 144 & 120 & 123 & 132 & 133 & 128 \\
\hline $15-19$ & 98 & 103 & 103 & 117 & 109 & 106 & 108 & 111 \\
\hline $20-29$ & 164 & 145 & 152 & 155 & 162 & 158 & 152 & 145 \\
\hline $30-39$ & 106 & 108 & 107 & 107 & 110 & 100 & 108 & 100 \\
\hline $40-49$ & 89 & 74 & 78 & 79 & 83 & 76 & 69 & 73 \\
\hline $50-59$ & 63 & 61 & 52 & 50 & 54 & 53 & 48 & 53 \\
\hline $60-69$ & 29 & 35 & 32 & 31 & 31 & 30 & 32 & 31 \\
\hline over & 16 & 14 & 14 & 17 & 17 & 18 & 17 & 18 \\
\hline All ages & 1,000 & 1,000 & 1,000 & 1,000 & 1,000 & 1,000 & 1,000 & 1,000 \\
\hline
\end{tabular}

Female children aged 0-4 years have always constituted a larger proportion of the total female population than have the males of these ages in their total, and this proportion has risen slightly over the years. There has been an almost parallel fall in the contribution of the age group 20-29 years to the female total, but all other age groups have maintained roughly the same proportions from one census to the next. The changes in the age structure of the male population are not dissimilar: the age group 0-4 years has contributed rather more to the total male population in reoent years, and this has been offset by some decrease in the proportions at ages 20-29 years, but even more in 1956 by the smaller contribution to the total made by the age group 10-14 
years. At the same time, the proportion of the male population contained in the age group 15-19 years increased.

In a distribution of this kind where the numbers contained in all age groups in any particular year must add to 1,000 , a decrease in the proportion of the total contributed by one age group must entail some increase in the contribution of at least one other age group. The emigration of persons in their twenties has already been demonstrated, and the decreasing contribution of the age group 20-29 years to the total could be sufficient to explain the rise in the share contributed by children aged 0-4 years. However, the numbers of children at these ages per 1,000 women aged 15-44 years have also increased consistently since 1936 and, ignoring the possible causes of these increases and the local variations in the ratio which will be discussed later, one would therefore expect some increase in the proportion of population at ages $0-4$ years. Had this been the only change to occur, one would also expect the proportions. of population at all other ages to have declined uniformly, and not be limited almost exclusively to the contribution of one age group. One can only conclude, therefore, that the changes which have accurred in the age structure of the Cook Islands population are the resultant of at least two and probably all three factors of population change.

TABLE 41 Numbers of children aged 0-4 years per 1,000 females 15-44 years enumerated in successive censuses

\begin{tabular}{lcccr}
\hline & 1936 & 1945 & 1951 & 1956 \\
\hline Rarotonga & 753 & 819 & 848 & 823 \\
Lower Group excluding Rarotonga & 854 & 900 & 952 & 1,067 \\
Northern Group & 808 & 688 & 769 & 948 \\
$\quad$ Cook Islands Total & 804 & 837 & 881 & 940 \\
\hline
\end{tabular}

The geographic differences in the values of the child-woman ratios in Table 41 imply that the changes in structure were not uniform throughout all islands of the Group. The populations of many of the islands are too small for individual analysis, and the only island whose population is examined alone in this study is Rarotonga. Despite the differences which may exist between them, the islands of the Northern Group are treated as one entity, as for most purposes are the islands of the Lower Group other than Rarotonga. The distributions over broad ranges of age of each 1,000 males and 1,000 females in these three populations at different times are given in Table 42 and again the 1956 distributions 
relate to the total population whereas those for earlier years concern the 'native' population only. Rarotonga's is the only population for which the comparisons with earlier years will be much affected by the inclusion of the non-Maori population in 1956, and the population least affected will be that of the Northem Group.

All of the populations show some variations in structure over the two decades. In the Northern Group the proportion of population aged less than 15 years declined between 1936 and 1945, and has risen in recent years. Not all of this variability can be attributed to indifferent enumeration because the relatively large numbers aged less than 15 years in 1936 are reflected in the high proportions of persons aged 15 to 29 years in 1951 and similarly, the small proportions aged less than 15 in 1945 are reflected in the numbers at ages 15 to 29 in 1956. There were relatively few females in the first half of the reproductive period in 1936 and this probably accounts for some of the decrease in the numbers of persons aged less than 15 years in the next two censuses. Conversely, the relatively larger number of females aged 15 to 29 in 1951 would be responsible for at least part of the increase in numbers at ages 0-4 years in both 1951 and 1956. Such changes in the distribution of females throughout the reproductive span would contribute to the variations recorded in the child-woman ratios given in Table 41.

The structure of the population of the Lower Group excluding Rarotonga is rather more stable than any of the others, and its most remarkable feature is the increase in the proportion of the population aged less than 15 years from about 45 to 50 per cent of the total over the two decades. If this was due solely to the better enumeration of young children, the increase in the child-woman ratios from 854 in 1936 to 1,067 in 1956 implies that 20 per cent of children aged 0-4 were omitted in 1936. It is more likely that this increase is due to a combination of factors-more complete enumeration of relatively larger numbers of children surviving to be recorded in successive censuses-but whatever its source, one would expect compensating decreases in the proportions of population at other ages. In this segment of the population, however, the decrease appears to be confined to the age group 15 to 29 years, and the fact that the proportions at higher ages remain virtually unaltered suggests that the smallness of this group is not due solely to the increasing predominance of the under 15 years group, but that there has also been some loss of young adults from this population.

But for the lack of comparability between the 1956 population and the preceding ones for Rarotonga, one might conclude that this was the destination of the young adults from the other islands of the Lower Group. Superficially the proportions of population at these ages in 
TABLE 42 Distribution with respect to age of males and females in various islands in successive censuses, each reduced to a common base of 1,000

\begin{tabular}{|c|c|c|c|c|c|c|c|c|}
\hline \multirow{2}{*}{$\begin{array}{l}\text { Age } \\
\text { group }\end{array}$} & \multicolumn{4}{|c|}{ Males } & \multicolumn{4}{|c|}{ Females } \\
\hline & 1936 & 1945 & 1951 & 1956 & 1936 & 1945 & 1951 & 1956 \\
\hline \multicolumn{9}{|c|}{ Rarotonga } \\
\hline $0-4$ & 153 & 151 & 155 & 150 & 166 & 166 & 167 & 173 \\
\hline $5-14$ & 262 & 302 & 282 & 256 & 260 & 294 & 292 & 277 \\
\hline $15-29$ & 276 & 245 & 275 & 313 & 287 & 259 & 256 & 272 \\
\hline $30-44$ & 154 & 150 & 153 & 149 & 158 & 140 & 148 & 142 \\
\hline $45-59$ & 112 & 107 & 87 & 85 & 85 & 94 & 85 & 86 \\
\hline $\begin{array}{l}60 \text { and } \\
\text { over }\end{array}$ & 43 & 45 & 48 & 47 & 44 & 47 & 52 & 50 \\
\hline \multicolumn{9}{|c|}{ Lower Group excluding Rarotonga } \\
\hline $0-4$ & 169 & 176 & 188 & 190 & 177 & 190 & 184 & 197 \\
\hline $5-14$ & 294 & 313 & 318 & 297 & 268 & 287 & 311 & 306 \\
\hline $15-29$ & 250 & 239 & 227 & 238 & 273 & 274 & 253 & 235 \\
\hline $30-44$ & 147 & 143 & 141 & 147 & 150 & 133 & 144 & 142 \\
\hline $45-59$ & 95 & 89 & 87 & 85 & 81 & 78 & 71 & 80 \\
\hline $\begin{array}{l}60 \text { and } \\
\text { over }\end{array}$ & 45 & 40 & 39 & 43 & 51 & 38 & 37 & 40 \\
\hline \multicolumn{9}{|c|}{ Northern Group } \\
\hline $0-4$ & 140 & 142 & 150 & 185 & 162 & 132 & 172 & 192 \\
\hline $5-14$ & 272 & 254 & 246 & 241 & 262 & 264 & 219 & 239 \\
\hline $15-29$ & 256 & 282 & 277 & 246 & 223 & 250 & 295 & 268 \\
\hline $30-44$ & 132 & 149 & 176 & 171 & 154 & 164 & 134 & 134 \\
\hline $45-59$ & 137 & 87 & 83 & 90 & 137 & 105 & 107 & 94 \\
\hline $\begin{array}{l}60 \text { and } \\
\text { over }\end{array}$ & 63 & 86 & 68 & 67 & 62 & 85 & 73 & 73 \\
\hline \multicolumn{9}{|c|}{ All Islands } \\
\hline $0-4$ & 158 & 161 & 169 & 172 & 170 & 172 & 176 & 186 \\
\hline $5-14$ & 277 & 300 & 293 & 272 & 264 & 287 & 290 & 283 \\
\hline $15-29$ & 261 & 248 & 254 & 272 & 270 & 264 & 260 & 256 \\
\hline $30-44$ & 148 & 146 & 151 & 151 & 154 & 141 & 144 & 141 \\
\hline $45-59$ & 109 & 96 & 86 & 85 & 92 & 88 & 82 & 85 \\
\hline $\begin{array}{c}60 \text { and } \\
\text { over }\end{array}$ & 47 & 49 & 47 & 48 & 50 & 48 & 48 & 49 \\
\hline All ages & 1,000 & 1,000 & 1,000 & 1,000 & 1,000 & 1,000 & 1,000 & 1,000 \\
\hline
\end{tabular}


Rarotonga increased between 1951 and 1956, but it is likely that at least part of this increase is due to the inclusion of the non-Maori population in 1956. Because the proportions at most other ages have declined over this period, it is probable that the concentration of the population at these ages is the dominant factor of change in population structure, and that the decrease recorded in the numbers of children aged 0-4 years relative to the women of reproductive age is of only secondary importance.

As the principal island in the group, Rarotonga attracts people from the other islands, either for what it offers socially and economically or as a prelude to overseas migration. In the census of 1956 , only 64 per cent of the population enumerated on Rarotonga were born there as compared with 73 per cent in 1945 and 67 per cent in 1936. If the 'native' or Maori population alone is considered, in 194574 per cent of Rarotonga's population were born there, and although the data are not available for other years, it is unlikely that the proportions of Rarotonga's 'native' population who were born there would differ much from the proportions quoted above for the total population. At the same time, persons born in Rarotonga show little inclination to live elsewhere in the Group, and in 1956, 87 per cent of persons born in Rarotonga were also enumerated there.

In the other islands of the Lower Group, only 74 per cent of both males and females were enumerated on their island of birth, although a further 4 per cent were on islands of the Lower Group other than Rarotonga or their island of birth. For the Northern islands, 65 per cent of males and 69 per cent of females were enumerated on their island of birth, but as 12 per cent of both sexes were on other islands of the Northern Group, their contribution to Rarotonga's population was relatively no greater than that of the Lower Group islands.

Such proportions of persons born and enumerated on the one island may be misleading, however, unless the population is classified according to age as well as birthplace. Children are born where their mothers happen to be at the time of their birth, and as long as they are children they will usually be enumerated in the same locality as one or both parents. Children under 10 years of age make up one-third of the total population, and consequently they may have a considerable weight in any generalization about the population as a whole. Even without them, inter-island migration has been occurring for more than a century, and the situation in regard to birthplace or geographic origin is now too complex to be sorted out in a simple population census.

All censuses since 1936 have shown a predominance of males in the total population, and this appears at most ages in all populations except 
that of the Northern Group. The ages at which this excess of males is most marked can usually be traced through from census to census, and this is perhaps some indication that the statement of age in any one census is reasonably consistent with the age given in the subsequent ones. In 1945, for example, there was an excess of males at ages 5-9 years; in 1951 there was an abnormally high proportion of males in the population aged 10-14 years, and in 1956, the sex ratio for this cohort at ages 15-19 years was comparable with its previous value. Similarly, there was a predominance of males in the Northern Group at ages $25-29$ years in 1945; this reappeared at ages 30-34 years in 1951 and was greater still at ages 35-39 years in 1956.

In the total population there was, however, some excess of males at ages 20 to 34 years in 1956 which was not in evidence in the earlier censuses, and although some part of this may be due to the inclusion of the non-Maori population in the 1956 tabulations, the emigration of females of these ages in the interval has also contributed. The excess of males at these ages was most marked for Rarotonga, and although the population of the Northern Group showed some deficit of males at these ages, the deviations from a strict one-to-one sex ratio do not attain levels of statistical significance.

\section{Registration of Births and Deaths}

Changes in the sex ratio at each age in the various populations and the age structure of these populations reflect the patterns of mortality and fertility as well as those of migrations, but it is only for comparatively recent years that any analysis of such patterns is possible. The civil registration of births and deaths in the Cook Islands was provided for in regulations made under Section 15 of the Cook Islands Act 1915, and though these were due to come into force on 1 July 1916, 'owing to the delay in the supply of registers, etc., the Administration could not take over the registration until 1st April, 1917' (N.Z.P.P. A-3, 1917, p. 15). Prior to this the London Missionary Society and other missions maintained their own registers of births and deaths, but registration was not compulsory and the information recorded was not always uniform.

The regulations gazetted on 29 June 1916 allowed the Governor of New Zealand or the Resident Commissioner of the Cook Islands to 'appoint such persons as he thinks fit to act as Registrars of Births and Deaths at such places as he may from time to time determine', and in practice the Resident Agents are the registrars within the areas assigned, to them for their normal duties. The regulations stipulated both the information to be supplied to the Registrars and the form of the registers; they also made provision for the registration within the first two years 
of their operation of the births of children born in the islands since 31 December 1899 and for the registration of deaths that occurred during the first six months of 1916. These have now been revoked by the Cook Islands Births and Deaths Registration Regulations 1962 (1962/67), but the extracts given below are from the initial regulations (New Zealand Gazette, 1916) because these are relevant to the period being considered here.

\section{REGISTRATION OF BIRTHS.}

2. (1.) Within one month after the date of the birth of any child born on or after the 1st day of July, 1916, the following particulars shall be furnished to a Registrar .....:-

(a.) The date and place of birth.

(b.) The Christian or first name and the sex of the child.

(c.) The names of the father and mother respectively and their place of residence.

(d.) Description of the father and mother (if Natives, state whether of full blood, or quarter, half or three-quarter caste).

(e.) Name and description of informant.

(2.) The persons hereinafter specified shall be deemed responsible for duly furnishing to the Registrar the particulars before referred to in respect of the birth of any child:-

(a.) The father and mother of the ohild.

(b.) Every occupier of the house or building in which the child was born.

(c.) Any person present at the birth of the child.

3. (1.) On receipt of the particulars of the birth of any child as aforesaid the Registrar shall enter the name in the Register of births, and on a duplicate sheet to be supplied for the purpose by the Resident Commissioner.

(2.) On receipt of any particulars of the birth of any child which the Registrar deems sufficient the Registrar may enter the same in the Register of Births and on the duplicate sheet aforesaid, notwithstanding that the full particulars required by these regulations have not been furnished.

6. At any time after one month and not later than six months next after the birth of any child the Registrar may, by notice in writing, require the parent or some person present at the birth to attend personally at his office within the time specified in the notice and give information of the particulars required to be registered, and the Registrar shall thereupon register the birth according to the information so given. 
REGISTRATION OF DEATHS.

7. (1.) Within one month from the date of the death of any person occurring on or after the 1st day of July, 1916, the following particulars shall be furnished to a Registrar .... . :-

(a.) The date and place of death.

(b.) The name and residence of the doceased.

(c.) The age of the deceased (if known).

(d.) The sex of the deceased.

(e.) The name and residence of the father and mother respectively of the deceased.

(f.) Description of the father and mother of the deceased (if Native, whether of full blood, or quarter, half, or threequarter caste, as the case may be).

(g.) If married, name of husband or wife.

(h.) Number and sex of children living (if any).

(i.) Whether deceased attended by medical practitioner during last illness, and, if so, the certified cause of death.

(j.) Name and description of informant.

(2.) The persons hereinafter specified shall be deemed responsible for duly furnishing to the Registrar the particulars hereinbefore referred to in respect of the death of any person:-

(a.) Every occupier of the house or building in which the death took place.

(b.) Any person present at such death.

9. (1.) On receipt of the particulars of the death of any person as aforesaid the Registrar shall enter the same in the Register of Deaths, and on a duplicate sheet to be supplied for the purpose by the Resident Commissioner.

(2.) On the receipt of any particulars of the death of any person which the Registrar deems sufficient the Registrar may enter the same in the Register of Deaths and on the duplicate sheet aforesaid, notwithstanding that the full particulars required by these regulations have not been furnished.

Regulations 10 and 11 concerned the medical certification of death and notice of burial respectively, and No. 12 instruoted the Registrars to forward the duplicate sheets of all registrations to the Registrar of the High Court at Rarotonga at 3-monthly intervals. The regulations concluded with

20. Where for any sufficient cause shown to the satisfaction of the Registrar any act, matter, or thing required by these regulations cannot be done within the time limited by or in strict compliance with 
the conditions imposed by these regulations, it shall be sufficient if such act, matter, or thing is done within a reasonable time thereafter, or if the conditions imposed are complied with so far as is reasonably possible.

There was no separate legal provision for still-births, and these were registered as births, with the word 'still-born' entered in the space for the name of the child. There was no corresponding entry in the register of deaths, and the same procedure has been written into the 1962 Regulations where a still-born child is defined as 'a child that has issued from its mother after the expiration of the twenty-eighth week of pregnancy and was not alive at the time of such issue. Under these regulations the ages of the parents at the birth of any child are required, but the number of children born previously to the mother is still not asked. The fines for failure to comply with the regulations remain as before.

In 1948 it was stated that 'full routine notification of death was not established in Rarotonga until late in 1947 and is not yet established in the outer islands. Figures, with causes of death, are at present available only from three islands, and many deaths are recorded without any cause being attached' (N.Z.P.P. A-3, 1948, p. 11). Such tests for completeness as are possible suggest that registration has improved in recent years, and if some of the births and deaths which occur on the smaller outer islands escape registration, almost all of those which occur on the larger islands nowadays are registered.

Formerly, if there was failure to report the occurrence of either a birth or a death, it was more likely the death which escaped notification. The regulations governing the inheritance of land tended to ensure the completeness of the registration of births and, in populations where infant mortality contributes largely to total mortality, the completeness of the registration of deaths is closely linked to that of births. The recording of still-born infants in the birth registers may be a further safeguard to the completeness of registration, but even when legally defined, the 'still-born' may well include some early neo-natal deaths which do not then appear in the death registers, and this may lead to under-statement of the infant mortality.

\section{Analyses of Mortality}

The deaths recorded on each island are summarized each year for the Annual Report of the Administration, but the form in which they are published varies from time to time. It is customary to show the total number of deaths in the 'native' or Maori population by sex, and until 
1945 the numbers of deaths of males and females on each island were usually given, sometimes with a classification according to the ages of the deceased, sometimes not. Since 1945, the numbers of deaths occurring at certain ages in each year have been published, but from 1945 to 1952 five of the eleven ages or age groups listed related to ages less than 1 year, and the deaths of males and females at these ages were not given separately. Since 1953 the Annual Reports show the numbers of persons who died at ages less than 1 year, 1-4 years, and in ten-year age groups thereafter up to 64 years, but again without distinguishing between males and females at any age. More consistent information about the deaths each year is kept on file in Rarotonga, but as this too was inadequate for an analysis of mortality, the deaths recorded in the registers for each island in the years 1944-6, 1950-2, and 1955-7 were summarized by sex and age in single years up to 5 years, and five-year groups of age thereafter.

The average annual age-specific mortality rates for males and females derived from these tabulations of deaths and the 1945, 1951, and 1956 census populations are given in Table 43. In order to keep the

TABLE 43 Average annual mortality rates per 1,000 population at each age for males and females in the Cook Islands in the years 1944-6, 1950-2, and 1955-7

\begin{tabular}{|c|c|c|c|c|c|c|}
\hline \multirow[t]{2}{*}{ Age group } & \multicolumn{2}{|c|}{$1944-6$} & \multicolumn{2}{|c|}{$1950-2$} & \multicolumn{2}{|c|}{$1955-7$} \\
\hline & Male & Female & Male & Female & Male & Female \\
\hline $0^{*}$ & $138 \cdot 1$ & $100 \cdot 4$ & $118 \cdot 6$ & $112 \cdot 0$ & $123 \cdot 7$ & $114 \cdot 4$ \\
\hline $1-4$ & $\dagger$ & + & $16 \cdot 6$ & $19 \cdot 3$ & $10 \cdot 6$ & $17 \cdot 3$ \\
\hline$(0-4)$ & $(45 \cdot 9)$ & $(35 \cdot 7)$ & $(42 \cdot 8)$ & $(42 \cdot 0)$ & $(39 \cdot 5)$ & $(42 \cdot 0)$ \\
\hline $5-9$ & $2 \cdot 8$ & $4 \cdot 4$ & $3 \cdot 8$ & $5 \cdot 9$ & $4 \cdot 3$ & $2 \cdot 7$ \\
\hline $10-14$ & $3 \cdot 5$ & $4 \cdot 8$ & $3 \cdot 4$ & $3 \cdot 9$ & $2 \cdot 9$ & $3 \cdot 3$ \\
\hline $15-19$ & $12 \cdot 9$ & $13 \cdot 3$ & $8 \cdot 9$ & $8 \cdot 6$ & $2 \cdot 6$ & $6 \cdot 0$ \\
\hline $20-24$ & $8 \cdot 7$ & $13 \cdot 4$ & $10 \cdot 3$ & $12 \cdot 3$ & $6 \cdot 2$ & $6 \cdot 3$ \\
\hline $25-29$ & $8 \cdot 7$ & $12 \cdot 4$ & $7 \cdot 4$ & $15 \cdot 7$ & $4 \cdot 5$ & $9 \cdot 0$ \\
\hline $30-34$ & $13 \cdot 7$ & $10 \cdot 2$ & $5 \cdot 5$ & $11 \cdot 5$ & $12 \cdot 4$ & $7 \cdot 4$ \\
\hline $35-39$ & $10 \cdot 7$ & $12 \cdot 8$ & $8 \cdot 5$ & $8 \cdot 9$ & $6 \cdot 8$ & $9 \cdot 4$ \\
\hline $40-44$ & $33 \cdot 3$ & $16 \cdot 7$ & $8 \cdot 0$ & $10 \cdot 5$ & $10 \cdot 3$ & $8 \cdot 1$ \\
\hline $45-49$ & $26: 6$ & $24 \cdot 4$ & $22 \cdot 1$ & $12 \cdot 5$ & $11 \cdot 0$ & $15 \cdot 7$ \\
\hline $50-54$ & $30 \cdot 2$ & $30 \cdot 2$ & $39 \cdot 8$ & $36 \cdot 2$ & $17 \cdot 0$ & $37 \cdot 7$ \\
\hline $55-59$ & $34 \cdot 0$ & $25 \cdot 8$ & $25 \cdot 5$ & $29 \cdot 9$ & $23 \cdot 4$ & $20 \cdot 9$ \\
\hline $60-64$ & $51 \cdot 3$ & $70 \cdot 5$ & $61 \cdot 6$ & $34 \cdot 7$ & $74 \cdot 6$ & $45 \cdot 5$ \\
\hline $65-69$ & $73 \cdot 7$ & $37 \cdot 5$ & $56 \cdot 1$ & $36 \cdot 6$ & $50 \cdot 9$ & $37 \cdot 4$ \\
\hline $70-74$ & & 27.1 & $149 \cdot 4$ & $117 \cdot 9$ & $95 \cdot 2$ & $91 \cdot 3$ \\
\hline 75 and over & & $221 \cdot 1$ & $132 \cdot 1$ & $185 \cdot 2$ & $134 \cdot 3$ & $91 \cdot 8$ \\
\hline All ages & $20 \cdot 8$ & $20 \cdot 1$ & $18 \cdot 1$ & $19 \cdot 0$ & $15 \cdot 8$ & $16 \cdot 6$ \\
\hline
\end{tabular}

*Infant mortality per 1,000 live births registered.

$\uparrow$ Not available. 
table as straightforward as possible, the standard errors of the rates are not snown but, because of the small numbers of males and females in each age group, most of the rates have standard errors of approximately half their own magnitude. The exceptions in this respect are the rates at ages less than one year, 1-4 years, and from 60-64 years on. The rates at age 0 , it should be noted, are the infant mortality, rates per 1,000 live births for the period shown, although the rates for ages $0-4$ given in parentheses are the customary mortality rates in which the deaths at ages 0-4 years were referred to the population recorded at these ages in the censuses.

Because of the large standard errors associated with the age-specific rates it is impossible to distinguish between random fluctuations due to the smallness of the base populations and differences attributable to some cause between the rates at various ages. In 1944-6, for example, both males and females showed a sharp increase in mortality at ages 15-19 years as compared with those in the two younger age groups, and for females this relatively high rate was maintained throughout the reproductive period. In 1950-2 the difference between the mortality rates at ages 10-14 and 15-19 was less marked than in the earlier period, and in 1955-7 it had disappeared for males, although a trace still remained for females. From circumstantial evidence it appears likely that the predominant cause of death at these ages was tuberculosis, and that this change in the pattern of mortality with age is a genuine refleotion of the increasing measure of control over this disease. None of the differences between the rates attains statistical significance, however, and this inference cannot be substantiated.

Nor can the excess of female mortality at certain ages be conclusively demonstrated by tests of significance. Nevertheless the mortality rates for females are consistently higher than those for males at most ages between 5 and 44 years, and among infants and persons at ages beyond 45 years the rates for males tend to exceed those for females. This pattern is uniform throughout the three series of rates, even though there has been a slight lessening of mortality over the docade. Again, none of the changes attains levels of statistical significance, but there has been a reasonably consistent fall in the mortality rates of males aged 35 to 54 years and of females in the reproductive ages.

The extent of this improvement is perhaps made clearer in Table 44, which attempts to compare the number of deaths registered for males and females in each period, and the numbers of deaths which would have occurred in the several populations had they experienced the agespecific mortality rates prevailing for males and females in the Group as a whole in 1955-7. There are some difficulties in doing this because 
TABLE 44 The numbers of deaths recorded for males and females in the various populations during certain years and the numbers which would have occurred had each population experienced the agespecific mortality rates of males and females in the total population in $1955-7$

\begin{tabular}{|c|c|c|c|c|c|c|c|}
\hline \multirow[b]{3}{*}{ Population } & \multirow[b]{3}{*}{ Years } & \multicolumn{6}{|c|}{ Number of deaths in populations } \\
\hline & & \multirow[b]{2}{*}{ Obs. } & \multicolumn{3}{|c|}{ Males Ratio } & \multicolumn{2}{|c|}{ Females } \\
\hline & & & Exp. & $\begin{array}{c}\text { Ratio } \\
\text { Obs./Exp. }\end{array}$ & Obs. & Exp. & $\begin{array}{c}\text { Ratio } \\
\text { Obs./Exp. }\end{array}$ \\
\hline \multirow{3}{*}{ Rarotonga } & $1944-46$ & 175 & $*$ & & 147 & $*$ & \\
\hline & $1950-52$ & 161 & $140 \cdot 4$ & $1 \cdot 15$ & 169 & $132 \cdot 7$ & $1 \cdot 05$ \\
\hline & $1955-57$ & 146 & $171 \cdot 1$ & $0 \cdot 85$ & 151 & $163 \cdot 7$ & 0.92 \\
\hline \multirow{3}{*}{$\begin{array}{l}\text { Lower Group } \\
\text { excluding } \\
\text { Rarotonga }\end{array}$} & $1944-46$ & 197 & $*$ & & 207 & * & \\
\hline & $1950-52$ & 200 & $157 \cdot 8$ & $1 \cdot 27$ & 166 & $151 \cdot 2$ & $1 \cdot 10$ \\
\hline & $1955-57$ & 182 & $171 \cdot 8$ & $1 \cdot 06$ & 170 & $165 \cdot 3$ & $1 \cdot 03$ \\
\hline \multirow{3}{*}{$\begin{array}{l}\text { Lower Group } \\
\text { including } \\
\text { Rarotonga }\end{array}$} & $1944-46$ & 372 & $279 \cdot 9 \div$ & $1 \cdot 33$ & 354 & $284 \cdot 5 \dagger$ & $1 \cdot 24$ \\
\hline & $1950-52$ & 361 & $298 \cdot 2$ & $1 \cdot 21$ & 335 & $283 \cdot 9$ & $1 \cdot 18$ \\
\hline & $1955-57$ & 328 & $342 \cdot 9$ & 0.96 & 321 & $329 \cdot 0$ & 0.98 \\
\hline \multirow{3}{*}{ Northern Group } & $1944-46$ & 76 & $56 \cdot 1 \dagger$ & $1 \cdot 35$ & 62 & $51 \cdot 4 \dagger$ & $1 \cdot 21$ \\
\hline & $1950-52$ & 53 & $57 \cdot 7$ & 0.92 & 72 & $62 \cdot 3$ & $1 \cdot 16$ \\
\hline & $1955-57$ & 83 & $68 \cdot 2$ & $1 \cdot 22$ & 76 & $67 \cdot 9$ & $1 \cdot 12$ \\
\hline \multirow{3}{*}{ Cook Islands } & $1944-46$ & 448 & $336 \cdot 0$ & $1 \cdot 33$ & 416 & $335 \cdot 9$ & $1 \cdot 24$ \\
\hline & $1950-52$ & 414 & $355 \cdot 9$ & $1 \cdot 16$ & 407 & $346 \cdot 2$ & $1 \cdot 18$ \\
\hline & $1955-57$ & 411 & $411 \cdot 1$ & $1 \cdot 00$ & 397 & $396 \cdot 9$ & $1 \cdot 00$ \\
\hline
\end{tabular}

*The form of the census tabulations in 1945 does not permit estimates for these populations.

$\dagger$ Assuming that all population other than 'native' was enumerated on islands of the Lower Group.

in 1945 the geographic distribution of the population in each age group was given for the 'native' population only, and the ages of all other populations were summarized for the Group as a whole.

To estimate the deaths expected for the Lower Group including Rarotonga, it was therefore assumed that all population other than 'native' resided in the islands of the Lower Group, with none at all in the Northern Group. The number of persons displaced from their rightful populations by this would be very small, but it may have caused minimal exaggeration of the mortality in the Lower Group, at the expense of the Northern Group. In 1951 only the 'native' population was tabulated by age and the deaths for 1950-2 are therefore those of 'natives' only, even though the rates from which the expected numbers 
were derived relate to the total population. As there are so few deaths amongst the population other than 'native', the expected numbers of deaths for the years 1950-2 are probably too low and consequently the ratios between these and the numbers recorded are probably too high. This ratio, the 'obs./exp.' of Table 44, will exceed 1 when the mortality in a population is at a higher level than was experienced in the population as a whole in 1955-7.

Despite their deficiencies, these data do permit the general conclusion that, for the population as a whole, mortality has fallen by roughly one-quarter for males and one-fifth for females. Neither from this comparison nor from the age-specific mortality rates does there seem to have been any significant change over the period in the mortality of females in either the Northern Group or in islands of the Lower Group other than Rarotonga. The mortality of males in these latter islands may have decreased a little, but it is the decline in the mortality of Rarotonga's population which accounts for much of the improvement for the population as a whole.

In populations such as these one might perhaps expect such improvements in mortality to be directly associated with changes in infant mortality. Here, however, this does not appear to be the case because, although the infant mortality rates in each area fluctuate from year to year, until 1958 there had been no steady or marked downward trend in any of them. During 1958 Child Welfare services were expanded and the infant mortality rate from January 1958 to December 1960 averaged 50 deaths per 1,000 births each year (N.Z.P.P. A-3, 1961, p. 47). The decline on Rarotonga was even more dramatic. The average infant mortality rates for males and females for three-year periods corresponding to the statistics of deaths are given in Table 45, and although standard errors are shown only for all infants irrespective of sex, the standard errors of the rates for males or females separately are approximately 50 per cent higher than these.

The rates for Rarotonga and the other islands of the Lower Group are slightly lower than those for the Northern islands at each period, but the differences are not statistically significant and there was no significant change in any of the rates over the period. There must, therefore, have been a.change in the mortality from diseases other than those associated with infancy to have produced this relatively greater improvement in the islands of the Lower Group as compared with those of the Northern Group. It is always possible, of course, that any such improvement is more apparent than real and that, in fact, it means nothing more than that more of the deaths in the Northern Group are being registered nowadays than was formerly the case. 
TABLE 45 Estimated infant mortality per 1,000 live births in the populations of the Cook Islands in the years 1944-6, 1950-2 and 1955-7

\begin{tabular}{lrrrrr}
\hline \multicolumn{1}{c}{ Population } & Years & $\begin{array}{c}\text { Male } \\
\text { rate }\end{array}$ & $\begin{array}{r}\text { Female } \\
\text { rate }\end{array}$ & \multicolumn{2}{c}{ All infants } \\
Rate & S.E. \\
\hline \multirow{2}{*}{ Rarotonga } & $1944-46$ & 116 & 101 & 108 & 12 \\
& $1950-52$ & 112 & 120 & 116 & 12 \\
& $1955-57$ & 87 & 96 & 91 & 10 \\
Lower Group excluding & $1944-46$ & 127 & 104 & 116 & 11 \\
Rarotonga & $1950-52$ & 117 & 92 & 105 & 10 \\
& $1955-57$ & 143 & 111 & 127 & 11 \\
Lower Group including & $1944-46$ & 123 & 103 & 112 & 8 \\
$\quad$ Rarotonga & $1950-52$ & 115 & 105 & 110 & 8 \\
& $1955-57$ & 115 & 104 & 109 & 7 \\
& & & & & \\
Northern Group & $1944-46$ & 238 & 85 & 164 & 25 \\
& $1950-52$ & 144 & 148 & 146 & 21 \\
& $1955-57$ & 162 & 167 & 164 & 19 \\
Cook Islands & $1944-46$ & 138 & 100 & 119 & 8 \\
& $1950-52$ & 119 & 112 & 115 & 7 \\
& $1955-57$ & 124 & 114 & 119 & 7 \\
\hline
\end{tabular}

\section{Analyses of Fertility}

If more of the deaths are now being registered it is likely that the registration of births is also more complete now than it was formerly. The numbers of births recorded in each year have increased quite markedly in recent years, and the increase in their numbers has been relatively greater than the increase in the numbers of women of reproductive age. The average annual fertility rates for each population during three-year periods centring on census years are given in Table 46 , and these represent the average numbers of births each year to each 1,000 women aged 15-44 years recorded in the censuses. The rates oited for all except the total population for 1945 may be a little too high because the non-Maori population would not be included in the denominators of the rates for this year whereas the births from this section of the population could not be exoluded from the numerators. The fertility rates for Rarotonga are the only ones likely to be much affected by this inconsistency and those for the Northern Group population scarcely at all. 
TABLE 46 Average annual fertility rates per 1,000 women aged 15-44 years recorded in successive censuses

\begin{tabular}{lccccc}
\hline \multicolumn{1}{c}{ Population } & 1936 & 1945 & 1951 & 1956 & $\begin{array}{c}\text { Approx. } \\
\text { standard } \\
\text { errors }\end{array}$ \\
\hline Rarotonga & 188 & 210 & 207 & 217 & 12 \\
$\begin{array}{l}\text { Lower Group excluding } \\
\text { Rarotonga }\end{array}$ & 217 & 220 & 226 & 254 & 12 \\
$\begin{array}{l}\text { Northern Group } \\
\text { Cook Islands }\end{array}$ & $*$ & 159 & 189 & 266 & 18 \\
\hline
\end{tabular}

*Not available.

The rates for all populations show an upward trend over the period although few of the changes are statistically significant. For the population as a whole, the increase was greater between 1951 and 1956 than between 1945 and 1951, and any theories as to the cause of such increases must take into account the changes which have occurred in the populations on which these rates are based. Earlier it was estimated that more than one-third of all females who had left the population between 1951 and 1956 were aged from about 18 to 33 years, and it is unlikely that these females were a random sample of all females at these ages. Emigration is more practicable for women without commitments to husbands and children, and thus the women who remain in the population are likely to be those with such commitments and therefore at greater risk for births than the emigrants. To a lesser extent some such selective factor probably operates in inter-island migration within the Group, but from the data that are available it is not possible to establish conclusively that this selection occurs, nor to assess the effect that it might have on the usual measures of fertility. The possibility that it does occur, however, cannot be ignored in any analysis of the patterns of fertility either in the population as a whole or in any part of it.

The greatest change in fertility rates has occurred in the population of the Northern Group, where the frequency of births has increased from 1 for every 6 women of reproductive age in 1945 to more than 1 for every 4 such women in 1956. Only for Rarotonga was the frequency of births less than 1 in 4 in 1956, and if the changes in frequency between 1951 and 1956 elsewhere were due to migration away from the Northern and Lower Group islands, an exercise in simple proportions 
indicates that 2 females in every 7 of reproductive age in the Northern islands and 1 in every 9 from the Lower Group either died or migrated away from their islands. The numbers recorded at ages 15 to 39 years in 1951 and 20 to 44 years in 1956 in the various populations are given in Table 47, and from this it will be seen that this group of cohorts in the Northern islands showed a decrease of only 1 in 6 between 1951 and 1956, whereas the numbers at these ages in the Lower Group excluding Rarotonga decreased by $2 / 9$.

TABLE 47 Numbers of females of specified ages recorded in censuses of 1951 and 1956

\begin{tabular}{lrrrrrr} 
& \multicolumn{3}{c}{$1951^{*}$-at ages } & \multicolumn{3}{c}{1956 -at ages } \\
\multicolumn{1}{c}{ Population } & $15-29$ & $30-39$ & $15-39$ & $20-34$ & $35-44$ & $20-44$ \\
\hline Rarotonga & 698 & 305 & 1,003 & 652 & 328 & 980 \\
$\begin{array}{l}\text { Lower Group excluding } \\
\quad \text { Rarotonga }\end{array}$ & 820 & 351 & 1,171 & 626 & 296 & 922 \\
$\begin{array}{l}\text { Northern Group } \\
\text { Cook Islands }\end{array}$ & 339 & 117 & 456 & 283 & 97 & 380 \\
& 1,857 & 773 & 2,630 & 1,561 & 721 & 2,282 \\
\hline
\end{tabular}

\footnotetext{
*'Native' population only.
}

Hence it is possible that the increased fertility rate shown by this latter group might be ascribable to the selective effects of migration, but on this basis, migration of females away from the Northern islands would account for less than half of their increased frequency of births. More complete registration of births in these islands could perhaps account for the remainder of the increase, but this would imply that formerly at least 15 per cent of births were not registered. Anticipating certain deductions from the census data, neither of these explanations seems sufficient for an increase of the magnitude recorded for the Northern Group, and although both may have contributed to the greater frequency of births in this population, it seems likely that the women there in 1956 had been having more births on the average than did their counterparts of 10 or 15 years earlier, and this lends support to the thesis that the women who do not emigrate are those who are most susceptible to births.

Until 1956 these birth rates were the only data available concerning the fertility of women in the Cook Islands. In 1951, married women 
were asked to 'state number of children born alive (whether still alive or not)' but these data were not tabulated. In 1956, when the Cook Islands census was of the same pattern as those for Fiji, Tonga, Western and American Samoa, all women aged 15 years and over were asked two questions on the number of children they had borne-the number still living at the time of the enumeration and the number who had died -and their age at the birth of their first child. As elsewhere, the framing of the question in this way may have caused some exaggeration of the average numbers of children born, so that the true mean would lie somewhere between this and the average number of surviving children.

In the Cook Islands there may also have been some variation in what was recorded from island to island which may distort comparisons between the data for individual islands, whose populations ranged in size from 32 to 7,212 and the numbers of adult women from 3 to 460 . With populations as small as these, it was not practicable to retain the distinotions between Maori and non-Maori populations throughout all tabulations, although the only island grossly affected by this was Rarotonga where nearly 15 per cent of the female population was other than Maori. This population also contained a high proportion of Maoris from other islands and altogether just less than half of the women recorded in Rarotonga at the time of the census had not been born there. As in all other analyses to date, the fertility of Rarotonga's population is examined separately from the remaining islands of the Lower Group.

The age composition of the various populations at earlier censuses suggested that the females in the Northern Group had fewer children than those in other islands, and this is confirmed by the average numbers of children born and surviving to women of completed fertility on each island. These data are shown in Table 48 and they relate to all females aged 45 years and over irrespective of marital status. Although there is the sort of variability one would expect from small populations, the averages are consistent and few of the differences between the means for individual islands attain levels of statistical significance. For the Northern Group as a whole the average completed family was smaller than in the islands of the Lower Group but not significantly different in size from families in Rarotonga. On the other hand, there were fewer survivors amongst all children born in the Lower Group than in the Northern islands, so that effectively the difference in family size was reduced from 1.54 to 0.75 children per woman.

This regional differential in family size was also apparent among women nearing the end of their reproductive life in 1956. The average numbers of children born to women in each age group in the three seotors of the population are shown in Table 49 , and there is a striking 
TABLE 48 Average numbers of children born and surviving to women of completed fertility on each island, 1956

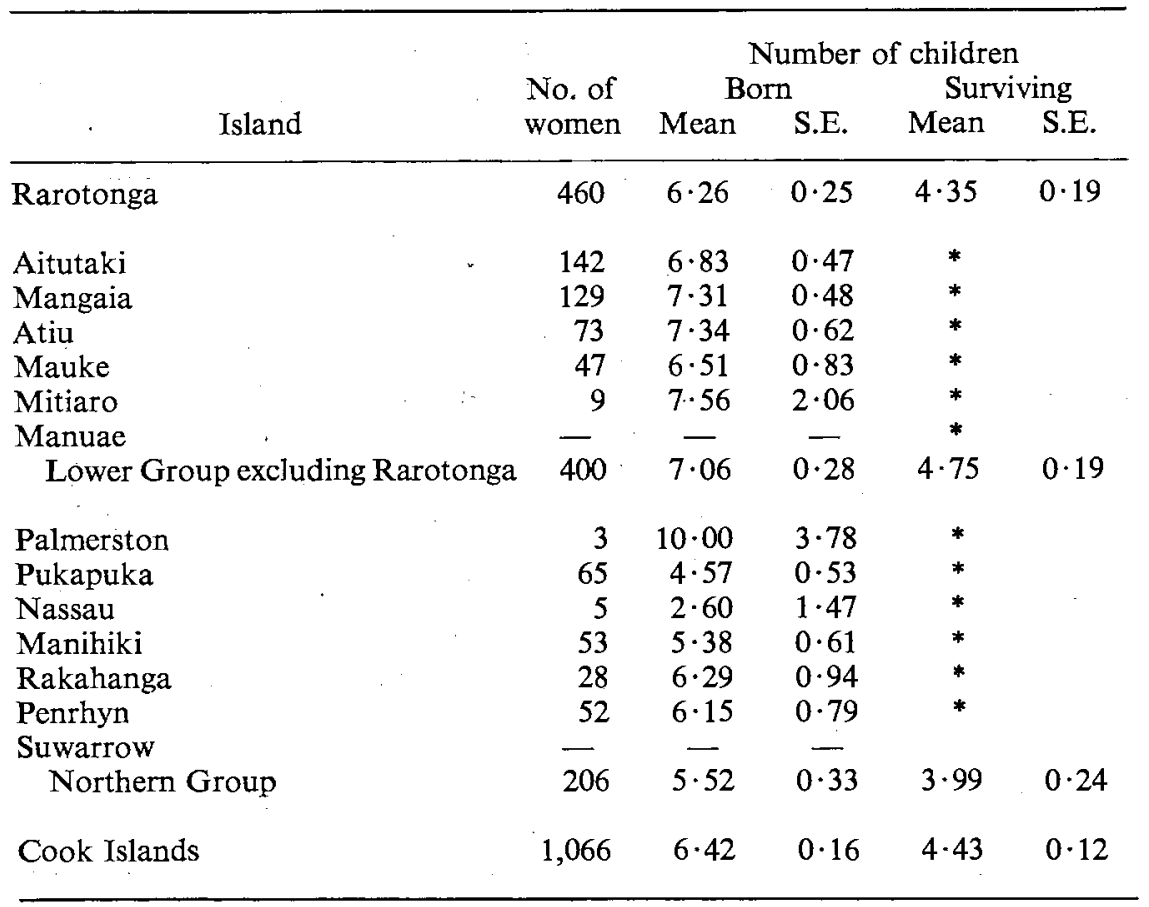

*Not available.

TABLE 49 Average numbers of children born to women in each age group in each area, 1956

\begin{tabular}{cccccc}
\hline $\begin{array}{c}\text { Age } \\
\text { group }\end{array}$ & Rarotonga & $\begin{array}{c}\text { Lower Group } \\
\text { excluding } \\
\text { Rarotonga }\end{array}$ & $\begin{array}{c}\text { Northern } \\
\text { Group }\end{array}$ & Mean & S.E. \\
\hline $15-19$. & $0 \cdot 12$ & $0 \cdot 13$ & $0 \cdot 19$ & $0 \cdot 13$ & $0 \cdot 01$ \\
$20-24$ & $1 \cdot 08$ & $1 \cdot 39$ & $1 \cdot 28$ & $1 \cdot 23$ & $0 \cdot 05$ \\
$25-29$ & $2 \cdot 88$ & $3 \cdot 31$ & $3 \cdot 36$ & $3 \cdot 14$ & $0 \cdot 10$ \\
$30-34$ & $4 \cdot 67$ & $5 \cdot 05$ & $4 \cdot 67$ & $4 \cdot 84$ & $0 \cdot 16$ \\
$35-39$ & $6 \cdot 03$ & $6 \cdot 63$ & $4 \cdot 74$ & $6 \cdot 11$ & $0 \cdot 22$ \\
$40-44$ & $5 \cdot 41$ & $7 \cdot 15$ & $4 \cdot 11$ & $5 \cdot 91$ & $0 \cdot 26$ \\
& & & & & \\
$45-59$ & $6 \cdot 60$ & $7 \cdot 57$ & $5 \cdot 81$ & $6 \cdot 85$ & $0 \cdot 21$ \\
$60-74$ & $6 \cdot 17$ & $6 \cdot 84$ & $5 \cdot 01$ & $6 \cdot 14$ & $0 \cdot 32$ \\
75 and over & $5 \cdot 52$ & $5 \cdot 62$ & $6 \cdot 75$ & $5 \cdot 91$ & $0 \cdot 62$ \\
\hline
\end{tabular}


difference between the average performance of women aged 35 to 44 years in the Northern islands and women of the same ages elsewhere in the Group. Only in the islands of the Lower Group other than Rarotonga did the females whose reproductive life would finish soon after 1956 have as many children as the women of completed fertility, and in both Rarotonga and the islands of the Northern Group the women aged 4044 years in 1956 had fewer children on the average than the women then aged 35-39 years.

The average numbers of births to women aged less than 35 years were relatively uniform throughout the population, although the younger Rarotongan women had had slightly fewer births on the average than women of the same age elsewhere. One of the factors contributing to this and to the smaller averages for women aged 35 to 44 years in the Northern Group was undoubtedly the greater frequency of childless women in these particular groups. The numbers of women per 1,000 in each age group in each sector of the population who had borne no children are given in Table 50, and comparisons between this and the preceding table show that each deviation in the average numbers of births for any sector of the population is matched by a converse deviation in the frequency of childless women.

TABLE 50 Numbers of women per 1,000 in each age group in each area who had borne no children, 1956

\begin{tabular}{ccccc}
\hline Age group & Rarotonga & $\begin{array}{c}\text { Lower Group } \\
\text { excluding } \\
\text { Rarotonga }\end{array}$ & $\begin{array}{c}\text { Northern } \\
\text { Group }\end{array}$ & Cook Islands \\
\hline $15-19$ & 900 & 900 & 831 & 891 \\
$20-24$ & 442 & 317 & 333 & 376 \\
$25-29$ & 194 & 141 & 160 & 166 \\
$30-34$ & 167 & 100 & 145 & 133 \\
$35-39$ & 114 & 109 & 269 & 136 \\
$40-44$ & 183 & 122 & 255 & 169 \\
$45-59$ & 188 & 157 & 216 & 180 \\
$60-74$ & 243 & 140 & 271 & 215 \\
75 and over & 217 & 346 & 250 & 275 \\
\hline
\end{tabular}

If the women who had borne no children are excluded from the computation, much of the geographic variation in the average numbers of births to women of reproductive age vanishes. For the population as a whole, the numbers increased progressively with the age of the women to a maximum of 6.80 births per mother aged $40-44$ years. This was one 
birth less than the corresponding average for women past reproductive age, and while there was still time for females in the first half of the reproduotive period to match the fertility performance of these older mothers, it is unlikely that those in the second half in 1956 would attain the former standard.

The most notable deviation from this pattern occurred amongst the mathers aged 40-44 years in the Northern Group, for whom the average number of births was smaller than the corresponding means for mothers aged 30-34 or 35-39 years in 1956. The average number of children born to mothers of completed fertility in the Northern islands was slightly below the means for such women on Rarotonga and the other islands of the Lower Group, and this suggests that there may have been some factors operating in the past to reduce the numbers of children born even to fertile women of the Northern islands.

The source of some of these regional variations emerges when one examines the ages at which women in the various seotors of the population began child-bearing. This age is likely to be remembered more accurately by women nearer their first parturition than by those for whom this is long since past, and consequently females beyond reproduotive ages are grouped together in Table 51 which shows the number of women per 1,000 at each age who had their first birth before the ages of 20,25 and 30 years.

Roughly one-third of all women had their first child before the age of 20 and nearly three-quarters attained motherhood before they were 25 years old. As one would expect, fewer women had their first child between the ages of 25 and 30 than between 20 and 25, and the likelihood of a first birth at ages beyond 30 was very small. The apparently later ages at which women aged 45 years and over at the time of the census attained motherhood as compared with those still of reproductive age probably stem from more frequent mis-statements of age at first birth for the older women rather than from inoreased chances of survival for those who delayed their first birth until more mature ages.

In the islands of the Lower Group other than Rarotonga rather more of the women had their first child before age 20 than did those elsewhere, and at the young ages particularly, there was quite a marked difference between them and the women on Rarotonga. At other ages there was little to choose between the women on Rarotonga and those of the Northern Group, where the average age at first birth tended to be rather higher than in the remaining islands of the Group. These data for Rarotonga are affected by the presence of women who were not born on Rarotonga, less than one-quarter of whom on the average attained motherhood before the age of 20 years, whereas 29 per cent of 
TABLE 51 Number of women per 1,000 at each age in 1956 who had borne their first child before each of the ages 20,25 , and 30 years

\begin{tabular}{|c|c|c|c|c|}
\hline $\begin{array}{l}\text { Age group } \\
\text { at census }\end{array}$ & Rarotonga & $\begin{array}{l}\text { Lower Group } \\
\text { excluding } \\
\text { Rarotonga }\end{array}$ & $\begin{array}{l}\text { Northern } \\
\text { Group }\end{array}$ & $\begin{array}{c}\text { Cook Islands } \\
\text { Total }\end{array}$ \\
\hline \multicolumn{5}{|c|}{ First birth before age 20 years } \\
\hline $20-24$ & 246 & 424 & 333 & 328 \\
\hline $25-29$ & 289 & 383 & 380 & 344 \\
\hline $30-34$ & 288 & 433 & 338 & 361 \\
\hline $35-39$ & 291 & 424 & 240 & 341 \\
\hline $40-44$ & 275 & 313 & 255 & 287 \\
\hline$(20-44)$ & $(274)$ & $(401)$ & $(325)$ & (334) \\
\hline 45 and over & 255 & 318 & 252 & 278 \\
\hline All ages & 268 & 375 & 299 & 316 \\
\hline \multicolumn{5}{|c|}{ First birth before age 25 years } \\
\hline $25-29$ & 749 & 786 & 780 & 770 \\
\hline $30-34$ & 731 & 828 & 721 & 772 \\
\hline $35-39$ & 766 & 818 & 540 & 759 \\
\hline $40-44$ & 621 & 748 & 660 & 677 \\
\hline$(25-44)$ & $(721)$ & $(798)$ & $(698)$ & $(749)$ \\
\hline 45 and over & 647 & 673 & 665 & 660 \\
\hline All ages & 692 & 750 & 684 & 714 \\
\hline \multicolumn{5}{|c|}{ First birth before age 30 years } \\
\hline $30-34$ & 814 & 889 & 853 & 854 \\
\hline $35-39$ & 851 & 879 & 680 & 841 \\
\hline $40-44$ & 745 & 863 & 723 & 789 \\
\hline$(30-44)$ & $(806)$ & $(878)$ & $(764)$ & $(830)$ \\
\hline 45 and over & 728 & 785 & 723 & 748 \\
\hline All ages & 768 & 834 & 741 & 790 \\
\hline
\end{tabular}

those born on Rarotonga had their first child before that age. This difference between the Rarotongan-born and others occurred both amongst women in the reproductive period and those of completed fertility, but it was more pronounced among the latter group.

All areas showed a curious slump in the relative numbers of women aged 40-44 years who had their first child before each of the ages specified, and in the Northern Group the younger cohort, aged 35-39 years, was similarly affocted. The effect of this later age at first birth on the average numbers of children born to women in the cohort aged 40-44 
in 1956 appeared in the Northern Group, Rarotonga and Cook Islands total, although it was not apparent among the women in islands of the Lower Group other than Rarotonga (Table 49). At the same time, there was a slight increase in the frequency of childlessness among women of these ages in all areas, but such increase was not statistically significant and if anything, there were fewer childless women in the cohort aged 40-44 years than there were amongst the women of completed fertility, who between them produced considerably larger numbers of children than had the women aged 40-44 years in 1956.

As there are no fertility data from earlier censuses with which these might be compared, doubts and suspicions as to the reality of these differences or the validity of conclusions cannot be checked. Though it seems unlikely that mis-statements of age alone would account for the later average age of this cohort of women at the birth of their first child in all three sectors of the population, and the smaller average number of births per woman in two of them, it is not impossible, especially in view of the inconsistency of the women of the Lower Group, excluding Rarotonga, in displaying this later age at first birth with no apparent decrease in the average number of children per woman.

Ignoring this possibility and accepting the ages as stated in 1956, this apparently aberrant cohort was born during the years 1912-16 and would have attained reproduotive age in the early 1930s: Tracing it through successive censuses, there seems always to have been a preponderance of males recorded both in the Group as a whole and on individual islands, and neither the sex ratio nor the size of the cohorts on either side of it suggest any demographic reason for later marriages among the 1912-16 cohort as compared with its neighbours. Although slightly fewer women of this cohort in the Northern Group had married by 1956-92 per cont as compared with 97 per cent in the Lower Group excluding Rarotonga and 95 per cent for Rarotonga and all the Cook Islands-the average numbers of children born to married women in each age group followed the same pattern as the means for all women irrespective of marital status.

By 1956, it was roughly twenty-five years since the 1912-16 cohort had attained reproductive age, and although the island on which they were then living was not necessarily the one on which they were enumerated in 1956, the island populations primarily responsible for this deviant behaviour were Pukapuka and Nassau (which is essentially the one population) in the Northern Group, and to a smaller extent, Atiu and Aitutaki as well as Rarotonga in the Lower Cook Islands.

With an average of less than 2 births per woman, 11 of the 24 women aged 40-44 years on Pukapuka and Nassau had no children and only 
4 had their first child before 20 years of age. Both Manihiki and Rakahanga contributed to a later age at first birth for the younger 1917-21 cohort, but this had less effect on their average number of births than would be expected on the Pukapukan experience. On Atiu, this same 1917-21 cohort had already an average of 6.9 births in 1956 whereas the older 1912-16 cohort had only 6.0 births per woman. The oorresponding figures for Aitutaki were 7.2 and 6.8 and the difference between them is not statistically significant. There was no dramatic change on any island of the Lower Group excluding Rarotonga between the 1912-16 cohort and its neighbours in regard to the frequency of childless women or the age at first birth, and despite the Atiuans' smaller number of births, only 4 of the 27 women aged 40-44 years in 1956 had had no children and 11 attained motherhood before 20 years of age.

The Annual Reports for the period when the 1912-16 and 1917-21 cohorts were marrying and starting their child-bearing disclosed no uniform sequence of events that may have delayed marriage or first birth in all of the populations affected, but there were some which may have contributed to the heterogeneity of the fertility patterns throughout the Group. In 1931 there was a hurricane east and south of Aitutaki and north of Rarotonga which caused considerable damage on both islands although neither was in its direct path. All of the food crops on Aitutaki were destroyed, the taro and puraka crops were swamped with seawater and the bananas and breadfruit trees were blown down by the gale. The domestic crops on Rarotonga escaped damage, and although food was sent from there to Aitutaki, later in the year there was much sickness on Aitutaki which was attributed to lack of food and malnutrition (N.Z.P.P. A-3, 1931, pp. 7, 8). Four years later another hurricane struck Rarotonga and the Lower Group, and caused so much damage to the staple food crops in all islands that there was grave concern as to how the population would exist for the year before new crops could be grown (N.Z.P.P. A-3, 1935, p. 9). Rarotonga's population experienced several epidemics during the following year and the increased incidence of tuberculosis there resulted in many deaths from this disease in 1936 (N.Z.P.P. A-3, 1936, p. 4).

Palmerston was the only island of the Northern Group to be damaged by either hurricane and that suffered severely in both. Hence, although the consequences of the hurricanes-famine and increased sicknessmay have delayed first births to some of the women in the islands of the Lower Group, they cannot be held responsible for the tardiness of the women in the Northern atolls. However, from 1926 onwards there was a continuing campaign to eradicate leprosy from these populations and patients, the majority of them from Penrhyn, were taken to the leper 
hospital in Fiji whenever opportunity offered (N.Z.P.P. A-3, 1927, p. 7; 1928 , p. $1 ; 1929$, p. 9; 1935, p. 2). At least 120 patients were transferred in the course of ten years, but there was no consistent record of their island of origin, sex or age and despite early optimism, few returned from Fiji (N.Z.P.P. A-3, 1932, p. 2).

Perhaps because of this, some of the Northern islands contained relatively few women aged 35 to 44 years in 1956, but Pukapuka was not one of these and it was seldom cited as the island of origin for lepers. In 1929 the Pukapukans experienced an epidemic of 'mild influenza' which caused only 3 deaths among the 300 cases on the island (N.Z.P.P. A-3, 1929, p. 10), and in November 1930 and January 1931 there were outbreaks of dengue fever, the mortality from which was not recorded (N.Z.P.P. A-3, 1932, p. 14). Quite often the island was not visited for more than a year and although Ernest and Pearl Beaglehole, who were on Pukapuka for seven and a half months from November 1934 to June 1935 , reported no unusual occurrences during their stay or in the immediately preceding years, the background is too sketchy to confirm or remove doubts as to the reliability of the information recorded on Pukapuka and Nassau in 1956.

The increased illness and malnutrition alleged for some of the populations of the Lower Group in the 1930s may have contributed to the poorer chances of survival noted earlier for the children of women beyond child-bearing age in 1956, but any advantages the children in the Northern atolls might have enjoyed formerly seem to have vanished in recont years, and the proportions of survivors amongst all children born to women of reproductive age in 1956 decreased uniformly with increasing ages of mothers in all areas. The average numbers of children surviving to women in each age group are given in Table 52, and again it was only in the Lower Group excluding Rarotonga that women nearing the end of their reproductive period in 1956 had more living children than those beyond the child-bearing ages.

Whether few children were born in the Northern atolls between 1936 and 1945 or few survived, comparatively small numbers at ages 5 to 14 years were recorded there in 1951 and again in 1956. The absence of children at school either in the Lower Group or in New Zealand may have accentuated this dearth, but in 1956 there were fewer females aged 5 to 14 years than there were aged 15 to 29 years. Unless the numbers away at schools were extraordinarily large, it can be expected that, even without the migration of females away from these islands, the rate of increase in their populations throughout the 1960s will be no greater than it was during the 1950s, and far slower than is likely, again without emigration, in the Lower Group where the numbers of females 
TABLE 52 Average numbers of children surviving to women in each age group in each area, 1956

\begin{tabular}{cccccc}
\hline $\begin{array}{c}\text { Age } \\
\text { group }\end{array}$ & Rarotonga & $\begin{array}{c}\text { Lower Group } \\
\text { excluding } \\
\text { Rarotonga }\end{array}$ & $\begin{array}{c}\text { Northern } \\
\text { Group }\end{array}$ & \multicolumn{2}{c}{ Cook IsTands } \\
Mean & S.E. \\
\hline $15-19$ & $0 \cdot 12$ & $0 \cdot 12$ & $0 \cdot 19$ & $0 \cdot 13$ & $0 \cdot 01$ \\
$20-24$ & $0 \cdot 94$ & $1 \cdot 22$ & $1 \cdot 00$ & $1 \cdot 06$ & $0 \cdot 05$ \\
$25-29$ & $2 \cdot 38$ & $2 \cdot 78$ & $2 \cdot 66$ & $2 \cdot 59$ & $0 \cdot 09$ \\
$30-34$ & $3 \cdot 84$ & $4 \cdot 16$ & $3 \cdot 38$ & $3 \cdot 91$ & $0 \cdot 14$ \\
$35-39$ & $4 \cdot 63$ & $5 \cdot 08$ & $3 \cdot 90$ & $4 \cdot 73$ & $0 \cdot 17$ \\
$40-44$ & $4 \cdot 36$ & $5 \cdot 27$ & $3 \cdot 30$ & $4 \cdot 57$ & $0 \cdot 20$ \\
& & & & & \\
$45-59$ & $4 \cdot 78$ & $5 \cdot 30$ & $4 \cdot 33$ & $4 \cdot 91$ & $0 \cdot 16$ \\
$60-74$ & $3 \cdot 76$ & $3 \cdot 80$ & $3 \cdot 46$ & $3 \cdot 71$ & $0 \cdot 20$ \\
75 and over & $2 \cdot 61$ & $3 \cdot 08$ & $3 \cdot 85$ & $3 \cdot 15$ & $0 \cdot 37$ \\
& & & & & \\
\hline
\end{tabular}

attaining reproductive age are far in excess of those passing out of the reproductive period.

\section{Summary}

The population of Rarotonga is the only one in the group for which there is much real information before 1900, and even this peters out in the latter half of the century to the same scattered and often inconsistent totals characteristic of the demographic data for the inhabitants of the other islands. The colourful glimpses now and then of the people themselves, and complementary reports from Tahiti and elsewhere, suggest that emigration began relatively early in the century, either directly away from the Northern atolls, or via Rarotonga or Aitutaki, the islands most frequented by trading and whaling ships. Although Rarotonga's is the only population known to have experienced very high mortality from introduced diseases, there may have been others which suffered similarly though perhaps less severely.

From a total of about 8,000 people in all of the islands in 1902, the population had more than doubled by 1956 , with each intervening census reporting more people than its predecessor, despite the several hundreds of Cook Islanders on the phosphate island of Makatea in French Polynesia, and the increasing emigration to New Zealand. By 1956, New Zealand was more attractive to the Cook Islanders than Makatea, and during the preceding five years, relatively large numbers of women aged between 20 and 34 years in 1956 had left the Cook Islands, and the inter-censal growth rates suggest that even in the six 
years preceding 1951 relatively more females than males were leaving the islands. Between 1951 and 1956 there was also some loss of males in their twenties.

It would be extraordinary if these emigrants were a random sample of the population at these ages. In most of the Polynesian populations censussed in 1956 only one-quarter of all males aged 20-24 years were already married, and the 37 per cent of Cook Island males at these ages reported as married probably reflects the selective emigration rather than an earlier age at marriage for males there. However, there was no parallel rise in the proportion of each cohort of females married, and the numbers of spinsters aged 20-24 were relatively higher than in either $F_{i j i}$ or Western Samoa. Whatever the reason for this, whether the deliberate postponement of marriage by young women hoping to emigrate, or some lack of opportunities for marriage because of the emigration of the eligible males, the proportions of males and females single at all ages other than 20-24 years did not deviate from the comparable figures for the Fijian and Samoan populations.

Among those who remained in the islands, the death rate had fallen slightly by 1956, probably less in the Northern Group than in the Lower Group, and the decline was most apparent for males aged between 15 and 29 years, and for females throughout the reproductive ages. Around 1956 the rates were high compared with those reponted for the Polynesian populations to the west, but not very much higher than those for French Polynesia. Partly because of the high infant mortality rates, the Cook Islanders then had an expectation of less than 50 years at birth, but offsetting this high death rate of about 16 per 1,000 population was a crude birth rate of about 45 per 1,000 , which is higher than the rates reported for all other populations except French Polynesia and the Indians in Fiji. The average numbers of children born to women at each age closely resembled those for Samoa, and the average of about $6 \%$ births before the end of the reproductive period falls midway between the performance of women in Samon and French Polynesia. If the mortality rates fall further, more than 80 per cent of children born will survive to reproduce, and without emigration or a reduotion in fertility this population will increase very rapidly indeed. 


\section{French Polynesia}

French Polynesia is the most easterly of the territories studied and for at least sixty years before 10 August 1957 its official title was Etablissements Français de l'Océanie, sometimes abbreviated to E.F.O. and known in English as French Oceania. To avoid confusion, its current title of French Polynesia will be used consistently here to designate the aggregate of the five archipelagos-the Society Islands, two clusters of islands often distinguished as the Windward and Leeward Islands though nowadays the Windward group is known administratively as Tahiti and Dependencies; the Tuamotu (or Paumotu) archipelago of approximately eighty low ooral islands and islets sweeping in a long arc to the Gambier Islands about 900 miles east-south-east of Tahiti; to the south, the widely separated Austral Islands and about 700 miles north-east of Tahiti the lonely Marquesas, the first group to be visited by Europeans.

Exoept for the Tuamotu, most of the islands are 'high' islands; originally volcanic, the rugged peaks fall away either to the sea or to narrow alluvial plains, and traditionally as now people lived in the larger valleys and on the coastal littoral. But this is a general description, and there are considerable differences between islands in physical character as well as in size. The total land area of roughly 1,544 square miles is divided unequally between the archipelagos; Tahiti alone contributes more than a quarter of the total area, and its dependencies and the ten Leeward Islands a further 244 square miles. Not all of the islands in the Tuamotu are inhabited, but all of its atolls would amount to no more than 275 square miles. The nine islands of the Marquesas and the five Austral Islands total 492 and 63 square miles respectively, and though the Gambier Islands are thought to have an area of 68 square miles, most of this is contributed by only three of the ten islands in the group.

Almost all of the expeditions famed for their exploits in the South Pacific touched some islands of French Polynesia. The Spanish navigator Mendaña is the first European known to have discovered some of its islands when he sighted the south-east cluster of the Marquesas in 1595 and anchored off Tahuata. Eleven years later his chief pilot Quiros 


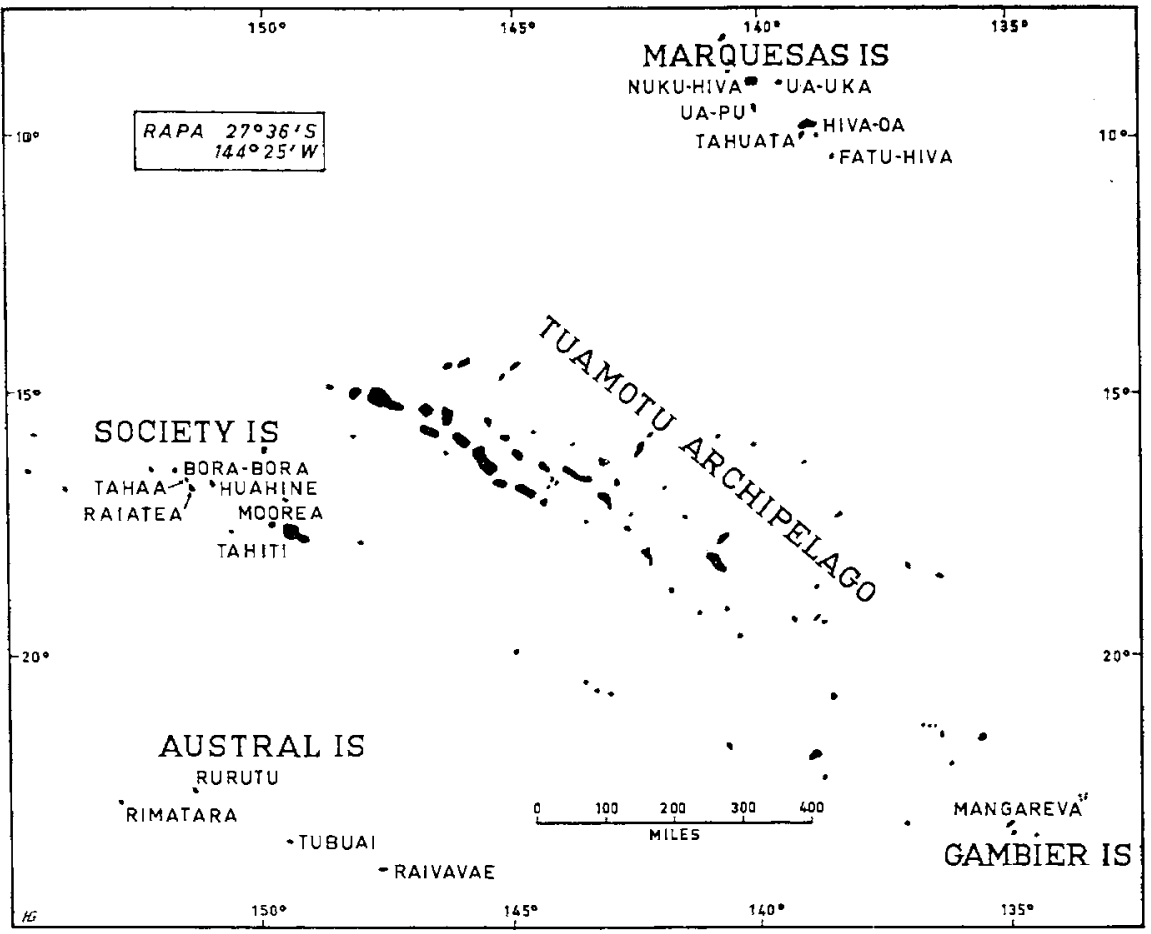

Map 5 The main islands and island groups of French Polynesia

voyaged through the eastern and oentral part of the Tuamotu arohipelago, landing at only one of the islands; and in 1616, Schouten and le Maire discovered and landed on several in the western sector of the archipelago. In 1722, one of Roggeveen's three ships was wrecked on one of these islands and the remaining vessels coasted uneasily thereafter through this western cluster of the Tuamotus to Makatea, from whence they sailed on to discover Samoa, sighting two islands en route which were probably the most northerly of the Leeward Islands (Sharp, 1960).

British exploration of this part of the Pacific began with Byron's voyage in H.M.S. Dolphin in 1765, but his discoveries on the northern fringe of the Tuamotus were overshadowed by the achievements of the ship's second voyage in 1767 when, under the command of Captain Wallis, H.M.S. Dolphin made landfall at Tahiti, beating the French explorer Bougainville to its discovery by only nine and a half months (Robertson, 1948, p. 136; Bougainville, 1771, p. 185). Less than three months after the Dolphin returned to England, Lieutenant James Cook set out for Tahiti in the Endeavour, commissioned by the Royal Society 
to observe the transit of Venus from this post in the southern hemisphere and, under Admiralty orders, to survey and map the island before proceeding southward in search of the great southern continent then thought to exist (Cook/Beaglehole, 1955, pp. cclxxix-colxxxiv).

The expedition stayed at Tahiti for three months and when they were leaving, Cook invited Tupaia, an aristocrat and a priest well-versed in native lore and navigation, to accompany them. Tupaia named the islands known to his people and sailing westward, Cook discovered the cluster which he called Society because the islands lay contiguous to one a nother' (Cooke/Beaglehole, 1955, p. I5I) and which now are regarded as only the Leeward Islands of the Society Group. When Cook changed course to begin the search for the unknown continent, Tupaia predicted that this would lead them to Rurutu, one of the Austral Islands, and though this was duly encountered, Cook decided to waste no time soarching for the other islands Tupaia reponted in the vicinity.

On his next two voyages, Cook refreshed his crews at Tahiti and the nearby Society Islands and learned that a Spanish vessel had visited Tahiti shortly before his second visit, and that in the interval between his third and fourth visits four men from this same vessel had lived on the island for about a year. Though Cook never knew it, the boat was the frigate Aguila, under orders from the Viceroy of Peru, which discovered in the course of its voyaging a few more islands in the Tuamotus and Raivavae, another of the Austral Islands. At the conclusion of his second voyage in 1775 , Cook wrote in his journal that

by twice visiting the Pacific Tropical Sea, I had not only settled the situation of some old disooveries but made there many new ones and left, I conceive, very little more to be done even in that part (Cook/Beaglehole, 1961, p. 643).

Nevertheless on his third voyage (1777-9) Tubuai was discovered and this was the island chosen as the first refuge of the mutineers of the Bounty more than a decade later.

The first ship the Tahitians saw after Cook's last visit in 1777 was the transport Lady Penrhyn, which put in for two weeks in July 1788 to rid its crew of scurvy after their long voyage from England to Botany Bay. In October of that year the Bounty anchored at Tahiti, and Bligh and his men remained there for more than five months collecting breadfruit cuttings for the English colonists in the West Indies. After the mutiny, the Bounty returned twice to the island, once to acquire stock for their proposod settlement on Tubuai, and again when this project was abandoned to land the sixteen mutineers who had elected to settle on Tahiti while the remainder went with Christian to Pitcairn Island. 
From then on there were few years when Tahiti and the surrounding islands lacked European visitors. The captains of whaling ships refreshed their crews there, and their preference for Tahiti continued even after the arrival of the first missionaries from England in 1797. For a few years around the turn of the nineteenth centiury Tahiti and the nearby islands conducted a thriving trade in salt pork with the newly founded colony in Australia (H. E. Maude, 1959), and some of the more remote islands became havens for whalers and beachcombers as missionary influence deepened in Tahiti. Despite the opposition of the missionaries, Tahiti was proclaimed a protectorate of France in 1842, only a short time after Admiral Dupetit-Thouars had taken possession of the Marquesas for France. Two years later the protectorate was extended to the Gambier Islands, and these were formally annexed to France in 1882. By then the Windward, Tuamotu and Austral Islands had also been annexed, but the Leeward Islands retained their independence until 1887.

As elsewhere, the missionaries were the first to attempt any systematic counts of the population, but few of the early navigators and their companions refrained from speculations on the numbers of people inhabiting the islands they visited, so that the chronological span is wider here than in the earlier chapters. The demographic data are also more uneven because some of the islands had had official censuses before there were even estimates of the population living on others; but as it was 1902 before almost all islands were censussed in the same year, the opening section will treat the history of the oonstituent islands or groups of islands separately up to this date, irrespective of the source of the data, even though they should probably be regarded as one group from a much earlier period.

\section{BEFORE 1900}

\section{Tahiti and Moorea}

Because of the numbers of people who flocked to the beach to see H.M.S. Dolphin as she sailed along the coast searching for an anchorage, her Master, George Robertson, described Tahiti as the most populous country I ever saw'. A month later as they sailed away from the island, he regretted his inability to give his 'King and Country an Aacurate description of the Extent of this Countrys', but he nevertheless dared venter to say their is upward of a hundred thousant Men Women and Children on it' (Robertson, 1948, pp. 140, 234). Bougainville was even more impressed than Robertson by the idyllic beauty of the island, and though he claimed to have ventured 'dans l'intérieur' during his nine 


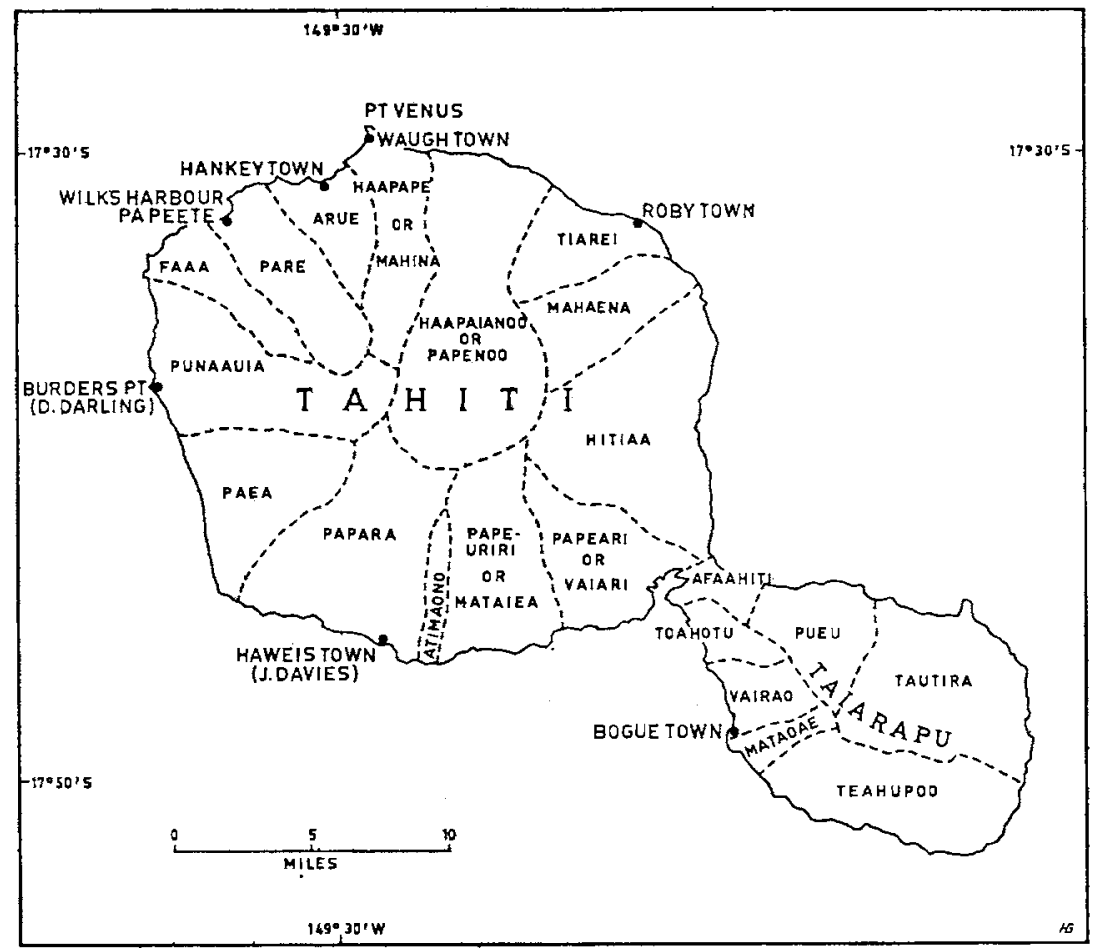

Map 6 Tahiti. The traditional districts and the sites of the mission stations established during the nineteenth century. (Adapted with permission from Newbury's map in Davies (1961))

days' stay, to him the inhabitants of this Garden of Eden were merely 'un peuple nombreux' living in houses shaded by fruit trees, 'dispersées sans aucun ordre \& sans former jamais de villages' (Bougainville, 1771, pp. 198, 211).

Some such description of the pattern of settlement is oommon to all the early accounts of Tahiti-houses scattered over the coastal plain and interspersed with gardens, orchards or plantations. After circumnavigating the island in 1769, Cook reckoned the coastal plain 'nowhere exceeds a mile and a half and this was where the greatest pant of the inhabitants' lived. The remainder dwelt in the many fertile valleys watered by streams and rivulets flowing down to the coast from mountaintops 'barren and as it were burnt up with the sun'. One of the transcripts of Cook's Endeavour journal continues the description of Tahiti with

Tupia informs us that the whole Island can Muster 6780 Fighting Men by which some Judgement may be form'd of the number of 
inhabitants, each district furnishes a certain number which the Chief is obliged to bring into the Field when Summon'd by the Eare de hi or King of the Island either to make War or repell an invation (Cook/Beaglehole, 1955, p. 120).

Joseph Banks, who accompanied Cook on this voyage, concluded his diary of their Tahitian visit with an account of the Manners \& customs of S. Sea Islands', in which he wrote

the districts which [the Ari'i] Possess are oblig'd in time of a general attack to furnish each their Quota of soldiers for the service of the Publick. Those of the Principal districts which Tupia recolected when added together amounted to 6680 men to which army it is probable that the small Quotas of the rest would not make any great addition (Banks/Beaglehole, 1962, p. 385).

This figure of 6,680 is, however, contradicted by what Beaglehole desoribes as 'a stray note' in Banks's handwriting where, under the heading of 'Forces of Otahite 6780', fourteen districts are listed by name and their respeotive quotas. The sum of these numbers depends on how one interprets two numerals, either or both of which might be a 9 or a 4 . If the more angular of the two is read as 4 and the other as 9, the figures add to 6,780; and the other two alternatives would give totals of either 6,280 or 7,280 . The handwriting is appalling, and in the list below the uncertain figures are asterisked.

Forces of Otahite 6780

$\begin{array}{lllc}\text { Oteihouroo } & 400 & \text { Whapiano } & 200 \\ \text { Parapara } & 900^{\circ} & \text { Whidia } & 600 \\ \text { Wyuridde } & 300 & \text { Whahite } & 400^{\circ} \\ \text { Opora } & 800 & \text { Tiarreboo } & 1800 \\ \text { O'whaa } & 200 & \text { Wyourou } & 200 \\ \text { Tettahu } & 200 & \text { Matawii } & 400 \\ \text { Matavii } & 200 & \text { Wyaru } & 180\end{array}$

(Banks, 1769)

Is this list complete, or are these only the 'Principal districts' which Tupaia recollected? The answer to both questions hinges on the number of districts into which Tahiti was traditionally divided, and there seems to be some difference of opinion on that. The island of Tahiti is virtually two islands joined by a narrow isthmus and the larger peninsula, Tahitinui, has an area roughly three times that of the smaller, Taiarapu or Tahiti-iti. The chart Cook drew of the island in 1769 has forty-four distriots named along the coast, twenty-four on Tahiti-nui and twenty in 
Taiarapu. If the isthmus of Taravao is excluded, this number does not confliot with his explicit statement in 1774 that Tahiti was divided into forty-three districts (Cook/Beaglehole, 1961, p. 409). Twenty-five years later Wilson (1799) used Cook's chart on his circuit of the island, but he located only thirty-nine distriots on either side of the isthmus (then uninhabited), and only nineteen of them were on Tahiti-nui.

On the other hand, the interpreter left with the Spanish missionaries by the Aguila in 1772 travelled much during the year he spent on the island, and he implied that there were thirteen districts in Tahiti-nui and either eight or nine in Taiarapu. Morrison, one of the Bounty mutineers who lived on the island for nineteen months in 1790-1, listed the 'Seventeen Districts' into which the island was then divided, and eleven were on the large peninsula and six on the small (Morrison, 1935, p. 166). On his seoond visit in 1792 Bligh claimed there were twelve 'counties' in each peninsula, though a thirteenth was 'sometimes' included for Tahiti-nui (Lee, 1920, p. 117n). Despite these first-hand accounts, Teuira Henry, a granddaughter of one of the early missionaries, stated categorically that "in the greater peninsula of Tahiti are thirteen districts, and in Tai'arapu, the smaller peninsula there are six'; but one of the thirteen districts she described for Tahiti-nui was a group of five islands which was 'an attachment' to one of the mainland districts, and when defining the boundaries of the distriots of Taiarapu she described seven contiguous areas other than the isthmus of Taravao (Henry, 1928, pp. 70, 76, 84-9). Both Arii Taimai (Adams, 1947) and Handy (1930, p. 45) imply only four districts on Taiarapu, and though neither mentioned a specific number for the larger peninsula, it might be inferred from both that it was divided into the same twelve districts which Henry defined.

More recently, Newbury (in Davies, 1961) has quoted from a manuscript 'History of Tahiti' which allowed five or possibly six 'great political distriots', some of which were governed by several chiefs among whom was one who was the 'principal chief.' Wilson (1799) also grouped his districts into six major political divisions, and according to Newbury, the distriots 'were fixed areas of settlement where lands and lagoons were worked by groups of inter-related families, or clans, ideally under the leadership of the family which stood in the most direct line of descent from founding ancestors. ... . Clans were also segments of local subtribes' so that the 'distriots and divisions ... were basically maximal lineages and groups of lineages' (Newbury in Davies, 1961, pp. xxxiiixxxiv). As such, these oould presumably be split or joined by the fortunes of war or marriage, and if occasionally a district name would be extended 'to other politically allied districts along the coast', some of the contradictions are resolved and Tupaia's list might well be complete. 
The names of some of the districts are easily identifiable with either modern or ancient names, but some are obscure and the districts are not listed in the sort of geographical order one would expect. Following Teuira Henry and going north from the isthmus, Tupaia's districts might be equated with those named by Henry as follows:

\begin{tabular}{|c|c|}
\hline Henry & $\begin{array}{c}\text { Tupaia } \\
\text { (from Banks) }\end{array}$ \\
\hline Hitia’a & Whidea \\
\hline Mahaena (or Ahu-'are) & O'whaa \\
\hline Tiarei & \\
\hline $\begin{array}{l}\text { Papeno'o (or Hapaiano'o } \\
\text { or Vavau) }\end{array}$ & Whapiano \\
\hline Ha'apape (or Uporo) & Matavii \\
\hline Teporionu'u (or Pare/Arue) & Opora or Opara \\
\hline $\mathrm{Fa}^{\prime} \mathrm{a}^{\prime} \mathrm{a}$ (or Tefana or Tetaha) & Tettahu \\
\hline Teoropa'a & Oteihouroo \\
\hline Papara & Parapara \\
\hline Atimaono & \\
\hline Pape'uriri (or Vaiuriri) & Wyuridde \\
\hline Papeari (or Vaiari) & Wyaru \\
\hline Tơhatu & \\
\hline Vairao (or Vaiuru) & Wyourou \\
\hline Mata'oae & Matawii \\
\hline Teahu’poo & \\
\hline Tautira & Tiarreboo \\
\hline Pueu & \\
\hline Afa'ahiti & Whahiti \\
\hline
\end{tabular}

Though six of Henry's distriots have no equivalent in Tupaia's list, two-Tiarei and Atimaono-are small distriots which might have been combined with one or other of their more powerful neighbours, and for a time at least, a third-To'ahotu-was combined with Vairao under one chief (Adams, 1947, p. 9). The remaining unpaired districts occupy the eastern half of the smaller peninsula, and Tupaia's 'Tiarreboo' might well refer to all three of these, though Handy's (1930, p. 45) map implies that Pueu is more likely to have been combined with Afa'ahiti than with Tautira, which would leave only Teahu'poo (then called Matahihae) and Tautira to be described as 'Tiarreboo'. This combination is quite plausible if 'Tiarreboo' was expected to furnish 1,800 fighting men while only half of this number or fewer were required from large distriots such as Teporionu'u, Papara, or Hitia'a.

Perhaps the most convincing argument for the completeness of Tupaia's listing is that only one of the unpaired districts was independent 
of the Teva clan whose chief's mother Tupaia served as high priest. Hence, though he was by birth a Raiatean and may have forgotten or not known the details of some districts, he was not likely to have been ignorant of either the names or 'quotas' of the Teva distriots which covered the whole of the small peninsula of Taiarapu and the south coast of the larger peninsula, from Papara through to Papeari. If one accepts these figures, therefore, the population of Tahiti in 1769 could soarcely have been more than 35,000 persons and it may have been smaller than this.

Before Cook returned to Tahiti, the island was visited by the Spanish frigate Aguila, under the command of Don Domingo Boenechea. During the month spent at Tahiti, a small party went around the island by launch and though they landed at several points, they did not go far inland. On their return, they reported that 'the Island will have about 10,000 inhabitants at the lowest computation', but as the Tahitians' language was 'unintelligible to all' the Spaniards, this estimate of the population was most probably based on the circumference of the island which had been measured as 41 leagues (Boenechea from Corney, 1913, pp. 326-30). Before the Aguila left on 20 December 1772 many of the Tahitians near the anchorage were suffering from 'a sort of epidemic catarrh . . . with sore throat, which troubled them a great deal and prostrated them severely' (Bonacorsi from Corney, 1914, p. 51). Boenechea (from Corney, 1913, p. 308) described it as 'sore throat and headache' and mentioned 'that there had been some deaths from this sickness' before 'several of the natives began to betake themselves towards the district farther to the southward'.

Reports of this disease which the Tahitians feared were given Cook on his return in August 1773: 'they say that it affects the head, throat and stomack and at length kills them'. On the other hand, 'the veneral disease ... is now far less common a mong them than in the year 1769, they even say they can cure it and so it fully appears, . . . but when ever it turns to a pox it is incurable' (Cook/Beaglehole, 1961, pp. 231-2). Unable to procure the food they needed at Tahiti, the Resolution and Adventure crossed to the Society Islands from whence they sailed to Tonga and New Zealand, returning to Tahiti via the Marquesas in April 1774.

To Cook's surprise, food was again plentiful and in their 'few excursions' along the north ooast they found 'built and building a great number of Canoes and houses both large and small, People living in spacious houses who had not a place to shelter themselves in Eight Months ago, several large hogs near every house and every other Sign of a riseing state' (Cook/Beaglehole, 1961, p. 383). On one such excursion 
they saw 'a number of large Canoes in Motion', and were surprised when they reached their destination 'to see upwards of three-hundred of them all rainged in good order for some distance along the Shore all Compleatly equip'd and Mann'd, and a vast Crowd of Men on the shore'. Later the canoes were counted and 'the Vessels of War consisted of 160 large double Canoes' and '170 Sail of Smaller double Canoes'.

In these 330 Canoes I judged there were no less than 7760 Men a number which appears incredable, especially as we were told that they all belonged to the districts of Attahourou and Ahopatea; in this computation I allow to each War Canoe one with a nother 40 Men, rowers and fighting Men, and to each of the Small Canoes eight, but most of the gentlemen who saw this fleet thinks the number of Men to the War Canoes were more than I have reckoned (Cook/Beaglehole, 1961, pp. 385-6).

A fow days later Cook watched a small fleet of ten canoes, which he thought 'thinly manned', exercise in the bay where his ships were anchored, and another day he saw yet another district's 'fleet ... of Forty Sail' being paraded before the chief he believed was king. It was this last district-Tettaha or more properly, Faaa-that Cook used as the base for his revised estimate of the island's population. Assuming that each of the forty-three districts into which he thought the island was divided could raise and equip forty war canoes, each of which was manned by forty men, this would require Sixty eight Thousand able bodied men and as these cannot amount to One third part the number of both Sex and the whole Island cannot contain less than two hundred and four thousand inhabitants' (Cook/Beaglehole, 1961, pp. 390, 401, 409).

With some justification Beaglehole concluded 'that the Captain's statistical method was regrettably loose' (footnote to Cook/Beaglehole, 1961, p. 409). Though Cook remembered, admittedly inaccurately, the magnitude of Tupaia's total for the 'Forces of Otaheite', he had obviously forgotten the variation between the districts both in Tupaia's series and in what he himself had observed going round the island five years earlier. His forty-three 'districts' were clearly the smallest units of clan lands, and the size of the first fleet of canoes becomes slightly more plausible if these belonged to two of the 'great political divisions' rather than districts in Cook's sense or in Henry's. Geographically, the political divisions most likely would be Teoropa'a (Cook's Attahourou) and the neighbouring Te-teva-i-uta, and if the latter's fleet was swelled by contributions from some of the Te-teva-i-tai districts of Taiarapu (although not, apparently, 'Tiarroboo' whatever that might signify), the number of 
canoes appears less incredible, although there is still a wide margin between Cook's figure of 7,760 men and Tupaia's tally of perhaps 3,000 warriors at most from these divisions.

The naturalists who were with Cook on this voyage were Johann Reinhold Forster and his son George. They too counted the first fleet of canoes and 'upon a very moderate calculation', George Forster reckoned that on this occasion there could not be less than fifteen hundred warriors, and four thousand paddlers, besides those who were in the provision-boats, and the prodigious crowds on the shore'. Allowing only twenty canoes per district, and 35 men to a canoe, 'the sum of men employed in the fleet, exclusive of the attending boats, would then be no less than thirty thousand; and these we assume as the fourth part of the whole nation'. This 'most moderate' total of 120,000 Tahitians was described in a footnote as 'very low' (G. Forster, 1777, pp. 65, 66).

His father was also moderate, though rather more elaborate, in his calculations. On the basis of ' 50 war canoes, and 25 small attending boats' per district, the 'very lowest computation' for the large peninsula led him to a total of 27,000 men or 81,000 persons if each man had a wife and one child. Taiarapu was allowed only half this number, and as 'some will be ready enough to question this great population, and to doubt, whether such numbers can find food in proportion to support them all: it is but just to establish the fact on a firm basis'. He had been told that three large breadfruit trees would feed a full-grown person for the eight months of their bearing, and as the largest trees accupied a space 40 feet in diameter, 40 square miles of land planted with breadfruit would provide sufficient food for 170,660 persons a year if the trees occupied a square space, or 204,800 persons if the space was round (J. R. Forster, 1778, pp. 217-21). This fantastic calculation fits Cook's population estimate so neatly that one suspects this was its starting-point, and the 40 square miles its end-point because this needed no justification, even though for an island alleged to be 'not forty leagues in circuit' it implies a solid belt of breadfruit trees about one-third of a mile wide all round the island.

The canoe fleets were assembling in readiness for an attack on nearby Moorea, and there was some thinly disguised impatience for Cook and his ships to be gone. They left in May 1774 and six months later the Aguila returned, accompanied by a storeship Jupiter. Two missionary padres were landed with an interpreter on the north coast of Taiarapu, and with a sailor to cook and garden for them, they remained there until November 1775. While their house was' being built, 'several Indians, nobles and commoners, died of a pestilence that attacked them, which was neither more nor less than a severe chill; . . . they say that this illness comes from our sojourn amongst them, because it was the same 
way during the first expedition of the frigate' (Rodriguez from Corney, 1918 , p. 30). To confirm the similarity of the two outbreaks, another observer described this sickness as an epidemic of catarrhal fevers from which many . . . died' (Gayangos from Corney, 1914, p. 141).

In the months that followed, the missionary padres 'never went beyond the immediate precinots of their hospice,' but Rodriguez, the interpreter, 'wandered freely all over the island by himself both coastwise and in the interior'. Although he later 'assured [the Viceroy of Peru] that the place is thickly peopled and was of opinion that the inhabitants exceed fifteen thousand persons' (Amat from Corney, 1913, p. 17), he recorded in his diary only one attempt to estimate numbers of people, and that on the ocoasion of his first visit to the district of Mataoae on the south-western coast of Taiarapu. There

The crowd was so great that I thought I would like to see how many there were of them, as nearly as might be; so I desired the people to arrange themselves on a piece of open ground, and they did accordingly, with much merriment. I made them out to number rather more than two thousand souls (Rodriguez from Corney, 1918, p. 52).

There was no suggestion that this was necessarily the usual population of the district because 'strangers' from Raiatea were visiting the peninsula at that time, and much to the discomfiture of the timid missionary padres, a great many people [had] arrived from the other districts to take part in the festivities that were to celebrate the visit' (Rodriguez from Corney, 1918, p. 43).

Some months later Rodriguez made a circuit of the larger peninsula, partly by canoe, partly on foot, and he described three of the thirteen distriots he visited as 'very populous', three others as 'pretty densely peopled', 'well-peopled' or 'populous', and one as 'not thickly peopled'. For two of the remaining distriots-one of them 'not a very large' district and the other 'none of the least the island is divided into'-he commented only that his presence attracted 'a numerous crowd' in the first and 'a great following' in the second, and the rest he passed by or through without specific comment, though it might be inferred that one of these was not densely populated (Rodriguez from Corney, 1918, pp. 164-75). In almost every district the crowds that gathered to greet him 'flustered' or 'harassed' him, and even assuming that there were some amongst these crowds who followed him from district to district, the total of 15,000 later attributed to him by the Viceroy of Peru seems altogether too modest an estimate of the population of the whole island.

The Aguila returned with provisions for the missionary party in November 1775 , but the cargo was not discharged because the padres, 
having spent a year "manifestly unprotected and in imminent danger of losing [their] lives' to such 'barbarous and inhuman people' as the Tahitians, desired nothing but to return to Peru (Langara from Corney, 1914, p. 377). Within two weeks of its arrival the Aguila departed and Tahiti had no European visitors until Cook returned again in August 1777. He had little to add to his earlier descriptions of the island, and though Caillot (1909, p. 71) and others have attributed a revised population total of seventy to eighty thousand to Cook, this figure does not appear in any of the journals of this voyage yet published. After little more than a month at Tahiti, the Resolution and Discovery crossed to Moorea. Cook had not visited this island before, and though he stayed longer than he intended while parties searched for the goat which had been stolen from them, he made no attempt to estimate the island's population.

A Lieutenant Watts who sailed with Cook on this voyage returned to Tahiti in July 1788 on the transport Lady Penrhyn. Because so many of her crew were sick with scurvy, "Mr. Watts did not think it prudent to go any great distance from the ship, or even to be much on shore, so that he was prevented from gaining much information'. Among the 'facts' ascertained during their stay of two weeks was that theirs was the first ship to call since Cook's last visit, so that food was plentiful and the hogs were multiplied amazingly'. However, 'great numbers of the natives had been carried off by the venereal disease, which they had caught from their connections with the crews of the Resolution and Discovery; nor were the women so free from this complaint as formerly' (Watts, 1790, pp. 249, 242, 247).

The Bounty arrived in October of that year and remained for five months collecting breadfruit cuttings for British colonists in the West Indies. After several weeks Bligh doubted the alleged ravages of venereal disease during the preceding decade because what we have seen of it hitherto has been of the mildest Nature, and the Men have been easily cured'. The chiefs who were his constant companions, dining with him daily, 'assert[ed] their Births exceed their Burials by many proportions' and 'were the Women moderately Chaste and to Marry I really beleive the Island would swarm with Inhabitants'. Families were commonly limited to 3 children, and from 3 to 8 are the number of Infants that have been killed by the assistants of many of our Cheif Women who visit the Ship'. 'Full of Inhabitants' though the island may have been, the population was not then such that 'every inch of Ground should be Cultivated' (Bligh, 1937, 2, pp. 9, 78, 79).

After the mutineers' unsuccessful attempt to settle on Tubuai, sixteen of them returned to Tahiti where they separated and attached themselves 
in twos and threes to various chiefs. James Morrison, who had been boatswain's mate on the Bounty, claimed 'the Number of Inhabitants in Taheite are Near 30,000 of which their warriors may be reckoned at near one third of that number'. If this figure was anything more than a guess, its origin was perhaps an assessment, like Tupaia's, of the fighting strength of the several distriots and political alliances. During their nineteen months' stay, the mutineers 'reduced . . . into Subjection' the eight districts which they thought 'were ever rebellious to the reigning King'-and thereby created a kingship over the seventeen districts into which Tahiti was then divided (Morrison, 1935, pp. 171, 165-6).

Morrison and the other fourteen survivors were captured in April 1791 by H.M.S. Pandora under the command of Captain Edwards. The Pandora was one of the ships suspected of having introduced a disease known as the lila or wasting sickness into Fiji in 1791-2 (Corney, Stewart and Thomson, 1896, pp. 34-5), and if Tahiti experienced any such sequel, it may have been confused with the scrophula, which breaks inwardly, and wastes them like a consumption' which, more than ten ycars later, some Tahitians attributed to the Bounty (Turnbull, 1813, pp. 367-8). The 'Chief Disorders' cited by Morrison (1935, pp. 228-9) were 'Madness or Insanity, Agues, Coughs \& Colds, Swelld legs \& Arms, Swellings under their Ears like the Evil, Ruptures \& some few others', amongst which was 'that terrible Disease the Venereal' which the Tahitians associated with the visits of European ships. By 1804 they were convinced that

all their diseases come from us. . . . They say, that Captn Cook brought the intermitting fever, the humpbacks (crooked backs) and the scrofula . . Vanoouver brought a bloody flux that in a few months killed a great number and then abated, but it is still among them. They are agreed, that all their mortal diseases are from the ships, but they are not agreed what ships brought particular diseases. Some say, that Captn Bligh brought the scrofula (Elder and Wilson, 1804).

Cook was apparently unaware of the legacy of 'intermittent fever', a 'most dangerous malady ... peculiar to the country' which was 'very prevalent, and, from their manner of treatment, or rather negleot, very Fatal' in the early years of the nineteenth century (Turnbull, 1813, p. 367). Vanoouver, pleased by 'the high state of health' his ship's company had enjoyad since leaving New Zealand, was likewise ignorant of the consequences of his three weeks' visit at the beginning of 1792, though he was upset to find that so many of the friends he had made and seen last in 1777 were dead, some of them from 'a disorder that is attended by a large swelling in the throat, of which very few rocover, but die a 
slow lingering death'. This disease was particularly prevalent in Taiarapu where it was believed to have been imported by a Spanish vessel which had anchored near the south part of Otaheite' (Vancouver, 1801, I, pp. $363,252-3,326-7)$.

The outbreak of dysentery which followed Vancouver's visit was reported to Bligh when he returned to Tahiti in April 1792-three months after Vancouver had sailed for North America-for a new cargo of breadfruit cuttings. On 8 May he was visited by the widow of the former chief of Hitia'a and 'nothing can exceed the vehemence with which [she] expressed herself against Captain Vanoouver's ship. It was there [her husband] caught his illness, as did many others . . . she described the disease to be a flux' (Lee, 1920, p. 99). However, Bligh's was the fourth ship to visit Tahiti after Vancouver's departure; within three weeks two British whaling ships had called for provisions, and one of these was wrecked a week after leaving the island. Her crew escaped in small boats and found their way back to Tahiti one week later. Within another three weeks some of the castaways were given passage to North America on another British ship, and almost all left the following year.

There were two Europeans on the island when the London Missionary Society's Duff brought the first missionaries to Tahiti in 1797, and one of them acted as interpreter to the Duff's chief officer and first mate, William Wilson, on his circuit of the island 'to try some methor of estimating the number of people in each district'. Some of the missionaries had already toured through various parts of the island and decided that 'the accounts of former navigators as to the populousness of the country [were] greatly exaggerated', and they 'supposed the number of inhabitants on both peninsulas to be about fifty thousand'. William Wilson was still sceptical and, armed with Cook's map, he set off on foot around the island, accompanied by the interpreter and three Tahitians (Wilson, 1799, pp. 181, 186).

In the first district he came to he asked the chief how many people lived there, and when told about 250 , he inquired how this figure had been computed. He then learned about the 'principal houses'-distinguished either by a degree of rank in its ancient or present owner, or by portions of land being attached to it; and sometimes on account of its central situation to a few other houses'-with which were associated other lesser houses, and though the numbers of persons in the households varied, the average number per household in this first district was near enough to six. Thereafter Wilson went from district to district, asking each chief how many houses there were, and in the forty districts he listed there were only 2,675 households, giving an estimated total population of 16,050 . 
As far as the district and place names can be reconciled with Teuira Henry's, and thence to Rodriguez's and Tupaia's lists, there is fair agreement between the numbers of households in 1797 and Rodriguez's descriptions, but rather less correlation with Tupaia's tally of warriors almost thirty years previously. It had, however, been a far from peaceful period as the Pomares struggled for power (Newbury in Davies, 1961, pp. xxxvi-xxxviii) and the defeated were either killed or forced to flee as their houses and gardens were destroyed. There had been epidemics too, which would not have fallen equally on all of the distriots around Tahiti's 90 miles of coast, although Wilson (1799, p. 186) did, in fact, include some houses that were 'totally deserted' but which he reckoned were allowed for in his estimate of six people to a house. Hence, unless a far greater proportion of the population was then living inland, away from the coastal littoral and the nearer valleys, than is implied by so many of the early visitors, it is difficult to see how Wilson's estimate can err by more than about 3,000 on either side, which suggests a population somewhere within the range of 13,000 to 19,000 towards the close of the century, and more probably somewhere within the upper half of this range.

The missionaries themselves made no attempt to check Wilson's count, and a year later conditions on Tahiti were such that eleven of the original eighteen missionaries left with their wives for Port Jackson. Though one returned early in 1800 , by then two others had defected and yet another left for Australia. Eight, including some who had left in 1798, arrived in the middle of 1801 (Newbury in Davies, 1961, pp. $\mathrm{xl}, \mathrm{xlvii}$ ), and in November 1802 the missionaries Scott and Jefferson made the tour of the whole Island . . . having spoken to 2051 persons capable of understanding the word on the larger peninsula and 1650 on the smaller . . they supposed the number of inhabitants on the whole Island did not exceed 7000' (Davies, 1961, p. 58). Excluded from this tour was a valley thought to contain 'many people far inland', but when it was visited in September 1803 the 'many' was 'thought' to be only 252. In October 1803 Scott and Jefferson made another tour of the large peninsula, and though Davies (1961, p. 66) commented merely on the usual unwillingness [of the people] to hear, and indifference to what they heard ... everywhere', the trader Tumbull (1813, p. 368) asserted that in both 1802 and 1803 the missionaries numbered the people; . . . according to their first calculation, they were seven thousand, but in the second, they very little exceeded five?.

Although at this time the missionaries meticulously recorded in their journals the numbers preached to each day, sometimes separating out mornings and afternoons, as they went about the islands, it would be 
hazardous now to try to assess their geographic coverage from the place names listed. Even if one could do this, what was the relationship between the numbers preached to at each place and the total population? Though it would seem that only adults were counted, how accurately could an audience of 168 or 152, for example (Elder and Wilson, 1804), be counted even though the missionaries travelled about in pairs and presumably only one preached at any one time? It seems, in fact, that it was not until 1829 that there was any systematic count that might properly be described as a census, so that, notwithstanding the missionaries' zeal, their own estimates and the many others attributed to them before this date should be treated reservedly as opinions rather than estimates.

For much of this time Tahiti was in a very unsettled state: revolts against Pomare increased until, in 1808, he took refuge in Moorea and all but two of the missionaries then in Tahiti escaped to New South Wales. When they returned in 1811 and 1812 Moorea became their headquarters and the native chiefs, demoralized by the events of the preceding years, were readier to be converted. After Pomare's victory in 1815 the mission strengthened its hold and in 1818 the missionaries ... separated to different stations' on Tahiti and the Leeward Islands while a nucleus remained on Moorea (Davies, 1961, p. 232). During the 1820 s there were seven stations on Tahiti, two on Moorea and one on each of Huahine, Raiatea and Borabora, all staffed by European missionaries and several by more than one. The total population of these islands was then thought variously to be about 12,000 (Threlkeld and Williams, 1818), 14,000 (Gyles, 1819) or 15,800 (Waldegrave, 1833, p. 174); and though these were only guesses, the evangelist John Williams (1823) considered that these Islands of themselves are not worth the labours of half the Missionaries that are on them'.

Before the people of Tahiti were 'numbered' by the missionaries in the latter half of 1829 there were reports of dysentery in some parts of the island (Darling, 1826), and a heavy affliction which . . . carried off many adults' (Wilson, 1826) elsewhere. This was a 'disorder resembling the dry belly ach', which was thought to have oaused the deaths of 'not less than 100 persons on this Island, and where it did not prove fatal, it terminated generally in the palsy' (Wilson, 1827). In the smaller peninsula the people were 'dying very fast. There are not half the inhabitants ... that there were ten years ago and they decrease rapidly'. During 1826, 74 people there had died and there were only 48 births (Crook, 1826), but in the six months ended 5 May 1827 there had been ' 20 births and but 10 deaths in a population of 1500 or more' 
(Crook, 1827). A little more than two years later the population of this area was 'numbered' at 1,816.

The census of 1829 was instigated by Davies (1830) who listed for each of the three Teva-i-uta districts the numbers of church members, baptized adults and children, and unbaptized adults and children, separating the males and females in each of the five categories. Another missionary (Darling, 1831) copied this pattern, but the figures from the other five stations on the island were merely total numbers, and the aggregate 'numbered' for Tahiti towards the end of 1829 was 8,674. Though several of the mission stations covered more than one traditional district, there is sufficient correspondence between the missionaries' figures and Wilson's household census of 1797 to suggest that, despite all that had happened in the interval, there had been no very great change in the geographic distribution of Tahiti's population, except that Wilson's estimate attributed relatively more people to Taiarapu than wero reported to be there in 1829 .

The districts which occupied the south-western half of the large peninsula contained 3,060 people, 1,140 of whom were described as children-660 boys and 480 girls. Although infanticide cannot be ruled out as the explanation for this excess of males, it is possible that the missionaries' criteria for distinguishing between male adults and children differed from those for women and girls. However, the excess of males was even more marked among those classified as adults-1,162 men, 758 women-and this distorted sex ratio may well have reflected the selective infanticide practised so few years previously. Whatever the criteria for children may have been, there were in these populations 1.5 children per woman, and this ratio would be still higher if women beyond the reproductive ages could be excluded from the total.

About this time some of the missionaries began to keep records of the births and deaths which occurred in their districts, and though some claimed they had no way of knowing the numbers for those not united with' them (Platt, 1838), three missionaries on Tahiti were fairly assiduous. There is a series covering about fourteen years for Davies's station, another for just over seven years for Matavai, and sporadic returns from Darling, some probably incomplete, especially the numbers of births. In very few of these years were there more deaths than births, though the difference was seldom large and Davies's reports indicate a gain of only 20-496 births and 476 deaths-from May or August 1829 (both dates are cited in Davies, 1830) to July 1843 (Davies, 1830, 1831, $1832,1834,1835,1836,1837 \mathrm{a}$ and $\mathrm{b}, 1839 \mathrm{a}$ and $\mathrm{b}, 1840,1841 \mathrm{~b}, 1842$, 1843). If all births were reported to him, the average annual crude birth rate in the three districts which were his station was only 18 per 
thousand population, and even allowance for the abnormal sex ratio would raise it only to about 24 . For Matavai (Wilson, 1833, 1834, 1835a and $b, 1836,1837,1839$ ) the crude birth rate was even lower than this, but it may have been a little higher in Darling's area (Darling, 1831, 1834a, 1836, 1839, 1840, 1842).

In 1833 there were disturbances in Taiarapu which involved the Teva people on the large peninsula as well (Davies, 1834), and Darling (1834) admitted that he could not 'form any very correct idea with respect to the increase or decrease of the inhabitants as there are many who are continually moving about from one place of residence to another as they have land at different parts of the island. I do not think the people are much (if any) on the increase.' Perhaps this movement of people about the island would explain the apparently dramatic increase in the population of Taiarapu from 1,816 in about 1830 to 2,820 in May 1834. "The census which was taken of the Peninsula [then] makes it appear that there are 684 Boys 586 girls-1270 Children 965 Men585 Women-1540 [sic] adults in all 2,820 souls on Taiarabu' (Orsmond, 1834). Two years later the missionary complained that 'taking the census we have more than 2,000, but in taking names of those [who] are familiar with us and who come oocasionally to hear we find about 1293 persons' (Orsmond, 1836).

During the 1830s the Tahitians began to cultivate food crops and rear stock which could be sold to the trading and whaling ships which called in increasing numbers for supplies and refreshment (Rodgerson, 1838; Henry, 1839; Darling, 1840). By the end of the decade a township had sprung up around the port which was visited by between seventy and eighty ships a year, and the growth of trade had encouraged America, England and France to appoint consuls to Tahiti. Though the traders and settlers favoured the separation of civil and religious affairs, the mission retained sufficient control over the government it had created to prevent the establishment of a French. Catholic mission in Tahiti in 1836 and again in 1838 (Newbury in Davies, 1961, pp. 333-4). As the number of settlers-'foreigners almost from all nations' (Darling, 1842) -increased the 'fragile edifice' of the Tahitian Government cracked, and while Pritchard, the missionary turned consul, was in England pleading for Britain to annex or establish a protectorate over Tahiti, some of the chiefs agreed with Pomare to accept French protection (Newbury in Davies, 1961, pp. 333, 337).

This was in 1842 and by then the smallpox epidemic had run its course. The disease was introduced at the beginning of June 1841 by an American vessel bound for Hawaii from Valparaiso. Five Hawaiians and the captain's brother had died of smallpox before the ship reached Tahit, 
but as the American consul wanted supplies from her and a doctor 'from the shore declared there was no sickness on board', 'the chiefs reluctantly consented to allow the vessel to come to anchor in [Matavai] Bay. Quarantine regulations were adopted, but not strictly observed, and too soon abandoned.' The boat remained there for two weeks and before she left for Papeete the doctor and three passengers disembarked. One of the passengers died within a few days and 'soon after many of the natives caught the infection, providentially the "Yorktown" ship of war came and brought the vaccine Lymph by which the lives of many persons [were] saved' (Wilson, 184la).

Though she stayed twelve days in Papeete, the offending ship-always curiously anonymous-had probably left Tahiti before the first cases occurred on the island. The 'vaccinating matter' supplied by the American warship was distributed widely throughout Tahiti and the neighbouring islands, and the missionaries believed it 'successful beyond [their] expectations' (Wilson, 1841b). At Matavai, where there were few who had not been vaccinated, only five adults and one child died of smallpox, and five children recovered (Wilson, 1841a). To the east of Matavai and in the north-eastern corner of the island 'about $20^{\circ}$ died of smallpox (Henry, 1842), but the disease seems not to have reached either Taiarapu (Orsmond, 1841) or the Teva districts on the south coast of the large peninsula (Davies, 1841). At Darling's station, which adjoined Davies's on the west coast, 'some $10 \mathrm{or} 12$ died' and 'all the persons that have taken the disease up to the present time 19th Sept. have not been vaccinated'. In Faaa, the district which separated his station from Papeete, 'more than 100 persons, men, women, and children belonging to that one district . . . have been cut off by the Small-Pox; at the rate of 3,4 and sometimes five in one day'. In Papeete itself, in the two or three weeks previous to 2 October 'about 60 persons had [died] of the Small-Pox, all it may be said through their own folly and obstinacy in refusing to be vaccinated' (Darling, 1842).

Almost all who refused to be vaccinated wero 'most astonishing[ly] ... of that class called Mamaias, or (unripe fruit) ... which have long troubled Tahiti with their nonsense ... ready to join the Catholic religion or anything else against the Gospel as taught in the Bible, because the[y] could not go on in sin as they wished' (Darling, 1842). Other unflattering epithets were 'those false doctrine gentlemen' (Orsmond, 1841) and 'a deluded class' (Simpson, 1841), but Mrs Pritchard may have been more sympathetic. 'The poor natives suffered dreadfully from vaccination-in one or two instances the sore became putrid-a lock'd jaw ensued-death of course followed. . . . The generality of the natives were ill for six weeks or two months-with dreadful wounds in 
the Arm- . . the inflammation extending below the elbow-and above the shoulder' (Mrs Pritchard, 1842).

Either as a result of the extensive vaccination of the people, or because those furthest from Papeete stopped others from coming into their districts once the epidemic started (e.g. the 'restriction which the people of Papara had put on the road' (Darling, 1842)), the outbreak was effectively confined to the north-western oorner of the island and prabably caused fewer than 200 deaths, either directly or indirectly. No doubt there were more people there in 1841 than there had been in 1829 or 1830 when they were last counted and a total of 1,140 was reported for the two districts of Faaa and Pare which suffered most.

The smallpox also spread to Moorea very soon after the initial outbreak in Tahiti. One of the chiefs, who was also a supreme judge and a church member, had gone to Tahiti several months earlier for treatment by the Mamaia for 'a sinful disease' and as his condition deteriorated instead of improving, he and his family, with a Mamaia priest, were returning to Moorea when they slept in a house where there was a case of smallpox. The priest died about four days after their arrival in Moorea, and thirteen other members of the family developed the disease soon after. The chief himself survived, 'almost the only survivor of a large family', but 29 of the 54 cases which occurred on the eastern side of the island proved fatal, and there were probably 13 other fatal cases on the north coast (Howe, 1841).

Though a missionary not long arrived in 1840 thought it improper that 2 missionaries . . . should be stationed at Eimoo for 1500 people' (Heath, 1840), there seems to be no evidence of any systematic count of Moorea's population at any time during the missionaries' régime. In 1804 Elder and Wilson (1804) toured Moorea, and preached to a total of 2,533 persons, but this becomes only 1,468 if only the largest numbers given for each place are included to ensure against double counting. This was probably not the whole population because the numbers preached to in the distriot which contained more inhabitants than any of the other districts' were smaller than those recorded for five other places. Early in 1805 the tour was repeated by Bicknell and Henry (1805) who 'saw in many places round the island the ruins of houses that had been burnt down in the late war, and several houses waste whose inhabitants [they] were informed had fled to Taheite for refuge'. Later that year Elder revisited the island with Youl and found the island 'very thin of inhabitants there is a visible decrease, many are sick, and some Districts almost without inhabitants' (Elder and Youl, 1805).

Pomare had taken refuge in Moorea in 1808 and when the missionaries retumed there from New South Wales in 1811 and 1812, there were at 
least 750 of his supporters from the Leeward Islands living on the island, and their number increased to perhaps 1,000 before Pomare's victory in Tahiti in 1815. In 1817 'there were many strangers going and coming' still (Davies, 1961, p. 213), and when the missionaries separated in 1818 one of the two stations on Moorea was closed and not manned again until 1824. In 1820 an outbreak of influenza 'made its ravages' on the island (Henry, Platt and Bicknell, 1820), and the people of Moorea suffered the same disease as many Tahitians during 1826 (Henry, 1827). In 1827 'disagreeable circumstances' persuaded the missionary who had baptized 628 adults and 626 children there to leave Moorea, but even Davies (1961, p. 241) could not decide how many people were living there, 'the far far greater part' of whom were 'abandoned to a Christian sort of Heathenism' (Orsmond, 1831).

The sporadic returns of births and deaths starting in 1829, and often referring only to the north side of the island, indicated a substantial net gain through natural increase before September 1839-145 births and 97 deaths (Simpson, 1829, 1833a and b, 1834, 1835, 1837, 1839); and as there was no mention of epidemics throughout the period covered, it might be surmised that the population had increased somewhat before the outbreaks of whooping cough in 1840 (Blossom, 1840), of smallpox in 1841 (Howe, 1841) and dysentery in 1843 (Blossom, 1843). Even then there were 49 births and only 24 deaths reported for a period which began sometime in 1841 and ended 20 February 1843 when 'several' people had already died of dysentery.

Dysentery was reported on Tahiti in that year, to 'an alarming extent among both adults and children' on the south coast (Buchanan, 1843), 'in every class' in Taiarapu (Orsmond, 1843), and in the first half of the year deaths from dysentery were 'uncommonly numerous ... all thro the Island Children and others' (Davies, 1843). In December, 'the islands were visited by a severe gale . . . which destroyed many villages and a great number of valuable bread fruit trees which in this season of scarcity is greatly to be lamented. There being so many vessels here and troops', the missionaries had to pay dearly for their 'scanty supply of native produce' (Buchanan, 1844a). The troops and four of the vessels were under the command of the Commissioner who had been appointed by the French Government to its new protectorate. They had arrived in November 1843 and as Pritchard, on his return from England, had successfully undermined the provisional administration set up in 1842, Commissioner Bruat promptly deposed Pomare and provisionally annexed Tahiti to France. Encouraged by Pritchard, the Tahitians rebelled and though Pritchard was deported in 1844 and the protectorate restored the 
following year, the rebellion continued until 1847 (Newbury, 1957, pp. 79-83; Newbury in Davies, 1961, p. 354n).

In March 1844 Tahiti was "considered in a state of siege . . . about 4000 natives under arms [had] assembled' at Hitia'a, the district on the east coast of the large peninsula near the isthmus of Taravao (C. Barff, 1844a), and those still living on the south coast did nothing-They will not plant food for themselves even-they say the French will take it' (Moore, 1844). In the first skirmish with the French troops only three Tahitians were killed and two wounded. A month later there was a 'more sanguinary meeting ... when 67 patriats were killed'. The Governor's tally of casualties was 104, at least 79 of whom were Tahitians (Buchanan, 1844b). Early in May their army was 'over 3000 men besides women and children each of whom they reckon as good as a Frenchman and a warrior to four Frenchmen. Their ranks are daily increasing' (Simpson, 1844).

Despite outbreaks of influenza and dysentery (Howe, 1844), the skirmishes between the rebels (or 'patriots' as some of the missionaries preferred to describe them) and the French continued. By December 1844 the Tahitians had 'lost about 100, the French upwards of 300' (Heath, 1844) in the fighting, and the war dragged on desultorily throughout 1845, when some of the French troops were diverted to the Leeward Islands. Only at Papeete were the people 'under the complete control of the French ... and their entire time [was] spent in debauchery and idleness'; many of the remainder were gathered into two encampments in the mountains and growing food in the valleys below (Thomson, 1845). In 1846 the French troops were reinforced to more than 2,000 and though they failed to dislodge the Tahitians from their strongholds, 'the valleys and villages near to them [were] pillaged and burnt, and a vast number of fruit trees and plantations destroyed by the assailants. ... As to the Patriots their loss of life [was] very trifling' (Heath, 1846), but these were battle casualties only, and it was believed there were also many deaths from disease and privation in the camps among the poorer classes ... as provisions [failed] them' and among 'the aged and infirm, the women and young children, ... driven to the farthest glens and recesses of the mountains' where the food was 'scanty and indigestible' (Johnston, 1846).

Early in January 1847 the Tahitians surrendered 'most unexpectedly' (Henry, 1847), and 'every family [went] to their own particular spot of land' (Darling, 1847) to restore their houses and gardens. There was 'much sickness' amongst 'the young people', especially 'the young women, who [were] exposed to very great temptations' (Johnstom, 1847); and by October, there was 'a very large amount of sickness among both natives 
and Foreigners' due to an outbreak of scarlet fever (Howe, 1847b). Though it was thought that the Tahitians suffered relatively less than the foreigners in the epidemic (Davies, 1847), 'the people being so far from the station scattered about that they neglect to give in the account, in many instances, when either a birth or a death takes place' (Darling, 1848).

'On the 1st of February it is reported that French officers are to commence taking the names of all the people and to write down each person's land with all other kinds of property of any kind which they may possess' (Darling, 1848). Two weeks later the census was completed, and showed 'a much more favourable aspect' than had been expected.

It is 8000 for Tahiti, and 1400 for Eimeo. The very great number of recent births in all the districts has given this favourable number, it being somewhat above that taken by Commander Nicholas in 1842 . There are 4 males to 3 females, which appears to be the same proportion as existed in 1829 when a census was taken by the missionaries (Howe, 1848).

Elsewhere these figures were quoted as 8,300 for Tahiti and 1,100 for Moorea (Charter, 1848), but data extracted by Newbury from the archives of the Ministère de la France Outre-Mer give totals of 8,082 indigenes on Tahiti and 1,372 on Moorea in February 1848. In addition there were 475 foreigners on Tahiti on 1 May of that year and 40 on Moorea, though this latter is probably approximate because it was not subdivided as were all the others into men, women, boys, and girls.

Not unexpectedly some of the people of Moorea participated in the war with the French, and 'a greater number' of them were away from their island in 1845 than had been in 1844 (J. Barff, 1845) when the population was believed 'not [to] exoeed 14 or 1500' (Joseph and Howe, 1846). After the surrender, many of 'the most influential people' returned to their own lands, away from the mission stations, because 'vegetables, and live stock bring very high prices ... a t Tahiti so that all who are able to labour are fully employed in this lucrative trade. There are nearly 20 boats which . . . constantly supply the Tahitian market' (Simpson, 1847), and the missionary saw little of the people except on the Sabbath.

In 1848 the populations were similar in that about 31 per cent of each were described as children. On Tahiti there was no very great difference between the numbers of boys and girls-1,329 boys, 1,220 girls; but on Moorea the excess of boys-238 as compared with only 188 girls-was almost as great as the excess of males in the adult population -558 men and 388 women. If the two populations are combined (as they 
probably should be) there were 3,695 men, 2,784 women, 1,567 boys and 1,408 girls, totalling an aggregate of 9,454 indigenes. The numbers of children and women were practically equal, so that there were fewer children per woman in 1848 than there had been in the south-eastern districts of Tahiti in 1829. Although still somewhat distorted, the sex ratio in the adult population in 1848 was lower than had been reported in the mission census, and over the interval between the two censuses Tahiti's indigenous population had decreased by perhaps 600, perhaps by slightly more than that if Taiarapu's population had been undercounted in 1829-30.

Although 1850 was a year of 'more than usual sickness and mortality' (Davies, 1850), there was no specific epidemic on Tahiti until the end of 1852 , when a disease known as 'the coast fever' was prevalent around Papeete (Spencer, 1853). Though painful, it seems not to have caused many deaths ( J. Barff, 1853), but as food was very scarce on the island and boats were sent to other islands for supplies, the epidemic was not confined to Tahiti alone. Nor was the measles epidemic which was started in April or May 1854 by 'an American vessel on her way from New Castle (N.S.W.) to San Francisco' (J. Barff, 1854). By September the epidemic had abated on Tahiti, but its ravages were frightful and did not stop until it had carried off upwards of 700 individuals of all ages, but chiefly of the male sex' (Howe, 1854).

The mortality was greatest in the western and southern parts of the island. At Darling's station the deaths were 'not far short of one hundred'; and at Davies's 'the effects . . . were quite as destructive'. 'For the scattered nature of the Population' along the east coast of the large peninsula 'the number of deaths was very great', but there were comparatively few deaths along the eastern half of the north coast, and no indication at all of what happened in Taiarapu (Howe, 1854b). Moorea was alleged to have 'lost nearly a tenth of the population' (Platt, 1854), but the mortality there might also have been rounded upwards as it was for Tahiti, or perhaps Cuzent's (1860, p. 42) total of 800 deaths from measles in 1854 refers to both Tahiti and Moorea, and not Tahiti alone.

Cuzent gave no source for this figure of 800 deaths, but as he visited Tahiti a few years after the epidemic, his information may have come from some of the four missionaries still there. This is a more likely source than the état civil which had been started in 1852, but was probably far from complete for some years afterwards. During Cuzent's (1860, p. 36 ) stay at Tahiti another census was taken, and though Teissier (1953, p. 17) discredited it because 'ce sont les authorités indigènes de cette époque qui en avaient été chargés', the population listed was 
classified in rather more detail than it had been in any previous count.

The total population enumerated in September of that year was 7,212 of whom 6,198 were on Tahiti, 54 on the islets of Tetiaroa (usually treated as part of Tahiti), and 960 on Moorea. Cuzent had somehow obtained the numbers of males and females in each population in the four descriptive age groups-'vieillards', 'age mur', 'adultes' and 'enfants'; and though his totals do not tally with those of the census, thery are sufficiently close not to invalidate a few simple deductions from the data. Basically, the sex composition of the population had not changed much since 1848; again there was a surplus of males in the adult population, especially on Tahiti, and a slight excess of boys amongst the children. On the other hand, the ratio of children to women had increased from little more than 1 child per woman in 1848 to about 1.3 in 1857 or more than 1.5 if the old women are excluded. About 10 per cent of both males and females were described as aged, 21 per cent middle-aged, 32 per cent adult and 37 per cent as children.

If this was a complete count, and we accept a mortality rate of 10 per cent of the population of all ages in the measles epidemic, what kind of a death rate is implied for the population to have decreased as it appears to have done between 1848 and 1857? Knowing nothing about the probable birth rate in the population, it is simpler to use the adult population only, assuming that one-half of the individuals described as 'children' in 1848 would, if they survived, have been described as adults in 1857. In this case a death rate of at least 5 per cent per year would have been needed to reduce the adult population to the numbers recorded in 1857, and though this may not be unreasonable in some circumstances, it is rather higher than any of the missionary reports suggest.

On the other hand, if an annual death rate of 3 per cent is accepted along with the other conditions, this would imply that perhaps one-fifth of the population was omitted from the 1857 census, and if the populations recorded then are inflated appropriately, Tahiti's population may have been nearer 7,700 than 6,250 and Moorea's nearer to 1,200 than 960 . If the death rate is set at 35 per 1,000 population in all years except 1854, this would have reduced the adult population of Tahiti to 4,450 by 1857 , and proportionate intlation would produce populations of 7,350 for Tahiti and 1,130 for Moorea. On this basis, about 15 per cent of the population may have been omitted in 1857.

According to Teissier (1953, p. 17) censuses were taken in both Tahiti and Moorea in 1860 and again in 1863. On both occasions foreigners were specifically exoluded, so that the totals of 7,169 and 7,642 for Tahiti and 1,114 and 1,242 for Morea in 1860 and 1863 $\mathrm{K}$ 
respectively refer exclusively to the indigenous inhabitants. Berchon (1865, p. 501) on the other hand acknowledged no census of Tahiti and Moorea betweeen 1848 and 1862, when the population including foreigners was 10,347 or a neat 400 fewer than Teissier claimed for 1863. If Teissier's dates are right, then the figures quoted by Berchon (1865, pp. 501-2) for the births and deaths recorded in the état civil for the indigenous populations of Tahiti and Moorea from 1855 to 1863, indicate a maximum net natural increase of 293 between 1860 and 1863; and if the censuses were accurate and the état civil complete, there had clearly been some migration into these populations between 1860 and 1863. Though the month in which the 1860 census was taken is not known, these same records indicate a gain of fewer than 237 through natural increase between September 1857 and the end of 1860, and if the 1860 census was accurate, the état civil complete and there had been no migration in the interval, the population of the two islands in 1857 may have amounted to fewer than 8,050 people.

Probably neither the censuses nor the état civil were completely accurate at this time, and there is no way now of discovering whether births or deaths were more likely to be reported. The births and deaths recorded for 1863 represent crude rates of about 35 births per 1,000 population and 23 deaths per 1,000, and though deaths had been more numerous in 1855 and 1858 than in 1863, more births were registered in 1863 than in any previous year. However, these rates can clearly be regarded as minimum estimates of the birth and death rates prevailing during this period, and if both births and deaths were recorded equally frequently, the population of the two islands was increasing at an average rate of about 1 per cent per annum without migration, though the growth recorded by the censuses indicates an average annual increase of nearly $2 \frac{1}{2}$ per cent between 1860 and 1863 .

In 1860 there were reputed to be 660 Europeans living on Tahiti and Moorea (Gros, 1896, p. 187), 558 of whom were colonists or traders (Messager de Tahiti, 1865). Three years later there were 1,863 nonindigenous inhabitants reported-1,137 foreigners, 307 French, 370 troops and 30 'fonotionnaires' on Tahiti and 13 foreigners and 6 French on Moorea (Teissier, 1953, p. 18). These numbers increased further over the next ten years as the European planters tried to cut their production costs by bringing in workers under indenture. By 1872 at least 243 Cook Islanders (147 of them from Penrhyn), 687 Gilbert Islanders (many from Arorae), 73 New Hebrideans, and 993 Chinese had been introduced, and although their contracts stipulated repatriation after three years for the islanders and seven for the Chinese, this was not feasible and most of them settled on Tahiti when their contracts expired 
(Newbury, 1957, pp. 161-3). From then on few of the censuses distinguish between Tahitians and other islanders, and though the Chinese and Europeans were sometimes kept apart, it is not at all clear how their part-Polynesian offspring may have been classified.

In 1877 there was at least a partial enumeration of Tahiti and Moorea. The data now extant (Archives du Ministère de la France Outre-Mer) cover fourteen districts on Tahiti and three on Moorea, and though these latter probably included about two-thirds of Moorea's population, the figures for Tahiti relate to probably less than half of the island's population. Papeete is not included, nor are the populous distriots of Faaa, Papara, and Mataiea. With these geographic limitations, the population in each district as of 1 July was divided into Tahitians, Oceanians (natives of other islands), Chinese, French, and other Europeans, with each group further classified by sex and whether married, widowed, single aged 15 years and over, and children aged less than 15 years.

In the districts of Tahiti there were 4,059 Tahitians enumerated (2,207 males, 1,852 females), and 1,242 of them were children. Of 1,250 adult women, 730 were married and 161 widowed, and the remaining 359 were single even though there were 607 single men available. The next largest group were the Oceanians, with 140 males and 119 females, and there were 244 Europeans in all, 143 of them French. Males predominated in the European sector and relatively large numbers of them were unmarried (82 in a total of 114 aged 15 years or over), as were 124 of the 127 adult Chinese males.

In the three distriots of Moorea which were enumerated there were 814 Tahitians, 88 Oceanians, 58 Chinese, 16 French, and 15 other Europeans, so that the non-indigenous population there contributed about 18 per cent of the total. As in the districts of Tahiti the immigrants were predominantly single males, but there were relatively fewer unmarried women in Moorea's indigenous population than in Tahitis. With 192 women who were either married or widowed, there were 285 children and the ratios between the numbers of children and the women who were or had been married are very similar in the two populations.

There is some doubt as to when the next census was taken. Teissier (1953, p. 18) favours 1881, but the Annuaire de Tahiti for 1885 cites 1882 as the census date-and repeats the census totals as though they referred to the population in 1884. According to Teissier, Tahiti's population in 1881 was 9,380 and Moorea's 1,428, giving an aggregate of 10,808. The Annuaire de Tahiti gave a slightly smaller figure of 10,682 for the two islands togother in both 1882 and 1884, and as 1,606 of these were 'whites' and 447 'asiatics', the indigenous total (which presumably 
included the people described as Oceanians in 1877) was 8,629. Caillot (1909, p. 71) ignored censuses between 1863 and 1887, and he alleged a total of 9,282 on Tahiti in that year and 1,557 on Moorea, making a total only slightly larger than the one Teissier attributed to the 1881 census.

Both islands were probably censussed twice more before the end of the century. Before the census was taken in 1892 there had been at least: one small outbreak of typhoid fever in the distriot of Tiarei around 1890, and a severe epidemic of dysentery in 1892 which Gros (1896, pp. 191-2), then serving as 'médecin de $2^{\text {me }}$ classe de la marine', claimed killed 'un assez grand nombre' of natives in Papeete and several distriots. Neventheless, the numbers given by Teissier (1953, p. 25) showed an increase of more than 2,000 in Papeete's population between 1881 and 1892, though the population in the remainder of Tahiti had decreased by 340 . The totals reponted were 11,097 on Tahiti and 1,407 on Moorea, making an aggregate of 12,504 for 1892. By 1897 Papeete's population had ostensibly fallen by more than 1,000 and the number in the distriats of Tahiti was restored to its 1881 level, but except for Papeete, Teissier's (1953, p. 29) figures differ from those filed in the Archives du Ministère de la France Outre-Mer which accord Tahiti a population of 10,733 and Moorea 1,383 inhabitants, whereas Teissier allowed Tahiti 10,250 inhabitants and Moorea 1,596. In the aggregate the difference is only 270 , but a difference of 213 between the two versions for Moorea is disconcerting. For 1902 Valenziani (1940, p. 173) cited a total of 1,558 for Moorea, 3,720 for Papeete and 7,457 for the remainder of Tahiti, making an aggregate of 12,735 for both islands.

The populations recorded for Tahiti and Moorea in the various counts from 1829 onwards are shown in Table 53; what is known of the population before this date needs to be so hedged round with qualifications that it is best summarized in words. Robertson's guess can be safely ignored, but as Tupaia was proved right about other things, there is no reason to doubt his tally of warriors provided it is regarded simply as an estimate. Nothing is known of the circumstances under which these figures were supplied to Cook and Banks, but given a total of between 6,000 and 7,000 warriors, and Bligh's contention twenty years later that families were commonly limited to three children, the most optimistic estimate for Tahiti's population at the time of their discovery by Europeans would be in the vicinity of 35,000 and probably less.

Cook's upward revision of Tupaia's count five years later becomes slightly more plausible if the canoes he counted were from two political divisions, or combinations of districts (in anybody's terminology), rather than districts as such; and more plausible still if $\mathrm{Tu}$ had support from 
TABLE 53 The populations reported for Tahiti and Moorea for various years between 1829 and 1902, and the sources of the figures

\begin{tabular}{|c|c|c|c|c|c|c|}
\hline \multirow{2}{*}{ Year } & \multicolumn{2}{|c|}{ Tahiti } & \multicolumn{2}{|c|}{ Moorea } & \multicolumn{2}{|c|}{ Total } \\
\hline & Indigenous & Other & Indigenous & Other & Indigenous & Other \\
\hline 1829 & 8,674 & $*$ & $*$ & $*$ & * & $*$ \\
\hline 1848 & 8,082 & 475 & 1,372 & 40 & 9,454 & 515 \\
\hline 1857 & $6,252 \dagger$ & $*$ & $960+$ & $*$ & $7,212 \dagger$ & $*$ \\
\hline 1860 & 7,169 & $*$ & 1,114 & $*$ & 8,283 & 660 \\
\hline 1862 & 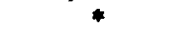 & $*$ & * & * & \multicolumn{2}{|c|}{10,347} \\
\hline 1863 & 7,642 & 1,844 & 1,242 & 19 & 8,884 & 1,863 \\
\hline 1881 & \multicolumn{2}{|c|}{9,380} & \multicolumn{2}{|c|}{1,428} & \multicolumn{2}{|c|}{10,808} \\
\hline 1882 & * & * & $*$ & * & 8,629 & 2,053 \\
\hline 1887 & \multicolumn{2}{|c|}{9,282} & \multicolumn{2}{|c|}{1,557} & \multicolumn{2}{|c|}{10,839} \\
\hline 1892 & \multicolumn{2}{|c|}{11,097} & \multicolumn{2}{|c|}{1,407} & \multicolumn{2}{|c|}{12,504} \\
\hline $1897 a$ & \multicolumn{2}{|c|}{10,250} & \multicolumn{2}{|c|}{1,596} & \multicolumn{2}{|c|}{11846} \\
\hline $1897 \mathrm{~b}$ & \multicolumn{2}{|c|}{10,733} & \multicolumn{2}{|c|}{1,383} & \multicolumn{2}{|c|}{12,116} \\
\hline 1902 & \multicolumn{2}{|c|}{11,177} & \multicolumn{2}{|c|}{1,558} & \multicolumn{2}{|c|}{12,735} \\
\hline
\end{tabular}

*Numbers not known or not available.

†Probably incomplete.

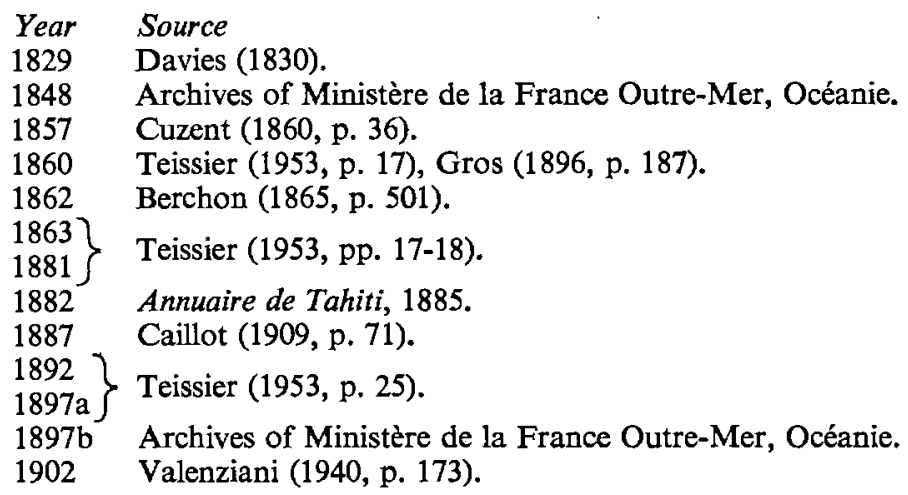

the Leeward Islands, and perhaps also the nearer Tuamotuan atolls, as did his namesake known as Pomare in the early nineteenth century. But Cook's reckoning, echoed by the Forsters, of more than 200,000 people on Tahiti is a gross exaggeration and quite incompatible with Rodriguez's contemporaneous account of the density and distribution of population throughout the island. Even so, the estimate subsequently attributed to Rodriguez of at least 15,000 inhabitants in 1775 was probably little more than a guess, and although Morrison's 'near 30,000' in 1790-1 may 
have had some basis, it seems likely that his journal was in fact written after his return to England (Darby, 1965, pp. 9-10) by which time he may have been quoting other estimates rather than his own observations.

The earliest count which has any firm basis is Wilson's in 1797, and before then the Tahitians had suffered epidemics of what may have been influenza in 1772 and 1774, and some now unidentifiable but probably infectious disease from Peru which persisted amongst them for several years. There was also at least one epidemic of dysentery, which caused quite high mortality in 1792, and a residual of venereal disease about which the early European visitors were far from unanimous either as to its origin or its prevalence and severity. There had also been much fighting, especially during the sojourn of the Bounty mutineers in 1790-1.

Wilson's count was of households rather than people, and though he may have missed some inland settlement, his system of principal houses with which other lesser households were associated is supported by recent archaeological evidence (Green, 1965). Wilson reported a total of 311 principal houses in the count of 2,675 households, so that on average there were $7 \frac{1}{2}$ lesser houses associated with each principal house. If one assumes that as many as 500 households were omitted from his tally, this would imply a further 60 principal houses hidden inland, which is perhaps rather too high an estimate but allows a safe margin if perchance Wilson's average of 6 persons per household was too low. If this average was too high-and on Bligh's evidence it might have been-the population may have been little more than 13,000 plus some unknown number in inland settlements. Either way a range of 3,000 on either side of Wilson's estimate of 16,050 inhabitants seems reasonable, and if this is thought too liberal the margin could probably be narrowed further to 2,000 , which would give a population of between 14,000 and 18,000 on Tahiti towards the end of the eighteenth century.

Had there been no epidemics, this supposed decrease of about 50 per cent in population size over thirty years would be feasible if infanticide was of the order of at least one-half, and probably more. Simulation with an initially stable population which had an expectation of life at birth of about thirty years for both males and females, and fertility rates such that the population would increase at about 1 per cent per year without infanticide, indicated that with infanticide at the level of one-half for children of both sexes, the population would be half its initial size after sixty-seven years, the next halving would take about fifty-two years, and thereafter the intervals between successive halvings would shorten, but so much more gradually than at first that it would take a very long time to reach a thirty-year interval. On the 
other hand, infanticide of the order of three-quarters of both males and females would reduce the population by $7 \frac{1}{2}$ per cent in the first five years, and the initial total would be halved after about thirty-seven years and thereafter at approximately twenty-year intervals. If Tahitian mortality (in the absence of epidemics) was lower than that used in the model, the level of infanticide would need to be rather more than onehalf to produce halving of the population within thirty years, though this process could be accelerated by the intervention of wars and sporadic epidemics of high mortality.

This demonstration of the effects of infanticide in a population does not prove that there was infanticide of this magnitude in Tahiti, or even that the population decreased by about a half over a thirty-year period. Missionary accounts such as John Williams's (1838, p. 561) of the 'three individuals, casually selected [who] had killed one-and-twenty children' between them never mention the numbers allowed to live, and Bligh's comment that 3 children were allowed to survive and 'from 3 to $8^{\prime}$ killed seems to relate to women of high rank and not the generality of Tahitian women. As the extent of mortality in the various epidemics is completely unknown, about all that can be deduced from this exercise is that if infanticide was of the order of one-half, then the population of Tahiti in 1769 may have been as large as 35,000; if the population then was larger than this, more extensive infanticide would be needed to reduce it to between 14,000 and 18,000 by 1797 , but this total could have been reached with less extensive infanticide from fewer than 35,000 inhabitants in 1769 .

Rather more than thirty years elapsed before the first missionary count of Tahiti's population, and by then there had been more fighting and more disease, but if there was any infanticide still it was probably less extensive than formerly. During the ten years that the mission stations had been established in various parts of the island, there had been at least one epidemic which killed 'many adults' in 1826, and dysentery in some areas as well. The populations reported for each of the seven mission stations towards the end of 1829 summed to 8,674 , but this total may have under-stated the population. Both the average numbers of children per woman reported for some districts, and the birth rates during subsequent years, suggest that infanticide was not completely suppressed by then, and there was a marked surplus of males amongst both adults and children.

Though this excess of males persisted among the adult population, by 1848 the numbers of boys and girls were more nearly equal. The census taken then by the French officials followed more than three years of rebellion, and epidemics of smallpox, influenza, dysentery and scarlet 
fever. There were 'about 100' Tahitians killed in one year's encounters with the French troops, but the casualties in later years were described as 'trifling' and probably fewer were killed before the Tahitian surrender in 1847 than had died in the smallpox epidemic in 1842. About 200 people died then, most of them in Papeete and the surrounding district, and the epidemic seems to have petered out as the distance from Papeete increased. At the centre of infection the mortality rate may have been as high as 10 per cent, though for the island as a whole it was probably not much more than 2 or $2 \%$ per cent. The numbers of deaths in the later epidemics are not known, but the indigenous population recorded for Tahiti in February 1848 was 8,082 , which was rather more than had been expected.

Moorea at this time had 1,372 indigenous inhabitants, and it seems that this was the first time this population had been counted. They had shared with the Tahitians the rebellion against the French and suffered the same epidemics, experiencing greater mortality than the Tahitians from smallpox, but this was probably because of the way in which the disease was introduced. The scrappy birth and death records for a few years before this epidemic suggest that Moorea's population had been increasing, but the natural increase may have been offset by an outflow of population as foreign settlement in Tahiti increased. After the surrender to the French in 1847 many returned from Tahiti to grow food for the Tahitian market, and the 1848 count may have exaggerated the numbers usually resident on the island.

In 1854 there were epidemics of measles on both islands and it was reported that 'upwards of 700 individuals . . . chiefly of the male sex' died on Tahiti, and Moorea lost nearly a tenth of the population'. It is impossible to assess the reliability of these figures, but as the incomplete count of the population in 1857 showed the same excess of males among the adults as had been reported in 1848, it is unlikely that males ran any greater risk than females in this epidemic. If the mortality rate was 10 per cent, nearly one-fifth of all marriages in existence before the epidemic would not have survived, and the births for a few years after the epidemic would have been proportionately reduced in number. The death rate in the population may not have been lowered much in the post-epidemic years, but by the early 1860 s immigration was probably contributing as much to the growth of these indigenous populations as natural increase.

The conflicting versions now extant of the numbers recorded in the few counts made before the end of the century suggest that these were not particularly reliable, though in the absence of even numbers of males and females in each ethnic group, neither check nor analysis is 
possible. However, it seems likely that the population which survived the measles epidemic in Tahiti and Moorea was smaller than at any time for at least a century, but thereafter the numbers increased, perhaps erratically as people came from and returned to other islands, even other countries, but there was probably some natural increase as well. Though only a few hundreds at most were involved, the most constant source of long- and short-term visitors to Tahiti throughout this century were the neighbouring Leeward Islands.

\section{Leeward Islands}

The Leeward Islands are Cook's Society Islands, discovered in 1769 when parties went ashore on Huahine, Raiatea, and Tahaa (Cook/ Beaglehole, 1955, pp. 140-50). On his second voyage in 1773-4 Cook twice revictualled his ships at Huahine and Raiatea, and spent about two weeks each time at these islands (Cook/Beaglehole, 1961, pp. 215-30, 412-25). He returned again on his third voyage, and spent almost three weeks at Huahine while a house was built for Omai, the Polynesian he had taken to England in 1774 (Cook, 1785, 2, pp. 89-126). The ships then crossed to Raiatea where they were 'windbound' for a week, and before leaving the group Cook made his first visit to Borabora. Though he had better opportunities than many of the visitors later in the century, Cook essayed no guesses at the numbers of inhabitants on any of the islands; nor, it seems, did any other seafarers, although Vancouver (1801, 1, pp. 326-7) reported the deaths of Omai and the two New Zealand Maoris Cook left with him, from 'a disorder that is attended by a large swelling in the throat, of which very few recover, but die a slow lingering death?

The missionaries first visited Raiatea and Huahine in 1807, and in November 1808 six of them moved to Huahine for safety until Tahiti became more settled or they could get passages to New South Wales. Two more joined them there in April 1809 and all were discouraged that in a circuit of the island they 'met with nothing encouraging, the natives in general [being] less hospitable than those of Tahiti and equally indifferent and averse to the Gospel' (Elder and Wilson, 1809). When the chiefs and many of the men went to Pomare's assistance in Tahiti, the missionaries had already decided to leave for New South Wales at the first opportunity and this came in October 1809. One chose not to accompany the rest, and though he stayed on Huahine for nearly a year then, the island was largely neglected from 1810 to 1818 when seven of the missionaries then on Moorea elected to go there. Two of them moved to Raiatea soon afterwards but there was so much coming and going both of missionaries and people between the two islands, and from there to Tahiti, that it would have been difficult to make any 
except a very rough guess at the sizes of the two populations (Davies, 1961, pp. 124-36, 221-2, 292-301).

One missionary guessed at a total of 2,000 inhabitants for Huahine (Gyles, 1818) shortly before the people suffered 'a distressing epidemic, which . . . proved fatal to many of the people' (Ellis, 1831, 3, p. 35). In 1820 'a new and commodious Chapel' was opened on the island, and 'about 1500 people attended' (Davies, 1961, p. 299). This number was perhaps the source for an assertion by the 'deputation' from London which visited the mission stations in 1822 and 1823 that Huahine had 'two thousand inhabitants' (Montgomery, 1831, 1, p. 342), which number was repeated by Waldegrave $(1833$, p. 174$)$ as by a census made by the missionaries, 1828. There may have been an enumeration of sorts in 1829 which listed a population of 867 adults and 683 children (Charter, 1838-56), and though this total of 1,550 is given elsewhere (Charter, 1847 ) as 1,505 , the former is probably the more correct.

Towards the end of 1826 the island's population had lately had considerable disease' (C. Barff, 1826) in common with the Tahitians and the other Leeward Islanders, but there are no figures which suggest the extent of mortality that might have been caused either by the disease or from the war of 1831, in which the people of Huahine supported the Raiateans against Borabora and Tahaa. Teissier (1953, p. 23) attributed the English missionaries with a count of 1,800 inhabitants on Huahine in 1834 , and though this is the first year for which records of births and deaths exist, it is unlikely that there was any systematic count of population in that year.

Although the returns of births and deaths are continuous from the end of 1834 until October 1838 and again from August 1839 to November 1844 , the births and deaths on Huahine are occasionally combined with those for the island of Maiaoiti (which was an outstation equidistant from Moorea and Huahine), and sometimes the returns ostensibly refer only to the outstations on the two islands though the numbers cited belie this. In 1819 the population of Maiaoiti was 'about 130', but in 1825 it was reported to be 210 (Davies, 1961, pp. 301-2). Except for the first year, 1834, when there had been 49 deaths and only 29 births-'a great decrease'-in the two islands, the returns indicate an excess of 92 births over deaths between January 1835 and October 1838, and of at least 157 between August 1839 and November 1844 (C. Barff, 1834, 1835, $1836,1837,1838,1840,1841,1842,1843,1844 b)$. Assuming they refer uniformly to the two populations, the births represent an average annual birth rate rising from about 20 per 1,000 population at the beginning of the period to about 25 per 1,000 ten years later.

However, the very small numbers of children's deaths reported 
suggest that infants who died soon after birth were probably not included in the returns as either births or deaths. There is also an inconsistency for the year 1843 which suggests that the returns were incomplete in other respects as well. Although Huahine and the other Leeward Islands escaped the smallpox epidemic in 1841, the people of Huahine at least did not escape the dysentery which 'raged round the Islands' in 1843 and 'near fifty' of them died of it before October. The returns for the year ended October 1843, however, record only 19 deaths, 4 of them from dysentery (C. Barff, 1843), so that the deaths at least would seem to refer only to a select group and not the total population of the island.

Early in 1846 the French landed 400 soldiers on Huahine and they 'proved to be savages, burning the houses and cutting down the people's breadfruit trees' (Platt, 1846a). After two days of fighting the French retreated, and the reports of their casualties ranged from 20 killed and 41 wounded (C. Barff, 1846a) to 250 killed (Platt, 1846a; Krause, 1846). 'Two natives were killed . . . several were slightly wounded, none of which proved fatal' (C. Barff, 1846b) and in July, Bruat 'granted peace to the Leeward Islands' (Platt, 1846c).

In March 1847 Charter (1838-56) 'finished taking the census . . . from which it appears there are 514 men; 425 women, 243 boys, and 214 girls. Total 1396. Probably some few may not have been written down though I went to almost every house on the island .... for Mai ao iti 220 persons.' Two months later there was 'great sickness and mortality . . . prevailing (a touch of the Dysentery again) but other complaints' (Platt, 1847), and though it might be inferred that there had been some scarlet fever on Huahine in 1848 , nevertheless 'the births ... had somewhat exceeded the deaths' in the fifteen months to the end of April (C. Barff, 1848). For the next few years the people of the island were reported to be rebuilding their houses and growing oranges and other food for trade with the numerous 'South Sea whalers, small traders and vessels from California' (C. Barff, 1851) which called there.

This peace was shattered in October 1852 by another outbreak of civil war in which 'much damage [was] done to the settlement in the destruction of fences, gardens etc. but not the new houses' (C. Barff, 1853). The rebels were vanquished 'with little loss of life' and for a time at least 'a large number of them' were banished to Raiatea (Chisholm, 1852), but in January 1853 the war was still 'raging'. Raiatea at this time was 'lying under a scourge of sickness' (Platt, 1853), and the same 'fever said to be originally prevalent at Panama' reached Huahine some time before April. 'Though it proved severe in most cases and was followed by very great prostration of strength yet it 
proved fatal in some few cases only of children and old people' ( $J$. Barff, 1853).

By May 1854 'two or three hundred of the inhabitants [had] either been exiled or voluntarily retired from the islands' as a result of the civil war, and measles had been introduced, 'generally of a mild form, but its attendant complaints ... proved fatal in the case of many of the aged and infirm' (J. Barff, 1854a). The 'numerical account' of deaths on Huahine during 1854 alleged that 12 of the 194 church members had died of measles and 23 of 'those not Church members'; in addition, 34 had died from other causes and there had been only 39 births so that the population was ' 30 decreased by deaths Besides the number banished and who followed the Queen' (C. Barff, 1854). The measles epidemic also spread to Maiaoiti where there were reckoned to be ' 300 inhabitants' in 1850 (C. Barff, 1850), but there it caused the deaths of 'only 3 children and two or three aged persons' (J. Barff, 1854b).

A census which had been promised in both 1855 and 1856 (C. Barff, 1855,1856 ) was made sometime between November 1856 and October 1857 when there were 372 men, 355 women, 311 boys, 291 girls, and 70 just returned from banishment' (C. Barff, 1857). During the next two years Huahine was 'the refuge of those who were compelled to fly for various causes' (C. Barff, 1860?), so that by 1862 the population had increased very much since . . . the last census. . . Numbers are frequently coming down from Moorea, and Tahiti and taking up their abode with us, besides the yearly increase', which was 41 in 1862, with 60 births and only 19 deaths reported (C. Barf, 1862).

By then whaling in the South Seas had been 'entirely given up', but as a plague of wasps had temporarily driven the rats from the coconut groves (C. Barff, 1861), both natives and foreign residents were making coconut oil again and growing sugar-cane and coffee (C. Barff, 1862). A year later the rats were back destroying the coconuts (C. Barff, 1863), and though Huahine suffered less than some of the islands in the severe gales which struck early in 1865 (Morris, 1865a), 'the perpetually unsettled state of the Natives' later that year was 'a continual source of disorder and trouble which materially diminishe[d] the efficacy of the Missionaries' toils' (Morris, 1865b).

The quarrel was principally between Raiatea and Tahaa, but some of the Huahineans joined Raiatea's 'rebel (or Anti-Christian) party' (Morris, 1865c) which deposed the king and remained in power on Raiatea for about eighteen months before they were overthrown and banished to Tahiti with their families, 'upwards of eighty members' (Morris, 1867a, 1867b). Towards the end of 1868 many of them either escaped to, or were allowed to return to Huahine where, in their dis- 
satisfaction, they provoked another war and gained a tenuous control over Huahine (Saville, 1868), making the island 'one of the most discouraging fields ... possible for a missionary to hold'. However, despite the 'great deal of ill-feeling and distrust' which continued 'on both sides' (Saville, 1869) for many years, all further fighting seems to have been averted (Green, 1874, 1876; Cooper, 1884).

A census 'recently taken' in 1868 indicated a population of 'about $1440^{\prime}$ on Huahine, and this total probably did not include 'certain Chinamen who had escaped from their employers in Tahiti, also . . . a number of Tahitian murderers and thieves who had escaped from the prisons of that island' (Saville, 1868). A few months later the missionary reported the arrival of another boatload of runaways, some of them Chinese but more Niueans who had been received freely by the Huahineans as in all former instances' (Saville, 1869). More than two years later there were still 'plenty' of Niueans on the island, together with 'a number of runaway Gilbert Islanders' and 'a great number of Raiateans ... banished from their land many years since in consequence of a war' who had been living on Tahiti until then (Saville, 1871), so that although it was claimed that Huahine contained the greatest population of any island in the group, in 1875 its size was given as 'from 1300 to 1500 persons', and these lived 'scattered in five settlements or sub districts besides the Capital' (Green and Pearse, 1875).

Whooping cough had 'passed through the island' in 1871 (Saville, $187 \mathrm{lb}$ ), but presumably caused few if any deaths, and there was no further mention of 'the health of the island' for more than a decade. In 1882 , when the population was reckoned to be 1,500 , there were 23 deaths, 'several being those of very aged people', and 52 births (Cooper, $1883 \mathrm{a}, 1883 \mathrm{~b}$ ), so that for this year at least there was a substantial increase in population. In 1885 the missionary himself suffered 'a most severe attack of the "Dengue" fever (recently imported to these islands from New Caledonia)" (Cooper, 1885), and as Gros (1896, p. 192) also reported epidemics of an exceptionally severe form of dengue throughout 1885-7, it might be presumed that the Huahineans were also attacked.

After 1874 there were seldom more than two English missionaries in Tahiti and the Leeward Islands, and until the London Missionary Society withdrew its representative from Tahiti in 1886 , one was usually stationed there, paying only short visits to the other islands. Maiaoiti was as rarely visited as before, but in 1868 it was reported there were then 'not more than 100 people upon the island' because 'many' had gone to Tahiti 'and other neighbouring islands' (Saville, 1868). In 1871 the king of Raiatea was 'dethroned for shooting a man', and when the French refused to allow him to land at Tahiti, he and his supporters 
went to Maiaoiti (Green, 1871), which was still 'thinly populated [with] not more than 100 inhabitants' (Saville, 1871b).

When Tahiti was annexed to France in 1880 the people of Raiatea and Tahaa had already asked for, and been provisionally accorded, French protection (Pearse, 1880), but the fate of the other islands in the group was undecided. After prolonged negotiations between Great Britain and France, the tricolor was hoisted in each of the main islands in March 1888; and although this had 'Iong been a foregone conclusion' (Cooper, 1888a) to the foreign residents, it met with the determined opposition of more than three-fourths of the natives' (Cooper, 1888b). For more than two years the islands were torn by the hatred between those who favoured the French and the numerically stronger anti-French party, and the one English missionary left there reluctantly concluded their Christianity under existing circumstances [was] nothing more than a name' (Cooper, 1889a). In 1890 the London Missionary Society decided to withdraw from the Leeward Islands, leaving the harvest of more than seventy years of missionary endeavour to the French, and the Huahineans to an epidemic of typhoid from which 'quelques' died (Gros, 1896, p. 191).

Although most islands in French Polynesia were censussed in 1892 the first official census of the Leeward Islands was taken in 1897, when Huahine's population was reckoned to be 1,237 (Teissier, 1953, p. 25). However, with Huahine so patently sharing the history of the other islands of the group-and Tahiti and Moorea as well-it would be futile to isolate its demographic history beyond the brief comment that the population seems to have been remarkably stable at about 1,400 or 1,500 for much of the century. If there were years in which the deaths and emigration exceeded the births and immigration, there were other years when the gains to the population exceeded the losses. Maiaoiti's population probably fluctuated in the same way, and though they may have shared some of the epidemics, emigration after the middle of the century was probably a more significant source of change.

Raiatea and Tahaa are about 25 miles east of Huahine, and both islands lie within the one encircling reef. In 1818 Raiatea's population was thought to be either no more than 2,000 (Threlkeld and Williams, 1818) or, alternatively, about 1,200 (Gyles, 1818). A year or two later the Raiateans probably suffered with the other Leeward Islanders ' $a$ distressing epidemic ... [of] a kind of influenza' (Ellis, 1831, 3, p. 35), and in 1826 another 'distressing disease ... something of the species of apoplexy' caused much suffering but only 8 or 10 deaths (Pitman, 1826). Two people died of this same disease on Tahaa (Bourne, 1826) where 
the population was thought to be 1,000 , and Raiatea's then 1,700 (Waldegrave, 1833, p. 174).

Raiatea and Tahaa 'were the actual seat of operation' in the civil war of 1831 (C. Barff, 1831), which continued until the middle of 1832 when the young chief of Tahaa was defeated and all his 'company ... killed or wounded' (Platt, 1832). After the war many of the people drifted away from the mission settlement and early in 1838 Raiatea's population was 'so scattered' that the missionary could not get 'exact accounts of the births and Deaths', but 'so far as [he could] gain information' there had been 53 births on Raiatea during 1837 and 'about 30 deaths' (Platt, 1838). In the following year 53 children were baptized on Raiatea, but there [had] been more than that born' (Platt, 1839a) and as the marriages appear[ed] on the increase perhaps the population will soon. The old childless families are dying off and though we have a greater proportion of unfruit families perhaps than most countries the proportion is much less than it was' (Platt, 1839b).

In September 1839 the supposed population of Tahaa [was] not more than two hundred, while that of Raiatea [was] calculated to be. from twelve to thirteen hundred' or was 'supposed to be from thirteen to fourteen hundred' (Charter, 1839). Three years later Platt and Charter toured the island, taking a census in which Charter recorded ' 315 married couples-60 old men most of whom are widowers, 46 old women most widows-90 unmarried young women,-112 unmarried young men, 342 boys; and 291 girls. Total 1571. Probably a few may not have been taken, but not many as I made it a point to go to every house' (Charter, 1838-56). In addition it was claimed there were 'upwards of a hundred' people from Raiatea living on other islands, but this may have been added merely to restore the total to the 1,700 supposed to have been there a decade earlier. The population of Tahaa was also much greater than Charter had been led to suppose'; after a tour round the island Platt 'consider[ed] there [were] about $600^{\circ}$ people there (Charter, 1843), and later this total was revised to 'about 550' (Krause, 1844).

Though the people of Raiatea and Tahaa seem to have been 'remarkably healthy' (Platt, 1840) for a few years before these counts, an outbreak of dysentery in 1843 caused 'about twenty' deaths, 'the majority of them children' (Charter, 1843a, 1843b). At the end of 1843 there was 'a tremendous storm and heavy sea by which immense damage was done'; very soon after this the people suffered 'a violent fever . . . with a very heavy cough' and though only three died of this, three women and two children had been drowned in the storm (Platt, 1844). The French made no attacks on either Raiatea or Tahaa in 1845-6, but on Raiatea the people lived two years in their entrenchments and scattered 
about to other parts' so that when peace was restored in 1846 the mission settlement had 'nearly vanished' (Platt, 1846c). On Tahaa, about 250 people lived at the mission settlement and about 150 more were 'frequent visitors and sometimes remain[ed] for a short time'. The other 150 appeared 'very seldom' if at all (Krause, 1847).

For almost a decade Raiatea lay 'under a scourge of sickness' (Platt, 1853a). In 1847 there were outbreaks of dysentery and scarlet fever, and more deaths that year than Platt (1848a) could remember in any of the thirty years he had been on the island. In the following year there were more deaths than births (Platt, 1849a) and in 1850 influenza was 'very prevalent' on both Raiatea and Tahara (Charter, 1850). At the end of 1852 'a strange kind of fever . . . severely afflicted' the people, and as elsewhere it caused only few deaths but left 'all who [had] been attacked very very weak' (Platt, 1853). Before August 1854, 54 people on Raiatea and Tahaa had died of measles (Chisholm, 1854b); 'nearly all the old people' among the church members succumbed, and there were 'about twice as many deaths as births' that year on Raiatea (Platt, 1854b).

While Barff was rejoicing about Huahine's flourishing trade with ever-increasing numbers of boats calling, the missionaries on Raiatea and Tahaa complained that the 'temporal prosperity' of both islands had declined because many of the small traders had left for California (Platt, 1849b; Krause, 1849). Rebellion flared again and in March 1852 at least 20 people were killed or died later of wounds received in the fighting (C. Barff, 1852; Charter, 1852). Between May and August 1853 the war was resumed and 8 or 10 were killed and many wounded ( $\mathrm{J}$. Barff, 1853); later that year it was reported that the war had 'made a clean sweep of all the men [from the mission settlement], except a few old men unable to go, or those prevented by circumstances' (Platt, $1853 \mathrm{~b}$ ), and as these were of the party which was defeated, 'a good quantity of land changed owners' (Platt, 1854a).

The fate of the dispossessed was not elucidated, but a census taken late in 1853 showed 'only 1232 individuals living upon [Raiatea] and on Tahaa 530 Total 1762' (Chisholm, 1854a). Apart from the enforced exile of some of the people as a result of the war, there were also "licentious girls going to Tahiti to cohabit with the french soldiers, etc. where many [met] their end being lost as mothers to build up the population' (Platt, 1853a). Assuming that some of the exiles returned before the measles epidemic started, the probable mortality from this outbreak was perhaps 60 deaths from a population of about 1,800 (i.e. 3 per cent), and when the disease 'abated, the people according to their custom after sickness ... scattered themselves all over the island to recruit their health' 
(Chisholm, 1854b). Before the year ended there was a renewed outbreak of war, and in the course of that year 'more than seventy' of Raiatea's population had died either of measles or in fighting and 'a many more' had been banished (Platt, 1854c).

The intervention of a British warship quelled an incipient bid for the independence of Tahaa from Raiatea (Chisholm, 1855, 1856a), and though there was 'quite a revival' of religion amongst the Raiateans in 1856, 'the increase of piety and morality still [came] far short of what might be expected from their zeal for the forms of religion' (Chisholm, 1856b). Nevertheless, there had been 41 marriages during the year, 59 children had been baptized and only 24 people had died. In the following year there were 23 deaths and 62 children baptized, but it was 'a year of much anxiety' (Chisholm, 1858a) which culminated in another outbreak of war in 1858 in which 25 people were killed (Chisholm, 1858b).

Encouraged by some Americans then resident on both Raiatea and Tahaa, some of the chiefs had petitioned the United States to establish a protectorate over these islands, but this was opposed by others who wished to retain their independence (J. Barff, 1859a). In the first conflict the 'American party' was vanquished and by the middle of 1859 they had been defeated again and the leaders banished. Nevertheless, "considerable uneasiness prevail[ed]' because the 'American citizens . . . threaten[ed] to bring American ships of war to redress their supposed grievances' (J. Barff, 1859b). A number of people had gone into voluntary exile with their leaders (Platt, 1859), and Raiatea's population was then thought 'not [to] exceed 1500' (Chisholm, 1859).

For three years there was peace, with a death like apathy to spiritual things' on Raiatea (Platt, 1860, 1863), but seemingly no attempt to record the population even though two young missionaries had joined the two old ones who had been in the islands so long. One of the newcomers was in charge of the training institution that had been started on Tahaa in 1857, when the population was reported as 'about 600 ' and it had increased by immigration about 50 during the year [because] Tahaans living at Tahiti and elsewhere [had] returned'. There were also 16 more births than deaths in that year (J. Barff, 1858). By the middle of 1859 Tahaa's population was 'considerably reduced' by the voluntary exile of the supporters of the 'American party' (J. Barff, 1859b), and two and a half years later the people were still 'struggling to overcome' the effects of the war. In 1861 there had been 23 baptisms and only 3 deaths on Tahaa (Green, 1861).

The fear of an epidemic of dysentery in 1864 roused Raiatea's 'thoughtless and reckless young people ... to serious thought', but there 
were few deaths except of 'several children whose cases were very bad' on either Raiatea or Tahaa (Platt, 1864a, 1864b). A year later the two islands were at war again because some of the Raiateans wanted to settle on Tahaa. Their king forbade it, partly because of his fear that Tahaa would 'eventually subdue Raiatea' (Green, 1865b), and though his party won the first engagements, the rebels called on the Huahineans for help and the king was defeated. He and 'about fifty' others were banished by the rebels (Vivian, 1865c) who remained in power until the middle of 1867. As most of the church members had supported the king the missionaries wisely removed to Huahine and Tahiti until he regained control and, in his turn, banished 'upwards of eighty' rebels to Tahiti (Morris, 1867a, 1867b). Two years later his government was still 'firm and making progress in the right direction' (Vivian, 1869a), but in 1871 he was deposed because. he had shot and killed a man while 'as usual with him under the influence of liquor' (Green, 1871). A new king was chosen in May 1872 and 'a few' of those who had supported the rival contender for the throne of Raiatea and Tahaa were banished to Borabora (Vivian, 1872).

Around 1870 Raiatea and Tahaa together had a population of 'about $1,900^{\circ}$ (Pearse, 1870), but their numbers were not known precisely because the people were scattered about both islands and no longer lived in or close to the mission settlements (Pearse, 1874). When the islands were provisionally accorded French Protection in 1880, 'Raiatea and Tahaa like twin brothers united in the preparations' for a great feast. 'Nearly two thousand men, women and children were busy at work for days before in getting together the necessary materials and provisions' (Pearse, 1880). Within a year the king was deposed and his eldest daughter made queen (Pearse, 1881a), and she promptly petitioned Great Britain to intervene to preserve the independence promised under a treaty of 1847 (Pearse, 1881b). When she died about three years later, it was feared that only a war would decide between the two rival candidates for the succession, and this might 'precipitate French interference' (Cooper, 1884a). Eventually the son of the queen of Huahine was amicably invited to 'accept the throne of Raiatea and Tahaa' (Green, 1884), and his 'good influence' was soon 'felt all through the islands' (Richards, 1886a).

There may have been typhoid fever on Raiatea late in 1885 (Cooper, 1885), but its spread may have been checked by the doctors on board the French warships which were then running frequently between Tahiti and various Leeward Islands, wooing the islanders with free passages (Richards, 1887a). During 1886 there was an unprecedented depression of the cotton and copra trade' (Richards, 1886b), and the 
disgruntled European residents persuaded the French admiral, backed by two men-of-war and a government schooner, to over-ride the rulings of the native courts for their advantage (Richards, 1887a). This roused the antagonism of the anti-French party still further, and when a French commandant demanded the surrender of its leaders, they went into hiding and the king abdicated rather than become the tool of the native French party. ... One or two villages [were] shelled and a great many native houses burnt down' (Richards, 1887b), and this made the Raiateans still more 'resolute' not to 'yield quietly' as the missionary advised. The island was 'in a state of continual defence' (Richards, 1888a) for several months before the tricolor was hoisted in March 1888, and nearly two years later it seemed that the anti-French party intended 'to compel the French to resort to force' (Cooper, 1889a) to bring matters to a close and assert French supremacy' (Cooper, 1889b).

The long period of political turmoil seems not to have interfered with the growth of the two populations, because in 1897 there were 2,138 people recorded on Raiatea and 1,099 on Tahaa (Teissier, 1953, p. 25). These numbers represent quite substantial increases in both populations since they were last counted in 1853, although the total then was probably temporarily reduced by the banishment of the losers in one of their intermittent wars. However, there are so few data concerning these two populations that it is impossible to guess how much of the apparent increase by the end of the century was due to natural growth and how much to immigration, but doubtless both contributed their share.

The last of the main islands in the Leeward Group is Borabora, northwest of Raiatea and about as far from it as Raiatea is from Huahine. Maupiti is a smaller island about as far west of Borabora as the other islands are from one another. Although no missionary was resident on Borabora until the end of 1820 , some of its people had lived at the mission settlements on Huahine and Raiatea before then, but Gyles's (1818) estimate of 1,500 people on Borabora was probably as remote from the actual number as Waldegrave's $(1833$, p. 174) of 1,800 reported for 1828. He also attributed 1,000 people to Maupiti (or Maurua) which was an outstation of the Boraboran mission. On the other hand, the mission's own accounts are not particularly consistent either. When the 'large and commodious chapel' was being built in 1821, 'the number of inhabitants was found . . . to be 545 adults on Borabora, and 291 children, and those of Maurua were 373 in all 1209 under the charge of Mr. O[rsmond]', the resident missionary (Davies, 1961, p. 312). Within three years the missionary had baptized 600 adults and 506 children on Borabora (Davies, 1961, p. 313), and as Maupiti then had 'a population 
of $400^{\circ}$ (Davies, 1961, p. 315), the joint population might be presumed to have been no more than 1,500 at the end of 1823 , probably fewer if some from Maupiti had been baptized on Borabora. This is not very different from the total for the two islands which Teissier (1953, p. 23) attributed to the English missionaries for 1834, though Borabora was assigned only 800 inhabitants then and Maupiti 600 .

Between 1823 and 1834 the people of Borabora had experienced the 'curious epidemic' of 1826 which, at its outset, killed 'nine or ten ... on a day', but the people themselves quickly devised a treatment of massage and herbal medicine and if this proved ineffective, the missionary 'gave an emetic or bled or both, which generally succeeded only 2 died that [were] prescribed for'. The disease spread from Borabora to Maupiti 'where in the first fit of consternation they lost 7 able men' (Platt, 1827), but no figures were given for the total number of deaths from this cause on either island.

Nor was it recorded how many people were killed in the war of 1831-2. Four had been killed and 'upwards of 20 wounded' before 'the Boraborans were driven from the field' (C. Barff, 1831) in 1831, but there were two more battles later, and in the last all of one chief's "company [were] killed or wounded" (Platt, 1832). Although there was no more fighting for a few years, Borabora had unhappily four or more chiefs of almost equal authority and influence-filled with no small degree of rancor one against another, and some of them at least still determined to cast off all law' (C. Barff and Platt, 1835), so that by 1835 the mission had 'gone backwards instead of forwards'. Fewer people attended church, no adults had been baptized for 'a long time [and] of children . . . as many are born of which we never even hear' (Platt, 1835). During 183830 children were baptized on Borabora, but 'more than that [number had been] born' (Platt, 1839).

At the end of 1840 there was an outbreak of whooping cough from which 'three or four very young ones' died (Rodgerson, 1841a), but there were no cases of smallpox on the island in 1841 because its harbour was closed to all shipping while the epidemic ran its course in Tahiti (Rodgerson, 1841b). During 1842 'a few individuals . . . left . . . to reside on other islands' (Rodgerson, 1842), and throughout 1843 dysentery was very common, 'the number of deaths [being] increased by the officiousness of some native quacks' (Rodgerson, 1843). Borabora probably suffered the most in the gale at the end of that year, and as on Raiatea, the storm was followed by sickness-'severe colds, accompanied with pain in the breast and back' which caused the deaths of 'a number of old people' (Rodgerson, 1844). The births and deaths reported from some time in 1839 to the end of 1845 showed a net loss of 25 from 
the population during this period-146 births, 171 deaths-though the births may have been under-stated because in at least one year the missionary Rodgerson (1842) did not pretend that he knew of all that had occurred (Rodgerson, 1841a, 1841b, 1842, 1843, 1845, 1846a).

Nevertheless in 1846, after five years' residence, Rodgerson (1846a) claimed that Borabora's population was 1,000 and Maupiti's 400 still. The French landed troops on Borabora in 1846, and though there was some fighting, the casualties were trivial-'one on each side fell, a few were wounded' (Rodgerson, 1846b)-but many houses and trees were destroyed (Platt, 1846b). The people had started to rebuild their houses at the mission settlement when scarlet fever 'made its appearance' but 'fortunately the natives ... hit upon some medicine that checked the disease' so that few if any except the missionary himself died (Platt, 1848a). For several years then there was no English missionary on Borabora, and though the island was visited periodically from Raiatea, 'the number of inhabitants [was] not exactly known' (Charter, 1848). Estimates ranged from about 700 (Krause, 1848) to more than 1,000 (Charter, 1849), with a further between 4 and 500' on Maupiti (C. Barff, 1849).

In the middle of 1850 the people of both islands were suffering the sickness that was prevalent on Raiatea-'pains in the head and breasts with violent coughs' (Platt, 1850)-and three years later Borabora had had 'two epidemics, the Panama fever and a very severe influenza [that] hardly spared one'. Despite these, 'the whole settlement [had begun] to wear the look of prosperity' (Krause, 1853); but this was shortlived because in February 1854 'a severe gale laid the schoolhouse of the settlement in ruin' and before this was rebuilt, 'Measles and Dissentery laid . . 2/3 of the population upon the sickbed'. 'About 10, principally old and infirm people' had died before July (Krause, 1854), and 'almost all the old members' had been 'cleared off' before the measles epidemic ended (Platt, 1855). In all about 60 people died during 1854 (Krause, $1855)$, but the numbers of deaths due to measles and dysentery were not stated.

After Krause, the missionary who had been 'a despotic ruler', left the island in 1855 the Boraborans, 'not satisfied with the prosperous conditions in which they [had] remained while the other islands of the group [had] been involved in all the miseries of disorganisation and strife ... [began] to contend among themselves about those very things which led to the troubles on Raiatea, and Huahine etc.' (Chisholm, 1856a). The island was visited occasionally by one or other of the few remaining missionaries, and apparently these contentions had no serious consequences because in 1863 it was reported that while Raiatea was in 
'a state of distraction', and Huahine had 'fallen . . . into a Moral Wilderness', Borabora and Maupiti were 'still quiet' (Green, 1863).

In 1864 'a many' died on Borabora, 'most among the children' (Platt, 1864a), from dysentery which had been introduced originally at Rapa by a vessel bringing back Polynesians from various islands who had been kidnapped and taken to Peru. Only 16 of the 360 who had embarked survived as far as Rapa, and with 'the disease still abiding on them' they were landed there (Green, 1864). Either 7 (Saville, 1871) or 9 of them and more than a third of Rapa's population died before April 1864 (Green, 1864), and the infection was spread to other islands. The Boraborans suffered more than any of the other Leeward Islanders, but late in May 'all the patients . . . [were] reported as returning to health' (Platt, 1864a). About a year later famine was reported on the island (Vivian, 1865a), presumably the consequence of the gale early in 1865 in which Borabora 'suffered to a certain extent' (Morris, 1865a).

Except for a period of about four years from 1870, the London Missionary Society was represented on Borabora only by a native teacher who was seldom visited by the English missionaries except for the "May meetings'-sometimes held in June or July-when the annual 'contributions' were received. In the middle of 1870 Borabora's population was thought to be 'about 1000 people', and together, Borabora and Maupiti had 'a population of about 1,300' (Pearse, 1870). Two years later it was reported that Maupiti's population 'from several calculations cannot be much under $400^{\circ}$ (Pearse, 1872), but there was no suggestion that there had been a census on either island. In 1873 there were 33 baptisms and 34 deaths on Borabora, and as 'the proportion of 1 in $26^{\prime}$ had died, this implies a population of approximately 884 , which 'exceed[ed] that of Tahaa by some 150 people' (Pearse, 1873a). In 1874 the baptisms outnumbered the deaths by 13 , and the 26 deaths reported were for the whole island, not merely those amongst the church members (Pearse, 1874).

In 1876 Borabora and Maupiti fought over the right to lease an outlying island, and though the fighting lasted less than twenty-four hours, 11 Maupitians and 6 Boraborans were killed and 34 were wounded before victory was conceded to Borabora (Green, 1876). This seems to have exhausted their warlike inclinations, and though they 'were strongly opposed to the [French] flag, and it was feared that blood would be shed' (Richards, 1888b) when the island was annexed in 1888, the Boraborans wisely appreciated their weakness and lack of mountain strongholds', and 'gradually settl[ed] down with bad grace into the inevitable' (Richards, 1888c). In 1897 1,264 people were enumerated on Borabora and 536 on Maupiti (Teissier, 1953, p. 25). 
If there was any house-to-house count of the populations of Borabora and Maupiti between 1821 and 1897, the details seem not to have survived. While the missionaries so listed the people of Huahine four times, and Raiatea and Tahaa twice before 1897, all of the numbers ever quoted for Borabora and Maupiti after 1821 are approximate, generally favouring 'about' 1,000 for Borabora and 'about' 400 for Maupiti. The data are too scrappy to put into a table, but if the probable populations of all the Leeward Islands are summed, it seems unlikely that the total population of the group varied much from about 5,000 or 6,000 for the greater part of the nineteenth century.

Though the extent of mortality in the two earliest epidemics reported for these islands cannot be assessed, none of the subsequent outbreaks -dysentery in 1843, scarlet fever in 1847-8, Panama fever in 1853, measles in 1854, dysentery again in 1864-seems to have caused very high mortality. Except perhaps on Borabora, where there was dysentery as well as measles in 1854, the highest mortality rates reported in epidemics were about 3 per cent in both 1843 and 1854. Nor were the casualties in their periodic wars particularly severe, and the exchanges of population between islands when the vanquished were banished seem to have been only temporary and the few who were exiled to Tahiti would scarcely affect the total population of the group.

Hence, if there were more deaths than births in some years, there were also other years when the births far exceeded the deaths, so that while the population numbers may have fluctuated somewhat, the general trend as the century progressed was probably upwards. If a mission estimate (Cooper, $1884 \mathrm{~b}$ ) of 'about 5,500 ' people in the Leeward Islands in 1884 was reasonable, the population had increased by nearly 1,000 by 1897 , and this represents an average annual increase of about 13: per cent. This is approximately twice as fast as the growth on Tahiti and Moorea over the same period, but it may be exaggerated a little by too low a figure for 1884 or by immigration from Tahiti. Though it is clear that demographically the Society Islands would best be treated as one population throughout this century, the only year for which this is possible is 1897 , when there were probably between 18,000 and 19,000 inhabitants in the group.

\section{Marquesas Islands}

The four southernmost islands of the Marquesas were discovered by Mendaña in 1595 (Rollin, 1929, pp. 225-6) and their next visitor was Cook in the Resolution in April 1774. Although landings were made only at Tahuata, three of Mendaña's four islands were circumnavigated, and one was found to be uninhabited. This occupied the ship's company for 
about five days, and then they returned to Tahiti through the northern fringe of the Tuamotus. Although Cook wisely refrained from guessing at the numbers of inhabitants, the two naturalists who had accompanied him on this voyage did not.

The younger Forster listed the circumference of Tahuata as 8 leagues, Hiva-Oa's as 15 and Motane's as 3, guessing that Fatu-Hiva was perhaps 5 leagues 'in circuit'. On this basis he concluded

The number of these good people cannot be very considerable, on acoount of the small size of the islands which they inhabit. The island of [Hiva-Oa], the largest of the Marquesas, is so excessively steep and craggy in many parts, that its inhabitants cannot be so numerous as those of [Tahuata] in proportion to its size. Such spots as are fit for culture are very populous in these islands; but as they are all very mountainous, and have many inaccessible and barren rocks, it is to be doubted whether the whole population of this group amounts to fifty thousand persons (G. Forster, 1777, 2, pp. 33-4).

His father was rather less circumspect, though he cited no figure for the group as they knew it.

The five Marquesas are . . very populous, for the natives cultivate and inhabit all the slopes of their hills. Between them, and the Society-Isles, are a vast number of low isles full of inhabitants. To the East and South-East of O-Taheitee are still more. . . . We cannot think the allowance too great, when we suppose all these islands, and the Marquesas to contain 100,000 inhabitants (J. R. Forster, 1778, pp. 222-3).

Neither of these estimates can be taken very seriously, nor any others that may have been made before 1800, either for Mendaña's south-east group or the north-west group that had been discovered by Ingraham of Boston in 1791 and rediscovered a month later by Marchand of Marseilles (Rollin, 1929, pp. 227-8; Sharp, 1960, pp. 166-8).

In June 1797 the missionary William Crook was left on Tahuata, but within a year he transferred to Nuku-Hiva and in January 1799 sailed for London. During this time he collected much information about Marquesan customs and was probably the source of an 'Account of the Marquesas Islands' which has been transeribed by G. M. Sheahan, who considers it either 'an abridgement by a third person of a Journal, or some other MS written by Crook' (Crook/Sheahan, c. 1800). Though from other accounts (e.g. Rollin, 1929, pp. 230-1) it seems doubtful that Crook visited, except perhaps briefly, islands other than Tahuata and Nuku-Hiva, already there were several beachcombers in the group who may have contributed details about them. 
One of the principal diversions of all the Marquesans seems to have been 'wars, in which they readily take part'. Sometimes 'the whole force of one Island, will be collected, to attack a part of another', sometimes 'independent nations, in the same Island, who maintain constant hostility' or 'smaller tribes, who are commonly in alliance together' would fight; occasionally even 'different families of the same neighbourhood; in which the ruling Chief is liable to be opposed, even by his own Kinsmen'. Hence it is not surprising that women and children were ignored and the distribution of population throughout the group was given in terms of warriors, even though the women [were] generally very prolific, commonly bearing 10 or 12 , sometimes 18 children'.

The numbers of warriors each of the inhabited islands was 'computed to raise' or 'reckoned to furnish' are given below.

$\begin{array}{lr}\text { Nuku-Hiva } & 6,000 \\ \text { Ua-Pu } & 1,200 \\ \text { Ua-Uka } & 800 \\ \text { North-west group } & 8,000 \\ \text { Hiva-Oa } & 10,000 \\ \text { Tahuata } & 1,200 \\ \text { Fatu-Hiva } & 5,000 \\ \text { South-east group } & 16,200 \\ \text { Total } & 24,200\end{array}$

The only island for which these numbers were translated into "persons including children' was Ua-Uka, which 'probably [had] a population of 3,000' (Crook/Sheahan, c. 1880, pp. cxxxv, cxxxvi, cxvii, cxli, clxv). If this same ratio is applied to the other islands, the population of the group around 1800 would have been more than 90,000 persons, each of the warriors being matched by $2 \cdot 75$ dependants. This ratio seems rather low if the women were as prolific as reported, but that is probably irrelevant compared with the likely accuracy of the tallies of warriors.

When Krusenstern visited Nuku-Hiva for ten days in 1804 he used an Englishman, Roberts, as his interpreter. Roberts claimed to have lived on the island for seven years, and on Tahuata for two years before that, but there was at least one valley on Nuku-Hiva that he had never visited, and Krusenstern described his estimates of the numbers of warriors in each of six valleys as numbers Roberts mentioned at random, having no positive information on the subject'. Their total of 5,900 is consistent with the reckoning of 6,000 four years previously, and given Roberts's period of residence on Nuku-Hiva, this suggests that he supplied the information to Crook as well as to Krusenstern. However, Krusenstern doubted Roberts's tally for the people of the valley which 
opened into the bay where the ships were anchored, because he never saw altogether more than from 800 to 1000 , of whom 3 or 400 were girls' and, except perhaps for mothers with young children, 'very few' people would have refrained from gathering on the beach when the visitors landed (Krusenstern, 1813, 1, pp. 135, 111, 144, 177-8). Hence he arbitrarily reduced the 'very arbitrary estimation' of population by onethird, from 18,000-three times the number of warriors-to 12,000 , incidentally impugning Roberts's reliability as an informant because the people whose numbers Krusenstern thought exaggerated were those amongst whom Roberts lived. Crooks's tallies for the various islands might well have been based on equally random guesses.

About two years after Krusenstern's visit 'une disette affreuse . . . désola cet archipel'. Because 'tous les fruits, et surtout le fruit à pain, manquèrent à la fois; le poisson même avait disparu . . . et c'en fut bientôt fait du peu de cochons et de gibier qu'ils avaient ... ils en furent réduits à se manger entre eux ... pour assouvir leur faims'. Before the famine ended in about 1812 '[elle] fit périr au moins les deux tiers de la population', which on Nuku-Hiva was 'antérieurement 16,000 âmes et plus' (Gracia, 1843, pp. 12, 13). Rollin (1929, p. 231), however, says the famine lasted only four years on Nuku-Hiva, while the population of the island decreased from about 16,000 to 9,000 , which is twice as many survivors as Gracia reckoned. Rollin gave no source for his tally of deaths from famine, but Gracia had his information from 'tous les anciens, qui l'avaient éprouvée'. The figure of 16,000 for the population initially is probably a garbled version of Krusenstern's estimate.

In October 1813 Captain Porter of the U.S. frigate Essex arrived at Nuku-Hiva with three of the 'prizes' he had captured during the preceding year. With about 250 men on board and 36 prisoners from the last of the captured British whalers, the Essex stayed for six weeks being cleaned and refitted and was joined there by Essex Junior, one of the 'prizes' that had been converted into a cruiser and carried a further 60 men. The small flotilla was met by a canoe containing three white men, one of whom was an Englishman, Wilson, who had been in the Marquesas 'for many years' and became Porter's interpreter. Later Porter $(1823$, p. 81$)$ had occasion to be satisfied that he was a consummate hypocrite and villain', and Rollin (1929, p. 231) described him as 'un maraudeur anglais qui, en qualité d'interprète [à Porter], devait lui jouer plus d'un tour'.

Doubtless it was Wilson who told Porter the number of warriors, which each tribe can send into the field, ... making in all 19,200'; and though most of the 'tribes' named can be matched with some Rollin (1929, pp. 69-70) listed, the numbers were probably as accurate as 
Wilson's information about the 'English missionary, who, about five or six years ago, remained a short time [there] with a view of converting the natives to Christianity', when Crook had been there fifteen years before and no one replaced him until 1831. It is impossible to guess whether Porter's estimate of 'upwards of four thousand natives, from the different tribes, [who] assembled at the camp with materials for building' was realistic, even though before night they had completed a dwelling house for [Porter], and another for the officers, a sail loft, a cooper's shop, and a place for [the] sick, a bake-house, a guard-house, and a shed for the sentinel to walk under. The whole were connected by the walls.' Certainly there are grounds for questioning the reliability of his statement that in the course of a battle, the enemy 'all made a stand, to the number of between three and four thousand' (Porter, 1823, pp. 86, 116, 97, 88).

Before Porter left the island his company of about 350 men had made severe inroads into the food supplies of the valleys near his anchorage, and provisions from the adjacent valley were obtained only after the villages had been sacked and burned (Porter, 1823, pp. 106, 108-10). If there were in fact 2,500 warriors among the tribes inhabiting the valley of Taiohae, this implies a population of at least 7,500 people and probably more, and it is a little curious that an extra 350 or 400 men for six weeks should impose any great strain on food supplies, especially as Porter found six of the larger hogs were 'fully sufficient to furnish an ample daily supply [of fresh provisions] to four hundred men'. Hence their total consumption during six weeks would have been at most 252 hogs or one hog from every 10 warriors, and fewer than this 'nearly exhausted all their stock' in the valley (Porter, 1823, pp. 91, 106). By 1829, population estimates then current, though it is not known from what source, attributed 'probably less than 8,000 ' people to two tribes which Porter believed contained 6,500 warriors in 1813 (Stewart, 1832, p. 237).

Crook had returned briefly to the Marquesas in 1825, escorting three 'teachers' from Tahiti and Huahine to try to re-establish the mission at Tahuata. This was the first of several attempts which all met with failure, the teachers leaving the islands after a few months or if they stayed, doing nothing in the work of the mission' (Davies, 1961, pp. 286-8). Darling visited the group in 1831 and returned again in 1834-5 for about eleven months. Though most of his time was spent at Tahuata where he visited all the inhabited valleys, listing the numbers of inhabitants, he also visited Hiva-Oa to look for a suitable site for the mission. After listing the numbers of people living in some of the valleys there he decided that the island contained 'about 5000 inhabitants or 
thereabouts'. His first estimate for Tahuata, based on his counts for the eight valleys he had visited, which he reckoned as 'two thirds of the island', was 1,500 inhabitants at most, and this he subsequently revised to 1,396 (Darling 1835b, 1835c).

At the end of 1837 he visited the Marquesas again and, accompanied by another missionary George Stallworthy, called for the first time at Fatu-Hiva, Nuku-Hiva, and Ua-Pu (Darling, 1837). Stallworthy (1839) later reported that Fatu-Hiva contained 'about 3000 inhabitants' and he had been informed by persons who have visited [Ua-Pu] that it may contain the same number', but he doubted his 'informants had ... taken much pains to ascertain the real amount'; Hiva-Oa contained ' 6 or 7000 inhabitants' and Ua-Uka had 'a population of 1000 ', though 'wars [were] frequent or almost perpetual on both'. On these estimates and Darling's earlier count for Tahuata the south-eastern group of islands contained about 11,000 people, and 'the [total] population cannot be estimated at less than 20,000'. Teissier (1953, p. 20) antedated this estimate by about five years and raised the population to 27,000 .

By 1841 it was asserted that a 'census of the Windward [i.e. southeast] group was taken by Mr. Stallworthy while visiting the islands. . . . That of [Nuku-Hiva] was taken by the American missionaries [Ua-Pu] and [Ua-Uka] are estimated by them, and from what I know of these islands I think their estimate is pretty correct' (Thomson, 1841a). The figures given for each of the islands belie much 'census'-taking, but Thomson may have been more honest than most of the missionaries.

$\begin{array}{ll}\text { Nuku-Hiva } & \text { 'a population of about } 6000 \text { ' } \\ \text { Ua-Pu } & \text { 'about } 1800^{\prime} \\ \text { Ua-Uka } & \text { 'estimated at } 1000 \text { inhabitants' } \\ \text { Hiva-Oa } & 6,500 \\ \text { Tahuata } & \text { 'about } 1000 \\ \text { Fatu-Hiva } & 3,000\end{array}$

Elsewhere Thomson claimed a population of 8,000 for Tahuata (Thomson/Sheahan, $1841 \mathrm{~b}, \mathrm{p} . \mathrm{cci}$ ) and a density of $18 \frac{1}{2}$ people to the square mile, but this must be an error because it implies that Tahuata, one of the smaller islands of the group, had an area of 432 square miles, and the total land area of the whole group is now estimated at about 492 square miles (Robson, 1956, p. 139).

Despite their rounding, these are probably the first figures which are more than remotely related to the people then living on the various islands, and they are repeated in Table 54 along with the estimates and counts reported for the later years of the nineteenth century. Although there is a reasonable correspondence between these numbers and Crook's 
for 1800 , the scepticism about tallies of five, six, or ten thousand warriors remains, especially when different informants ascribed to one valley numbers which range from 800 to 2,500 , and an independent observer thought the figure of 800 exaggerated by about one-third.

By 1840 there were probably at least 60 Europeans scattered throughout the islands. In 1835 Darling expressed surprise when ' 10 or 12 foreigners came on board' the mission ship at Nuku-Hiva, and told him there were 'about 20 living on the island'. Early in 1838 'some Spaniards' who were then living on Tahuata helped Stallworthy (/Sheahan, 18.3741, p. clxxxvi) build a new house; and 7 men deserted from an American whaling ship that called soon after and only 5 were recovered before she sailed. In 1841 Thomson (/Sheahan, 1841b, p. ccv) claimed there was 'not one whaler in 10 which does not leave some of their crew behind them; . . . upon [Nuku-Hiva] there are at present from 20 to 30 such characters; upon [Ua-Pu] 5 or $6-[\mathrm{Ua}-\mathrm{Uka}] 1$ or 2-[Hiva-Oa] 2 or 3-[Fatu-Hiva] 1 or 2 and upon Tahuata about 20. Many he considered 'settled for life', and those who left after a few months on the islands both replaced and were replaced by other absconders. In addition there were, depending on one's source, either 5 (Rollin) or about 10 (Thomson) Catholic missionaries; the first of them arrived at Tahuata in 1838 and they were reinforced from the Gambier Islands the following year. Through his protégé, a young chief of Nuku-Hiva, Thomson incited the people of the island to reject the priests, but in 1841 he wrote sadly from Tahuata that 'most of them are still here, some have gone to Sandwich Islands and others have come here in their place' (Thomson/ Sheahan, 1841b, p. cciii; Rollin, 1929, pp. 237-8).

In 1842 the Marquesas were declared French territory by Commander Dupetit-Thouars, and when a governor was appointed by the French Government in 1843 , his instructions were that a census should be taken and the education of the people be left to the Catholic missionaries (Newbury, 1957, p. 72). Before he left France he was also commissioner to the protectorate of the Society Islands, and it seems he never did visit the Marquesas. Dupetit-Thouars's estimate for the population of the various islands is widely quoted, though their source is never explained. The only figures he himself mentioned in his report to the Minister of the Navy and Colonies refer to Fatu-Hiva and Tahuata, the first, 'assure-t-on', contained between 1,500 and 1,800 inhabitants and Tahuata at that time no more than 700 or 800 , although four years previously it had 1,100 or 1,200 inhabitants (Dupetit-Thouars in Gracia, 1843, pp. 293, 298).

The primary source of these and the other population figures attributed to Dupetit-Thouars was probably one or both of the Catholic 


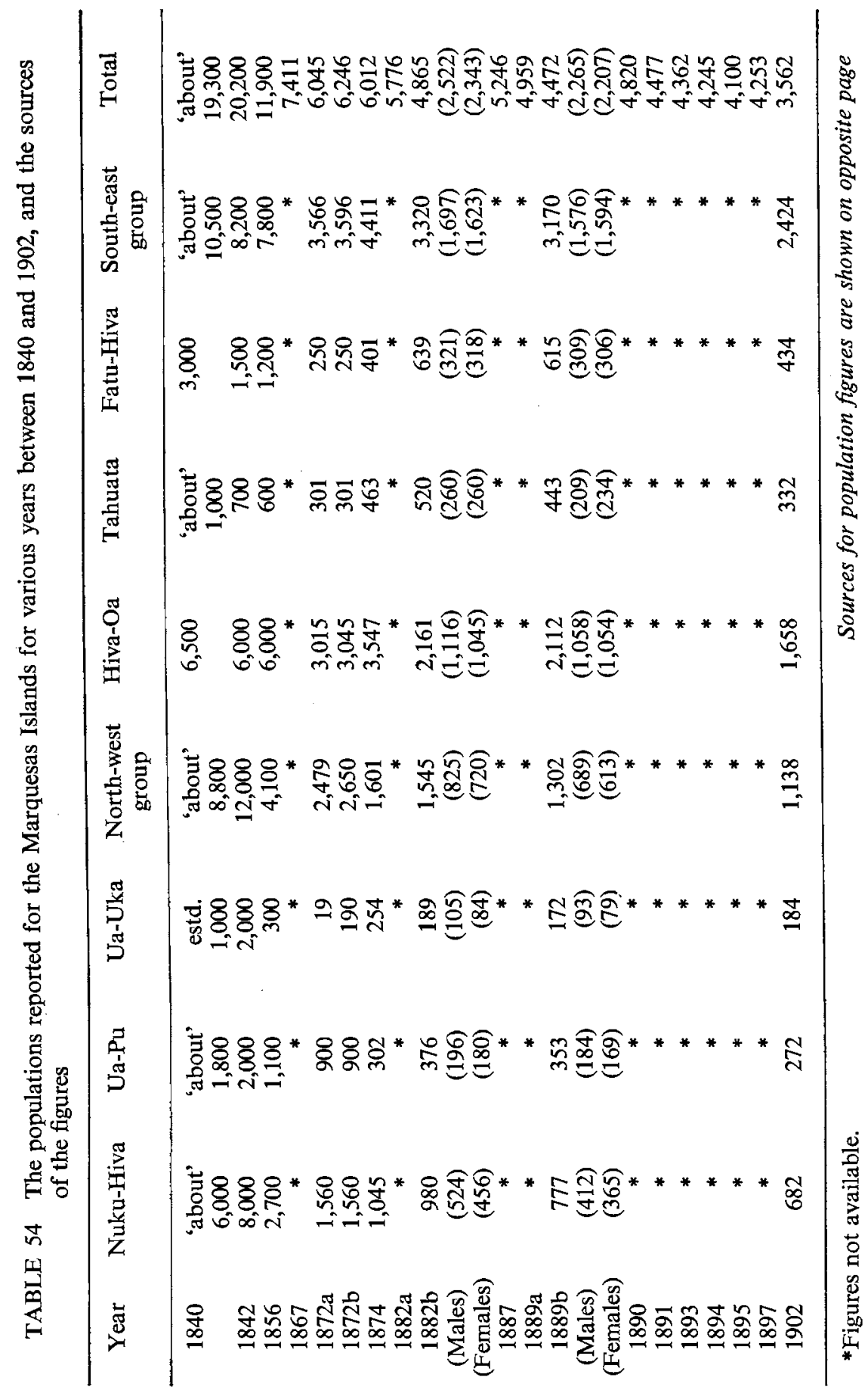




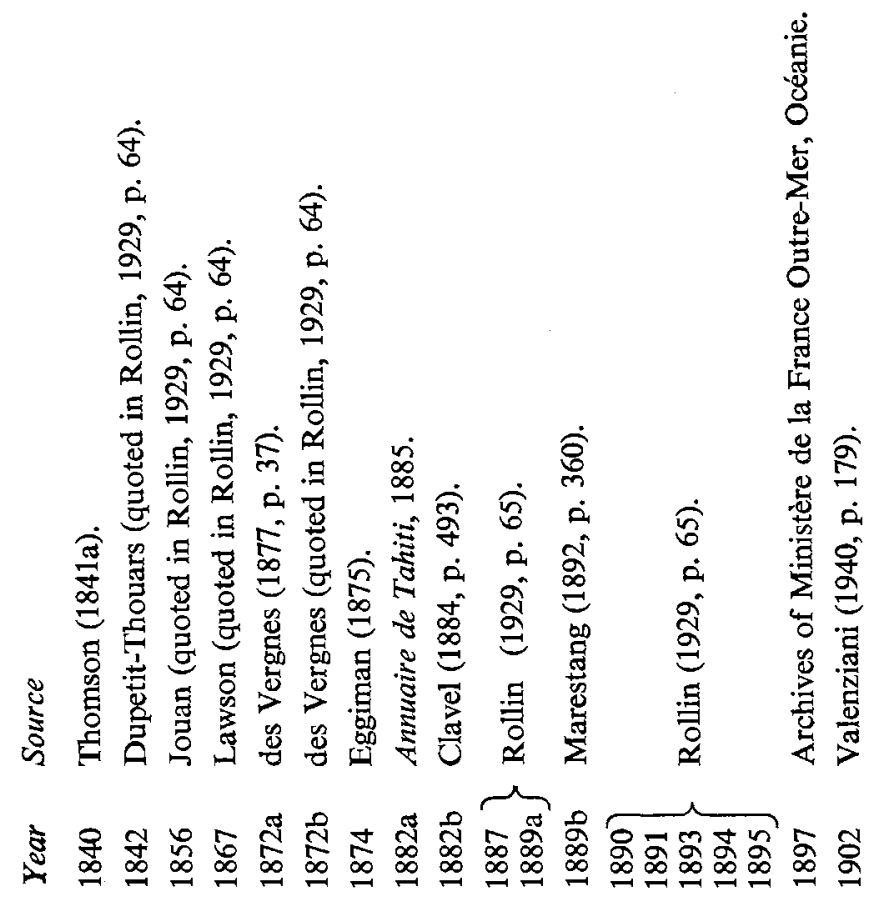


missionaries who had been living on Tahuata for less than three and a half years. Their information about the numbers of people living on other islands could have been at best only hearsay, because although three others had been on Nuku-Hiva for nearly two years before the local wars forced them to move to $\mathrm{Ua}-\mathrm{Pu}$, they had left the group before Dupetit-Thouars arrived (Gracia, 1843, p. 299; Rollin, 1929, p. 239). Hence, the London Missionary Society's estimate for 1840 or thereabouts is to be preferred to the one attributed to Dupetit-Thouars for 1842 , which alleged 12,000 inhabitants in the north-west group of islands, and 8,200 in the south-east group (Rollin, 1929, p. 64).

Another estimate frequently quoted as a census was made by Jouan who was Résident at Nuku-Hiva about 1856. If Quatrefages (1864, p. 70) reported him correctly, Jouan estimated there were between 2,500 and 5,000 warriors in all the islands, and from this he inferred a total population of 11,000. Elsewhere (des Vergnes, 1877, p. 37; Marestang, 1892, p. 360; Rollin, 1929, p. 64) this figure is given as 11,900. The wide range in the probable number of warriors suggests that Jouan was not too wellinformed about some islands at least, and if his number of warriors had a wide margin of error, so too did his population estimates for at least some of the islands, and therefore the total also, even though he thought it 'probablement trop élevé' (Quatrefages, 1864, p. 70). Jouan's (1858) book on the Marquesas is not available in Australia, but on this evidence his population estimates seem not to warrant the confidence accorded them by a later Résident, des Vergnes (1877, p. 37).

Des Vergnes was Résident from 1868-74 and he made a census in 1872, 'aidé . . . par les missionaires'. Between his and Jouan's censuses the periodic skirmishes between tribes continued as they had both before and after the French occupation, though they were perhaps heightened after annexation by French interference or provocation. Hiva-Oa was reported as being "en ébullition continuelle", its people continuing their 'orgies, assassinats, repas cannibales, guerres' as in the past despite all protests. A special regulation promulgated for NukuHiva made the chiefs directly responsible for the good behaviour of their people, who were forbidden to perform any of their pagan rites, to make or buy alcoholic liquors, to visit ships or buy guns or powder without the permission of their chief (Rollin, 1929, pp. 269, 267).

In December 1862 two Peruvian slavers called at the Marquesas and captured 35 men who were returned some months later, 5 to Tahiti and the remainder direct from Callao to Nuku-Hiva. Smallpox had broken out on the ship after leaving Callao, and the sick were landed on NukuHiva to be cared for by one of the missionaries. 'La curiosité indigène sut vaincre les mesures d'isolement', and the epidemic spread quickly 
to a neighbouring valley on Nuku-Hiva and to Ua-Pu. It lasted six months, 'tuant le quart de la population des deux îles, malgré le dévouement absolu des religieux' (Rollin, 1929, p. 269). Rollin cited no authority for this estimate of mortality, but mission records of 1865 ( $\mathrm{P}$. Chaulet) attribute 960 deaths on Nuku-Hiva and 600 on Ua-Pu to this epidemic.

Either separately or together these numbers are inconsistent with a mortality rate of one quarter and Jouan's population figures of 2,700 and 1,100 for the two islands. Clavel $(1884$, p. 495) claimed there were '2,000 victimes sur un population d'environ 4,000 âmes', and Marestang (1892, p. 361) that the epidemic 'décima . . . près de la moitié de la population'. If the mortality was only 25 per cent and the mission records of deaths not exaggerated, then Jouan must have grossly under-estimated the populations of Nuku-Hiva and $\mathrm{Ua}-\mathrm{Pu}$ in 1856. Alternatively, if the mission records were accurate and Jouan's estimates reasonable, then the mortality in the epidemic was more than one-third on Nuku-Hiva and about half on Ua-Pu.

Rollin (1929, p. 64) attributed a census of some kind for 1867 to Lawson, when the total throughout the islands was 7,411 . The origin of this cannot be found, though the number was repeated by Valenziani (1940, p. 179) and also by Teissier (1953, p. 20) who believed it T'estimation la plus juste' because Tahiti's population in 1863 was 9,486 . Teissier also listed the approximate population of each island as of 1863 without citing his source, but these repeat numbers given by Cuzent (1883, pp. 9-10) for no known date and of no known source except that they resemble Jouan's for most of the islands.

Compared with most other years described in Rollin's account of the Marquesans in contact with civilization, 1872 seems to have been a peaceful year and the Résident may have been able to collect population statistics undisturbed. There are, however, two versions of his total6,045 given by des Vergnes $(1877$, p. 37) himself and repeated by Marestang (1892, p. 360), Zaborowski (1892, p. 663) and Caillot (1909, p. 71), or 6,246 given by Rollin (1929, p. 64) and quoted subsequently by Valenziani (1940, p. 179) and Teissier (1953, p. 20)-the difference being accounted for by the substitution of 190 for des Vergnes's total of only 19 people on Ua-Uka, and an apparently equally arbitrary increase in Hiva-Oa's population from 3,015 to 3,045. Either way there is a spurious accuracy in a number such as 301 for Tahuata's population when, except for this and Ua-Uka, the populations were rounded to 5 or 10; and by comparison with later census figures, a population of 900 for Ua-Pu appears exaggerated.

Des Vergnes's successor Eggiman also took a census of the group 
and as his report is dated 26 January 1875 (Archives Coloniales) the interval between the two counts could not have been more than three years. Nevertheless, his figures (which include 150 foreigners of various nationalities and origins) bear little resemblance to des Vergnes's. In the north-west group, Nuku-Hiva's population had ostensibly decreased by one-third, Ua-Pu's by two-thirds, and Ua-Uka's had increased by onethird over the interval; in the south-eastern islands Hiva-Oa's population had increased by about one-sixth, Tahuata's by one-half and Fatu-Hiva's by three-fifths. Eggiman also listed the numbers of births and deaths that had occurred in each of the districts of Nuku-Hiva during 1874, and these amounted to 21 births and 42 deaths in a total population of 1,045. Rollin (1929, p. 273) described this Résident as an 'excellent administrateur [qui] travailla sincèrement au bien de la Colonie', and so his census may have been the first worthy of the name in this group of islands.

In 1881 the military administration was replaced by a civil administration, and Clavel was sent to the Marquesas for six months to report on the 'état sanitaire'. In the course of this visit he made a census, distriot by district, for each of the islands and though the Annuaire de Tahiti for 1885 quoted a total population in the Marquesas almost 20 per cent higher than Clavel's (1884, p. 493), the latter is probably the more correct. For the first time the population of each island was divided into males and females, and though there was a small excess of males in the populations of the north-west islands, the numbers of males and females were almost equal in the south-east group.

Assuming that this and Eggiman's census were reliable, the populations of the south-east islands showed the greatest change during the seven- or eight-year interval. There had been a dramatic decline of about 40 per cent in the numbers on Hiva-Oa, which was offset by a small increase on Tahuata and an increase of more than 50 per cent on FatuHiva. The reality of these changes is hard to assess because there seems to have been little real contact between the French administration and two of these islands for many years. Fatu-Hiva was an island peu frequentée' where the mission had been abandoned in 1855. A missionary went there in 1877 to try to re-establish it, but he was forced to flee little more than a year later because "la guerre, accompagnée de sacrifices humains, devenait cruelle'. The war stopped in 1879 'par lassitude des deux partis'; but the people of Hiva-Oa seemed never to tire of their orgies and assassinations. During 1876 there were forty violent deaths amongst a population of about 400 living in one valley, and in 1880 the French decided to launch a 'campagne de conquête' in an effort to control this island whose population dominated all the nineteenth 
century estimates. The campaign was launched in June, and from then until 1889 Hiva-Oa was in a state of siege, with people forbidden to leave their valley without permission, the penalty of transgression being enforced labour on roads and other public works (Rollin, 1929, pp. 274-6).

It is possible that some of the people took refuge on the other islands, especially the neglected Fatu-Hiva and perhaps also Ua-Pu. Assuming that Eggiman's census of the troublesome islands was as reliable as Clavel's might have been under the system of control then in force, the population of the south-east islands had decreased by about a quarter over the interval, whereas the decline in the north-west group was about 31: per cent. For the Marquesas as a whole, the population decreased by about one-fifth, which represents an average annual decline of more than $2 \frac{1}{2}$ per cent, but this is heavily weighted by the average decrease of $3 \frac{1}{2}$ per cent per year in the populations of the south-east islands.

Rollin (1929, p. 64) mis-dated Clavel's census as 1884, and although he listed seven more enumerations before the end of the century, none showed the distribution of the total population throughout the islands. The first count, made in 1887, recorded a total of 5,246 in the whole archipelago and successively fewer people were enumerated in each of the censuses taken almost annually from 1889 to 1895 . Both the 1887 and 1889 aggregates were larger than Clavel's total for 1882, and that for 1889 exceeded the number quoted by Marestang (1892, p. 360) as deriving from a census of 1889 , which provided the numbers of males and females on each island and allowed Marestang to construct an age pyramid.

Marestang did not explain how or whence his data were obtained, but like Clavel's they showed a small excess of males in the north-west islands and virtual equality in the numbers of males and females in the south-east group. The north-west islands had lost relatively more of their population since 1882 than had the south-east islands, but the rate of decline for the population as a whole was less than half the average annual rate between 1874 and 1882. Although the ages can only be approximate, the age pyramid (Fig. 3) is extremely interesting because, in addition to the similarity of the distributions for males and females, there were fewer people aged 10 to 19 years than at any age below 45 years, and fewer aged 15-19 than at any age below 50 years. This suggests either that there were considerably fewer births during the decade 1870 to 1880 than was customary or there was an exceedingly high mortality amongst those born during this time, or perhaps both factors operated.

Reconstructing the numerical distributions from the pyramid, about 


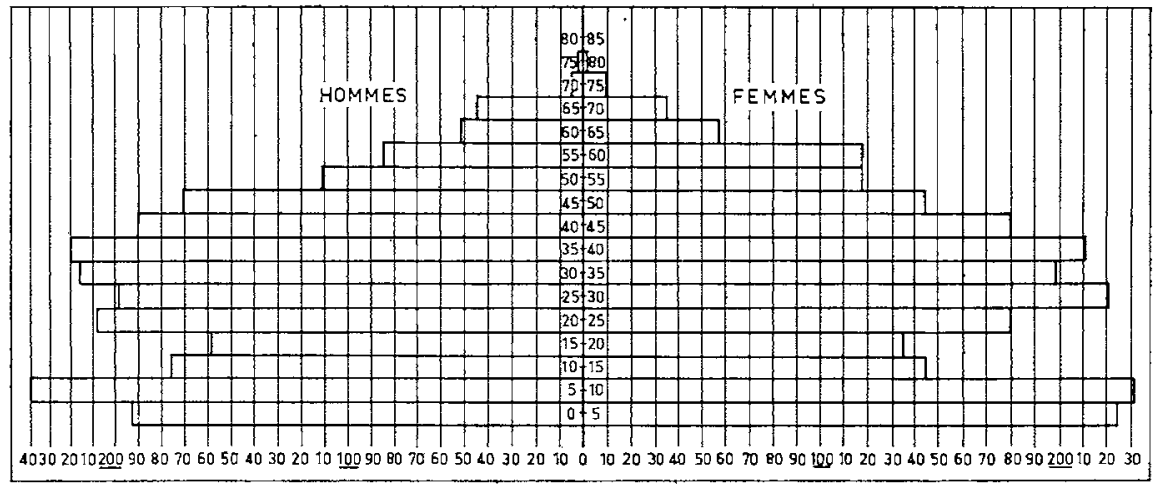

Fig. 3 The age pyramid of the population of the Marquesas Islands in 1889, redrawn from Marestang (1892, p. 361)

27 per cent of both males and females were less than 15 years of age, less than 25 per cent were aged from 15 to 29 years and about 27 per cent aged from 30 to 44 years. Thus more than 50 per cent of the population were of reproductive ages, yet only 20 per cent were children aged less than 10 years. About 17 per cent were aged from 45 to 59 years, leaving less than 5 per cent at ages beyond this. There were fewer than 400 children aged 0-4 years per 1,000 women of reproductive ages, and though some part of this low child-woman ratio may have been due to the omission of young children or mistaken estimates of age, both Clavel and Marestang submitted evidence of a high incidence of sterility.

Clavel (1884, p. 497) had found that 20 women in a sample of 47 beyond the age of menopause had had no children, and the other 27 had borne a total of 199 infants, 'un grand nombre' of whom were either still-born or died soon after birth. About two-thirds of these women he described as 'très fécondes', the remaining one-third 'peu ou d'une façon moyenne'. Marestang's (1892, p. 362) sample was rather larger than Clavel's, but 259 women ( 48 per cent) in his total of 539 aged more than 15 years had borne no children. The average annual birth rate for the years 1886 to 1890 inclusive he reckoned at 20 per 1,000 population, or 99 births per 1,000 women aged 15 to 50 years; whereas the death rate at this time was 41 per 1,000 population annually.

Presumably the births and deaths were summarized from the état civil which had been instituted in 1882 , but was not completely organized throughout the islands until 1884 (Rollin, 1929, p. 276), and one might doubt the completeness of the records at such an early date. Moreover; 
the birth and fertility rates quoted are inconsistent: a crude birth rate of 20 in a population of 4,472 implies an average of 89 births a year whereas Marestang's fertility rate requires an average of 126 births a year. Nor is an annual average of 89 births consistent with a total of 417 children aged less than 5 years in 1889 and an annual death rate of more than 6 per cent for children of those ages. At least three-quarters of the deaths at these ages ${ }^{*}$ would have been of children under 1 year of age, and 417 survivors at ages 0-4 in 1889 implies an initial birth cohort of about 520, which represents an average of 104 births a year and an infant mortality rate of about 20 per cent. If, as the age pyramid suggests, there was under-enumeration of children aged 0-4 or exaggeration of the ages of some of them, the crude birth rate at this period may have been nearer to 25 per 1,000 population than the 20 indicated by the état civil.

Provided all of the other estimates of age were reasonable, the birth rate was not likely to increase over the next fifteen years because the numbers of females of reproductive age were likely to decrease quite sensibly during this period. In 1889 there were about 1,125 women between the ages of 15 and 44 years, but only 1,090 aged from 10 to 39, 1,110 aged from 5 to 34 years, and 1,135 under 30 years of age. With a mortality of about 3 per cent per year throughout the reproductive ages, and about 2 per cent between ages 5 and 15 (Marestang, 1892, p. 361 ), the numbers aged 15 to 44 in 1894, 1899 and 1904 would be about 950,830 and at the most 750 respectively. Hence, even if sterility was rarer among the girls attaining reproductive age than was alleged for the older generation, the margin between births and deaths each year was likely to widen unless mortality declined markedly, especially at ages beyond 30 years because in 1889 almost half the population were of these ages. If Marestang's figure for the total population was correct, then the mortality may have fallen slightly before 1902; but if the population in 1889 was larger than Marestang's total, and the number cited by Rollin (1929, p. 65) was correct, then the population decreased by about $2 \frac{1}{2}$ per cent per year between 1889 and 1902 and the mortality level had not changed.

However, the question still unanswered is why were the 1870-9 birth cohorts deficient? The 1864 epidemic of smallpox may have contributed a little, though the greatest effect of that would have been in the births of 1865-9. The epidemic was confined to Nuku-Hiva and Ua-Pu, which between them contained perhaps one-third of the population of the Marquesas, and if the mortality rate in the epidemic was 30 per cent,

* In 1950-2 there were 172 infant deaths registered in the outer islands of French Polynesia, and 52 deaths of children aged 1-4 years. 
irrespective of sex or age, just over half of the marriages then in existence would have been broken by the death of one or both spouses. In the following year or two, the number of births would have been halved, but effectively this would reduce the total number of births in the group by only one-sixth in the first year or two and by less than this fraction in the later years of the quinquennium 1865-9. The survivors of this birth cohort would have been 20-24 years of age in 1889, and though Marestang's age estimation may have been at fault so that some who were in fact less than 20 years old were recorded as 20 years or more, this could hardly account for the deficit in the younger cohort.

The mothers of these cohorts would have been aged 30 to 59 years in 1889, and if Marestang's estimates of age were reasonable, the cohort which contained the greatest number of people at any age beyond 10 years was the one borm between 1850 and 1854, and the numbers in the two older cohorts in 1889 are consistent with the numbers of survivors expected after five or ten additional years when the mortality rate was about 3 per cent per year. Hence, if there had been no change in the level or pattern of mortality, there must have been fewer births each year after 1855 than there had been for at least a decade before, and probably even longer. Since the numbers in the two cohorts aged 25 to 34 years in 1889 were not so very much smaller than the group aged 35-39 years, this gradual decrease in the number of births suggests that the reproductive potential of the population started to decline in about 1855 , and assuming constant mortality, this would reflect back to the births that had occurred in the 1830s.

This was the decade during which the survivors of the children born just before the famine of 1806-10 or thereabouts and any born in the course of it would have been at the ages where they would normally contribute most to the births each year. If few or none of these children survived, there would have been relatively few births for about fifteen years from the late 1820s through to 1840, the period of greatest scarcity being from about 1830-5. As the Marquesans who had survived the famine admitted to Gracia (1843, p. 12) about thirty years later that 'ce furent les plus forts qui égorgèrent et dévorèrent les plus faibles', and even earlier Krusenstern (1813, I, p. 166) was convinced that in times of famine the men ate their wives and children, there is some circumstantial evidence for supposing greater cannibalistic depredations amongst the child population than in any other sector. If children born before the famine were spared, but none born during it were allowed to survive, the greatest deficiency of births would still have occurred during the 1830s; so that far-fetched though it may seem to ascribe these deficient cohorts of 1870-9 to something which happened more 
than sixty-five years before they were born, it may not be such an unreasonable hypothesis.

At the least it is more reasonable than to presume that any of the causes generally advanced for the decline in population applied more specifically to one decade than to any other. The women of reproductive age in 1870-9 would have been born between about 1826 and 1865, and hence many of them would have lived through the era when visiting whaling and trading ships came to anchor only if the captains could be assured of a plentiful supply of women (Darling, 1835a); but while it is possible that their sterility had its origin in venereal disease, it would be odd if the effects should be so marked in just one decade.

Nor is there any evidence that the turmoil which Rollin reported throughout the 1870s was necessarily any more widespread or more vicious than it had been at other times. The only new vice to which the Marquesans became addicted in this decade was opium, which was imported originally for the Chinese who had been employed by a company in Tahiti to grow cotton on 4,000 acres of land on Nuku-Hiva, and who remained on the island when the project failed in 1873, growing cotton and trafficking in opium. Although this trade was officially suppressed in 1894, supplies were smuggled in for many years afterwards (Rollin, 1929, p. 276), and again it would be curious if its effects on births-if there were any-or on the deaths of infants and children should have been confined more specifically to the first decade of its use than to any other.

Had Marestang given the age distribution of each island's population, and not merely of the population as a whole, some less hypothetical explanation might have been possible because such figures as may be reliable for the various populations show no particular uniformity in their changes over time. Except for the famine which is presumed to have affected all islands-though it may not have done-and the smallpox epidemic known to have occurred on two islands more or less simultaneously, there is little to suggest causes of decline which were common to all islands for specific periods. Many of their inter-tribal wars would have been unrelated to events occurring at the same time on other islands, and their resistance to French annexation was as sporadic as the administrative control was uneven. Except in the later years of the century there is little information on the numbers of children born, and even that is somewhat dubious. In fact, few of the data available inspire much confidence, so that, indisputable though it may be that the Marquesas contained more people at the beginning of the century than at its close, it is impossible to chart the course and magnitude of the decline for any island or for the group as a whole. 


\section{Austral Islands}

Rimatara is the smallest and most westerly of the Austral Islands, and it had probably not been visited by Europeans before 1811 (Sharp, 1960, p. 192). In 1822 two mission teachers from Raiatea were left on the island, and when they were visited the following year, between 200 and 300 , that is almost the whole population' attended the service held in the chapel. 'About 130' of these were described as 'children in the schools' although less than two years later the school had only 90 children (Davies, 1961, pp. 284-5). About the same time Ellis wrote that Rimatara's population was 'small, not much exceeding $300 . .$. Diseases are few, and an unusual number of very aged persons are found among them' (Ellis, 1831, 3, p. 389). The Belgian trader Moerenhout (1837, 1, pp. 152-3) painted a different picture altogether when he wrote mournfully about the sickness that had come to the island in the wake of Christianity, and which caused so many deaths that the population decreased from 1,000 or 1,200 to scarcely 200 , almost all of whom were females.

There is no mention of such disease in the missionaries' reports, but their visits were often hurried and from the shortness of ... time on each [island], and the many little things to be attended to, [they] could not take a correct census' (Chisholm, 1857). It had been feared that a boat which left Tahiti for Rimatara during the smallpox epidemic in 1841 might start an epidemic (Darling, 1842), but the next report in 1846 commented merely on the 'present healthfulness of the inhabitants' (C. and J. Barff, 1846). For many years there was no mention of numbers, but in 1858 there were 100 children in the schools and 124 people 'in communion' (C. Barff, 1858), which would suggest a population not very different from Ellis's for the 1820 s. Little more than three years later 'the chief' claimed there were 600 people on the island, which was thought 'perhaps too high a computation' (Morris, 1862a); in 1869 there were 'only 200 people' on Rimatara (Vivian, 1869b), and in 1881, 'under 400 souls' (Green, 1881). When the first official census was made in 1892 there were reputed to be 550 people on the island (Teissier, 1953, p. 21).

Some of the apparent inconsistency in these numbers could be resolved if the epidemic of dysentery which broke out on Rapa in 1864 had spread to Rimatara. Alternatively, the missionaries might have confused Rimatara with one of the other islands in their reports, or there may have been exchanges of population between the islands from time to time. Certainly the numbers cited for Rimatara in the official censuses from 1892 onwards are not much more consistent than the missionaries' totals, and it seems likely that some of the people reported for Rimatara 
in 1892 may either have belonged to or later migrated to the neighbouring island of Rurutu.

Rurutu was the first island of this chain to be discovered by Europeans and on 15 August 1769 Cook described it in his journal as '13 miles in circuit and tolerable high, it appears to be neither populous nor firtile' (Cook/Beaglehole, 1955, p. 156). The naturalist Banks was in the pinnace sent ashore from the Endeavour and although no landing was made, he reckoned 200 people gathered on shore while the boat was searching for a landing place. Neither he nor Cook guessed at what the total population might have been, but Banks commented that they had seen only two canoes on the island, which was one more than Tupia allowd them who said they had but one' (Banks/Beaglehole, 1962, 1, pp. 330-1).

Rurutu's next recorded visitor was the missionary William Henry, returning to Tahiti from New South Wales in January 1800 . He thought there were many inhabitants there', but they behaved so inhospitably the attempt to land was abandoned. In 1813 or 1814, however, 'a number of the inhabitants' were taken to Tahiti on a European ship and 'some time after' were returned home to Rurutu. Early in 1821 a large canoe returning from Tubuai to Rurutu was blown off course, and eventually fetched up at Raiatea. Some of the people on board had got ashore at Borabora, and although well-treated there, they soon rejoined the others at the mission station on Raiatea. This group of 'about 25 ' men and women split again when some, accompanied by two of the Raiatean mission teachers, were taken back to their island in July, and the remainder followed less than a year later (Davies, 1961, pp. 282-3).

Towards the end of 1822, the 'deputation' from the London Missionary Society which was then visiting the mission stations in the Pacific accidentally made landfall at Rurutu, and an American who had been living on the island for about seven years told them there had been full 3000 persons . . . beside Children but that a disease broke out among them which destroyed from 6 to 10 persons daily he knew of 12 dying in one day. He supposed it a fever as they dropped down suddenly and died.' There were few women among the ' 370 souls' who were 'the whole of the inhabitants' in 1822: 'in the school the proportion is 3 boys to one Girl, in the adults it is much worse' (Ellis and Tyerman, 1822). The published account of this visit (Montgomery, 1831, 1, p. 497) assumed as many children as adults on Rurutu before 'the pestilential disease-ague and violent fever-broke out', claiming that the population had decreased from more than 6,000 to 314 or fewer in 1822 .

Within a year, ' 48 persons [had] fallen victims' to 'another fatal disease' (Threlkeld and Williams, 1823), and at the end of 1823 it was 
'thought all the inhabitants did not exceede 250', which total was revised to 'about 200' in October 1825 (Davies, 1961, pp. 283-4). It can be assumed that some of the deaths which occurred during this three-year period were due to the same 'pestilential disease' because two and a half years later there was still one person linger[ing] under the fatal disease that swept away the majority. A British botanist and conchologist, Hugh Cuming, stayed on Rurutu for a week in May 1828 and he reported that 2,500 persons had died from this 'strange disorder' and that only two of the population that survived were aged more than 25 years (Cuming, 1828, pp. 106, 112).

According to Ellis (1831, 3, p. 395), the distressing and contagious disease' first appeared 'in the end of $1820^{\circ}$, and if there had been an average of 8 deaths a day for two years, the losses from the population would have amounted to 5,840. This figure might be reconciled with Cuming's 2,500 dead either by interpreting 'persons' as 'persons other than children', or by assuming that Cuming's informant was the Raiatean teacher who was regarded as one of the most intelligent of the London Missionary Society's agents, but who had been on the island only since June- 1821.

Either way, the population supposed to have been there in 1820 is far greater than the number Moerenhout attributed to the island before the introduction of Christianity. He claimed that Rurutu, like Rimatara, had about 1,000 or 1,200 inhabitants before 'la maladie' reduced their number to scarcely 200; but in unhappy contrast to Rimatara, almost all of the survivors on Rurutu in 1830 or thereabouts were males (Moerenhout, 1837, 1, pp. 152-3). In January 1829 John Williams reported there were ' 50 or 60 young men from 15 to twenty years of age and not a single young woman on the island . . there are very few children, and but few women that have children'. If this was the case, it is scarcely surprising that there were still 'only about 200 people' on Rurutu in 1840 , but as the mission party was 'on shore for half a day' only on this occasion (Heath, 1840), this number is probably very approximate. By 1846 there was 'a decided change for the better . . . in the Rurutu people ... [who] were both more intelligent and more orderly in their deportment' than they had been four and a half years previously (C. and J. Barff, 1846), and in 1852 the population was reputed to be 'about $500^{\prime}$ (Lind, 1852).

It is somewhat difficult to reconcile this figure with the reports of few children in 1829 and a total population of about 200 in 1840 unless there was a wide margin of error in both guesses, or there had been considerable migration to Rurutu. On the face of it, the latter seems unlikely because 'a few years' before 1853 the Rurutuans' taro plots were 
invaded by 'immense swarms of caterpillars' which 'utterly destroyed' the crop that was their main item of food. When the substitute crops of potatoes and yams failed in 1853 , there was 'a considerable scarcity' and 'trying want', which was not helped by a climate which caused 'a good deal of sickness' with 'ague, asthma, consumption and rheumatism . . . common diseases' (Lind, 1853). Then in August 1854 measles was introduced, and it 'attacked every individual in the island. . . . A few have died. Still the mortality has not much if at all exceeded the average of this place' (Lind, 1855).

Nevertheless, in 1858 the schools contained 200 children and the church had increased from 100 to 150 (C. Barff, 1858), and by 1862 Rurutu's population was reported as 670 (Morris, 1862b). 'Three fourths of the houses and 2 Chapels' were destroyed in the gales in 1865 (Morris, 1865a), and in 1869 the population 'of about $600^{\circ}$. was living in three settlements (Vivian, 1869b). Two years later the population did not 'number more than 600' (Saville, 1871b), but in 1875 'an aggregate population of about 700 persons' was reported (Green, 1875), and this increased further to 'not more than 800 souls' by 1881 (Green, 1881). For the first official census Teissier (1953, p. 21) quoted a total of 380 on Rurutu in 1892, but in the light of subsequent enumerations and the preceding mission counts this would seem to have been an underestimate.

Less than one hundred miles east-south-east of Rurutu is Tubuai, 22 miles in circumference and one of the largest of the Austral Islands. Discovered by Cook on his third voyage, this was the island Fletcher Christian selected as the hideout for the mutineers of the Bounty, and they first anchored there on 29 May 1789. Next day the Tubuaians began to assemble on the beach and some canoes circled round the ship, and during the night more people and more canoes arrived in the bay. Early the next afternoon 'about 50 Canoes mannd with 15 or 20 men each paddled round' the ship, while a party of 18 women and 5 men boarded her 'without Ceremony'. The women were given presents, but as the men began to steal 'evry thing they Could lay hands on', Christian ordered them back to their canoe. Suddenly aware of the weapons which had been concealed in all the other canoes, Christian fired at the native who cut loose a buoy and the ship's boats pursued the canoes to the shore. Their landing was 'vigourously disputed' and 12 natives11 men and 1 woman-were killed before the rest retired into the woods. Next morning Christian landed with gifts at several points along the coast, but the houses were all deserted and no natives were seen again before the Bounty sailed for Tahiti to procure the stock needed for their proposed settlement on Tubuai. 
When they returned from Tahiti three weeks later, 'the Natives [were] quite Friendly' and remained so for the next two months while the mutineers were building their fort. Before this was completed, however, another mutiny threatened and when Christian learned that twothirds of his men wished to return to Tahiti, he agreed to land them anywhere they chose provided he retained the boat and its command. The stock brought from Tahiti had been turned loose on landing, and the parties sent to round them up before departure met with opposition from the natives. One group was ambushed by 'about 700' Tubuaians, and 60 men and 6 women were reported killed and many more wounded in this and a subsequent retaliatory skirmish. On 17 September 1789 the Bounty sailed again for Tahiti (Morrison, 1935, pp. 48-50, 53, 61-4).

The mutineers had been at Tubuai for nearly three months and in Morrison's opinion, the island was 'full of Inhabitants for its size and may Contain 3000 souls'. Assuming that between one-third and onequarter of the total population were adult males, this figure is consistent with the number of canoes and men noted on the mutineers' first visit, when 'Most of the Inhabitants of the Island flockd' to the bay where the Bounty was anchored (Morrison, 1935, pp. 65, 71). This might be presumed to have formed the basis for his estimate of the population because, difficult though it would be to make an accurate count of canoes bobbing on the water and circling the ship, no one surprised in an ambush is likely to pause to count opponents armed with spears and stones. Hence if the figure of 700 combatants has any validity at all, it must have been estimated later from other considerations.

Tubuai at that time was divided into three districts which bore the names of three of the Society Islands. These names had been given them four or five generations previously by a chief from Raiatea whose canoe had been blown to Tubuai, 'then but thinly inhabited by some people, who had been driven to it in the Same Manner' from Rurutu and Mangareva. The Raiatean was acknowledged as chief of the whole island, but in 1789 each district had its own chief and although two were related by marriage, wars between the districts were frequent. Infanticide was not then practised, although Morrison knew of two young men who were offered as sacrifices during the mutineers' stay. These and the casualties- 12 on arrival, one during their stay, and 66 before departure-were the only deaths Morrison mentioned: the only sickness reported was the 'Colds, Agues, \& Sore Eyes Running at the Nose \&c.' which followed the Tubuaians' initial encounter with the mutineers, and which caused them to be more hospitable when the Bounty returned (Morrison, 1935, pp. 71, 73, 65).

For several years Tubuai had no European visitors. The island was 
sighted by the Duff on its way to Tahiti in 1797, but none of the missionaries wished to land (Wilson, 1799, pp. 51-2). During 1813 and 1814 ships engaged in the sandalwood trade called there occasionally, and in 1817 William Ellis, bound for Tahiti, visited the island. Its population then 'appeared but small' (Ellis, 1831, 3, p. 382) and in 1819, Pomare visited both Tubuai and Raivavae to persuade the people to abandon their old religion and become Christians. Their request for teachers was met in June 1822 when the missionary Henry Nott accompanied two Tahitian teachers to Tubuai. On their arrival they found 'the whole of the small population of the island engaged in war'. The missionary interposed and 'the chieftains, with their adherents, probably not exceeding one hundred on either side' were reconciled (Ellis, 1831, 3 , pp. 385-6). Although Nott was detained on the island for several weeks and travelled round it preaching to the people, he seems not to have made any estimate of their number, but assuming that only adult males fought, Ellis's guess at the number of warriors would suggest a population of between 600 and 800 in the middle of 1822 .

In 1823 there were reports that the 'fatal disease' which had killed 48 Rurutuans was 'raging dreadfully' at Tubuai (Threlkeld and Williams, 1823), and when the 'deputation' from London landed on 3 January 1824 they were told it had

swept away one half of the population within the last four years. Several persons are still afficted with it. The symptoms are pains in the head and stomach, followed by shivering fits and fever. The sufferer then rapidly wastes away, till death finds him a mere skeleton (Montgomery, 1831, 2, p. 75).

The public service held on the following day was attended by all except the sick, the very young and the aged. As the congregation dispersed, the 'deputation'

counted them up to two hundred and sixty-nine; so that the whole population of this beautiful and fruitful isle cannot be computed at more than three hundred. Three years ago they were nearly thrice that number (Montgomery, 1831, 2, pp. 75-6).

Accepting the total of approximately 300 in 1824, the first excerpt implies a population of 600 in 1820 , and the second a total of 900 one year later.

Hugh Cuming crossed from Rurutu to Tubuai in May 1828 and he learned that the disease had been introduced about ten years previously when a canoe from Anaa, one of the Tuamotuan atolls north-west of Tubuai, made landfall at the island with all on board diseased and 
dying. In 1828 there were not more than 230 people left on Tubuai, and as two-thirds of these were males, there were 40 men 'without a single female among them'. There was also a group of 12 or 14 natives of Raivavae on the island who were anxious to go 'to their homes' (Cuming, 1828, pp. 114-16). Almost exactly two years later, Moerenhout (1837, 1, p. 145) was met at Tubuai by the whole population 'qui ne monte pas aujourd'hui à deux cents personnes', and one report of a census conducted by the missionary David Darling in June 1831 alleged a total population then of $182-85$ men, 45 women, 29 boys, and 23 girls (Davies, 1961, p. 279). Although this record duplicates both the distorted sex ratio and the lack of women noted by Cuming, later evidence (Darling, 1837) suggests that this count was incomplete.

Assuming that the mothers of some of the children surviving in 1831 had died of the disease during the preceding decade, the average of about one child per woman in this population is extraordinarily low unless all of the women who survived were young or children were more susceptible than adults to the disease. Tyerman and Bennet alleged that the plague [had] been most destructive among those who had been previously tainted with an abominable disease, introduced here by the crew of a vessel, in their profligate intercourse with the natives' (Montgomery, 1831, 2, p. 75). The 'vessel' alluded to was, of course, the Bounty whose surgeon listed treatments for venereal disease for 9 of the 25 mutineers after their stay in Tahiti and for 2 others before then (Smith, 1936, pp. 216-17 quoted in Maude, 1958, p. 107). As the mutiny occurred only twenty-four days after leaving Tahiti, it is unlikely that all were cured before they retumed there to collect stock for their settlement on Tubuai, and this visit doubtless provided opportunities for further infection. However much this may have spread through the population during the next thirty years, the epidemic from Anaa may well have started in a population numerically smaller than the mutineers had left in 1789.

During 1836 Darling (1837) visited 'the outstations etc.' again and 'wishing to get the number of Inhabitants on the island', he wrote down the names of all the people belonging to' each of the two chiefs. 'The state of the Inhabitants at Tupuai at present are as follows:-Men 113 Women 58 Boys 51 Girls 38 Total 260.' Their numbers had 'greatly decreased' since his previous visit-in 1831, when according to Davies he had recorded only 182-because 'many of the people ... [had] been lost at sea'. Four years later the population was reported to be between 200 and $300^{\prime}$ (Heath, 1840), but on that occasion the missionary had not gone ashore.

Tubuai became a protectorate of France in 1842, and its first official 
census was held in 1844 when 268 persons were enumerated. Teissier (1953, p. 21) also quoted populations of 216 in 1847 and 253 in 1863 without citing his source. A missionary visiting the island in 1847 attributed Tubuai with a population of ' 200 , which is an increase of six during the last 3 years' and presumably excluded the three foreigners then living there (Howe, 1847a). In $1858 \mathrm{C}$. Barff made 'the most gratifying visit . . . for many years' to Tubuai, and reported there were 'from 300 to 310 inhabitants', though four years later there were allegedly only 256 on the island (Morris, 1862b). In the 1865 gales ' 66 houses and the Chapel' were 'wáshed away. . . . The trees were snapped off. Plantations were destroyed. Their food and clothing and all their Bibles and other Books were washed away. The consequent distress is fearful to contemplate' (Morris, 1865a). By the end of 1869 there were 'only 150 people' living in the three settlements on the island and it was admitted that for a decade 'mormonism' had been 'the popular religion' on Tubuai (Vivian, 1869). Despite an epidemic of influenza in 1871 (Saville, 1871b), the population was still ' 150 ' in 1873 (Pearse, 1873b).

France took possession of the island in 1880, and Aitken (1930, p. 4) listed the results of official censuses made in 1887, 1892 and 1897, in which the populations recorded increased from 397 to 429 to 472 respectively. Though the initial increase is dramatic, it and the subsequent increases may reflect some gains from migration as well as any natural increase that occurred, because Aitken (1930, p. 25) asserted that 'for a long time Tubuai has received some immigrants from other Polynesian islands, not only from nearby Raivavae and Rurutu, but also from the more distant islands, including even Hawaii. ... On the other hand, there is a remarkable lack of emigration'.

Nearby Raivavae was discovered by Boenechea's successor, Thomas Gayangos, on the homeward journey of the Aguila in 1775. A boat was sent in to land, but the natives were so importunate that the party returned to the ship without going ashore 'where about 400 or 500 Indians of all sexes and ages were grouped, shouting and hullaballooing' (Gayangos from Corney, 1914, p. 176). The island was sighted by the Chatham in December 1791 (Vancouver, 1801, 1, p. 245) and rediscovered about twenty years later when sandalwood was found growing there. A few of the natives were taken to Tahiti and back on trading boats, and Pomare visited there on one such in 1819. The principal chiefs of the island were then at war with one another, but Pomare persuaded them to stop fighting and soon afterwards some Raivavaeans beaame Christians. There are two versions of the number who attended a service there in either January or February 1821, although the same informant -the seafaring son of the missionary William Henry-is cited for each. 
Ellis (1831, 3, p. 376) and the 'deputation' (Montgomery, 1831, 1, p. 89) favour a congregation of 848 in January, whereas Davies (1961, p. 274) claimed that 'an assembly of between 700 and 800 came together for worship' in February 1821.

Captain Henry considered that Raivavae's population at this time was 'little more than sixteen hundred souls' (Montgomery, 1831, 1, p. 82). Three mission teachers were taken there in June 1822 and when they were visited by the 'deputation' in December 1823 every valley 'consisting of from two to three hundred acres each', was planted with taro,

every bed being in good order, and kept quite clean-a circumstance indicating a large population for so small a spot. This, we learn, is not less than two thousand, there being eight hundred men, and, as the custom of destroying children never obtained here, the proportions of the sexes are nearly equalized, both among old and young (Montgomery, 1831, 2, p. 71).

If the key to this estimate is the number of men (presumably known to the mission teachers), the allowance of $1 \frac{1 / 2}{2}$ women and children per man seems rather low for a community not practising infanticide and in which the sexes were evenly balanced.

Certainly Moerenhout (1837, 1, pp. 142-3) accepted a more conservative estimate-'d'après tous les rapports'-of 'au moins de douze cents' inhabitants in 1822, but the 'deputation' contended that 'scarcely fewer than sixteen hundred persons . . . twelve hundred within and four hundred on the outside of the building' attended the opening of a new chapel on Raivavae on 1 January 1824 (Montgomery, 1831, 2, p. 73). Both the date and the number present on this occasion were changed in Ellis's (1831, 3, p. 377) account of it-the date to 1825 and the number to 1,300 , but none stated the dimensions of the building. Many years later Platt (1848b) asserted that ' 3400 and upwards were counted' on this occasion.

Towards the middle of 1828, Raivavae was still described as 'very populous' (Cuming, 1828, p. 122), but when the missionaries Pritchard and Simpson visited there in April 1829 the population did not exceed 800 , 'death [having] lately carried away a great part of the inhabitants' (Davies, 1961, p. 276). These deaths were ascribed to

a kind of malignant fever, ... originally brought from Tubuai, and, for a considerable time after it appeared, from ten to fifteen deaths occurred daily. If a healthy person came in contact with the body or clothes of one diseased, the malady was generally communicated. During the first stages of the progress of the disease, whole families, 
from attending the sick, were simultaneously attacked with the dreadful complaint, and often buried in one common grave (Ellis, 1831, 3, p. 378).

According to Moerenhout (1837, 1, p. 143) this disease had already decimated the population when he first touched at the island in 1830 , and the survivors numbered no more than 'cent vingt environ'. However, a mission census conducted by David Darling in June 1831 gave a more optimistic picture, and even though the numbers reported by Davies (1961, p. 276) contain arithmetic errors, the discrepancies are too small to eliminate the difference between 120 and more than 700 . Accepting the numbers quoted by Davies for the three kinds of adults distinguished - church members, adults who were baptized but not communicants, and adults not baptized-the population consisted of 234 men, 138 women, and 353 'children not grown up'. These sum to 50 fewer than Davies's (or perhaps Darling's) total of 775, but as 210 of the children were males, the disparity in the sex ratio was uniform for both adults and children and of the same order as Cuming had noted earlier on Tubuai. Assuming that there had been no imbalance in Raivavae's population in 1823-4, it would seem that females were perhaps more susceptible than males to this curious disease which allegedly took such toll of these island populations.

If Moerenhout is to be believed, the population of Raivavae in March 1834 amounted to only 90 to 100 persons, but this is probably unreliable or perhaps related to only part of the island. Revisiting Raivavae in 1836, Darling was astonished at the decrease in population during the preceding five years. Lists of the inhabitants of the four settlements produced a total of 409 of whom 241 were males and 168 females. There was an average of 1.7 children per woman, with a marked deficit of young girls. A disease 'something like the Cholera' had 'raged for some time and carried off 4, 5, 6, and 7 persons every day' (Darling, 1837). Some four years later, when the island was again visited and the missionary was on shore for half a day, the population was reported as 360 (Heath, 1840); and a census taken by an Englishman who was living on the island in about 1846 gave a total of 380 people (C. and J. Barff, 1846).

More than a decade later Raivavae's population was reported as 'from 400 to $450^{\prime}$ (C. Barff, 1858), and in 1862 the island had lately [been] brought under the French Protectorate ... against the wish of the inhabitants who number[ed] about 400' (Morris, 1862a). In 1869 this total was reduced to 'about 300 ' (Vivian, 1869b), and perhaps because of the 'many manifestations of drunkenness and dissipation among young people' (Saville, 1871b) it was no larger in 1871. By 1873 there 
was an increase in either precision or population to 'about 340 ' (Pearse, 1873b).

According to Teissier (1953, p. 21), Raivavae was not censussed officially until 1892, but he nevertheless included a figure of 300 for its population in 1863 and the Annuaire de Tahiti for 1885 reported a total of 679 inhabitants-345 males, 334 females-for Tubuai and Raivavae which seemingly derived from a census of 1882 . Whatever may have happened to the individual populations over the preceding fifty years, the sexes were evenly matched in their joint population in 1882 , though Gros (1896, p. 181) claimed that males predominated in Raivavae's population of 307 in 1891. In the census of 1892 only 273 people were enumerated on Raivavae.

Situated about $5^{\circ}$ south of the Tropic of Capricorn, Rapa is the most southerly island of French Polynesia and 'on ne peut trouver un sol plus tourmenté que celui de cette île' (Caillot, 1932, p. 11). Vancouver circumnavigated it in December 1791 and was struck by its cluster of high craggy mountains ' rising almost perpendicularly from the sea, with 'vacancies' between them which 'would more probably be termed chasms than vallies'. 'About thirty' canoes quickly gathered around the ship and these contained 'on a moderate computation, three hundred' men, 'all adults and apparently none exceeding a middle-age; so that the total number of inhabitants on the island can hardly be estimated at less than fifteen hundred' (Vancouver, 1801, pp. 214-17).

The only habitations' Vancouver saw on the island were block houses' on the summits of some of the hills, with 'rows of pallisadoes' down the slopes on which it seemed there were people on guard. Some later writers (e.g. Moerenhout, 1837, 1, p. 137) have doubted Vancouver's observations, but Caillot (1932, pp. 67-8, 39, 36) avers that during the eighteenth century the population of the island was so large that the people built their houses on high ground so that all of the land in the valleys could be used for growing taro. Guards were mounted all day over the valleys to prevent thefts of food by the people of neighbouring valleys, and wars between the districts-usually consisting of only two or three villages at the head of a valley and its outlet to the sea-were both frequent and ruthless. Cannibalism was practised 'dans toute son horreur' and only the first three children born in a family were allowed to live.

The nails and other pieces of iron either filched or given them from the Discovery in 1791 precipitated further inter-tribal wars, and eventually a pact between the two most powerful chiefs instituted the monarchy which later European visitors encountered on Rapa (Caillot, 1932, pp. 71-2). A trading vessel was becalmed there in 1814 and in 
January 1817 the ship that was taking William Ellis to Tahiti was greeted at Rapa by 'not less than thirty' canoes, manned only by adult men (Ellis, 1831, 3, p. 365). About eight years later a passing cutter took two men from Rapa to Tahiti, where they were warmly welcomed by the missionaries and stayed for eight or nine weeks. When they were returned to their island, two Tahitian mission teachers accompanied them 'to ascertain the number and disposition of the inhabitants whether peacable and friendly or otherwise' (Davies, 1961, p. 280). The teachers returned to Tahiti favourably impressed and so anxious to go back to Rapa that in January 1826 John Davies set out in the mission schooner Active with a party of six teachers for that island.

In the few months since their previous visit, there had been 'much sickness and death in the island' (Davies, 1826), but Davies nevertheless 'supposed the population to amount to about 2000' (Ellis, 1831, 3, p. 364). In April 1829 the missionaries Pritchard and Simpson identified the sickness on Rapa with the disease then prevalent on Raivavae and Tubuai, and reckoned the survivors on Rapa numbered only 500. However, in June 1831 David Darling wrote down the names of all the present inhabitants of Rapa and found the adults to be 357 and children 243 viz. 600 in all' (Davies, 1961, p. 281). Moerenhout (1837, 1 , p. 139) visited the island in February 1834 when there were allegedly fewer than 300 inhabitants and their number was decreasing each day.

For a few years during the 1830s a French trader, Armand Mauruc, employed the people of Rapa to dive for pearls and pearl-shell around the island, and when the local beds were exhausted, some were engaged as divers in the Tuamotus, while others joined the crews of vessels trading around the south Pacific (Caillot, 1932, p. 75). When Darling visited Rapa in 1836 'from 50 to 60 men' were away diving for shell, and his lists of 'the whole of the inhabitants on the island' at that time contained the names of 254 adults-92 men and 162 women-and 199 children-117 boys and 82 girls (Darling, 1837). In 1840, 'an hour or two' ashore convinced one missionary (Heath, 1840) that the people of Rapa were 'dying off rapidly-scarcely 200 left', and in 1845 another reported that 'the people [were] reduced to a very few' (Platt, 1845). Charles Barff and his son John translated this into numbers a year later when, without indicating how the figures had been obtained, they claimed that 'the population amounts to about 150 or 160, having been reduced to that number by disease, chiefly consumption, dysentery, worms and spasms of stomach and bowels, occasioned by their diet and damp climate. ... The proportion of children was small and that number unhealthy' (C. and J. Barff, 1846).

Nowhere do the missionaries support Caillot's (1932, p. 76) contention 
that when the men who had been diving in the Tuamotus returned home through lack of employment, they started a trade in taro between Rapa and the Tuamotuan atolls, and small schooners plied back and forth between the islands for about twenty years. However, when Charles Barff revisited the island in 1858 he reckoned there were from 300 to 350 inhabitants' (C. Barff, 1858), so that in the intervening twelve years the population had apparently doubled, and a continuing increase is indicated by the total of 360 reported for 1862 (Morris, 1862b). In February 1863 a Peruvian trading boat came to the island, but instead of capturing slaves for the copper mines in Peru, the boat with its captain and crew was seized by the people of Rapa and delivered up to the French Government at Tahiti (Green, 1864; Caillot, 1932, p. 77).

Shortly afterwards a boat chartered by the Peruvian Government to return some of the kidnapped to their home islands sighted Rapa, and as 344 of the 360 Polynesians who had embarked had already died of smallpox and dysentery, 'after almost brutal treatment and inhuman neglect', the captain refused to take the sixteen survivors any further. Nine of them-'natives ... from Tokerau Níua of the Tongan group the Penrhyn group Manihiki, Atiu and various other islands'-and 'over one third' of the people of Rapa died before April 1864 (Green, 1864) and by June 1865 the island was 'almost depopulated'. Though it was reported then that there were 'only about 20 male adults left on the Island' (Green, 1865a), the island was not visited between 1864 and 1871 when 'the whole of the population 200 or 250 were present' at the church services. 'Nine of the poor people cast ashore from the slaver . . . survived the calamity', and were then 'comfortably married to Rapans and have children some of whom' Saville (1871b) baptized.

Whether seven or nine of the castaways survived, the mission version of this epidemic differs from Caillot's (1932, p. 77) in which the captured vessel was the source of the infection, and 128 people survived the epidemic. However, Caillot himself was not particularly consistent in dates and numbers because in his table of populations-'aussi exact que possible-at different dates, he listed a total of 300 for 1863 and the two figures, 153 and 110, for 1864 (Caillot, 1932, p. 25). Teissier (1953, p. 21) had another version of the initial incident in which 300 of Rapa's inhabitants were forcibly removed by the Peruvian slaver, but some nevertheless remained on the island and the epidemic was not mentioned.

In 1867 a French artillery officer Lieutenant Méry was sent to Rapa to investigate its deposits of coal. These were found to be of poor quality, but on behalf of the French Government, Méry established a protectorate over Rapa, whose population was then reported to be 120 . In 1881 the island was annexed to France, and the Messager de Tahiti 
(3 March 1881) reported this event, declaring that there were no more than 150 people on the island (Caillot, 1932, pp. 78-80). On the other hand, Teissier (1953, p. 21) attributed a total of 176 people to a semiofficial census of Rapa in 1881, and although he claimed that the first official census was made in 1892 when 182 people were enumerated, Caillot (1932, p. 25) labelled totals of 192, 200, and 191 for 1887, 1889, and 1891 respectively as 'd'après recensement officiel'.

Gros (1896, pp. 182-3) also claimed a total population of 191 for Rapa on 1 January 1891 and as he included some details of sex and marital status for a population alleged to be Rapa's in 1889, there must have been some record, official or otherwise, for that year. Gros's figures do not add to Caillot's 200, or even to his own proclaimed total of 183; but accepting the numbers given, there were 85 children aged less than 14 years in a population of 185 , despite an outbreak of dengue fever in 1887 in which a number of children had died. Several women had aborted spontaneously at the same time, but apparently none of the adults had died of dengue and in 1889 there were 30 married couples, 9 widowers and 6 widows, and 14 males and 11 females who had attained puberty but not yet married. With only 36 boys aged less than 14 years, there was a small excess of females at younger ages; but an average of almost 3 surviving children per married couple and 46 per cent of the population aged less than 14 years suggest that, in the absence of emigration and further epidemics, Rapa's population was not likely to decrease. Even with the outbreak of dengue fever and its effect on women then pregnant, Gros (1896, p. 183) reported 23 deaths and 29 live births registered in the four years 1887-90, and 14 of the deaths had occurred in 1887.

Teissier's (1953, p. 21) total for the inhabitants of all five Austral Islands in 1892 was 1,814 , and whether this was correct or not, their distribution over the individual islands was very different from the supposed pattern of settlement a century earlier. Though contacts between the various islands may not have been frequent, and not always deliberate, there clearly were some movements from island to island before Europeans much frequented the area in the early nineteenth century. The aggregate of guesses at the numbers living on each island then suggests a total of about 9,000 for all five islands, but one must allow an even more generous margin for error in this than in Ellis's (1831, 1, p. 102) estimate of a population of about 5,000 in the mid1820s, when 4,000 were thought to inhabit the two islands of Rapa and Raivavae where the curiously contagious disease then prevalent on Tubuai had not yet appeared. By 1831 four of the five island populations had been devastated by outbreaks of disease, and although mission 
censuses in the three western islands indicated a total for them of about 1,500 , at least one population was probably reported incorrectly. Guessing that there may have been about 500 people on Rimatara and Rurutu in this year, the population on the five islands in 1831 may have amounted to more than 2,000 .

The numbers reported both before and after this date are frequently so inconsistent that it is hard to have much confidence in them, either for individual islands or the total, and therefore impossible to assess the effects and extent of the mortality from the disease which allegedly wrought such havoc on all islands except Rimatara. It seems fairly clear that Tubuai was the source of infection for the outbreak on Rapa in 1826, and almost certain that the epidemic on Raivavae followed the return of natives from Tubuai towards the end of 1828. It is less clear whether the disease was introduced to Tubuai by the crew of the canoe from the Tuamotus, or whether it came from the Rurutuans who had crossed to Tubuai to escape the sickness that was causing so many deaths on their own island in 1820-1. Or was theirs a different disease?

By 1857 it was thought there were 'about 1700' (Chisholm, 1857) people in all five islands, and though the numbers reported for 1862 indicate about 500 more than this, the population may then have been about 2,000. Rapa's is the only population known definitely to have experienced the dysentery epidemic in 1864, but if this infection had 'been going through different Islands' in the Leeward group (Platt, 1864) -though apparently not Tahiti-it is unlikely that all of the other Austral Islands escaped, and by 1870 the population of all five islands may have been as low as 1,500 . Within a decade this had seemingly increased again to about 2,000 , and probably changed little from this total by the end of the century.

\section{Tuamotu and Gambier Islands}

Although some of the Tuamotuan atolls were amongst the first islands of French Polynesia to be discovered, Teissier (1953, p. 22) claimed that the first estimate of the population of the archipelago coincided with the censuses taken in 1863 on Tahiti, Moorea, Tubuai and Raivavae. Certainly Moerenhout (1837, 1, p. 159) dismissed any enumeration of the population as either impossible or 'aussi fastidieuse qu'inutile'.

There are figures for some of the islands earlier than 1863 because some of the Tuamotuans living temporarily on Tahiti had been converted to Christianity, and after two of them had returned to their own islands as teachers in 1821 (Davies, 1961, p. 271), they and others who had followed their example were visited sporadically by the missionaries from the Society Islands when they toured the outstations. But as the 
Tuamotuans were 'much given to travel about from island to island' (Darling, 1837), the numbers reported for the very few islands visited usually included 'several' who 'belonged' to other islands (Davies, 1961, p. 272). Anaa, for example, was visited in 1845 and the population was reported to have decreased 'amazing[ly] ... within [a] few years'. When questioned, the people themselves 'attribute[d] it to a kind of ague or consumption, though the children appeared very healthy' (Platt, 1845). The following year the island-'a slender oblong of land upon a reef which is 30 miles in circumference and enclosing a lake of nearly the same extent'-was described as 'populous, containing about 2000 people' (C. and J. Barff, 1846).

In 1865 two teachers were sent from the Leeward Islands to extend the 'mission, through native agency, to the yet uncivilized Islands of the Paumotuan group' (Green, 1865; Vivian, 1865b); and though the number of 'heathen uncivilized' was 'variously reported', one of the missionaries 'conclude[d]' that the forty-five inhabited islands contained 'about 20,000' inhabitants (Green, 1866). The mission venture was not successful, and the still unnumbered heathen were left to their own pursuits when the missionary enterprise there was regretfully abandoned in 1871 (Saville, 1871a).

From some unstated source Teissier (1953, pp. 22-3) listed thirty-four islands and the numbers thought to be living on all but one of them in 1863. By comparison with the eighty-one islands named by Cuzent (1884, p. 36), Teissier's list is complete only if some of his figures cover more than one island, and later censuses designate these same place names as 'communes ou districts' rather than 'illes'. There is neither date nor source given for Cuzent's population figures, but many are identical with Teissier's-and neither series adds to the total claimed. In a summary table Teissier (1953, p. 25) gave a total for the Tuamotus of 6,588 which is 240 more than the sum of the individual numbers, and Cuzent's figures lead to a total of 5,393 and not the 5,770 assertedperhaps because no numbers were given for three islands or any indication that they, like twenty others, might be presumed to have been uninhabited.

Teissier (1953, p. 25) also gave an approximate figure for the total population in 1881 , and as this $-5,500$-accords reasonably well with Cuzent's, it seems likely that the numbers quoted by both were largely from the one source and that they were estimates rather than counts, even though some tally reasonably well with the numbers cited by Teissier as purporting to come from a census in 1897. However, according to the Annuaire de Tahiti of 1885 there was a census of all the outer groups in 1884, which completed a partial count made in 1882, 
and in this the Tuamotus were accorded a population of 7,270 (Newbury, 1957, p. 252).

There may also have been a census of some kind in 1892 , but as Teissier (1953, p. 25) has quoted only the total number for this year, it is impossible to guess whether all island populations were counted or some still estimated. Superficially the 1897 census seems not to have been complete because Teissier (1953, pp. 22-3) gave no figures for ten of the thirty-four districts, and these districts were thought to contribute more than one-tenth of the estimated total population in 1863. However, once again the figures given for individual districts do not sum to the total cited for the archipelago, although here the sum of the district populations exceeds that for the archipelago by 360 . In later censuses six of the ten districts ostensibly missing for 1897 are grouped with the Gambier Islands, but this seems not to have been the case in 1897, and hence the population of the Tuamotus may have increased by more than is implied by total numbers of 4,743 in 1892 and 4,896 in 1897.

Mangareva, the principal island of the Gambier group, was discovered by the Duff in 1797 (Sharp, 1960, p. 178), but no landings were made and if the London Missionary Society's Tahitian mission ever contemplated extending to this group, it was frustrated by the arrival of the French Catholic missionaries Laval and Caret in 1834 (Leborgne/Hamy, 1872, p. 683). They established themselves on Mangareva, but several of the other islands-Taravai, Aikena, and Akamaru-and islets-Makaroa, Manui, and Kamaka-were inhabited, and as the group was known alternatively as the Gambier or Mangareva Islands, it is seldom clear which (if any) of the lesser islands might be included with Mangareva in the early population estimates and which not.

The missionaries' first 'dénombrement' in 1838 recorded 2,141 persons who shared in a distribution of clothes sent from France to cover their nakedness (Leborgne/Dareste, 1874, p. 103). But if Caillot (1932, pp. 74-5) is correct, the population had already experienced one epidemic 'qui fit de grands ravages' amongst them, and it is by no means clear whether the disease-'une maladie où la diahrée dominait' (Laval, P)was introduced by a group of about 40 people from Rapa, themselves newly converted to Christianity, who went to the Gambier Islands in four canoes in 1831 to convert the people there; or whether it came from a European vessel then fishing for pearl-shell in Mangareva's lagoon, and which eventually returned the unofficial missionaries to Tahiti. Laval (?) blamed the people of Rapa for this outbreak before his arrival, but he suggested no source for the smallpox epidemic which started shortly after he and Caret arrived, and persisted until 1837.

Nevertheless, he claimed a total of 1,900 people on Mangareva and 
Taravai in 1840; whereas a retrospective estimate compiled by Leborgne (/Hamy, 1872, p. 683) in 1871 from the mission records indicated only 1,630 inhabitants in the group in 1840, with 1,130 of them on Mangareva. The seeming contradiction between this and a mission estimate of 1,600 for Mangareva in 1842 (Liausu, ?) might be explained if the people living on the smaller islands had sought refuge on Mangareva after a severe hurricane in 1840 . On the other hand, a naval officer who escorted troops to the Marquesas in 1844 called at the Gambier Islands en route, and 'd'aprés les renseignements qui [se] sont fourni à la Mission' the population was then about 3,000 and growing 'd'une manière alarmante'. Because the young breadfruit trees planted to replace those destroyed by the hurricane four years before were not yet bearing, the food supply was adequate for only half the number of people (Caillet, 1918, pp. 174-5).

France had established a protectorate over the group in June 1842 (Dupetit-Thouars, 1842) and as the food shortage continued, cargoes of flour were sent in to alleviate the islanders' plight. Nevertheless, Laval (1846?) reported a marked increase in the death rate on Mangareva between 1841 and 1845, part of which was probably due to an outbreak of dysentery in 1844, and part perhaps to the increasing incidence of tuberculosis noted at about this time. By 1871 the mission had recorded a total of 1,581 births and 2,061 deaths on Mangareva during the preceding thirty years (Leborgne/Hamy, 1872, p. 683), though the only known epidemic was one of 'gale chinoise' which was introduced by a trading schooner in 1865 and allegedly 'decimated' the infant population on all islands. Food was again scarce because there had been a prolonged drought and the land was exhausted by years of over-intensive cultivation instigated and enforced by the mission (Newbury, 1955).

Throughout the 1850s and 1860s 'parties of despairing natives tried to escape in canoes' from Laval's hierocratic dictatorship' (Furnas, 1947, pp. 286-8), and by 1871 it was estimated that between 150 and 200 young people had emigrated from Mangareva (Leborgne/Hamy, 1872, p. 683). As the population dwindled, 'minée par les affections tuberculeuses' (Leborgne/Dareste, 1874, p. 103), Laval tried to replace the dead and deserters with people from the Tuamotus, but in 1871 Leborgne (/Dareste, 1874, p. 103) counted only 936 people in all the Gambier Islands. Ten years later Clavel (1884, p. 490) twice visited the group, reporting on the 'état sanitaire' there as well as in the Marquesas, and he reckoned the population then was only 480 -'et quels habitants!' On the average there was only one woman to 12 men, and in some years the ratio between the numbers of births and deaths was 1 in 20.

The islands were annexed to France in 1882, and the Annuaire de 
Tahiti for 1885 reported a census of 1884 which recorded 547 inhabitants then in the Gambier Islands (Newbury, 1957, p. 252). However, Caillot (1909, p. 71) claimed an official census in 1887 which revealed only 463 people, and if 100 or so Tuamotuans joined the population in 1888 (Newbury, 1955), Caillot's figure is not inconsistent with the totals of 508 and 580 which Teissier (1953, p. 25) cited for 1892 and 1897 respectively. The aggregate populations reported for the Tuamotu and Gambier Islands in these various years jump from about 6,000 in 1881 to nearly 8,000 in 1884 , and then fall back to about 5,500 or fewer for the decade 1887-97.

This is an unlikely sequence even for an aggregate of nearly one hundred small populations, but the data now available about them are so inadequate and often inconsistent that, as in the Marquesas, all that can be deduced from them now is that the populations of some islands were smaller at the end of the nineteenth century than they had been seventy years previously. This would not necessarily be the same for all islands, and neither the magnitude of the change, nor the relevance of events which might have contributed to the change, can be gauged for either the Tuamotu or the Gambier Islands. However, the beginning of the twentieth century does not mark the end of uncertainties for these or any other islands of French Polynesia.

\section{Census Enumerations in the Twentieth Century}

Except in secondary sources little has survived from the pre-war census enumerations. The most complete data are given by Valenziani (1940, pp. 173-5) who collated the results of successive censuses from 1902 to 1911 and from 1921 to 1936 . As they were usually taken at five-year intervals, he presumed that the census which should have been taken in 1916 or 1917 had been abandoned, and though he found some details pertaining to the 1921 census in the government archives at Papeete, they were not complete. Table 55 summarizes the populations Valenziani reported for the several islands or island groups at the various dates.

Nothing is known of the procedure used in these enumerations, and it is impossible to gauge from the published figures how efficiently or how accurately the population was enumerated. Sometimes it seems that certain islands or districts may have been omitted, but on the other hand, they may have been combined occasionally with other areas for administrative purposes. Valenziani $(1949$, p. 95) considered that they were relatively complete, and 'sur cette base, on peut admettre que, dans l'ensemble, les résultats sont plutôt erronés par défaut, ce qui concorderait d'ailleurs avec les appréciations de fonctionnaires et d'agents indigènes interrogés à ce sujet.' This opinion was not shared by the 


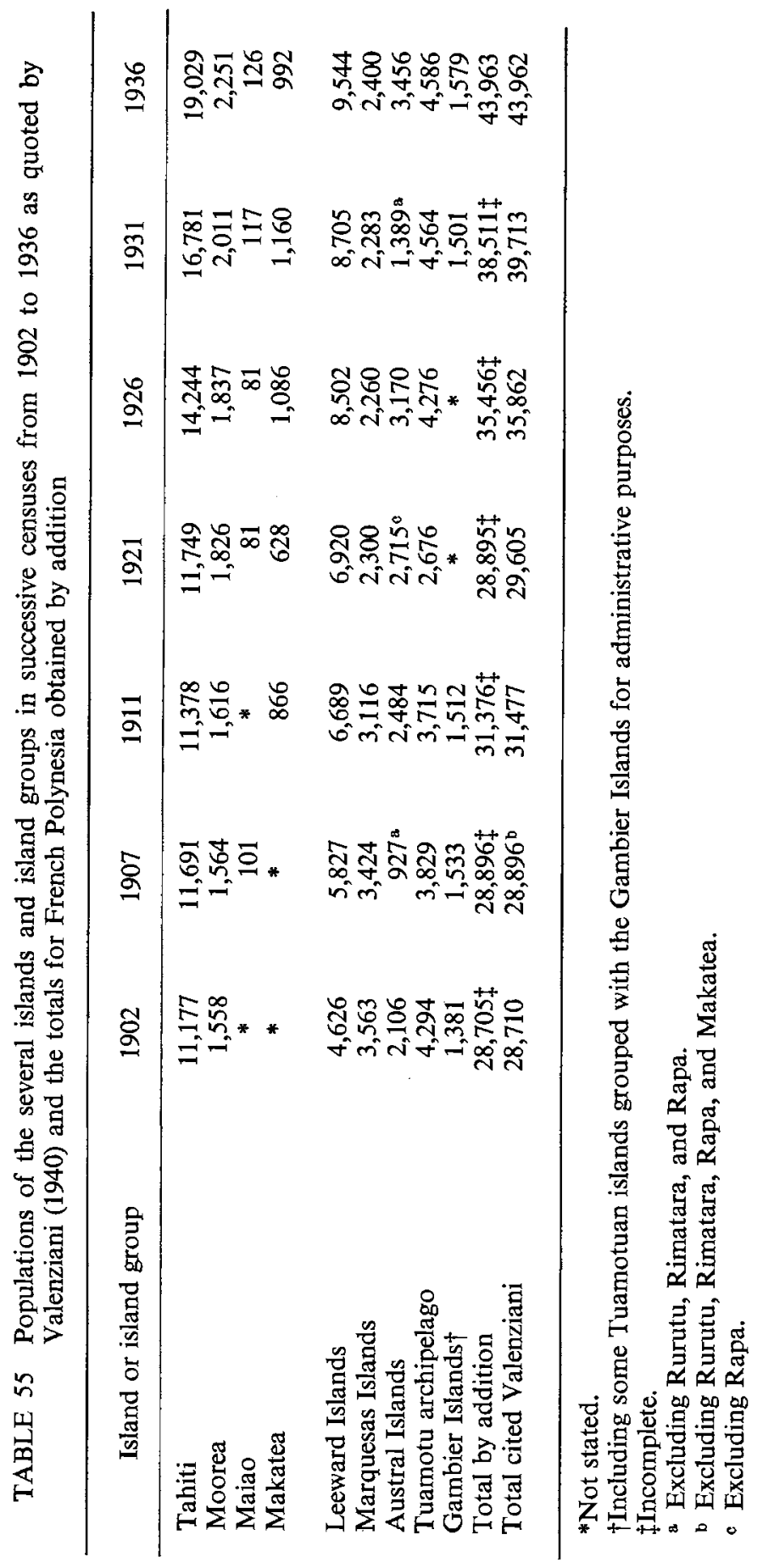


Institut National de la Statistique et des Etudes Economiques, which described the pre-war enumerations as

opérations dites 'recensements' . . . qui ont probablement été basés sur des évaluations, recoupées éventuellement par les renseignements tirés des registres de naissances et de décès. Les résultats publiés sont des plus sommaires ... et souvent partiels. ... Ces chiffres sont très approximatifs au moins pour les. dates les plus reculées et de plus difficilement comparables entre eux: recensements incomplets n'englobant pas la totalité des îles, méthode probablement différente selon les lieux et les époques (I.N.S.E.E., 1950, pp. 3-4).

In the postwar years the Metropolitan Government has shown more interest in colonial censuses, and the form of enumeration in French Polynesia has been dictated by that being used in other overseas French possessions. Though it is difficult to ascertain from the published reports precise details of the enumeration procedures, the tabulation of data is doubtless less haphazard than formerly, but as its publication was so long delayed, one might question its ultimate usefulness to the government of French Polynesia. In practice, less elaborate preliminary tabulations were prepared in Tahiti before the schedules from the 1946, 1951, and 1956 censuses were sent to Paris, and the results of these were published in the Journal Officiel-with no more details of local organization than the fuller reports from the I.N.S.E.E.

In both 1946 and 1951 the population was enumerated on 'bulletins individuels', and though the questionnaire used in June 1946 has not been sighted, the tables prepared from it suggest it was only slightly less extensive than the one used in 1951 which was reproduced in the report published by I.N.S.E.E. (1954, p. ii). This had obviously been designed for the non-indigenous populations of French territories, and several of the questions were inapplicable, if not inappropriate, to the majority of the people enumerated. All of the demographic data-sex, marital status, numbers of children born and surviving, date and place of birth, and nationality-were grouped together in one section; questions concerning sojourns in tropical countries in another, with details of occupation and educational attainment in a third. Ostensibly this also sought information on religion, but no direct question was asked, even though both the local and metropolitan tabulations contain a classification of the population by religion.

The 'avertissement' printed on the reverse of the schedule suggests that everybody completed their own questionnaire because 'de nos jours l'utilité des recensements de population n'est plus guère discutée et chacun accepte sans trop de récriminations de remplir le questionnaire 
qui lui est remis et dont certains questions peuvent paraître ne pas devoir présenter un gros intérêt, d'autres pouvant peut-être même paraître indiscrètes'. The only instructions given related to the third section of the questionnaire, with no indication that somebody would have to complete a form for such people as were either too young or too old to do their own.

This instruction may have been conveyed to the 'agents recenseurs', generally either school-teachers or local registrars of births and deaths, who distributed the schedules from two to four weeks before the census date-18 September 1951-and collected them on 19 September (Teissier, 1953, p. 7), but in 1953 nothing could be learned of the written instructions sent 'en temps et en nombre voulu' to the 'chefs de centre' who were responsible for the census in their district. In fact, two of them from the Tuamotus did not return the census forms, but merely sent in nominative lists of their people (I.N.S.E.E., 1954, p. iii; Teissier, 1953, p. 8), and it seems that the 'agents recenseurs' in other districts acted more as 'enumerators' than 'collectors' because of 'la méconnaissance de la langue francaise' amongst the people.

When the questionnaires were received in Paris for processing, 'très nombreuses lacunes dans la transcription des renseignements demandés' were discovered, and these attested to T'absence du contrôle le plus élémentaire des bulletins avant leur centralisation. Il semble que le renouvellement des opérations dans ce territoire doive tenir compte de la nécessité de prévoir un tel contrôle’ (I.N.S.E.E., 1954, p. iii). Hence it would seem that the arrangements for the collection of the basic data in these two postwar censuses were probably only a little less haphazard than in the pre-war enumerations.

In 1956 the census was taken for the night of 12-13 December, and in contrast with the previous de facto counts, this was both a de jure enumeration of households and a de facto count of all who spent the night in each dwelling. A household was defined as the group of people who ordinarily lived together in the same dwelling and 'dont les ressources sont communes'. Members of the household temporarily absent were listed but designated by ' $A$ ' on the schedule, and any visitors who slept in the dwelling on census night were also listed and designated by ' $V$ '. Spouses or unmarried children under 21 years who did not habitually live with the head of the household were listed separately on the reverse of the schedule.

There were eighteen questions, ranged horizontally, with quite precise instructions both as to the sort of replies to be given and the order in which the members of the household were to be listed. Although these were given in French, the column headings and general instructions 
concerning who was expected to answer the three blocks of questions were also translated into Tahitian. The first block, to be answered for everybody, were name, relation to head of household, sex, presence or absence, date and place of birth, year of first arrival, nationality, and ethnic origin. The questions in the second block required answers from all aged 14 years or over, and covered marital status, educational attainment, number of live-born children, and whether engaged in the public, semi-public, private, military, or other sectors. The last three questions related only to persons engaged in activities which were described as public, semi-public, or private, or military and contained explicit instructions as to what was required from each.

Once again the report, published in December 1960, gave only the briefest outline of the organization and procedure of enumeration. The mayors of Papeete and Uturoa (the township on Raiatea) were responsible for the census in these urban areas, and elsewhere the presidents of the District Councils were the 'chefs de centre' under the direction of the administrative officers who headed the government in each 'circonscription'. The 'agents recenseurs' were either school-teachers, 'infirmiers', or 'les personnes volontaires les plus qualifiées', and the Service des Affaires Politiques et Administratives was again responsible for the whole operation.

As instructions in both French and Tahitian were issued 'au public et au personnel' during November, it would seem that the responsibility for completing the questionnaire rested with the householder rather than with the 'agents recenseurs'. However, it seems likely that there was more and better supervision than in the previous censuses, although once again the questionnaire caused difficulties because of its 'complexité relative . . . pour la population originaire” (Service de Statistique, 1960, pp. 5-6). As this was, and will continue to be, the most numerous sector of the population, perhaps a little more thought might be given in future to designing a questionnaire comprehensible to them, or to changing the form of enumeration so that the schedules are completed by the presumably more sophisticated 'agents recenseurs' who might be trained specifically for this task.

\section{Growth of Population in the Twentieth Century}

The populations which Valenziani (1940, pp. 173-4) reported for the several island groups in each of the pre-war censuses after 1902 are shown in Table 55, and all except perhaps the 1936 enumeration appear incomplete. There are, moreover, discrepancies between the totals claimed and the sum of the individual figures which suggest attempts sometimes to allow for deficiencies in coverage, as in the 1911 total when 
the number reported for Maiao in 1907 was included. There is another series of numbers given by Teissier (1953, p. 28) for quinquennial censuses from 1926 to 1951, which have been summarized in Table 56 together with the numbers derived from the metropolitan tabulations of the 1946, 1951, and 1956 censuses.

Given the various omissions apparent in the early censuses, it seems likely that the population increased slowly during the early years of this century, though not uniformly throughout all groups. No doubt wisely, the Service de Statistique (1960, p. 7) rounded the total populations from 1911 onwards to the nearest hundred, but unless the data accessible to them are better than those from secondary sources, it is difficult to see the reasoning underlying the changes in the numbers for 1911 and 1921 from those reported by Valenziani to 26,500 and 31,700 respectively. Their figure for 1911 represents approximately 5,000 fewer people than Valenziani reported, and though the total he gave for the 1921 census excluded Rapa, the Gambier Islands and probably some of the Tuamotus as well, the addition of only 2,000 for these is perhaps conservative.

The totals reported for the various groups in 1911 are fairly consistent with the numbers in earlier censuses, especially if one allows that the count for the Leeward Islands in 1902 may have been incomplete. If this was so, the total population in 1902 may have exceeded 29,000; and had all the Austral Islands been enumerated in 1907, probably between 30,000 and 30,500 people would have been recorded then. Four years later the population might well have been approximately 31,500; and given the omissions from the 1921 count, the population then was probably nearer to 32,500 at least than to 31,700 . Over the next five years it seems to have increased sharply to perhaps 37,000 if an estimate for the Gambier Islands is added to the total reported.

The slowing-down of the population growth over the decade 1911-21 and its subsequent acceleration affect particularly the populations of Tahiti and the Leeward Islands. The Marquesans decreased in numbers between 1911 and 1921, but they contributed only a very small share of the total and their numbers did not change much after 1921. Tahiti, however, contained more than one-third of the total population in 1911, and it was reported from Fiji that it is said that on the main island of the Tahitian group over 30 per cent of the aboriginal inhabitants perished' in the influenza epidemic of 1918-19 (Boyd and Stewart, 1922, p. xii).

No doubt this report exaggerated the extent of mortality-perhaps by as much as 50 per cent as in Samoa-but it is the only reference which has been found concerning the epidemic in French Polynesia, and it gives 


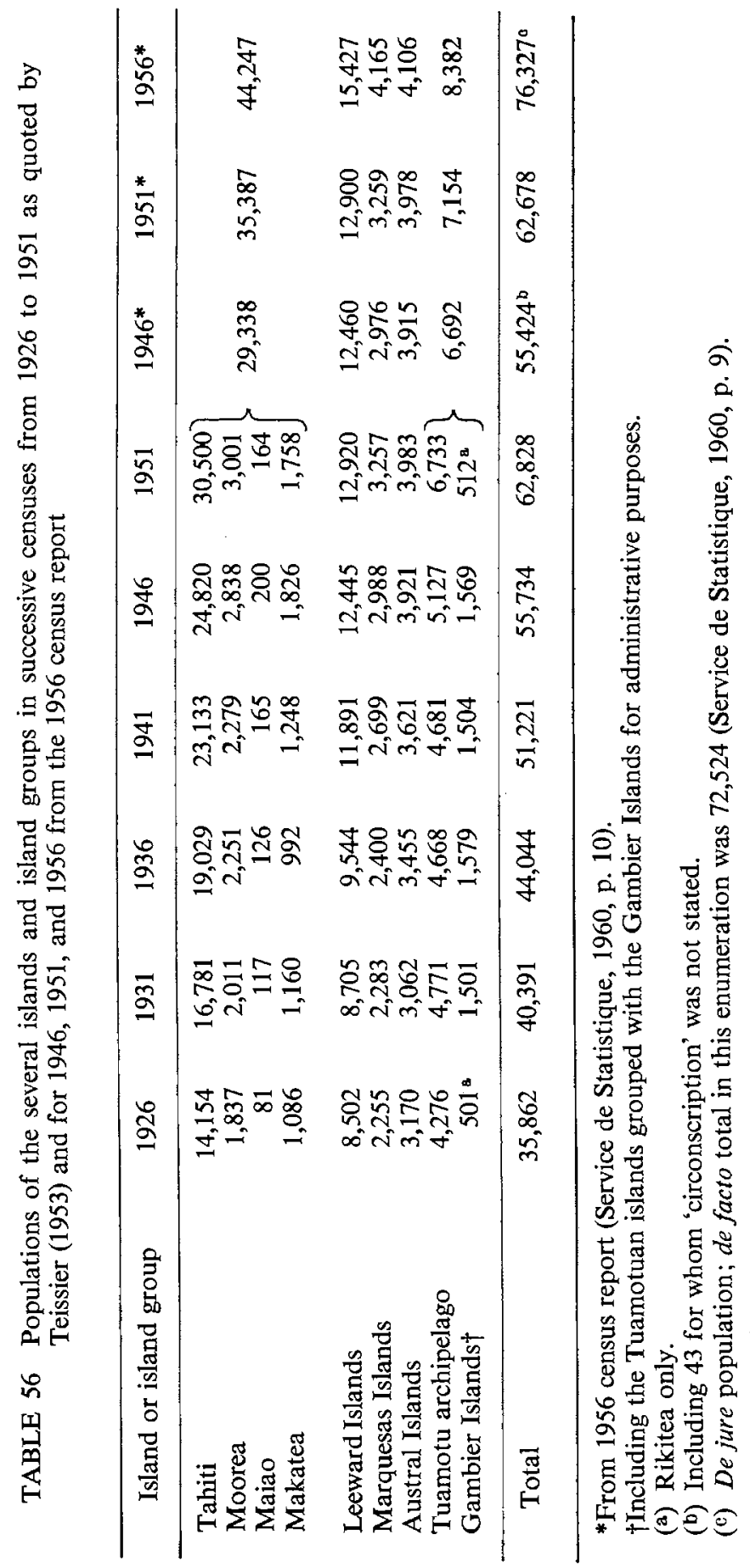


no indication whether the infection was spread to any of the other islands, either in the central group or the outer island groups. If it was, their varied experience in the nineteenth century outbreaks makes it unlikely that all suffered equally. Being nearest to Tahiti, the Leeward Islanders may have suffered to a similar extent; but there is no indication from Valenziani's (1940, pp. 182, 198) summary of the numbers of births and deaths registered in the Marquesas that they experienced the epidemic, and as the populations reported for the Austral Islands increased over the decade even though Rapa was omitted from the 1921 count, it is possible that the people in these islands also escaped infection. Some of the Tuamotuan populations may have suffered in the epidemic, but even given their peripatetic tendencies, it is unlikely that more than a third of their total would have died, especially when the increase alleged for the five years after 1921 amounted to more than 50 per cent of the 1921 total.

The numbers of births and deaths registered each year at this time are not readily accessible, but judging by the number of persons at relevant ages in the postwar censuses, the births during the period 1917-21 probably amounted to about 85 per cent of the number during the preceding five-year period. Under ordinary circumstances one could expect the numbers of births to increase each year, so that effectively the reduction in numbers due to the epidemic would be more than 15 per cent; and assuming that the deaths of some babies born shortly before the epidemic were matched by the increase in births by 1921 from the new marriages contracted after the epidemic, a moderate estimate of the reduction in births as a result of the epidemic would be about one-fifth.

This, in turn, implies a mortality rate of at least 10 per cent amongst adults of reproductive age, and if the epidemic was confined to Tahiti and the Leeward Islands, the mortality rates there must have been considerably higher than this. On the basis of the numbers reported for Tahit, Moorea, and the Leeward Islands in 1911, compared with the estimated total for French Polynesia, the mortality rate amongst adults would perhaps have been 16 per cent, perhaps higher on Tahiti and lower in the other islands.

In a population which had been growing at the rate of less than 1 per cent per year, mortality of this magnitude in one year would cancel out the gains from natural increase during the seven or eight years preceding the epidemic, and with its peculiar concentration amongst adults of reproductive age, it would effectively slow down the rate of growth for at least one or two years after the epidemic. The deaths of few old people would have been hastened by influenza, but the 
dissolution of marriages would have reduced the births likely to occur by almost twice the mortality rate. Over the next five years, however, the death rate was likely to decrease and the numbers of births to increase quite sharply as new marriages were contracted, both amongst those widowed in the epidemic, and the relatively large numbers attaining marriageable ages who had been less susceptible than their elders to the influenza virus.

For a decade after 1926 the population seems to have increased at an average annual rate of less than 2 per cent, and the accelerated growth between 1936 and 1941 fell again in the later war years. Theoretically one would have expected some slackening of growth in the indigenous population between 1936 and 1941 when the depleted cohorts born just before and just after the influenza epidemic attained reproductive age, but this may have been offset by immigration after the outbreak of war so that the effects of the small cohorts on the annual births and growth rates were not apparent until the quinquennium 1941-6.

Since 1946 the growth has accelerated again, and though part of this may be due to improved enumeration, there has also been a fall in the death rate. Whereas 6,100 deaths were registered between July 1946 and August 1951, there were only 4,700 registered between September 1951 and December 1956. The births recorded during these same periods were 12,400 and 16,000 so that natural increase contributed largely to the net inter-censal increase of 7,300 between 1946 and 1951, and between 1951 and 1956 it exceeded the de facto population increase of 9,840 . This last figure excludes the 1,200 spouses and unmarried children under 21 who were members of families of householders living in French Polynesia in 1956, but who themselves usually lived elsewhere. Although they were excluded from most of the tabulations for this census, they were for some reason included in both the de jure and de facto totals in the text of the report (Service de Statistique, 1960, pp. 7-9).

The decrease in the number of deaths reported for the later intercensal period probably exaggerates the extent of the fall in mortality in this population because the 1951 census was preceded by an epidemic of measles, which began on Tahiti and spread from there to the outer islands. The disease was introduced by some local seamen returning from Fiji at the end of 1950, and as there had been no measles in Tahiti for twenty-two years, practically everyone under this age and some older persons were attacked. There was an 'enormous number of cases' on Tahiti early in January 1951 and although the dates of its spread to other islands are not known, the outbreak was probably over before September. In March of the same year there was also an explosive 
epidemic of poliomyelitis in Tahiti and the nearer Tuamotu islands, but as only 8 of the 128 cases observed-109 of them on Tahiti-died, this would have added little to the number of deaths reported for $195 \mathrm{I}$ (Rosen and Thooris, 1953, pp. 240-4).

The deaths which were registered in each administrative district in each year from 1950 to 1952 are shown in Table 57, and though some of the registers for 1951 were still incomplete when these data were extracted in 1953, the probable effect of the measles epidemic is apparent. In Tahiti and its dependencies the increase in mortality in 1951 was confined to males and females under 25 years of age, but in all other districts there was an increase in the numbers of deaths of older people as well. If all of this increase in mortality was ascribable to the measles epidemic, it must have been more than twenty-two years since most of the islands had had outbreaks of measles, and although the deaths of some people may have been advanced by the epidemic, the crude death rate in 1951 was probably raised by about 50 per cent because of it.

The people most affected by this epidemic would have been the population of Polynesian origin, which cannot now be distinguished in most of the pre-war censuses. Since 1946 it has increased from 44,738 to 52,583 to 61,403 in 1956, which represents an average annual growth of 3 per cent or a little more, whereas the rate for the total population over the decade averaged less than 3 per cent per year. However, the definition of 'Polynesian origin' has varied from census to census so that the data are not strictly comparable. In 1946 the classification was based solely on the provenance of the personal names given on the bulletins individuels', in 1951 on the place of birth of the 'recenses's' and their parents, and only in 1951 on the direct response to the question on nationality asked on the household schedule (Service de Statistique, 1960 , p. 15). Their contribution to the total population rose from just over 80 per cent in 1946 to 84 per cent in 1951, and to between 82 and 85 per cent in 1956 depending on whether the de jure or de facto totals are used, but these differences may merely reflect the different methods of classification.

The largest 'foreign' population in each census since 1926, if not earlier, is the Chinese. Probably few of those brought in under indenture in the 1860s survived to the twentieth century, but according to Valenziani (1940, pp. 173-4) there were at least 412 Chinese in French Polynesia in 1902. Though the numbers may be incomplete, the later censuses show a population rising from fewer than 500 in 1907 to about 1,000 in 1911 , and to about 4,000 by 1926 . There were only small increases over the next decade, but between 1936 and 1946 their number 
TABLE 57 Numbers of deaths registered in each administrative district of French Polynesia in each of the years 1950 to 1952 , by sex and age of deceased

\begin{tabular}{|c|c|c|c|c|c|c|c|}
\hline \multirow{3}{*}{$\begin{array}{c}\text { Administrative } \\
\text { district }\end{array}$} & \multirow{3}{*}{$\begin{array}{c}\text { Age } \\
\text { in } \\
\text { years }\end{array}$} & \multicolumn{6}{|c|}{ Numbers of deaths registered in } \\
\hline & & \multicolumn{2}{|c|}{1950} & \multicolumn{2}{|c|}{1951} & \multicolumn{2}{|c|}{1952} \\
\hline & & M & $F$ & $\mathbf{M}$ & $\mathbf{F}$ & $\mathbf{M}$ & $\mathbf{F}$ \\
\hline \multirow[t]{2}{*}{ Tahiti and dependencies } & $\begin{array}{l}0-24 \\
25+\end{array}$ & $\begin{array}{l}114 \\
204\end{array}$ & $\begin{array}{l}117 \\
142\end{array}$ & $\begin{array}{l}231 \\
156\end{array}$ & $\begin{array}{l}163 \\
103\end{array}$ & $\begin{array}{l}140 \\
140\end{array}$ & $\begin{array}{l}110 \\
102\end{array}$ \\
\hline & Total & 318 & 259 & 387 & 266 & 280 & 212 \\
\hline \multirow[t]{2}{*}{ Leeward Islands } & $\begin{array}{l}0-24 \\
25+\end{array}$ & $\begin{array}{l}37 \\
35\end{array}$ & $\begin{array}{l}30 \\
29\end{array}$ & $\begin{array}{l}80 \\
61\end{array}$ & $\begin{array}{l}76 \\
46\end{array}$ & $\begin{array}{l}48 \\
31\end{array}$ & $\begin{array}{l}41 \\
20\end{array}$ \\
\hline & Total & 72 & 59 & 141 & 122 & 79 & 61 \\
\hline \multirow[t]{2}{*}{ Marquesas Islands } & $\begin{array}{l}0-24 \\
25+\end{array}$ & $\begin{array}{l}11 \\
11\end{array}$ & $\begin{array}{l}12 \\
13\end{array}$ & $\begin{array}{l}34^{*} \\
32^{*}\end{array}$ & $\begin{array}{l}50^{*} \\
26^{*}\end{array}$ & $\begin{array}{l}16 \\
13\end{array}$ & $\begin{array}{l}17 \\
10\end{array}$ \\
\hline & Total & 22 & 25 & $66^{*}$ & $76^{*}$ & 29 & 27 \\
\hline \multirow[t]{2}{*}{ Austral Islands } & $\begin{array}{l}0-24 \\
25+\end{array}$ & $\begin{array}{l}32 \\
28\end{array}$ & $\begin{array}{l}40 \\
21\end{array}$ & $\begin{array}{l}41 \\
41\end{array}$ & $\begin{array}{l}38 \\
28\end{array}$ & $\begin{array}{r}22 \\
7\end{array}$ & $\begin{array}{l}24 \\
12\end{array}$ \\
\hline & Total & 60 & 61 & 82 & 66 & 29 & 36 \\
\hline \multirow[t]{2}{*}{ Tuamotu Islands } & $\begin{array}{l}0-24 \\
25+\end{array}$ & $\begin{array}{l}21 \\
42\end{array}$ & $\begin{array}{l}22 \\
38\end{array}$ & $\begin{array}{l}66^{*} \\
61^{*}\end{array}$ & $\begin{array}{l}48^{*} \\
58^{*}\end{array}$ & $\begin{array}{l}35 \\
28\end{array}$ & $\begin{array}{l}19 \\
21\end{array}$ \\
\hline & Total & 63 & 60 & $127^{*}$ & $106^{*}$ & 63 & 40 \\
\hline \multirow[t]{2}{*}{ Gambier Islands } & $\begin{array}{l}0-24 \\
25+\end{array}$ & $\begin{array}{l}10 \\
18\end{array}$ & $\begin{array}{r}5 \\
14\end{array}$ & $\begin{array}{l}17 \\
35\end{array}$ & $\begin{array}{l}12 \\
29\end{array}$ & $\begin{array}{r}8 \\
13\end{array}$ & $\begin{array}{r}2 \\
17\end{array}$ \\
\hline & Total & 28 & 19 & 52 & 41 & 21 & 19 \\
\hline \multirow[t]{2}{*}{ French Polynesia Total } & $\begin{array}{l}0-24 \\
25+\end{array}$ & $\begin{array}{l}225 \\
338\end{array}$ & $\begin{array}{l}226 \\
257\end{array}$ & $\begin{array}{l}469^{*} \\
386^{*}\end{array}$ & $\begin{array}{l}387^{*} \\
290^{*}\end{array}$ & $\begin{array}{l}269 \\
232\end{array}$ & $\begin{array}{l}213 \\
182\end{array}$ \\
\hline & Total & 563 & 483 & $855^{*}$ & $677^{*}$ & 501 & 395 \\
\hline
\end{tabular}

*Incomplete. 
rose from about 4,500 to either 6,390 (Annuaire statistique, 1948) or between 5,712 and 6,474 , the difference between these last two being the number of persons to whom no nationality could be assigned (I.N.S.E.E., 1954, p. xii; Service de Statistique, 1960, p. 15). In 1951 there were 6,833 Chinese reported and 6,948 in 1956, but this last did not include the 520 persons 'de souche asiatique' who had acquired French nationality, and many of these probably should be added to the 'foreign' Chinese if one wished to compare the rate of growth of the Chinese component with the population of Polynesian origin.

There may in fact be overlaps between the two, because it is never stated how any Chinese-Polynesian offspring may have been classified, though from the names of parents recorded in the birth registers these must be relatively common. But however the Chinese component may be defined, since 1926 it has contributed more than one-tenth of the total population, and as 1,501 people in 1956 reported China as their birthplace, its natural growth has been augmented by immigration.

French citizens of various kinds predominated in the remaining 5 per cent or less of the population. Perhaps because of changes in definition, the numbers 'd'origine métropolitaine' fell from 2,920 in 1946 to 2,153 in 1951 , but rose to 3,019 in 1956. There was also a sharp increase in 1956 in the numbers of French citizens who were neither metropolitan French nor of Polynesian origin, and more than two-thirds of these were described as 'de souche étrangère, S.A.I.', their anonymity preserved in a vast array of birthplaces (Service de Statistique, 1960, pp. 15, 29). Unfortunately it is not always possible to include or exclude this small sector of the population in the analyses which follow, because some tabulations permit the dissociation of ethnic groups or nationalities in some years, while others treat the population as a whole.

\section{Age and Sex Composition}

According to Valenziani (1940, p. 175) the only information on age sought in the pre-war censuses was the distinction between children under 14 years of age and unmarried persons more than 14 years old. Those married or divorced were automatically placed in the adult category, and presumably anyone who was exactly 14 was arbitrarily assigned to one or the other. More detailed information was sought in the postwar censuses, and although the form of the question in 1946 is not known, both the 1951 and 1956 schedules asked for date of birth -day, month, and year in 1951, month and year (or at worst the year) in 1956.

In 1946 the Oceanian-now called Polynesian but probably still limited to those Polynesians who have French nationality by birth- 
population of each administrative district was summarized by sex in five-year groups of ages, with the youngest age group divided into those aged less than 1 year and the group 1-4 years. If comparable data were published for the remainder of the population they are not available in Australia. The 1951 report contains similar tables for the ages of the Polynesian population and the remainder for each sex, but there is also a table listing the numbers of males and females in each of these two sectors who were born in each year from 1916 onwards, and a pyramid showing the numbers of each sex with each year of birth from 1875 onwards. The Chinese population can also be isolated by sex and grouped age, as can each of eleven other nationality groups. This table of nationalities by sex and grouped age was extended in 1956, but contrarily only the total population was summarized by sex and single years of birth, and no details were given of the ages of males and females in the various administrative districts.

This last is an omission which is hard to comprehend when Tahiti's population of Polynesian origin increased by nearly 40 per cent in five years, which is almost double the rate for the population of Polynesian origin as a whole. Tahiti's share of this total rose from less than 44 per cent in 1951 to nearly 52 per cent in 1956, and the growth seems evenly distributed between males and females. Tahiti is clearly attracting people from other islands, but who are they and whence have they come?

Although the comparison of the several age distributions in 1946 and 1951 provides a crude indication of the ages and origins of the migrants of Polynesian origin during that inter-censal period, there seem to have been deficiencies in the enumerations which might not affect all district populations equally. If the tabulated ages are converted into what would be the corresponding years of birth had all censuses been taken at the end of December, and the people who failed to state any date of birth distributed pro rata, the numbers of males and females of Polynesian origin in successive birth cohorts in each census year are as shown in Table 58. As the censuses were taken in June 1946, September 1951, and mid-December 1956, the designated birth cohorts will not necessarily define precisely the same people each time, but as the criteria for classifying people of Polynesian origin changed with each census, and in 1951 there were also 1,178 Polynesians whose sex was not specified, refinements of the data are scarcely justified.

The proportions of each birth cohort who survived from each census to the next are given in Table 59, and though the patterns of survival rates for males and females in each approximately five-year period run parallel, there is a striking difference between the chances of survival for all cohorts from 1946 to 1951 as compared with the later period. 


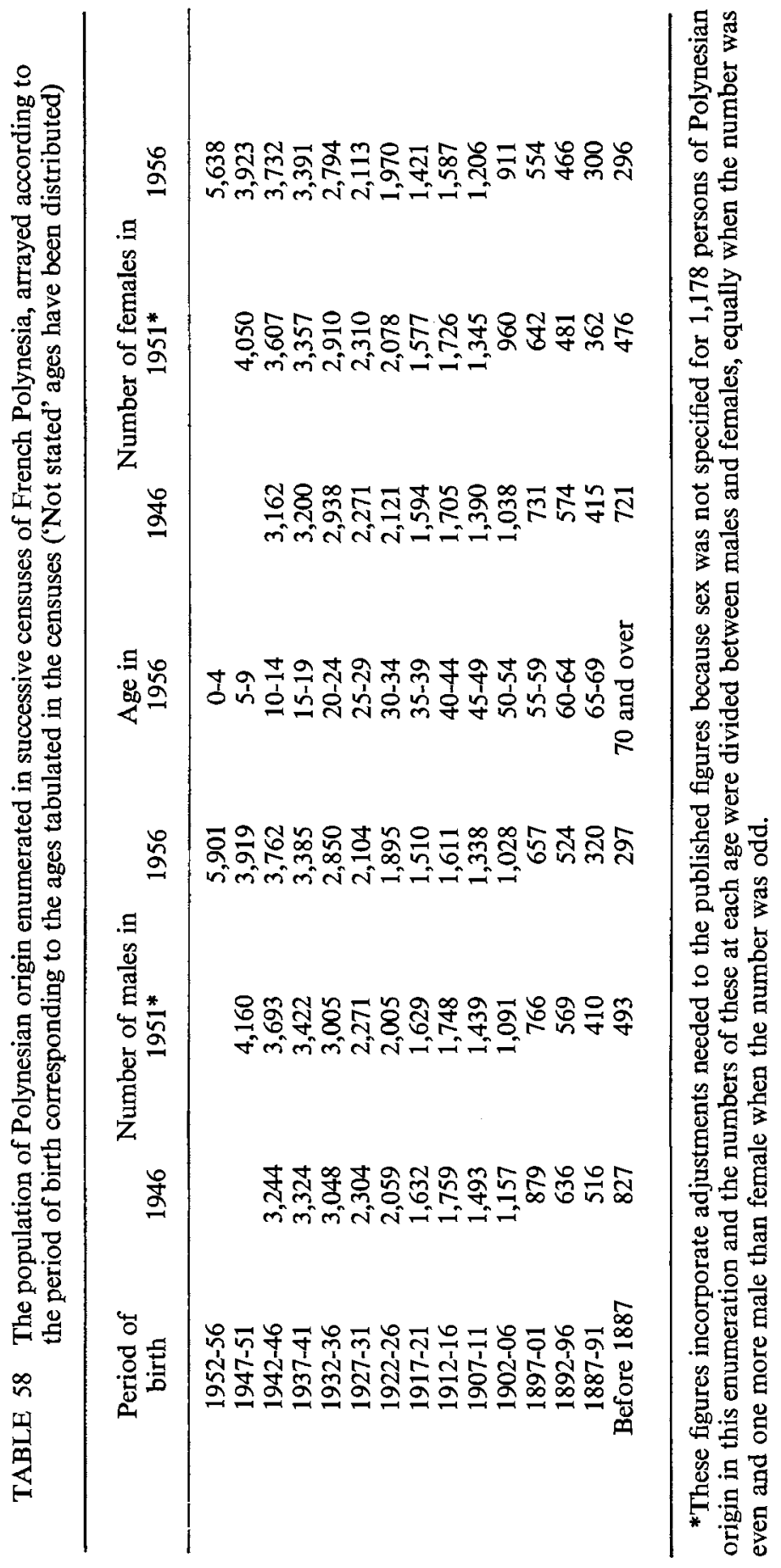


TABLE 59 Numbers of survivors in each birth cohort of Polynesian origin in 1956 and 1951 per 1,000 enumerated about five years previously

\begin{tabular}{ccccc}
\hline & \multicolumn{2}{c}{$\begin{array}{c}\text { Survivors in 1956 per 1,000 } \\
\text { enumerated in 1951 } \\
\text { Males }\end{array}$} & $\begin{array}{c}\text { Survivors in 1951 per 1,000 } \\
\text { enumerated in 1946 } \\
\text { Males }\end{array}$ & Females \\
\hline $1947-51$ & 942 & 942 & & \\
$1942-46$ & 1,019 & 1,035 & 1,138 & 1,141 \\
$1937-41$ & 989 & 1,010 & 1,030 & 1,049 \\
$1932-36$ & 948 & 960 & 986 & 990 \\
$1927-31$ & 926 & 915 & 986 & 1,017 \\
$1922-26$ & 945 & 948 & 974 & 980 \\
$1917-21$ & 927 & 901 & 998 & 989 \\
$1912-16$ & 922 & 919 & 994 & 1,012 \\
$1907-11$ & 930 & 897 & 964 & 968 \\
$1902-06$ & 942 & 949 & 943 & 925 \\
$1897-01$ & 858 & 863 & 871 & 878 \\
$1892-96$ & 921 & 969 & 895 & 838 \\
$1887-91$ & 780 & 829 & 795 & 872 \\
Before 1887 & 602 & 622 & 596 & 660 \\
& & & & \\
\hline
\end{tabular}

As there were fewer deaths reported between 1951 and 1956 than in the preceding five years (Service de Statistique, 1960, p. 8), the generally greater likelihood of surviving the first inter-censal period is unlikely.

An alternative explanation is that it was due to the different definitions of 'Polynesian' adopted in 1946 and 1951, and if this was so, one would expect all cohorts to be affected to more or less the same extent. (The qualification is needed, particularly for females, because Polynesian women married to Europeans would be less likely to have been classified as Polynesian in 1946 than if their husbands were also Polynesian.) As children aged 5-9 years in 1946 probably had greater chances of surviving for five years than any other cohort, their survival rates suggest that perhaps about 4 or 5 per cent of those who should have been classified as Polynesians in that census were not so classified. Inflation of the size of cohorts to allow for this produces survival rates which more nearly approximate those for the 1951-6 period for most cohorts, but it still leaves a very large increase in the size of the 1942-6 cohort before 1951, which suggests that perhaps 10 per cent or more of the infants and young children were omitted from the 1946 count.

The size of this cohort increased still further between 1951 and 1956, but as the younger cohort decreased quite remarkably and the older cohort of females at least increased, there may have been some 
confusion about the precise dates of birth for some of these children. As it is impossible to distinguish 'Polynesian' births in the birth registers, any estimate as to the completeness of enumeration of children under 5 years in the later censuses can only be very approximate, but as Polynesians constitute about 85 per cent of the total population, they could be expected to contribute about 80 to 85 per cent of all births. Depending on which of these is chosen, the 8,210 children aged between $0-4$ years in 1951 and the 11,539 in 1956 represent survival ratios of either 78 or 83 per cent from birth to ages $0-4$ in 1951, and from 85 to 90 per cent in 1956.

The infant mortality rate calculated from the births and infant deaths registered in the three years $1950-2$ was about 140 deaths per 1,000 live births, and had this average rate applied throughout the five years preceding the 1951 census, one would expect about 85 per cent of the children born to survive to be recorded at ages $0-4$ years. In the three years 1955-7, the average infant mortality rate was only 95 per 1,000 births, and one would therefore expect rather more than 90 per cent of all children born in the five years ended December 1956 to have survived until then. However, the infant mortality recorded in 1950-2 may have been above the average rate for 1946-51 because of the measles epidemic in the first half of 1951. Consequently, the numbers of Polynesians reported at ages $0-4$ years in both censuses could be reasonably complete only if Polynesians contributed less than 80 per cent of all births registered.

Amongst the older cohorts both series of survival ratios show a dip in the proportion of survivors as both males and females passed from ages 20-24 years in one census to 25-29 in the next, and relatively high survival rates for those passing from ages 25-29 to 30-34 years. Though more marked for females than for males, this pattern was repeated for most cohorts between 1951 and 1956, and inspection of the tabulation of the total population in 1956 by single years of birth indicates the probable avoidance of years of birth ending with the digits 1 and 9 , which was partly compensated by a preference for years ending in 0 . People aged 40 years or more also showed some preference for 'round' ages corresponding with years of birth having 6 as the terminal digit. The limited data published for 1951 confirm the probable avoidance then of years ending with 9 but not those with terminal digits of 1 . Hence it would seem that for some people at least an approximate age might be the starting point in the estimation of a year of birth, and the ages favoured tend to be those in the first half of a decade.

Despite this, each census population shows fewer people in the cohort born 1917-21 than in the cohorts on either side of it, even though 
they aged from 25-29 years in 1946 to 30-34 years in 1951 and to 35-39 years in 1956. This is the cohort born just before, during, and just after the influenza epidemic of 1918-19, and it probably had its greatest effect in depressing the numbers of births each year for a decade or so after 1937. From about 1946 on the numbers of females of reproductive age increased again, and as the relatively large cohorts born in the 1930s attained the ages associated with highest fertility, the numbers of births each year could be expected to increase sharply. The contrast between the sizes of the two youngest cohorts in 1951 and 1956 may have been less but for the measles epidemic in 1951.

Except for an increase in the proportion of population aged less than 15 years from 41 per cent in 1946 and 1951 to nearly 44 per cent in 1956, and a compensating decline in the proportion aged 15 to 44 years, there have been only minor changes in the age composition of this sector of the population at each census. The sex ratios deviate little from half at most ages up to about 45 years when there was a small excess of males, but these may well reflect age preferences rather than any real differences in the probability of survival. With the increased proportion of children in 1956, the median age fell from about 22.5 to 21.5 years, and there were 870 children aged 0-4 per 1,000 women aged 15 to 44 years as compared with 632 in 1946 and 691 in 1951.

In 1946 and 1951, however, there was some heterogeneity in the age structure of the populations in the various administrative districts. In the Leeward, Marquesas, and Austral Islands nearly one-half of the population was under 15 years of age, whereas in Tahiti and its dependencies, and the Gambier and Tuamotu archipelagos only 40 per cent were of these ages. These differences were of course reflected in the child-woman ratios for each population, shown here in Table 60, some

TABLE 60 Number of children aged $0-4$ years per 1,000 women aged 15 to 44 years in the population of Polynesian origin in each administrative district of French Polynesia at the censuses of 1946 and 1951

\begin{tabular}{lll}
\hline \multicolumn{1}{c}{ Administrative district } & 1946 & 1951 \\
\hline Tahiti and dependencies & 511 & 603 \\
Leeward Islands & 782 & 832 \\
Marquesas Islands & 894 & 971 \\
Austral Islands & 972 & 907 \\
Tuamotu and Gambier Islands & 542 & 627 \\
$\quad$ Total & 632 & 691 \\
\hline
\end{tabular}


of which may be artificially depressed because of the way Polynesians were classified in 1946 and by the suspected under-enumeration of children in that year, if not in 1951 as well. Nevertheless the pattern is consistent, with the lowest ratios each time for Tahiti and the Tuamotu and Gambier Islands, the highest for the Marquesas and Australs which are most remote from the centre, and the Leeward Islands also comparatively high.

Perhaps more interesting historically was the absence of any deficit in the 1917-21 cohort in the populations of the outer islands, whereas on Tahiti this cohort contained roughly 300 fewer people than the older cohort, and 700 fewer than the younger one. Although less dramatic in the Leeward Islands population, the deficit was in evidence in both censuses, and this tends to confirm that the 1918-19 influenza epidemic was most severe on Tahiti, less so in the Leeward Islands or perhaps some islands escaped the infection, as did many of the more remote islands such as the Marquesas and the Australs. Though they were probably less fortunate in the measles epidemic of 1951, the highest death rate reported for that year was about 50 per 1,000 population in the Tuamotu and Gambier Islands, and the rates for the Marquesas and Austral Islands were about 45 and 36 per 1,000 respectively. Some individual islands may have suffered more than others, but average rates of this magnitude would not make any grave impact on the age composition of the aggregate populations.

The Chinese who had been born in French Polynesia probably suffered as did the Polynesians in this epidemic, and in 1951 these were the majority, the numbers born in China amounting to only 30 per cent of the males and 15 per cent of the females. The numbers of Chinese reported in that year are shown in Table 61, arrayed in birth cohorts corresponding to the ages tabulated for them. There were more males than females in all cohorts, and this surplus was most marked at ages beyond 35 years. This and probably some of the excess at younger ages were no doubt the result of immigration which, until the communist victory in China in 1949, was relatively unimpeded, if somewhat capricious.

Since 1950 migration has been curtailed, and though some Chinese may have left French Polynesia between the censuses, the attrition of the younger cohorts between 1951 and 1956-shown here in Table 61is roughly halved if the naturalized French of Asiatic origin are added to the appropriate cohorts of the Chinese who were still classed as aliens in 1956. The majority of those who became naturalized were aged less than 30 years in 1956, but about one-third were older than this and at these ages more women than men changed their nationality. 
TABLE 61 The Chinese population of French Polynesia enumerated in 1951 and 1956 arrayed according to the period of birth corresponding to the ages tabulated in the censuses ("Not stated" ages have been distributed)

\begin{tabular}{cccccc}
\hline $\begin{array}{c}\text { Period of } \\
\text { birth }\end{array}$ & $\begin{array}{c}\text { Number of males in } \\
1951^{*}\end{array}$ & 1956 & $\begin{array}{c}\text { Age in } \\
1956\end{array}$ & $\begin{array}{c}\text { Number of females in } \\
1951^{*}\end{array}$ & 1956 \\
\hline $1952-56$ & & 511 & $0-4$ & & 512 \\
$1947-51$ & 594 & 541 & $5-9$ & 526 & 464 \\
$1942-46$ & 550 & 481 & $10-14$ & 501 & 453 \\
$1937-41$ & 449 & 396 & $15-19$ & 423 & 356 \\
$1932-36$ & 388 & 304 & $20-24$ & 342 & 272 \\
$1927-31$ & 337 & 310 & $25-29$ & 311 & 256 \\
$1922-26$ & 234 & 200 & $30-34$ & 205 & 181 \\
$1917-21$ & 152 & 140 & $35-39$ & 134 & 120 \\
$1912-16$ & 159 & 149 & $40-44$ & 110 & 90 \\
$1907-11$ & 114 & 101 & $45-49$ & 82 & 62 \\
$1902-06$ & 181 & 160 & $50-54$ & 84 & 84 \\
$1897-01$ & 212 & 175 & $55-59$ & 65 & 50 \\
$1892-96$ & 185 & 171 & $60-64$ & 59 & 55 \\
$1887-91$ & 169 & 133 & $65-69$ & 58 & 42 \\
Before 1887 & 163 & 135 & 70 and over & 46 & 44 \\
\hline
\end{tabular}

*Includes 8 persons for whom sex was not specified.

As children born after their parents' naturalization would be French citizens who cannot be distinguished from the others 'de souche étrangère S.A.I.', the combination of the alien and naturalized Chinese will not accurately depict the whole of the population of Chinese origin in French Polynesia.

That it was essentially a youthful population is evident from its age distribution in both censuses, and in 1951 the child-woman ratio matched those for the Polynesians in the outer islands. In 1956, the Chinese women who were still classed as aliens had fewer children aged less than 5 years than the generality of women of Polynesian origin, but as the cohorts in the early and most productive part of the reproductive period suffered relatively more attrition from naturalization than did the older cohorts, the lower child-woman ratio for 1956 is not necessarily indicative of a change in the fertility of this sector of the population.

As the Polynesian and Chinese components constitute about 95 per cent of the total population, they will dominate both the composition of and much of the change in the total. After the distribution of persons for whom either sex or age or both was not stated, the numbers of males and females in each birth cohort corresponding to the tabulated ages 
in 1951 and 1956 are as shown in Table 62. As before, the cohorts do not define precisely the same people each time even if there were no migration, but a more serious discrepancy between the two series is that the population recorded for 1951 was de facto, whereas the numbers for 1956 relate to a de jure population which contained 4,560 persons absent from their usual place of residence at the time of the enumeration, and although 3,556 of these were allegedly domiciled in French Polynesia, only 1,395 of the 1,957 visitors reported in households on census night habitually lived in the islands (Service de Statistique, 1960, p. 9).

TABLE 62 The population of French Polynesia enumerated in 1951 and 1956 arrayed according to the period of birth corresponding to the ages tabulated in the censuses ('Not stated' ages have been distributed and persons whose sex was not stated have been assigned equally to males and females when their number was even, favouring males when the number was odd)

\begin{tabular}{cccccc}
\hline $\begin{array}{c}\text { Period of } \\
\text { birth }\end{array}$ & \multicolumn{2}{c}{$\begin{array}{c}\text { Number of males in } \\
1951\end{array}$} & 1956 & \multicolumn{2}{c}{ Age in } \\
1956 & \multicolumn{2}{c}{ Number of females in } \\
1951 & 1956 \\
\hline $1952-56$ & & 6,931 & $0-4$ & & 6,649 \\
$1947-51$ & 4,901 & 4,860 & $5-9$ & 4,763 & 4,806 \\
$1942-46$ & 4,352 & 4,621 & $10-14$ & 4,215 & 4,506 \\
$1937-41$ & 3,954 & 4,090 & $15-19$ & 3,891 & 4,092 \\
$1932-36$ & 3,501 & 3,473 & $20-24$ & 3,317 & 3,310 \\
$1927-31$ & 2,998 & 2,707 & $25-29$ & 2,702 & 2,591 \\
$1922-26$ & 2,472 & 2,377 & $30-34$ & 2,394 & 2,408 \\
$1917-21$ & 1,942 & 1,871 & $35-39$ & 1,806 & 1,711 \\
$1912-16$ & 2,080 & 1,979 & $40-44$ & 1,916 & 1,809 \\
$1907-11$ & 1,720 & 1,624 & $45-49$ & 1,495 & 1,410 \\
$1902-06$ & 1,400 & 1,344 & $50-54$ & 1,102 & 1,091 \\
$1897-01$ & 1,095 & 951 & $55-59$ & 756 & 679 \\
$1892-96$ & 827 & 779 & $60-64$ & 563 & 580 \\
$1887-91$ & 651 & 526 & $65-69$ & 460 & 379 \\
Before 1887 & 798 & 555 & 70 and over & 607 & 418 \\
\hline
\end{tabular}

The recorded excess of absentees might account for the apparent net gain in the cohorts aged between 10 and 20 years in 1956, and especially in those aged 10-14 years. The gains are accentuated if survival rates, estimated from life tables derived from the average annual mortality experienced in the three years 1955-7, are applied to the adjusted 1951 cohorts to estimate the numbers of survivors expected in each in 1956. Whereas the agreement between the recorded and expeoted numbers is reasonably good for all but one of the cohorts born before 1936, the three youngest cohorts in 1951 exceeded their expected 
aggregate for 1956 by about 1,300 , and the largest increase was in the numbers of males and females reported at ages 10-14 years in 1956. The other aberrant cohort were the males born 1927-31 whose number decreased by rather more than might have been expected between the censuses.

If the mortality rates of 1955-7 exaggerate the probabilities of survival from 1951 to 1956 for all cohorts, the discrepancies between the numbers recorded and expected at ages 5 to 19 in 1956 would be larger than the 1,300 estimated, and the seeming loss of males in their twenties smaller. As the population is not closed, such changes in cohort size between censuses might be due to migration, though this is a less feasible explanation for the increases at young ages than for the loss of older males. On balance, under-enumeration of children in 1951 and/or duplication in 1956 are perhaps more likely than immigration; if the first, there may have been 5 per cent more children under 15 years than were reported in 1951; if the second, perhaps as many as 1,500 children and young adults were recorded twice in 1956. If there was both underenumeration in 1951 and duplication in 1956, the range of error in the total population count would be smaller than 1,500 , so this may be the upper limit of the error likely in both counts.

The omission of about 5 per cent of children in 1951 would increase the proportion of the population aged less than 15 years from less than 42 per cent to nearly 43 , and the proportions at all other ages would fall to compensate. If 1,500 people were duplicated in 1956, children under 15 would have contributed 0.5 per cent less to the total than the 43 per cent reported, and the proportions at other ages would have increased minimally. But slight though the effect of these uncertainties about numbers not counted or counted twice may be on the age composition of the population, they will prejudice the reliability of the estimates of mortality and the analysis of fertility which follow. Effectively they will exaggerate the differences between the relevant agespecific rates-those for 1951 probably being too high, and those for 1956 too low-but as the mortality for 1951 was probably untypical because of the measles epidemic, the uncertainties are less important than they might have been.

\section{Registration of Births and Deaths}

Civil registration of births and deaths throughout French Polynesia varied in time as the pattern of annexation and indigenous acceptance of French control varied. In Tahiti and Moorea the état civil was begun in 1852 , and the next to be established was probably in the Marquesas in 1882, although this may have been preceded by civil registration in 
the Gambier Islands where the Catholic missionaries had kept records of births and deaths since 1840. It was started in the Austral Islands in 1885 and in the Leeward Islands about a decade later, but it was probably later still that it was fully implemented in the Tuamotu Islands.

The regulations governing such registrations are identical with those for France, and the forms or 'actes', sometimes printed in Tahitian but more usually in French, were presumably adapted from their equivalents in France. Procedurally, the local chiefs or headmen act as registrars for their districts, and are responsible for the maintenance of a duplicate set of registers. At the end of each year these registers are sent to the administrative centre of each district for inspection, and one copy is retained there, the other forwarded to the Records Office in Papeete. Both births and deaths must be registered within three days of their occurrence, and the responsibility for registering a birth rests with the father of the child, the doctor or any person assisting at the birth, and for a death any relative of the deceased or any person present at the time of death.

The 'acte de naissance' records the date and place of birth, the name of the child and its sex, the father's name, date of birth, occupation and domicile, and the mother's name, date of birth, occupation and domicile. There is no provision for recording the number of children born previously to the mother. The 'acte de décès' requires the date, place and time of death, the name, date of birth, occupation, and donicile of the deceased, and the names and domicile of the parents of the deceased. The sex is not explicitly stated, but it is given indirectly as either son or daughter of the parents, and if the deceased is a female, the appropriate feminine endings are usually added in the text of the declaration. Stillbirths are recorded on a special form, and in all areas except Papeete the still-born child must be presented before the registrar, but in Papeete this physical presence is not required.

Although it is difficult if not impossible to assess the completeness of the records from the data which are available, Valenziani (1949, p. 95) considered that the system functioned efficiently and well. With respect to details of age, however, the scrutiny of more than 17,000 birth registrations and the records of nearly 6,000 deaths indicated a remarkable coincidence between the birthdays of mothers and their children, and between the day and month of birth and death for many who died. Although it is possible that the years of birth were reasonably reliable, exact dates of birth were clearly irrelevant in both contexts, and as both forms demand exact days, months and years the dates recorded are probably those chosen by the local registrars. 
Except for the numbers published in the 1956 census report or in secondary sources such as Valenziani's (1940, pp. 182-212) study for the Marquesas, no summaries of even the numbers of births and deaths occurring each year are compiled and published. In 1953 and again in 1959 access was granted to the registers in the Records Office at Papeete, and the births and deaths which had been recorded in the six years 1950-2 and 1955-7 were summarized, the deaths by the age and sex of the deceased, and the births by the sex of the infant and the mother's age at its birth. For 1951, the registers of births and deaths on the island of Hakahau in the Marquesas and Amanu in the Tuamotus were not available, and the figures for these two districts in that year are therefore incomplete. As the registers for 1957 for Maiao and the Gambier administrative district had not been received in Papeete late in 1959, the averages of the numbers of births and deaths reported for males and females in the several age groups in 1955 and 1956 in these areas were substituted. It has not been possible to check whether these exaggerated or under-stated the actual fertility and mortality, but as there were only 41 'estimated' deaths in the total of 2,506 for French Polynesia in 1955-7, their effect on the death rate at any age will be slight.

Initially, and somewhat optimistically, births and deaths of Chinese were tabulated separately because these could be more easily identified than the people of Polynesian origin who were often indistinguishable by name from other French citizens and foreigners. Provided they were not naturalized, all Chinese aged 18 years or more were required to register as aliens, and the number of their identity card was inscribed along with their name should they be a parent of a child just born, or die or be the parent of someone who died. Although few Chinese had been naturalized before 1952, more than 500 had acquired French citizenship before 1957, and there are therefore even more anomalies between the annual statistics of births and deaths than for the populations at risk as reported in the censuses. The analyses which follow consequently treat the population as a whole.

\section{Analyses of Mortality}

The average annual death rates estimated for males and females in each age group in the three-year periods centred on 1951 and 1956 are shown in Table 63, together with their standard errors to indicate the likely range of variability consequent upon small numbers of people at risk. The rates cited for age 0 are in each case the numbers of deaths at ages less than 1 year per 1,000 live births reported, and the deaths of persons of unspecified age were distributed pro rata over all ages except 0 before 
TABLE 63 Estimated average annual mortality rates in the total population of French Polynesia, by sex and age: deaths per 1,000 population in each age group at censuses of 1951 and 1956

\begin{tabular}{|c|c|c|c|c|c|c|c|c|}
\hline \multirow{3}{*}{$\begin{array}{l}\text { Age } \\
\text { group }\end{array}$} & \multicolumn{4}{|c|}{ Males } & \multicolumn{4}{|c|}{ Females } \\
\hline & \multicolumn{2}{|c|}{$1950-2$} & \multicolumn{2}{|c|}{$1955-7$} & \multicolumn{2}{|c|}{$1950-2$} & \multicolumn{2}{|c|}{$1955-7$} \\
\hline & Rate & S.E. & Rate & S.E. & Rate & S.E. & Rate & S.E. \\
\hline $0^{*}$ & $156 \cdot 1$ & $10 \cdot 2$ & $106 \cdot 3$ & $7 \cdot 5$ & $120 \cdot 2$ & $9 \cdot 4$ & $82 \cdot 5$ & 6.9 \\
\hline $1-4$ & $13 \cdot 9$ & 1.9 & $8 \cdot 3$ & $1 \cdot 2$ & $12 \cdot 7$ & $1 \cdot 8$ & $7 \cdot 0$ & $1 \cdot 2$ \\
\hline $5-9$ & $3 \cdot 1$ & $0 \cdot 8$ & $1 \cdot 1$ & 0.5 & $3 \cdot 8$ & 0.9 & $1 \cdot 0$ & 0.4 \\
\hline $10-14$ & $4 \cdot 6$ & $1 \cdot 1$ & $1 \cdot 2$ & $0 \cdot 5$ & $4 \cdot 8$ & $1 \cdot 1$ & $1 \cdot 2$ & 0.5 \\
\hline $15-19$ & $7 \cdot 3$ & $1 \cdot 4$ & $2 \cdot 2$ & 0.7 & $11 \cdot 2$ & $1 \cdot 8$ & $2 \cdot 8$ & 0.8 \\
\hline $20-24$ & $8 \cdot 1$ & $1 \cdot 6$ & $2 \cdot 6$ & 0.9 & 9.0 & $1 \cdot 8$ & $3 \cdot 6$ & $1 \cdot 0$ \\
\hline $25-29$ & $6 \cdot 7$ & $1 \cdot 6$ & $3 \cdot 7$ & $1 \cdot 2$ & $7 \cdot 4$ & $1 \cdot 7$ & 3.9 & $1 \cdot 2$ \\
\hline $30-34$ & $12 \cdot 5$ & $2 \cdot 5$ & $4 \cdot 2$ & $1 \cdot 3$ & $11 \cdot 0$ & $2 \cdot 5$ & $4 \cdot 3$ & $1 \cdot 3$ \\
\hline $35-39$ & $12 \cdot 2$ & $2 \cdot 4$ & $6 \cdot 1$ & $1 \cdot 8$ & $13 \cdot 5$ & $2 \cdot 6$ & $6 \cdot 6$ & $2 \cdot 0$ \\
\hline $40-44$ & $15 \cdot \overline{5}$ & $3 \cdot 0$ & $8 \cdot 1$ & $2 \cdot 0$ & $15 \cdot 8$ & $3 \cdot 2$ & $11 \cdot 1$ & $2 \cdot 5$ \\
\hline $45-49$ & $19 \cdot 0$ & $3 \cdot 6$ & $12 \cdot 3$ & $2 \cdot 7$ & $19 \cdot 0$ & $4 \cdot 1$ & $9 \cdot 2$ & $2 \cdot 5$ \\
\hline $50-54$ & $29 \cdot 0$ & $5 \cdot 1$ & $16 \cdot 6$ & $3 \cdot 5$ & $32 \cdot 6$ & $6 \cdot 8$ & $10 \cdot 1$ & $3 \cdot 0$ \\
\hline $55-59$ & $45 \cdot 2$ & $7 \cdot 2$ & $29 \cdot 8$ & $5 \cdot 5$ & $27 \cdot 1$ & $6 \cdot 8$ & $20 \cdot 6$ & $5 \cdot 5$ \\
\hline $60-64$ & $59 \cdot 2$ & $9 \cdot 3$ & $29 \cdot 1$ & $6 \cdot 0$ & $45 \cdot 2$ & $9 \cdot 7$ & $28 \cdot 4$ & $6 \cdot 8$ \\
\hline $65-69$ & & & $70 \cdot 3$ & $11 \cdot 12$ & 105,2 & & $36 \cdot 9$ & $9 \cdot 7$ \\
\hline $\begin{array}{l}70 \text { and } \\
\text { over }\end{array}$ & $103 \cdot 8$ & $10 \cdot 9$ & $79 \cdot 8$ & $11 \cdot 5\}$ & $105 \cdot 3$ & $12 \cdot 1$ & $86 \cdot 9$ & $13 \cdot 8$ \\
\hline
\end{tabular}

*Infant mortality rate per 1,000 live births registered.

computing rates which were based on the census populations in which 'not stated' ages had been similarly distributed.

Except among infants there was no very great difference between the mortality rates for males and females at either period, and the mortality at all ages for 1950-2 was undoubtedly exceptional because of the measles epidemic in 1951. The rates for males and females at ages 15 to 24 years were exceptionally high, and the slightly lower rates recorded for both sexes at ages 25-29 may reflect the level of immunity to measles in the population. However, from the age compositions of the district populations recorded in September 1951 and the ages reported for people who died during 1951, it is likely that it was only on Tahiti that many persons older than 22 years were immune to the disease, and this apparent advantage for people aged 25-29 may have no real significance.

Because the epidemic may have hastened the deaths of some older people, it is not possible to assess what fraction of any rate should be 
TABLE 65 Estimated annual age-specific fertility rates in French Polynesia: average numbers of births registered annually 1950-2 and 1955-7 per 1,000 females at each age in the censuses of 1951 and 1956

\begin{tabular}{|c|c|c|c|c|}
\hline \multirow[b]{2}{*}{ Age group } & \multicolumn{2}{|c|}{1951} & \multicolumn{2}{|c|}{1956} \\
\hline & Rate & S.E. & Rate & S.E. \\
\hline $10-14$ & * & * & 1 & $*$ \\
\hline $15-19$ & 108 & 5 & 123 & 5 \\
\hline $20-24$ & 273 & 9 & 320 & 8 \\
\hline $25-29$ & 251 & 9 & 300 & 9 \\
\hline $30-34$ & 214 & 10 & 227 & 9 \\
\hline $35-39$ & 138 & 8 & 171 & 9 \\
\hline $40-44$ & 58 & 6 & 60 & 6 \\
\hline $45-54$ & 5 & 2 & 6 & 1 \\
\hline Total fertility & \multicolumn{2}{|c|}{5,235} & \multicolumn{2}{|c|}{6,040} \\
\hline
\end{tabular}

*Less than 1.

since 1951 in the numbers of births reported for women of all ages. The most significant changes were in the frequencies with which women aged 20 to 29 were having children, but their birth rates may have been depressed in 1951 and 1952 because the measles epidemic would have broken the marriages of some women who survived it to be recorded in the 1951 census. However, the rates at other ages increased too, and given the probable reliability of the dates of birth reported for the mothers by the informants to the local registrars, there may have been a fairly uniform increase of about 15 per cent throughout all ages.

If the registration system functioned as efficiently as Valenziani (1949, p. 95) believed, it is unlikely that all of the increase was due to improved registration, though this may have contributed. In 1950-2, however, the age-specific fertility rates for the Marquesas and Austral Islands were already as high as, if not higher than, those reported for the total population in 1956, and to make any real impact on the rates the deficient registration would need to be concentrated in the administrative districts of Tahiti and dependencies, Leeward Islands, and the Tuamotu and Gambier Islands, but especially in Tahiti which contributed 56 per cent of all births registered in both 1950-2 and 1955-7. Had the population of each district in 1956 been tabulated by age, the difference between the rates for the various areas could have been explored further, and this may have provided a clue as to the reality or otherwise of the seeming increase in fertility between 1951 and 1956 which also appears in the census data. 
Each of the postwar censuses asked the respondent to state the number of children born alive and the number still surviving, ${ }^{*}$ but each census report has summarized these replies with such a curious and ingenious diversity of tabulations that few are strictly comparable from census to census. The report on the population of Polynesian origin recorded in 1946 concentrated on the numbers of living children and the parents of each number of children were sifted by sex, age, and marital status. For those reported as married, the range of the number of surviving children terminated with 8 or more, but for the single and widowed and in the total people who had 5 or more surviving children were grouped together. The only table which included information on the numbers of children ever born was one which showed the numbers of males and females of each marital status classified according to each number of live-born children up to 7 and then 8 or more and the number of children surviving, with different cut-off points for the different categories of marital status, and no summary total regardless of marital status.

The 1951 report showed the numbers of males and females at each age who had had each number of live-born children up to 6 , with all who had had 7 or more grouped together, in each of three sectors of the population-persons of metropolitan origin or naturalized French citizens, aliens, and persons of Polynesian origin-further distinguishing the married men and women in each sector. In addition there was a table which showed the average number of children surviving to males and females of Polynesian origin as distinct from those who were not, according to their age and marital status; and another for the same two sectors of the population showing the numbers and proportions of survivors amongst the children ever born to males and females who had had each number of children up to 6 and those with 7 or more.

The tables for the numbers of children reported in 1956 did not retain the distinction between people of Polynesian origin and others; instead the population was divided into French citizens and foreigners of each sex, omitting for the first time to give the numbers at each age who had had no children, but extending the range of numbers of children to 9 and grouping only those who had had 10 or more live-born children. There was a similar table for males and females in each of three categories of marital status, and although none of these showed the numbers of women who had failed to state the number of children they had borne, there was also a final summary giving the numbers of females in each age group who had reported each number of children from 0 to

"Both questions were omitted from the 1962 schedule. 
9 and then 10 or more, and the numbers for whom no reply was recorded.

Hence it is only for the total population that the data collected in 1951 and 1956 are comparable, and the average numbers of children born to women in each age group in each census who stated both their date of birth and their births are given in Table 66. This also contains

TABLE 66 Average numbers of children per woman at each age as recorded in the censuses and as estimated from the age-specific fertility rates for 1950-2 and 1955-7

\begin{tabular}{|c|c|c|c|c|}
\hline \multirow[t]{2}{*}{ Age group } & \multicolumn{2}{|c|}{ Average numbers reported for } & \multicolumn{2}{|c|}{$\begin{array}{l}\text { Average numbers expected } \\
\text { from fertility rates for }\end{array}$} \\
\hline & 1951 & 1956 & 1951 & 1956 \\
\hline $15-19$ & $0 \cdot 18$ & 0.48 & $0 \cdot 27$ & 0.31 \\
\hline $20-24$ & $1 \cdot 15$ & $1 \cdot 83$ & $1 \cdot 22$ & $1 \cdot 42$ \\
\hline $25-29$ & $2 \cdot 41$ & $3 \cdot 11$ & $2 \cdot 53$ & $2 \cdot 97$ \\
\hline $30-34$ & $3 \cdot 41$ & $4 \cdot 22$ & $3 \cdot 94$ & $4 \cdot 29$ \\
\hline $35-39$ & $3 \cdot 96$ & $5 \cdot 14$ & $4 \cdot 58$ & $5 \cdot 28$ \\
\hline $40-44$ & $4 \cdot 07$ & $5 \cdot 47$ & $5 \cdot 06$ & $5 \cdot 86$ \\
\hline $45-49$ & $4 \cdot 24$ & $5 \cdot 54$ & $5 \cdot 17$ & $6 \cdot 03$ \\
\hline $45-59$ & $4 \cdot 22$ & $5 \cdot 62$ & $5 \cdot 23$ & $6 \cdot 04$ \\
\hline 60 and over & $3 \cdot 92$ & $5 \cdot 53$ & $5 \cdot 24$ & $6 \cdot 04$ \\
\hline
\end{tabular}

simple estimates of the average numbers of children expected if the age-specific fertility rates of 1951 and 1956 had applied indefinitely, and it must be regretted that no category of 'not stated' was included for the women in each sector of the population which was distinguished in 1956 because much valuable information was lost thereby.

Except in the youngest age groups where it is unsafe to assume that the women who omitted to state the number of children they had borne should be equated with those who did not-which is the assumption implied by ignoring all except those women at each age who did specify their births-there is close agreement between the average numbers of children reported for women in 1956 and those expected from the agespecific fertility rates current around 1956. Although the agreement is less good for 1951, there were obviously some mis-statements then because the figures imply that practically all women aged from 35 years on-including those beyond reproductive age unless there was a highly selective mortality amongst them-had an average of 1.5 children during the five-year period between 1951 and 1956.

As the numbers of women reported as having borne no children fell from about 25 per cent at all ages above 25 years in 1951 to about 10 
per cent or less in 1956, it seems likely that some women who failed to reply in 1951 were wrongly classified as childless. The proportions of women at each age who were described as 'célibataires' were slightly higher in 1956 than in 1951, but as most of those aged more than 35 years in 1956 had produced at least 3 children, their single status was clearly not a barrier to reproduction. If it is assumed that only 10 per cent of all women over the age of 25 years had borne no children by 1951, and the excess reported as childless at these ages discarded as were all the others who omitted to state the number of children they had borne, the average numbers of children born to the remainder are closer to the averages reported for 1956 than those for 1951, and closer still to the average numbers expected on the basis of the 1950-2 agespecific fertility rates.

Hence there may have been a slight rise in the level of fertility since 1956 , and not merely improved or more prompt registration of the births which occurred. With more than one half of all births registered occurring on Tahiti, one of the contributing factors may have been the campaign against filariasis which began there around 1950. An initial survey in 1949 indicated that about 30 per cent of Tahitians aged between 10 and 19 years were carriers of the disease, and their frequency increased to about 55 per cent for males at ages beyond 30 , and to 45 per cent for females by the end of their reproductive period. By treating the carriers with new drugs and spraying to kill the mosquito vectors, the incidence of infected persons fell quite markedly (Beye, Kessel, Heuls, Thooris, and Bambridge, 1953, pp. 145-61), and though this may have had little effect on conceptions by 1951, the continuing campaign against the spread of this disease may have increased the likelihood of conceptions subsequently.

\section{Summary}

As a result of falling mortality and some immigration, and perhaps also higher fertility in recent years, the population of French Polynesia has increased from perhaps 38,000 to more than 72,000 in a century. The origin is vague because it contains dubious figures for the Marquesas and Tuamotu Islands which between them contribute about half of the total of 38,000 . The growth was far from uniform either in time or place, because there were epidemics on some islands which were not necessarily experienced on all, and for the few about which there is information, their fatality varied quite markedly from island to island. There were also civil wars and active resistance to French annexation on several islands, but the effects of these various disturbances to growth, either for individual populations or in the aggregate, are difficult to ascertain because the data are so often either inadequate or inconsistent. 
The devastating population declines alleged for Tahiti and the Austral Islands belong to an earlier period. Although on Tahiti the decline may have been due to the distorted age structure consequent upon prolonged infanticide, there were also outbreaks of introduced diseases which probably hastened its fall. In the Austral Islands the initial decrease was certainly due to some disease of unknown origin which all but one of these populations suffered between 1820 and 1830 . During the second half of the nineteenth century there was probably a continued-and somewhat mysterious-decline in population only in the Marquesas and perhaps the Gambier Islands, while most other island populations were either fairly stationary or may have increased slowly for some periods, only to have such increases in numbers as had occurred wiped out by the occasional epidemics or famines following droughts or hurricanes.

Since 1900 the population has probably increased by a factor not very different from $21 \%$, though once again the true extent of its growth is masked by uncertainties about the counts. Even during this century the total population seems to have increased at different rates at different periods as the components of the aggregate suffered and recovered from epidemics, especially the influenza epidemic of 1918-19; but the natural growth rates in the various island groups may well have been more uniform than the census figures imply because these take no account of migration between the islands. This has probably accelerated in the postwar years because the administrative district populations which showed the slowest rates of increase are generally those which have the greatest proportion of their total aged less than 15 years, and Tahiti's indigenous population has increased very much more quickly than the aggregate.

If all children born survived, the average size of the completed family in French Polynesia would be nearer 6 than 5, and probably 88 per cent of girls and 85 per cent of boys do survive to reproduce. The death rates around 1956 indicate life expectancies from birth of 54.5 years for males and 58.5 for females, with 87 per cent of the women who attain reproductive age surviving through the child-bearing period. The standardized mortality rate for comparison with the other populations considered here is $11 \cdot 3$ per 1,000 population for 1956 , which is almost identical with the crude death rate, and although this is higher than all except the standardized death rate for the Cook Islands, the level of fertility in French Polynesia in 1956 was higher than the American Samoans' and approaching the Fiji Indians' in both pattern and level. 


\section{One Word More}

The implications of the growth rates current around 1956 in these island territories are better suited to some more ephemeral publication, but it is clear that all of the populations are increasing rapidly and will continue to do so unless there is some radical change in the levels of either mortality or fertility, or far more emigration than has yet occurred. While the crude birth rates around 1956 ranged from 36 to 45 per 1,000 population, the recorded death rates were within the range of from 7 to 16 , although some rates may have been higher than this if the registration systems function as inefficiently as some appear to do. The process of growth has been accelerated in recent years by declining mortality, and there may also have been some small increase in fertility for some of the populations as public health measures and modern medicine have reduced mortality and alleviated the incidence of some debilitating diseases.

Since about 1900, Fijis population has increased from 120,000 to 346,000 by 1956 -though only from 94,000 to 148,000 if only Fijians are counted-Tonga's from 21,000 to 57,000 , Samoa's from 40,000 to 117,000 , the Cook Islands' from 8,000 to 17,000 and French Polynesia's from more than 29,000 to about 72,000 . In the aggregate these populations have almost trebled in about fifty-five years from 218,000 to 609,000 , yet the total land area remains the sarne and in 1956 about two-thirds of all economically active males were dependent on agriculture or other primary industry for their livelihood.

In the latter half of the last century the populations changed very much more slowly. In 1900, despite the immigration of Indians, Fijis population was perhaps 15,000 fewer than its total before the measles epidemic, and its size in 1850 was probably not very different from the 135,000 guessed for 1875 . The Tongan population seems to have varied little throughout the nineteenth century and an estimate for mid-century would be the same 20,000 as at its end. The number of Samoans may have increased by about 6,000 between 1850 and 1900, whereas the Cook Islanders probably decreased from perhaps 11,000 around 1850 to 8,000 in 1900 . The aggregate of the five island groups now constituting 
French Polynesia also declined during this period from a dubious 38,000 at the start to about 29,000 in 1900, but almost all of this decrease can be attributed to the early and unreliable estimates for the Marquesas Islands. If Fiji is omitted, the numbers in the Polynesian islands decreased from perhaps just over 100,000 to just under that figure, but only the eastern Polynesians declined while the Tongan and Samoan populations either fluctuated or increased slowly.

There is little point in going any further back in the aggregate figures for the area, because such estimates as were made for the islands which had Europeans there in about 1800 were likely to have as wide a margin of error as one of the two for Tahiti in 1797-the 50,000 people supposed by the missionaries in their first tour of the island as compared with the 16,050 estimated from Wilson's tally of houses when he made the same journey a few days later. Without disparaging the efforts of the missionaries, who were almost always the first to try to get population numbers, there were few who actually went from house to house or village to village 'taking the census', even when they had relatively small islands or districts in their charge.

Nor would this have been easy when the people came out from the village to meet them, and afterwards escorted them along the path to the next village, or later when they declined to live in the mission settlements and dispersed to their own lands 'scattered about'. Where the missionaries merely visited an island briefly or had larger districts to care for, they had perforce to rely on informants who probably appreciated the need for accuracy in this information less than the missionaries or the London Missionary Society, and may even have had their own reasons for distorting the numbers reported. Clearly not all population figures provided by the missionaries have equal reliability, and though some were carefully compiled, others were probably no more valid than the estimates given by some more transient visitors.

Despite these deficiencies in the data, there were undoubtedly some island populations which declined in the years following European contact, though not necessarily because of it. Perhaps the most notable of these were the Tahitians and the Marquesans, but while the advent of Europeans might be blamed for part of Tahiti's loss of population, there is scant evidence of any alien influences in the decline in the Marquesas. Although less publicized, Rarotonga's population halved within the first sixteen years of missionary rule, and because this was such a small island with either one, or more often two European missionaries living there, the course and sources of the decline were fairly well-documented. There at least there can be little doubt that the loss of population was due to mortality from diseases introduced 
from outside, as was measles to Fiji in 1875. In the Austral Islands the greatest loss of population occurred before they were much visited by European ships, but the disease which killed so many of the islanders may nevertheless have originated with one.

None of these cases is parallel because there were exceptional factors involved in each. The Tahitians almost certainly experienced epidemics of influenza after two of the visits of the Aguila, and Vancouver's crew was held responsible for an epidemic of dysentery in 1792. In addition there were the non-epidemic but apparently contagious diseases which the Tahitians attributed to the Spaniards' and Cook's visits, which may have increased the non-epidemic mortality above what had been normal, and may also have been age-selective in their incidence. The influenza epidemics may also have been more fatal to people of certain ages, but this probably did not apply to the dysentery epidemic.

For an epidemic to initiate a sustained decline in an initially stable population, age-selective mortality is a pre-requisite, because although the number of births might decrease after an epidemic relatively more than the population decreased as a result of it, uniform mortality throughout all ages would preserve the age structure of the pre-epidemic sector of the population so that within very few years the birth and death rates could return to their former levels. If the population had been increasing before the epidemic, in the absence of any other epidemic outbreaks it would begin to increase again within a few years, and would suffer a setback to its growth only when the depleted cohort caused by the epidemic passed through the ages when they would normally be responsible for relatively more births than women of other ages.

Nothing is known of the extent of mortality from the diseases introduced to Tahiti in the eighteenth century, but the highest mortality reported for any nineteenth century epidemic there was probably less than 1.0 per cent, and this was from measles in 1854. Assuming that the conditions for the spread of any infectious disease were neither more nor less favourable then than ever before, the three known epidemicstwo of influenza and one of dysentery-alone would have reduced the initial population by at most 27 per cent, and if the population halved between about 1770 and 1800 , the average rate of decrease in nonepidemic years must have been more than 1 per cent per year. If the mortality in any of the epidemics was less than 10 per cent, the rate of decline in the intervening years would need to be much higher than 1 per cent, but rates even of this magnitude are not necessarily unreasonable when infanticide is acknowledged.

Simulation of the effects of epidemics, with mortality unknown in both level and pattern, on populations which have been practising 
infanticide to an unknown extent for an unknown number of years offers endless possibilities, but probably none would advance the interpretation beyond demonstrating that if only half of all children born for at least fifty years had been allowed to survive, there may have been more people in each five-year age group between 15 and 44 years than in any other group in the population except children aged less than 5 years. If one-quarter of all infants born were killed at birth, it is likely that within about thirty years of beginning infanticide of this order the age structure of the population would be 'normal' in the sense that cohorts would decrease progressively in size as age increased, but the slope of the age pyramid would be steep.

Given a population practising the higher rates of infanticide, it may not have been necessary for the epidemics to be age-selective to initiate population declines, because uniform mortality at all ages, superimposed on an already distorted population age structure, would accelerate the process of decline whereas some age-selective mortality patterns may have alleviated it. Consequently one is no further advanced towards deciding between endogenous and exogenous causes, and thence assessing the reality of the presumed decline on Tahiti, than in weighing the evidence from the Marquesas.

There too the population probably diminished after European contact but whether this was a consequence of the famine of 1806-10 (or perhaps longer), or the almost incessant internal conflicts, or mortality from introduced diseases-not necessarily epidemic-it seems impossible to unravel from the evidence now available. Although the famine might be presumed to have affected most if not all islands in the north-west group, it is only conjectural that the south-east islands suffered as well. The only epidemic reported for the nineteenth century was the outbreak of smallpox on Nuku-Hiva and Ua-Pu in 1864, and the disease did not spread to the other islands. However, many of the islands were not visited often by either missionaries or officials until the 1870s, and their populations might well have suffered epidemics of diseases introduced by visiting ships.

As the people lived in groups in the valleys, there may have been only infrequent contact between those remote from one another, and especially on the larger islands, the conditions for the spread of an epidemic throughout the entire population would not be very favourable. If the people living in one valley succumbed, their demography subsequently may have been no different from that of smaller island populations, and a succession of small epidemics, each affecting only the people living in one or two valleys, might have been as damaging demographically as one which caused high mortality throughout the 
island. However, this is hypothetical and except for the continuing decline in the Marquesas population after 1890, which was inherent in its age composition, neither the process nor the extent of the earlier decrease has yet been resolved.

There is no mystery about the diminution of Rarotonga's population. Its comparative isolation ended when the London Missionary Society mission was established there, and although the island was not then as popular with the whaling ships as it was to become by the 1850 s, some of the ships which called initiated epidemics among the susceptible Rarotongans, who were perhaps rendered more susceptible by the periodic famines which ensued when their food crops were destroyed by heavy rains or hurricanes or predators. Not all of the people were living in the four mission settlements when dysentery was introduced late in 1829 , and although it was not specifically stated that it originated with a ship, the epidemic began in the district nearest the harbour most frequented by shipping and 600 people had died before the infection reached the other side of the island. Perhaps because of the famine which had preceded it, there was much higher mortality in this epidemic than in the later outbreaks of dysentery, and only about 55 per cent of the marriages in existence before the epidemic would have survived it, so that the numbers of children born during the next year or two would have been commensurately reduced.

The 'scrofulous' disease which appeared soon afterwards was perhaps the same disease that the Tahitians attributed to the visits of the Spanish ships in 1772-4. The first victims on Rarotonga were members of the household where a mission teacher who had come from Tahiti lived, and the infection spread from there and persisted in the population, with diminishing virulence, for more than ten years after about 1835. This probably caused a more prolonged reduction in the numbers of children born than any sharp outbreak could have done, especially during the early years when it was most virulent. In either one and a half or two and a half years before June 1836 there had been 248 births in one district where only 58 were reported for the year ended June 1839, so that although the numbers of births each year may have recovered slightly in the years immediately preceding the onset of this disease, there were probably comparatively small cohorts of children born throughout the period 1830 to 1845 .

Throughout this period, the reduction in births would have been relatively greater than the loss of population through excessive mortality, so that even if neither the dysentery epidemic nor the scrofulous disease had been age-selective in their incidence, and the population stable in 1829 , there would have been very little difference between the numbers 
in successive cohorts by 1845 . Hence, any growth which might have occurred subsequently could only have been very slow, and easily cancelled out by quite minor increases in mortality consequent upon the numerous epidemics or by emigration, though probably not all of the emigrants from the island were Rarotongans, and Rarotonga may have gained some population from other islands in the group.

Rarotonga's epidemic in 1830 may have been typical of outbreaks of infectious disease on many small islands where the population lived near the coast, and within a radius of only a few miles from the source of infection. The entire population could be infected within a short time and the infective agent lose none-or not much-of its initial virulence in transmission. On the larger islands the disease might spread from its focus as rapidly in a susceptible population, but much more time would be needed to infect the entire population and people living far from the source might escape or be infected by a less virulent strain. The smallpox epidemic on Tahiti in 1841 illustrates the diminishing incidence as the distance from Papeete increased, and the people living on the south coast (and probably those in the lesser peninsula as well) seem not to have suffered at all.

They were less fortunate in the measles epidemic of 1854, which was probably the Tahitians' first experience of the disease. Then the mortality was greatest in the western and southern parts of the island, and the infection seems to have spread southwards down the west coast of the larger peninsula, along the south coast and from there to the east coast. It possibly skipped the smaller peninsula altogether, and seems to have caused few deaths along the northern coast east of Papeete. In Samoa's first known epidemic of measles in 1893 the mortality was also variable; in some villages along the north coast of Upolu, presumably those nearest to Apia, about 10 per cent may have died, but there seem to have been few deaths in the villages on the south coast, even if the epidemic reached them. From Tonga it was reported that 5 per cent of the population had died from measles in the same year, and dubious though this estimate is, none of the reports from Samoa suggest mortality higher than this. Although Tonga has one relatively large island, the progress of an epidemic through the small islands of the Ha'apai group, for example, may not have been very different from the usual experience for islands as large as Upolu or Savaii.

Fiji's first experience with measles was probably quite exceptional and whether the virus had extraordinary virulence or not, the conditions for its spread were extraordinarily favourable. As with most of the other measles epidemics Australia was the source of infection. Thakombau's son and his servant were greeted on their return from Sydney by 
representatives from probably every province and tikina in the larger islands, and perhaps some from even the smaller islands as well. When the festivities were over the assemblage dispersed, probably to be met on their return home by similar gatherings of people anxious to hear the news from the capital. Levuka itself, situated on a narrow coastal plain with a backdrop of precipitous mountains, must have been so very crowded that few of those present could have escaped infection, and within four months perhaps one-fifth or more of the population died. On some islands the mortality may have been higher than this, on others lower, but even given the circumstances of this outbreak, there probably were some geographic variations in both the incidence of and mortality from measles and its sequelae throughout the group.

Though the age pattern of mortality is not known, the epidemic may have been age-selective, with much higher risks of death for adults than for any except perhaps the youngest children. If the total mortality rate was about one-quarter, the death rate among adults may have been as high as one-third, and this would mean that less than half of all marriages survived the epidemic. The commensurate reduction in births in subsequent years, coupled with the probably higher than average mortality risks for unweaned female children born before the epidemic, would yield a cohort very much smaller than its older neighbour, which was probably larger than any born for about 15 years after the epidemic. If the mortality risk had been more or less uniform throughout all ages, the contrast in size between the pre- and postepidemic cohorts would have been less marked, but given the probable level of mortality in this epidemic, the 1873-7 cohort in Fiji was almost certainly smaller than the cohort five years older.

The impact of this depleted cohort on the births reported in later years was apparent in the numbers registered in the 1890s. By then there had been several other, but comparatively minor, epidemics which may also have contributed to the declining numbers of births each year, and the births were probably recorded rather more completely than the deaths during this period. Had all been reported equally reliably during the years before 1890, the contrast between the numbers of births each year before the depleted cohorts attained the ages associated with high repraductivity, and the numbers in the years when they were there, may have been even greater.

The numbers of Fijian births registered in the early years of this century do not show the increase that might have been expected after the depleted cohort had passed its peak of fertility, and although registration of births may then have been less assiduous than formerly, there may also not have been very much difference in the size of cohorts 
born between the measles epidemic and 1890. The equivalence in the numbers of births and deaths each year between 1905 and 1910, and the excess of births over deaths after 1911 was due to the fall in mortality rather than an increase in the numbers of births. Then came the influenza epidemic in 1918 in which more than 5,000 Fijians died. The numbers of births each year fell to fewer than 3,000 in most years before 1930, and then began to increase from an annual average of 3,400 in $1930-4$ to more than 3,650 in $1935-9$. The increase in the next five years was slowed by the entry of the small cohorts born in the postinfluenza years to the population of reproductive age, and at least part of the increase apparent since 1945 is due to more complete registration.

Fiji's was not the only island population which experienced the 1918 influenza epidemic, and the mortality there was probably considerably less than in either Western Samoa or Tahiti, where perhaps one-fifth or more of the adults died. The Leeward Islanders may have suffered less than the Tahitians, and in Tonga there were probably between 1,000 and 1,595 deaths in a population of about 24,000 , so that the death rate there may not have been very different from Fijis. In the Cook Islands the outbreak was effectively confined to Rarotonga, where only 45 people died in a population of about 3,000 . The outer islands of French Polynesia may have escaped the epidemic, as did the American Samoans whose harbour was closed to shipping which would not observe the five days' absolute quarantine imposed when influenza became epidemic on Upolu.

The source of the outbreak on Tahiti is not known, but the disease was carried from there to Rarotonga in September 1918 (N.Z.P.P. A-3, 1919 , pp. 2-3). New Zealand was in the throes of an epidemic when the S.S. Talune left Auckland early in November, with a captain who did not know that influenza was an infectious disease and Suva as her first port of call. There she discharged and loaded cargo under quarantine and, as was then customary, about 90 Fijians stayed on board to perform the same service in each port. Passengers destined for Fiji were landed after medical inspection, and though none of the crew was allowed ashore in Suva, there was no restriction on the movements of either the remaining passengers or the crew when the ship called at Levuka before proceeding to Samoa. Their quarantine in Suva was not mentioned when the ship arrived at Apia on 7 November, and passengers were allowed to disembark. The Talune left Apia two days later for Vava'u, and within two days about 70 of the Fijians were ill, so presumably local labour was used to discharge and load cargo there and at Ha'apai and Tongatapu where she called before returning to Suva, twelve momentous days after she had left it. 
All of the Fijians were placed in quarantine on their return, but the epidemic had already begun and though the first known cases occurred in Suva, there was probably some spread of infection from Levuka as well. The dispersal of Fijians from Suva as the incidence increased may have been repeated by the Samoans in and around Apia, or perhaps the arrival of a ship was sufficiently novel in 1918 to attract numbers of people from a wide radius up and down the coast. The disease spread rapidly in both Upolu and Savai'i and soon 'practically all the Natives were down with influenza or fright, and they either could or would not do anything to help themselves or others' (N.Z.P.P. H-31c, 1919, p. 9). Although the Talune called at each of the main ports in Tonga, the mortality reported for the whole population is so low compared with the Samoans' that the epidemic may have been confined to Tongatapu and the island of Vava'u, with perhaps only few of the Haapai people affected.

Tahiti's is the only population which clearly shows the imprint of this epidemic in its age structure, and though it is also detectable in the aggregate for the Leeward Islands, there is no trace in the Western Samoan population which probably suffered mortality of the same order as Tahiti. This similarity can only be inferred indirectly because the number of deaths on Tahiti in 1918 is not known, but no doubt there as in Samoa the system of registration would break down if the men responsible for recording births and deaths were either ill for a period or died, so the true extent of mortality in either population can never be established. Nevertheless, the growth of Western Samoa's population between censuses has closely followed the pattern that would be expected after high and age-selective epidemic mortality, and perhaps if the Samoans were more sophisticated in regard to chronological age, there would be an indentation or flattening at the relevant ages in their age pyramid.

Whether the mortality in these 1918 epidemics of influenza reached the same level as some of the nineteenth century epidemics or not, none of the populations experienced any sustained decline in numbers after 1918 , and this was probably because there was no longer the precarious balance which had existed between the numbers of births and deaths occurring each year. As the several populations became less susceptible to the more common communicable diseases with each outbreak that occurred, and especially to those which confer a high degree of immunity after one attack, it is conceivable that the death rates began to fall quite early in the century, thereby providing a margin for population growth. In addition, some governments had provided health services of a sort, and though by 1918 these were meagre, and more often than not limited 
to the main island or the administrative centre of the island group, by then probably most oversea shipping used only the principal port where quarantine regulations might be imposed with some hope of their being enforced.

Since then, all of these territories except French Polynesia have networks of small hospitals or dispensaries staffed by graduates of the Central Medical School in Suva, and medical care is no longer restricted to the towns or central islands. The effect of this on the level of mortality in any population cannot be assessed because the data available are not sufficiently reliable to gauge the real extent of the changes which may have occurred. The demonstrable inadequacies and incompatibilities which existed even in 1956 between sets of data that should be comparable indicate the need for a much more comprehensive approach to data collection in these populations, but also the need for utmost caution by researchers in accepting many of the historical population estimates, and thence interpreting social changes in terms of population change.

By 1956 the Fijian population of Fiji had almost returned to the size it was thought to be before the measles epidemic in 1875. At the other extreme, Tahiti's was less than one-fifth of the number Cook estimated in 1774 , though not much above an estimate he might have derived from Tupaia's tally of warriors in 1769 . The numbers reported for the Cook Islands in 1956 barely exceeded the number John Williams thought to inhabit the islands in the Lower Group in the 1820s. In 1956 Samoa's population was little more than twice the number given Wilkes by some of the eleven missionaries who had been in Samoa less than three years, though Tonga's population was about three times as big as the number reported by Wilkes. But if it is as difficult as it seems to have been for administering governments to organize competent censuses in the twentieth century, how much confidence can be placed in the earlier unofficial counts?

Admittedly some may have been better, because responsibility was less dispersed and there were fewer people to be counted, but it could be more difficult for one person to list 1,000 people living scattered on their own lands than several thousands living in several mission settlements, and more difficult still to be informed of the births and deaths which occurred among them. Nor can any of the figures be dissociated from the circumstances of either the people at the time, or of those responsible for counting-and in Polynesia there was disillusion enough for a zealot without his being required to compile censuses and record the births and deaths in his wayward and plaguy flock. The missionaries have been succeeded by administrators, historians, and demographers; for some the sense of frustration remains. 


\section{References}

Adams, H. (1947) Tahiti. Memoirs of Arii Taimai e Marama of Eimeo etc. Scholars' Facsimiles and Reprints, New York.

Aitken, R. T. (1930) Ethnology of Tubuai. B.P.B.M. Bull. 70, Bayard Dominick Expedition Publication No. 19, Honolulu.

Annuaire statistique de PUnion Française Outre-Mer 1939-1948 (1948)

Ministère de la France d'Outre-Mer: Service des Statistiques. Paris.

Annuaire de Tahiti (1885) Imprimerie du gouvernement, Papeete.

Bachi, R. (1953) 'Measurement of the tendency to round off age returns'. Bulletin de linstitut International de Statistique (28th session-Rome), 34, pt 3, pp. 129-38.

Banks, J. (1769) Note: Forces of Otaheite. MS. British Museum PS3/2882, add. 27889 , f 71 .

Banks, J./Beaglehole, J. C. (1962) The Endeavour Journal of Joseph Banks 1768-71. J. C. Beaglehole (ed.). The Trustees of the Public Library of New South Wales in association with Angus \& Robertson, Sydney.

Barff, C. (1826) S.S.L., Huahine, 25 Nov.

- (1831) Ibid., 21 Dec.

(1834a) Return from 1 Jan. 1833 to 1 Jan. 1834 for Huahine and Maiaoiti outstation.

(1834b) Return from Fare for 1834.

- (1835) Report for 1835, Huahine and Maiao, 31 Dec. 1835; enclosing

Return for Huahine and Maiao, 31 Dec. 1834 to 31 Dec. 1835.

(1836) Return for Huahine, 31 Dec. 1835 to 20 Sept. 1836.

(1837) Return for Huahine and Maiva, Oct. 1836 to 6 Oct. 1837.

(1838) Report etc. of the Stations on Huahine and Maiaoiti from 6

Oct. 1837 to 6 Oct. 1838; enclosing Return for outstations.

(1840) Return from Fare and outstations, 23 Aug. 1839 to 2 Nov. 1840.

(1841) Return for Maiva and other outstations from 30 Oct. 1840 to 16 Oct. 1841.

(1842) Report etc. for Huahine, 5 Nov. 1842; enclosing Return for

Fare and outstations, Oct. 1841 to Oct. 1842.

- (1843) Annual Report from Huahine, 21 Oct. 1843; enclosing Return for Fare and outstations, Oct. 1842 to 26 Oct. 1843.

(1844a) S.S.L., Papeete, 22 Mar.

(1844b) Report from Huahine, 4 Nov. 1844; enclosing Return for

Fare and outstations from 21 Oct. 1843 to 4 Nov. 1844.

(1846a) S.S.L., Paofai, Tahiti, 22 Jan.

(1846b) Ibid., 12 Feb.

(1848) Ibid., Huahine, 20 May.

(1849) Ibid., 17 July.

(1850) Ibid., Paofai, Tahiti, 20 June.

(1851) Report etc. from Huahine for 1851.

(1852) S.S.L., Maiaoiti, 22 May.

(1853) Ibid., Huahine, 16 Feb. 
- (1855) Ibid., 5 Dec.

—. (1856) Ibid., 14 Nov.

- (1857) Report etc. from Huahine, 31 Oct.

_- (1858) S.S.L., John Williams, 2 Dec.

- (1860?) Report of station and institution, Tahaa, undated.

- (1861) S.S.L., Huahine, 7 Nov.

- (1862) Ibid., 17 Nov.

- (1863) Report of the Missionary Station at Huahine, 19 Nov.

$\longrightarrow$, and Barff, J. (1846) S.S.L., Huahine, 2 July.

- and Platt, G. (1835) S.S.L., Raiatea, 28 July.

Barff, J. (1845) Ibid., Papeete, 27 June.

- (1853) Ibid., Huahine, 12 Apr.

- (1854a) Ibid., 12 June.

- (1854b) Ibid., 4 Sept.

- (1858) Ibid., Tahaa, 8 Feb.

$\longrightarrow$ (1859a) Ibid., 4 Feb.

- (1859b) Ibid., 25 June.

Beaglehole, E. and Beaglehole, Pearl (1938) Ethnology of Pukapuka. B.P.B.M. Bull. 150, Honolulu.

Berchon, E. (1865) 'Sur les derniers recensements de la population des îles Tahiti et Moorea'. Bull. de la Soc. d'Anthrop. de Paris, 6, pp. 499-502.

Beye, H. K., Kessel, J. F., Heuls, J., Thooris, G. and Bambridge, B. (1953) 'Nouvelles recherches sur l'importance, les manifestations cliniques, et la lutte contre la filariose à Tahiti, Océanie Française'. Bulletin de la Société de Pathologie exotique, 46, No. 1, pp. 144-63.

Bicknell, H. and Henry, W. (1805) L.M.S. Journal Round Eimeo, Tahiti, 22 Jan. to $11 \mathrm{Feb}$.

Bingham, H. (1878) Letter to Clark, No. 39 from Honolulu, 7 Feb. Boston Mission Correspondence. (By courtesy of H. E. Maude.)

Bleazard, C. (1894) Savaii Circuit Report, 1894: District Committee Minutes and Proceedings, Methodist Mission Society Papers (Mitchell Library), Vol. 25, 1893-4.

- (1896) Savaii Circuit Report, 1896: District Committee Minutes and Proceedings, Methodist Mission Society Papers (Mitchell Library), Vol. 26, 1895-6.

Bligh, W. (1937) The log of the 'Bounty'. O. Rutter (ed.). 2 vols., Golden Cockerel Press, London.

Blossom, T. G. (1840) S.S.L., Eimeo, 26 Oct.

- (1843) Ibid., 21 Feb.

de Bougainville, L. A. (1771) Voyage autour du monde, par la frégate du Roi 'La Boudeuse', et la flute 'L'Etoile'; en 1766, 1767, 1768 \& 1769. Saillant \& Nyon, Paris.

Bourne, R. (1826) S.S.L., Tahaa, 4 Dec.

Boyd, R. (1911) Report by the Commissioner appointed to superintend the taking of the Census of the Colony, 2 Apr. 1911. Council Paper No. 44, Legislative Council Fiji.

- , and Stewart, D. R. (1922) Fiji Census 1921: Report of the Census taken 24.4.1921. Council Paper No. 2, Legislative Council Fiji.

Brenchley, J. L. (1873) Jottings during the cruise of H.M.S. Curacoa among the South Sea lslands in 1865, Longmans, Green \& Co., London. 
Buchanan, E. (1843) S.S.L., Papara, Tahiti, 18 Jan.

(1844a) Ibid., Paofai, Tahiti, 10 Jan.

- (1844b) Ibid., 23 Apr.

Buck, Peter H. (1932a) Ethnology of Tongareva. B.P.B.M. Bull. 92, Honolulu. - (1932b) Ethnology of Manihiki and Rakahanga. B.P.B.M. Bull. 99, Honolulu.

Bullen, T. (1846) S.S.L., Leone, 29 June.

Burrows, W. (1936) A report on the Fiji Census, 1936. Council Paper No. 42, Legislative Council Fiji.

Buzacott, A. (1834) S.S.L., Rarotonga, I July.

- (1838a) Ibid., 1 Jan.

- (1838b) Ibid., enclosing Returns for 1838, 8 Dec.

- (1840) Ibid., 1 July.

- (1841) Ibid., 4 Mar.

- (1852) Ibid., enclosing Vital Statistics for 1852, Nov.

__ (1854a) Ibid., enclosing Vital Statistics for 1853, 12 Jan.

— (1854b) Ibid., enclosing Census for 1854, 5 Dec.

- (1856) Ibid., enclosing Vital Statistics for 1855, 22 Mar.

- (1858) Ibid., from Sydney enclosing Vital Statistics for 1857, 9 Feb.

Caillet, F. X. (1918) 'Pages oubliées de M. Fr. X. Caillet'. Bulletin de la Société d'études océaniennes, No. 4, pp. 167-81.

Caillot, A. C. E. (1909) Les polynésiens orientaux au contact de la civilization. Leroux, Paris.

- (1932) Histoire de l'île Oparo ou Rapa. Leroux, Paris.

Carew, W. S. (1878) Memorandum to Colonial Secretary, 22 Nov. C.S.O. $78 / 1715$.

Carne, A. H. (1893) Upolu and Manono Circuit Report, 1893: District Committee Minutes and Proceedings, Methodist Mission Society Papers (Mitchell Library), Vol. 25, 1893-4.

Chalmers, J. (1867) S.S.L., Rarotonga, 16 Nov.

- (1870) Annual Report to L.M.S. from Rarotonga, 19 Dec.

- (1872) Annual Report to L.M.S. from Rarotonga, 23 Dec.

- (1890) Annual Report to L.M.S. from Rarotonga, Nov.

Charter, G. (1838-56) Journal of the Reverend George Charter, 11 Apr. 1838 to 12 Sept. 1856. L.M.S., Sydney, MS. (By courtesy of N. Gunson.)

- (1839) S.S.L., Raiatea, 28 Sept.

- (1843a) Ibid., 11 Apr.

- (1843b) Ibid., $26 \mathrm{May}$.

- (1847) Ibid., 2 June.

$\longrightarrow$ (1848) Ibid., 11 Jan.

_- (1849) Ibid., 19 Jan.

- (1850) Ibid., 18 June. (1852) Ibid., 10 June.

Chaulet, P. (1865) Lettres Lithographiées, Archives Picpus. (By courtesy of C. W. Newbury.)

Chisholm, A. (1852) S.S.L., Raiatea, 5 Oct.

- (1854a) Ibid., 2 Jan.

- (1854b) Ibid., 28 Aug.

- (1855) Ibid., 20 Apr.

_ (1856a) Ibid., Borabora, 28 Mar. 
(1856b) Ibid., Raiatea, 31 Dec.

(1857) Ibid., from on board the John Williams between Rurutu and Rimatara, 29 Sept.

- (1858a) Ibid., Raiatea, 8 Jan.

- (1858b) Ibid., 27 Dec.

- (1859) Ibid., 16 Aug.

Churchward, W. B. (1883) Despatch to Foreign Office, No. 1 Commercial, 20 Jan. 1883: Report on Trade and Commerce for 1882. B.C.S.-N.A. Series 3, Vol. 4. (By courtesy of R. P. Gilson.)

Clavel, M. (1884) 'Le dépopulation aux îles Marquises'. Bull. de la Soc. d'Anthrop. de Paris, 7 (3 $\left.{ }^{\mathrm{eme}}\right)$, pp. 490-7.

de Coetlogon, H. (1889) Despatch to Salisbury 16 July 1889, No. 35 F.O.C.P. No. 5921, 1890 Part 6 (new series): 'Further Correspondence Respecting the Navigators' Islands-July to December 1889'. (By courtesy of R. P. Gilson.)

Collier, J. W. (1893) Savai'i Circuit Report, 1893: District Committee Minutes and Proceedings, Methodist Mission Society Papers (Mitchell Library), Vol. 25, 1893-4.

(1895) Upolu and Manono Circuit Report, 1895: District Committee Minutes and Proceedings, Methodist Mission Society Papers (Mitchell Library), Vol. 26, 1895-6.

- (1896) Upolu and Manono Circuit Report, 1896: District Committee Minutes and Proceedings, Methodist Mission Society Papers (Mitchell Library), Vol. 26, 1895-6.

Cook, J. (1785) A voyage to the Pacific Ocean, undertaken, by the command of His Majesty, for making discoveries in the Northern hemisphere, Vols. 1 and 2. Hughs, London.

- (1821) The three voyages of Captain James Cook round the World, Vol. 5. Longman, Hurst, Rees, Orme and Brown, London.

-,Beaglehole, J. C. (1955) The voyage of the 'Endeavour', 1768-71. The journals of Captain James Cook on his voyage of discovery. J. C. Beaglehole (ed.), Cambridge University Press for Hakluyt Society.

- (1961) The journals of Captain James Cook on his voyages of discovery. The voyage of the 'Resolution' and 'Adventure' 1772-1775. J. C. Beaglehole (ed.), Cambridge University Press for Hakluyt Society.

Cool, J. C. (1957) Census of American Samoa, September 25, 1956. (Roneoed)

Cooper, E. V. (1883a) S.S.L., Huahine, 29 Jan.

(1883b) Ibid., 24 May.

- (1884a) Ibid., 28 Apr.

- (1884b) Ibid., 29 July.

- (1885) Ibid., 23 Oct.

- (1888a) Ibid., Auckland, N.Z., 18 May.

- (1888b) Ibid., Tahiti, 22 Oct.

- (1889a) Ibid., 9 Nov.

- (1889b) Ibid., Huahine, 27 Dec.

Corney, B. G. (1884) 'The behaviour of certain epidemic diseases in natives of Polynesia, with especial reference to the Fiji Islands'. Trans. Epidem. Soc. London, 3, 1883-4, pp. 76-95.

- (1913) The quest and occupation of Tahiti by emissaries of Spain in 
1772-76. Translated and compiled by B. G. Corney, Vol. 1, issued for 1913. Cambridge University Press for Hakluyt Society.

(1914) The quest and occupation of Tahiti by emissaries of Spain in 1772-76. Translated and compiled by B. G. Corney, Vol. 2, issued for 1914. Cambridge University Press for Hakluyt Society.

(1918) The quest and occupation of Tahiti by emissaries of Spain in 1772-76. Translated and compiled by B. G. Corney, Vol. 3, issued for 1918. Cambridge University Press for Hakluyt Society.

- Stewart, J. and Thomson, B. H. (1896) Report of the Commission appointed to inquire into the Decrease of the Native Population: 1893. Govt Printer, Suva.

Coulter, J. W. (1941) Land utilisation in American Samoa. B.P.B.M. Bull. 170. Honolulu.

Cowan, J. (1936) Suwarrow Gold. Jonathan Cape, London.

Crocombe, R. (1961) Personal communication.

Crook, W. P. (1826) S.S.L., Taiarapu, Tahiti, 28 Dec.

- (1827) Report of the Missionary Station at Bogue Town, Taiarapu, Tahiti, 9 May.

— ? S/Sheahan, G. M. (c. 1800) Account of the Marquesas Islands. Transcribed by G. M. Sheahan: Marquesan source material, Appendix II, pp. cxiii-clxxxiii. MS., Mitchell Library.

Crozier, Dorothy (1954) Personal communication.

- (undated) 'Tonga, a study in stability and change'. Unpublished MS. (By courtesy of A. M. and H. E. Maude.)

Cuming, H. (1828) Journal, MS., Mitchell Library A1336. (By courtesy of N. Gunson.)

Cusack-Smith, T. B. (1893) Despatch to Rosebery 9 Oct. No. 56, F.O.C.P.

No. 6437, 1894. Part 12 (new series): 'Further Correspondence Respecting the Navigators' Islands-July to December 1893'. (By courtesy of R. P. Gilson.)

Cuzent, G. (1860) Iles de la Société, Tahiti. Thèze, Rochefort.

- (1883) Archipel des îles Marquises. Halégonet, Brest.

(1884) Archipel des Pomotu. Halégonet, Brest.

Darby, Madge (1965) Who caused the mutiny on the 'Bounty'? Angus \& Robertson, Sydney.

Darling, D. (1826) S.S.L., Burder's Point, Tahiti. 24 Aug.

- (1831) Ibid., Burder's Point, Teoropaa, Tahiti, 25 Apr.

— (1834a) Return for Burder's Point filled up 1 Jan. 1834.

— (1834b) S.S.L., Burder's Point, Punaauia, Tahiti, 27 Jan.

— (1835a) L.M.S. Journal-Marquesas, 19 Feb.

- (1835b) S.S.L., Vaitahu, Tahuata, 27 Feb.

— (1835c) Ibid., Burder's Point, Punaauia, Tahiti, 7 Oct.

— (1836) Ibid., Burder's Point, Tahiti, 30 Mar.; enclosing Return for 1835. (1837) Report of a voyage in the Ulitea to visit the outstations belonging to the Windward Division of the Tahitian Mission commenced on Wednesday the 12th of October 1836 and finished on January 17th 1837. Undated.

- (1839) S.S.L., Burder's Point, Tahiti, 20 Aug.

- (1840) Ibid., 8 Dec.

- (1842) Ibid., 18 Jan.

(1847) Ibid., Punaauia, Tahiti, 14 Jan. 
(1848) Ibid., 26 Jan.

Davidson, J. W. (1961) The transition to independence in Western Samoa: the final stage. Australian National University, Canberra. (Roneoed)

Davies, J. (1826) L.M.S. Journal, July 1825-Mar. 1826.

- (1830) S.S.L., Haweis' Town, Papara, Tahiti, 9 Dec.

(1831) Return for Haweis' Town from Dec. 1830 to end Dec. 1831. (1832) Return for Haweis' Town from Dec. 1831 to Dec. 1832. (1834) S.S.L., Haweis' Town, Papara, Tahiti, 2 Feb.; enclosing Return for Dec. 1832 to 31 Dec. 1833.

— (1835) Return for Haweis' Town from 30 Dec. 1833 to 31 Dec. 1834. (1836) S.S.L., Haweis' Town, Papara, Tahiti, 6 Jan.; enclosing Return for 30 Dec. 1834 to 30 Dec. 1835.

- (1837a) Return for Haweis' Town from 31 Dec. 1835 to 31 Dec. 1836. (1837b) Return for Haweis' Town from 31 Dec. 1836 to 2 Dec. 1837. (1839a) S.S.L., Haweis' Town, 14 Jan.; enclosing Return for 2 Dec. 1837 to 31 Dec. 1838.

- (1839b) Return for Haweis' Town, 31 Dec. 1838 to 18 Sept. 1839.

- (1840) Return for Haweis' Town, 18 Sept. 1839 to 9 Dec. 1840.

- (1841a) Letter to G. Bennet, L.M.S., from Haweis' Town, 13 Dec. (1841b) S.S.L., Haweis' Town, 27 Dec.; enclosing Report from Haweis' Town Station, 9 Dec. 1840 to 27 Dec. 1841.

- (1842) S.S.L., Haweis' Town, Papara, 31 Dec.

- (1843) Ibid., Papara, Tahiti, 5 July.

— (1847) Ibid., Haweis' Town, Papara, 31 Dec.

- (1850) Ibid., 30 Dec.

(1961) The history of the Tahitian Mission 1799-1830. C. W. Newbury (ed.), Cambridge University Press for Hakluyt Society.

Dawson, T. (1879) Despatch to Payson, 17 Nov. 1879. U.S.C.D.-U.S.N.A. Vol. 7, No. 120. (By courtesy of R. P. Gilson.)

Derrick, R. A. (1950) A history of Fiji. Vol. I. (Revised ed.) Printing \& Stationery Dept., Suva.

Des Voeux, G. W. (1881a) Despatch to Kimberley, 103, 18 July. C.O. 83/ 26. (By courtesy of Ethel Drus.)

- (1881b) Despatch to Kimberley, 132, 23 Aug. C.O. 83/27. (By courtesy of Ethel Drus.)

Dods, M. T. (1901) Report on Census, 1901. Fiji Royal Gazette, No. 49 of 1901.

Dupetit-Thouars, ? (1842) Rapport de la prise de possession des Marquises, par M. le Contre-Amiral du Petit-Thouars, à M. le Ministre de la Marine et des Colonies. Taiohae, 18 June. Printed in Gracia (1843) pp. 293-306.

Eggiman, ? (1875) Report by French Resident, Marquesas, 26 Jan. Archives Coloniales, Océanie, Paris. (By courtesy of C. W. Newbury.)

Elder, J. and Wilson, C. (1804) L.M.S. Journal Round Eimeo, 26 Jan.-21 Feb. 1804.

- (1809) L.M.S. Journal Round Huahine, 25 Apr.-1 May 1809.

— and Youl, J. (1805) L.M.S. Journal Round Eimeo, 11 Oct.-1 Nov., Tahiti, 1805.

Ellis, W. (1831) Polynesian Researches. 4 vols., 2nd ed. Fisher, Son \& Jackson, London. 
, and Tyerman, D. (1822) S.S.L., Rurutu, 11 Nov.

Ellison, J. W. (1938) Opening and penetration of foreign influence in Samoa to 1880. Studies in History, No. 1 Oregon State Monographs, Oregon State College, Oregon.

Emberson, H. J. (1875) Memorandum to Secretary, Native Affairs, Levuka, 29 June. C.S.O. miscellaneous 1875.

(1881) Report of the Registrar-General upon census taken 4 Apr. 1881. (Encl. to Despatch 183 of 29 Dec. to Sec. of State.) Unnumbered MS., C.A.F.W.P.H.C.

Erskine, J. E. (1853) Journal of a cruise among the islands of the Western Pacific ... in Her Majesty's Ship Havannah. (1849) John Murray, London.

Fiji Blue Book (1878)

Fiji Times (1880) 17 Mar. (By courtesy of R. G. Ward.)

Forster, G. (1777) A voyage round the world in His Britannic Majesty's Sloop Resolution, commanded by Captain James Cook, during the years $1772,1773,1774$ and 1775. 2 vols. White, Robson, Elmsly \& Robinson, London.

Forster, J. R. (1778) Observations made during a voyage round the world, on physical geography, natural history, and ethic philosophy. G. Robinson, London.

Foster, S. S. (1875) Consul to Hunter, 8 Feb. U.S.C.D.-U.S.N.A. Vol. 3. (By courtesy of R. P. Gilson.)

Furnas, J. C. (1947) Anatomy of Paradise. William Sloane Associates Inc., New York.

Gifford, E. W. (1929) Tongan Society, B.P.B.M. Bull. 61, Honolulu.

Gill, G. (1845) S.S.L., Mangaia, 10 Oct.

- (1846) Ibid., 1 Jan.

(1848) Ibid., 17 June.

— (1850) Ibid., 22 Nov.

- (1851) Ibid., 30 Sept.

- (1854) Ibid., 9 Dec.

Gill, W. (1841) S.S.L., Arorangi, 26 Mar.

- (1845a) Report to L.M.S. enclosing statistics for 1844, Rarotonga, 11 Apr.

(1845b) S.S.L., Rarotonga, 10 June.

- (1846) Ibid., enclosing statistics for 1845, Rarotonga, 16 June.

- (1847a) Ibid., Arorangi, Feb.

(1847b) Ibid., 3 July.

(1847c) Ibid., 20 Dec.

(1847d) Ibid., enclosing Vital Statistics for 1847, Rarotonga, 26 Dec.

- (1848) Ibid., enclosing Vital Statistics for 1848, Rarotonga, 31 Dec.

(1849) Ibid., Rarotonga, 4 Dec.

- (1850) Ibid., enclosing Vital Statistics for 1850, Rarotonga, 31 Dec.

- (1851) Ibid., enclosing Vital Statistics for 1851, Rarotonga, 31 Dec.

- (1852) Ibid., Rarotonga, 28 Aug.

- (1856) Gems from the Coral Islands. Vol. II, Eastern Polynesia. Ward \& Co., London.

Gill, W. W. (1854) S.S.L., Mangaia, 28 Oct.

— (1863a) Journal, Samoa to Mangaia, 9 Feb. to 23 Mar. 


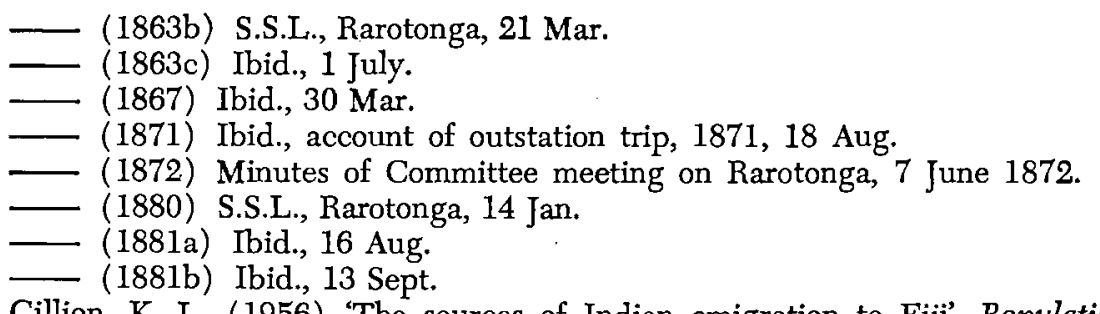

Gillion, K. L. (1956) 'The sources of Indian emigration to Fiji'. Population Studies, Vol. 10, pp. 139-57.

Gilson, R. P. (1952) Administration of the Cook Islands. M.Sc.(Econ.) Thesis, University of London.

- (1955) Personal communication.

(1957) Personal communication of information derived from an extensive study of historical documents relating to Samoa.

Gittins, J. W. (1947) A report on the results of the Census of population, 1946. Council Paper No. 35, Legislative Council Fiji.

Gordon, Sir Arthur (1880a) Despatch to Hicks-Beach, 5 Mar. (Letterbook copy, C.A.F.W.P.H.C.)

— (1880b) Despatch to Secretary of State, 120, 8 Nov. C.O. 83/23. (By courtesy of Ethel Drus.)

Gorrie, J. (1879) Acting High Commissioner to Hicks-Beach, 23 June. F.O.C.P. No. 4127, 1880. Part 3 (old series): 'Further Correspondence Respecting Affairs in the Navigators' Islands-1878-79'. pp. 104-8. (By courtesy of R. P. Gilson.)

Goward, G. (1878) Commercial report to Seward, 28 Dec. F.O.C.P. No. 4127, 1880. Part 3 (old series): 'Further Correspondence Respecting Affairs in the Navigators' Islands-1878-79'. pp. 18-32. (By courtesy of R. P. Gilson.)

Gracia, M. (Le P. Mathias G**) (1843) Lettres sur les lles Marquises. Chez Gaume Frères, Libraires, Paris.

Graves, J. H. (1879) Despatch to Foreign Office, 20 Dec. Report on Samoan Trade and Commerce for 1879. B.C.S.-N.A. Series 3, Vol. 4. (By courtesy of R. P. Gilson.)

Green, J. L. (1861) S.S.L., Tahaa, 6 Dec.

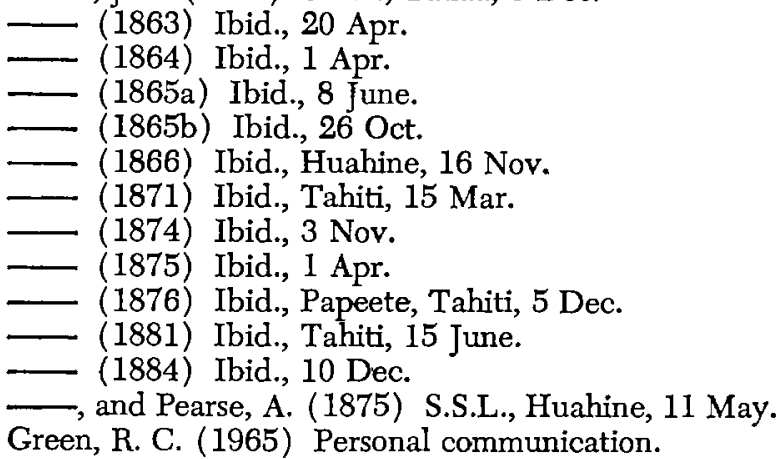

Gros, H. (1896) 'Les populations de la Polynésie française en 1891. Etude ethnique'. Bull. de la Soc. d'Anthrop. de Paris, 7 (4th series), pp. 144-97. 
Gyles, J. (1819) L.M.S. Journal-Tahiti and Eimeo, 14 Aug. 1818 to 8 Sept. 1819.

Handy, E. S. C. (1930) History and culture in the Society Islands. B.P.B.M. Bull. 79, Honolulu.

Hardie, C. and Turner, G. (1850) Annual Report for Missionary Seminary, Malua, Sept. 1850.

Harris, G. A. (1873) Annual Report to L.M.S. from Mangaia, 22 Apr.

- (1876) S.S.L., Mangaia, 4 Mar.

(1877) Ibid., 9 Oct.

(1881a) Census of Mangaia for 1881: photocopy by courtesy of L.

Trenn.

- (1881b) Ten years' report for Mangaia to L.M.S., 28 Aug.

- (1882) S.S.L., Mangaia, 28 July.

- (1890) Chronicle of the London Missionary Society.

(1891) Minutes from Rarotonga to L.M.S., 3 June.

(1892) S.S.L., Mangaia, 28 May.

Heath, T. (1840) S.S.L., Tahiti, 8 Dec.

- (1844) Letter to Rev. Mark Wilks, Paris, from Huahine, 12 Dec. (1846) S.S.L., Tahiti, June.

Henderson, G. C. (1931) Fiji and the Fijians: 1835-1856. Angus \& Robertson, Sydney.

(1933) The discoverers of the Fiji Islands. John Murray, London.

Henry, Teuira (1928) Ancient Tahiti. B.P.B.M. Bull. 48, Honolulu.

Henry, W. (1836) S.S.L., Roby Town, Tiarei, Tahiti, 26 Sept.

- (1839) Ibid., Tahiti, 27 Feb.

- (1842) Ibid., Tahiti, 18 Jan.

(1847) Ibid., Eimeo, 15 Jan.

Hill, J. A. (1922) Fourteenth census of the United States taken in year 1920, Vol. 3: Composition and characteristics of the population by States pp. 1232-7. Department of Commerce, U.S. Bureau of the Census, Washington.

Hooper, A. (1961) 'The Migration of Cook Islanders to New Zealand'. Jour. Poly. Soc., 70, No. 1, pp. 11-17.

Howe, W. (1841) S.S.L., Afareaitu, Eimeo, 20 Oct.

(1844) Ibid., 19 June.

- (1847a) Ibid., Papeete, 14 Aug.

- (1847b) Ibid., 15 Oct.

- (1848) Ibid., Tahiti, 14 Feb.

- (1854a) Ibid., Papeete, 5 Sept. (1854b) Ibid., 30 Oct.

Hutchin, J. (1885) S.S.L., Rarotonga, 4 Aug.

— (1886) Ibid., 28 Apr.

- (1891b) Eight-year report to L.M.S., 1882-1890, Rarotonga, 16 Feb.

- (1891c) S.S.L., Rarotonga, 21 Feb.

I.N.S.E.E. (1950) Résultats du recensement de 1946-Territoires d'OutreMer, Etablissements Français d'Océanie. $1^{\text {te }}$ partie: Population Océanienne. Supplément série statistique No. 11, Bulletin Mensuel de Statistique d'Outre-Mer. Institut National de la Statistique et des Etudes Economiques/ Service des Statistiques, Faris.

- (1954) Résultats du recensement de 1951-Territoires dOutre-Mer. $4^{\text {me }}$ 
partie: Océanie (Ensemble de la Population). Supplément série statistique No. 17, Bulletin Mensuel de Statistique d'Outre-Mer. Institut National de la Statistique et des Etudes Economiques/Service des Statistiques, Paris. Johnston, J. (1846) S.S.L., Papara, Tahiti, 12 Aug.

- (1847) Ibid., Tahiti, 11 May.

Joseph, T. and Howe, W. (1846) Letter to L.M.S. from Camberwell, England, 13 June.

Journal Officiel des Etablissements Français de l'Océanie. No. 11, 15 June 1957, pp. 336-8.

Jupp, Kathleen M. (1958) Report on the Population census, 1956: Territory of Western Samoa. Govt Printer, Wellington.

Keesing, F. M. (1934) Modern Samoa. Allen \& Unwin, London.

King, J. (1864) S.S.L., Falealupo, Samoa, 30 Sept.

Krause, E. (1843) S.S.L., Tahiti, 16 May.

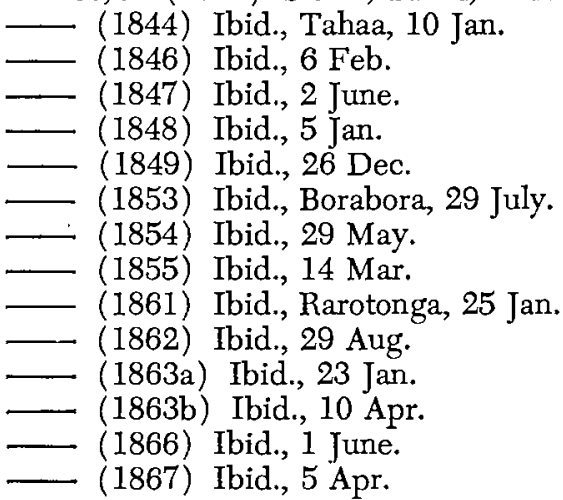

Krusenstern, A. J. von (1813) Voyage round the world, in the years 1803, 1804, 1805 \& 1806 by order of His Imperial Majesty Alexander the First, on board the ships Nadeshda and Neva under the command of Captain A. J. von Krusenstern of the Imperial Navy. Translated from the original German by R. B. Hoppner Esq. 2 vols. Printed for John Murray, London.

Labillardiere, M. (1800) Voyage in search of La Perouse . . . during the years 1791, 1792, 1793 and 1794, translated from the French. Vol. 2, John Stockdale, London.

Lamaze (Msgr) (1882) Circular letter, dated 19 Mar. 1882, quoted in unpublished manuscript 'Un premier siècle d'Apostolat à Samoa' by Bishop J. Darnand, 1945. (By courtesy of R. P. Gilson.)

Lambert, S. M. (1926) Health Survey of Cook Islands. Appendix to N.Z.P.P. A-3, 1926: Appendix to the Journals of the House of Representatives of New Zealand.

- (1934) The depopulation of Pacific races. B.P.B.M. Spec. Publication 23, Honolulu.

- (1938) East Indian and Fijian in Fiji: their changing numerical relations. B.P.B.M. Spec. Publication 32, Honolulu.

Lamont, E. H. (1867) Wild Life among the Pacific Islanders. Hurst \& Blackett, London.

Laval, ? (?) Mémoires, II, MS. Picpus Archives. (By courtesy of C. W. Newbury.) 
(1846?) Lettres diverses. MS. Picpus Archives. (By courtesy of C. W. Newbury.)

Lawrence, W. N. (1884) S.S.L., Mangaia, 26 Dec.

- (1887) Ibid., Aitutaki, 23 Sept.

- (1890) Annual Report to L.M.S. from Aitutaki, 18 Dec.

- (1898) S.S.L., Aitutaki, 18 July.

Lawry, W. (1850) Friendly and Feejee Islands: a missionary visit to various stations in the South Seas in the year 1847, E. Hoole (ed.). Charles Gilpin, London.

(1851) A second missionary visit to the Friendly and Feejee Islands in the year 1850, E. Hoole (ed.). John Mason, London.

Leborgne, ?/Hamy, ? (1872) 'Sur la dépopulation des îles Gambier'. Bulletin de la Soc. d'anthrop. de Paris, 7, (2 $2^{\mathrm{me}}$ serie), pp. 682-7. (Summary by M. Hamy of Leborgne's thesis entitled 'Géographie médicale de l'archipe] des îles Gambier'.)

- /Dareste, C. (1874) 'Rapport sur le concours du prix Godard'. Bulletin de la Soc. d'anthrop. de Paris, 9 (2me série), pp. 100-4.

Lee, Ida (1920) Captain Bligh's second voyage to the South Sea. Longmans, Green \& Co., London.

Le Hunte, G. R. (1878) Memorandum to Colonial Secretary, 14 Sept. C.S.O. $78 / 1322$.

Liausu, ? (?) ? MS. Picpus Archives. (By courtesy of C. W. Newbury.)

Lind, W. (1852) S.S.L., Rurutu, 25 Oct.

- (1853) Ibid., 28 Nov.

$\longrightarrow$ (1855) Ibid., 22 Jan.

McArthur, Norma (1958) Report on the census of the population, 1956. Council Paper No. 1, Legislative Council Fiji.

- (1959) 'Fijians and Indians in Fiji'. Population Studies, 12, pp. 202-13. (1961) Introducing Population Statistics. Oxford University Press, Melbourne.

MacDonald, H. (1912) Report by District Medical Officer, Rotuma: Annual Medical Report for 1911. Council Paper No. 28, Legislative Council Fiji.

McGregor, W. and Solomon, P. S. (1880) Report of a Commission appointed to investigate certain alleged errors in the recent census of the Native population and other matters thereto pertaining. Levuka, Ovalau.

Marestang, M. (1892) 'La dépopulation aux îles Marquises'. Revue Scientifique, 44 (1), pp. 360-6.

Maretu (1871) MS. on history and culture of the Cook Islands. (Translated by Marjorie Crocombe.)

Marsters, W. (1888) Letter to Governor of Fiji, 6 Jan. C.A.F.W.P.H.C., Fiji.

Martin, J. (1818) An account of the natives of the Tonga Islands, compiled and arranged from the extensive communication of Mr. William Mariner, 2 vols. 2nd ed. John Murray, London.

Mathieson, J. (1883) Upolu and Manono Circuit Report, 1883: District Committee Minutes and Proceedings, Methodist Mission Society Papers (Mitchell Library), Vol. 20, 1881-3.

Maude, A. M. (1966) 'Population, Land and Livelihood in Tonga'. Ph.D. Thesis, Australian National University, Canberra.

Maude, H. E. (1958) 'In search of a home'. Jour. Poly. Soc., 67, No. 2, pp. 104-31. 
(1959) 'The Tahitian pork trade 1800-1830'. Jour. de la Soc. des Océanistes, 15, No. 15, pp. 55-95.

—, and Crocombe, Marjorie T. (1962) 'Rarotongan Sandalwood. An ethnohistorical reconstruction’. Jour. Poly. Soc., 71, No. 1, pp. 32-56.

Maxse, E. G. B. (1899) Despatch to Salisbury, 16 Feb. No. 9 F.O.C.P. No. 7233, 1899. Part 23 (new series): 'Further Correspondence Respecting the Navigators' Islands-January to March 1899'. (By courtesy of R. P. Gilson.)

Meade, H. (1871) A ride through the disturbed districts of New Zealand; together with some account of the South Sea Islands, R. H. Meade (ed.). John Murray, London, 2nd ed.

Messager de Tahiti (1881) 3 Mar.

Mills, W. (1839) S.S.L., Apia, 4 Nov.

Moerenhout, J.-A. (1837) Voyages aux îles du grand océan. 2 vols., reproduction of edition of 1837, Adrien, Maisonneuve, Paris, undated.

Montague, A. (1919) Report on the Medical Department for the year 1918. Council Paper No. 31, Legislative Council Fiji.

__ (1929) Annual Medical Report for 1928. Council paper No. 57, Legislative Council Fiji.

Montgomery, J. (1831) Journals of voyages and travels by the Rev. Daniel Tyerman and George Bennet, Esq. deputed from the London Missionary Society, to visit their various stations in the South Sea Islands, China, India, bc., between the years 1821 and 1829. Compiled from original documents by J. M. Frederick Westley and A. H. Davis, London.

Moore, J. (1844) S.S.L., Papara, Tahiti, 18 Apr.

Morris, G. (1861) S.S.L., Raiatea, 29 June.

— (1862a) Ibid., 29 Mar.

- (1862b) Ibid., 27 Oct.

—_ (1865a) Ibid., Papeete, Tahiti, 28 Feb.

- (1865b) Ibid., 4 Aug.

- (1865c) Ibid., 4 Dec.

- (1867a) Ibid., 1 June.

- (1867b) Ibid., 22 July.

Morrison, J. (1935) The journal of James Morrison, Boatswain's Mate of the Bounty, describing the mutiny of subsequent misfortunes of the mutineers, together with an account of the island of Tahiti. Golden Cockerel Press, London.

Murray, A. W. (1839) S.S.L., Pago Pago, 10 June.

- (1856) Ibid., Apia, 25 June.

- (1858) Ibid., Apia, 9 Nov.

(1863) Missions in Western Polynesia. John Snow, London.

Myers, R. J. (1940) 'Errors and bias in the reporting of ages in census data'. Trans. Act. Soc. of America, 41, pp. 395-415.

- (1954) 'Accuracy in age reporting in the 1950 U.S. census'. Jour. Am. Stat. Ass., 49, pp. 826-31.

Newbury, C. W. (1957) 'The Administration of French Oceania, 1842-1906'. Ph.D. Thesis, Australian National University, Canberra.

N.Z. Census Reports (1906-1945) Govt Printer, Wellington, 1907, 1912, $1920,1925,1926,1937,1947$. 
New Zealand Gazette (1916) No. 72, 29 June.

New Zealand Official Year Book (1903) Govt Printer, Wellington.

N.Z.P.P. A-3 (1896-1961) Annual Reports for the Cook Islands. Appendices

to the Journals of the House of Representatives of New Zealand each year.

N.Z.P.P. A-4 (1922-1957) Annual Reports for Western Samoa.

N.Z.P.P. A-4A (1924) Supplementary Report of the Department of Health,

Mandated Territory of Western Samoa for the year ended 31st March, 1924. Appendix to the Journals of the House of Representatives of New Zealand, 1924.

- (1926) Annual Report of the Department of Health, Mandated Territory of Western Samoa for the year ended 31st March, 1926. Appendix to the Journals of the House of Representatives of New Zealand, 1926.

N.Z.P.P. H-31C (1919) Report of Samoan Epidemic Commission. Appendix to the Journals of the House of Representatives of New Zealand, 1919.

Orsmond, J. M. (1831) S.S.L., Griffin Town, Eimeo, 23 Mar.

— (1834) Ibid., Bogue Town, Taiarapu, 25 Dec.

- (1836) Ibid., 28 Dec.

- (1841) Ibid., 12 Oct.

- (1843) Ibid., 29 June.

Pearse, A. (1870) S.S.L., Borabora, 11 July.

- (1872) Ibid., 26 June.

- (1873a) Ibid., 23 Jan.

- (1873b) Ibid., 16 July.

- (1874) Ibid., 12 Feb.

- (1880) Ibid., Raiatea, 20 June.

- (1881a) Ibid., 28 May.

(1881b) Ibid., 31 May.

Pitman, C. (1830a) S.S.L., Rarotonga, 2 July.

- (1830b) Ibid., 17 Aug.

- (1832) Ibid., 29 Sept.

- (1833) Ibid., 7 Apr.

- (1836) Returns for Ngatangiia, June 1836.

- (1837) S.S.L., Rarotonga, 27 Feb. 1837 to 20 Mar. 1837.

- (1839) Returns for Ngatangiia, 31 July.

- (1841) Ibid., 31 Dec.

— (1843a) S.S.L., Rarotonga, 3 July.

- (1843b) Ibid., 5 Sept.

- (1844) Ibid., 27 Dec.

- (1847) Ibid., 28 Oct.

- (1848) Ibid., Dec.

- (1849a) Ibid., 3 July.

- (1849b) Ibid., enclosing Vital Statistics for 1849, 28 Nov.

- (1850) S.S.L., Rarotonga, 11 Nov.

- (1851) Ibid., 1 Jan.

Platt, G. (1827) S.S.L., Borabora, 28 Feb.

- (1832) Letter to W. Ellis from Huahine, 12 July. (1835) S.S.L., Borabora, 18 Feb.

(1838) Ibid., Raiatea, 4 Jan.

(1839a) Return for Borabora and Maupiti, 7 Jan. 1838 to 8 Jan. 1839.

(1839b) S.S.L., Raiatea, 14 Jan. 


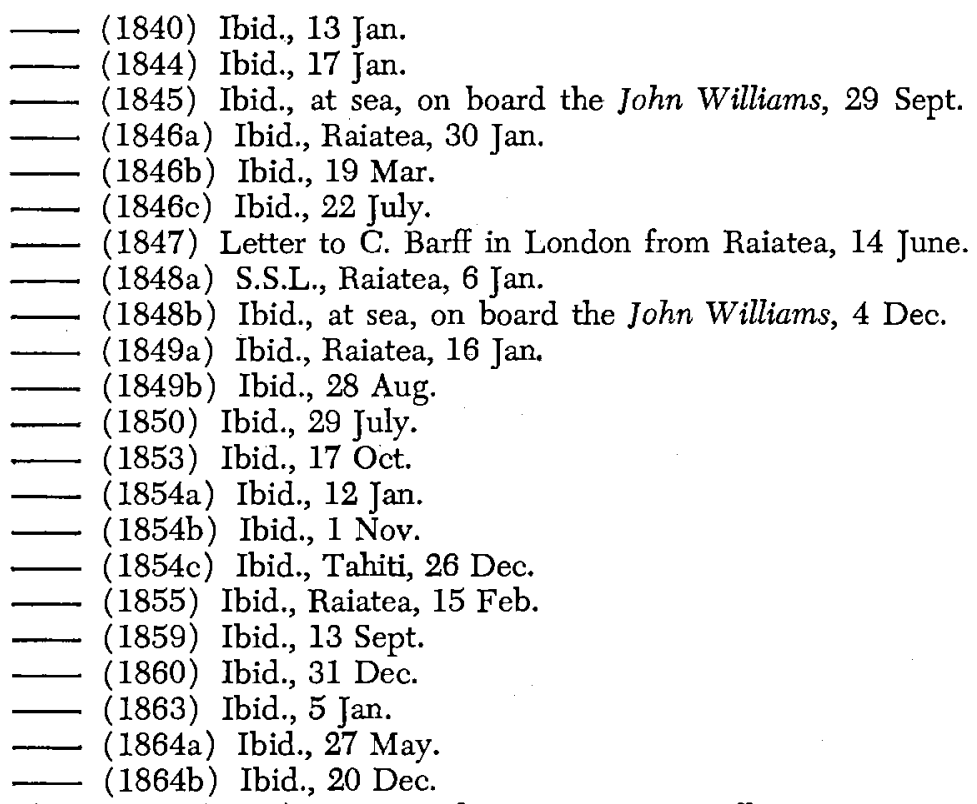

Plessen, L. (1887) Memorandum to Foreign Office, 3 Mar. F.O.C.P. No. 5532, 1887. Part I (new series): "Correspondence respecting the Navigators' Islands-January to June 1887'. (By courtesy of R. P. Gilson.)

Porter, D. (1823) A voyage to the South Seas in the years 1812, 1813 and 1814. Phillips \& Co., London.

Powell, T. (1853) S.S.L., Pago Pago, 14 July.

- (1854) Ibid., Manu’a, 29 July.

- (1856) Ibid., Pago Pago, 14 Jan.

- (1858) Ibid., 29 June.

- (1862) Ibid., Tutuila, 3 Oct.

— (1865a) Ibid., Leone, 27 July

- (1865b) Ibid., Apia, 20 Sept.

(1868) Chronicle of the London Missionary Society (reprinted in N.Z.P.P. A-3a Appendix, 1872, p. 19).

Pratt, G. (1849) S.S.L., Matautu, Samoa, 1 Nov.

Pritchard, G. (1845) Consul to Foreign Office, 31 Dec. F.O. 58/38 to Aberdeen. (By courtesy of R. P. Gilson.)

- , and Simpson, A. (1829) L.M.S. Journal-Voyage to the Austral Islands, Apr. 1829.

Pritchard, Mrs G. (1842) S.S.L., Tahiti, 13 Feb.

Pritchard, W. J. (1866) Polynesian Reminiscences. Chapman \& Hall, London. de Quatrefages, A. (1864) Les Polynésiens et leurs migrations. Arthus Bertrand, Libraire de la Soc. de Geog., Paris.

de Ricci, J. H. (1875) Fiji: our new province in the South Seas. Edward Stanford, London.

Richards, W. E. (1886a) S.S.L., Tahiti, 2 Feb.

- (1886b) Ibid., Raiatea, 1 June. 
(1887a) Ibid., 30 Sept. (Private and confidential to Foreign Secretary.)

- (1887b) Ibid., 29 Dec.

(1888a) Ibid., 2 Feb.

(1888b) Ibid., 21 May.

(1888c) Ibid., 9 July.

Robertson, G. (1948) The discovery of Tahiti. A journal of the second voyage of H.M.S. Dolphin round the world under the command of Captain Wallis, R.N., in the years 1766, 1767 and 1768. H. Carrington (ed.). Cambridge University Press for Hakluyt Society, Second Series, No. 98, issued for 1948.

Rodgerson, J. (1838) S.S.L., Tahiti, 25 Aug.

- (1841a) Ibid., Borabora, 1 Feb.

- (1841b) Ibid., 24 Dec.

- (1842) Ibid., 14 Dec.

- (1843) Ibid., 18 Dec.

—. (1844) Ibid., 25 May.

- (1845) Ibid., 14 Jan.

- (1846a) Ibid., 21 Jan.

(

Rollin, L. (1929) Les îles Marquises. Société d'éditions géographiques, maritimes et coloniales, Paris.

van Rooyen, C. E. and Rhodes, A. J. (1948) Virus diseases of man. Thomas Nelson \& Sons, New York.

Rosen, L. and Thooris, G. (1953) 'Poliomyelitis in French Oceania'. Amer. Jour. Hygiene, 57, No. 2, pp. 237-52

Royle, H. (1840) S.S.L., Aitutaki, 25 Dec.

— (1843) Ibid., 9 May.

- (1847) Ibid., 19 Sept.

- (1854) Ibid., 8 Nov.

- (1865) Ibid., 17 May.

Samoa Times (1893) 2 Sept., 9 Sept., 30 Sept., 21 Oct.

(1894) 16 Feb. (By courtesy of R. P. Gilson.)

Samoan Reporter No. 5, Mar. 1847; No. 13, July 1851; No. 15, Jan. 1854;

No. 18, Jan. 1857; No. 21, Mar. 1860. (By courtesy of R. P. Gilson.)

Saville, A. T. (1868) S.S.L., Huahine, 10 Oct.

- (1869) Ibid., 31 Mar.

(1871a) Minutes of Committee Meeting held in Tahiti 16, 17 and 18 May 1871.

- (1871b) S.S.L., Huahine, 14 Sept. to $23 \mathrm{Dec}$.

Service de statistique (1960) Recensement général de la population (Décembre 1956). Territoire de la Polynésie Française-Résultats définitifs. Paris.

Sharp, A. (1960) The discovery of the Pacific Islands. Oxford University Press, reprinted 1962.

Simpson, A. (1829) Return for Papetoai, Roby's Place, from June 1829 to end Sept. 1829.

(1833a) Return for Roby's Place, Blest Town, Eimeo to Jan. 1833. 18 May.

(1833b) Return for Blest Town, 18 May to 2 Nov. 1833.

(1834) Return for Blest Town, 2 Nov. 1833 to 12 Nov. 1834. 
(1835) Return for Papetoai, Eimeo to Nov. 1835. 22 Oct.

(1837) S.S.L., Eimeo, 15 Nov.

(1839) Return from Papetoai, Eimeo, June 1838 to 17 Sept. 1839.

(1844) S.S.L., Moorea, 10 May.

(1847) Ibid., 24 July.

Smith, D. B. (1936) "Some remarks about the mutiny of the "Bounty" . Mariner's Mirror, XXII, pp. 200-37, quoted in H. E. Maude (1958).

Smythe, Mrs S. M. (1864) Ten months in the Fiji Islands. John Henry and James Parker, Oxford and London.

Spencer, G. (1853) S.S.L., Papeete, 11 Mar.

Stair, J. B. (1897) Old Samoa. The Religious Tract Society, London.

Stallworthy, G./Sheahan, G. M. (1839) Extracts from the Journal of George Stallworthy, Missionary, Vaitahu, Tahuata, Marquesas. MS. No. 117 of L.M.S., transcribed by G. M. Sheahan: Marquesan Source material, Appendix II, pp. clxxxiv-clxxxix. MS., Mitchell Library.

Sterndale, H. B. (1874) Memoranda by Mr. Sterndale on some of the South Sea Islands. Part III of Papers relating to the South Sea Islands. Appendix A-3B to the Journals of the House of Representatives of New Zealand.

Stewart, C. S. (1833) A visit to the South Seas in the U.S. ship 'Vincennes'. Edited and abridged by W. Ellis. Fisher, Son \& Jackson, London.

Stewart, J. (1892) Minute by the Assistant Colonial Secretary, accompanying 12th Annual Report on the Vital Statistics of the Native Population; year 1890 and 1891. (Reprinted in Comey, Stewart and Thomson, 1896.)

Sunderland, J. P. and Buzacott, A. (1866) Mission life in the islands of the Pacific. John Snow \& Co., London.

Sutherland, W. (1902) Report on Fijian Population; Census 1901. Fiji Royal Gazette, No. 10 of 1902.

Teissier, R. (1953) 'Etude démographique sur les Etablissements Français de l'Océanie de Cook au recensement des 17/18 Septembre 1951'. Bull. de la Soc. des Etudes Océaniennes, No. 102, t. IX (No. 1), pp. 6-31.

Te Karere Feb. 1900, Jan. 1901. (By courtesy of R. P. Gilson.)

Thomson, B. H. (1892a) Twelfth Annual Report on the Vital Statistics of the Native Population; year 1890 and 1891. (Reprinted in Comey, Stewart and Thomson, 1896.)

- (1892b) Reply to Circular Letter of Colonial Secretary. (Published in Corney, Stewart and Thomson, 1896.)

- (1894) The diversions of a Prime Minister, Blackwood and Sons, London.

—. (1902) Savage Island, John Murray, London.

Thomson, R. (1841a) L.M.S. Journal-The Marquesas Islands: a brief account of discovery and early history-general and geographic description etc.

- (1841b) The Marquesas Islands: a brief account of discovery and early history, transcribed by G. M. Sheahan, Marquesan source material, Appendix II, pp. cxc-ccv. MS., Mitchell Library.

(1845) S.S.L., Papeete, 5 Aug.

Threlkeld, L. E. and Williams, J. (1818) S.S.L., Raiatea, 30 Oct. (1823) Ibid., 20 Nov.

Thurston, J. B. (1876a) Memorandum upon the Establishment of District Plantations in the Colony of Fiji, for the purposes of enabling the Native Population to provide for their Taxes in a manner accordant with Native 
Customs. 16 Feb. G.B.P.P. 1876, LIV, pp. 73-80. (By courtesy of Ethel Drus.)

(1876b) Inclosure 4 in No. 30. 16 Feb. G.B.P.P. 1876, LIV, pp. 84-94.

(By courtesy of Ethel Drus.)

(1879) Despatch to Chief Secretary, Victoria, 14 June. C.S.O. 79/593.

(By courtesy of Ethel Drus.)

- (1881) Despatch to Des Voeux, 3 Nov. C.S.O. 81/1996 (P5). (By courtesy of Ethel Drus.)

- (1886) Report upon the Condition of the Samoan Islands. British Command Papers-C.5629, No. 25. (By courtesy of R. P. Gilson.)

Tonga Government Gazette 1912, 1921, 1932, 1933, 1934, 1935, 1937, 1938, 1940.

Trenn, L. (1954) Personal communication.

Tupouniua, M. U. (1958) Report on the results of the 1956 census, Kingdom of Tonga.

Tupper, ? (1899) Report of the Commander of H.M.S. Pylades on a tour of the Northern Cook Group in September 1899. B.C.S.-N.A. (By courtesy of R. P. Gilson.)

Turnbull, J. (1813) A voyage round the world in the years 1800, 1801, 1802, 1803, 1804: in which the author visited Madeira, the Brazils, Cape of Good Hope, the English settlements of Botany Bay and Norfolk Island, and the principal islands in the Pacific Ocean. 2nd ed. A. Maxwell, London.

Turner, G. (1861) Nineteen years in Polynesia: missionary life, travels and researches in the islands of the Pacific. John Snow, London.

- (1869) S.S.L., Malua, 16 Apr. (1870) Ibid., 3 Sept.

U.N.P.D. (1948) The population of Western Samoa. Reports on the Population of Trust Territories, No. 1. Lake Success, New York.

Valenziani, C. (1940) 'Renaissance démographique en Océanie Française'. Comitato italiano per lo studio dei problemi della popolazione, Serie 3, Vol. 3. Tipografia Consorzio Nationale, Rome.

- (1949) 'Enquête démographique en Océanie Française'. Population, 4, pp. 93-114.

Vancouver, G. (1801) A voyage of discovery to the North Pacific Ocean and round the world undertaken by His Majesty's command . . . in the years $1790,1791,1792,1793,1794$ and 1795 in the Discovery sloop of war, and armed tender Chatham under the command of Captain G. Vancouver. New ed. with corrections, 6 vols. John Stockdale, London.

des Vergnes, P.-E. (1877) L'Archipel des Iles Marquises. Berger-Levrault et Cie, Paris.

Vivian, J. C. (1865a) S.S.L., Raiatea, 11 July.

- (1865b) Ibid., 20 Nov.

- (1865c) Ibid., 20 Nov.

- (1869a) Ibid., 23 June.

- (1869b) Ibid., 16 Nov.

-_ (1872) Ibid., 19 May.

Waldegrave, W. (1833) 'Extract from a private journal kept on board H.M.S. Seringapatan, in the Pacific, 1830, Jour. Roy. Geog. Soc. London, 3, pp. 185-94.

Watkin, J. (1833) Account of Ha'apai group: Papers of the Rev. J. Watkin 1832-3. Mitchell Library. 
Western Samoa Gazette. No. 47, 12 Jan. 1928; No. 97, 26 Oct. 1936.

Wilkes, C. (1845) Narrative of the United States Exploring Expedition during the years 1838, 1839, 1840, 1841, 1842. Wiley \& Putnam, London.

Wilkinson, D. (1879) Memorandum to H.E. the Governor, 12 June. C.S.O. $79 / 1021$.

Williams, J. (1823) Letter to W. Ellis from Raiatea, 1 Oct.

—_ (1829) S.S.L., Raiatea, 26 Jan.

(1838) A narrative of missionary enterprises in the South Sea islands. John Snow, London.

Williams, J. C. (1863) Consul to Foreign Office, 9 Feb. B.C.S.-N.A. Series 3, Vol. 2. (By courtesy of R. P. Gilson.)

- (1864) Consul (Apia) to Foreign Office, No. 8, 19 June. B.C.S.-N.A. Series 3, Vol. 3. (By courtesy of R. P. Gilson.)

- (1870) Consul to Foreign Office, 12 Jan. B.C.S.-N.A. Series 3, Vol. 3.

(By courtesy of R. P. Gilson.)

(1871) Consul to Foreign Office, 20 Mar. Trade report for Tutuila for 1870. B.C.S.-N.A. Series 3, Vol. 3. (By courtesy of R. P. Gilson.)

Williams, S. F. (1875) Acting-Consul to Foreign Office, 1 Jan. B.C.S.-N.A. Series 3, Vol. 3. (By courtesy of R. P. Gilson.)

Williams, T. (1858) Fiji and the Fijians. Vol. I. The islands and their inhabitants. G. S. Rowe (ed.). Alexander Heylin, London,

Wilson, C. (1826) S.S.L., Waugh Town, Matavai, Tahiti, 4 Dec.

- (1827) Annual Report of the Missionary Station at Waugh Town, Matavai, and Papara. May.

- (1833) Annual Report of the Mission Station at Waugh Town, Matavai, Tahiti from 1 Dec. 1831 to 31 Déc. 1832 inclusive. 11 Jan.

- (1834) A Report of the state of the Mission at Waugh Town, Matavai, Tahiti from 1 Jan. to 31 Dec. 1833 inclusive, enclosing Return.

- (1835a) S.S.L., Waugh Town, Matavai, 15 Oct., enclosing Return for 1834 .

(1835b) A Report of the Mission Station at Waugh Town, Matavai, Tahiti from 1 Jan. to 31 Dec. 1835 inclusive, enclosing Return.

(1836) Return for Waugh Town, 31 Dec. 1835 to 30 Sept. 1836.

- (1837) Return for Waugh Town, Papenoo, Haapaiano, from Oct. 1836 to 23 Nov. 1837.

- (1839) Return for Waugh Town, Papenoo, 31 Oct. 1837 to 30 Apr. 1839.

- (1841a) Letter to Geo. Bennet from Matavai, Tahiti, 9 Nov.

- (1841b) A Report of the Missionary Station, Waugh Town, Matavai, Tahiti from 30 Sept. 1840 to 30 Nov. 1841.8 Dec.

Wilson, W. (1799) A missionary voyage to the Southern Pacific Ocean, performed in the years 1796, 1797, 1798, in the ship Duff, commanded by Captain James Wilson. Compiled from Journals of the Officers and the missionaries . . . by a committee appointed for the purpose by the Directors of the Missionary Society. Chapman, London.

Wood, A. H. (1938) History and geography of Tonga, Wilson \& Horton Ltd, Auckland.

Zaborowski, M. (1892) 'Disparités et avenir des races humaines'. Bull. de la Soc. d'Anthrop. de Paris, 3 (4th series), pp. 617-65. 


\section{Index to Persons}

Adams, H., 238-9

Aitken, R. T., 303

Amat, Don Manuel de, 243

Ari'i Taimai, 238

Bachi, R., 44

Baker, Rev. S., 75

Bambridge, B., 343

Banks, J., 237, 260, 297

Barff, C., 254-6, 266-8, 271-2, 276-7, $296,298-9,303,305,307-8,311$

Barff, J., 268, 272-3, 296, 298, 305, 307, 311

Beaglehole, E., 188, 229

Beaglehole, J. C., 234, 237-8, 240-1, 265, 297

Beaglehole, Pearl, 188, 229

Bennet, G., 302

Berchon, E., 258, 261

Beye, H. K., 343

Bicknell, H., 252-3

Bingham, H., 186

Bleazard, C., 110-11

Bligh, W., 1, 234, 238, 244-6, 260, 262-3

Blossom, T. G., 253

Boenechea, Don Domingo, 240, 303

Bougainville, L. A. de, 98, 233, 236

Bourne, R., 270

Boyd, R., 20, 32, 34

Brenchley, J. L., 74

Brown, P., 191

Bruat (Commissioner), 253

Buchanan, E., 253-4

Buck, Peter H., 184-5, 187

Bullen, T., 104

Burrows, W., 22, 35

Buzacott, A., 166-7, 169-70, 174-5, 180

Byron, J., 233

Caillet, F. X., 313

Caillot, A. C. E., 244, 260-1, 289, 306$9,312,314$

Caret, ?, 312

Carew, W. S., 14

Carne, A. H., 109

Carrington, H., 233, 235

Chalmers, J., 171-2, 177, 180

Charter, G., 255, 266-7, 271-2, 277

Chaulet, P., 289
Chisholm, A., 267, 272-3, 277, 296, 310

Christian, F., 234, 299

Churchward, W. B., 108

Clavel, M., 287, 289-92, 313

Coetlogon, H. de, 109

Collier, J. W., 109-11

Cook, J., 68-9, 71, 162, 181-2, 189, 233$4,236-8,240-2,244-5,260-1,265$, $279-80,297,299,347,354$

Cool, J. C., 143

Cooper, E. V., 269-70, 274-5, 279

Corney, B. G., 6, 9, 15, 26, 240, 243-4, 246,303

Coulter, J. W., 151

Cowan, J., 189

Crocombe, Marjorie T., 162

Crocombe, R., 165

Crook, W. P., 248-9, 280-4

Crozier, Dorothy, 76, 81-2

Cuming, H., 298, 301-2, 304-5

Cusack-Smith, T. B., 109

Cuzent, G., 256-7, 261, 289, 311

Darby, Madge, 262

Dareste, ?, 312-13

Darling, D., 248-52, 254-6, 283-5, 295$6,302,305,307,311$

Davidson, J. W., 112

Davies, J., 236, 238, 247-51, 253-6, 261, $266,275-6,283,296-8,302,304-5$, 307,310

Dawson, T, 108

Derrick, R. A., 2, 6, 74, 96

Des Voeux, G. W., 15, 18

Dods, M. T., 20

Dupetit-Thouars, ?, 235, 285, 287-8, 313

Edwards, E., 245

Eggiman, ?, 287, 289-91

Elder, J., 245, 248, 252, 265

Ellis, W., 266, 270, 296-8, 301, 304-5, 307,309

Ellison, J. W., 98, 112

Emberson, H. J., 10, 18

Entrecasteaux, A. R. J. d', 69

Erskine, J. E., 4, 73, 100-4, 114

Forster, G., 242, 280

Forster, J.' R., 242, 261, 280 
Foster, S. S., 101, 105-6

Furnas, J. C., 313

Gayangos, T., 243, 303

Gifford, E. W., 69, 71, 73, 77-8, 82-3

Gill, G., 176-8

Gill, W., 165-9, 179-82, 184, 187

Gill, W.'W, 17I-2, 177, 180, 182, 184-8

Gillion, K. L., 12

Gilson, R. P., 101, 104, 107-8, 111, 114, 124,164

Gittins, J. W., 23, 28

Goodenough, P., I62, 164

Gordon, Sir Arthur, 12, 15, 26

Gorrie, J., 107

Goward, G., 107

Gracia, M., 282, 285, 288, 294

Graves, J. H., 108

Green, J. L., 269-70, 273-4, 278, 296, 299, 308, 311

Green, R. C., 262

Gros, H., 258, 260-1, 269-70, 306, 309

Gyles, J., 248, 266, 270, 275

Hamy, ?, 312-13

Handy, E. S. C., 238-9

Hardie, C., 104

Harris, G. A., 171, 177-8, 180-2, 186, 188

Heath, T., 252, 254, 298, 302, 305, 307

Henderson, G. C., 2

Henry, S. P., 304

Henry, Teuira, 238-9, 241, 247

Henry, W., 250-4, 297, 303

Heuls, J., 343

Hill, J. A., 141,147

Hooper, A., 200

Howe, W., 252-6, 303

Hunt, J., 4

Hutchin, J., 172, 18I-2

Ingraham, J., 280

Jefferson, J., 247

Johnston, J., 254

Joseph, T., 255

Jouan,? 287-9

Jupp, Kathleen M., 121, 123, 128-30, 134, 138-9

Keesing, F. M., 109

Kessel, J. F., 343

King, J., 105

Kotzebue, O. von, 98

Krause, E., 171, 181, 184, 267, 271-2, 277

Krusenstern, A. J. von, 281-2, 294

Labillardiere, M., 69

Lamaze, (Msgr), 108

Lambert, S. M., 83, 110, 185-6

Lamont, E. H., 185

Langara, C. de, 244

La Perouse, J. F. de, 98
Laval, ?, 312-13

Lawrence, W. N., 180-2

Lawry, W., 5, 73

Lawson, ?, 287, 289

Leborgne,?, 312-13

Lee, Ida, 238,246

Le Hunte, G. R., 13

Liausu, ?, 313

Lind, W., 298-9

Ma'afu, 74

MacDonald, H., 36

Malietoa, 100, 111

Maire, J. le, 233

Marchand, E., 280

Marestang, M., 287-9, 291-5

Maretu, 164-5, 175

Marsters, W., 189-90

Martin, J., 72

Mata'afa, 111

Mathieson, J., 108

Maude, A. M., 68

Maude, H. E., 162, 235, 302

Maui Pomare, 186

Maunelle, F. A., 68

Mauruc, A., 307

Maxse, E. G. B., 101, 112

McArthur, Norma, 35, 40-1, 43, 63, 65-6

McGregor, W., 14-15

Meade, H., 74

Mendaña, A. de, 232, 280

Mery, (Lieut), 308

Mills, W., 102

Moerenhout, J.-A., 296, 298, 302, 304-7, 310

Montague, A, 33-4, 37, 83

Montgomery, J., 266, 297, 301-2, 304

Moore, J., 254

Morris, G., 268, 274, 278, 296, 299, 303, 305,308

Morrison, J., 238, 245, 261, 300

Murray, A. W., 100, 102-5

Myers, R. J., 44

Newbury, C. W., 190, 236, 238, 247, $250,254-5,259,285,312-14$

Newcastle, Duke of, 7

Nott, H., 301

Omai, 265

Orsmond, J. M., 250-1, 253, 275

Pearse, A., 269-70, 274, 278, 303, 306

Pirie, P. N. D., 141

Pitman, C., 165-7, 169, 176, 179, 270

Platt, G., 249, 253, 256, 267, 271-4, 276$8,304,307,310-11$

Plessen, L., 101, 108

Pomare, 248, 252-3, 261, 265, 301, 303

Porter, D., 282-3

Powell, T, 104-5, 114

Pratt, G., 103

Pritchard, G., 102, 250, 253, 304, 307 
Pritchard, Mrs G., 251-2

Pritchard, W. J., 7

Quatrefages, A. de, 288

Quiros, P. F. de, 232

Rhodes, A. J., 34

Ricci, J. H. de, 7-8

Richards, W. E., 274-5, 278

Roberts, ?, 281-2

Robertson, G., 233, 235

Robson, R. W., 284

Rodgerson, J., 250, 276-7

Rodriguez, M., 243, 247, 261

Roggeveen, J., 98, 233

Rollin, L., 279-80, 282, 285, 287-93, 295

Rooyen, C. E. van, 34

Rosen, L., 323

Royle, H., 169, 179-80, 184-5

Saville, A. T., 269-70, 278, 299, 303, 305, 308,311

Scott, W., 247

Schouten, W. C., 233

Sharp, A., 233, 280, 296, 311

Sheahan, G. M., 280-1, 284-5

Simpson, A., 251, 253-5, 304, 307

Smith, D. B., 302

Smythe, W. J., 7

Smythe, Mrs S. M., 5

Solomon, P. S., 14-15

Spencer, G., 256

Stair, J. B., 100, 102, 113

Stallworthy, G., 284-5

Sterndale, H. B., 74, 106-7, 185-90

Stewart, C. S., 283

Stewart, D. R., 21, 34

Stewart, J., 6, 9, 15, 18-19, 25, 30, 80, 245

Sunderland, J. P., 166-7, 169, 175

Sutherland, W., 19

Tamasese, 109

Tasman, A. J., 1, 68

Taufa'ahau, 73
Teissier, R, 256-61, 266, 270, 275-6, 278, $284,289,296,299,303,306,309-12$, $314,317,319-20$

Thakombau, $6,7,74$

Thomson, B. H., 6, 9, 15, 18-19, 23, 25-7, $30-1,71,75-9,110,245$

Thomson, R., 254, 284-5, 287

Thooris, G., 323, 343

Threlkeld, L. E., 248, 270, 297, 301

Thurston, J. B., 7, 11, 14-16, 108

Trenn, L., 201

Tupaia, 234, 236-9, 241-2, 245, 247, 260 , 354

Tupouniua, M. U., 80-1, 91

Tupper, (Capt.), 186, 188-90

Turnbull, J., 72, 245, 247

Turner, G., 102, 104, 106

Tyerman, D., 297, 302

Valenziani, C., 260-1, 287, 289, 314-16, $319,321,323,325,335-6,340$

Vancouver, G., 246, 265, 303, 306, 347

Vergnes, P.-E. des, 287-90

Vivian, J. C., 274, 278, 296, 299, 303, 305,311

Waldegrave, W., 72, 248, 266, 271, 275

Wallis, S., 233

Watkin, J., 72

Watts, (Lieut), 244

Weber, T., 106

Wilkes, C., 4-5, 8, 72-3, 100-4, 113

Wilkinson, D., 14

Williams, J., $98,100,162-5,174,176$, $179,181-2,248,263,270,297-8,301$, 354

Williams, J. C., 105-6, 186

Williams, S. F., 107

Williams, T., 5-6

Wilson, C., 245, 248-52, 262, 265, 282-3

Wilson, W., 238, 246-7, 301, 346

Wood, A. H., 69, 71, 83

Youl, J., 252

Zaborowski, M., 289 


\section{General Index}

\section{Adventure, 244}

Age. 33, 118-20, 142, 147, 173, 178, 191-2, $325-6$; at first birth, 63-5, 94-5, 139$41,156,159,222,225-6,228$; descriptive, $13-16,20,25,31,80,84,114$, $116-20,127,167,176,257,325$; preferences, 201, 329, (for unit digits) 40-2, 44, 85-7, 128, 147, 149; pyramid, 291-3, 353; unreliability of, 40,42, $44,52-3,59,85,87,89,92,128-31$, $135,137,147,201-2,211,227,329$

Age composition, 347-8; distortion of, 30 , $33,96-7,175,205,292-5,329-31,348$, 353; in Cook Islands, 168-9, 173-4, 20I-II, 222; in Fiji, 6, 31, 33, 36-46, 67, 78; in French Polynesia, 255-6, $292-3,308,325-34,349,353$; in Samoa, 124, 126-31, 145, 147-51, 353; in Tonga, 78, 84-9, 97

Aguila, 234, 238, 240, 242-4, 303, 347

Aitutaki, $162,164,169,176,179-80$, $182-3,186-7,193,227-8,230$

Anaa, 301, 311

Annexation: Austral Islands, 235; Cook Islands, 164; French Polynesia, 235, 343; Gambier Islands, 235; Marquesas Islands, 235, 285; Penrhyn, 186; Rapa, 308; Rotuma, 2; Society Islands, 235; Tahiti, 270; Tuamotu, 235

Apolima, 98, 101, 108, 112, 117-18

Atiu, 162-3, 181-3, 193, 227-8, 308

Austral Islands, 232, 234-5, 296-310, $319-21,330-1,340,344,347$; see also Raivavae, Rapa, Rimatara, Rurutu, Tubuai

Australia, 235, 350; Colonial Sugar Refining Company of, 12; New South Wales, 100, 256; Sydney, 162, 350; Victoria, 14

Birth rates, crude, 345; Cook Islands, $174,177,231$; Fiji, 32, 57, 78, 114; French Polynesia (Tahiti), 249-50, 258, 338-9; Samoa, 103, 114-15, 124, 16I; Tonga, 76-9, 96-7

Birth registration, $117,127,147,161$, $198,256,292,334-5$; completeness of, 51-2, 92, 94, 96-7, 117, 129, 134, 137$8,152-3,155,201,214,218,221,335$,
$340,345,351-3$; regulations for, 46-50, $89-91,113,126,131-4,151-2,211-14$, 335

Births: in Cook Islands, 166-71, 174-8, 180, 191, 218, 349; in Fiji, 26, 29-30, $32,34,36,40-2,52,57,78,351-2$; in French Polynesia, 244, 248-50, 253, $255,258,266-7,270-3,276-7,279$, $290-4,309,313,321,336,338-9$; in Rotuma, 36; in Samoa, 103, 105, I14$15,124-7,129,134,137-8,151,155-$ 61 ; in Tonga, $73,76-9,83-5,87-9,92$, 96-7

Borabora, 248, 265-6, 274-9, 297

Bounty, I, 162, 234, 238, 244-5, 299-300, 302

Cannibalism, 162, 282, 288, 294, 306

Catholic missionaries and missions, 108, $238,242-4,250,285,288,312,335$

Census enumerations: in Cook Islands, $172-3,178,180-3,186,188-90,191$ 200 ; in Fiji, 11, 13-28; in French Polynesia, 235, 255-60, 270, 275, 278, $289-91,296,299,303,306,309-12$, 314-25; in Samoa, 112-13, 115-23, 127, 141-5, 160-1; in Tonga, 75-83; procedures for, $14,16-24,75-6,79-81$, $116-21,141-3,191-3,196-7,314-18$

Cession: of Fiji, 2, 7, 30, 107; of Manu'a, 113; of Tutuila, 113, 147

Chatham, 184, 303

Children: average numbers born, 59-60, $62-3,67,95,138-9,156,159,161,222-$ $8,231,342-3$; average numbers surviving, $95,139,222-3,229-30,309$; per woman, $168,173,244,249,256-7$, $259,263,281,292,302,305,309$

Child-woman ratios, 45-6, 95, 131, 151, $173,207-8,292,330-1$

Chinese: Cook Islands, 174; Fiji, 35; French Polynesia, 258-9, 269, 295, 323-6, 331-2, 336, 338; Samoa, 117-20

Cohort survival: Cook Islands, 202-5; Fiji, 40-3; French Polynesia, 293, 32633; Samoa, 129-30, 147-9; Tonga, 87-8 Commissions of enquiry: 1879 Census of Fiji, 14-15; depopulation of Fiji $(1893), 6,8-9,15,29-30,71,75$; 
Commissions of enquiry-continued Samoan Epidemic (1919) , 125, 353

Cook Islands, 115, 160, 162-231, 258, 344-5, 354; Lower Group, 162, 164, $174,180-3, \quad 190-2, \quad 207-10,217-18$, 221-31, 354; see also Aitutaki, Atiu, Mangaia, Manuae, Mauke, Mitiaro, Rarotonga; Northern Group, 164, 184, 189-90, 192, 207-11, 217-18, 220-31; see also Manihiki, Nassau, Palmerston, Penrhyn, Pukapuka, Rakahanga, Suwarrow

Counts of populations: by missionaries, $73,100,102,104-7,113-15,160,166-$ $8,171,175-8,180-1,188,190,197$, $235,248-50,263,266-9,271-2,275$, $279,284,301-5,307,310,312,346$; others, $9-10,24,81,105,255,262$, $288-9,305,313$; see also Census enumerations

Death rates: crude, 345; Cook Islands, 174, 231; Fiji, 32, 36, 57; French Polynesia, 258, 266, 292, 338-9, 344; Samoa, 103, 114-15, 124, 161; Tonga, 76-7, 96-7

Death registration, $110,117,127,161$, $198,256,292,334-5$; completeness of, 51-2, 92, 96-7, 117, 129-30, 134-6, $152-3,155,199,214,218,335,345$, 351,353 ; regulations for, $46-50,89-$ $91,113,131-4,151-2,211-14,335$

Deaths: in Cook Islands, 165-70, 172, $174,176-8,180,185-6,191,199,214$ 15, 217-18; in Fiji, 26, 29, 32-4, 42, 52, 351-2; in French Polynesia, 248-9, 253 , $255,257-8,266-7,270-3,276-9,289-93$, $296-300,304-5,307,309,313,321-3$, 336,353 ; in Rotuma, 36; in Samoa, $103,105,109-10,114-15,124,126-7$, 134-5, 153-5, 160; in Tonga, 71, 76-7, $79,83-5,89-92,96-7$

Dengue fever, 26, 229, 269, 309

Dido, 8

Discovery, 244, 306

Disease, see Dengue fever, Dysentery, Filariasis, Influenza, 'Intermittent' fever, Leprosy, Measles, Mumps, 'Nondescript' scrofulous disease, Panama or coast fever, 'Pestilential' disease, Scarlatina, Smallpox, Tuberculosis, Typhoid fever, Venereal disease, Whooping cough

Dolphin, 233, 235

Duf, 69, 71, 246, 301, 312

Dysentery, 6, 26, 42, 74, 104, 110-11, $123-4,126,161,165,167,176,179$, $181,245-6,248,253-4,260,262-3$, $267,271-3,276-9,296,307-8,310$, $313,347,349$

Easter Island, 184

Emigrants, emigration: Cook Islands,
$167,171-3,175,177-80,190-1,199-$ $200,202,204-5,207,211,220-1,229-$ $31,345,350$; Fiji, 12, 34, 40, 345; French Polynesia, 264, 270, 313, 345; Samoa, 127, 129-31, 139, 141, 144$6,151,159,161,345$; Tonga, 74,96 , 345

Endeavour, 233, 236, 297

Epidemics, effect: on births, 30-2, 34, $36,114-15,125-6,170,172,264,293-$ $4,321-2,330,340,347,349,351$; on deaths, 29-30, 32, 114, 264, 321-3; on marriages, $31,125,264,294,322$, $340,349,351$; on population numbers, $6,103,127,161,347$

Epidemics: in Cook Islands, 165-70, 174, $176-7,179-81,185,189,228-9,349-$ 50,352 ; in Fiji, 6, 8-11, 26, 30-5, 42, 66$7,347,350-4$; in French Polynesia, $240,242-3,245-7,250-6,260,262-$ $73,276-9,288-9,293,295-9,301-3$, $308-10,312-13,319-23,329-31,334$, $337-8,343-4,347-8,350,352-3$; in Rotuma, 20, 36-7; in Samoa, 102-4, $109-11$, 114-15, 123-6, 144, 160-1, 350,352 ; in Tonga, 69, 71, 74-5, 77-8, $83,96,350,352$; see also Dengue fever, Dysentery, Influenza, Measles, Mortality (epidemic), Mumps, Panama or coast fever, Scarlatina, Smallpox, Typhoid fever, Whooping cough

Essex, 282

Estimates of populations, 2, 113, 354; by mariners, 4, 68-9, 73, 181, 235-7, 240$2,244-6,260-2,280-3,285-8,300$, $304,306,346$; by missionaries, 4-5, $72-3,100-8,113-14,164,175,181-2$, $184-8,246-8,255,266,270-1,274-$ $5,277-9,281,283-4,296-9,301$, $303,307-8,311-12,346$; by others, $7-8,10-11,66,74,105,107-9,112$, $186,188,240,242-3,260-1,282-3$, $296-8,302,304-5,346$

Etablissements Français de l'Océanie (E.F.O.), see French Polynesia

'Eua, 68, 72, 76-7, 83

Expectation of life at birth: Cook Islands, 231; Fiji, 67; French Polynesia, 262, 344; Samoa, 161

Family size, 66-7, 97, 139, 156, 222, 244, 344

Famine, food scarcity: Cook Islands, 165, 167, 174, 181-2, 228, 349; French Polynesia, 253, 256, 278, 282, 294-5, $299,313,344,348$; Samoa, 103-4, 108$11,115,123$; Tonga, 71

Fatu-Hiva, 280-1, 284-5, 290-1

Fertility, 137, 140,143,156, 199, 222, $262,343,345$; census questions on, $24,62,65,94-5,137,140-1,156$, $221-2,316,341$; rate, $94,137-8,219-$ 
Fertility-continued

21, 292-3, 339; rates, age-specific, 589, 66-7, 94, 137-8, 155-6, 339-40, 342; age-parity specific, 60-2, 137, 155-7; see also Births

Fiji, 1-67, 71-2, 74-5, 78, 83, 95-6, 100, $107-8,110,115-16,125,137,139,156$, $159,161,229,231,319,322,344,345-$ 7, 350-4; see also Kandavu, Koro, Lau, Lakemba (Lakeba), Levuka, Mathuata, Mba, Mbua, Naitasiri, Namosi, Nandronga, Ovalau, Rambi, Rewa, Serua, Suva, Tailevu, Taveuni, Thakaundrove, Tholo, Vanua Levu, Viti Levu, Yasawas

Filariasis, 343

French Oceania, see French Polynesia

French Polynesia, 115, 200, 230-344, 345-50, 352-4; see also Austral Islands, Gambier 1slands, Marquesas Islands, Society Islands (including Tahiti), Tuamotu Islands

Gambier Islands, 232, 235, 285, 310-14, 319 , 330-1, 335-6, 339-40, 344; see also Mangareva

German, Germany, 106, 108-9, 112, 115, $124,131,144,161$

Gilbert Islands, islanders, 35, 106, 186 , 258,269

Great Britain, 2, 7, 12, 75, 107, 109, 112, 186,274

Ha'apai, 68-9, 71-3, 77, 83, 350, 352-3

Hawaii, 186, 188, 303

Hiva-Oa, 280-1, 283-5, 288-91

Huahine, 248, 265-70, 274, 277-8, 283

Immigrants, immigration: Cook Islands, 171-2, 175, 205; Fiji, 11-12, 34-5, 67, $74,96,345$; French Polynesia, 258-9, $264,268,270,273,279,285,300,303$, $313-14,331,334,343$; Samoa, 106, $108,115-19,144-6$

Indenture, see Immigrants, immigration

Infanticide, $244,249,262-3,300,304$, $306,347-8$

Influenza, 6, 26, 32-5, 37, 67, 83, 96, $102,109,114,125-7,144,161,166-7$, $180,229,253-4,262-3,270,272,303$, $319-22,330-1,344,347,352-3$

'Intermittent' fever, 185,245

John Williams, 187

Kandavu, 1, 8

Koro, 9-10

Lady Penthyn, 234, 244

Lakemba (Lakeba), 10

Lau Islands, 1-2, 8, 10, 74

Leprosy, 186, 228-9
Levuka, 8, 10, 351-3

Life expectancies, see Expectation of life at birth

London Missionary Society, 346; in Cook Islands, 163, 175, 181, 184-5, 187, 246, 349; in French Polynesia, 246, $269-70,278,280,283-4,288,297$, 312 ; in Samoa, 100, 110, 160; in Tonga, 69, 71-2

Maiaoiti, 266-70

Mangaia, 162, 164, 169, 171, 175-9, 191-3

Mangareva, 300, 312-13

Manihiki, 162, 184, 186-8, 190-1, 228, 308

Manono, 98, 100-2, 104, 106-8, 112, $117-18$

Manu'a, 98, 101, 105-6, 108-9, 112-14, $143-4,160$

Manuae, 162, 182-3, 186, 191

Marital status, 20-1, 59, 80, 119-20, $141-2,177-8,196,222,259,309,316$, 341

Marquesas Islands, 232, 235, 240, 279$95,313-14,319,330-1,336,340,343-$ 4, 346, 348-9; see also Fatu-Hiva, Hiva-Oa, Nuku-Hiva, Tahuata, Ua-Pu, Ua-Uka

Marriage patterns: Cook Islands, 227-8, 231; Fiji, 13, 30, 65-7; French Polynesia, 343; Samoa, 159-60; Tonga, 78, 95

Marshall Islands, 106

Mathuata, 5, 8, 10

Mauke, 162-3, 181-2, 191, 193

Maupiti, 275-9

Mba, 8-9, 18

Mbua, 8

Measles, 6, 8, 11, 20, 26, 30-2, 36, 66, 76-7, 96, 109-10, 123-6, 161, 169-70, $177,180,256,264-5,268,272-3,277$, $279,299,322-3,329-31,334,337-8$, $345,347,350-2,354$

Messenger of Peace, 100,102

Migration, 3, 35, 40, 117, 123, 129-30, $134,137,141,149,152-3,188,198-9$, $210,258,331,334,344$; see also Emigrants, emigration; Immigrants, immigration

Mitiaro, 162, 182, 191, 193

Moorea (Eimeo), 235, 242, 244, 248, $252-3,255-61,264-5,268,279,310$, 321

Mortality, 35-6, 78-9, 96-7, 161, 168-9, $174-5,180,190,199,205,231,256-7$, $263,293-4,333-4,343,345-9$; epidemic (in Cook Islands) 165, 167, $171,174,179-80,185,230,352$, in Fiji) 9-11, 26, 29-34, 36, 83, 110, 125, $351-2$, (in French Polynesia) 180, $240,243,251-2,256-7,263-4,267-$ 
Mortality-continued

$8,270-3,276-9,289,308,319,321-3$, $331,343-4,350,352-3$, (in Samoa) $102-3,109-11,114,124-7,160,350$, $352-3$, (in Tonga) $76-7,83,96,110$, $350,352-3$; rates (age-specific) 53-5, $57,93-4,97,135-6,153-5,204,215-$ $18,293,336-8$, (infant) 53-5, 92-3, $131,135-6,153,214-16,218-19,293$, $329,336-8$, (standardized) 56-7, 67, $94,136,153,155,344$; see also Deaths

Motherhood, attainment of, see Age at first birth

Mumps, 104, 167

Naitasiri, 8

Namosi, 8

Nandronga, 8

Nassau, 162, 227, 229

New Guinea, 116

New Hebrides, 12, 258

New Zealand, 74, 76, 112, 117-20, 125, $131,133,161,164,173,191-3,198$, $200,211,230,245,352$

Niuafo'ou, 68, 72-3, 77, 92

Niuatoputapu, 68, 73, 76-7

Niue, 106, 116, 269, 308

'Nondescript' scrofulous disease, 166, $174-6,349$

Nuku-Hiva, 280-2, 284-5，288-90，293, 295,348

Opium, 295

Ovalau, 7, 9

Palmerston $_{x}$ 162, 188-91, 201, 228

Panama or coast fever, $256,267,277$, 279

Pandora, 98, 245

Penrhyn (Tongareva) , 162, 184-6, 189$91,193,228,258,308$

Peruvian slave trade, 105, 177, 181, 184$8,190,278,288,308$

'Pestilential' disease, 297-8, 301-2, 304$5,307,309-10,347$

Port-au-Prince, 72

Pukapuka, 162, 184, 188-9, 201, 227-9

Pylades, 186

Raiatea, 243, 248, 265-6, 268-75, 277, 297,300

Raivavae, 234, 301-6, 309-10

Rakahanga, 162, 186-8, 190, 228

Rambi, 4

Rapa, 278, 296, 306-10, 312, 319-21

Rapa Nui, see Easter Island

Rarotonga, 162-79, 184-5, 191-3, 196, $207-11,217-19,221-30,346,349-50$

Rebellion, see War

Resolution, 244, 279

Rewa, 8

Rimatara, 296, 298, 310
Rotuma, 2, 18, 20, 36-7, 116

Rurutu, 234, 297-300, 303, 310

Samoa, 95, 98-115, 160-1, 186, 344-6, 354; American, 112-13, 123-4, 130 , 137, 141-59; German, 112-13, 115-17, 123; Western, 112-13, 115-41, 143-5, $147,149,151,155-6,159-61,192,231$, 352-3; see also Apolima, Manono, Manu'a, Savai'i, Tutuila, Upolu

Savai'i, 98, 100-5, 107-8, 110-12, 114, $117-18,123-5,160,350,353$

Scarlatina, 176, 255, 272, 277

Scarlet fever, see Scarlatina

Serua, 8

Sex ratios: Cook Islands, $166,168,173$, 178, 182, 210-11, 227; Fiji, 45; French Polynesia, 249-50, 255-7, 263-4, 2901, 297-8, 302, 304-6, 313, 330; Samoa, 149; Tonga, 72, 83, 89

Smallpox, 250-3, 263-4, 267, 276, 288$9,293,295-6,308,312,348,350$

Society Islands, $163,232-4,240,280$, 285 , 300; Windward, 232, 235; see also Tahiti and Moorea; Leeward, 232$3,248,253,261,265-79,310,319-20$, $330-1,340,352-3$; see also Borabora, Huahine, Maiaoiti, Maupiti, Raiatea, Tahaa

Spaniards, 238, 240, 242-4, 246, 285, 347

Suva (Fiji) , 32, 352-4

Suwarrow, 162, 189

Tafahi, 73

Tahaa, 265-6, 268, 270-5

Tahiti, 71-2, 160, 169, 173-5, 177, 179 $81,184-5,188,190,230,232-65,268-$ $9,274,279-80,283,289,297,299-$ $302,307,310,319-22,330-1,337$, $340,343-4,346-50,352-4$; traditional districts of, $237-43,245-7,249,260$

Tahiti-nui, 237-8

Tahuata, 232, 279-81, 283-5, 288-90

Taiarapu, 237-8, 241-3, 246, 248-50, 253, 256

Tailevu, 8

Talune, 125, 352-3

Taveuni, 4, 7

Thakaundrove, 8

Tholo (Colo), 13-15

Tonga, $1,68-97,100,110,137,141$, $240,345-6, \quad 350,352-3$; see also Ha'apai, Niuafo'ou, Niuatoputapu, Tafahi, Tongatapu, Vava'u

Tongatapu, 68-9, 71-3, 77, 83, 352-3

Tuamotu (Paumotu) Islands, 232-3, 235, $261,280,307-8,310-14,319-21,330-$ 1, 336, 339-40, 343; see also Anaa

Tuberculosis, 176, 216, 313

Tubuai, 234, 244, 297, 299-304, 306, 309-10 
Tutuila, 98, 100-6, 108, 112-13, 143-4 Typhoid fever, 274

Ua-Pu, 281, 284-5, 288-91, 293, 348 Ua-Uka, 281, 284-5, 289-90

United States of America, 107, 109, 11213, 142, 147, 149, 161, 273; California 104, 177; Exploring Expedition, 4, 72, 100; San Francisco, 256

Upolu, 98, 100-9, 111-14,117-18, 123, $125,160,350,353$

Vanua Levu, 1-2, 4-5, 7-8

Vava'u, 68-9, 71-3, 77, 83-4, 352-3

Venereal disease, 240, 244-5, 252, 262, 295,302
Viti Levu, 1-2, 4-5, 7-8

War: casualties in, 71, 104-6, 108-9, $111,114-15,164,254,263,267,272-$ 3, 277-9; (Cook Islands) 164, 181-2, 185; (Fiji) 2, 5; (French Polynesia) $247,252-5,262-3,266-9,271-9,281$, $284,288,290,295,300-1,303,306$, 343, 348; (Samoa) 100, 102, 104-11, $113-15,124,144,160$; (Tonga) 69, $71-3,79,96$

Wesleyan mission: Fiji, 2; Samoa, 100, 106, 110; Tonga, 72

Whooping cough, $26,42,103,114,123-$ $4,126,161,167,180,253,269,276$

Yasawas, 1-2, 8-10 